\title{
Design Validation Methodology Development for an Aircraft Sensor Deployment System
}

\author{
Zenovy S. Wowczuk \\ West Virginia University
}

Follow this and additional works at: https://researchrepository.wvu.edu/etd

\section{Recommended Citation}

Wowczuk, Zenovy S., "Design Validation Methodology Development for an Aircraft Sensor Deployment System" (2008). Graduate Theses, Dissertations, and Problem Reports. 3020.

https://researchrepository.wvu.edu/etd/3020

This Dissertation is protected by copyright and/or related rights. It has been brought to you by the The Research Repository @ WVU with permission from the rights-holder(s). You are free to use this Dissertation in any way that is permitted by the copyright and related rights legislation that applies to your use. For other uses you must obtain permission from the rights-holder(s) directly, unless additional rights are indicated by a Creative Commons license in the record and/ or on the work itself. This Dissertation has been accepted for inclusion in WVU Graduate Theses, Dissertations, and Problem Reports collection by an authorized administrator of The Research Repository @ WVU.

For more information, please contact researchrepository@mail.wvu.edu. 


\title{
Design Validation Methodology Development for an Aircraft Sensor Deployment System
}

\author{
Zenovy S. Wowczuk
}

Dissertation submitted to the College of Engineering and Mineral Resources at West Virginia University in partial fulfillment of the requirements for the degree of

\author{
Doctor of Philosophy \\ in \\ Civil Engineering
}

\author{
James Smith, PhD., Research Chair \\ Hota GangaRao, PhD., Academic Chair \\ Udaya B. Halabe, PhD. \\ Kenneth Means, PhD. \\ Gregory Thompson, PhD.
}

Department of Civil Engineering

West Virginia University

Morgantown, WV

2008

Keywords: Aircraft Sensor Platform, Sensor Deployment System, Experimental Flight Testing, C-130 Aircraft 


\section{ABSTRACT \\ Design Validation Methodology Development for an Aircraft Sensor Deployment System}

\section{Zenovy S. Wowczuk}

The OCULUS 1.0 Sensor Deployment concept design, was developed in 2004 at West Virginia University (WVU), outlined the general concept of a deployment system to be used on a C-130 aircraft. As a sequel, a new system, OCULUS 1.1, has been developed and designed. The new system transfers the concept system design to a safety of flight design, and also enhanced to a pre-production system to be used as the test bed to gain full military certification approval. The OCULUS 1.1 system has an implemented standard deployment system/procedure to go along with a design suited for military certification and implementation. This design process included analysis of the system's critical components and the generation of a critical component holistic model to be used as an analysis tool for future payload modification made to the system.

Following the completion of the OCULUS 1.1 design, preparations and procedures for obtaining military airworthiness certification are described. The airworthiness process includes working with the agency overseeing all modifications to the normal operating procedures made to military C-130 aircraft and preparing the system for an experimental flight test. The critical steps in his process include developing a complete documentation package that details the analysis performed on the OCULUS 1.1 system and also the design of experiment flight test plan to analyze the system. Following the approval of the documentation and design of experiment an experimental flight test of the OCULUS 1.1 system was performed to verify the safety and 
airworthiness of the system. This test proved successfully that the OCULUS 1.1 system design was airworthy and approved for military use.

The OCULUS 1.1 deployment system offers an open architecture design that is ideal for use as a sensor testing platform for developmental airborne sensors. The system's patented deployment methodology presents a simplistic approach to reaching the systems final operating position which offers the most robust field of view area of rear ramp deployment systems. 


\section{Acknowledgements}

"It is good to have an end to journey toward; but it is the journey that matters, in the end,” - Ursula K. Le Guin

The above quote is incredibly indicative of the process of obtaining a doctorate of philosophy in an engineering discipline. At the beginning of one's research the concentration must always be directed to accomplishing the goal of the research or one may stray and never find the path (or paths) that lead to completion. Throughout this process an immeasurable amount of knowledge, skills and self growth are gained and in the end these are the true accomplishments of one's work.

There are several people that have been involved in this work both intimately and externally, and without their support a successful end to this process would never have been accomplished. I would like to begin by thanking those that were intimately involved in this research, namely those who guided me and those who worked along side of me. The majority of the guidance I received evolved from the diverse members of my research committee: Dr. Gregory J. Thompson, Dr. Kenneth H. Means, Dr. Udaya B. Halabe, Dr. Hota V. GangaRao and Dr. James E. Smith. Each member's guidance was instrumental in keeping me on track and providing me with the knowledge necessary to successfully complete this work. I would like to specifically thank Dr. Thompson and Dr. Smith for their patience and support.

During this process Dr. Thompson has gained my respect and praise as the best design engineer I have ever had the pleasure of being in the presence of and work along side with. The knowledge he instilled in me will be with me always during my professional career.

During my graduate career I have not only had a great mentor but have gained a colleague and a friend in Dr. Smith. His guidance and knowledge transfer vested long beyond the boundaries of theory and problem solving. He has made me a better man and prepared me for any project/problem my engineering career and life in general will encounter. 
In closing I would like to thank my family and friends that have supported me throughout this demanding process. The overwhelming support from my mother and father was a major factor in me continuing and completing this journey. I thank you both. Throughout this demanding process my two brothers, Yurij and Borys, have always come to my assistance with a fine bottle of 18 year old Scotch - I thank you both for the good conversations while enjoying a relaxing drink. I would also like to acknowledge Bruce Sparks who has become both a mentor and a colleague - I look forward to our long friendship and continued professional success in the future. 


\section{Table of Contents}

Chapter/Section

Abstract

Acknowledgements

Table of Contents

Tables Listed

Figures Listed

Nomenclature

I. Introduction

1.1 Need for a Roll-on/Roll-off Deployment System for a C-130 Aircraft

1.2 Roll-on/Roll-Off Pallet Concept (Historical Review)

1.3 OCULUS 1.0 Concept

1.3.1 System Design Requirements

1.3.1.1 Electrical Limitations

1.3.1.2 Structural Limitations

1.3.1.3 Operator Design Requirements

1.3.1.4 Autonomous Attachment System

1.3.1.5 Commercial off-the-Shelf (COTS)/Government off-the-Shelf (GOTS) Components

1.3.1.6 System Mission Capabilities

2. Concept to Prototype

2.1 Safety of Flight Design

2.1.1 Critical Component Analysis

2.1.1.1 Bearing Stand System Review and Analysis

2.1.1.2 Mechanical Arm Review and Analysis

2.1.1.3 System Fastener Upgrade

2.1.1.4 EMI Shielding Design

2.1.1.5 Electrical Shock Resistance Design

2.1.1.6 Sensor Pod to Rear Ramp Contact Design
Page \#

ix

X

xiii

1

1

2

9

11

12

13

16

17

18

18

21

22

22

24

29

39

40

45

46 
2.3 The Nest Step - Plan for Testing/Certifying the OCULUS 1.1 System 51

3 Airworthiness/Flight Testing $\quad 52$

3.1 Certification Process $\quad 52$

3.2 Review of Military Airworthiness Certification Processes (Literature Review) 52

3.3 Obtaining Clearance for a Flight Test 53

3.3.1 Formal Request for Flight Testing

3.3.2 OCULUS 1.1 System Engineering Review for Flight Test

3.4 OCULUS 1.1 Engineering Documentation Package $\quad 54$

3.4.1 OCULUS 1.1 Drawing Package

3.4.1.1 Level II Drawing Package Description $\quad 56$

3.4.1.2 Mechanical \& Electrical System Drawing Package 56

3.4.2 OCULUS 1.1 Structural Analysis $\quad 58$

3.4.3 Electrical Analysis $\quad 59$

3.4.3.1 Electrical Load Analysis $\quad 59$

3.4.3.2 EMI/EMC Analysis $\quad 59$

3.5 Command Control Board (CCB) Approval $\quad 60$

4. Flight Test Plan Development 61

$\begin{array}{ll}4.1 \text { Hardware Setup } & 61\end{array}$

4.1.1 Strain Gage Setup $\quad 62$

$\begin{array}{ll}\text { 4.1.2 Accelerometer Setup } & 66\end{array}$

$\begin{array}{ll}\text { 4.1.3 Data Acquisition (DAQ) Setup } & 67\end{array}$

$\begin{array}{ll}4.2 \text { Test Matrix } & 74\end{array}$

5 Experimental Flight Test $\quad 82$

5.1 Data Collected

5.2 Flight Test Visuals $\quad 85$

6. Experimental Flight Test Data Results $\quad 91$

6.1 Strain Gage Data Reduction $\quad 91$ 
6.2 Strain Measurement Results $\quad 92$

6.3 Vibration Measurement Data Reduction 99

6.4 Vibration Measurement Results 99

$\begin{array}{ll}\text { 7. Conclusions } & 109\end{array}$

7.1 Strain Gage Data Conclusions $\quad 109$

7.2 Accelerometer Data Conclusions 110

7.3 OCULUS 1.1 Airworthiness Certification 112

7.4 Mechanical Arm FEA Comparison to Experimental Data 112

$\begin{array}{ll}7.4 \text { New Certification Process } & 115\end{array}$

8. References 116

$\begin{array}{ll}\text { Appendix A } & 121\end{array}$

$\begin{array}{ll}\text { Appendix B } & 123\end{array}$

$\begin{array}{lr}\text { Appendix C } & 126\end{array}$

$\begin{array}{ll}\text { Appendix D } & 131\end{array}$

$\begin{array}{ll}\text { Appendix E } & 227\end{array}$

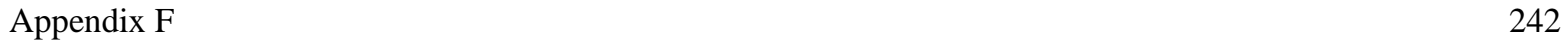

$\begin{array}{ll}\text { Appendix G } & 247\end{array}$

$\begin{array}{ll}\text { Appendix H } & 261\end{array}$

$\begin{array}{lr}\text { Appendix I } & 268\end{array}$

$\begin{array}{ll}\text { Appendix J } & 279\end{array}$

$\begin{array}{ll}\text { Appendix K } & 281\end{array}$

$\begin{array}{ll}\text { Appendix L } & 286\end{array}$

$\begin{array}{ll}\text { Appendix M } & 289\end{array}$ 
Table 1-1. On-Board Power for all C-130 Variants 13

Table 2-1: Aerodynamic test results at varying speeds and ramp angle. 30

Table 2-2: Mechanical arm’s Pro Engineer part features. 32

Table 2-3: Maximum principal stress value results of the mechanical arm FEA. 39

Table 4-1: Strain Indicator Limits $\quad 71$

Table 4-2: OCULUS 1.1 deployment test flight matrix. $\quad 75$

Table 4-3: OCULUS 1.1 maneuver test flight matrix. $\quad 86$

Table 6-1: Strain and stress results reduced from raw data collected during the

OCULUS 1.1 systems deployment process, at straight and level flight. 95

Table 6-2: Strain and stress results reduced from raw data collected while the OCULUS 1.1 system was in the FOP and performing left banking maneuvers. 96

Table 6-3: Strain and stress results reduced from raw data collected while the OCULUS 1.1 system was in the FOP and performing right banking maneuvers.

Table 6-4: Strain and stress results reduced from raw data collected while the OCULUS 1.1 system was in the FOP and performing left/right slip maneuvers. 
Figure 1-1: National Guard $137^{\text {th }}$ Airlift Wing sensor pallet system.

Figure 1-2: Location of camera’s and mounting points on National Guard $137^{\text {th }}$ Airlift

Wing sensor pallet system. 3

Figure 1-3: National Guard $137^{\text {th }}$ Airlift Wing sensor pallet system deployed in flight. 4

Figure 1-4: National Guard $152^{\text {nd }}$ Airlift Wing sensor platform camera arrangement. 6

Figure 1-5: National Guard 152 ${ }^{\text {nd }}$ Airlift Wing sensor platform loaded on a C-130 aircraft. $\quad 7$

Figure 1-6: National Guard 152 ${ }^{\text {nd }}$ Airlift Wing operator station. $\quad 7$

Figure 1-7: (a) Command and Control Center (operator station).

(b) Locator system (sensor platform).

Figure 1-8: OCULUS 1.0 System concept design inside a fuselage model of a C-130 aircraft.

Figure 1-9: C-130 weight and height limitation chart (2). 15

Figure 2-1: OCULUS 1.0 concept deployment system. 21

Figure 2-2: Highlighted bearing stand connection (4 stands) of the mechanical arm system $\begin{array}{ll}\text { to the sensor platform. } & 23\end{array}$

Figure 2-3: Highlighted 4-arm connection system of the OCULUS 1.0 Mechanical Arms. 23

Figure 2-4: OCULUS 1.0 bearing stand with highlighted weldment connections. 24

Figure 2-5: OCULUS 1.1 proposed bearing stand design. $\quad 25$

Figure 2-6: Stress (left) and displacement (right) graphical resultant display of the FEA performed on the connection bearing stand.

Figure 2-7: (left) OCULUS 1.0 rotational system support design. (right) Upgraded $\begin{array}{ll}\text { OCULUS } 1.1 \text { rotational system support design } & 28\end{array}$

Figure 2-8: Aerodynamic test rake mounted on the rear cargo ramp of the C-130 aircraft. 30

Figure 2-9: (top) Mechanical arm/pod system at the vertical position in the rotation stage of the deployment process. (bottom) Mechanical arm/pos system during the $\begin{array}{ll}\text { deployment stage. } & 31\end{array}$

Figure 2-10: Finite element model (FEM) of the OCULUS mechanical arm. 32 
Figure 2-11: Simplified loading and restraint characteristics of the OCULUS 1.1 mechanical arm analysis.

Figure 2-12: Stress distribution for Trial 1 loading.

Figure 2-13: Stress distribution for Trial 2 loading.

Figure 2-14: Stress distribution for Trial 3 loading.

Figure 2-15: Stress distribution for Trial 4 loading.

Figure 2-16: Stress distribution for Trial 5 loading.

Figure 2-17: Stress distribution for Trial 6 loading.

Figure 2-18: Stress distribution for Trial 7 loading.

Figure 2-19: Stress distribution for Trial 8 loading.

Figure 2-20: CE-102 conduction noise limits for fixed wing aircraft (36).

Figure 2-21: LISN, used for measurement of conducted emissions, schematic (36.

Figure 2-22: Specific DC LISN measurement system setup (36).

Figure 2-23: Fixed winged aircraft radiated emissions level (RE102) limits (37).

Figure 2-24: Rod Antenna (10kHz-30Mhz) for RE-102 tests (37).

Figure 2-25: Biconical Antenna (30MHz-1GHz) for RE-102 tests (37).

Figure 2-26: Double Ridge Horn (1GHz-18GHz) for RE-102 tests (37).

Figure 2-27: OCULUS 1.1 EMI shielded enclosure design.

Figure 2-28: OCULUS 1.1 enclosures with gold iridite coating.

Figure 2-29: OCULUS 1.1 enclosures with shielded cabling running in and out.

Figure 2-30: Operator Station safety cover examples implemented for safety-of-flight measures.

Figure 2-31: C-130 rear ramp inside structure (Lockheed Martin Clarksburg, WV).

Figure 2-32: Operator testing contact between C-130 ramp and OCULUS 1.1 System

Figure 2-33: Schematic of the OCULUS 1.1 electrical system power distribution design (41).

Figure 2-34: (top) OCULUS 1.1 Sensor Platform System on a C-130 aircraft.

(bottom) OCULUS Operator Station in the fuselage of a C-130 aircraft.

Figure 4-1: OCULUS 1.1 instrumentation and DAQ concept setup. 
Figure 4-3: High stress locations in the mechanical arm of the OCULUS 1.1 system.

Figure 4-4: Highlighted strain gage locations on the OCULUS 1.1 system. 65

Figure 4-5: Example strain gage mount on the OCULUS 1.1 system. 66

Figure 4-6: Approximate accelerometer location on the OCULUS 1.1 system sensor pod assembly. 67

Figure 4-7: OCULUS 1.1 data collection software GUI. $\quad 70$

Figure 4-8: Example of strain gage configuration GUI.

Figure 4-9: Example of accelerometer configuration GUI. 73

Figure 4-10: The OCULUS 1.1 system on a C-130 aircraft in the stow position. 78

Figure 4-11: The OCULUS 1.1 system on a C-130 aircraft at the end of the linear extension phase. 79

Figure 4-12: The OCULUS 1.1 system during the rotational process of deployment. 80

Figure 4-13: The OCULUS 1.1 system at the end the rotational process of deployment. 80

Figure 4-14: The OCULUS 1.1 system in the final operating position. 81

Figure 5-1: Final instrumentation setup on the OCULUS 1.1 Sensor Platform. 82

Figure 5-2: Final instrumentation setup in the OCULUS 1.1 Operator Station. 83

Figure 5-3: In-flight picture of computers displaying the instrumentation data being collected. 84

Figure 5-4: Sample data display (accelerometer data on top and strain gage data on bottom). 85

Figure 5-5: The OCULUS 1.1 sensor platform system during a flight deployment phase. 96

Figure 5-6: The OCULUS 1.1 operator station (during flight) with personnel inside. 87

Figure 5-7: View of the OCULUS 1.1 system inside the C-130 aircraft in the deployed position. 88

Figure 5-8: A second View of the OCULUS 1.1 system inside the C-130 aircraft in the $\begin{array}{ll}\text { deployed position. } & 88\end{array}$

Figure 5-9: View of the OCULUS 1.1 from ground level in the deployed position. 89

Figure 5-10: A second view of the OCULUS 1.1 from ground level in the deployed position. 90

Figure 6-1: Orientation of individual gages in a 3-element rosette. 91

Figure 6-2: Vibration measurements during Linear Translation (100 lbs). 102

Figure 6-3: Vibration measurements during Pod Rotation (100 lbs). 103

Figure 6-4: Vibration measurements during Linear Retraction (100 lbs). 104

Figure 6-5: Vibration measurements during Final Operating Position (100 lbs). 105 
Figure 6-6: Vibration measurements during Final Operating Position (200 lbs).

Figure 6-7: Vibration measurements during Final Operating Position (263 lbs).

Figure 7-1: Fatigue analysis of the mechanical arm system showing life greater then $10^{6}$ cycles (32).

Figure 7-2: Maximum principal stress comparison between the mechanical arm FEA and experimental values collected from the flight test. 


\section{Nomenclature}

\begin{tabular}{|c|c|}
\hline SAR & Synthetic Aperture Radar \\
\hline LIDAR & Light Detection and Ranging \\
\hline RoRo & Roll-on/Roll-off \\
\hline IR & Infrared \\
\hline FLIR & Forward Looking Infrared \\
\hline FOV & Field of View \\
\hline CIRA & Center for Industrial Research Applications \\
\hline WVU & West Virginia University \\
\hline CD & Counter Drug \\
\hline TR & $\underline{\text { Transformer-Rectifier }}$ \\
\hline APU & Auxiliary Power Unit \\
\hline COTS & Commercial off-the-Shelf \\
\hline GOTS & Government off-the-Shelf \\
\hline \multirow[t]{2}{*}{$\mathrm{C}^{4} \mathrm{ISR}$} & Command, Control, Communications, Computers, Intelligence, \\
\hline & Surveillance and Reconnaissance \\
\hline COMINT & Communications Intelligence \\
\hline ELINT & Electronics Intelligence \\
\hline UAV & Unmanned Aerial Vehicle \\
\hline $\mathrm{LOS} / \mathrm{OTH}$ & Line of Site/Over the Horizon \\
\hline DoD & Department of Defense \\
\hline FOP & Final Operating Position \\
\hline GTRI & Georgia Tech Research Institute \\
\hline FEA & Finite Element Analysis \\
\hline FEM & Finite Element Model \\
\hline MIL & Military \\
\hline EMI & Electro-Magnetic Interference \\
\hline CE & Conducted Emissions \\
\hline
\end{tabular}




$\begin{array}{ll}\text { RE } & \text { Radiated Emissions } \\ \text { LM } & \text { Lockheed Martin } \\ \text { NGB } & \text { National Guard Bureau } \\ \text { WRAFB } & \text { Warner Robins Air Force Base } \\ \text { WVANG } & \text { West Virginia Air National Guard } \\ \text { NGB-CD } & \text { National Guard Bureau -CounterDrug } \\ \text { CNTPO } & \text { Counter NarcoTerrorism Technology Program Office } \\ \text { NOP } & \text { Normal Operating Procedure } \\ \text { CCB } & \text { Command Control Board } \\ \text { EMC } & \text { Electromagnetic Compatibility } \\ \text { DAQ } & \text { Data Acquisition } \\ \text { AC } & \text { Aircraft Commander } \\ \text { TD } & \text { Test Director } \\ \text { VMC } & \text { Visual Meteorological Conditions } \\ \text { KIAS } & \text { Knots Indicated Air Speed }\end{array}$




\section{Introduction}

Military Laboratory's and agency's need a versatile airborne platform capable of testing and running missions for developmental and existing sensor technology. The scope of this work is to design, analyze and validate a robust sensor deployment system, for military use, based upon previously attempted platform systems and the OCULUS 1.0 roll-on/roll-off concept system.

The concept of a roll-on/roll-off sensor platform system for aircraft has been investigated on several platforms. Decades of research have gone into the development of a system that can be used universally by multiple agencies within the United States military. However, the lasting issue has been to select an aircraft that is operational across all military agencies. The military identified selection is the C-130 aircraft because of the high volume availability, its multi-agency role and its half-century dependable reputation (1).

\subsection{Need for a Roll-on/Roll-off Deployment System for a C-130 Aircraft}

Because the C-130 is used for parachute drops, the plane may also be flown with the rear ramp down during flight. The value of this aircraft as a reconnaissance platform has already been recognized and exploited by many agencies. This platform can be modified to perform a variety of missions without compromising the main role of the aircraft, a tactical supply aircraft (2). This is done by packaging specialized equipment (i.e. Synthetic Aperture Radar (SAR), light detection and ranging (LIDAR), etc.) onto pallets that can be loaded into the aircraft and unloaded at the end of each mission (3). The C-130 has been, used as a reconnaissance asset for both domestic and international missions utilizing a variety of packaged sensors.

Each of the current reconnaissance missions have deployed a variety of sensors in a myriad of configurations sometimes requiring alteration of the aircraft or requiring a change in 
the flight allowances or performance requirement. A common, inexpensive and versatile palletized sensor support system was requested to be developed for universal deployment. The palletized system, using standard military pallets, requires the use of the cargo roller loading system found on the floor of the C-130 aircraft (both the fuselage and rear ramp). This rollon/roll-off (RoRo) concept standardizes the loading and attachment of the system to the airframe by making it a system package built on top of standard cargo pallets used regularly by the military (4).

\subsection{Roll-on/Roll-Off Pallet Concept (Historical Review)}

With the development of a variety of new sensor technologies in the past decade, much emphasis has been placed to integrate these sensors into aircraft reconnaissance systems. The military has committed to researching to the development of fully operational sensor systems (primary called sensor pallets) to be used on the C-130 aircraft.

Currently, there are three Airlift Wings that have already completed prototypes of sensor pallets for "counterdrug" use. These are the $137^{\text {th }}$ National Guard Airlift Wing, the $146^{\text {th }}$ National Guard Airlift Wing, and the $152^{\text {nd }}$ National Guard Airlift Wing. A view of the complete system is shown in Figure 1-1.

After succeeding on the C-130 aircraft another sensor pallet was developed by the $137^{\text {th }}$ Airlift Wing. The new $137^{\text {th }}$ sensor pallet accommodates a mapping camera (KC-1B), a framing camera (KS-87), and a panoramic camera (KA-91A). The location of these cameras is shown in Figure 1-2. These wet-film cameras are able to take aerial photographs in daylight during reconnaissance missions. The platform itself is stabilized within the $\mathrm{C}-130$ by two mounting connections to the rear cargo door of the C-130 aircraft. The location of the mounting position on the C-130 is shown in Figure 1-2 (5). 


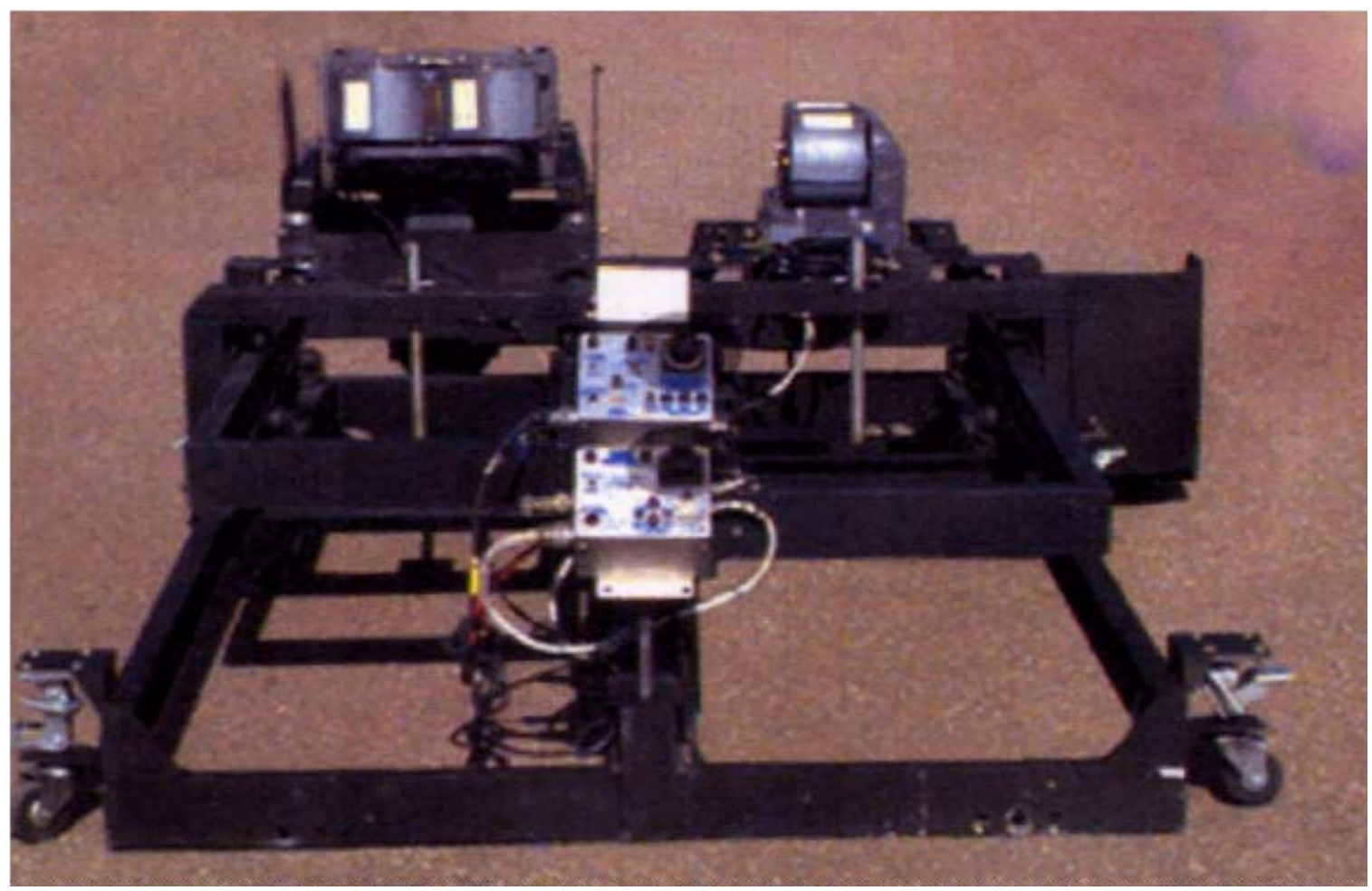

Figure 1-1: National Guard $137^{\text {th }}$ Airlift Wing sensor pallet system (6).

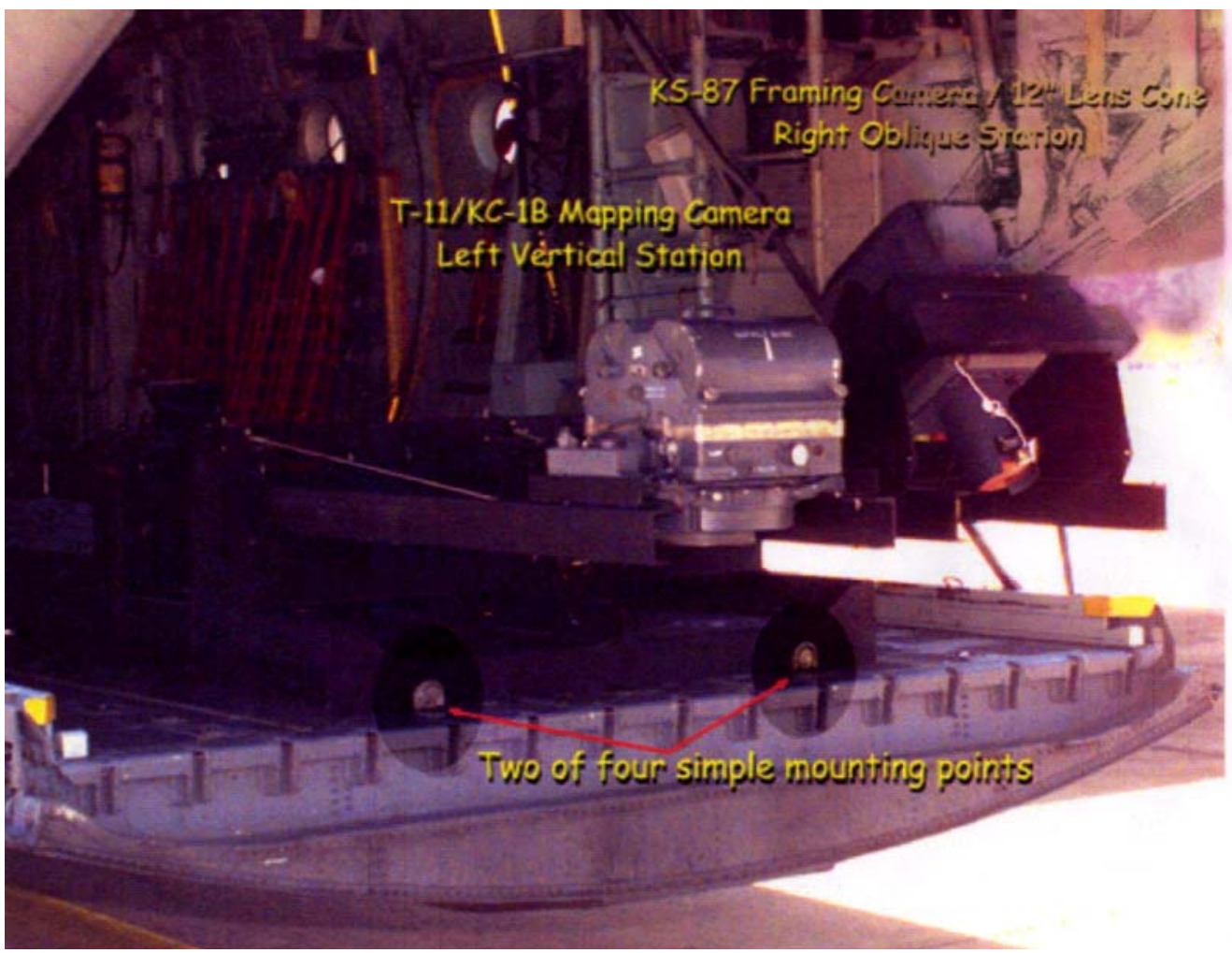

Figure 1-2: Location of camera's and mounting points on National Guard $137^{\text {th }}$ Airlift Wing sensor pallet system (6). 
Figure 1-3 shows the deployed sensor platform on board a C-130 aircraft during flight. The pallet is mounted to the rear ramp of the aircraft, where the door remains open during flight. Any two of the three cameras are attached to two individual arms that are extended over the rear of the ramp. This arrangement allows the cameras to take images directly below the aircraft during flight. The retractable arms allow in-flight film and camera changes when the arms are retracted inside the $\mathrm{C}-130$ rear door. The $137^{\text {th }}$ Airlift Wing has discontinued the use of this pallet and halted the development of another similar palletized system (2).

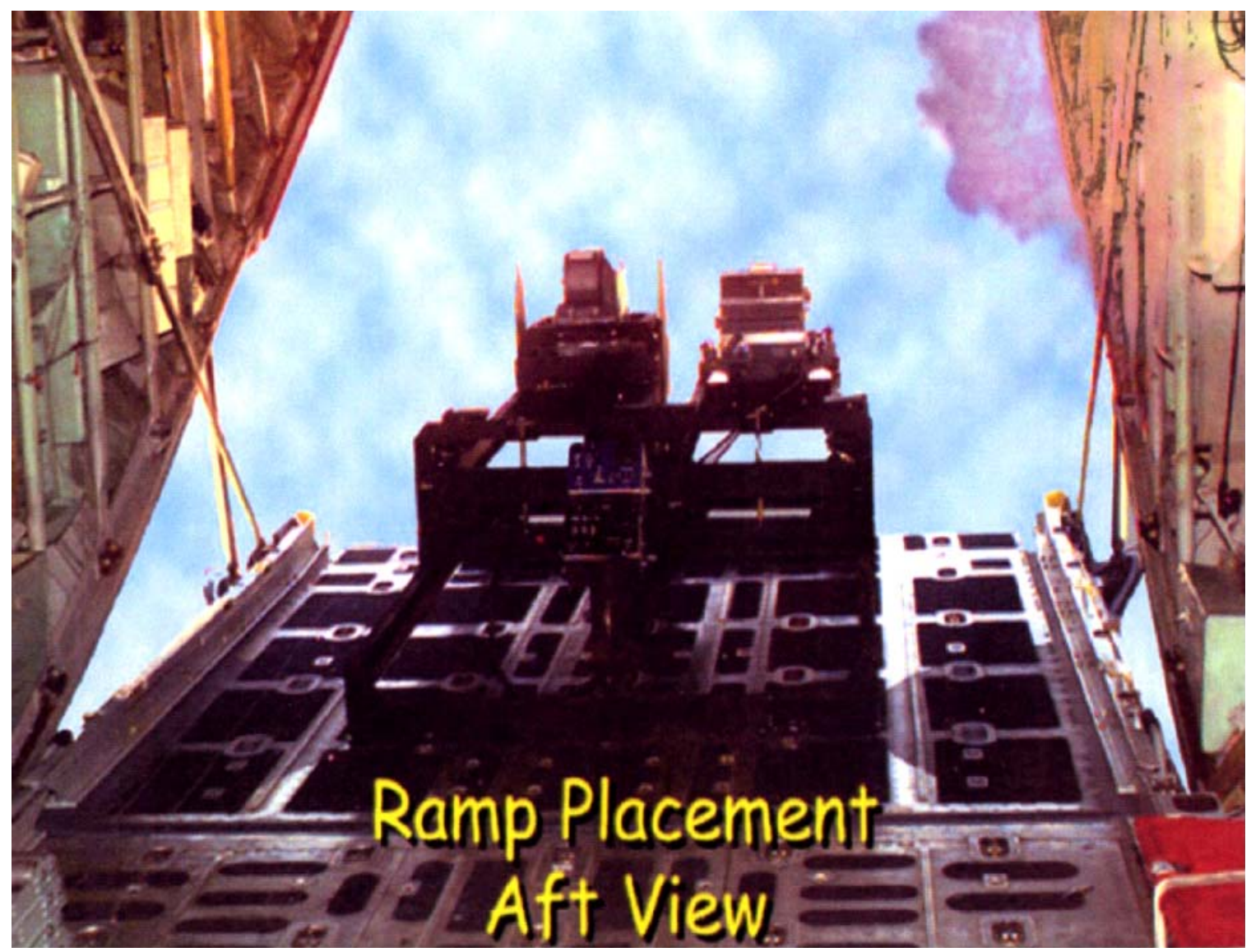

Figure 1-3: National Guard $137^{\text {th }}$ Airlift Wing sensor pallet system deployed in flight (6).

The $146^{\text {th }}$ pallet system (Port Hueneme, CA) is similar to the $137^{\text {th }}$ Airlift Wing's sensor pallet. The $146^{\text {th }}$ Airlift Wing sensor pallet has a KS-87 framing camera and a KS91 panoramic 
camera. The pallet is mounted to the rear ramp of the aircraft and is to be used with the ramp open during flight. The cameras are attached in a position so they stick out over the edge of the rear ramp. This position gives the pallet the capability of taking aerial photographs directly below the aircraft. The pallet has the capability of a three camera mounting system. No illustrations for this system are currently available (7).

The $146^{\text {th }}$ Airlift Wing is currently investigating the incorporation of new sensors into their sensor pallet. These new sensors are Synthetic Aperture Radar (SAR) and Infrared (IR) and can be used for various missions. This updated system is intended to fly with the rear cargo door ramp closed during flight. Test for this new system are ongoing.

The National Guard $152^{\text {nd }}$ Airlift Wing at Reno, Nevada has developed a pallet similar to that of the $137^{\text {th }}$ Airlift Wing. The $152^{\text {nd }}$, s pallet was developed to accommodate the KS-87 and KS-91 cameras (along with the KS-87 long lens), and it also has them mounted on two retractable arms. Figure 1-4 shows the location of the three cameras on the sensor platform. The pallet is mounted to the rear ramp of the aircraft with the intention of being flown with the ramp open. Figure 1-5 shows the placement of the sensor platform on the C-130 aircraft. In addition to the common sensor pallet design, the $152^{\text {nd }}$ Airlift Wing has developed a Scathe view system to act as a surveillance system (8).

The Scathe view system provides a near-real-time imaging capability to support humanitarian relief and non-combatant evacuation operations. This system contains a Gimbal turret mounted underneath the nose of the aircraft, a palletized workstation in the cargo hold of the aircraft and a satellite-linked ground station. Figure 1-6 highlights the two-operator workstation for the system. The Gimbal turret houses a forward looking infrared (FLIR) unit, color day TV camera, a spotter scope, and a laser rangefinder. These sensors give the C-130 an 
equivalent sensor platform to that of the C-26B, which is a specific version of the C-26 Metroliner dedicated to Counterdrug operations (7). Presently, the $152^{\text {nd }}$ Airlift Wing is working to further develop Scathe view technology further to incorporate newer sensors therefore, updating and enhancing the entire sensor platform (9).

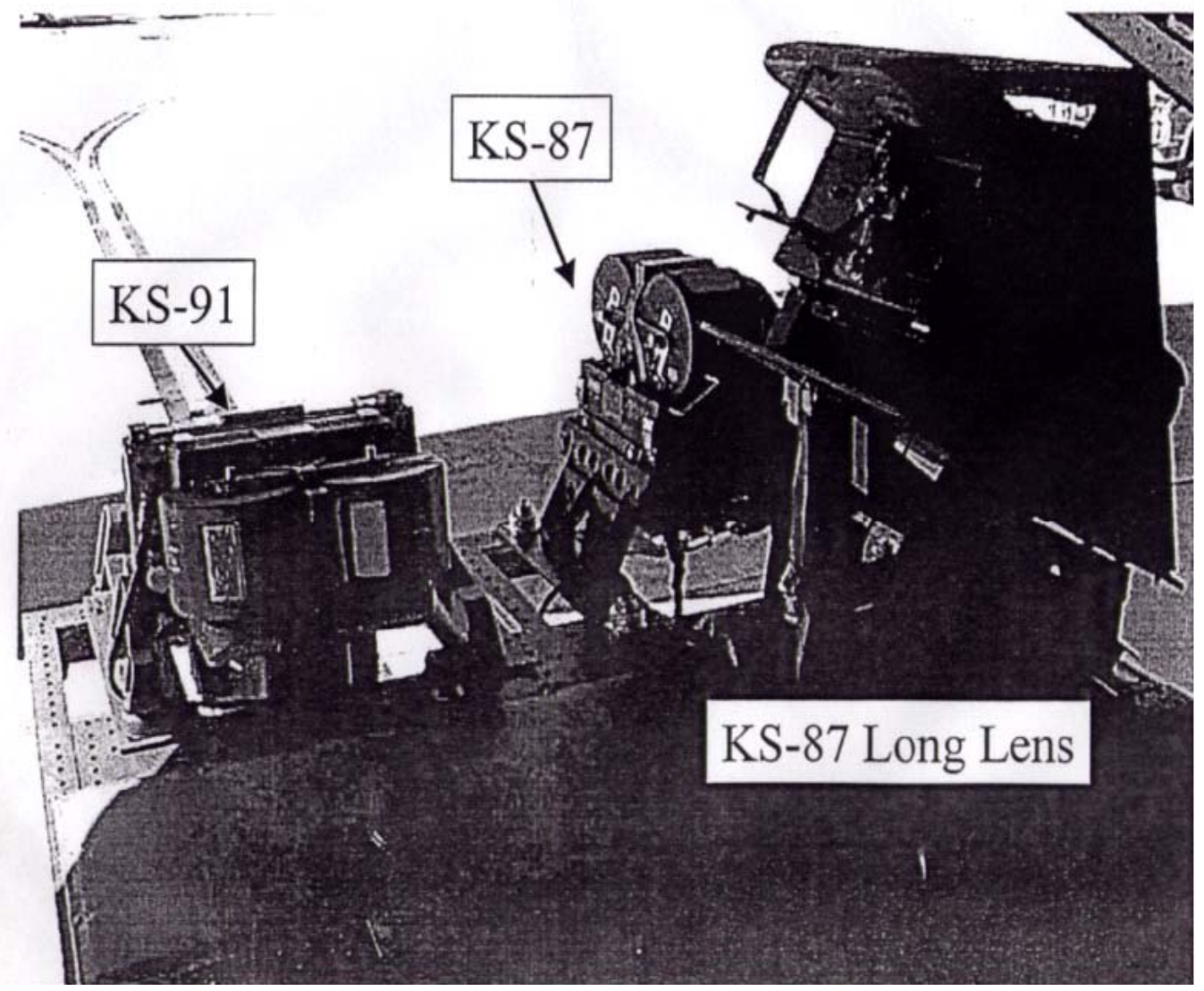

Figure 1-4: National Guard $152^{\text {nd }}$ Airlift Wing sensor platform camera arrangement (10). 


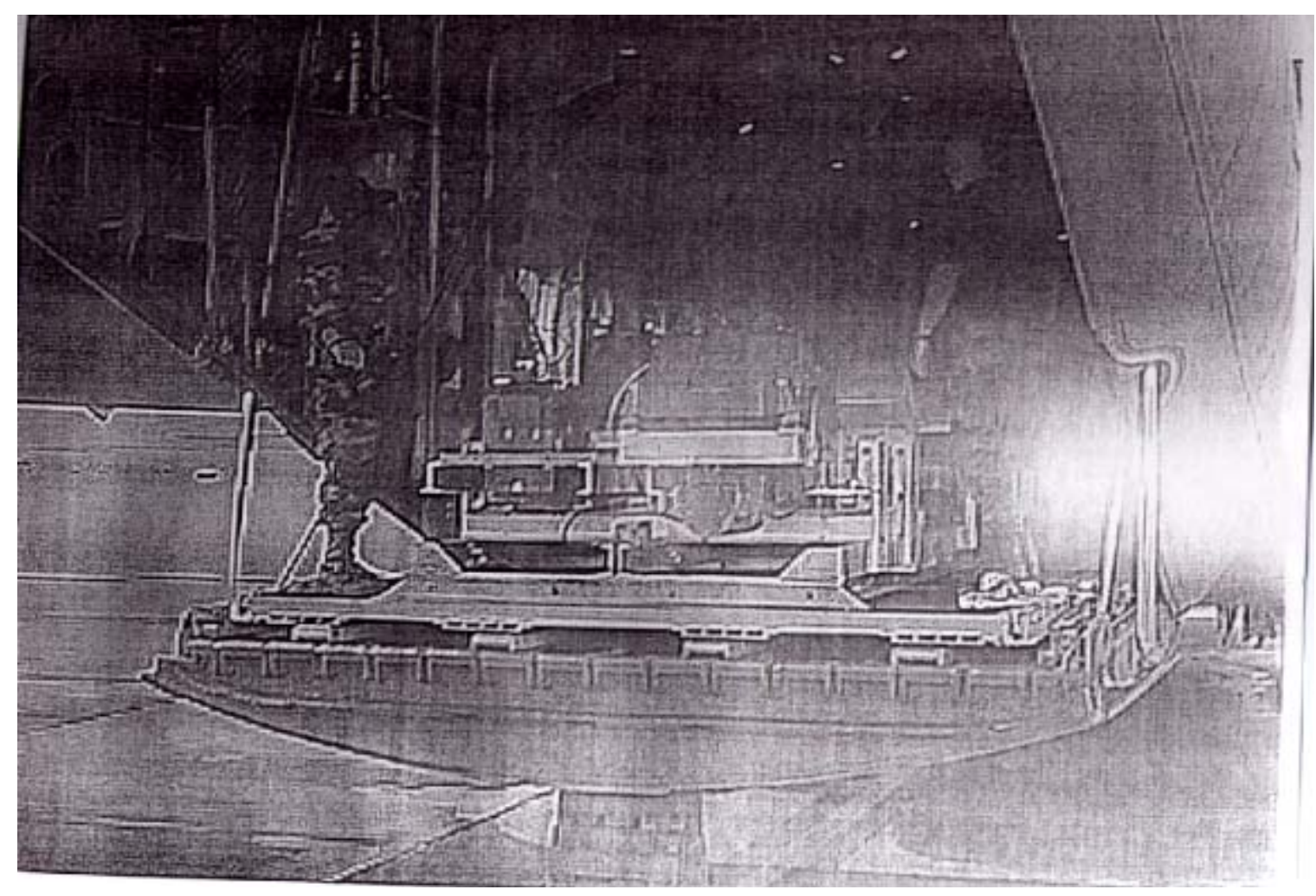

Figure 1-5: National Guard $152^{\text {nd }}$ Airlift Wing sensor platform loaded on a C-130 aircraft (10).

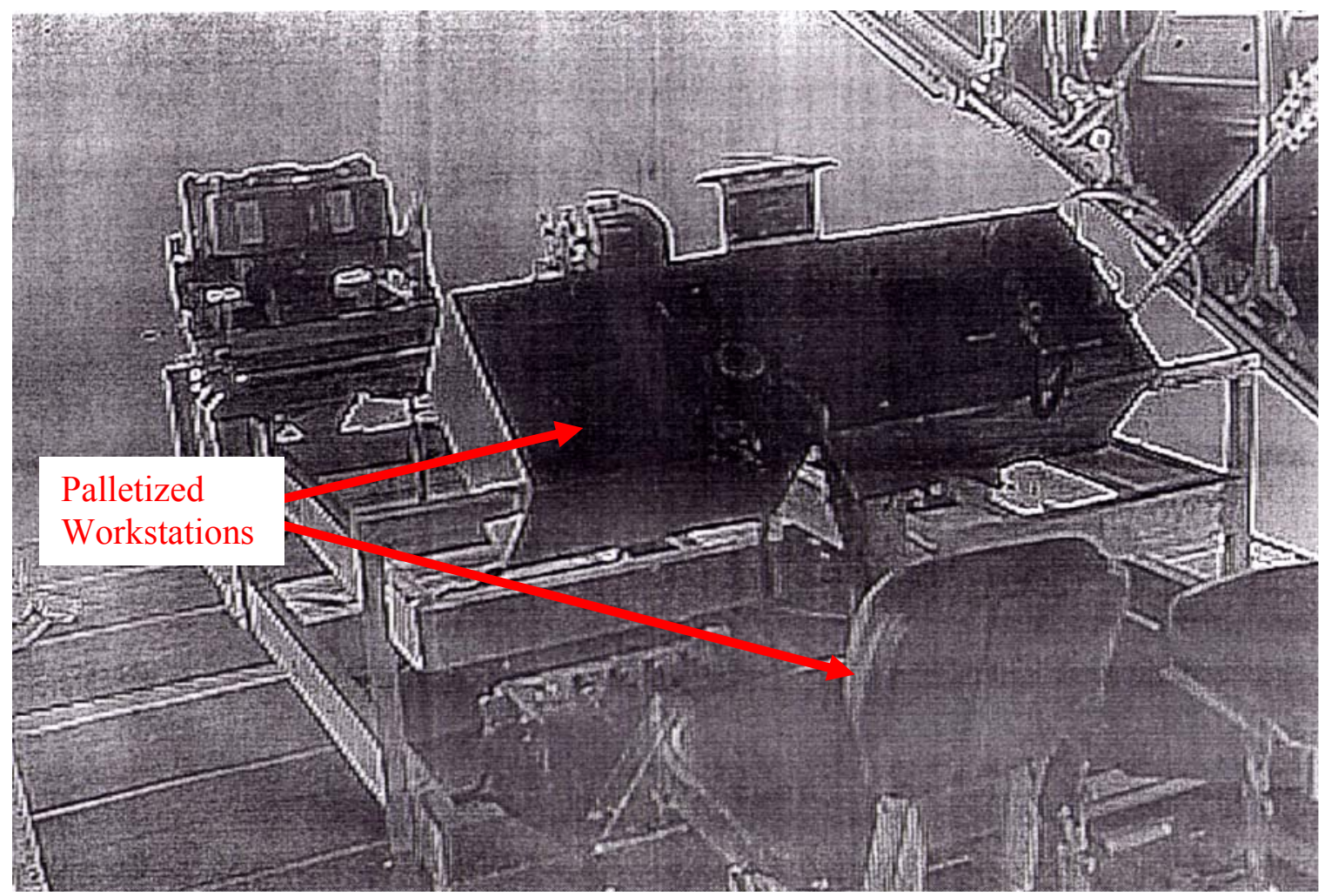

Figure 1-6: National Guard $152^{\text {nd }}$ Airlift Wing operator station (10). 
Similar in concept to the $152^{\text {nd }}$ system is the US Coast Guard's turreted system, Casper. This system is installed on a modified C-130 aircraft beneath the crew door. It is principally a FLIR sensor which also uses an installed sensor station, where data from the FLIR system is analyzed (11).

A proposed Ro-Ro system from Lockheed Martin called "Hairy Buffalo" requires the removal and alteration of the paratroop door and would deploy a robust suite of remote sensors. This array was designed to be controlled from a work station located within the C-130 cargo hold $(12,13)$. One downside to this concept is that it would limit the C-130's mission envelope to only that of reconnaissance or surveillance, as the system could not be re-situated in flight. Another proposed system with this drawback is a patented design $(\# 4,593,288)$ under the title of “Airborne Early Warning System with Retractable Dome”. This system proposed the removal of both the upper and lower Cargo doors to allow for a large aerodynamically molded pod to be deployed and retracted. This sensor system also included six workstations utilizing the remaining cargo area of the aircraft $(14,15,16)$.

Each of these developed sensor pallet systems use a non-standard pallet system that translates linearly outside of the rear cargo door of the C-130 aircraft into the air stream. This final position (parallel with the rear cargo door) limits the field of view (FOV) of the system because of the geometry of the C-130 fuselage and cargo door components. No system developed prior to OCULUS has the capability of generating a full (FOV) underneath the aircraft. The proposed system, OCULUS, allows the sensors to rest underneath the rear cargo door of the C-130 aircraft, thus maximizing its (FOV) capabilities (17). 


\subsection{OCULUS 1.0 Concept}

The Center for Industrial Research Applications (CIRA) at West Virginia University (WVU) has designed and developed a two-pallet system to meet the developmental sensor testing and experimental mission testing needs of government agencies. This type of testing allows for the agencies to apply specific sensor (based on performance) to a wide variety of mission (below 10,000 feet) including Environmental Impact Assessment, Counter Drug and (CD) Counter Terrorism operations, Homeland Security activities, Resource Surveys, Environmental Surveys, and Search and Rescue operations. This two-pallet system was produced to justify the conceptual design and deployment procedure of the system, and was not intended to satisfy the military's safety-of-flight/airworthiness testing and evaluation. This "safety-of-flight" or "airworthy" design requires that the flight dynamics and general aviation safety of a military aircraft be unchanged with the addition of add-on system.

This sensor pallet system features two roll-on/roll-off (RoRo) pallet assemblies which correspond to the OCULUS 1.0 System (18). The first assembly, Figure 1-7(a), the operator station, is used as a command and control center (referenced to as ' $a$ ') of the system and is stationed within the main cargo hold of the aircraft (17). The operator station houses the mission operators, electrical inverters, and the control computers for the sensor arrays used in data acquisition and reduction, and the communications equipment to relay the mission information to their designated end-users (field operators). The second assembly, the sensor platform (referenced to as ' $b$ '), is the locator system that attaches to the rear cargo ramp of the aircraft. The mechanical arm/pod system of the sensor platform has been designed around the multiple criteria's of stability, (FOV), modular attachments and ease of use for the operator. It has also 
been designed to eliminate any need for modification of the aircraft i.e. the removal of doors or fuel pods or changes in the electrical system or flight requirements (19).

The two-pallet system also uses the Aft. Escape Hatch of the C-130 aircraft as the median for the positioning unit, figure 1-8. The positioning unit communicates GPS coordinate readings directly to the two pallet system to govern location of the target area to the field operators on the ground. The positioning system is independent of the positioning units on-board the C-130. Figure 1-8 shows a concept model of the two-pallet system in final operating position on a C-130 aircraft.
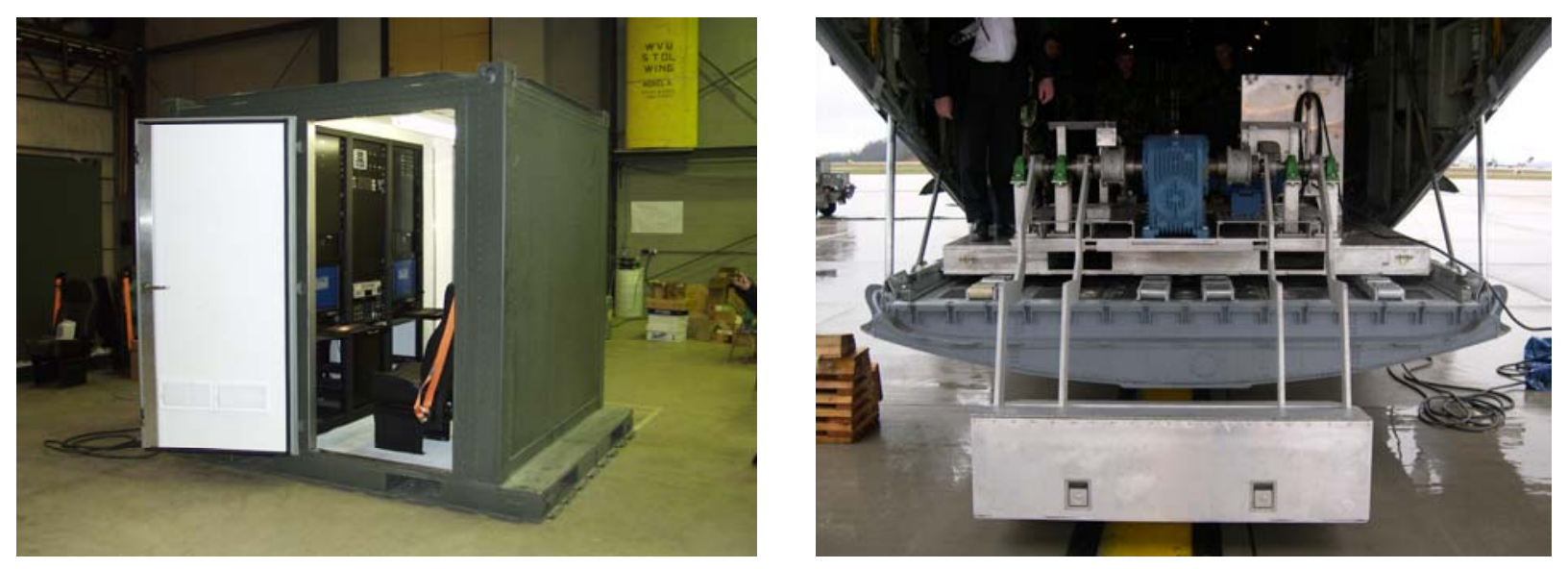

Figure 1-7: (a) Command and Control Center (operator station). (b) Locator system (sensor platform). 


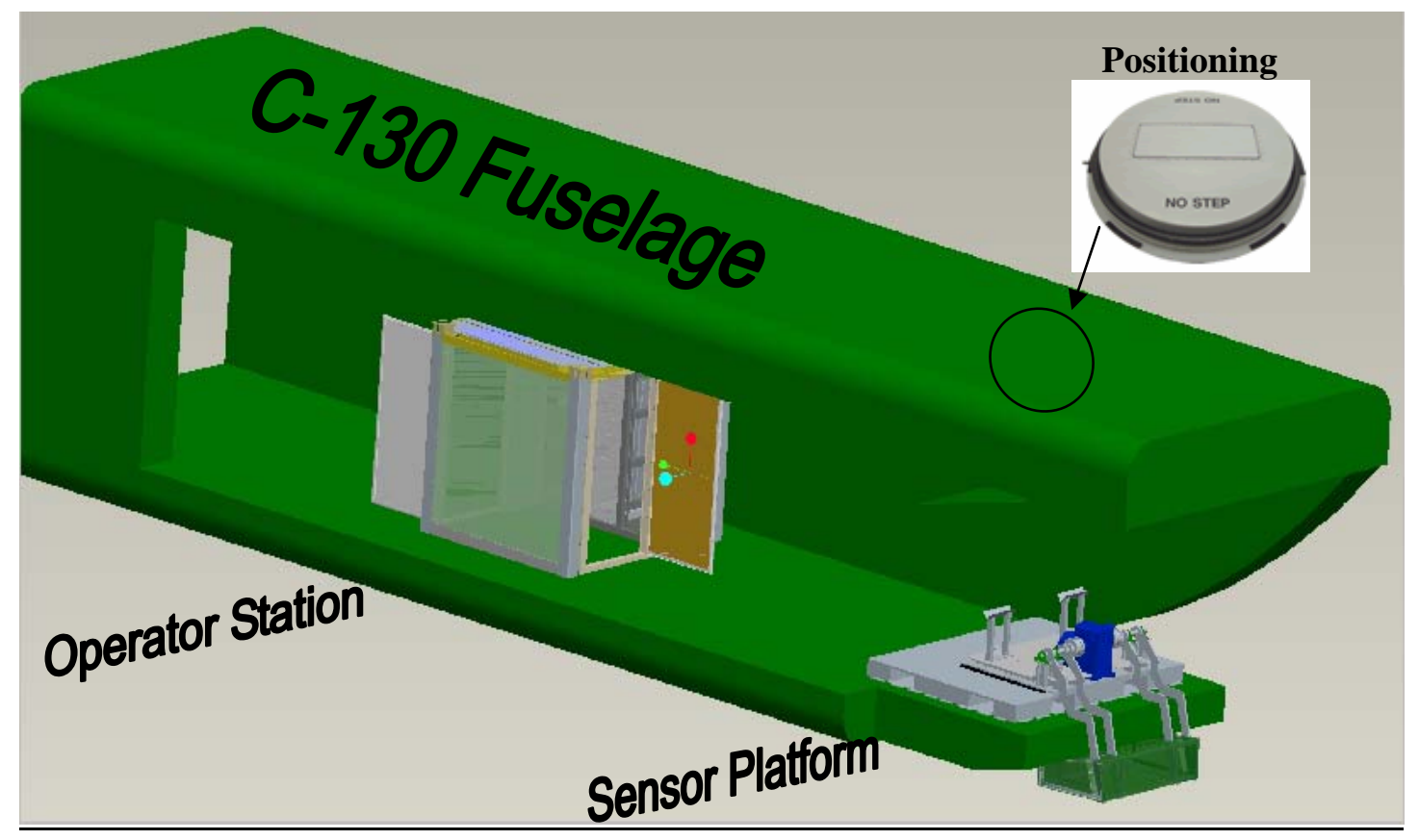

Figure 1-8: Oculus 1.0 System concept design inside a fuselage model of a C-130 aircraft (17).

From the ground up, OCULUS has been structurally designed for ease of use by military personnel. To standardize the sensor pallet system, both structures are constructed on standard cargo pallets that are easily secured (using standard military pallets as the base of the system) within the C-130 cargo hold. These pallets are standard in size and are used in all U.S. military cargo aircraft and have a strengthened perimeter for securing up to $10,000 \mathrm{lbs}$ of cargo.

The choice of this pallet fulfills another important requirement. It was essential that the complete deployment system be compatible with all C-130 aircraft because the C-130 has been produced in A through $\mathrm{J}$ variants for over fifty years in appreciable numbers. Using a standardized pallet insures that any in-use C-130 will be able to transport and utilize the OCULUS system, which translates into even broader use.

\subsubsection{System Design Requirements}

In developing a system for an existing airframe, the initial step in the design process is to establish the major design limitations. The design constraints established for this RoRo sensor 
platform system are categorized as electrical/power limitations (Section 1.3.1.1), structural limitations (Section 1.3.1.2), operator design requirements (Section 1.3.1.3), airframe modification limitations (Section 1.3.1.4), standardized componentry limitations (Section 1.3.1.5), and system mission capabilities (Section 1.3.1.6). These requirements and limitations establish the majority of the boundary conditions and constraints that governed the design process to develop the standardized system and are covered in detail as follows.

\subsubsection{Electrical Limitations}

The electrical power supplied by the C-130 aircraft is of vital importance to the full functionality of the deployed equipment. Special attention has been paid to this aspect of the OCULUS system's development. Structuring an assembly of equipment to fulfill the needs of a particular mission is constrained by the capability of the aircraft to supply sufficient power without impacting the performance or safety of the aircraft. The normal source of direct current (DC) power is four transformer-rectifier (TR) units. These units change the three-phase AC power from the AC generators to 28 volt DC power. A 24-volt battery is provided as an emergency source of DC power. Two of the TR units are connected to what is referred to as the essential AC bus with their output supplying power to the essential DC bus that supply power to the overall aircraft safety and flight control systems. The other two TR units are connected to the main $\mathrm{AC}$ bus with their output supplying the main DC bus. In the event of total AC power failure, the essential DC and main DC buses will also lose power. In this case the only remaining power source is the aircraft battery system that will power the battery bus and the isolated DC bus to provide basic instruments and communications for the flight crew (20).

The electrical power aboard current C-130's is supplied by five 40 KVA generators, 4 driven by the engines, and one driven by the Auxiliary Power Unit (APU). On earlier models, the 
power is supplied by four $40 \mathrm{KVA}$ engine-driven generators, and a $20 \mathrm{KVA}$ generator. DC power is provided from AC sources through four 200 ampere transformer rectifiers and one 24 volt, 36 ampere-hour battery. These components produce both AC and DC power that is available at various locations inside the cargo hold (Table 1-1). This power is available to all sections of the aircraft because there are no restrictions on cord pathways inside of the cargo hold as long as the emergency corridor along the left side of the fuselage is not blocked (20).

Table 1-1: On-Board Power for all C-130 Variants

\begin{tabular}{|l||l||c||c||c|}
\hline \multicolumn{1}{|c||}{ Location } & $\begin{array}{c}\text { Connector } \\
\text { Label }\end{array}$ & $\begin{array}{c}\text { Voltage } \\
\text { Label }\end{array}$ & Current Label & $\begin{array}{c}\text { CC(Hz)/D } \\
\text { C }\end{array}$ \\
\hline \hline \multirow{2}{*}{ Jump Door } & DC outlet & $28 \mathrm{~V}$ & $10 \mathrm{~A}$ & $\mathrm{DC}$ \\
& Iron Lung & $\begin{array}{c}28 \mathrm{~V} \\
115 \mathrm{VAC}\end{array}$ & $25 \mathrm{~A}$ & $\mathrm{DC}$ \\
& Galley & $20 \mathrm{~A}$ & $400 \mathrm{~Hz}$ \\
\hline \multirow{3}{*}{ Winch Cable } & DC outlet & $28 \mathrm{~V}$ & $200 \mathrm{~A}$ Current Limiter & $\mathrm{DC}$ \\
(forward & rectangular & $28 \mathrm{~V}$ & $200 \mathrm{~A}$ & $\mathrm{DC}$ \\
bulkhead) & (small round) & $28 \mathrm{~V}$ & $10 \mathrm{~A}$ & $\mathrm{DC}$ \\
& (big round) & $115 / 200 \mathrm{VAC}$ & $50 \mathrm{~A}$ & $400 \mathrm{~Hz}$ \\
\hline \multirow{3}{*}{ Forward Right } & & & & \\
Side & DC outlet & $28 \mathrm{~V}$ & $10 \mathrm{~A}$ & $\mathrm{DC}$ \\
& (ron Lung & $28 \mathrm{~V}$ & $25 \mathrm{~A}$ & $\mathrm{DC}$ \\
& Galley & $115 \mathrm{VAC}$ & $20 \mathrm{~A}$ & $400 \mathrm{~Hz}$ \\
& (giant round) & $115 \mathrm{VAC}$ & $20 \mathrm{~A}$ & $400 \mathrm{~Hz}$ \\
\hline
\end{tabular}

Section 1.3.1.1 outlines the electrical boundary conditions of the aircraft that will dictate the electrical design constraints of the OCULUS 1.1 system for safety of flight certification. In regards to the electrical design, the key concern for the testing and certification process is to ensure the OCULUS 1.1 System's electrical design does not violate the electrical distribution capabilities of the aircraft, and does not expose the aircraft's electrical system to potential overloads induced by the OCULUS 1.1 system.

\subsubsection{Structural Limitations}

The C-130 aircraft has long been considered one of the most structurally dependable and sound airframes developed in all of military history (1). The aircraft was designed to log long 
hours of flight and to endure these long flight conditions with a high cycle life over the course of the airframes total service life. The system's dependable structural makeup and relatively open architecture provides vast opportunities for designers of mount sensor systems to the platform system (1). Some of the key structural design limitations include: add-on system size and mass restraints, aircraft speed capabilities, aircraft weights and balances, and aircraft vibration transmittance (1).

The major design constraint that must be considered when designing an add-on system for an airframe is size and mass distribution capabilities (weights and balances). The C-130 aircraft was designed as a cargo/troop transport airframe and therefore it has large size (over 360 square feet of area) and mass (45,000 pound payload) capabilities for a fixed wing airframe. Figure 1-9 provides an overview of the airframe's size and mass carrying capabilities. In addition to the general size and mass limitations, the add-on system must also comply with the weight and balance ratio specific to the airframe to ensure maximum flight dynamics control and safety. 


\section{Palletized Cargo Restrictions TOTAL PLTS \\ C-130 \\ 6 \\ RESTRICTIONS \\ PLT 3-4 \\ 6" inch aisle on \\ short side \\ PLT 6 \\ 18" inch aisle \\ 84LX98WK76H}

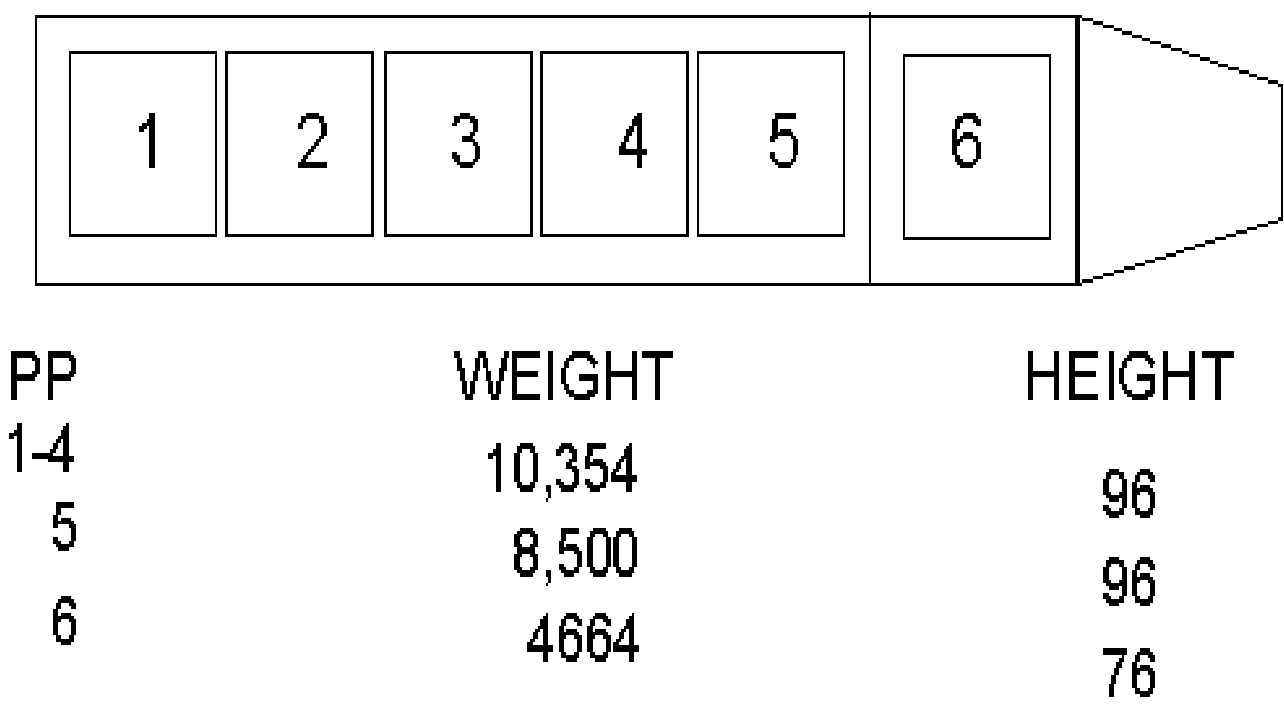

Figure 1-9: C-130 weight and height limitation chart (2).

The second limitation that directly relates to the design of the add-on system is the speed limitations of the airframe. The $\mathrm{C}-130$ has maximum speed limitations with both the cargo ramp in the closed and open positions. The airframes speed limitation with the rear cargo ramp in the open position is 150 KIAS. This is an important design limitation because it will determine the maximum aerodynamic drag that will result when the add-on system is deployed outside of the aircraft.

The third major structural design criteria is the vibration generation and transmittance produced by the C-130 airframe. This vibration generation will primarily be caused by four propeller blade systems that drive the airframe. This generated vibration will transmit through the body of the cargo aircraft at various amplitudes and frequencies based on specific locations 
internally and externally of the aircraft. These vibrations can have a significant impact on the dynamic loading seen by the add-on system (and the general structural life of the components), as well as its data taking capabilities.

Section 1.3.1.2 outlines major structural design constrains/requirements necessary to incorporate into the safety-of-flight design of OCULUS 1.1. These boundary conditions dictate the key structural parameters the system must abide to so it does not have any negative affects on the aircrafts safety and performance.

\subsubsection{Operator Design Requirements}

In designing add-on componentry for military aircraft a major set of design considerations are generated by the capability of the aircraft operators. The add-on systems should not impair the crew from performing standard flight operations and procedures. The additional operator design limitation is that the add-on system should not be designed to require intense/advanced training during standard and problematic situations, which the system may encounter.

The C-130 aircraft includes a cargo pallet roller system that lines the entire cargo ramp floor of the airframe. This roller system has individual pallet stations that mate with standard cargo pallets designated $463 \mathrm{~L}$ type pallets. Figure 1-9 overviews an outline of the 5 fuselage pallet stations and the additional cargo ramp pallet station. These pallets have standard locking flanges that mate with the locking mechanisms included in the floor roller system. The use of these pallets in the design of the add-on sensor platform system will ensure standard loading and unloading procedures for the flight operators and thereby classify the add-on system as cargo (21). 
The second major operator design constraint is simplicity of use during standard and problematic operational situations. The add-on system needs to be a universal military asset that will be implemented into several branches of the military and be operated by several skill levels of personnel. This requires that the system be designed to operate with minimal training and background knowledge of the system. The system's controls must adhere to the "one choice approach" concept to eliminate the possibility of operational error or misuse. Also the system must be designed with redundant back-up devices in the case that power is lost to the aircraft system.

This section explained a major concept requirement for the OCULUS system - simplicity of operator use. The system must not significantly alter the common practice of aircraft loadmasters and other personnel from their standard routines. The system must also have several safety back-up retraction capabilities to counteract any problems that may occur during flight. This is a major requirement in any safety-of-flight check prior to flight.

\subsubsection{Autonomous Attachment System}

A major structural design limitation that is its own sub-category in this design process is that the add-on sensor platform system must not create any modification to the base airframe. As mentioned earlier, several sensor platforms have been designed for the C-130 airframe but they have either had severe technology limitations or they have had to modify the airframe in some way. The main problem with modifying the airframe is that once the add-on system is installed, the airframe is completely dedicated to running the add-on sensor platform therefore, it cannot perform any additional tasks until the platform has been removed, the aircraft maintenanced, and then re-approved for flight. This causes severe limitations by not allowing the airframe to run multiple missions during the same flight. In addition, when the system is removed (in order to 
run a different mission i.e. cargo drop) the airframe is grounded for a considerable amount of time (1-2 weeks) for maintenance and to reapply any components that the add-on system altered.

\subsubsection{Commercial off-the-Shelf (COTS)/Government off-the-Shelf (GOTS) Components}

The major requirement from the maintenance perspective is to design the system using standardized components that are readily available in the event of component failure or for routine maintenance. The COTS/GOTS requirement removes all items that usually require special tooling to remove and reapply and especially those that require a long lead-time for delivery. This allows the military units that own the add-on system to carry additional components for the systems that require more care (maintenance, change out, etc.) than the components with a higher cycle life.

\subsubsection{System Mission Capabilities}

Many C-130 based missions are currently executed without the full advantage of advanced technologies that may enhance operations that require detecting, identifying, mapping, characterizing, modeling, targeting, tracking, and surveillance of targets of interest from the air. Missions requiring these technologies could include Counterdrug (CD) as well as Command, Control, Communications, Computers, Intelligence, Surveillance and Reconnaissance (C $\left.{ }^{4} \mathrm{ISR}\right)$ airborne sensing capabilities. Given the proper capabilities, C-130 missions could also be expanded to include toxin detection, airborne early warning and control, fire characterization, search and rescue, communications intelligence (COMINT), electronics intelligence $($ ELINT)/warfare, reconnaissance, surveillance and targeting, marine, terrestrial mine and obstruction detection, combat (SAR), and unmanned aerial vehicles (UAV's) control, all of which may be used to relay control in support of the warfighter and Homeland Security (HLS) applications $(22,23,24,25,26)$. 
To further support the engineering process and to optimize the OCULUS system's credentials as a valuable tool of assistance for Counterdrug and $C^{4}$ ISR Support, it was important to develop and adhere to some form of sensor requirements. This begins with a compilation of fundamental and preferred mission requirements as determined through contacts with multiple agencies and various National Guard Airlift Wings interested in enhancing mission capabilities, with the use of the C-130 aircraft. In addition, it was important to verify the practicality and effectiveness of any given sensor technology, as many advances have not yet been matched with mission needs and stand as theoretically useful until successfully applied. These determined requirements were then matched against remote data needs, current and future sensor capabilities and with those sensors and technologies that were defined through previous studies and/or contacts with vendors. Some of these capability requirements included stability, mounting space, and the means of arranging equipment for maximum effectiveness for the airframe.

Sensors listed below are preferred as readily accommodated by the C-130 airframe. These remote sensor technologies and supporting electronics are those that have the greatest potential use in supporting C-130 Counterdrug and $\mathrm{C}^{4}$ ISR based missions and fall within the listed specification of effectiveness for this airframe.

- $\quad$ Spectral Sensors (Multi-spectral, Hyper-spectral, etc.)

- $\quad$ Electro - Optical (FTIR, etc.)

- LIDAR

- $\quad$ Imaging Radar (SAR)

- Digital or wet film Cameras with Mosaic Capability

Additionally, a modular system capable of supporting ELINT/COMINT, on-board data processing and Line of Site/Over the Horizon (LOS/OTH) antennae systems was found to be 
preferable. Ultimately, the inclusion of all remote sensor categories in the design process ensures that Oculus is adequately robust and designed to support current and future Counterdrug and $\mathrm{C}^{4}$ ISR needs. The choice of these sensors, their weights and measures, and their usage requirements are all factors that affect the usefulness of the OCULUS system. These system requirements have been used to create the design requirements for OCULUS and also serve as the constraints for the design of experiment for the final flight test and certification. 


\section{Concept to Prototype}

The OCULUS 1.0 deployment system, shown in figure 2-1, was specified by the mission requirements set forth by the Department of Defense (DoD) sponsoring agency (17). These requirements gave the deployment system the design parameters to finalize a design that could eventually become a certified and mission approved system by the United States Air Force.

The OCULUS 1.0 system provided a conceptual design of the OCULUS system and determined the process by which the system would deploy outside of the rear cargo area of the C-130 aircraft into a final operational position for mission use. This concept design did not include a safety-of-flight design which is the required basis for the certification process. The two major design constituents implemented into the OCULUS 1.1 system are safety-of-flight design and the specific deployment procedure, with emphasis on minimizing the aerodynamic affect acting during flight.

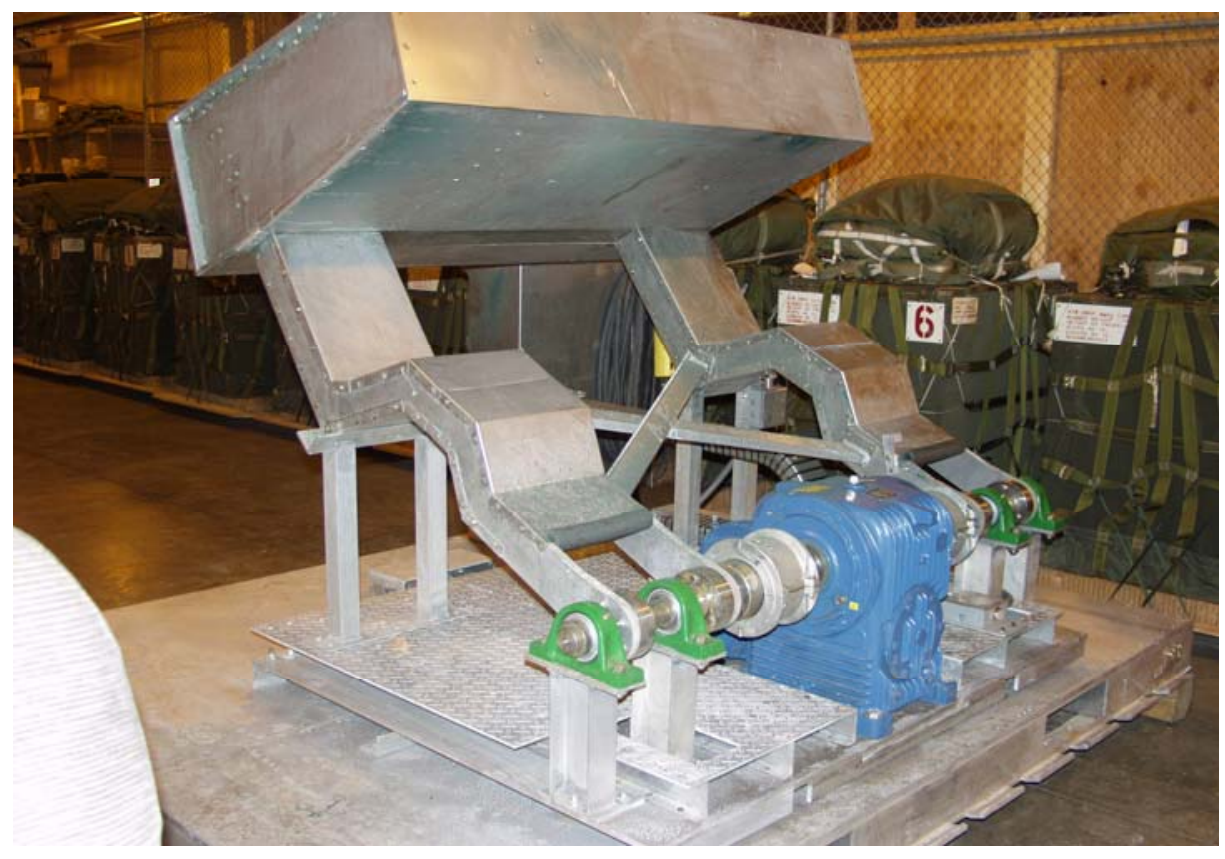

Figure 2-1: OCULUS 1.0 concept deployment system. 


\subsection{Safety of Flight Design}

The OCULUS Concept 1.0 system was completely re-designed and analyzed with a safety-of-flight focus for this study. Structurally this focus includes: locating, analyzing and potentially upgrading critical components, implementing improved fabrication techniques to include removal of weldments and adding high quality fasteners and connections. Electrically the safety-of -flight design focused on: an upgraded EMI shielding design and an increased safety design to minimize the potential of electrical shock during flight. The last major safetyof-flight design change is to improve the contact position (against the C-130 ramp belly) of the OCULUS 1.1 Sensor Pod in the final operating position (FOP). Overall, in this section, the major safety of flight design flaws in the OCULUS 1.0 system are acknowledged, and the design improvements implemented for the OCULUS 1.1 system are explained.

\subsubsection{Critical Component Analysis}

The concept capability of the OCULUS system is to deploy a system from inside the fuselage of the C-130 and deploy it outside and underneath the rear cargo ramp. The structurally critical components of the system will be those that are affected by additional aerodynamic wind loading outside of the rear of the aircraft. The assembly of the OCULUS system that comes in contact with the air flow outside of the airframe is the mechanical arm/pod assembly. This assembly is connected to the rotational shaft of an output gear reducer which is stabilized to the sensor platform by means of four bearing stand components. The two connection mechanism arms of this system are the four bearing stands (which connect the mechanical arms to the sensor platform by means of the rotational shaft, detailed in Figure 2-2, and the four mechanical arms which connect the sensor pod to the rotation shaft system detailed in Figure 2-3. 


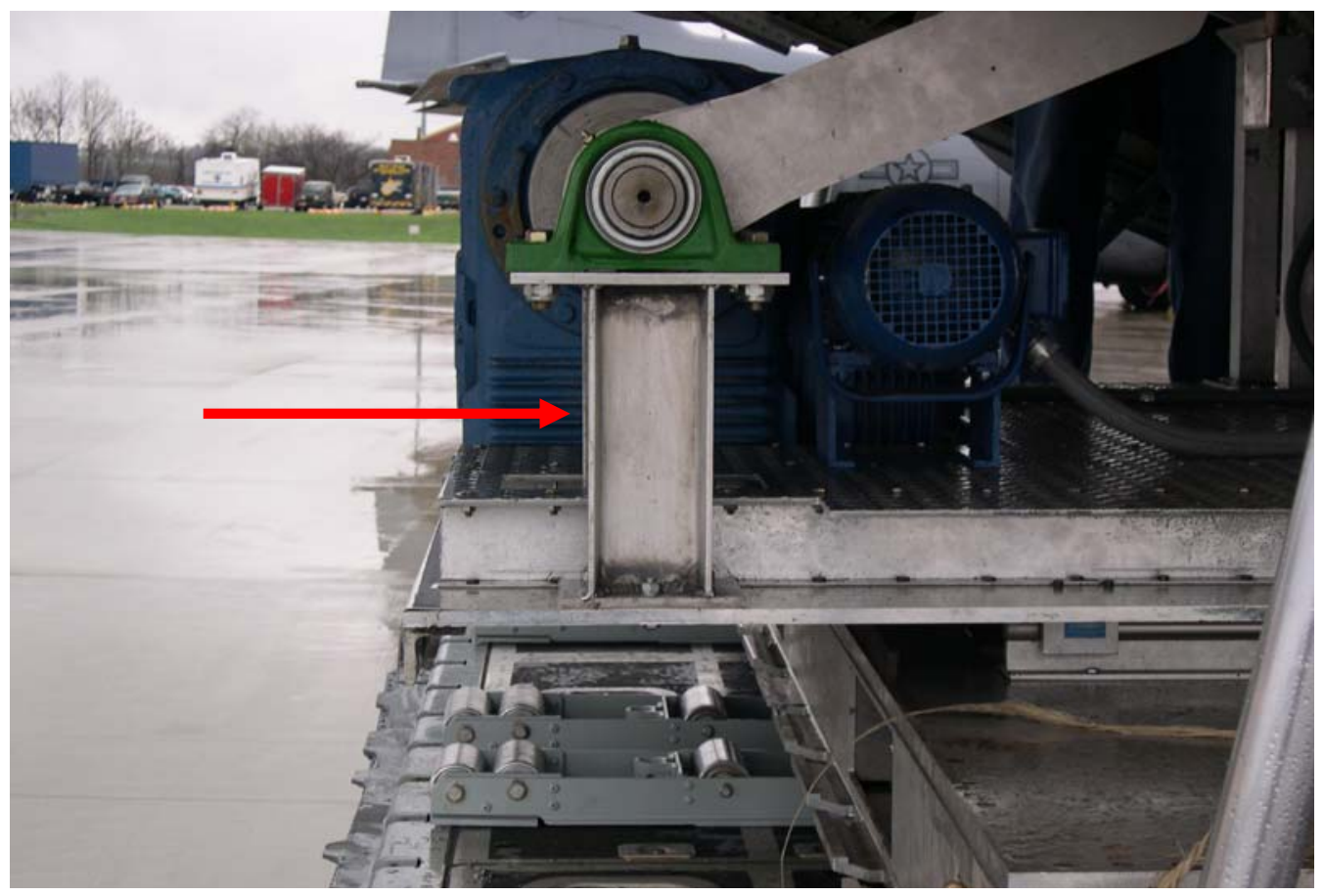

Figure 2-2: Highlighted bearing stand connection (4 stands) of the mechanical arm system to the sensor platform.

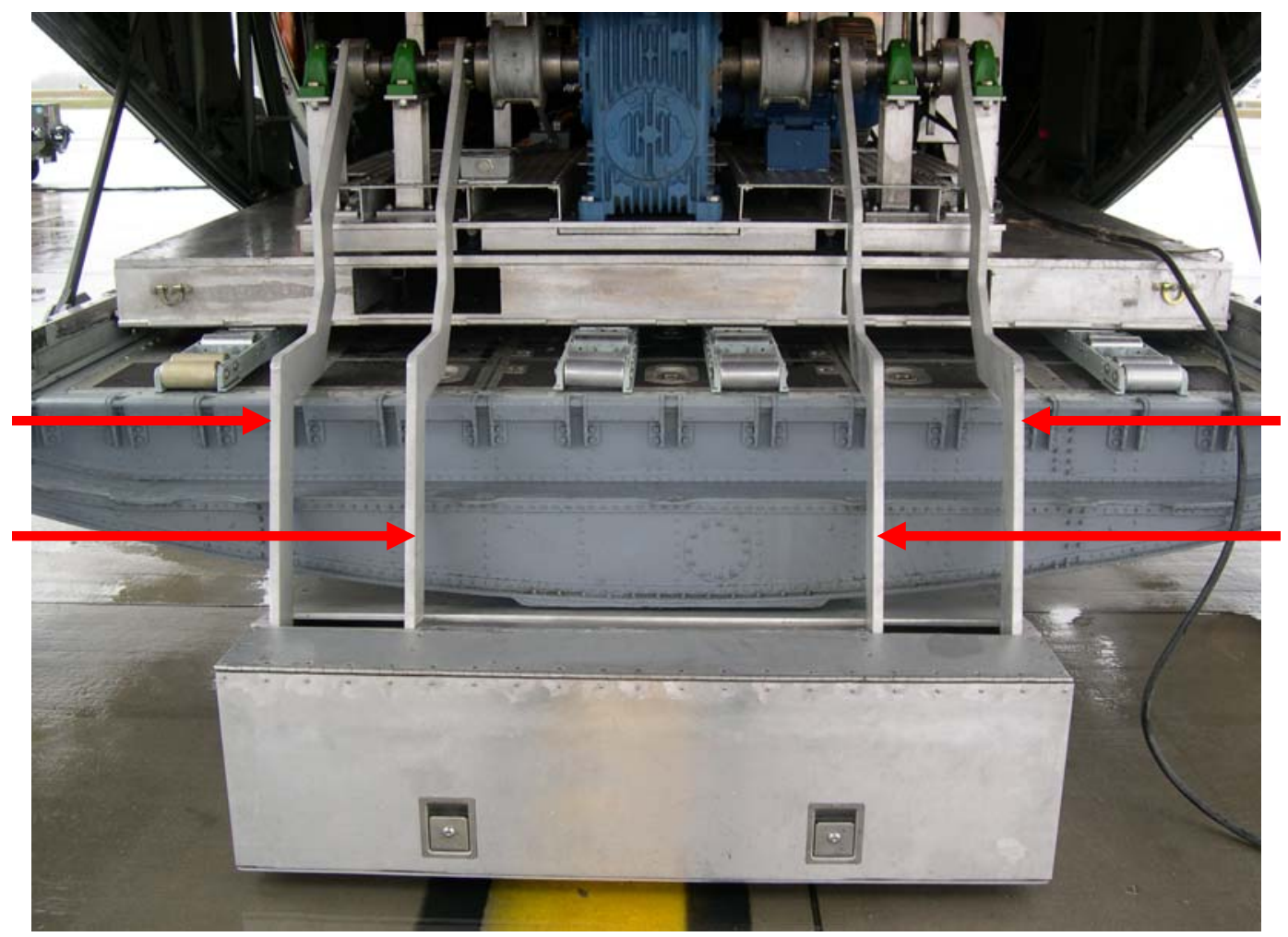

Figure 2-3: Highlighted 4-arm connection system of the OCULUS 1.0 Mechanical Arms. 


\subsubsection{Bearing Stand System Review and Analysis}

The OCULUS 1.0 concept bearing stands (Figure 2-4) were made of an aluminum Ibeam with welded $1 / 4$ " plate at the top and bottom. This design produced high stress locations at the weldments and also relied on the quality of fabrication (the welds) of the assembled system. Figure 2-4 highlights the fabrication errors in the welds at the potential critical stress points of the assembled system. These flaws were noticed and checked using a dye-penetrate test performed at Georgia Tech Research Institute (GTRI). This type of reliance on an incomplete weldment is not acceptable for aircraft structures or systems to be used on aircraft structures.

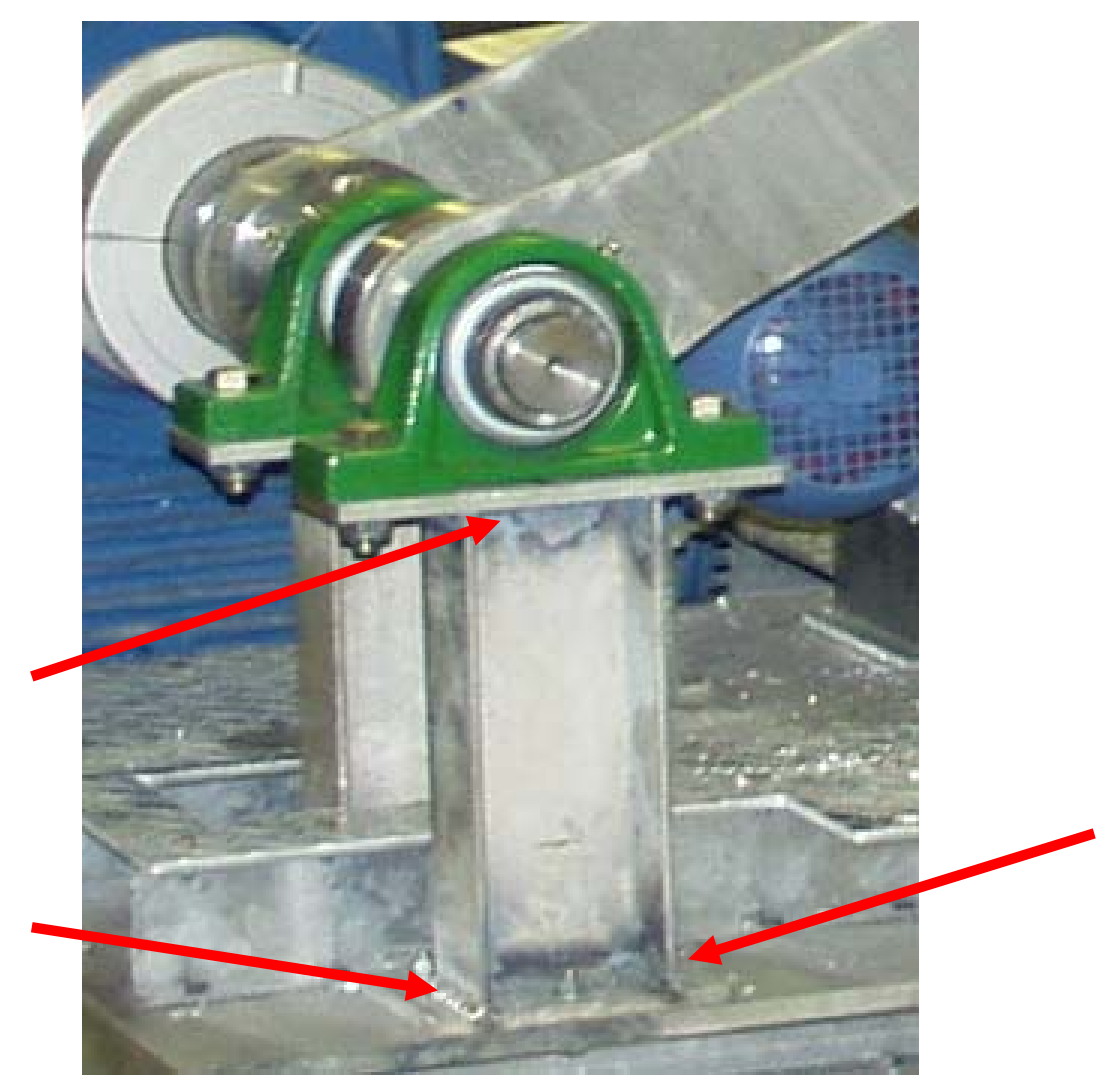

Figure 2-4: OCULUS 1.0 bearing stand with highlighted weldment connections.

A new design of a bearing stand must first eliminate high stress concentrations of the original system and second be fabricated in a manner to ensure quality. This design must incorporate the same dimensional features as the previous design so as to ensure it will fit into 
the existing assembly concept of the system. It must also incorporate the same attachment capabilities (i.e. bolt holes) to not alter the location or geometry of the components it is associated with in the assembly. Figure 2-5 shows the proposed new bearing stand design (modeled in Pro/Engineer). One of the noticeable design changes is the increased wall thickness of the center support ( 2 inches) and the mounting bases (half inch at the top and bottom).

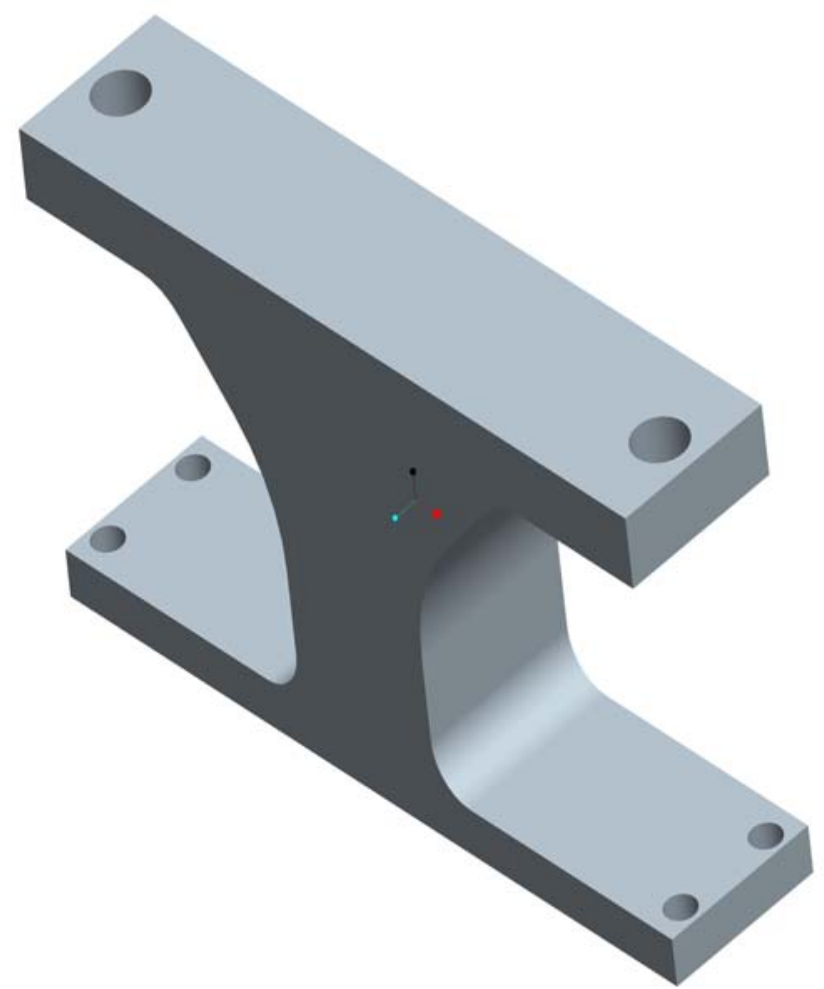

Figure 2-5: OCULUS 1.1 proposed bearing stand design.

To ensure this design exceeds the strength and reliability of the OCULUS 1.0 bearing stand, a finite element analysis (FEA) was conducted (using Pro/Engineer and Pro/Mechanica) on the system using approximated loads during flight conditions which included the aerodynamic drag forces collected during an experimental aerodynamic rake test on-board a C-130 aircraft. (27). 


\section{$\underline{\text { FEA Approach }}$}

There are two widely used methods in performing FEA using software: the H-element approach and the P-element approach. When using the H-element approach, the FEA program uses low order polynomials as the governing equations, and for accurate results this requires that there be many elements. For example, strain is obtained by taking the derivatives of the displacement field and the stress are computed from the material strain (28).

For a first order interpolating polynomial within the element, this means that the strain and stress components within the element are constant everywhere. This also means that if the elements are not small enough, errors will occur within the FEA. Also, areas with larger gradients will be very inaccurate because of the constant values through the elements. The means for solving this in the past was to use finer meshes so that the elements would be smaller. However, the finer the mesh the harder it is for the computer to calculate the FEA. This is due to the increased amount of equations from the increased amount of elements in the finer mesh. By using the method of mesh refinement, a convergence test could be done, but if the computing power is lacking the user will never truly know if the test converged.

The alternative to the H-element method is the P-element method, and this uses higher order interpolating polynomial equations. Therefore, instead of continually refining the mesh, the degree of the interpolating polynomial is increased until convergence is reached. This allows for the mesh to stay the same for each test, and uses far less interpolating equations. Pro/Mechanica allows for the order of the interpolating polynomial to reach as high as a ninth order. In most FEA software the mesh refinement method does work to reduce the errors. However, the amount of mesh refinements it would take to match the accuracy of the higher order P-element would 
involve an incredible amount of elements. This is why the P-element method is much more efficient and faster to use due to the lesser number of equations.

\section{Boundary Conditions}

The boundary conditions of the system assumed a complete restraint on the bearing stand four attachment holes and the loading applied is transferred through the two connection holes which are attachments for the rotational shaft bearing which is the attachment mechanism for the

mechanical arms. This loading used on the bearing stands is the maximum drag (from report $\sim 322 \mathrm{lbs}$ ) transferred through the mechanical arm moment arm with an additional dynamics loading factor of 1.5 to give a total of $\sim 600 \mathrm{lbs}$ of pull-up force against the rear of the stand (27). Figure 2-6 shows the graphical resulting stresses and displacements on the bearing stand.
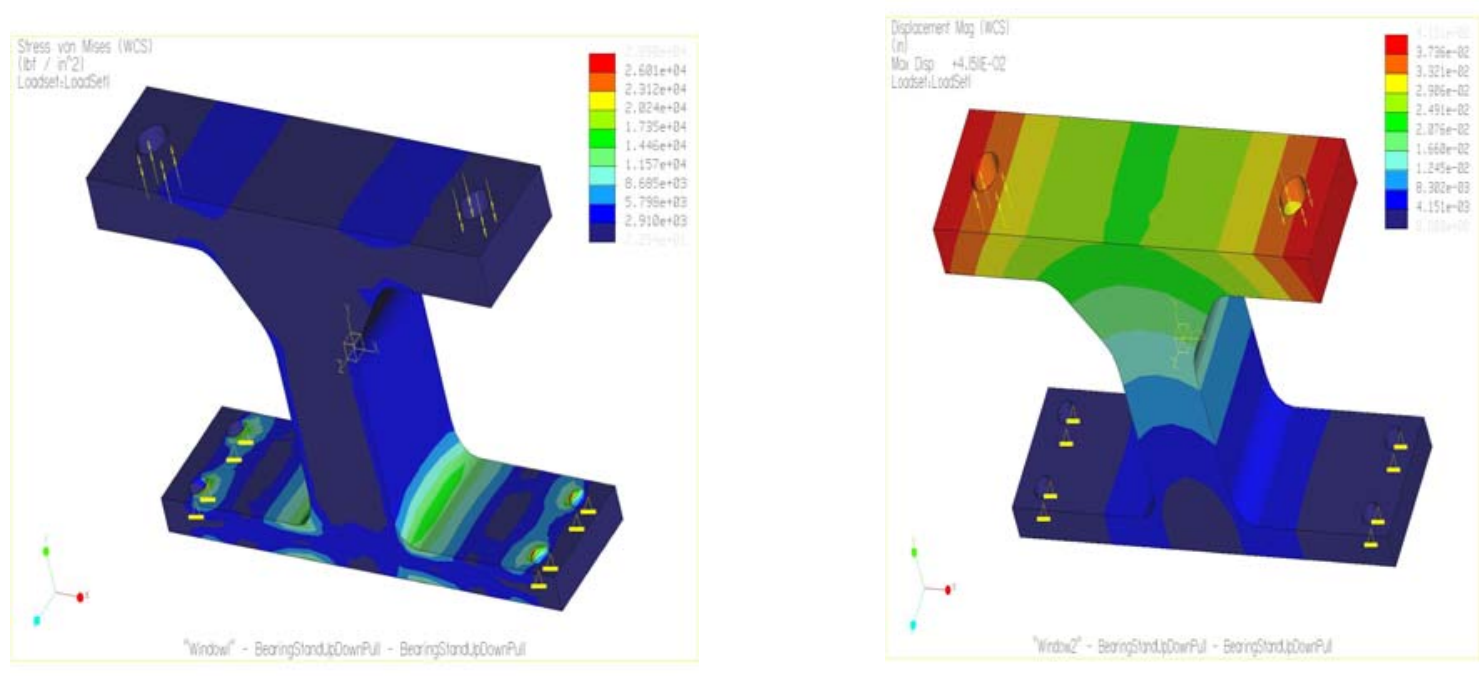

Figure 2-6: Stress (left) and displacement (right) graphical resultant display of the FEA performed on the connection bearing stand.

The maximum stress seen in the stand at the analysis conditions is $\sim 17,400 \mathrm{psi}$. This stress is well below the allowable yield strength of the specified Aluminum 6061-T6 material. This maximum stress does not include the high stress seen inside the fastener holes. These high 
stress points are considered point loads and are not indicative of the actual stresses acting on the component.

This new proposed design was made from a solid piece of aluminum with the specific geometry cut-out using a precision water-jet. The corrected bearing stands (Figure2-7 right) were cut from a solid piece of 6061-T6 Aluminum, which completely eliminated a high stress concentration and vertical alignment issues because they were fabricated using the highly accurate cutting capabilities of a water-jet. This type of stand for bearings also increased the strength of the rotational system supports by approximately $50 \%$ based upon a previous analysis performed on the OCULUS 1.0 bearing stand (this earlier analysis was performed assuming a complete welded connection).
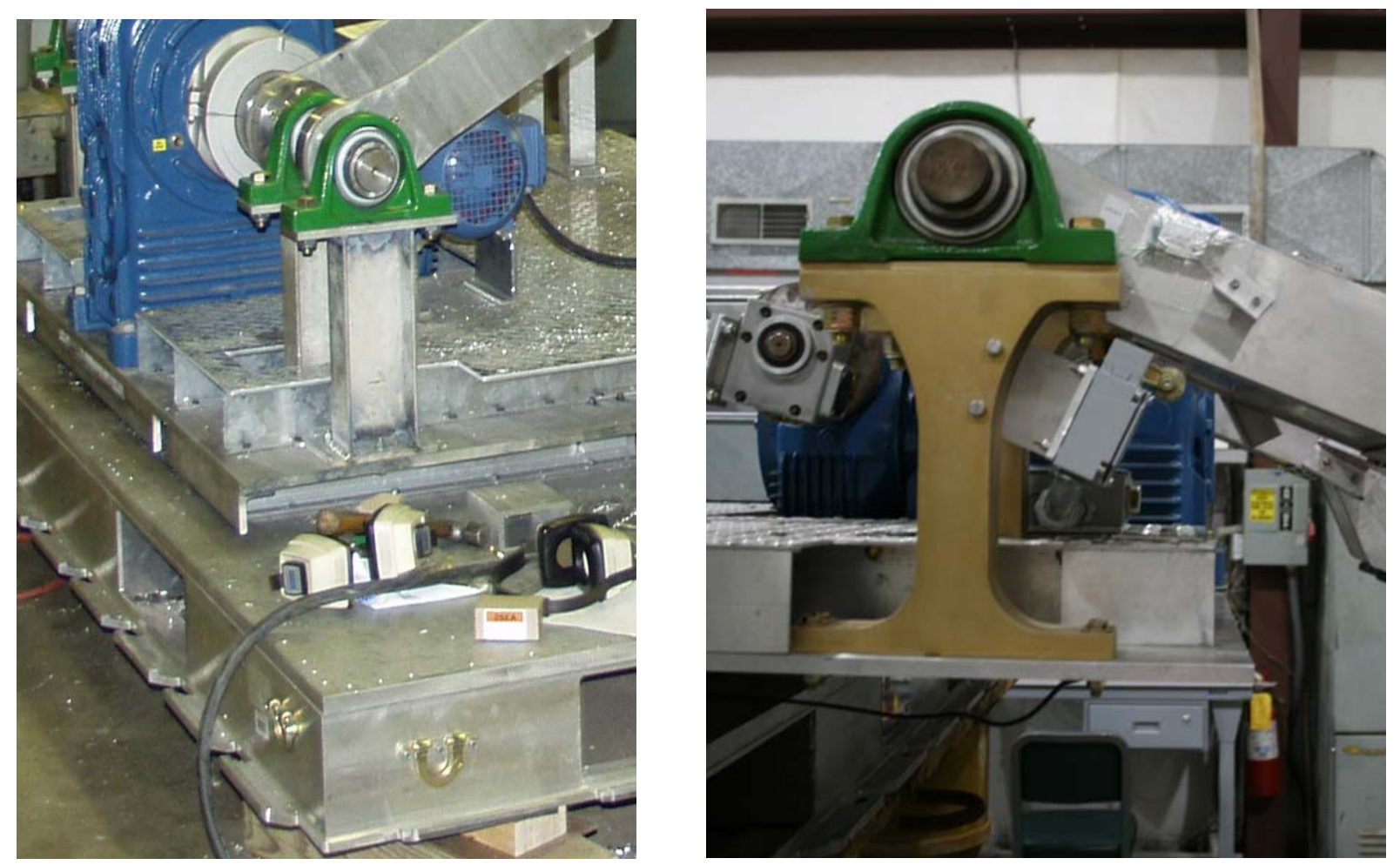

Figure 2-7: (left) OCULUS 1.0 rotational system support design. (right) Upgraded OCULUS 1.1 rotational system support design 


\subsubsection{Mechanical Arm Review and Analysis}

Aerodynamic Loading

The aerodynamic loading affect on the mechanical arm/pod system is taken directly from aerodynamic load data obtained from an aerodynamic rake test performed by WVU on a C-130 aircraft. The results from the test give a worst case loading scenario that was designed during the development of the system (27).

The mechanical arm system is fastened to a customized 6.5-inch thick reinforced standard military C-130 pallet, which is the foundation and anchor for the arm. The pallet is locked and secured onto the $\mathrm{C}-130$ ramp, making the plane and mechanical arm act as one rigid body, leaving the arm with two degrees of freedom. The aerodynamic test rake's accelerometer gave measurements of vibration and acceleration of the $\mathrm{C}-130 \mathrm{ramp}$, and the pitot tubes measured the airflow 12-16 inches below the C-130 ramp door in the open position (0-degrees) during flight at two indicated airspeeds of 130 knots and 150 knots. The test rake on the C-130 aircraft is shown in Figure 2-8. This is the location in which the sensor pod sits underneath the rear cargo ramp in the final operating position. The results showed the design and optimization of the overall mechanical arm's natural frequencies where outside the power spectrum frequency range of the vibration profile found (29). They generated minimal amplitudes of deflection in the principle $\mathrm{X}, \mathrm{Y}$ and $\mathrm{Z}$ directions and reduced the probability of early fatigue failures. The results (used in this mechanical arm analysis) from the aerodynamic rake test are shown in Table 2-1. 


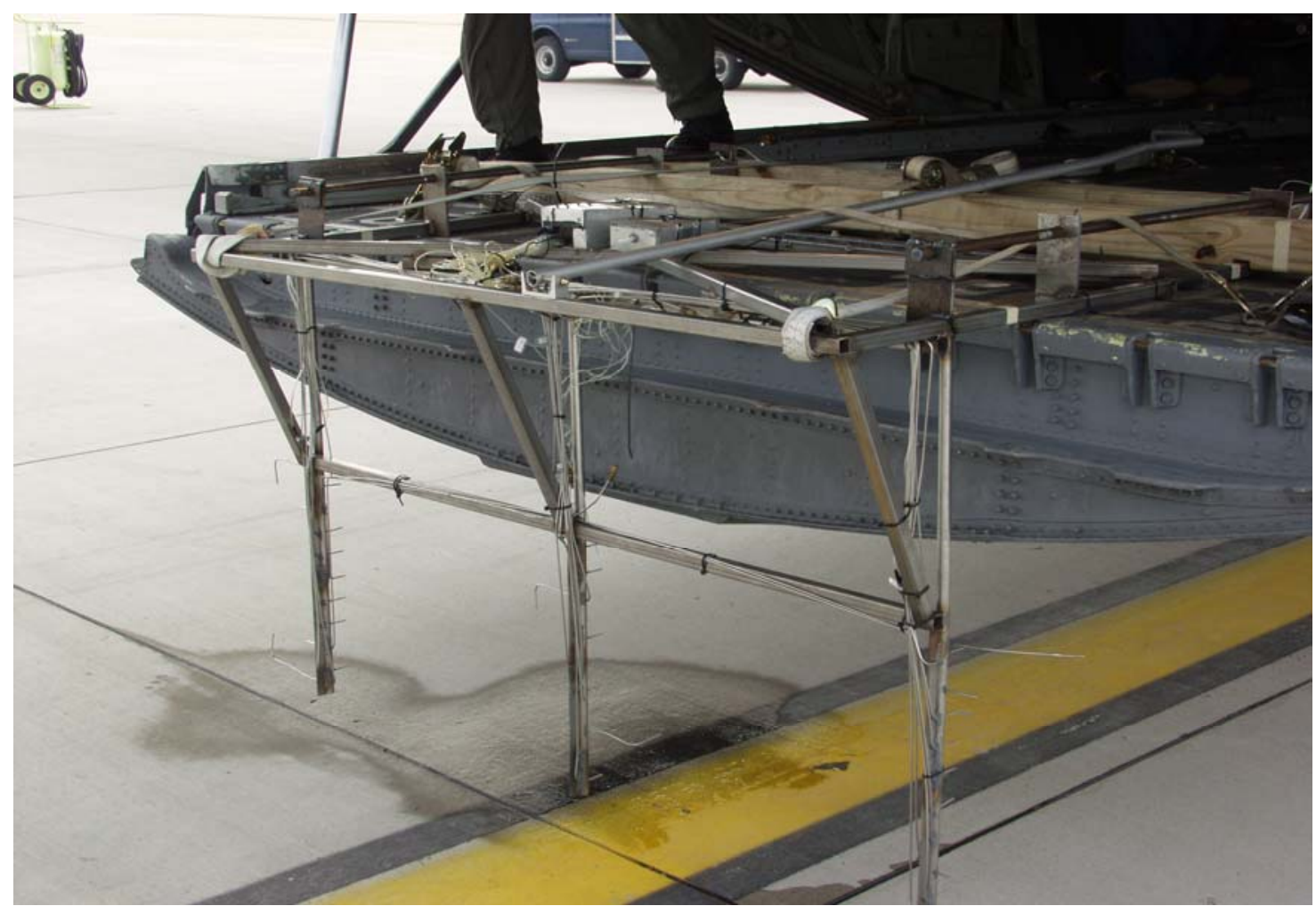

Figure 2-8: Aerodynamic test rake mounted on the rear cargo ramp of the C-130 aircraft (29).

Table 2-1: Aerodynamic test results at varying speeds and ramp angle (29).

\begin{tabular}{|c|c|c|c|c|}
\hline Test & $\begin{array}{c}\text { Velocity } \\
\text { (kias) }\end{array}$ & $\begin{array}{c}\text { Deck Angle } \\
\text { (deg) }\end{array}$ & $\begin{array}{c}\text { Ramp } \\
\text { Angle } \\
\text { (deg) }\end{array}$ & $\begin{array}{c}\text { Drag } \\
\text { (lbs) }\end{array}$ \\
\hline 1 & 130 & 0 & open & 253 \\
\hline 2 & 130 & 0 & 10 & 233 \\
\hline 3 & 130 & 0 & 20 & 199 \\
\hline 4 & 130 & 5 & 20 & 226 \\
\hline 5 & 130 & 5 & 10 & 222 \\
\hline 6 & 150 & 5 & open & 248 \\
\hline 7 & 150 & 0 & open & 322 \\
\hline 8 & 150 & 0 & 10 & 263 \\
\hline 9 & 150 & 0 & 20 & 240 \\
\hline 10 & 150 & 0 & closed & 111 \\
\hline
\end{tabular}

The OCULUS 1.1 mechanical arm/pod system will only be deployed when the cargo ramp is in the horizontal position and the cargo door is in the complete open and locked position. At no point in time will the sensor platform pod be deployed while the cargo ramp and cargo door are in any other position. The mechanical arms, Figure 2-9, support the sensor pod and 
carry the loading through the rotational support structure. This assembly was re-designed and modeled in Pro/Engineer to meet safety-of-flight requirements.
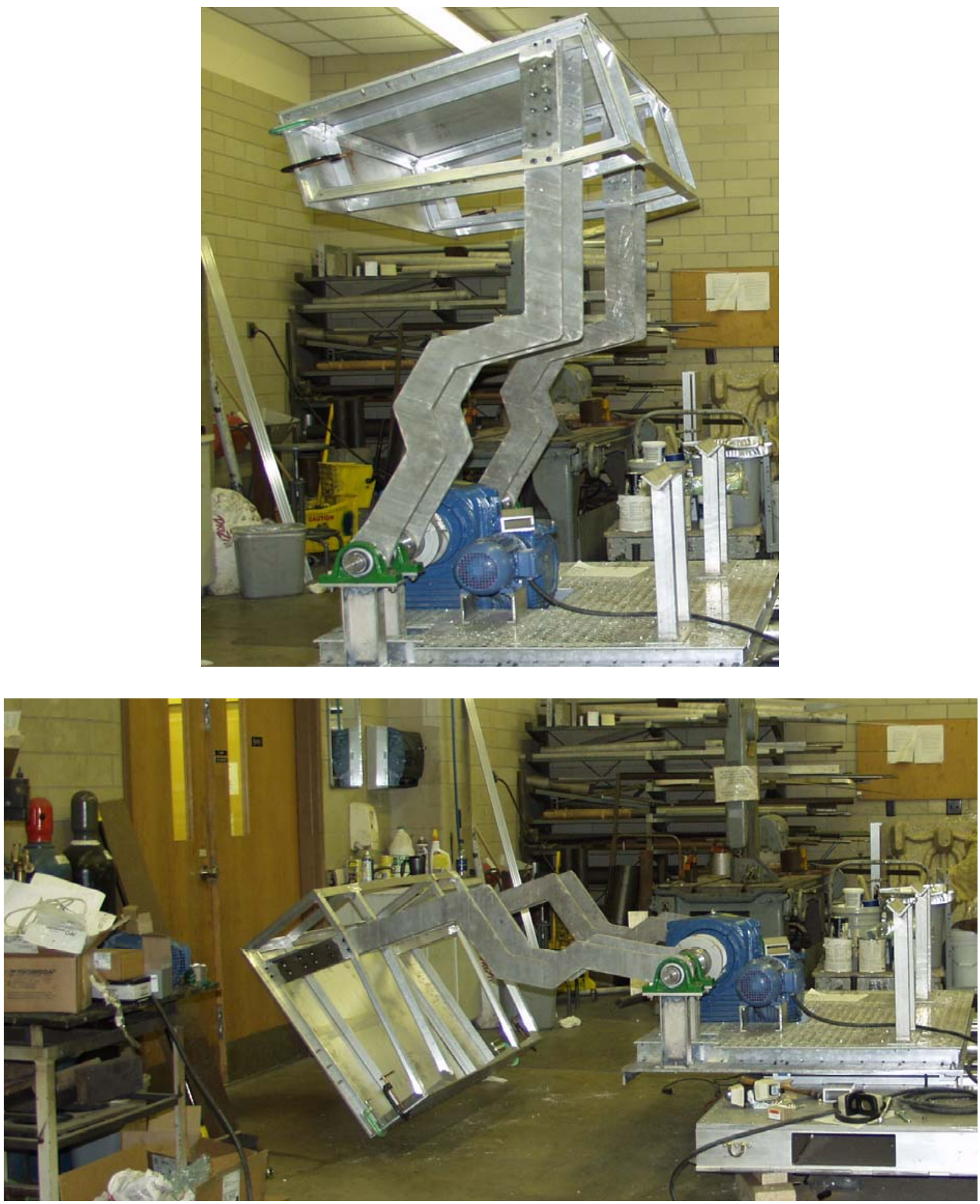

Figure 2-9: (top) Mechanical arm/pod system at the vertical position in the rotation stage of the deployment process. (bottom) Mechanical arm/pos system during the deployment stage. 


\section{Mechanical Arm Model}

This model was created and modified in Pro/Engineer modeling package. Figure 2-10 shows the finite element model (FEM) created using Pro/Engineer. As the model shows, the complex geometry of the arm (used to fit the ramp face of the C-130 aircraft) has several extreme bends and radii that will likely cause higher stress concentrations on the model. The Pro Engineer mechanical arm model's features are listed in table 2-2 below.

Tables 2-2: Mechanical arm's Pro Engineer part features.

\begin{tabular}{|lc|}
\hline Model Type: Three Dimensional \\
\hline Points & 619 \\
Edges & 2710 \\
Faces & 3478 \\
Springs & 0 \\
Masses & 0 \\
Beams & 0 \\
Shells & 0 \\
Solids & 1411 \\
Elements & 1411 \\
\hline
\end{tabular}

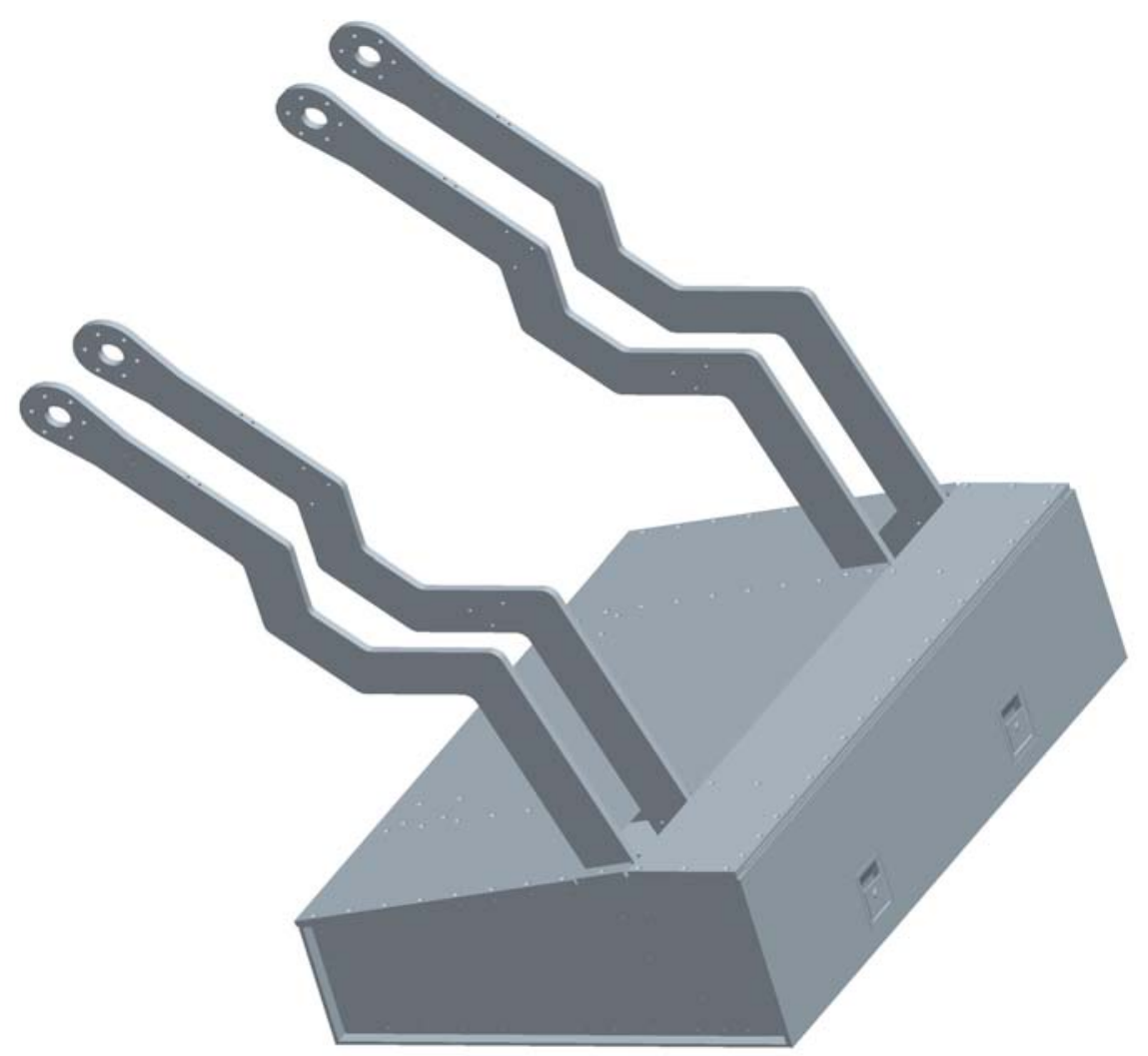

Figure 2-10: Finite element model (FEM) of the OCULUS mechanical arm. 


\section{$\underline{\text { Boundary Conditions }}$}

The mechanical arm/pod system consists of four mechanical arms and a sensor pod attached at the end of each arm (shown previously in Figure 2-3). For simplicity in the mechanical arm analysis, it was assumed that all loading and payload weight is evenly distributed between the four arms, and that the system is abutted up against, and engaged, with the bottom of the rear ramp of the C-130 aircraft. This scenario would ultimately reduce the stresses that may be seen on the arms as opposed to if the system is hanging in the air stream without a support to rest against. This system is only intended to remain out in the airstream for approximately 45 seconds during the deployment period. Once this assumption was made the FEM can be simplified to an analysis of loading vectors on one arm. These loading directions, on the simplified mechanical arm model, are displayed in Figure 2-11.

\section{Hub Bolts and Rotational Shaft Restraints}

\section{Drag Force Loading}

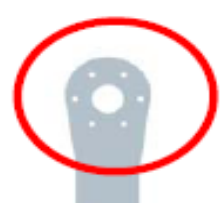

Sensor Pod and

Mechanical Arm Weight

Figure 2-11: Simplified loading and restraint characteristics of the OCULUS 1.1 mechanical arm analysis. 
The loading directions of the pod weight (with payload) are angled due to the center of gravity $(\mathrm{CG})$ of the pod system being displaced in that direction. The material used for the arms is Aluminum 6061-T6 material cut to the specific geometry using a water jet machine. Material properties of this aluminum material are listed in Appendix A.

The boundary conditions applied to the mechanical arm system are explained by displacement restraints applied to the model along with load/force representation. The load/force representation action on the mechanical arm system is based on the anticipated payload of the sensor pod. The system was designed to normally handle up to 300 pounds of centered, evenly distributed payload in the sensor pod. To get a general concept of the stresses acting on a mechanical arm, the loading intervals for the simulation began with no loading and extended to 300 pounds at intervals of 100 pounds at each trial $(32,33,34)$.

The goal of this analysis was to simulate the stress reaction of the mechanical arm system at the loading anticipated during normal flight conditions. Due to the arms unique geometrical makeup this model's fundamental goal is to predict the regions at which the high stresses will be seen using simulated and assumed, evenly distributed loading throughout the pod and arms assembly. It should be noted that for validation of this model the assumed flight conditions are at level flight and do not incorporate banking and slips.

The results of the loading analysis (Trials 1-8) are shown collectively in Table 2-3 and individually (stress color display) in figures 2-12 thru 2-19. In Table 2-4 the 130 KIAS speed is the minimum because anything below that is on the verge of a "stall" speed for the aircraft and the 150 KIAS speed is a normal maximum operating speed for the aircraft, at the anticipated altitude range of 5,000-8,500 feet with the ramp open. 
Trial 1: Payload Weight (0 pounds), Aircraft Speed (130 kias)

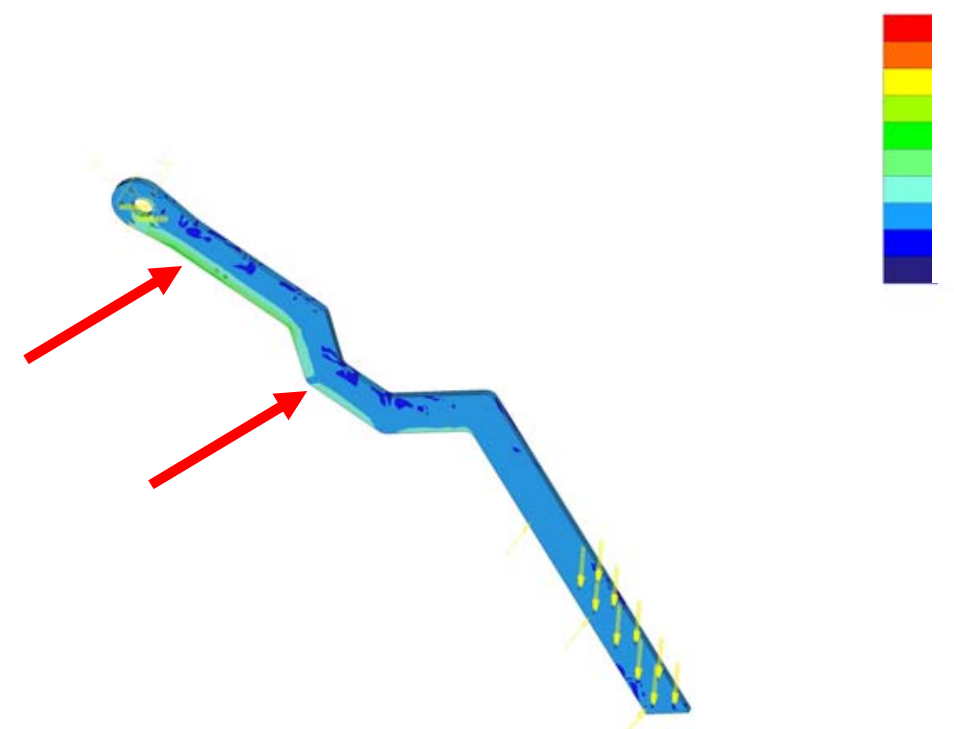

Figure 2-12: Stress distribution for Trial 1 loading.

Trial 2: Payload Weight (0 pounds), Aircraft Speed (150 kias)

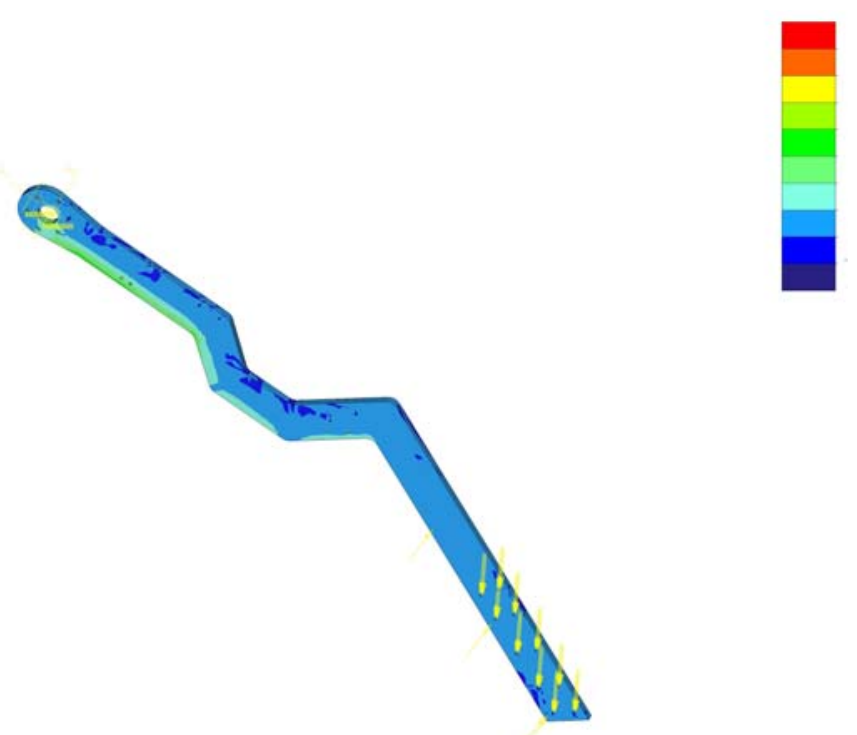

Figure 2-13: Stress distribution for Trial 2 loading. 
Trial 3: Payload Weight (100 pounds), Aircraft Speed (130 kias)

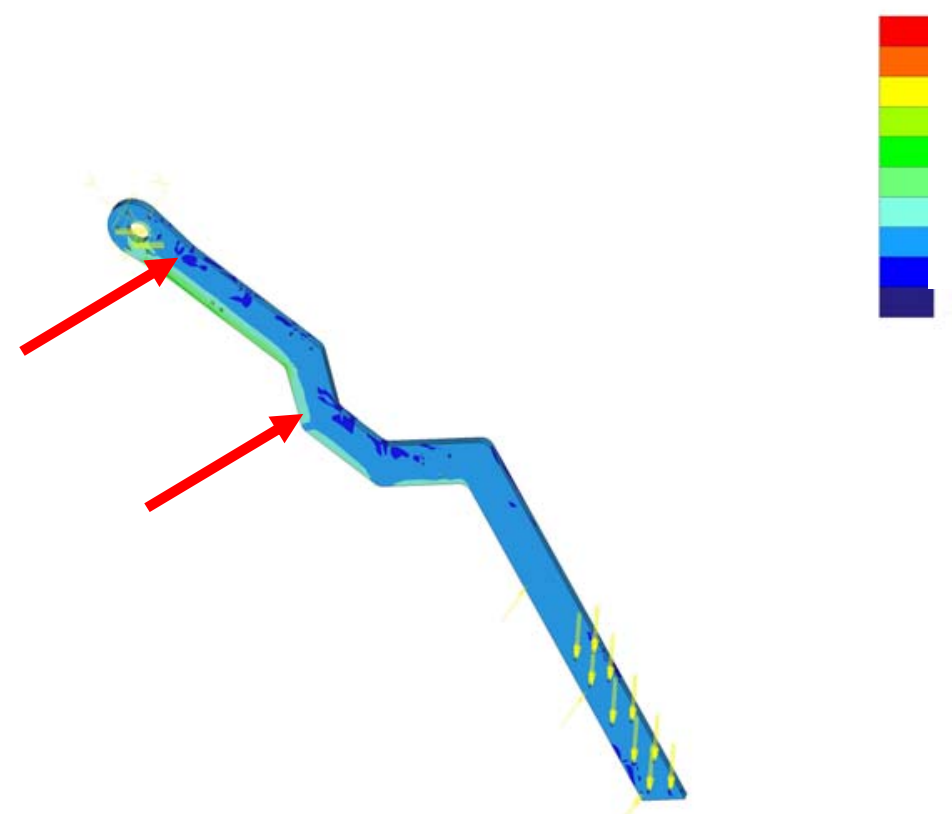

Figure 2-14: Stress distribution for Trial 3 loading.

Trial 4: Payload Weight (100 pounds), Aircraft Speed (150 kias)
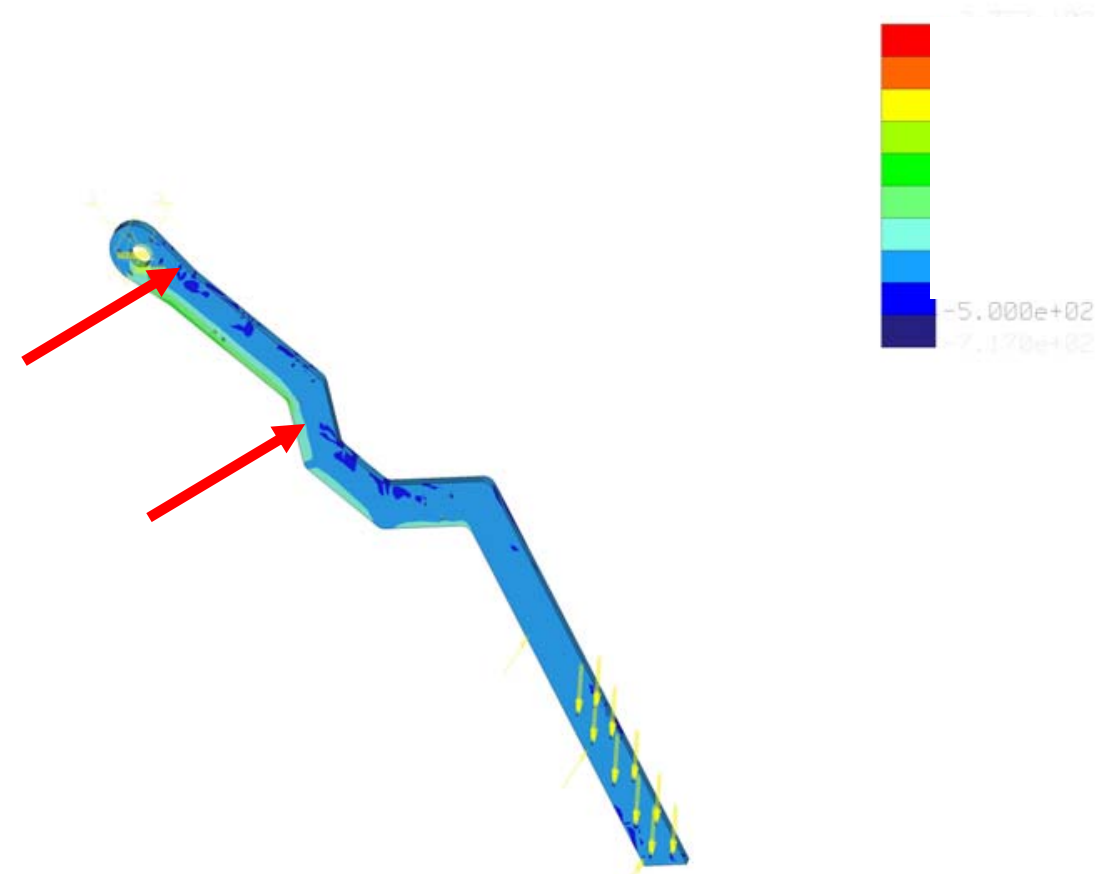

Figure 2-15: Stress distribution for Trial 4 loading. 
Trial 5: Payload Weight (200 pounds), Aircraft Speed (130 kias)

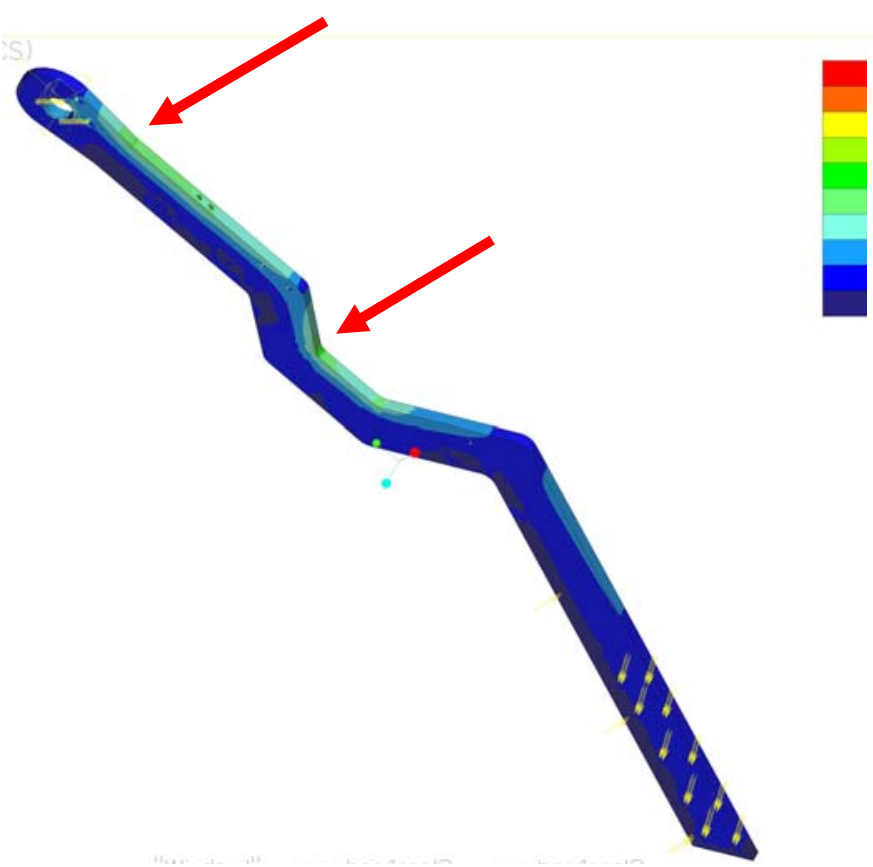

Figure 2-16: Stress distribution for Trial 5 loading.

Trial 6: Payload Weight (200 pounds), Aircraft Speed (150 kias)

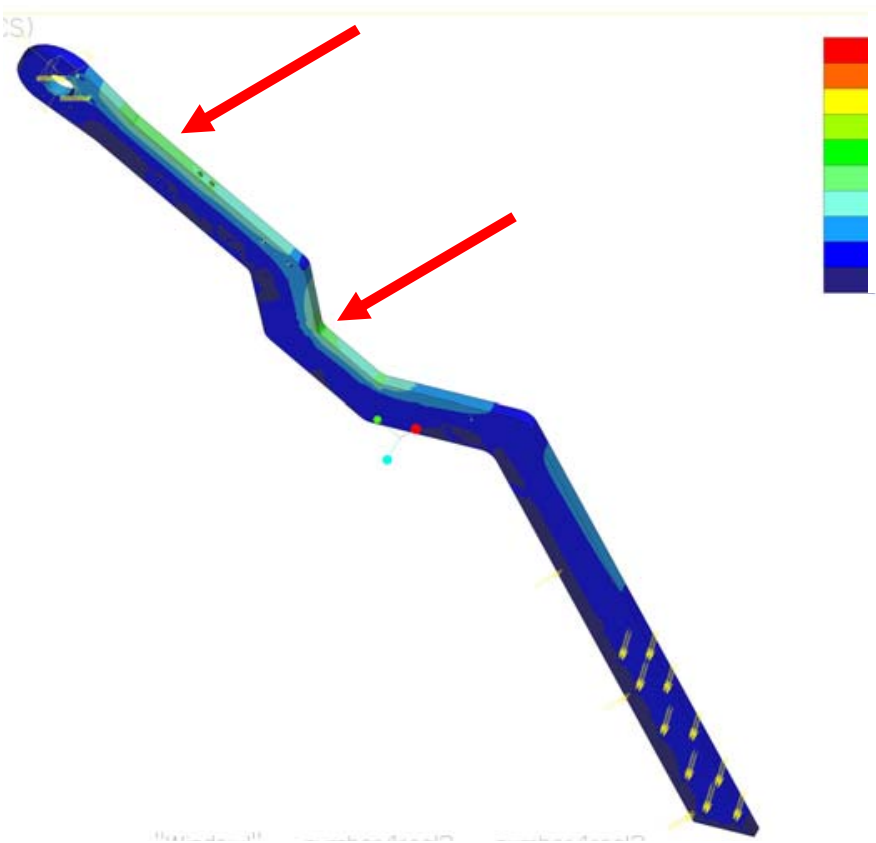

Figure 2-17: Stress distribution for Trial 6 loading. 
Trial 7: Payload Weight (300 pounds), Aircraft Speed (130 kias)

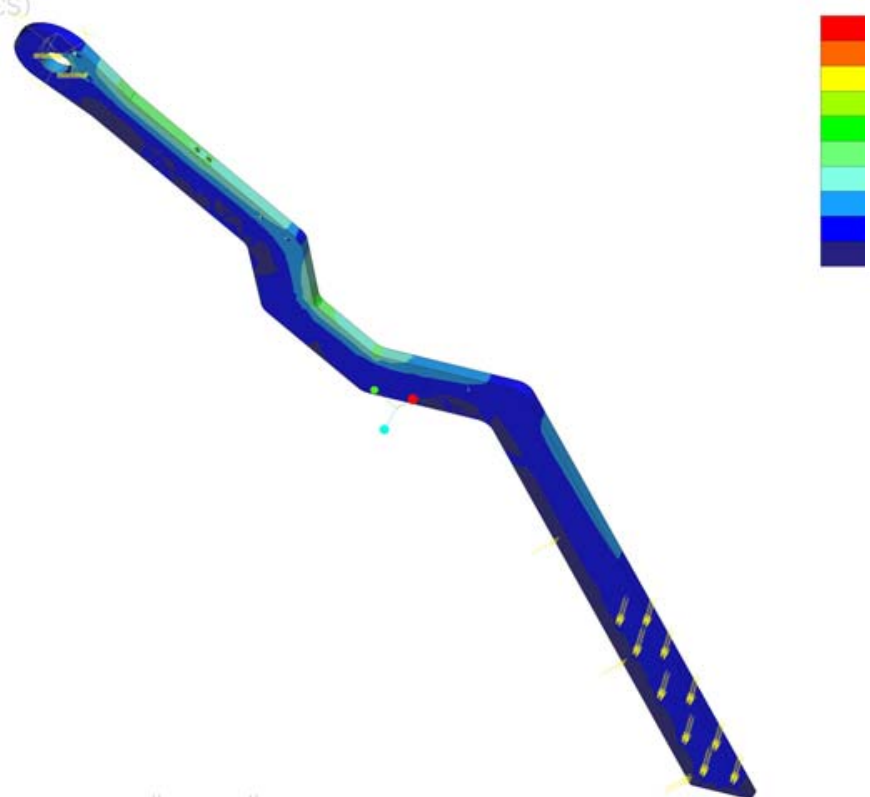

Figure 2-18: Stress distribution for Trial 7 loading.

Trial 8: Payload Weight (300 pounds), Aircraft Speed (150 kias)

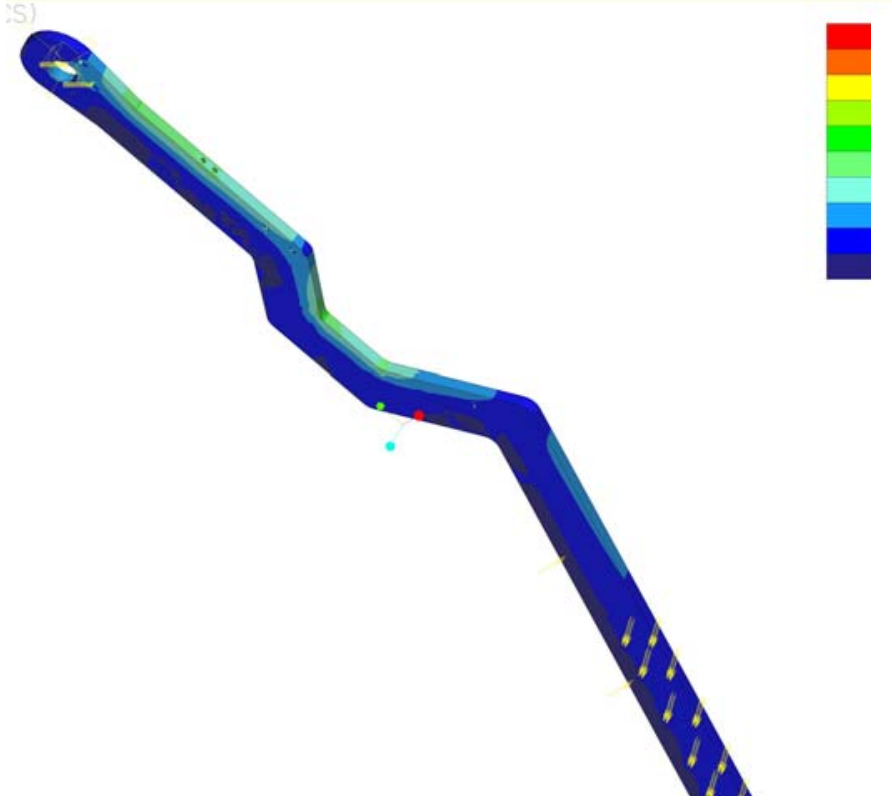

Figure 2-19: Stress distribution for Trial 8 loading. 
Table 2-3: Maximum principal stress value results of the mechanical arm FEA.

\begin{tabular}{|c|c|c|}
\hline $\begin{array}{c}\text { Payload } \\
\text { Weight } \\
\text { (lbs) }\end{array}$ & $\begin{array}{c}\text { Aircraft } \\
\text { Speed } \\
\text { (kias) }\end{array}$ & $\begin{array}{c}\text { Max } \\
\text { Stress } \\
\text { (psi) }\end{array}$ \\
\hline 0 & 130 & 4,565 \\
\hline 0 & 150 & 6,235 \\
\hline 100 & 130 & 3,901 \\
\hline 100 & 150 & 5,053 \\
\hline 200 & 130 & 3,342 \\
\hline 200 & 150 & 3,906 \\
\hline 300 & 130 & 3,690 \\
\hline 300 & 150 & 4,085 \\
\hline
\end{tabular}

As predicted, the high stress regions of the arm (highlighted by the green to red coloration) are seen at the connection end bends of the arm (indicated by the green color region on the model), and at the top neck region where the arm attached to a rotational shaft used for the rotational deployment. It should be noted that the models high stress concentration regions actually move from under the arm (due to the aerodynamic drag having the dictating loading affect) to the top side of the arm (due to the payload loading having the dictating loading affect) as the loading increases during the analysis. This occurs when the payload in the system exceeds 100 pounds (the transition is shown from trials 3 to 6 and from trials 4 to 6 ). This can be seen in the transition from Figures 2-14 to 2-16 and from 2-15 to 2-17.

\subsubsection{System Fastener Upgrade}

The fasteners used on OCULUS 1.0 consisted of commercial grade 8 type bolts and standard industrial pop-style rivets and did not have military certification specifications associated with them. This is viewed as a certification quality issue for a system on a military aircraft (35).

All fasteners implemented into the design of the OCULUS 1.1 system have proper certification specification as well as (NAS) or military (MIL) spec numbers. The grade 
(strength) of the bolts still meets and exceeds all structural requirements as originally designed for the system. The rivets used in the Oculus 1.1 system design are aircraft grade Cherry Max rivets with NAS 9301 and MS 20470 part/spec numbers.

\subsubsection{EMI Shielding Design}

The OCULUS 1.0 system was not originally designed for electro-magnetic interference (EMI) compatibility. To properly analyze a system of its EMI magnitude, a laboratory EMI test must be completed.

In order to understand the EMI measure that OCULUS emits and is required to electrically comply with to receive flight certification, a brief overview is provided of what and how the EMI test is performed. The EMI standards that electrical devices must comply with, for operation on military aircraft, are defined in MIL-STD-461 (36). The two testing categories that are required for OCULUS are the conducted emissions (CE-102), and the radiated emissions (RE-102) specifications (36.37).

Conducted emissions (CE) involve the electromagnetic noise conducted on electrical lines to other equipment. The frequency range of concern is $10 \mathrm{kHz}$ to $10 \mathrm{MHz}$, according to CE102. Figure 2-20 shows the limit lines for this specification.

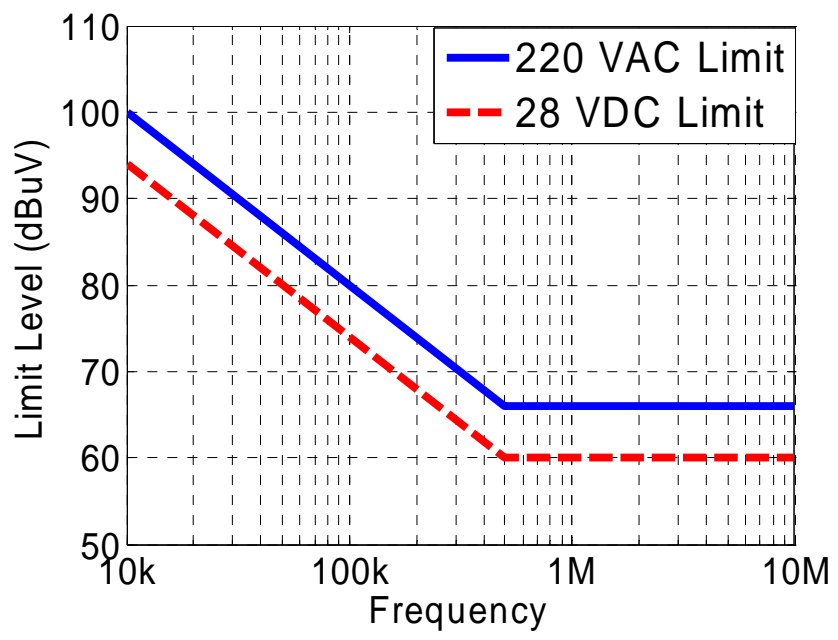

Figure 2-20: CE-102 conduction noise limits for fixed wing aircraft (36). 
According to MIL-STD-461, a line impedance stabilization network (LISN, Figure 2-21) must be used in the setup for measuring conducted emissions (Figure 2-21). In order to reduce the effects of impedance mismatches, and for protecting measurement equipment, a $20 \mathrm{~dB}$ attenuator is also specified by the standard. Both the LISN and $20 \mathrm{~dB}$ attenuator losses must be compensated for to obtain measurement results that can be compared to the limit curves.

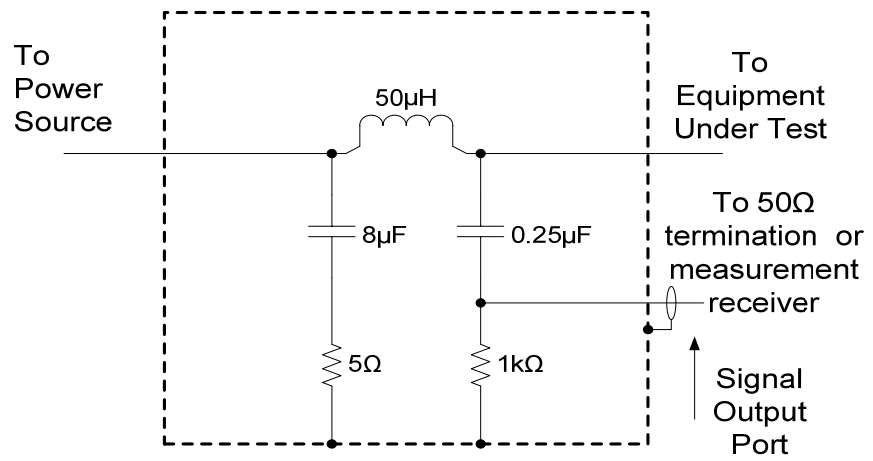

Figure 2-21: LISN, used for measurement of conducted emissions, schematic (36).

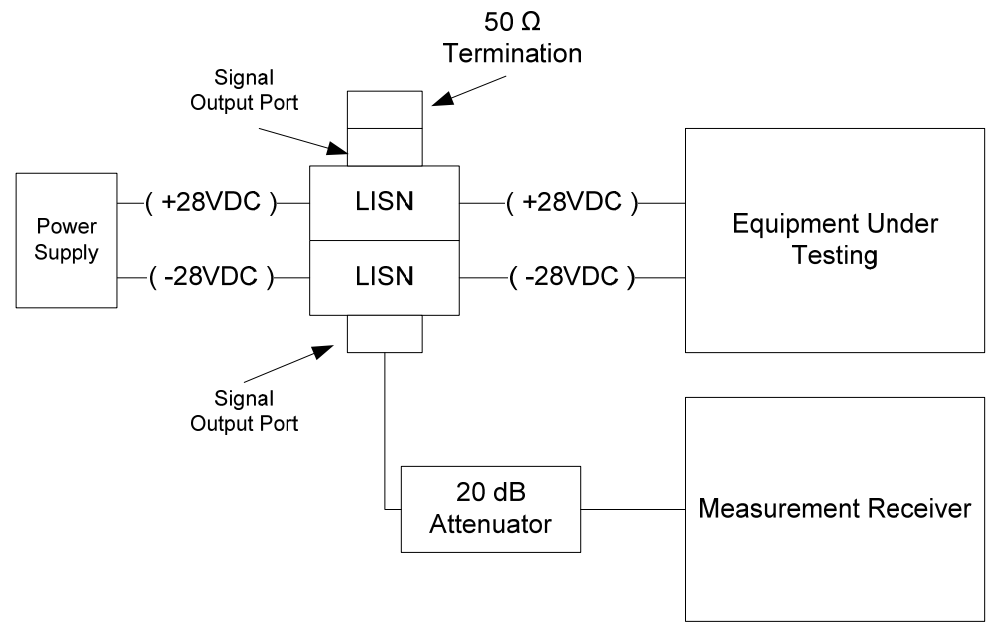

Figure 2-22: Specific DC LISN measurement system setup (36).

Radiated emissions (RE) deal with electromagnetic radiation emitted from an electrical device (36). The transmitting sources for this type of interference can be any conductor or metallic structure, enclosures, cables and openings. The range of frequencies of interest per RE102 is $10 \mathrm{kHz}$ to $18 \mathrm{GHz}$ which is shown in Figure 2-23. The dashed limit line applies to the 
operator station, as it is housed internal to the C-130 aircraft, which per the specification is greater than $25 \mathrm{~m}$ in length. The solid limit line applicable for external aircraft equipment was applied to the sensor pallet.

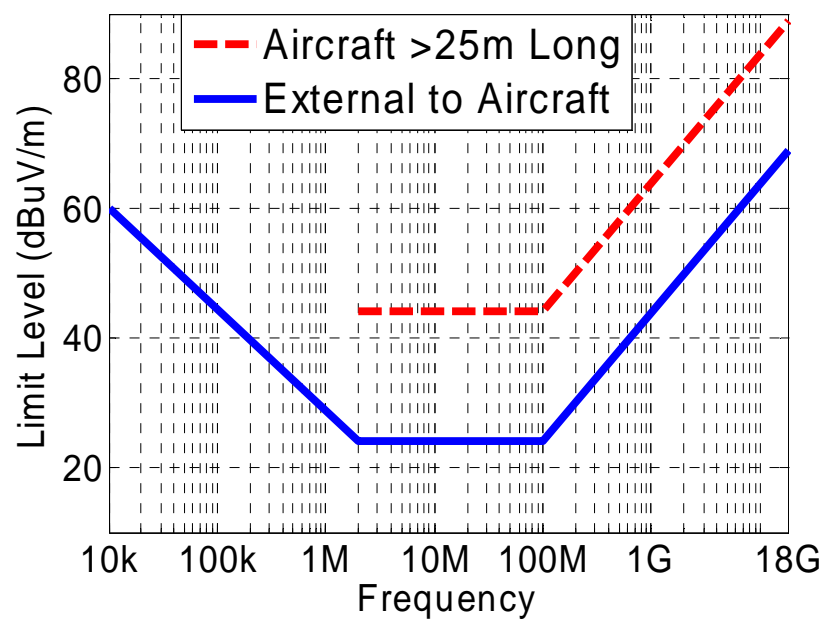

Figure 2-23: Fixed winged aircraft radiated emissions level (RE102) limits (37).

RE-102 levels are measured using three different antennas in order to cover the required frequency range. A rod antenna (Figure 2-24), a biconical antenna (Figure 2-25), and a horn antenna (Figure 2-26) are used. RE measurements are often more complicated than CE measurements due to the numerous antennas, broad spectral range, and the generally complex behavior of radiated fields (39).

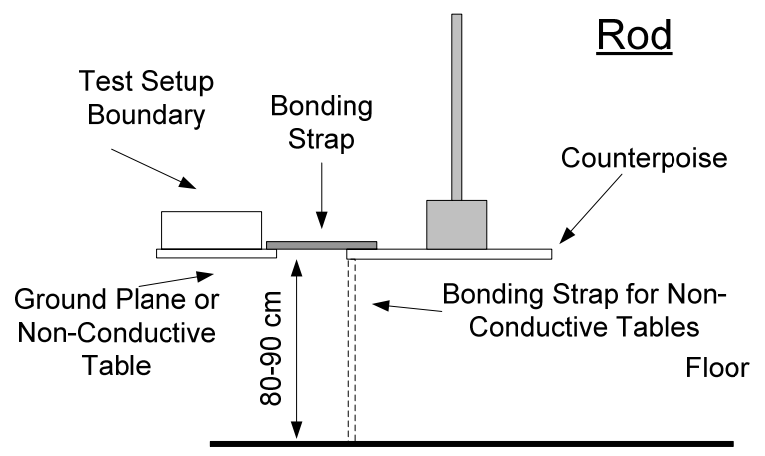

Figure 2-24: Rod Antenna (10kHz-30Mhz) for RE-102 tests (37). 


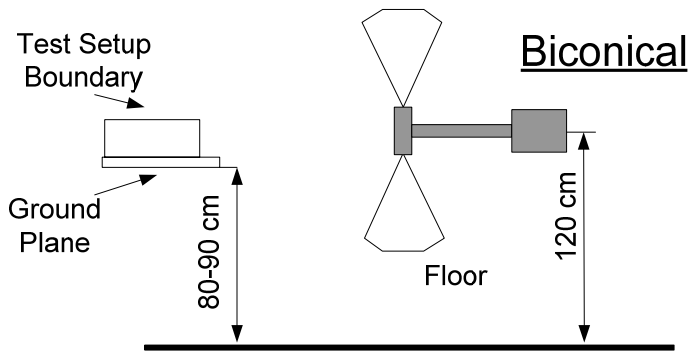

Figure 2-25: Biconical Antenna (30MHz-1GHz) for RE-102 tests (37).

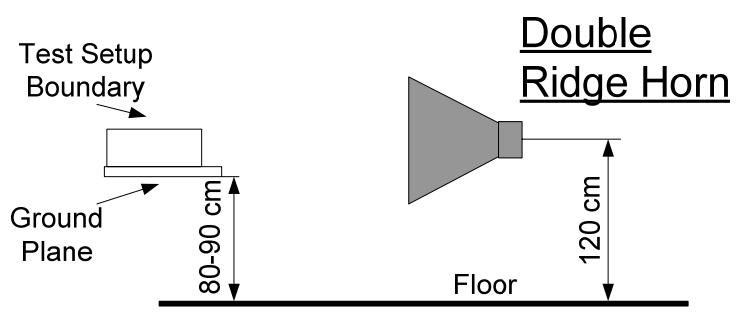

Figure 2-26: Double Ridge Horn (1GHz-18GHz) for RE-102 tests (37).

The OCULUS 1.1 system was designed from the ground up to be EMI compatible per fixed wing aircraft requirements. Figure's 2-27 thru 2-29 show examples of the improved EMI shielding capabilities of the OCULUS 1.1 system. These include enhanced enclosure design to include EMI gasketing (Figure 2-26) and EMI specific coatings (gold iridite), as well as shielded cabling and filtering to reduce emmitence through connections (Figure 2-27 and 2-28) (40). 


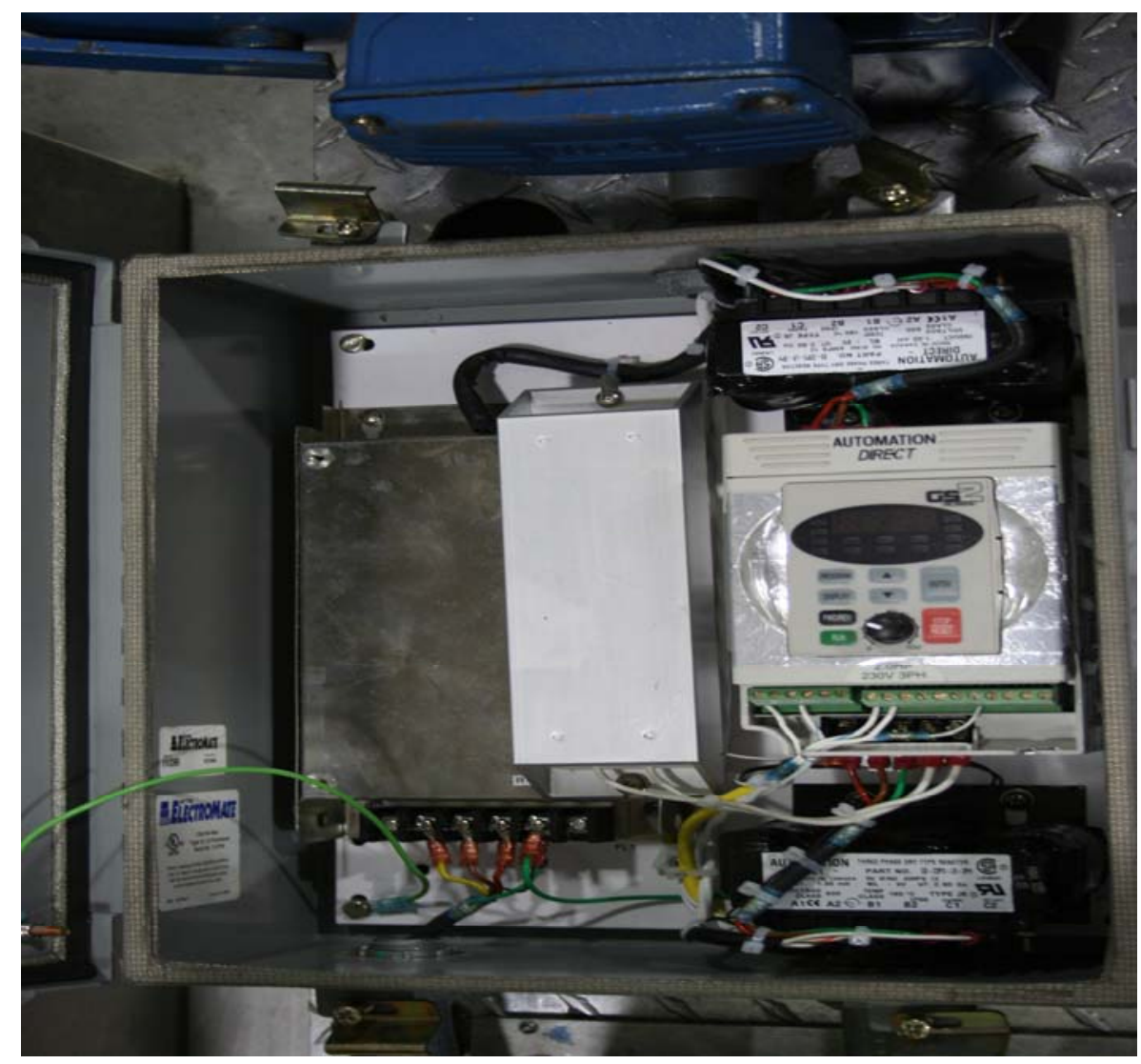

Figure 2-27: OCULUS 1.1 EMI shielded enclosure design.

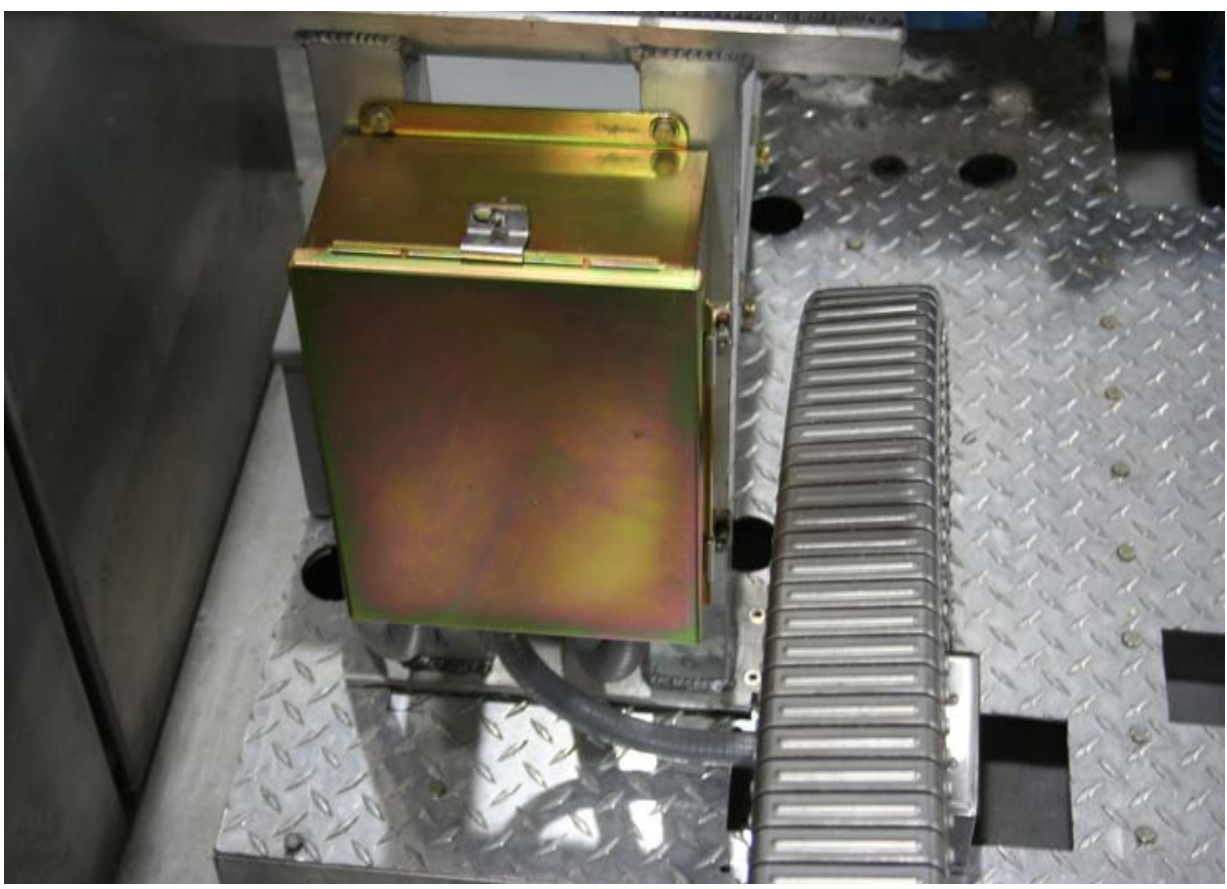

Figure 2-28: OCULUS 1.1 enclosures with gold iridite coating. 


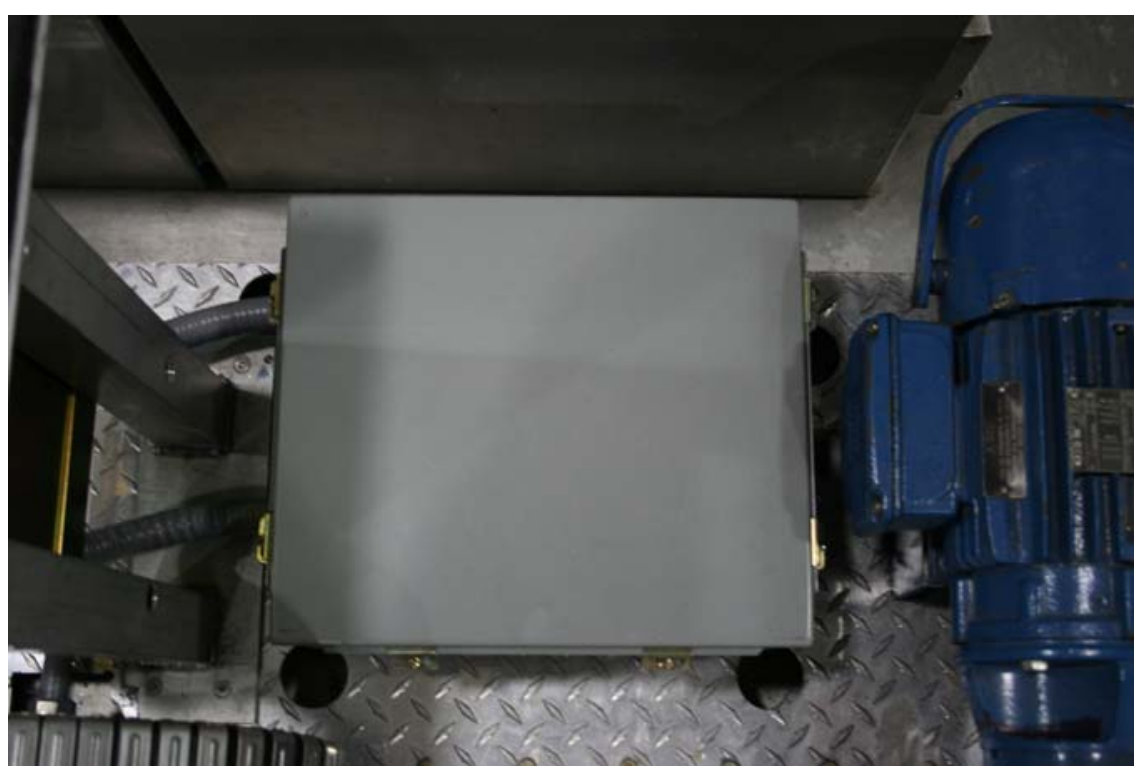

Figure 2-29: OCULUS 1.1 enclosures with shielded cabling running in and out.

\subsubsection{Electrical Shock Resistance Design}

The OCULUS 1.0 system did not include any electrical shock resistance covers for the operators that would be inside the system's operator station. The potential was there for a component to fall in contact with a live/open electrical junction and cause a shock or spark while in use in the aircraft. Once again this was a major safety-of-flight concern.

The OCULUS 1.1 system design implemented housings (Lexan material) for all electrical components that could potentially come in contact with objects or operators. Figure 2-30 shows examples of the safety design implemented to remove objects or operators from contacting the electrical components inside the operator station. 


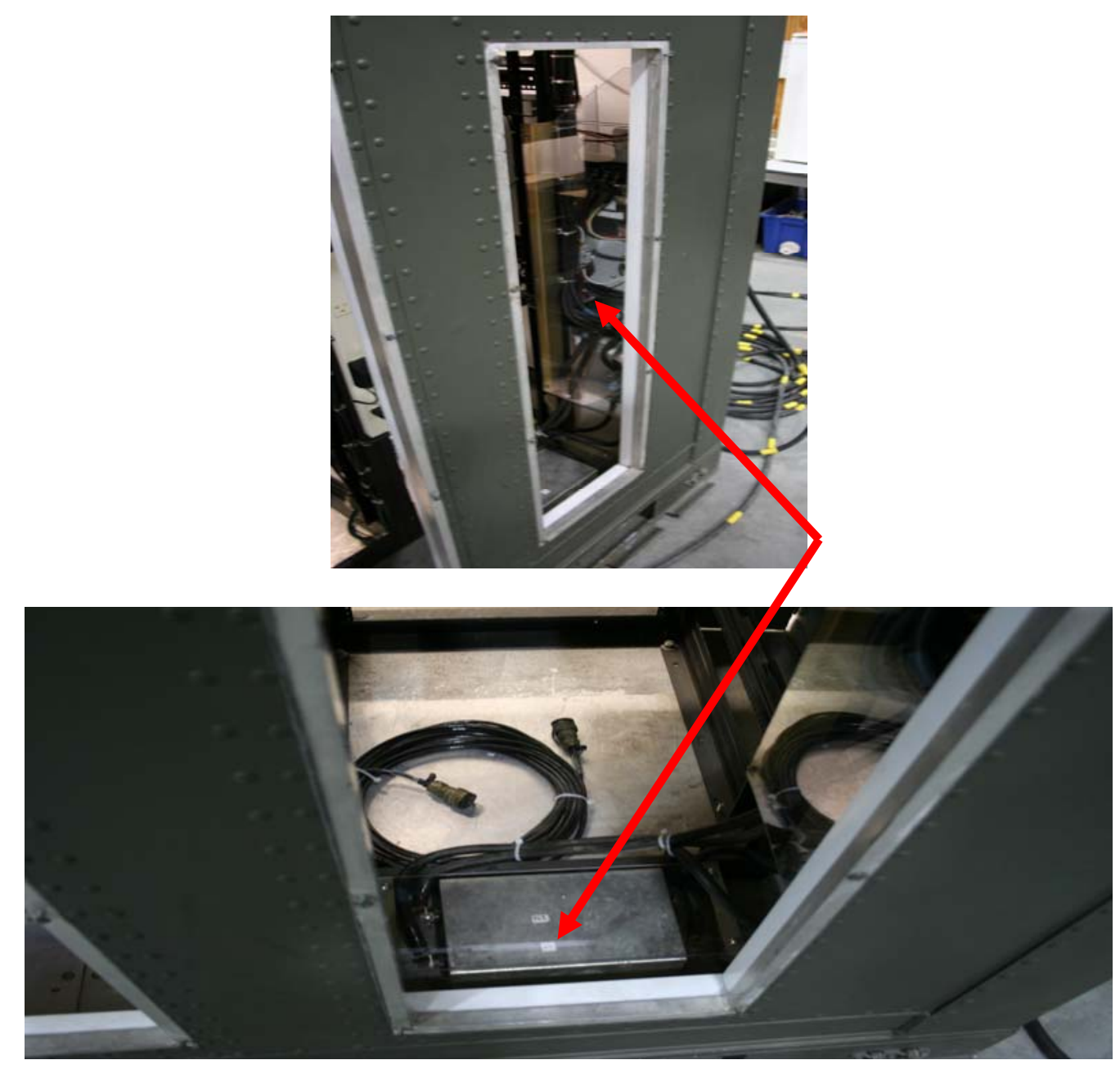

Figure 2-30: Operator Station safety cover examples implemented for safety-of-flight measures.

\subsubsection{Sensor Pod to Rear Ramp Contact Design}

One of the major design objectives of the OCULUS 1.1 system was to reduce the aerodynamic load as much as possible while the system is in the final operating position. The OCULUS 1.0 system concept outlines the deployment methodology and describes the final operating position of the system as being "abutted against the bottom of the rear ramp of the system (17)." In order to transfer these design concepts and implement them into the actual system a thorough understanding of the airframe is necessary.

The systems general deployment methodology was outlined in the OCULUS 1.0 design. This methodology described the systems deployment in three stages: (1) linear translation out of 
the aircraft, (2) rotational deployment and (3) linear retraction against the airframe. This basic methodology was transformed into a position controlled design that was controlled with both electrical positioning "stops" and mechanical switches. This design also controlled the deployment speed based on the amount of load resistance seen during flight or experimental ground testing.

For the operational positioning of the system, the bottom of the rear cargo ramp of the C130 aircraft was investigated at the Lockheed Martin (LM) Facility in Clarksburg, WV. This facility of LM fabricates and assembles the rear cargo ramp of the C-130 aircraft. During these multiple visits to the facility, better understandings of the hard point locations of the rear ramp were clarified. The reinforcement structure region of the rear ramp, shown in Figure 2-31, became the major contact point location of the OCULUS 1.1 system in the final operating position. The OCULUS 1.1 sensor pod was designed to come into contact, through the means of a polyurethane plate, with the reinforced structured region.

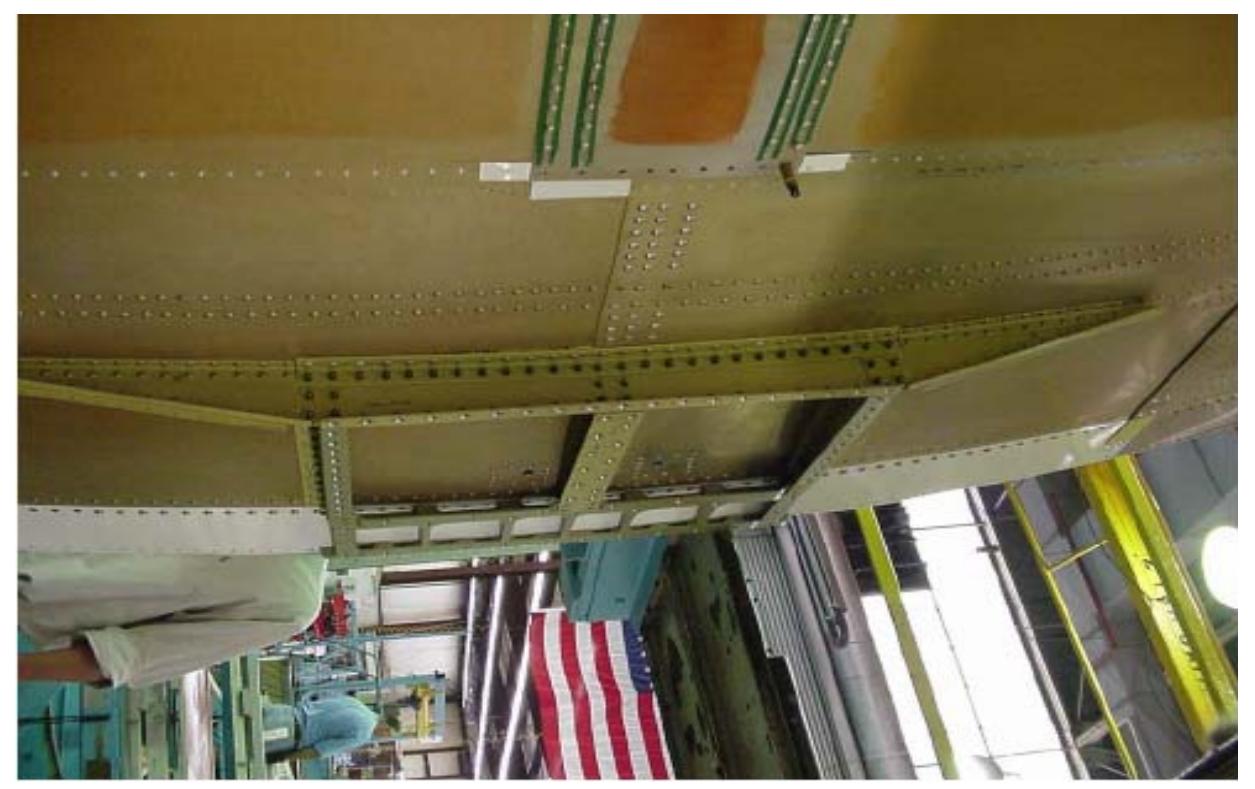

Figure 2-31: C-130 rear ramp inside structure (Lockheed Martin Clarksburg, WV). 
Figure 2-32 displays the OCULUS 1.1 system in the final operating position on the C130 aircraft. The operator, shown in the picture, is performing a contact test to see how well the OCULUS 1.1 system is wedged up against the rear ramp support section. A "hard" durometer polyurethane sheet was chosen (80A rating) to be attached to the pod and come in contact with the ramp. This high durometer rated material was chosen because it would not have tearing issues when wedging up against the ramp rivets, and it would still offer a compressive contact between the pod and the rear ramp.

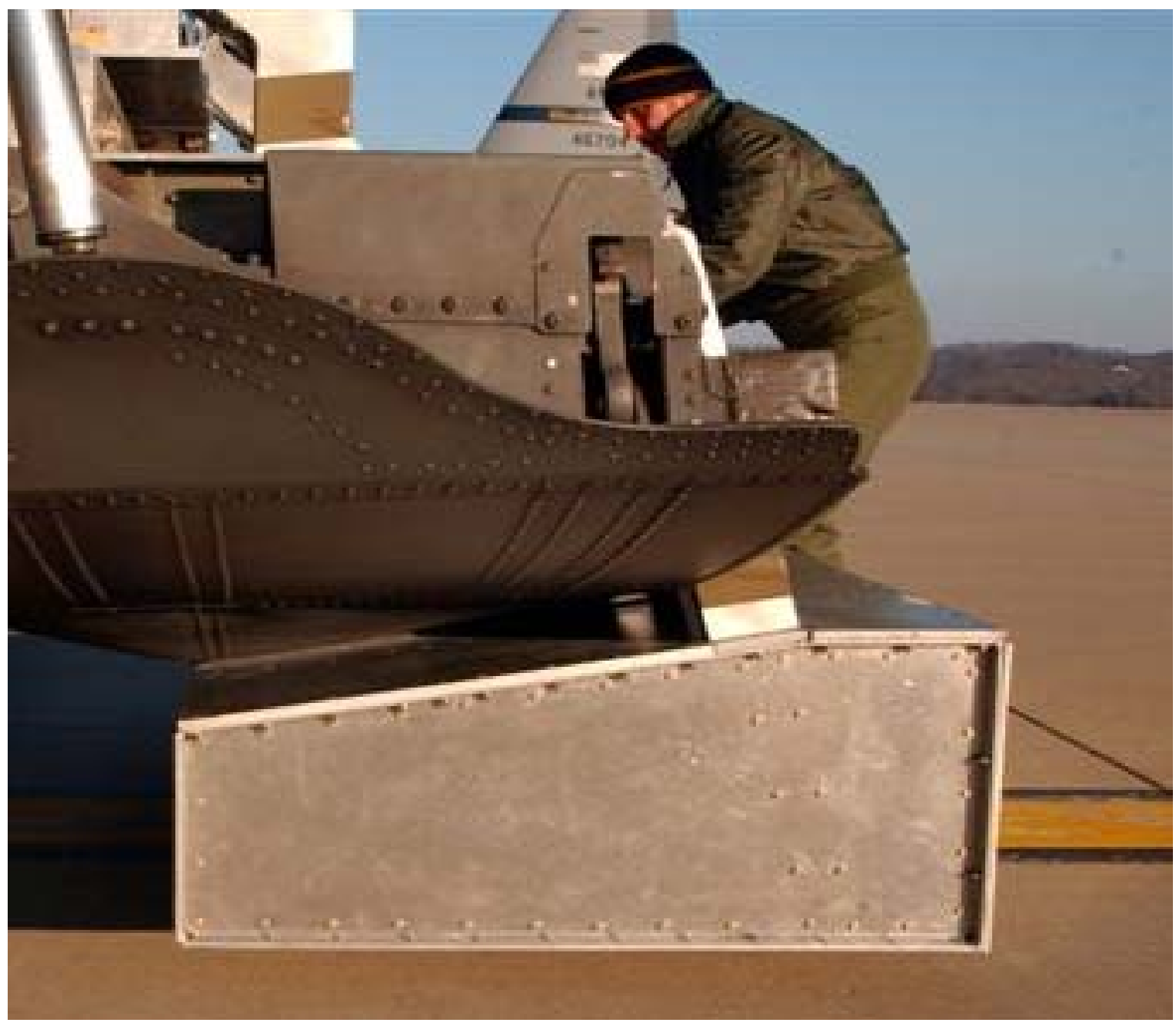

Figure 2-32: Operator testing contact between C-130 ramp and OCULUS 1.1 System. 


\subsection{Final OCULUS 1.1 System Design}

The OCULUS 1.1 electrical system design expanded the capabilities of the OCULUS 1.0 concept design to include additional power options for the sensor platform and inside the operator station. Figure 2-33 shows the power capabilities for the sensor platform (28 VDC and $20 \mathrm{VAC}$ ) and the power sources of the C-130 used by the operator station to distribute power throughout the system. Some of the additional safety-of-flight design features incorporated in the OCULUS 1.1 design include the addition of redundant fuses to prevent any potential overload when the system is in use.

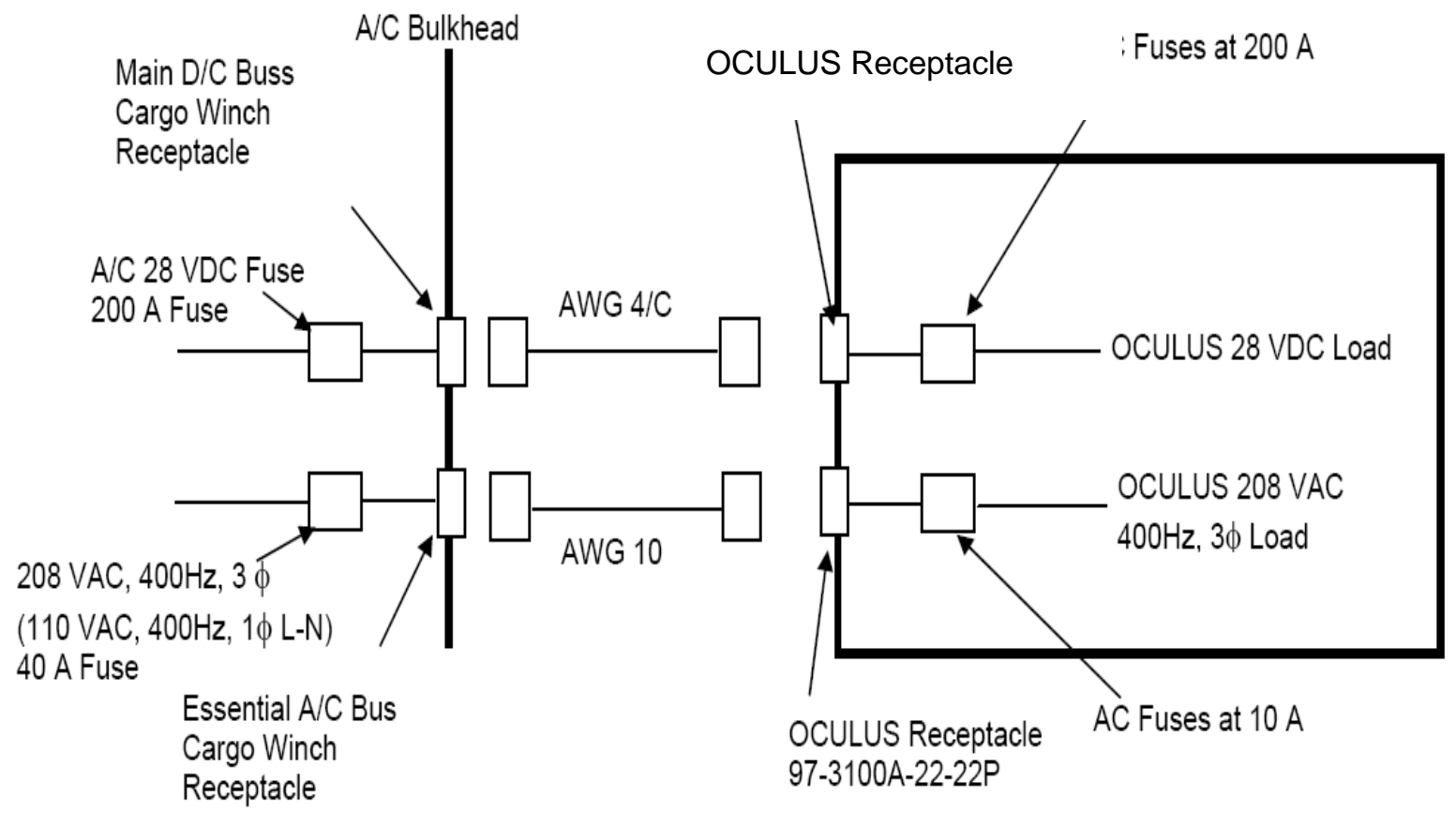

Figure 2-33: Schematic of the OCULUS 1.1 electrical system power distribution design (41).

The OCULUS 1.1 System meets all of the safety-of-flight requirements, which included the improved fabrication methods and techniques, and continues through the upgrade of the critical components listed in section 2.1.1. Figure 2-34 shows the operator station and sensor platform components of the OCULUS 1.1 System. 

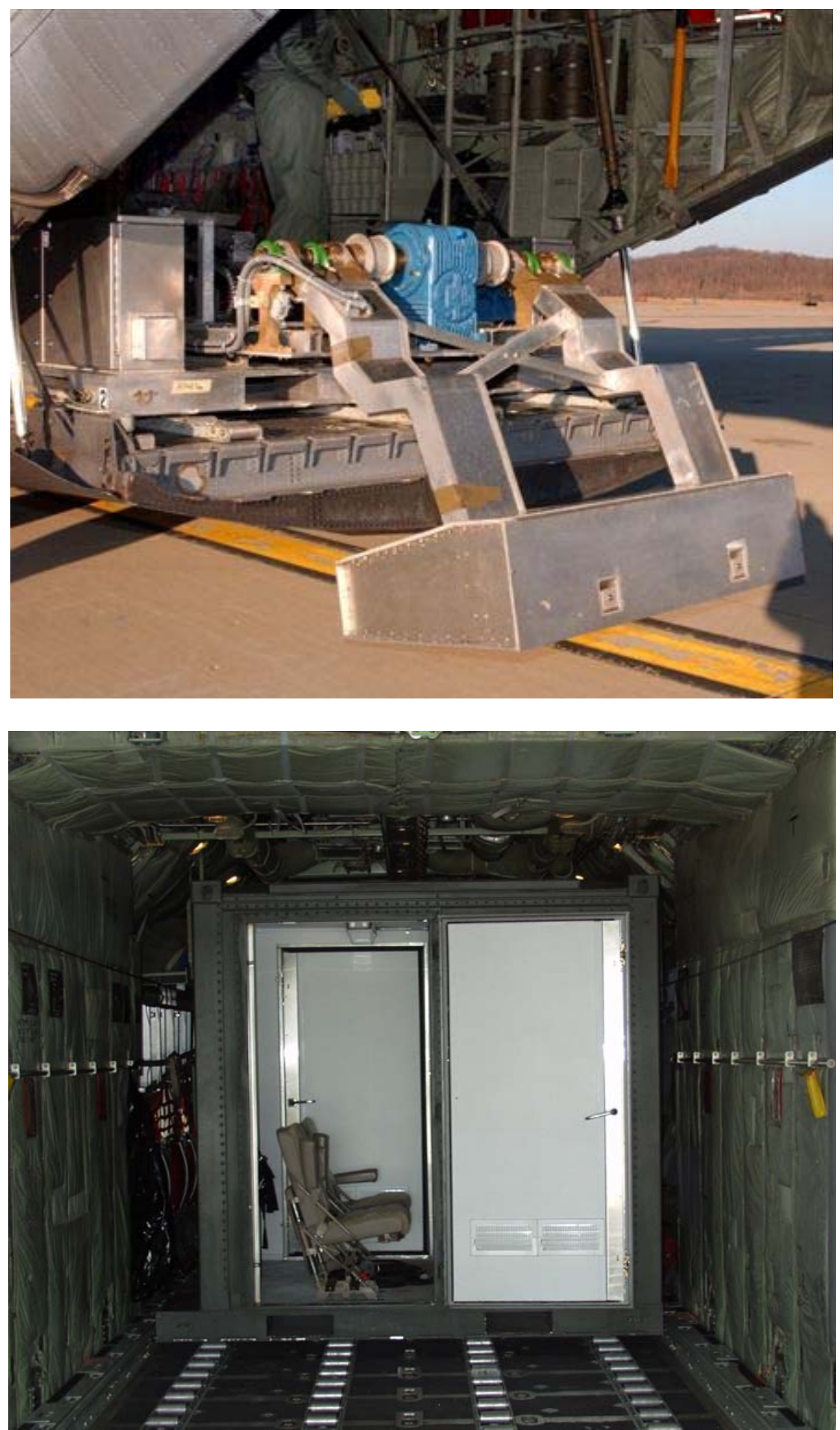

Figure 2-34: (top) OCULUS 1.1 Sensor Platform System on a C-130 aircraft. (bottom) OCULUS Operator Station in the fuselage of a C-130 aircraft. 


\subsection{The Next Step - Plan for Testing/Certifying the OCULUS 1.1 System}

The OCULUS 1.1 Sensor Deployment System, with all of the implemented design changes and the analysis performed to verify the system to be flight worthy, must now begin the process of implementation into the United States Military. This military implementation process is unlike any commercial effort of transferring a new product into society because of the strict quality requirements established by the military. This process requires the understanding of military product reliability concerns (i.e. safety and longevity) and product safety certification procedures. In this particular case of interacting with a military system that is to be used on an aircraft, the main way to alleviate any concerns regarding reliability and safety is to successfully perform a flight test that proves the system performed as it was designed, and is safe for military use. This process of gaining a flight certification for the OCULUS 1.1 system (Chapter 3) includes: designing a flight test plan to collect data to validate that the system performed safely (Chapter 4), performing an airworthiness flight test under the auspices of military personnel and test pilots (Chapter 5), and reducing the data from the test to validate the system design is safe and should be certified for military use (Chapter 6). 


\section{Airworthiness/Flight Testing}

Safety of flight testing continues to remain an essential step in the development or modification of an aircraft (42). Modern fixed-wing aircrafts are highly complex systems that push the edges of aerodynamic, propulsion, and control system technologies. Many of these technologies are integrated together and dependent upon each other. Certainly, modern military aircraft ranging from the F-22 to the EF2OOO, push the boundaries of capabilities that can be built into an aircraft. Commercial transportation such as Airbus' A310 and Boeing's 777, incorporate many advances that were first used in military airplanes. The ever-increasing complexity of the aircraft presents new challenges to those who are involved in the flight testing of those vehicles and/or components.

\subsection{Certification Process}

Once the OCULUS 1.1 system had been designed and a system had been fabricated, the next step was to get it tested and certified as an airworthy system the military could implement into its arsenal. The process of certifying a newly developed system as airworthy and implementing it differs for each branch of the military. This process has not been standardized for the entire military and each branch has a different set of requirements which must be met before they are considered for inclusion (43).

\subsection{Review of Military Airworthiness Certification Processes (Literature Review)}

Each branch of the US military (along with foreign military's) has its own process for airworthiness certification, but each process does have some of the same basic principles and requirements (44). The difficulty in these processes is that the requirements established are very broad and do not include specific tasks (45). Each branch however, does have a general 
approach and process outline for obtaining a flight test clearance. The process steps for obtaining a clearance for a Naval/Air Force airworthiness test are given below (46):

General Airworthiness Testing Process:

- Capabilities need identification

- Planning meeting is needed to familiarize everyone with scope and requirements

- Appropriate authority generates and submits a request

- Review is conducted by appropriate engineering disciplines

- Flight clearance is finalized

- Flight clearance is released to the requested parties

In this specific case, the two agencies that handle certification associated with the C-130 airframe are NAVAIR (Navy) and Warner Robins Air Force Base (Air Force). The OCULUS project was initially funded by the National Guard Bureau (NGB) which has direct association with the Air Force regarding the C-130. This association required that the OCULUS 1.1 system certification process use must WRAFB as the policing agency.

\subsection{Obtaining Clearance for a Flight Test}

The airworthiness testing process as applied to the OCULUS system becomes: (1) identifying a need for a roll-on/roll-off deployment system for a C-130 aircraft, (2) submitting a formal request for flight testing by the sponsoring agency for the OCULUS project, (3) conducting a formal engineering review of the OCULUS system, and finally (4) having WRAFB authorize a flight test of the system on-board a C-130 aircraft. Step 1 of this process has been covered earlier in this document and the other three steps are covered in the following sections.

\subsubsection{Formal Request for Flight Testing}

The 1067 certification form is a military add-on system flight test certification document, which in this case is airworthiness and safety-of-flight certification that ensures the add-on system and provides no added safety risks to the pilots and crew, or civilians and property in the 
flight path involved in standard C-130 flight missions (47). Each 1067 form has system specific requirements determined by the high level structural and safety engineers at WRAFB.

The OCULUS 1.11067 certification form was drafted and completed by representatives from the policing agency of the C-130 (WRAFB), the test organization in charge of the eventual flight test, the West Virginia Air National Guard (WVANG), and the co-sponsoring agency that established the requirements for the deployment system (National Guard Bureau-CounterDrug (NGB-CD) and Counter NarcoTerrorism Technology Program office (CNTPO)). This form, shown in completed form in Appendix B, authorizes a flight test by the policing agency to investigate using the OCULUS 1.1 Sensor Deployment System as a potential modification to the normal operating procedure (NOP) of the C-130 aircraft.

\subsubsection{OCULUS 1.1 System Engineering Review for Flight Test}

The 1067 Form acceptance initiates the WRAFB engineer's involvement in the airworthiness certification process. This step in the process begins with formal overview of the system to the WRAFB engineers. This overview includes review of general documentation describing the system, participation in on-site physical audits, and review of the deployment process video while the system is on-board a C-130 aircraft. From this, the WRAFB engineers develop a list of documentation they would like to review to ensure the system has been properly designed, analyzed and fabricated, prior to a flight test.

\subsection{OCULUS 1.1 Engineering Documentation Package}

The underlying documentation package overviews the task areas to be supported or addressed with the objective of obtaining a final OCULUS 1.1, 1067 certification approval. During the course of the design and development of the OCULUS system for the DoD, WVU has provided technical services that support the integration of sensors into the OCULUS 1.1 
platform system with additional support provided for the modifications necessary to accommodate the flight testing approval. The prototype system flight test will require the successful in-flight deployment of the two-pallet Ro-Ro System with an array of remote sensors to validate the efficiency and capability of the OCULUS design and analysis. The analysis components will be validated with experimental structural data taken during the flight test. While the safety-of-flight certification is a complex and long term process, the critical and most important component of the requirements is structural safety. Because this is an add-on to an existing airframe there is no established procedure for this process. This research focused on the development of the process methodology, the flight test design of experiment and the flight test procedures for these tests, which relied on the four following areas of study, each of which were required by the certification process:
A. System Drawing Package (Mechanical and Electrical)
B. Stress Analysis of Critical Components - Sensor Pod Arms
C. Crash Survivability Analysis
D. System Electrical (Load and EMI) Analysis

\subsubsection{OCULUS 1.1 Drawing Package}

The OCULUS 1.1 drawing package gives a complete mechanical and electrical part/wiring overview along with a complete physical drawing representation of the system. This drawing package has been formatted to the specification of WRAFB in a Level II drawing format. The drawing package includes an indentured document list outlining the subassemblies of the OCULUS system, and detailed electrical and mechanical drawings of both the operator station unit, as well as the sensor platform unit with concentration on the sensor suite array. 


\subsubsection{Level II Drawing Package Description}

There are three "Levels" in dimensional drawing hierarchy and the basic understating of them is:

Level I -- Conceptual and Developmental Design

Level II -- Production Prototype and Limited Production

Level III - Production

The OCULUS 1.1 system has been deemed a limited production system and will therefore abide by the drawing principles of Level II as set by the sponsor. The drawings for a Level II package must be considered as detailed to the point that a skilled assembly organization could reproduce the system based on the drawings (48).

\subsubsection{Mechanical \& Electrical System Drawing Package}

The OCULUS 1.1 Mechanical \& Electrical System Drawing Package outlines in detail the components, sub-assemblies, and assemblies that make up the OCULUS 1.1 Sensor Deployment System. The development of this drawing package consisted of four major steps: (1) to generate a solid model representation of the OCULUS 1.1 system (this step was completed during the final design process of the system), (2) to convert the solid model representation of the OCULUS 1.1 system to a 2-D Computer Animated Drawing (CAD) package, which details each component, sub-assembly and assembly of the system, (3) develop an assembly/subassembly methodology breakdown of the system, and (4) to generate a component/subassembly/assembly drawing tree and number system to organize the arrangement of the drawing package.

The solid model representation of the OCULUS 1.1 mechanical system was generated using Pro/Engineer modeling software. The computer generated model was initially generated 
as the "designed" system (to represent the pre-fabrication assembly of the system) but was then modified to represent the fabricated final prototype system to be used during the certification process.

The electrical schematic representation of the OCULUS 1.1 system was developed using Protel modeling software. These drawings overview the electrical connection and wiring of the OCULUS 1.1 system also detailing specific hardware terminals used in the connection design of the system.

Once the solid model representation of the OCULUS 1.1 system was completed it was then converted to a 2-D representation of the system. This process involved converting the solid model representation into a format that could be used for a complete reproduction of the system. This process includes working directly with machinist and assembly workers to properly represent the structural component, assemblies and sub-assembly's of the system. It also includes working closely with electricians to properly represent wiring diagrams and electrical schematics so the electrical system could be reproduced.

A very important process in developing a Level II drawing package is to develop a system which simplifies the componentry breakdown of the system based upon a systematic outline of the components and sub-assemblies of the system. This package is the main reference manual for the system and needs to be systematically arranged in order to locate specific drawings in case of an emergency or failure. The Indentured Drawing List (drawing package tree outline) in Appendix $\mathrm{C}$ shows the drawing number breakdown using a step-indentation approach to differentiate between assemblies, sub-assemblies, sub-assembly components, and individual components. The complete OCULUS 1.1 Mechanical and Electrical Drawing Package are shown in Appendix D. 


\subsubsection{OCULUS 1.1 Structural Analysis}

The most integral aspect of gaining the support of the WRAFB during the certification process was thorough, structural analysis of the critical areas of the OCULUS 1.1 system using standards (MIL-HNBK-1791) set by prior military crash analyses and using any historical experimental data relating to the OCULUS 1.1 system's dynamics and deployment range (49). Because a portion of the OCULUS 1.1 system deploys outside of the rear cargo ramp of the C130 aircraft, it enters an additional loading condition caused by aerodynamics drag created during flight of the aircraft. The OCULUS 1.1 Critical load Analysis was explained in Section 2.1.1 and the analysis results were provided to WRAFB.

The second major structural analysis that requires a thorough analysis is the system crash analysis. The flight safety crash criteria for a cargo system onboard a fixed wing aircraft is governed by MIL-HDBK-1791. This military handbook outlines the G-force criteria the add-on system and its individual components must be able to withstand during normal flight operations on the C-130 aircraft (49). The MIL-HDBK-1791 criteria must be satisfied without the add-on system design changing the dynamics and standard operating capabilities of the airframe.

The purpose of this study is to show that during an emergency situation, the OCULUS system units, sub-assemblies; parts, components, and cabling that comprise the system do not fail or break free and become flying projectiles that could cause fatal injuries to crew members or passengers or potential damage to people and property in the aircrafts flight path. The Crash Analysis document in Appendix E details the analysis procedure and results for the analysis showing that the OCULUS system meets the load criteria of MIL-HDBK-1791 for installation in a C-130 aircraft. The intent behind establishing the load criteria for C-130 cargo is to provide guidelines for cargo equipment/container/pallet/airframe designers so that their designs will 
provide a reasonable opportunity for $\mathrm{C}-130$ crew members and passengers to survive a relatively minor crash situation.

This analysis showed that the major structural components, which may have had the possibility of detachment or dislodging from the system, of the OCULUS 1.1. Deployment System met the safety requirements for a system on-board a fixed winged aircraft as dictated by MIL-HDBK-1791 (50).

\subsubsection{Electrical Analysis}

Outside of ensuring the OCULUS 1.1 system does not structurally affect the C-130 aircraft and its safety of flight, the additional potential safety concern is the effect the system has to the aircrafts electrical system. The two major concerns electrically are the additional loading the system may bring to the aircraft and the potential Electro Magnetic Interference (EMI) the system may add to the aircraft.

\subsubsection{Electrical Load Analysis}

The OCULUS 1.1 system electrical load analysis was performed to ensure the system does not provide electrical overloading or a short-circuit hazard to the C-130 aircraft. Appendix F provides the electrical load analysis performed on the OCULUS 1.1 system in connection with

the C-130 aircraft. The results show that the OCULUS 1.1 system's power requirements fall well below the distributive power available from the C-130 aircraft.

\subsubsection{EMI/EMC Analysis}

The purpose of this analysis was to show EMI test results indicating that the OCULUS 1.1 system (without sensors, radars, or communications equipment) has conducted and radiated emissions that fall within the guidelines given in MIL-STD-461E. Appendix G provides the results of EMI-461E testing performed on the OCULUS 1.1 system at DLS Electronic Systems, 
Inc. The results show that the system's conducted and radiated emission levels are within the safety guidelines of the C-130 aircraft (41).

\subsection{Command Control Board (CCB) Approval}

All of the documentation provided on the OCULUS 1.1 system was reviewed and discussed thoroughly with WRAFB engineers. This process involved several TELCONs (approximately 15), emails explaining several detailed questions regarding structural and electrical safety and two on-site meetings at WRAFB to discuss potential hazards of a flight test and how to minimize any chance of a failure or problem during the flight. Following the discussions, the engineers agreed (based on the analysis performed on the OCULUS 1.1 system and provided to them) that the system is a safe design and has clearance for a flight test on-board a C-130 aircraft. Once the engineer's approval was documented the request for a flight test of the OCULUS 1.1 system went to the WRAFB Command Control Board for official delegation of a flight test.

The WRAFB CCB approved flight tests for the OCULUS 1.1 system on-board a C-130 aircraft. The approval was issued for 4 days of flight test sessions to be conducted at the WVANG in Charleston, WV. The purpose of the test flights are to determine: the effect the OCULUS system has on the flight capabilities of the C-130 aircraft, the response of the OCULUS 1.1 system while subjected to flight conditions, and the response to the C-130 aircraft while subjected to force/vibration loading caused by the OCULUS system before/during/after deployment. In order to generate the data required to understand these scenarios a specific assembly of instrumentation, data acquisition and viewing/data logging equipment has been determined and is outlined in Section 4 the Flight Test Plan Development. 


\section{Flight Test Plan Development}

The WRAFB CCB along with WVU and the WVANG outlined a plan for the OCULUS 1.1 flight test. The purpose of this test was to (1) demonstrate that normal flight dynamics of the aircraft are not significantly affected during or after deployment of the OCULUS sensor pod and the sensor pod support arms are not stressed beyond safe limits (2) demonstrate that the OCULUS pod does not produce vibrations or forces beyond safe limits for the ramp structure, hinges, or braces when the ramp is in a horizontal position, in flight, and the pod is deployed, (3) characterize the motion of the pod sensor platform and (4) demonstrate electromagnetic compatibility (EMC) with the C-130 aircraft systems.

\subsection{Hardware Setup}

The two major OCULUS load cases that will be developed during the OCULUS system flight test are the stresses caused by aerodynamic drag forces (and payload weight of the system) and vibration loading caused by the forces induced by the aircraft (i.e. propellers, turbulence, etc.). The instrumentation necessary for determining the stresses on specific locations of the OCULUS system are strain gages. The location of the strain gages to be used and placed on the system was determined through FEA and experimental ground testing of the system subjected to loading caused by the weight of the componentry and aerodynamic loads incurred during flight, established earlier in the wake rake test

The instrumentation necessary for determining the vibration loads/frequencies applied to the OCULUS system and the rear ramp of the C-130 aircraft are accelerometers. The number and location of the accelerometers to be used and placed on the OCULUS system and rear ramp of the aircraft was determined using published vibration profiles of the $\mathrm{C}-130$ and vibration profiles found during the experimental aerodynamic test (51). The sensor pod, because it will eventually 
house the aerial sensors, also required a number of accelerometers. Figure 4-1 shows the complete instrumentation setup for the OCULUS 1.1 flight test.

\section{Oculus Instrumentation System Layout}

(1) Power Supply for DAQ and Signal Conditioning

(2) Shielded Carriers and Modules

(3) Rack Mountable CPU

(4) 32 Analog Input DAQ Cards

(5) Accelerometers

(6) Strain Gages

(7) Shielded Cable

(8) Remote Desktop

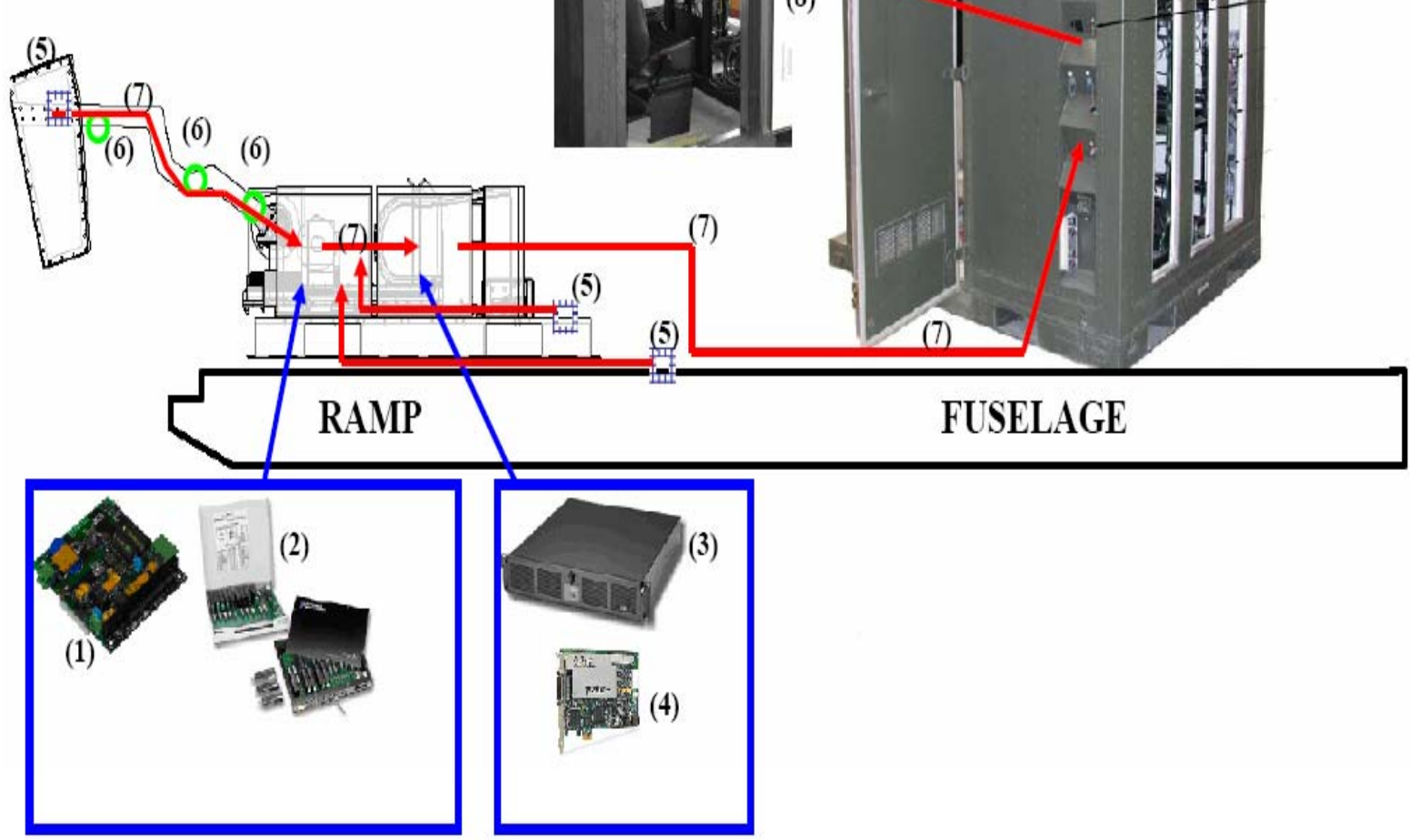

Figure 4-1: OCULUS 1.1 instrumentation and DAQ concept setup.

\subsubsection{Strain Gage Setup}

The location of each strain gage unit was determined using anticipated loading conditions. Figure 4-2 shows the loading force vectors applied to a single arm with a load magnitude equal to one-quarter of the total loading anticipated due to the aerodynamics forces 
and weight of sensor pod and mechanical arms. The three high stress intensity value regions found in the preliminary FEA performed on the mechanical arm are highlighted in Figure 4-3.

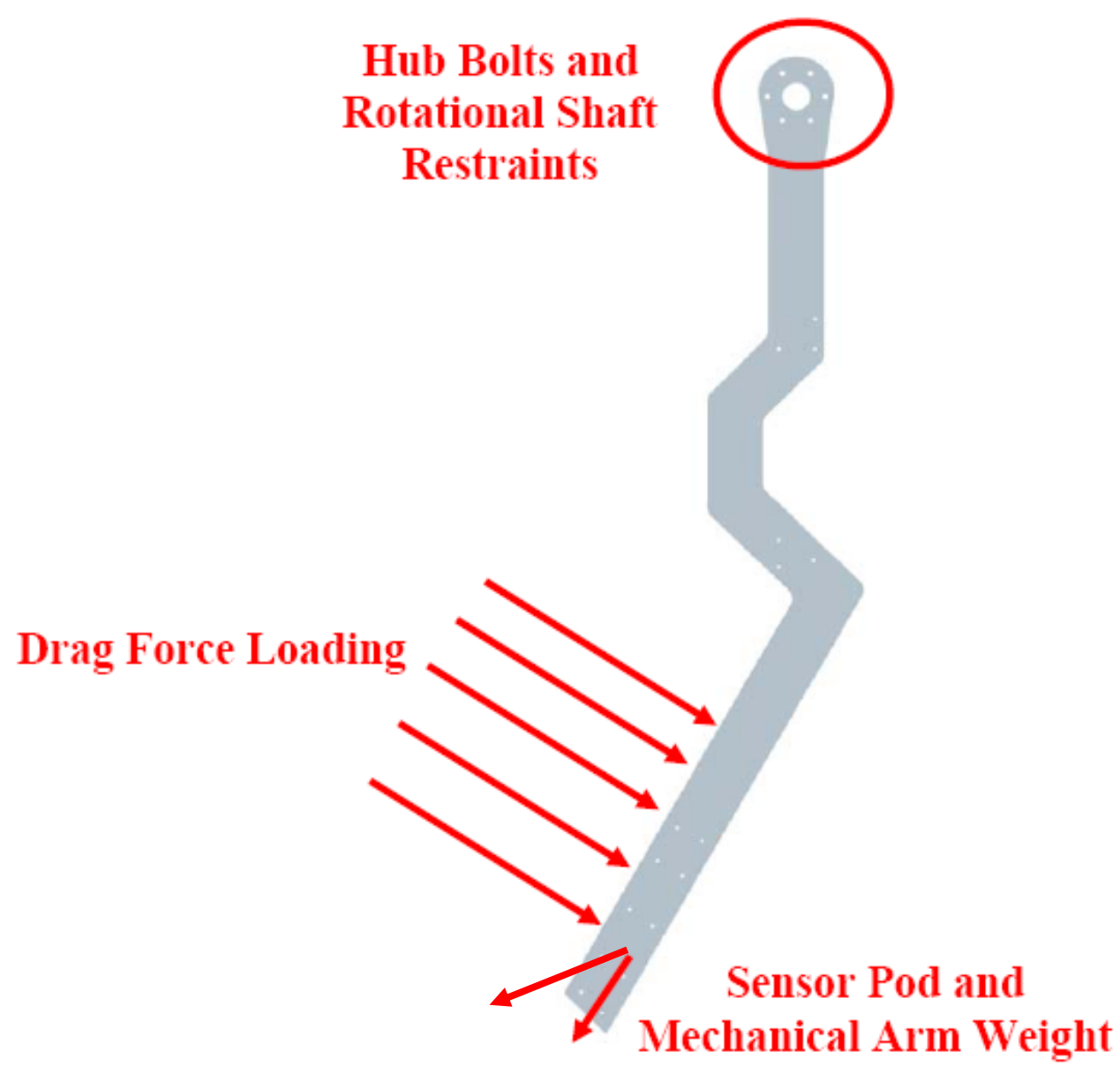

Figure 4-2: Loading and force vectors applied to the FEM. 


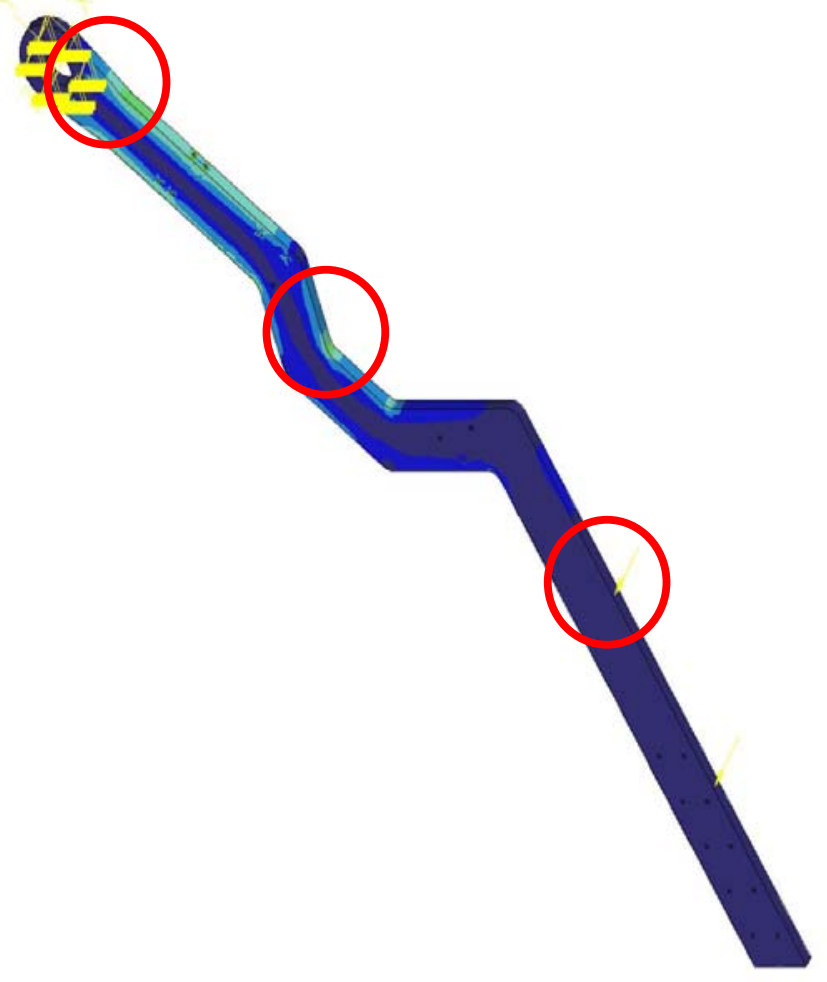

Figure 4-3: High stress locations in the mechanical arm of the OCULUS 1.1 system.

The proposed setup of the strain gages will include (3) - 90 degree, 3 element rosettes mounted to the 4 in. cross-section of an outside arm at the locations highlighted in Figure 4-4. The highest stress concentration point was found to be at the neck-connection of the mechanical arm. The right outside arm was selected to have all 3 stress locations outlined with a strain gage. Each of the other three arms will have 1 - 90 degree, 3 element rosettes mounted to the arm in the location closest to the connection to the rotational system (example shown as Location (A) in Figure 4-5). This type of arrangement was necessary because of the limited data acquisition (DAQ) channels that could be used based upon the equipment that was available and permitted for the flight test. The approximate locations of the gages are shown on the model (denoted by red circles) of the sensor pod and mechanical arm assembly in Figure 4-4. This setup was chosen to perform an equivalency load distribution study to analyze the load distribution on each arm during the dynamic loading from the aircraft. Location (A), in Figure 4-5, was chosen because it 
shows the highest stress concentration on the arm model using FEA. The inner two arms will have the strain gages mounted on the 4 in. cross-section that faces each of them. Every rosette gage will need a corresponding "dummy" gage (6 total) mounted to a similar piece of aluminum of equivalent thickness as the mechanical arm (this was positioned on the sensor pod). The lead wire from each individual rosette gage (6 total) that attaches to each individual dummy gage must be of approximately the same length to neutralize lead wire effects.

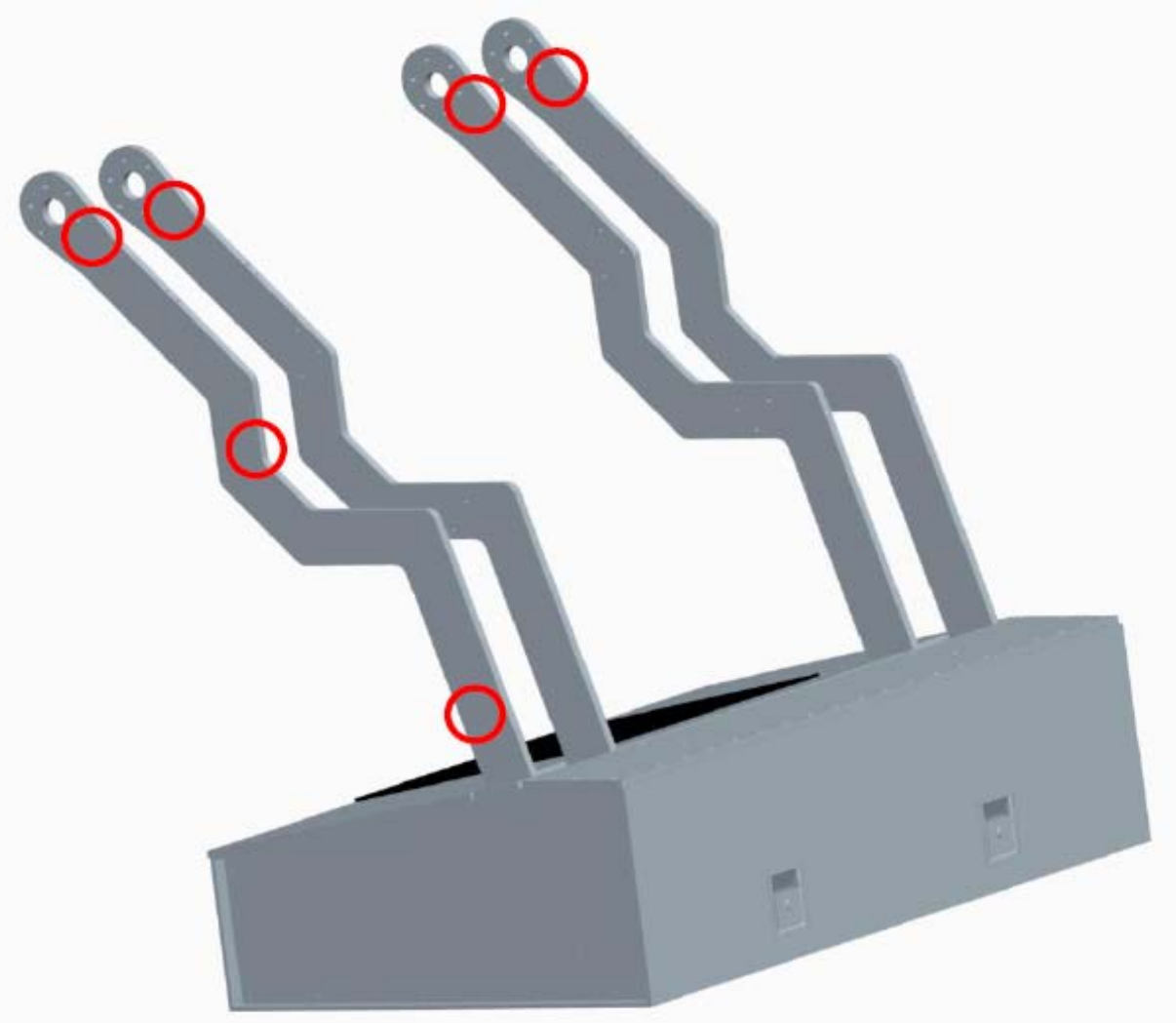

Figure 4-4: Highlighted strain gage locations on the OCULUS 1.1 system. 


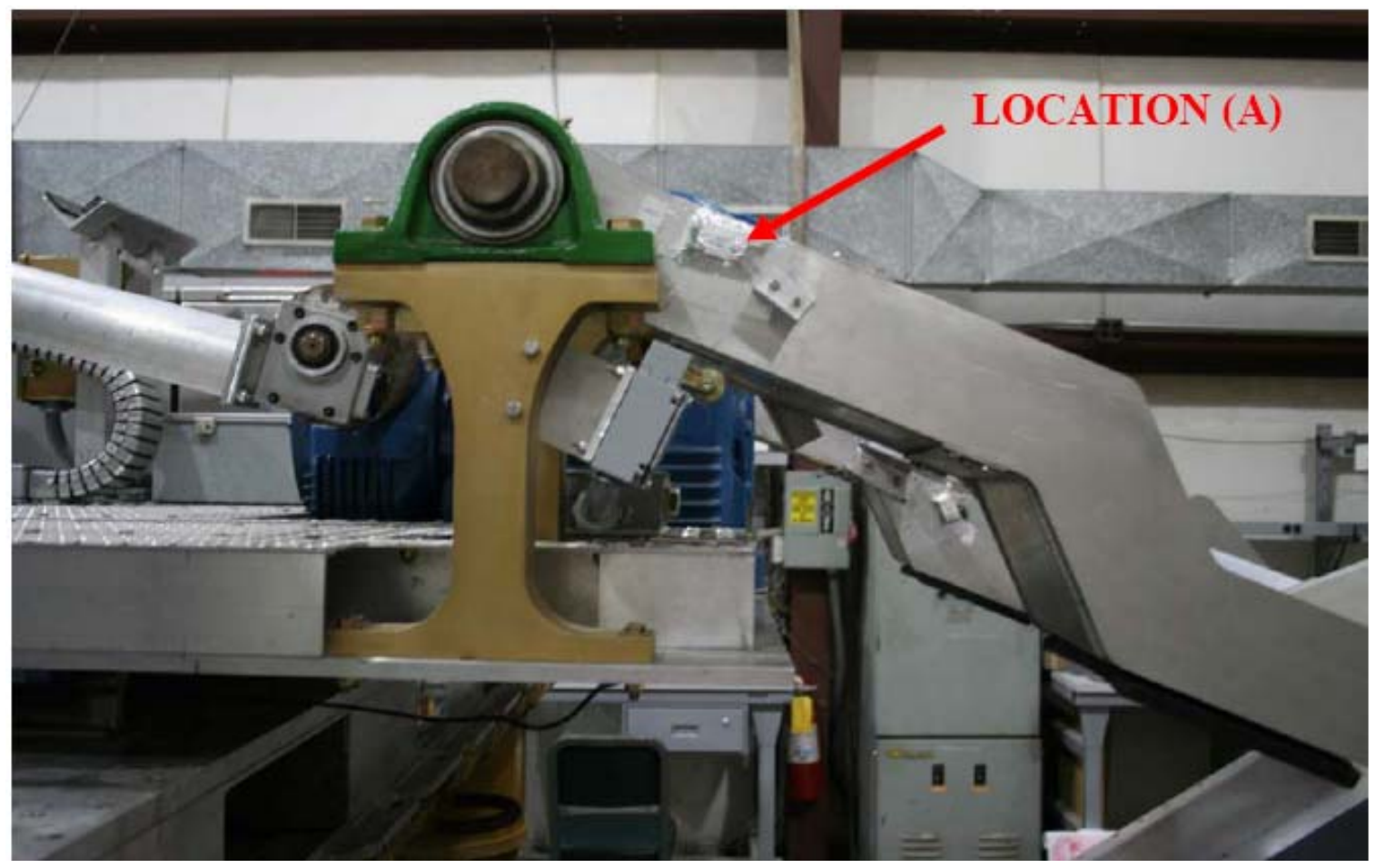

Figure 4-5: Example strain gage mount on the OCULUS 1.1 system.

\subsubsection{Accelerometer Setup}

A total of (4) -3 axis accelerometers were used during the flight test to collect the vibration data of the fuselage, the sensor pod frame and the base of the deployment system. All four accelerometers were mounted in the same manner and in the same orientation. The first accelerometer was mounted to the railing system of the fuselage at a location within 10 feet (fore) of the hinge of the rear ramp (in pallet position 5). This accelerometer will act as the baseline reading of the movement caused by the airframe. The second accelerometer was mounted on an inner frame member of the sensor pod. The purpose of this accelerometer was to get a comparison reading between the vibrations seen in the fuselage and the vibrations seen on the pod frame while underneath the rear ramp of the aircraft. The third accelerometer was mounted in the center of the deployment system pallet. The fourth unit was mounted to the vibration isolator plate inside the sensor pod (Figure 4-6). It should be noted that because of a 
compressed schedule for the flight tests, the specific isolators for the anti-vibration plates were not changed out. Because of this, the vibration profile collected from the isolation plate will not be indicative of the ideal tuning based on the specific payload.

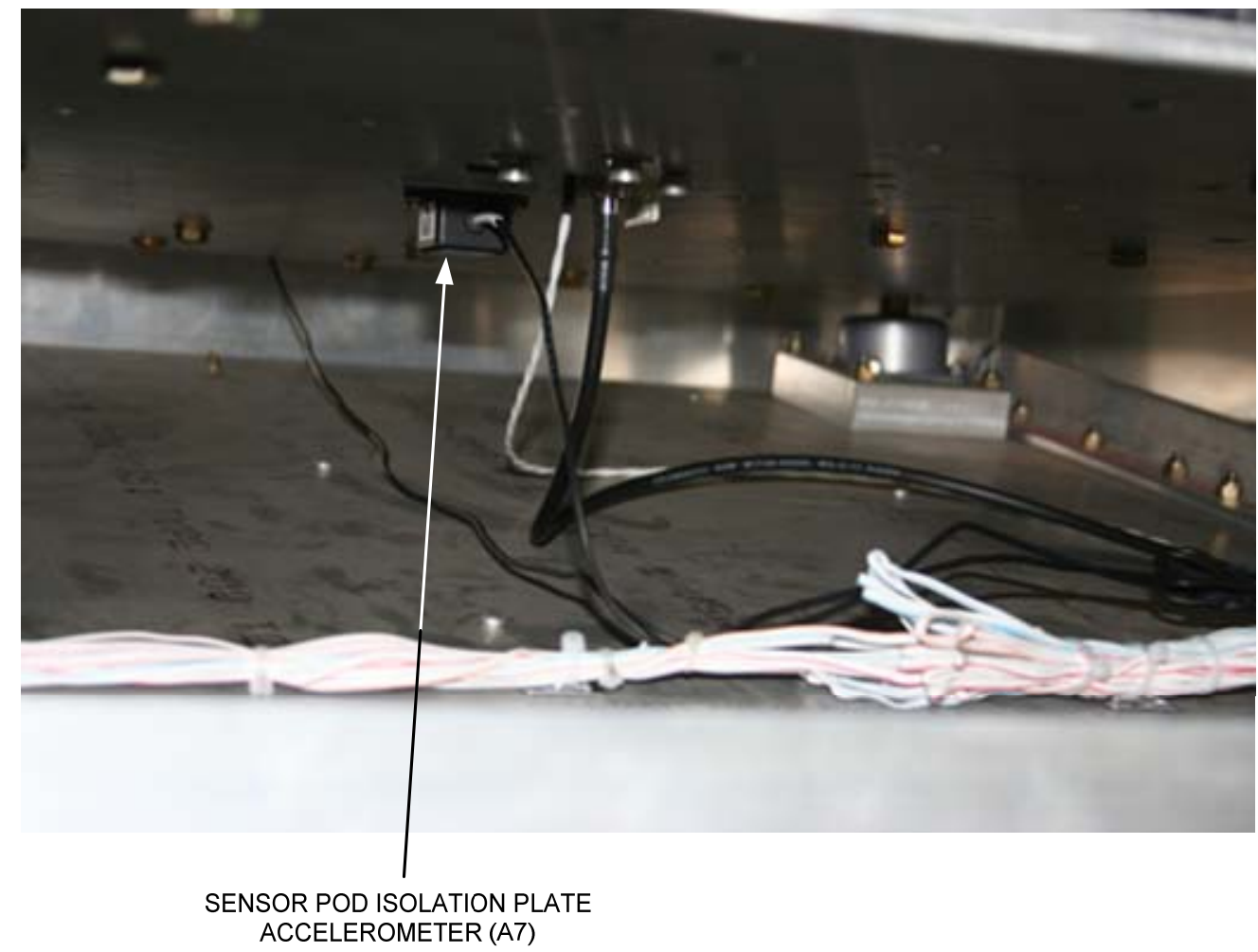

Figure 4-6: Approximate accelerometer location on the OCULUS 1.1 system sensor pod assembly.

\subsubsection{Data Acquisition (DAQ) Setup}

The layout shown in figure 4-1 has numbers designating the location and connection of components. Each specific component used in this experimental setup is described in Appendix H. Components (1) and (2) were rack-mounted in the sensor enclosure box nearest to the outside of the aircraft. The power supply (1) was used to support the carriers and modules (2). For this test a finite number of data acquisition channels was used in the data collection process $(6-$ rosette strain gages, 6- dummy gages, 4- 3 axis accelerometers with one channel necessary per axis) which required the use of a 32 channel carrier and 21 modules (or 2-16 channel carriers and 21 modules). 
Each of the 6 three element rosette strain gages (6) was connected to an individual "dummy" gage located on the back 0.5 in. plate of the sensor pod. The locations of the "dummy" gages were evenly spaced on the back plate. The reasoning for this location of the dummy gages was because their performance is optimized if they are placed on the same material with the same approximate thickness (this plate is $0.5 \mathrm{in}$. and the arms are $0.75 \mathrm{in}$.).

Each of the $4-3$ axis accelerometers (5) was connected and run through shielded wire (7) to the carrier/module system (2). Once again all accelerometers was mounted and oriented in the same manner. Each wire (shielded (7)) out of each strain gage and accelerometer was run into the shielded carrier and module (2) rack mounted in the aft most sensor enclosure. This carrier/module was powered by either a $5 \mathrm{~V}$ or $3 \mathrm{~V}$ power supply that is also mounted in the aft most sensor enclosure. This system was then sent through shielded cable (7) and an amphenol connector into the enclosure just next to it. This foremost side sensor enclosure houses the CPU (3) which houses the data acquisition card (4) and the measurement software necessary for obtaining the data.

Another shielded cable, with an amphenol connector, was run out of the foremost sensor enclosure along the fuselage floor of the $\mathrm{C}-130$ and into the operator station waterfall connection area by an amphenol connection. Inside the operator station the CPU shielded cable was fed into one (or both) computers that acted as a remote desktop (8) for the system on the sensor pallet.

The data collection software used for the OCULUS Flight Test (customized by the Center for Industrial Applications, WVU) was a graphical virtual instrument created with National Instruments LabView version 8.2. The software resided on the computer that was mounted on the OCULUS 1.1 Sensor Platform. The program was controlled by a remote client computer located in the OCULUS 1.1 Operator Station using an Ether net connection and a web server. 
When the pallet $115 \mathrm{VAV}, 60$ Hertz was applied, the computer powered up and the data collection software would begin to run. The program GUI, see Figure 4-7, was displayed on the remote client along with continuous readings from the pallet sensors.

The user can configure parameters such as sample rate and strain gage indicator limits. A sample rate of 100 hertz was the default used for the Flight Test. The GUI contained visual indications of the strain gage readings relative to the structural limits of the pallet. The indicators would change colors reflecting the amount of measured strain. Green, Orange, and Red corresponded to Normal, Warning, and Fault conditions (see Table 4-1) for the indicator limits. Recording of the sensor data was started and stopped by clicking on a button on the GUI. Data files were named automatically and stored in a predetermined directory on the data collection computer (the data collected with a Timestamp is shown in Appendix I). 


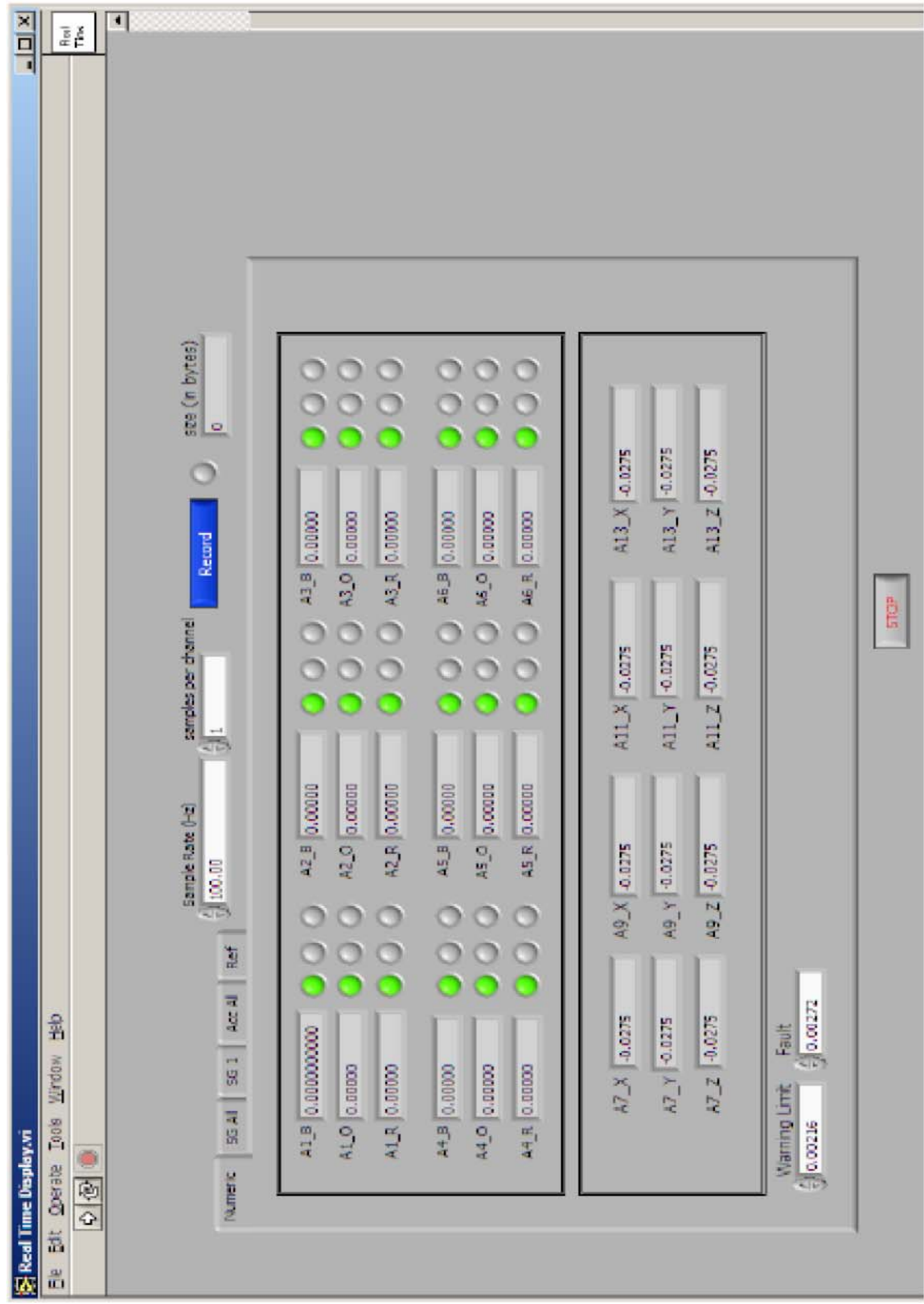

Figure 4-7: OCULUS 1.1 data collection software GUI. 
Table 4-1: Strain Indicator Limits

\begin{tabular}{|c|c|}
\hline Color & Strain Value $(\varepsilon)$ \\
\hline Green & 0 to $+/-0.002159$ \\
\hline Orange & $+/-0.00216$ to $+/-0.002719$ \\
\hline Red & $\geq+/-0.002720$ \\
\hline
\end{tabular}

During the pallet flight test preparation, National Instruments Measurement and Automation Explorer (MAX) software was used to configure the OCULUS sensor channels (18 strain gages and 12 accelerometers). A configuration GUI set parameters for each strain gage. The strain gage parameters included, minimum and maximum values, scaled units (Strain), Gage factor (2.1) gage resistance (119.9) and stain gage configuration (Half Bridge II). The accelerometer configuration was for a general purpose +/- 5 VDC Analog Input. Figures 4-8 and 4-9 show examples of the strain gage and accelerometer configuration GUIs. 


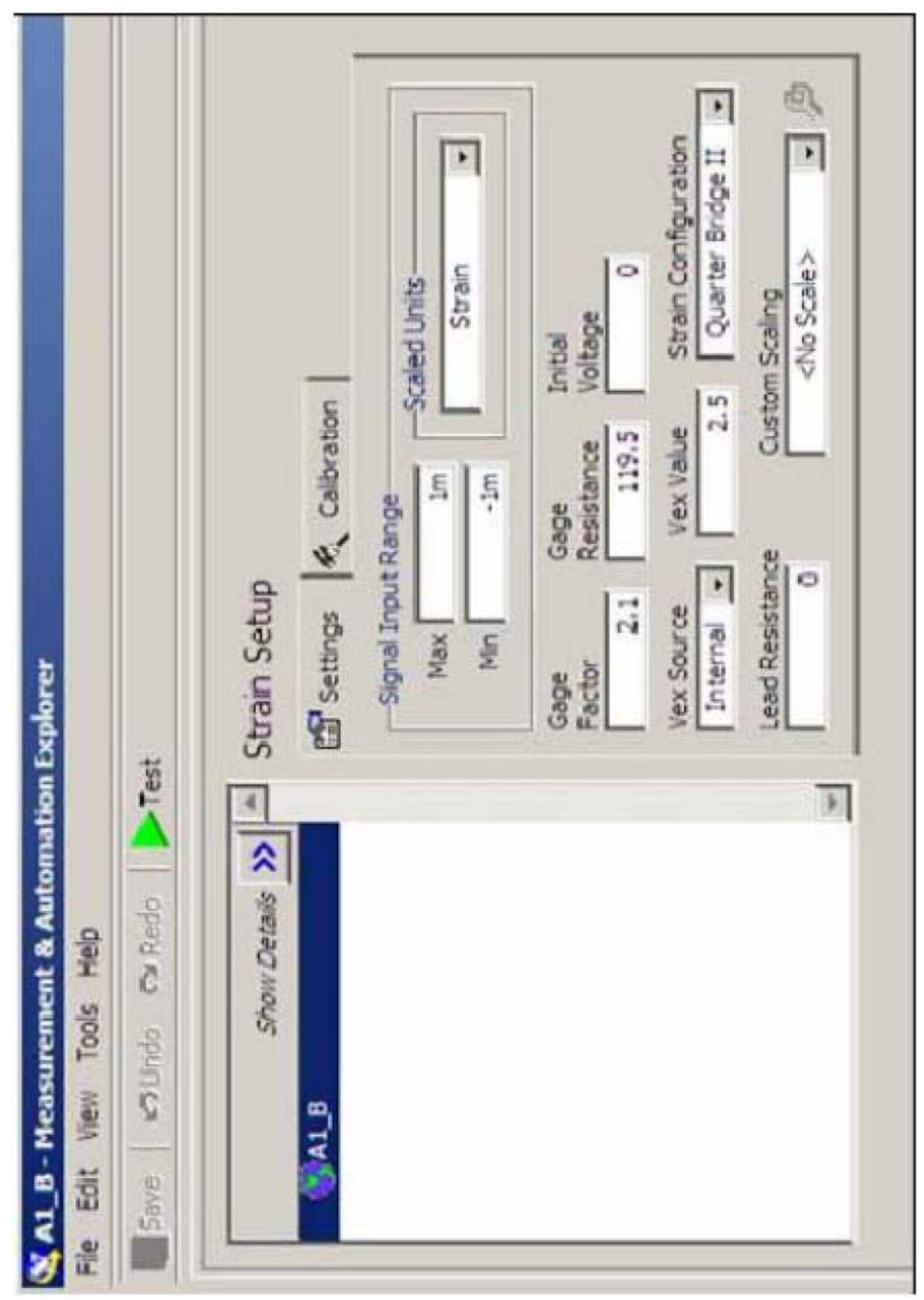

Figure 4-8: Example of strain gage configuration GUI. 


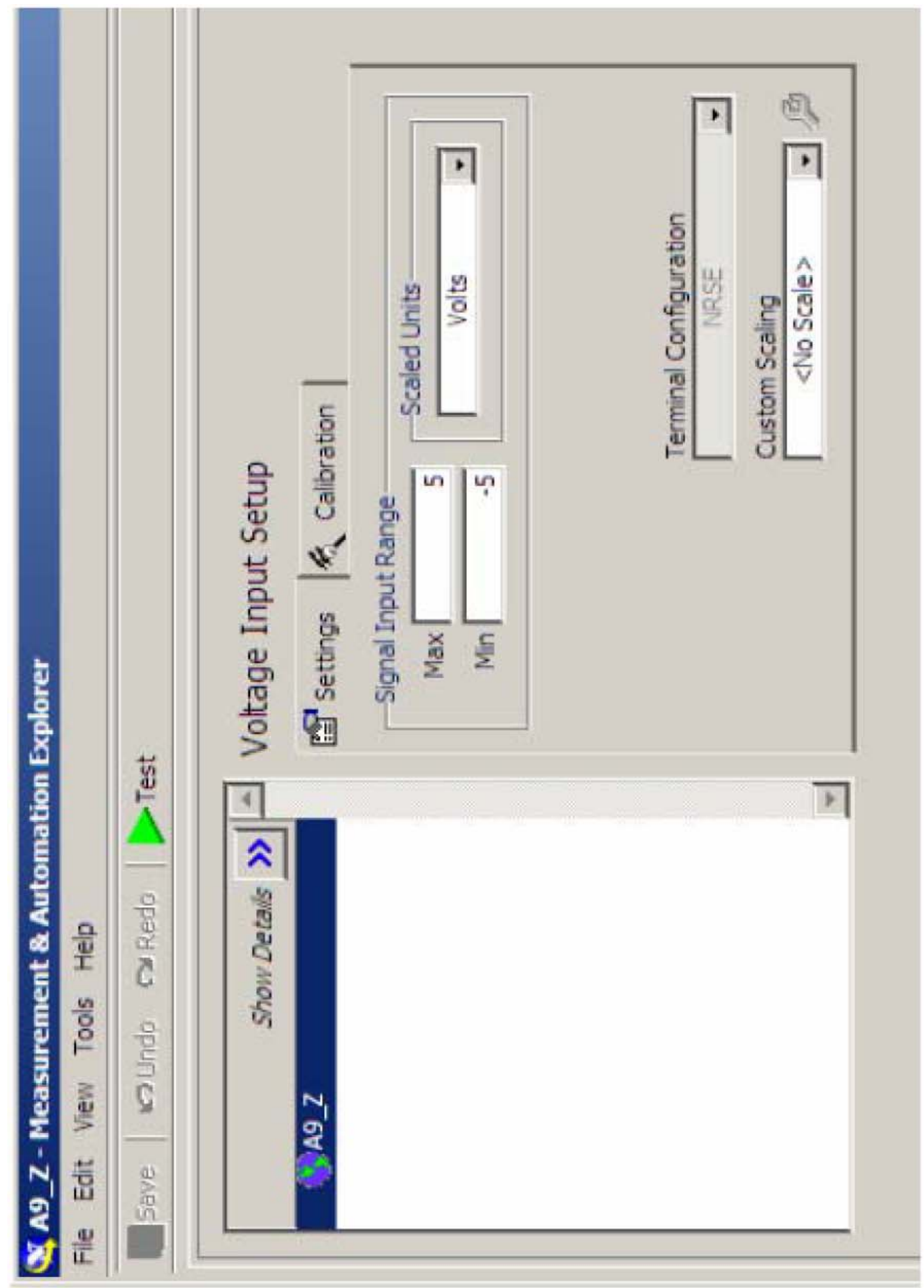

Figure 4-9: Example of accelerometer configuration GUI. 


\subsection{Test Matrix}

The following test matrices for the OCULUS flight was outlined by the WRAFB. The test matrix covers standard (and some non-standard) C-130 maneuvers during mission scenarios. These include aircraft banking at various degree angels and performing aircraft slips in both the right and left directions. Strain and vibration data will be taken and recorded for each of the listed speeds at each of the three different dummy load weights inside the pod (to simulate various sensor package masses). This data will also be taken at 15, 30 and 45 degree banking maneuvers as well as left and right slips. These speeds, weights and maneuvers to be performed in the test flight are the selected flight parameters for the aircraft with the OCULUS system attached. The test parameters, as outlined in the test matrix are:

- Sensor Pod Position: (1) stowed, (2) deployment stage and (3) final operating position

- Sensor Pod Payload Weight: (1) Beginning payload weight - $100 \mathrm{lbs}$, (2) intermediate payload weight $-200 \mathrm{lbs}$ and (3) Final payload weight $-263 \mathrm{lbs}$

- Aircraft Speed: (1) Initial speed - 130 KIAS, (2) Final speed - 150 KIAS

- Flight Maneuvers: (1) Straight and Level (S\&L), (2) 15 degree left bank, (3) 30 degree left bank, (4) 45 degree left bank, (5) 15 degree right bank, (6) 30 degree right bank, (7) 45 degree right bank, (8) left slip and (9) right slip

- Rear Ramp Position: (1) open and (2) partially raised

A build-up approach (this refers to successful completion of the previous test) will be taken during the testing process to ensure safety to both the crew and the airframe. Once objectives 1 and 2 have been successfully completed the actual in-flight deployment (with payload) of the system will begin. The initial set of tests for in-flight deployment will occur at 
straight and level flight, at both 130 and 150 kias and with the three pre-determined weights as the payload. This initial matrix is shown in Table 4-2.

Table 4-2: OCULUS 1.1 deployment test flight matrix.

\section{Straight and Level Flight}

\begin{tabular}{|c|c|}
\hline \multicolumn{2}{|c|}{ Deployment - Rotation } \\
\hline Pod Weight (Ibs) & Speed (kias) \\
\hline 100 & 130 \\
\hline 100 & 150 \\
\hline 200 & 130 \\
\hline 200 & 150 \\
\hline 263 & 130 \\
\hline 263 & 150 \\
\hline \multicolumn{2}{|c|}{ Deployment - Linear Retraction } \\
\hline Pod Weight (lbs) & Speed (kias) \\
\hline 100 & 130 \\
\hline 100 & 150 \\
\hline 200 & 130 \\
\hline 200 & 150 \\
\hline 263 & 130 \\
\hline 263 & 150 \\
\hline Final Operating Position \\
\hline Pod Weight (lbs) & Speed (kias) \\
\hline 100 & 130 \\
\hline 100 & 150 \\
\hline 200 & 130 \\
\hline 200 & 150 \\
\hline 263 & 130 \\
\hline 263 & 150 \\
\hline
\end{tabular}

Following successful completion of the tests in Table 4-2, the next step in the testing of the system incorporates aircraft maneuvers while the system is in the final operating position. These tests will collect the strain and accelerometer data of the system during 15, 30 and 45 degree maneuvers and left and right slip maneuvers at the pre-determined payload weight and aircraft speeds while the system is on the final operating position. This specific test matrix is shown in Table 4-3. 
Table 4-3: OCULUS 1.1 maneuver test flight matrix.

\section{Sensor Pod in Final Operating Position (FOP)}

\begin{tabular}{|c|c|}
\hline \multicolumn{2}{|c|}{15 Degree Left Bank } \\
\hline Pod Weight (Ibs) & Speed (kias) \\
\hline 100 & 130 \\
\hline 100 & 150 \\
\hline 200 & 130 \\
\hline 200 & 150 \\
\hline 263 & 130 \\
\hline 263 & 150 \\
\hline \multicolumn{2}{|c|}{30 Degree Left Bank } \\
\hline Pod Weight (Ibs) & Speed (kias) \\
\hline 100 & 130 \\
\hline 100 & 150 \\
\hline 200 & 130 \\
\hline 200 & 150 \\
\hline 263 & 130 \\
\hline 263 & 150 \\
\hline
\end{tabular}

45 Degree Left Bank

\begin{tabular}{|l|l}
\hline Pod Weight (lbs) & Speed (kias) \\
\hline
\end{tabular}

\begin{tabular}{|c|c|}
\hline 100 & 130 \\
\hline 100 & 150 \\
\hline 200 & 130 \\
\hline 200 & 150 \\
\hline 263 & 130 \\
\hline 263 & 150 \\
\hline
\end{tabular}

15 Degree Right Bank Pod Weight (Ibs) $\quad$ Speed (kias)

\begin{tabular}{|c|c|}
\hline 100 & 130 \\
\hline 100 & 150 \\
\hline 200 & 130 \\
\hline 200 & 150 \\
\hline 263 & 130 \\
\hline 263 & 150 \\
\hline
\end{tabular}

30 Degree Right Bank \begin{tabular}{|l|l}
\hline Pod Weight (Ibs) & Speed (kias) \\
\hline
\end{tabular}

\begin{tabular}{|c|c|}
\hline 100 & 130 \\
\hline 100 & 150 \\
\hline 200 & 130 \\
\hline 200 & 150 \\
\hline 263 & 130 \\
\hline 263 & 150 \\
\hline \multicolumn{2}{|c|}{45 Degree Right Bank } \\
\hline Pod Weight (lbs) & Speed (kias) \\
\hline 100 & 130 \\
\hline 100 & 150 \\
\hline
\end{tabular}




\begin{tabular}{|c|c|}
\hline 200 & 130 \\
\hline 200 & 150 \\
\hline 263 & 130 \\
\hline 263 & 150 \\
\hline Left Slip & \\
\hline Pod Weight (Ibs) & Speed (kias) \\
\hline 100 & 130 \\
\hline 100 & 150 \\
\hline 200 & 130 \\
\hline 200 & 150 \\
\hline 263 & 130 \\
\hline 263 & 150 \\
\hline Right Slip & \\
\hline Pod Weight (lbs) & Speed (kias) \\
\hline 100 & 130 \\
\hline 100 & 150 \\
\hline 200 & 130 \\
\hline 200 & 150 \\
\hline 263 & 130 \\
\hline 263 & 150 \\
\hline
\end{tabular}

The OCULUS 1.1 test matrix was assembled to take constant data at specific intervals during the OCULUS 1.1 systems deployment process with concentration on data collection while the system is in the final operating position. The deployment process includes 2 preliminary stages, the stowed stage and linear extension stage, that were used as baseline readings for the system because they did not involve any additional loading acting on the system, and 3 stages that included additional loading: (1) rotational deployment, (2) linear retraction and (3) final operating position.

Prior to stage (1) in the test matrix a preliminary stage is used to establish baseline readings for the data while the OCULUS 1.1 system is in the stowed position. This baseline stage includes when the system is in the stow position and during the linear extension of the system in the deployment process. This baseline stage sets the "zero" baseline reading of the instrumentation equipment. These baseline readings were used, instead of a zero reading, during the post processing stage in calculating maximum strain seen during the test. During this stage, 
is assumed that most of the strain in the system is released by the mechanical arms resting of the arms stands therefore not having to directly support the weight of the mechanical arm/pod system. Figures 4-10 shows a picture of the OCULUS 1.1 system on a C-130 aircraft in the stow position. Figure 4-11 show the OCULUS 1.1 system with its linear translation plate extended (highlighted in the figure) at the end of the linear extension process.

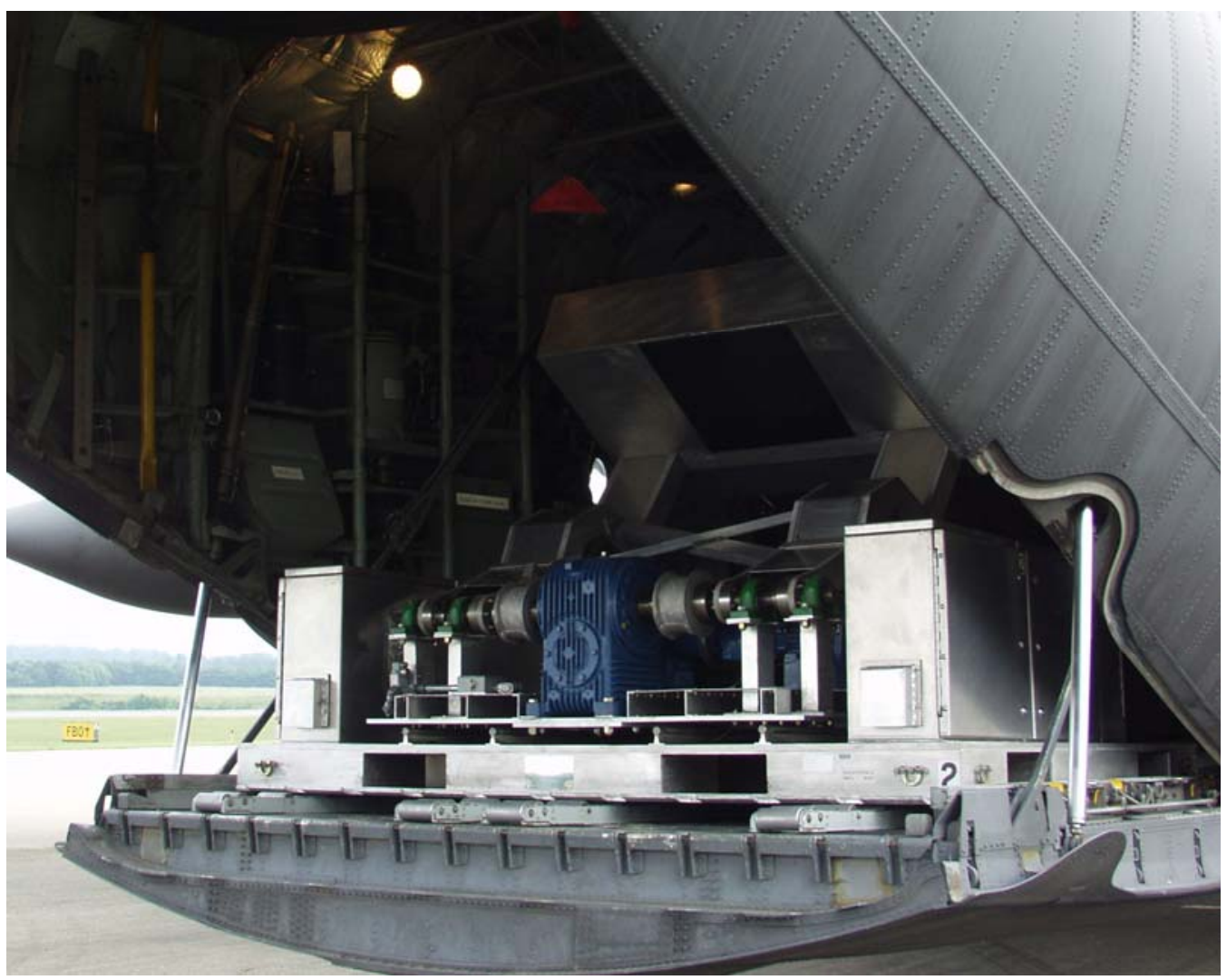

Figure 4-10: The OCULUS 1.1 system on a C-130 aircraft in the stow position. 


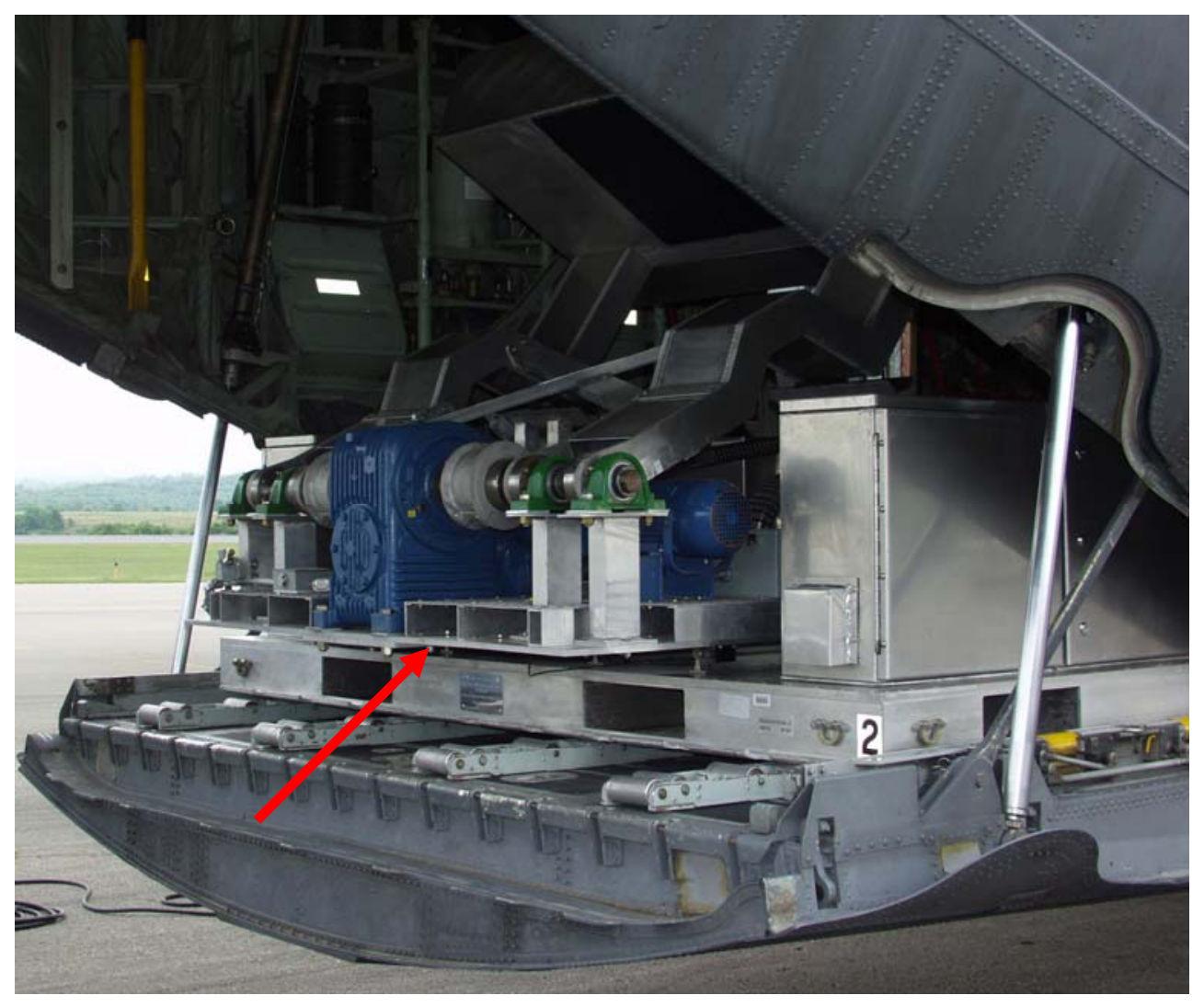

Figure 4-11: The OCULUS 1.1 system on a C-130 aircraft at the end of the linear extension phase.

The first stage in which initial loading is seen on the system is the rotational stage of the OCULUS 1.1 system's deployment process. During this stage the system rotates off of the mechanical arms stands approximately 235 degrees and outside of the aircraft. At the end of this stage the mechanical arm/pod system is outside of the aircraft and in the airstream. Figures 4-12 and 4-13 show the system during the rotational process and at the final position of the process. 


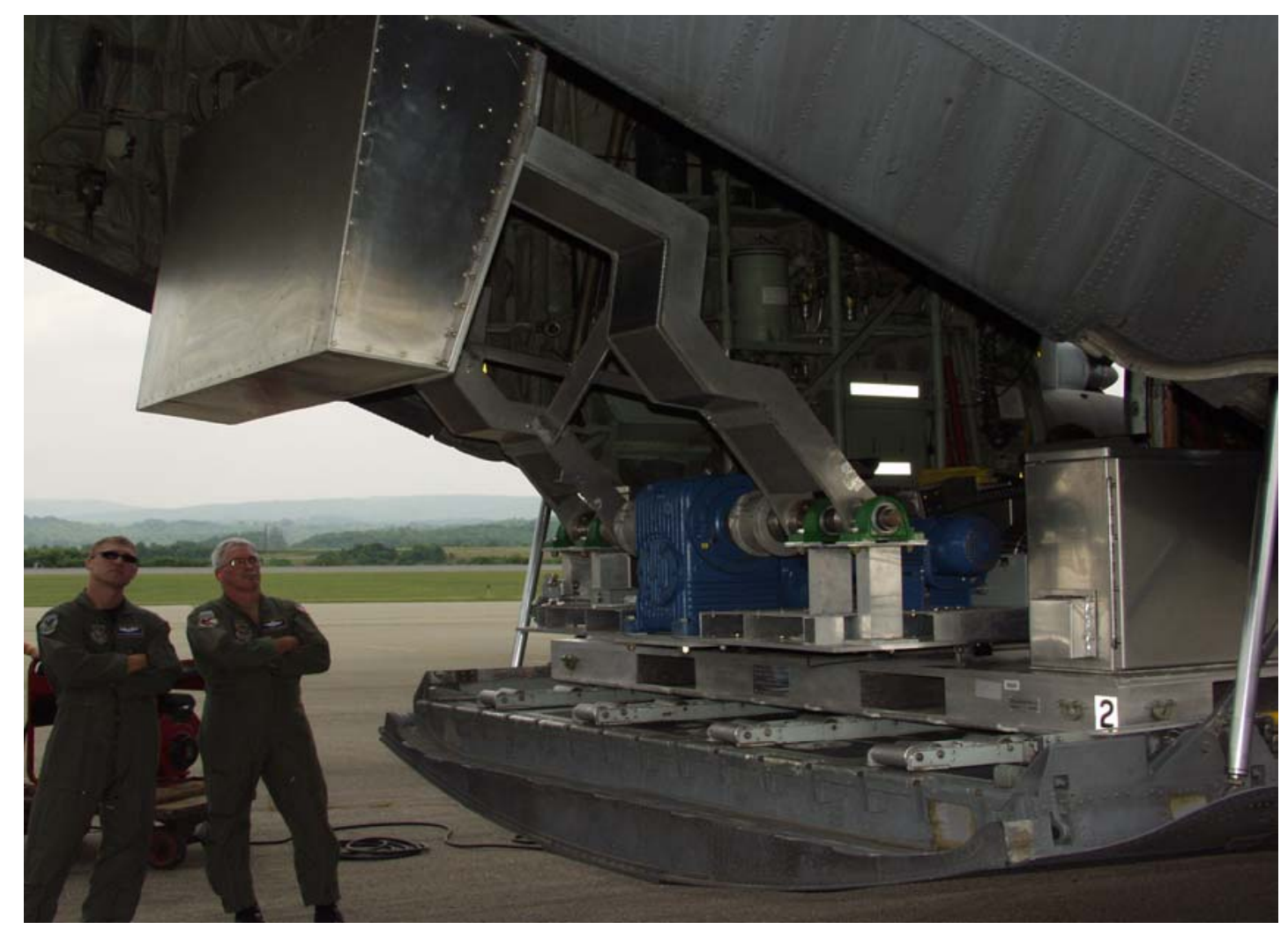

Figure 4-12: The OCULUS 1.1 system during the rotational process of deployment.

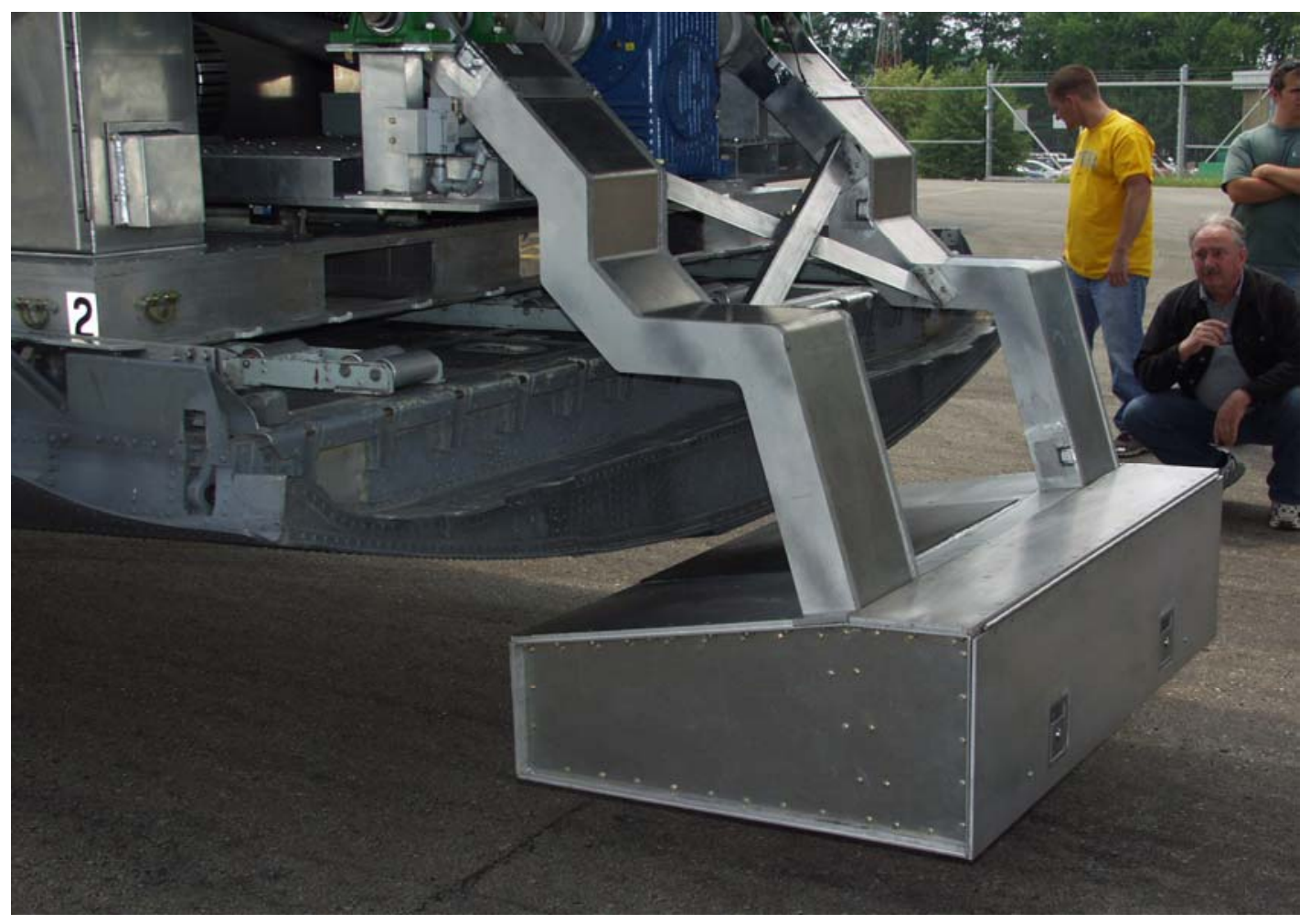

Figure 4-13: The OCULUS 1.1 system at the end the rotational process of deployment. 
The second load encountering stage is the linear retraction procedure of the deployment process. During this stage the system is retracted toward the aircrafts forward (fore) direction up to and against the rear ramp "belly" of the C-130 aircraft. At the end of this stage the OCULUS 1.1 system will be abutted up against the rear ramp of the aircraft with contact being made between the polyurethane plate and the reinforced skin section of the rear ramp. Once the linear retraction is completed the system is now in the final operating stage (the third load encountering stage) of the deployment process. The OCULUS 1.1 system in the final operating stage is seen in Figure 4-14.

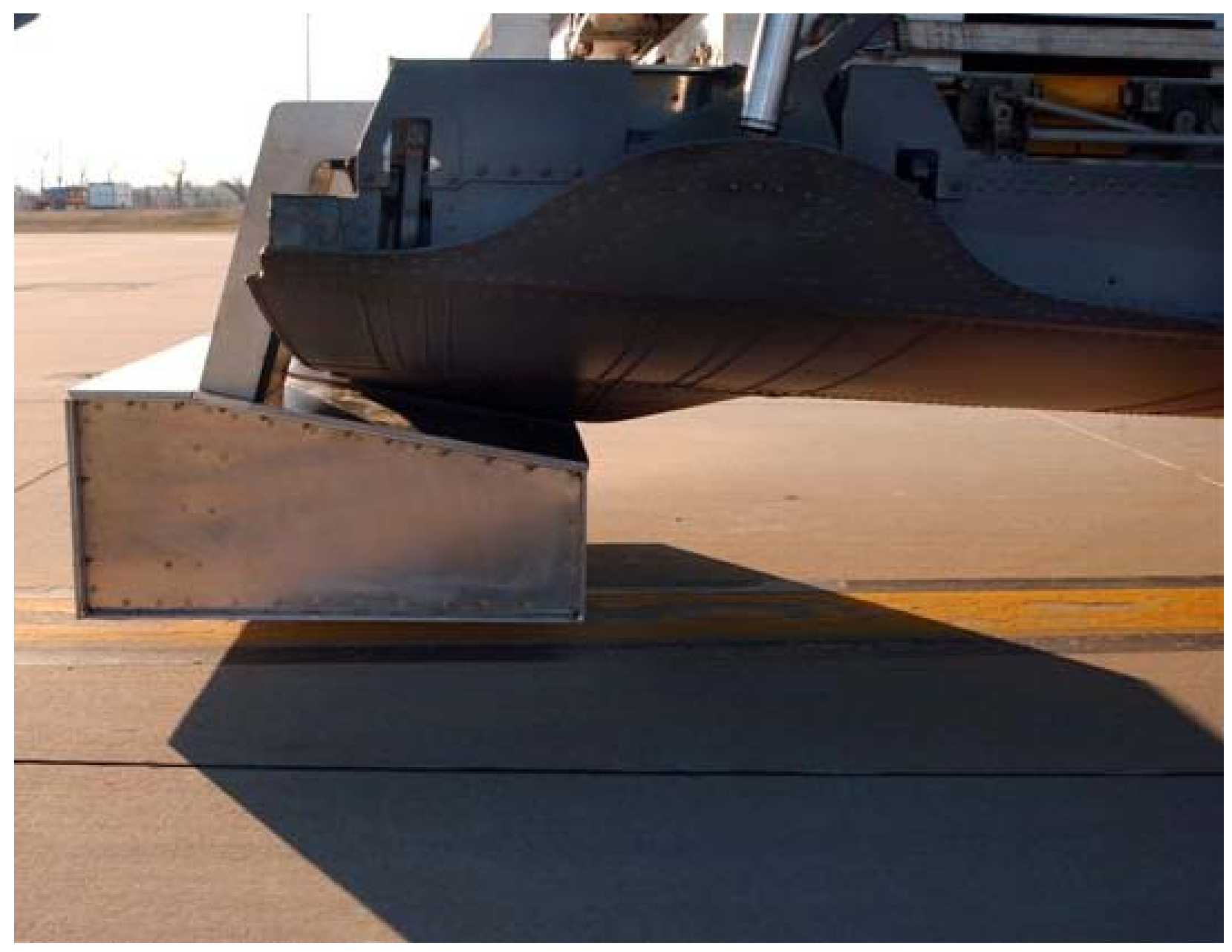

Figure 4-14: The OCULUS 1.1 system in the final operating position. 


\section{Experimental Flight Test}

The flight test design and setup (Section 4), which was developed by WVU and GTRI, was approved by WRAFB and the next step in the process was to perform the flight tests. With all of the instrumentation and DAQ equipment installed and ready for testing (Figures 5-1 and 52) the system was ready to perform the scheduled test at the West Virginia Air National Guard Base in Charleston, WV.

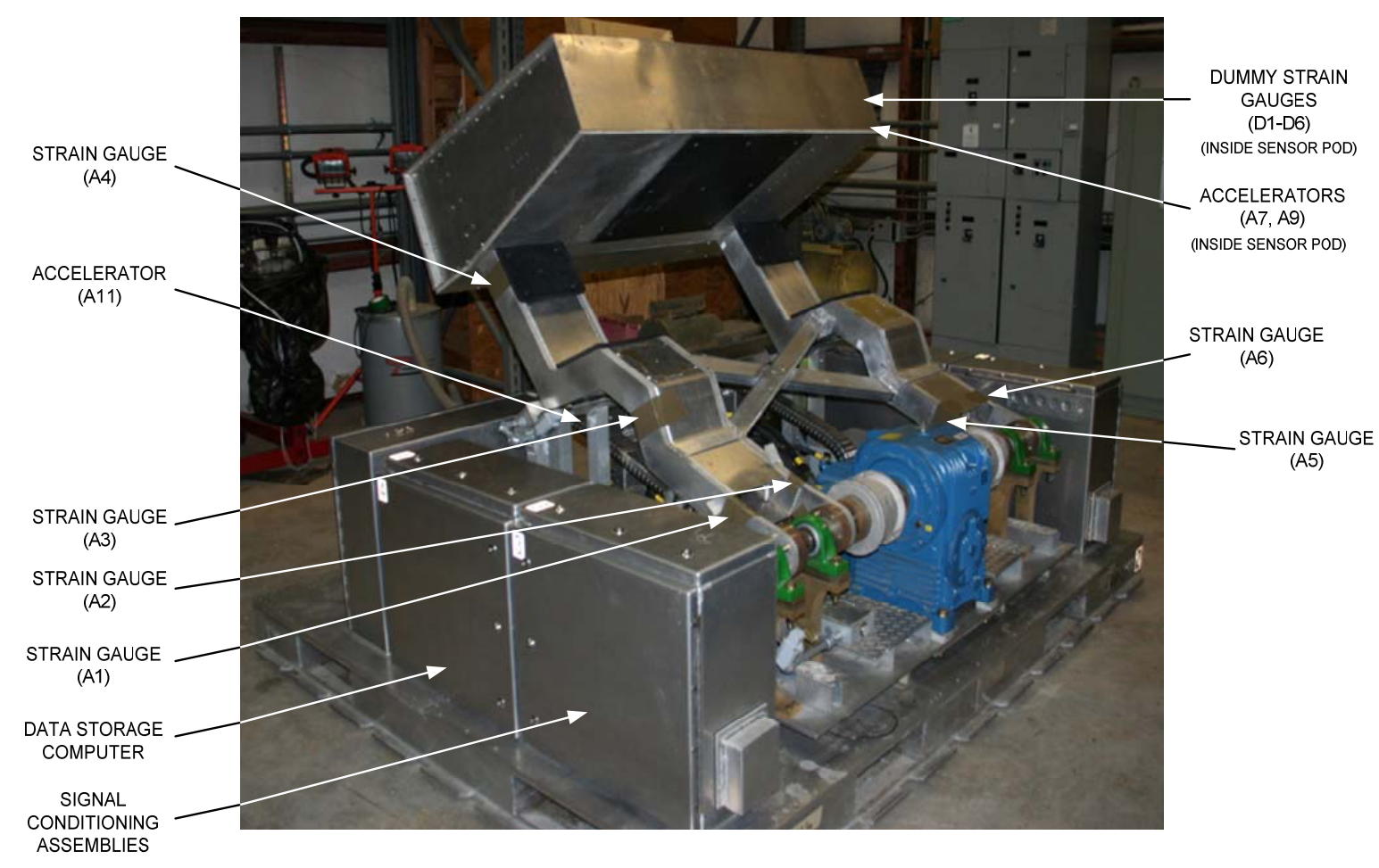

Figure 5-1: Final instrumentation setup on the OCULUS 1.1 Sensor Platform. 


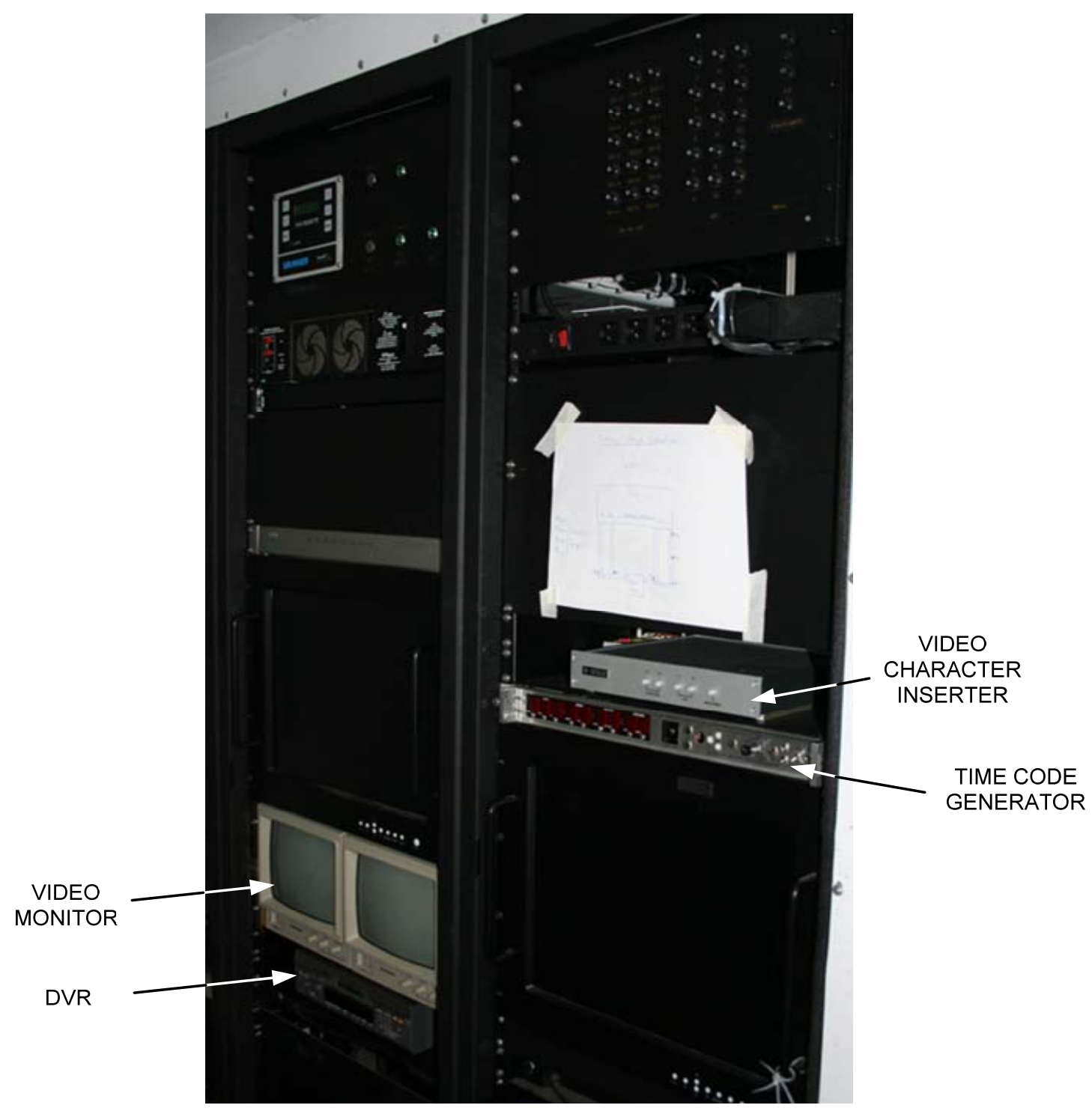

Figure 5-2: Final instrumentation setup in the OCULUS 1.1 Operator Station.

\subsection{Data Collected}

During the flights (based upon the test matrix outlined in Section 4.4) the recorded data was written to a file in ASCII format and was later converted to a Microsoft Excel file. The data recorded included: raw data for each DAQ channel (each strain gage channel and each accelerometer channel) along with a separate data log time stamp of the start time and date of the test, the number of channels, and samples per channel in addition to the sample readings. A 
sample of the raw data output file collected is seen on Appendix I. As mentioned previously, the complete data collection time stamp output file for all tests performed is seen in Appendix J. Figure 5-3 shows a snapshot picture of the data being collected during flight. The sample per procedure can be derived from time stamp information included with each sample. Figure 5-4 shows an example plot of accelerometer and strain data for a typical test.

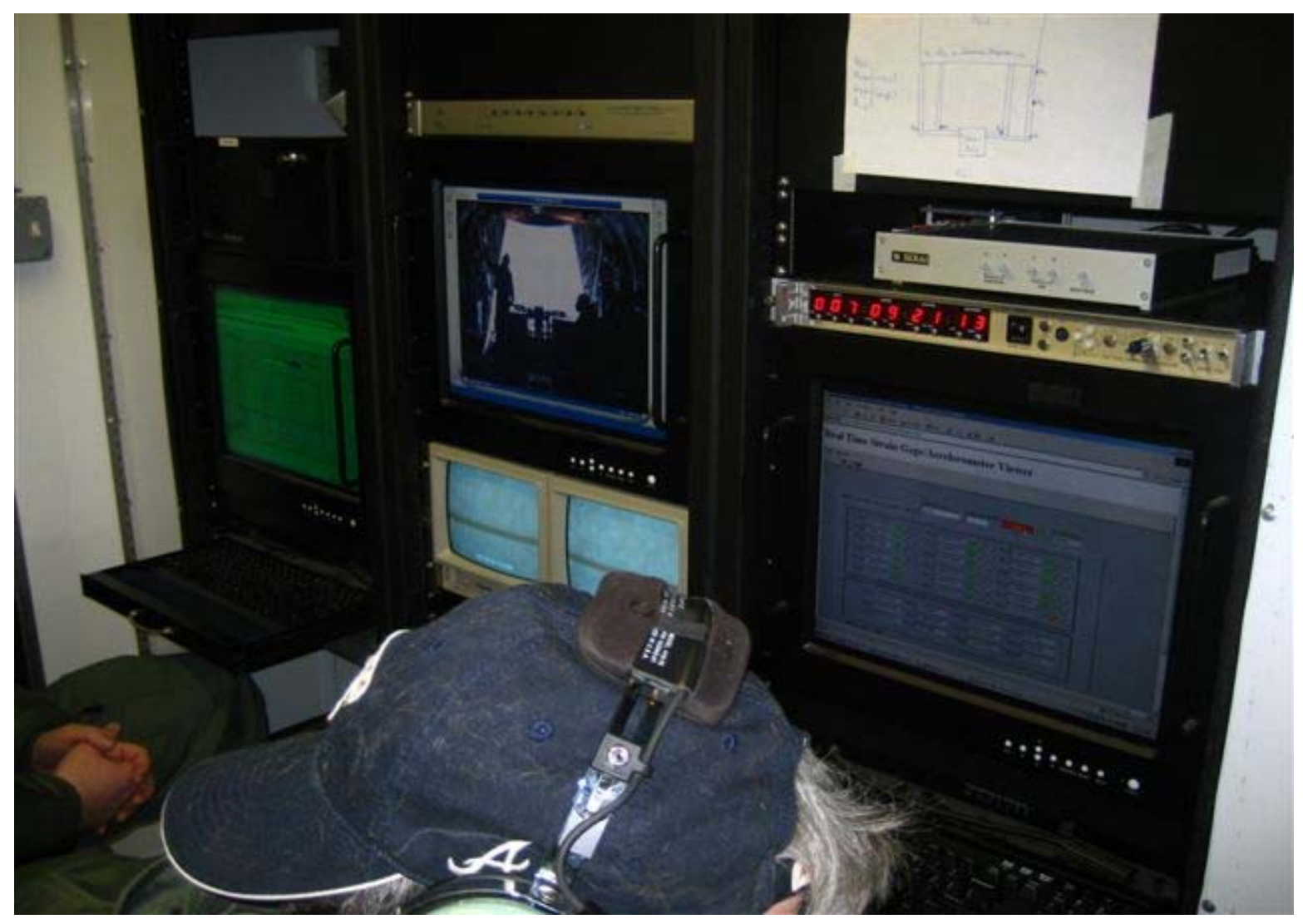

Figure 5-3: In-flight picture of computers displaying the instrumentation data being collected. 


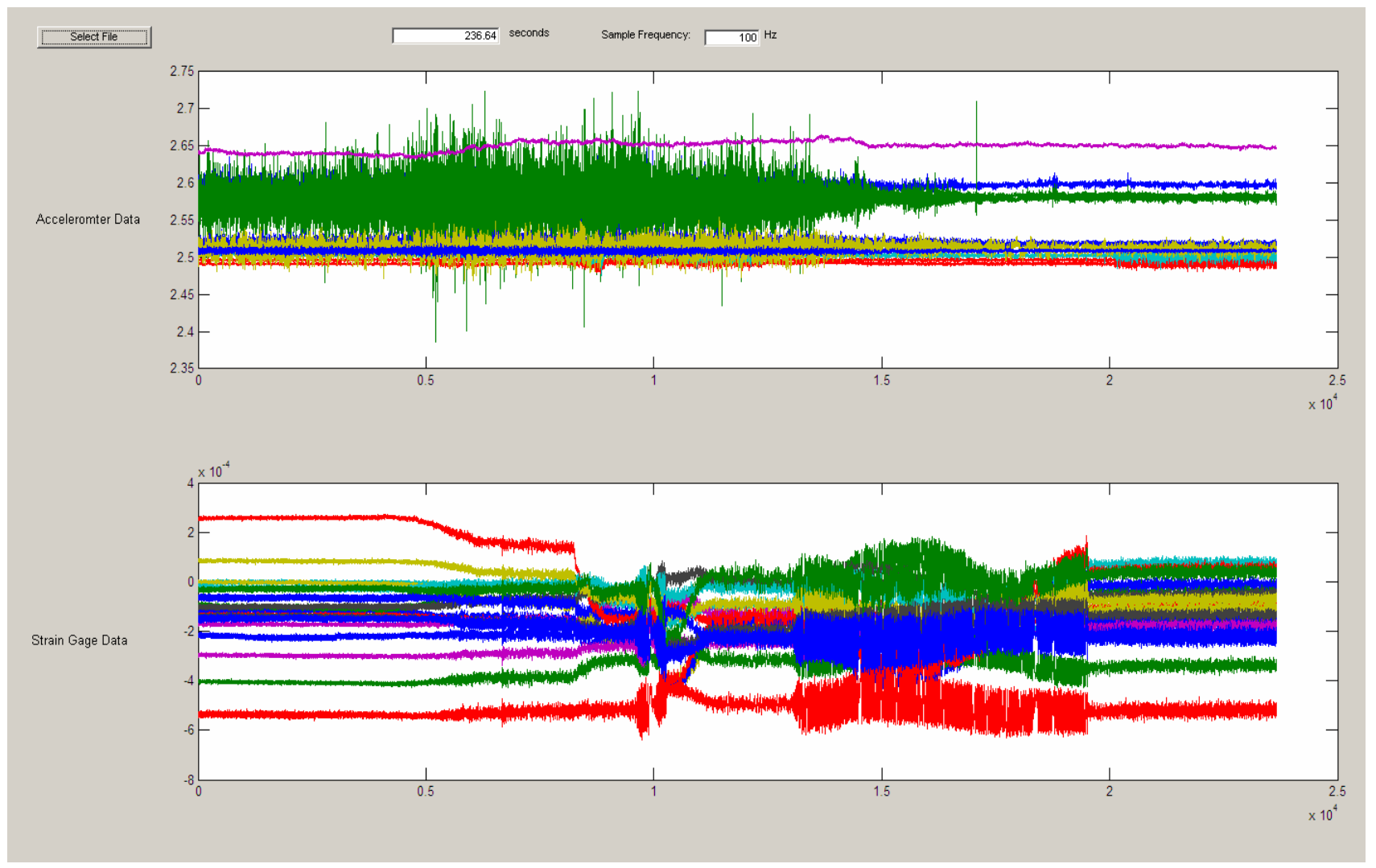

Figure 5-4: Sample data display (accelerometer data on top and strain gage data on bottom).

The flight test data was collected using at $100 \mathrm{~Hz}$ frequency which was selected based upon maximum data storage capacity during the flight test. The average data points collected per deployment cycle of the OCULUS 1.1 exceeded 16,000 and this amount differed on cycle by cycle bases because of operator delays during deployment and stops in the deployment procedure to make visual checks on the system. The average data points collected while the OCULUS 1.1 system was in the FOP exceeded 17,000. This increased data collection at the FOP reflects the test matrix outlines concentration on the OCULUS systems response while in the FOP. In total more then 450,000 raw data points were collected during the OCULUS 1.1 flight tests.

\subsection{Flight Test Visuals}

The OCULUS 1.1 system completed safety of flight testing in Charleston, WV on a C$130 \mathrm{H} 3$ aircraft. The system was able to safely perform all parameters outlined in the test matrix 
in section 4.4. The test successfully collected data from the instrumentation on-board and was able to perform all deployment scenarios (i.e. manual and electrical deployment) without any complications. Figures 5-5 thru 5-10 shown are from the flight tests, both inside the aircraft and from the ground level.

Figure 5-5 shows the OCULUS 1.1 system during the rotational stage of the deployment cycle during flight. At this point in the rotational stage the OCULUS 1.1 system began to experience the effect of aerodynamic wind loading and it could visibly be seen by the slight buffeting of the mechanical arm/pod system. At no point during the deployment process was there significant buffeting of the mechanical arm/pod system or noticeable stresses on the connection systems.

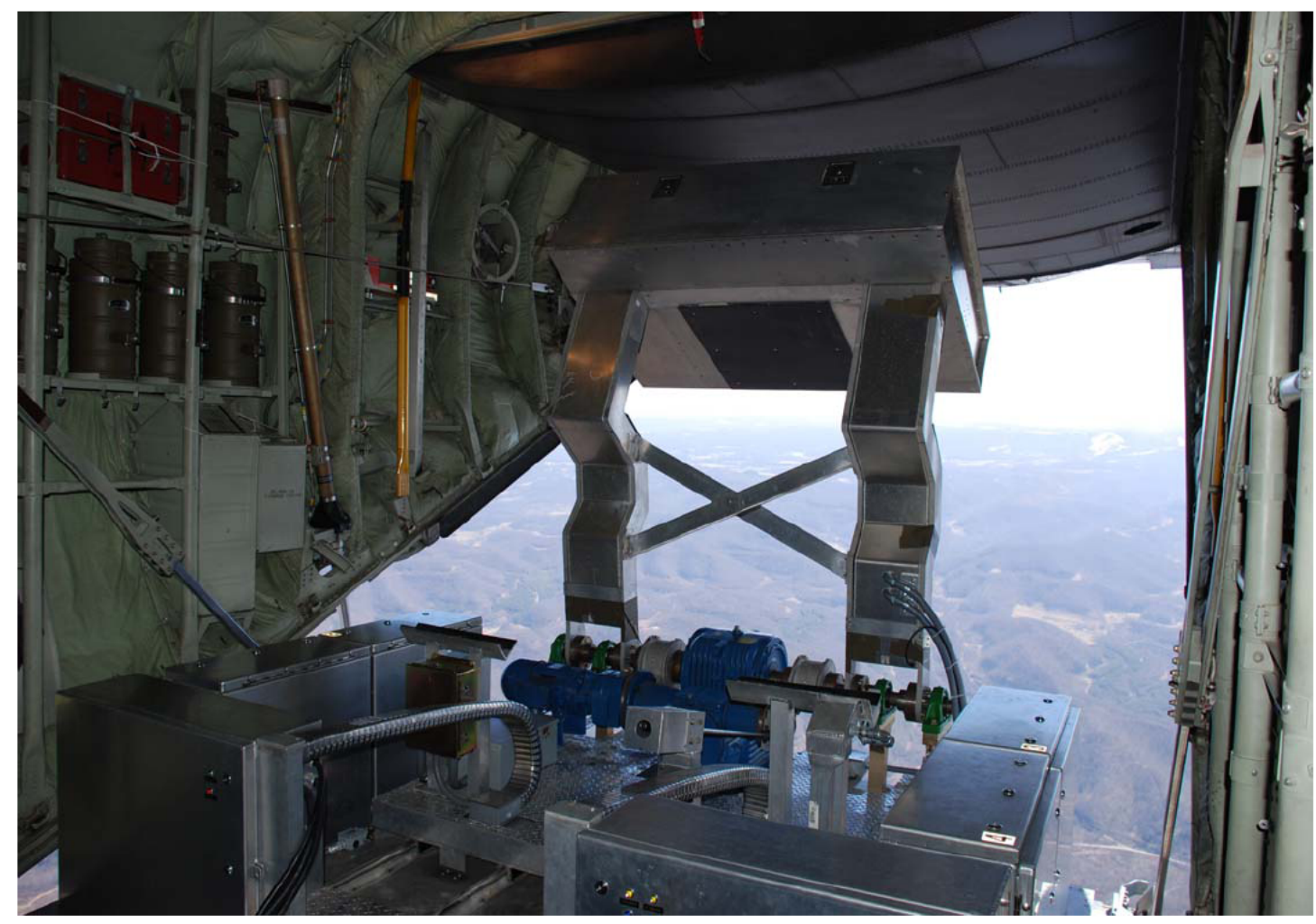

Figure 5-5: The OCULUS 1.1 sensor platform system during a flight deployment phase.

Figure 5-6 shows an in flight picture taken by the test flight loadmaster from the WVANG. This picture shows the OCULUS 1.1 operator station with the door open and flight 
test operators at the computer terminals evaluating the data being collected. The doors to the operator station remained open throughout the flight so constant communication visual could be maintained between operators in addition to audio communication through the aircraft headsets.

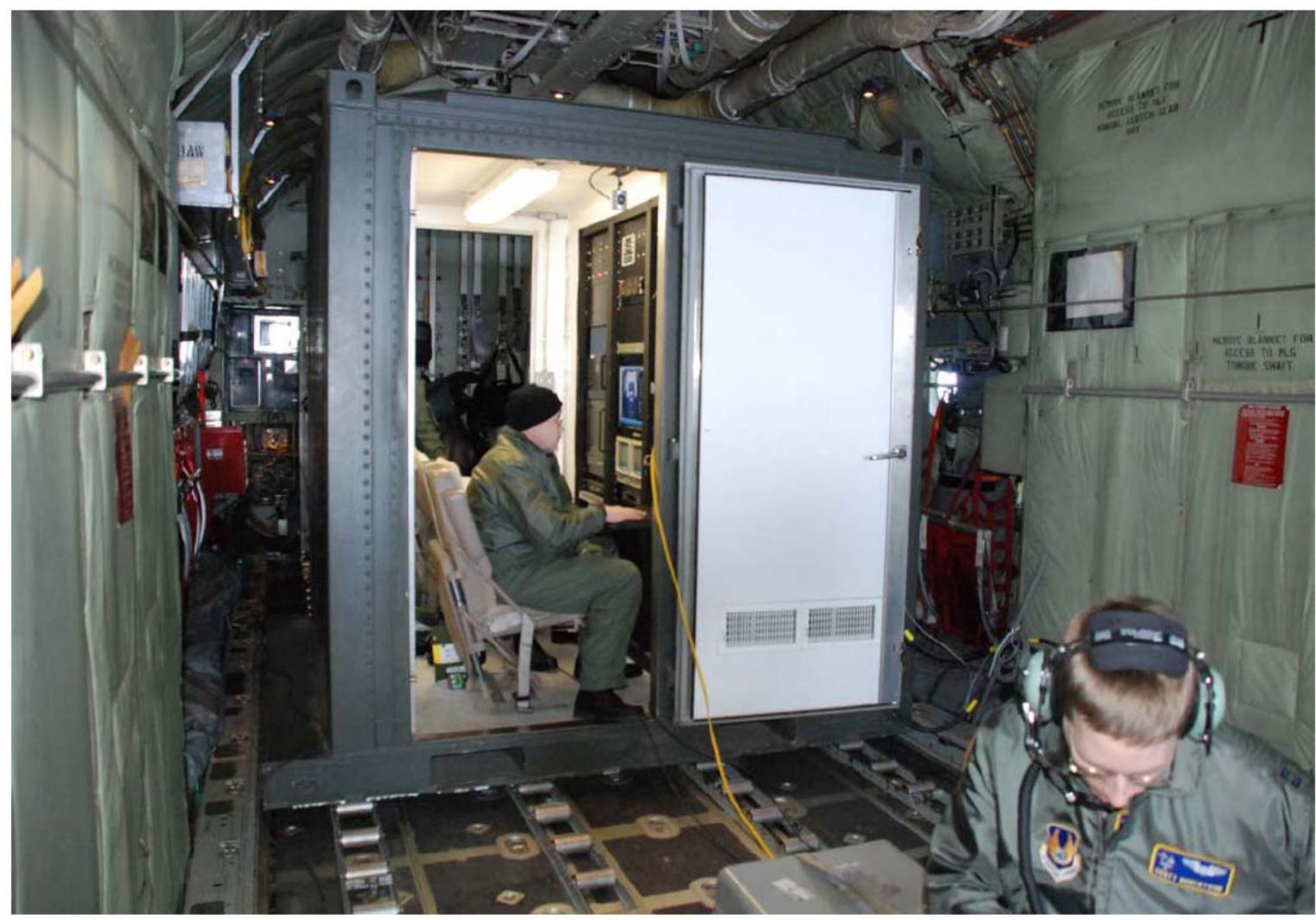

Figure 5-6: The OCULUS 1.1 operator station (during flight) with personnel inside.

Figure 5-7 below is a self taken photograph while the OCULUS 1.1 system is in the FOP. This photograph was taken during a 30 degree banking maneuver as can be see by the orientation of the ground level with respect to the OCULUS system. These types of Photographs (on the rear ramp of the $\mathrm{C}$-130) were safely taken in flight because all operators are required to be tethered in with safety harnesses that connect into D-rings on the fuselage floor. 


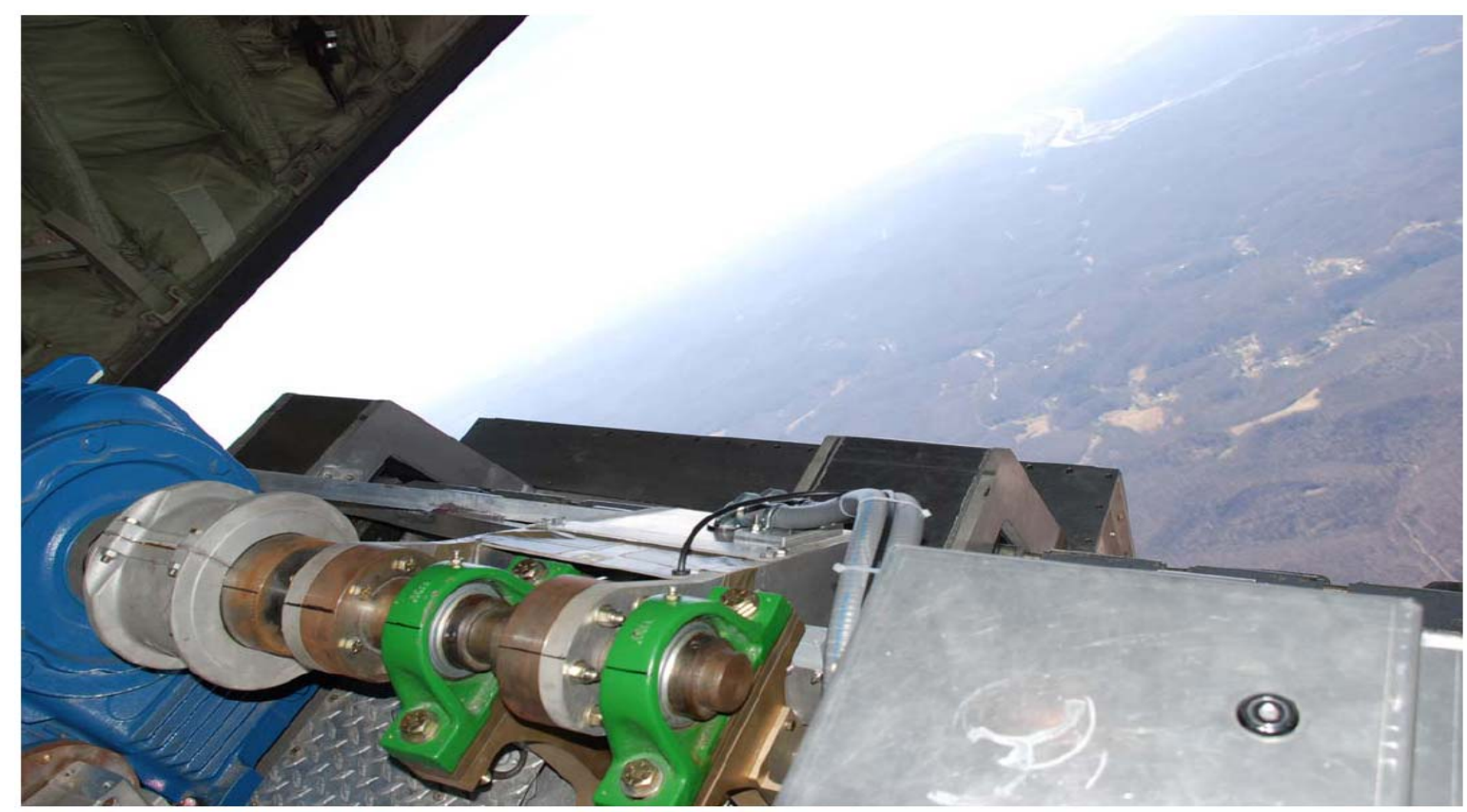

Figure 5-7: View of the OCULUS 1.1 system inside the C-130 aircraft in the deployed position.

Figure 5-8 was taken from the rear ramp of the C-130 during flight during a "touch and go" maneuver. This type of maneuver is performed when the aircraft initializes a decent as if it was intending to land and then aggressively performs an ascension maneuver as if it were just taking off.
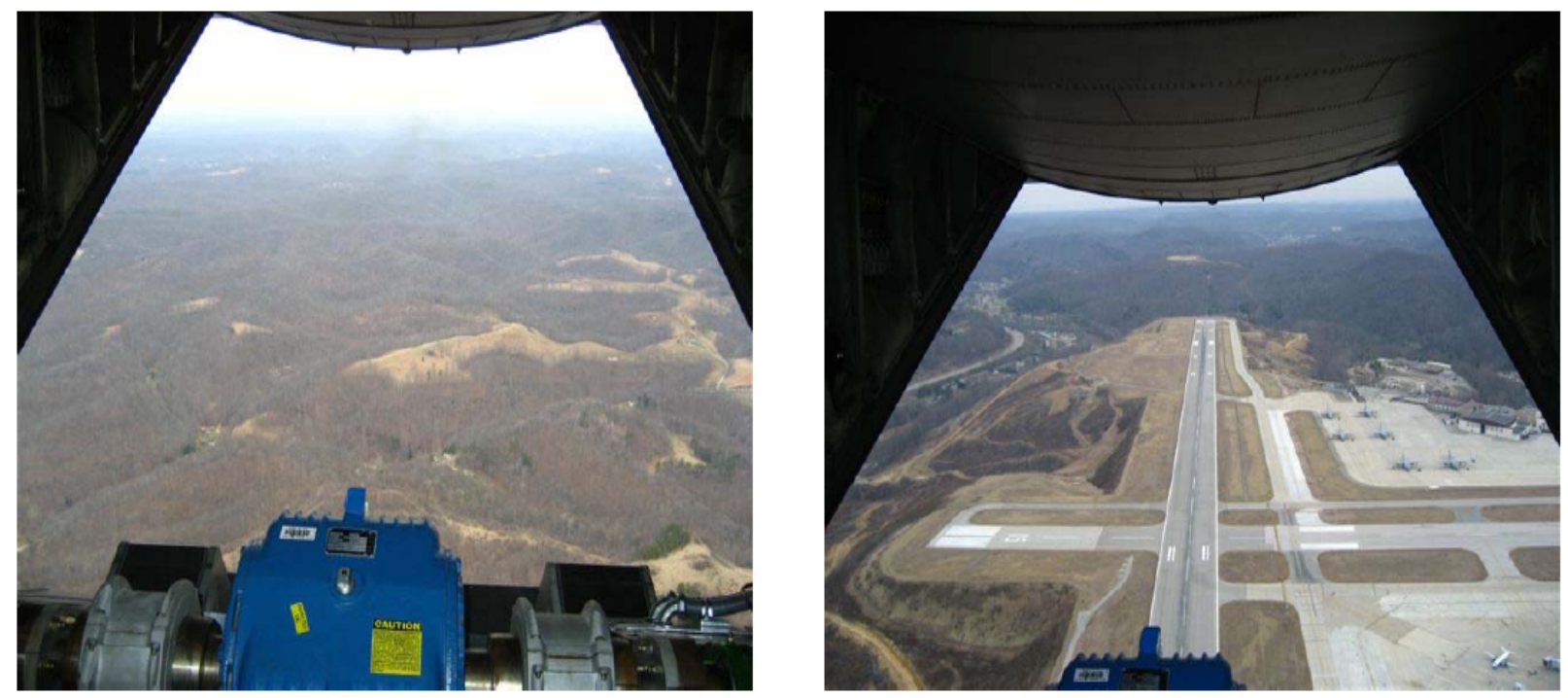

Figure 5-8: A second view of the OCULUS 1.1 system inside the C-130 aircraft in the deployed position. 
Figures 5-9 and 5-10 are photos taken from ground level of the test flight C-130 with the OCULUS 1.1 system in the FOP. In these photographs the rear ramp of the C-130 is in the partial closed position while the OCULUS 1.1 system is deployed. This procedure was not required as outlined by the test matrix but was performed after all of the proposed testing was successfully performed. One of the noticeable visuals of Figure 5-9 and 5-10 is the relative obscurity of the system in flight when deployed from a C-130 aircraft. This obscurity is based on the OCULUS 1.1 system's size in respect to the airframe and the visible color-blend to the airframes structure.

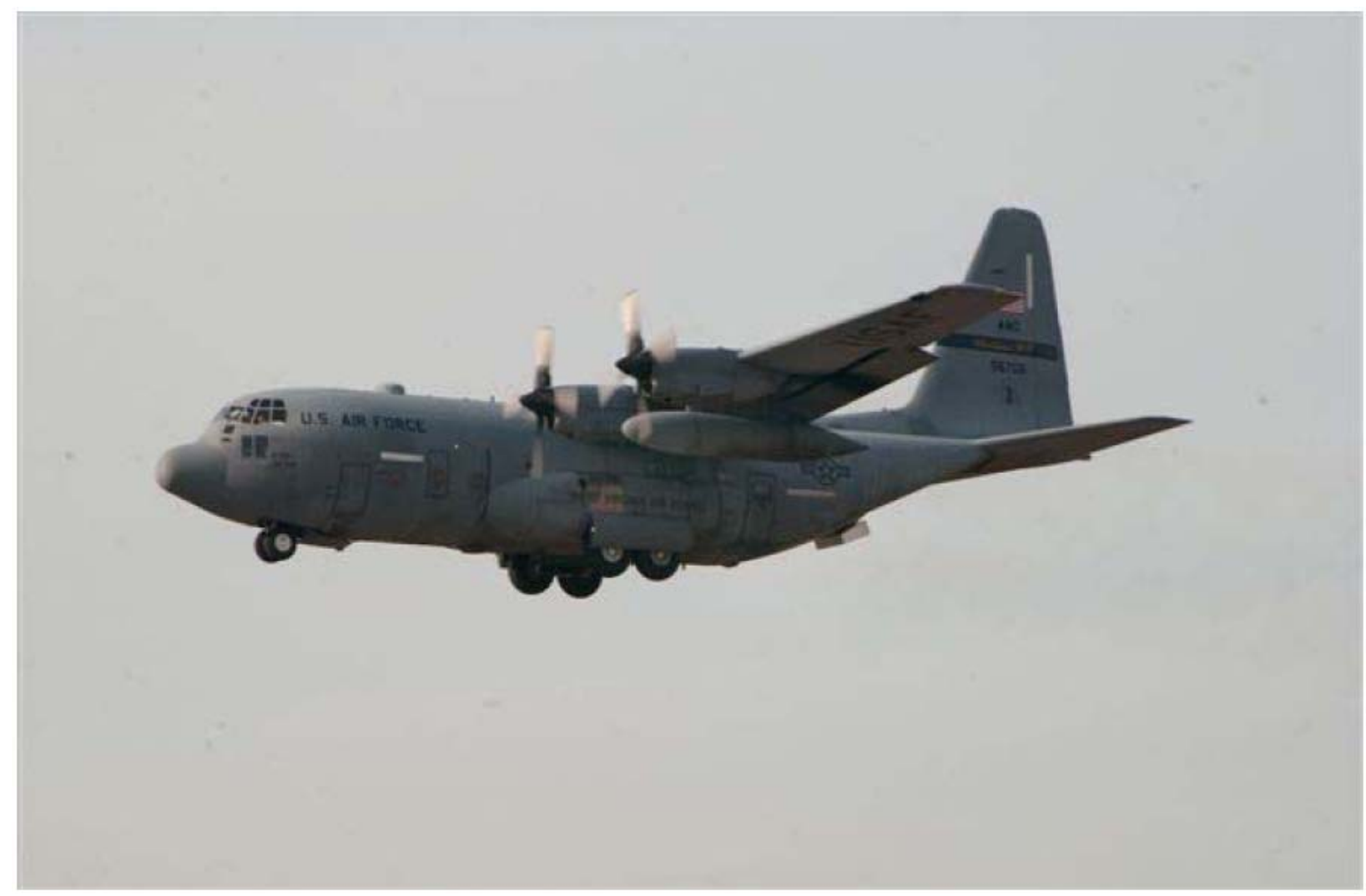

Figure 5-9: View of the OCULUS 1.1 from ground level in the deployed position. 


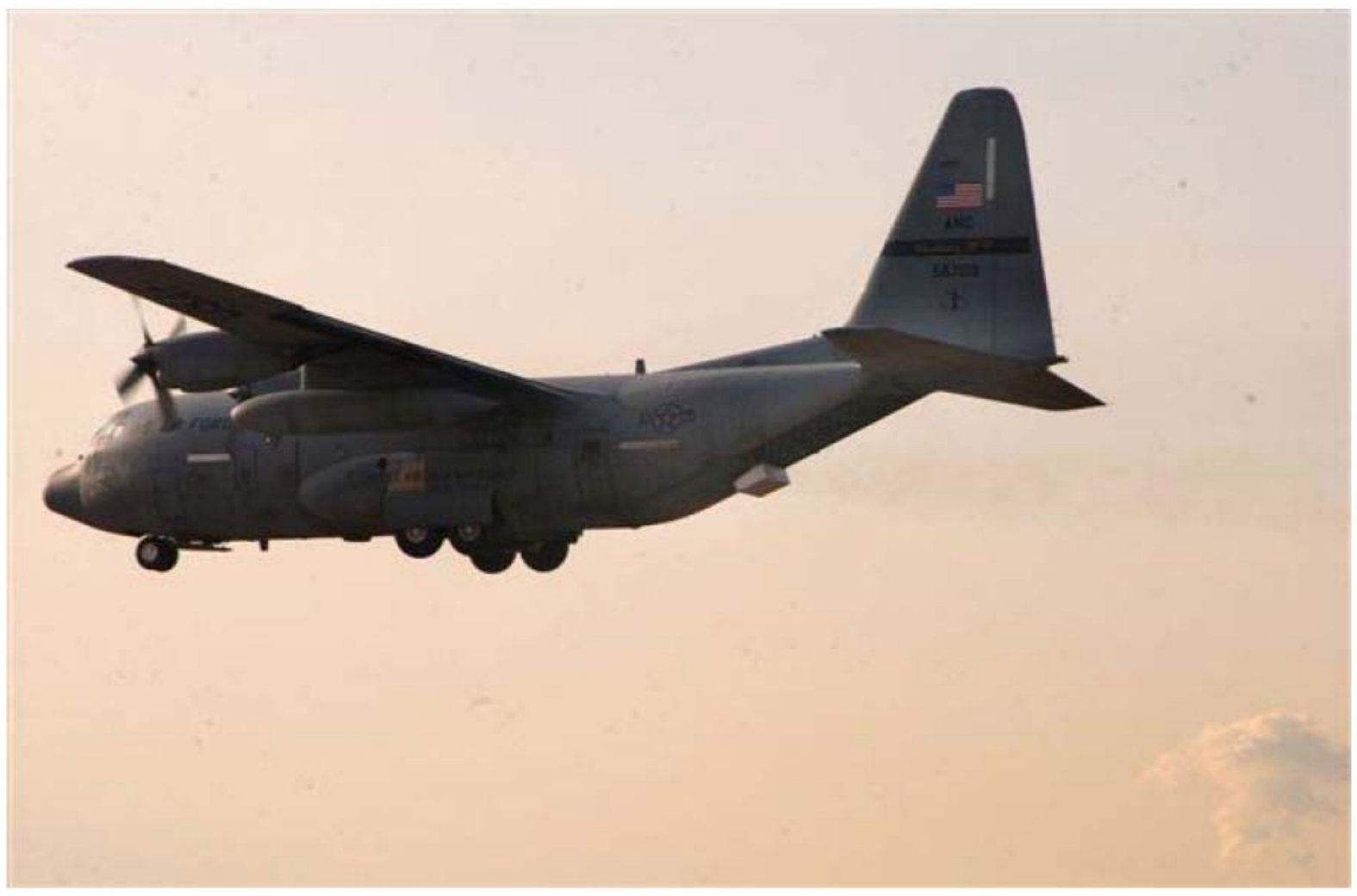

Figure 5-10: A second view of the OCULUS 1.1 from ground level in the deployed position. 


\section{Experimental Flight Test Data Results}

Once the OCULUS 1.1 flight tests were completed, the raw data was post-processed and presented in a form that could be analyzed and evaluated. The following sections provide the process by which the strain gage and accelerometer data were reduced from the raw form and placed onto a format for analysis. This post processed data was also displayed and characterized by the conditions the data was taken during flight (i.e. by airspeed, payload weight, deployment process and maneuver).

\subsection{Strain Gage Data Reduction}

The three element rosette employs gages placed at 0,45 and 90 degree positions shown in Figure 6-1 below. By measuring the strains from the gages $\left(\varepsilon_{\mathrm{A}}, \varepsilon_{\mathrm{B}}\right.$, and $\left.\varepsilon_{\mathrm{C}}\right)$ the principal strains can be found using Equations 1 and 2. These principal strains were then used to determine the principal stresses at the point of the rosette using Equations 3 and 4. The maximum values of the two principal strains and stresses were used as the critical strains and stresses at each rosette location.

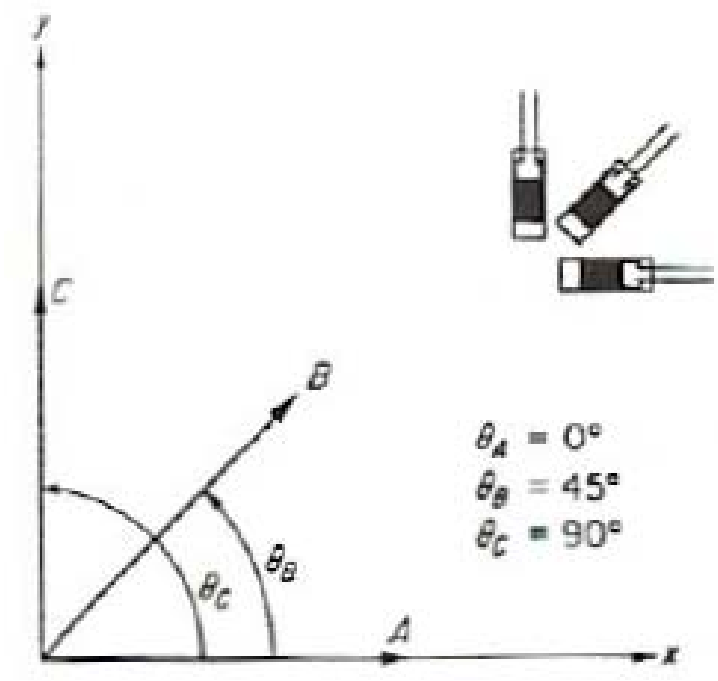

Figure 6-1: Orientation of individual gages in a 3-element rosette (53). 


$$
\begin{aligned}
& \varepsilon_{1}=\frac{1}{2}\left(\varepsilon_{A}+\varepsilon_{C}\right)+\frac{1}{2} \sqrt{\left(\varepsilon_{A}-\varepsilon_{C}\right)^{2}+\left(2 \varepsilon_{B}-\varepsilon_{A}-\varepsilon_{C}\right)^{2}} \ldots \ldots \ldots . . \\
& \varepsilon_{2}=\frac{1}{2}\left(\varepsilon_{A}+\varepsilon_{C}\right)-\frac{1}{2} \sqrt{\left(\varepsilon_{A}-\varepsilon_{C}\right)^{2}+\left(2 \varepsilon_{B}-\varepsilon_{A}-\varepsilon_{C}\right)^{2}} \ldots \ldots \ldots . \\
& \sigma_{1}=E\left[\frac{\varepsilon_{A}+\varepsilon_{C}}{2(1-v)}+\frac{1}{2(1+v)} \sqrt{\left(\varepsilon_{A}-\varepsilon_{C}\right)^{2}+\left(2 \varepsilon_{B}-\varepsilon_{A}-\varepsilon_{C}\right)^{2}}\right] \ldots \\
& \sigma_{1}=E\left[\frac{\varepsilon_{A}+\varepsilon_{C}}{2(1-v)}-\frac{1}{2(1+v)} \sqrt{\left(\varepsilon_{A}-\varepsilon_{C}\right)^{2}+\left(2 \varepsilon_{B}-\varepsilon_{A}-\varepsilon_{C}\right)^{2}}\right] .
\end{aligned}
$$

The values used in the equation above were difference values from a baseline reading obtained prior to each data collection period. Before collecting the data, for a particular test, a baseline "zero" reading was measured while the system was at rest in the stowed position. The baseline readings for each test were taken because some noise in the data collection process shifted the baseline from test case to test case $(54,55)$. In this position it was assumed the majority of the strain seen in the arm was relieved. For the individual test, an average difference and a maximum difference strain values were reduced from the data collected and the maximum values were used in the calculations. This ensures the "worst case" scenario during each test was analyzed.

\subsection{Strain Measurement Results}

The results of the strain gage data analysis are given in Table 6-1 thru 6-3, below. The tables show a given test number for the test performed, the test payload, the aircraft speed, the converted maximum principal strain value (using equation 1 and 2) and maximum principal stress value (using equation 3 and 4 , along with a calculated material factor of safety based upon 
the mechanical arms material properties. Also included in the table is an indication of whether the strain value were in the safe range based upon the material properties of the mechanical arms Deployment Cycle Maximum Strain and Stress Value Results

The raw data collected by strain gages analyzed and the maximum differential value from the baseline readings taken while the system was in the stow position was used in the conversion to principle strains using equations 1 and 2 listed in section 6.1. The maximum principal strain values were then converted to maximum principal stress values using equations 3 and 4 listed in table 6-1. The maximum values of the principal strains and principal stresses found were then recorded in columns 4 and 5 of table 6-1.

Table 6-1 shows consistently higher safety factor value while the system is in the final operating position. The table also shows that stresses throughout the deployment process are low with a minimum safety factor of 4.39 occurring during the rotation stage of deployment and maximum safety factor of 12.08 occurring while the system is on the final operating position. This indicates that some contact is being made between the sensor pod and the C-130 rear ramp as to alleviate some of the stresses that could be seen if the mechanical arm/pod system were resting in the airstream with no frontal contact being made with the aircraft.

$\underline{\text { Final Operating Position Strain and Stress Value Results during Aircraft Maneuvers }}$

Tables 6-2 and 6-3 show very low stresses in the mechanical arms during all of the attempted aircraft maneuvers while the system was in the final operating position. The high safety factors may be contributed to better contact made between the pod and the aircraft rear ramp. These tests were performed after the initial basic deployment tests were performed and a more aggressive concentration on contact between the sensor pod and aircraft was implemented. 
Some data from specific test was Not Available (N/A) because a connection in the data recorders (Ethernet cable) was loose and was unable to record during some tests. 
Table 6-1: Strain and stress results reduced from raw data collected during the OCULUS 1.1 systems deployment process, at straight and level flight.

\begin{tabular}{|c|c|c|c|c|c|c|}
\hline \multicolumn{7}{|c|}{ Deployment - Rotation } \\
\hline Test & Pod Weight (Ibs) & Speed (kias) & Max Strain $(\varepsilon)$ & Max Stress (psi) & Safe Range & Material Factor of Safety (Yield) \\
\hline 1 & 100 & 130 & 467 & 6002 & YES & 6.7 \\
\hline 2 & 100 & 150 & 424 & 5148 & YES & 7.8 \\
\hline 3 & 200 & 130 & 253 & 3600 & YES & 11.1 \\
\hline 4 & 200 & 150 & 676 & 9086 & YES & 4.4 \\
\hline 5 & 263 & 130 & 269 & 3787 & YES & 10.5 \\
\hline 6 & 263 & 150 & N/A & $\mathrm{N} / \mathrm{A}$ & $\mathrm{N} / \mathrm{A}$ & $\mathrm{N} / \mathrm{A}$ \\
\hline \multicolumn{7}{|c|}{ Deployment - Linear Retraction to Final Operating Position } \\
\hline Test & Pod Weight (Ibs) & Speed (kias) & Max Strain $(\varepsilon)$ & Max Stress (psi) & Safe Range & Material Factor of Safety (Yield) \\
\hline 7 & 100 & 130 & 332 & 4291 & YES & 9.3 \\
\hline 8 & 100 & 150 & 501 & 5532 & YES & 7.2 \\
\hline 9 & 200 & 130 & 410 & 5828 & YES & 6.9 \\
\hline 10 & 200 & 150 & 256 & 3645 & YES & 10.9 \\
\hline 11 & 263 & 130 & 504 & 7030 & YES & 5.7 \\
\hline 12 & 263 & 150 & N/A & $\mathrm{N} / \mathrm{A}$ & N/A & N/A \\
\hline \multicolumn{7}{|c|}{ Final Operating Position - Straight and Level } \\
\hline Test & Pod Weight (Ibs) & Speed (kias) & Max Strain $(\varepsilon)$ & Max Stress (psi) & Safe Range & Material Factor of Safety (Yield) \\
\hline 13 & 100 & 130 & 308 & 4061 & YES & 9.8 \\
\hline 14 & 100 & 150 & 379 & 5180 & YES & 7.7 \\
\hline 15 & 200 & 130 & 259 & 3301 & YES & 12.1 \\
\hline 16 & 200 & 150 & 265 & 3672 & YES & 10.9 \\
\hline 17 & 263 & 130 & 316 & 4285 & YES & 9.3 \\
\hline 18 & 263 & 150 & 303 & 4174 & YES & 9.6 \\
\hline
\end{tabular}


Table 6-2: Strain and stress results reduced from raw data collected while the OCULUS 1.1 system was in the FOP and performing left banking maneuvers.

\begin{tabular}{|c|c|c|c|c|c|c|}
\hline \multicolumn{7}{|c|}{ Final Operating Position - $15^{\circ}$ Bank Left } \\
\hline Test & Pod Weight (Ibs) & Speed (kias) & Max Strain $(\varepsilon)$ & Max Stress (psi) & Safe Range & Material Factor of Safety (Yield) \\
\hline 19 & 100 & 130 & $\mathrm{~N} / \mathrm{A}$ & $N / A$ & $N / A$ & $N / A$ \\
\hline 20 & 100 & 150 & 176 & 2288 & YES & 17.4 \\
\hline 21 & 200 & 130 & 211 & 2988 & YES & 13.4 \\
\hline 22 & 200 & 150 & 261 & 3613 & YES & 11.1 \\
\hline 23 & 263 & 130 & 287 & 3874 & YES & 10.3 \\
\hline 24 & 263 & 150 & 305 & 4204 & YES & 9.5 \\
\hline \multicolumn{7}{|c|}{ Final Operating Position - $30^{\circ}$ Bank Left } \\
\hline Test & Pod Weight (Ibs) & Speed (kias) & Max Strain $(\varepsilon)$ & Max Stress (psi) & Safe Range & Material Factor of Safety (Yield) \\
\hline 25 & 100 & 130 & $N / A$ & $N / A$ & $N / A$ & N/A \\
\hline 26 & 100 & 150 & 175 & 2275 & YES & 17.5 \\
\hline 27 & 200 & 130 & 222 & 3178 & YES & 12.6 \\
\hline 28 & 200 & 150 & 261 & 3620 & YES & 11.1 \\
\hline 29 & 263 & 130 & 305 & 4133 & YES & 9.7 \\
\hline 30 & 263 & 150 & 303 & 4190 & YES & 9.5 \\
\hline \multicolumn{7}{|c|}{ Final Operating Position - $45^{\circ}$ Bank Left } \\
\hline Test & Pod Weight (Ibs) & Speed (kias) & Max Strain $(\varepsilon)$ & Max Stress (psi) & Safe Range & Material Factor of Safety (Yield) \\
\hline 31 & 100 & 130 & $\mathrm{~N} / \mathrm{A}$ & $\mathrm{N} / \mathrm{A}$ & $N / A$ & $N / A$ \\
\hline 32 & 100 & 150 & 179 & 2338 & YES & 17.1 \\
\hline 33 & 200 & 130 & 245 & 3415 & YES & 11.7 \\
\hline 34 & 200 & 150 & 267 & 3678 & YES & 10.9 \\
\hline 35 & 263 & 130 & 318 & 4324 & YES & 9.2 \\
\hline 36 & 263 & 150 & 286 & 4032 & YES & 9.9 \\
\hline
\end{tabular}


Table 6-3: Strain and stress results reduced from raw data collected while the OCULUS 1.1 system was in the FOP and performing right banking maneuvers.

\section{Final Operating Position - $15^{\circ}$ Bank Right}

\begin{tabular}{|c|c|c|c|c|c|c|}
\hline Test & Pod Weight (Ibs) & Speed (kias) & Max Strain $(\varepsilon)$ & Max Stress (psi) & Safe Range & Material Factor of Safety (Yield) \\
\hline 37 & 100 & 130 & $\mathrm{~N} / \mathrm{A}$ & $N / A$ & $\mathrm{~N} / \mathrm{A}$ & $\mathrm{N} / \mathrm{A}$ \\
\hline 38 & 100 & 150 & 176 & 2288 & YES & 17.4 \\
\hline 39 & 200 & 130 & 211 & 2988 & YES & 13.4 \\
\hline 40 & 200 & 150 & N/A & $\mathrm{N} / \mathrm{A}$ & N/A & $\mathrm{N} / \mathrm{A}$ \\
\hline 41 & 263 & 130 & N/A & $\mathrm{N} / \mathrm{A}$ & $\mathrm{N} / \mathrm{A}$ & $\mathrm{N} / \mathrm{A}$ \\
\hline 42 & 263 & 150 & $\mathrm{~N} / \mathrm{A}$ & $\mathrm{N} / \mathrm{A}$ & N/A & $\mathrm{N} / \mathrm{A}$ \\
\hline \multicolumn{7}{|c|}{ Final Operating Position - $30^{\circ}$ Bank Right } \\
\hline Test & Pod Weight (Ibs) & Speed (kias) & Max Strain $(\varepsilon)$ & Max Stress (psi) & Safe Range & Material Factor of Safety (Yield) \\
\hline 43 & 100 & 130 & N/A & $\mathrm{N} / \mathrm{A}$ & N/A & N/A \\
\hline 44 & 100 & 150 & 175 & 2275 & YES & 17.5 \\
\hline 45 & 200 & 130 & 222 & 3178 & YES & 12.6 \\
\hline 46 & 200 & 150 & 261 & 3620 & YES & 11.1 \\
\hline 47 & 263 & 130 & 305 & 4133 & YES & 9.7 \\
\hline 48 & 263 & 150 & 303 & 4190 & YES & 9.5 \\
\hline \multicolumn{7}{|c|}{ Final Operating Position - $45^{\circ}$ Bank Right } \\
\hline Test & Pod Weight (Ibs) & Speed (kias) & Max Strain $(\varepsilon)$ & Max Stress (psi) & Safe Range & Material Factor of Safety (Yield) \\
\hline 49 & 100 & 130 & N/A & N/A & $\mathrm{N} / \mathrm{A}$ & $\mathrm{N} / \mathrm{A}$ \\
\hline 50 & 100 & 150 & 179 & 2338 & YES & 17.1 \\
\hline 51 & 200 & 130 & 245 & 3415 & YES & 11.7 \\
\hline 52 & 200 & 150 & 267 & 3678 & YES & 10.9 \\
\hline 53 & 263 & 130 & 318 & 4324 & YES & 9.2 \\
\hline 54 & 263 & 150 & 286 & 4032 & YES & 9.9 \\
\hline
\end{tabular}


Table 6-4: Strain and stress results reduced from raw data collected while the OCULUS 1.1 system was in the FOP and performing left/right slip maneuvers. Final Operating Position - Left Slip

\begin{tabular}{cccccccc|}
\hline Test & Pod Weight (Ibs) & Speed (kias) & Max Strain $(\boldsymbol{\varepsilon})$ & Max Stress (psi) & Safe Range & Material Factor of Safety (Yield) \\
$\mathbf{5 5}$ & 100 & 130 & N/A & N/A & N/A & N/A \\
$\mathbf{5 6}$ & 100 & 150 & N/A & N/A & YES & 10.8 \\
$\mathbf{5}$ & 200 & 130 & 262 & 3701 & YES & 10.5 \\
58 & 200 & 150 & 277 & 3811 & N/A & N/A \\
59 & 263 & 130 & N/A & N/A & N/A & N/A \\
60 & 263 & 150 & N/A & N/A & & \\
\hline
\end{tabular}

Final Operating Position - Right Slip

\begin{tabular}{cccccccc} 
Test & Pod Weight (lbs) & Speed (kias) & Max Strain $(\varepsilon)$ & Max Stress (psi) & Safe Range & Material Factor of Safety (Yield) \\
61 & 100 & 130 & N/A & N/A & N/A & N/A \\
62 & 100 & 150 & N/A & N/A & YES & 11.1 \\
63 & 200 & 130 & 261 & 3615 & YES & 10.3 \\
64 & 200 & 150 & 280 & 3867 & N/A & N/A \\
65 & 263 & 130 & N/A & N/A & N/A & N/A \\
66 & 263 & 150 & N/A & N/A & \\
\hline
\end{tabular}




\subsection{Vibration Measurement Data Reduction}

The accelerometer instrumentation used on the OCULUS 1.1 flight test was selected to analyze the variation in vibration readings between the OCULUS 1.1 sensor platform system and the C-130 airframe. The accelerometers were attached to the vibration isolated plate inside the sensor pod, the sensor pod frame structure, the sensor pallet base itself and to an accelerometer support structure which was strapped down to the fuselage floor of the C-130 airframe (just behind the rear cargo ramp hinged section). The vibration data was used to determine if the pod system has different vibration readings than the C-130 airframe (i.e. when the system is in the final operating position). The data was also used to determine what (if any) variations there are in the vibration magnitudes of the airframe and the pod when it is in the final operating position underneath the rear ramp of the C-130 aircraft.

The accelerometers used in this experiment had output data that read in volts. The conversion (based upon the Crossbow Technology Inc. settings for the instrument) of the output data to a vibration representation (in g's) had an association of 0.01 volts differential equal to 1.0g. This data could best be determined plotting the entire data range graphically and visually analyzing the peak to origin maximum values.

\subsection{Vibration Measurement Results}

The data analysis of the vibration data collected during the flight tests included a review of the vibration signals to determine if the OCULUS 1.1 system had a tendency to produce any resonance conditions that could lead to catastrophic failure to the system. The data analysis also investigated the peak amplitudes seen by the system and determined if these peak magnitudes might cause structural damages while the system was in the final operating position. 
A complete set of vibration profile data collected during a complete in-flight deployment process (linear extension, rotation, linear retraction and final operating position), at a specific payload and weight, is shown is Figures 6-2 thru 6-5 and discussed below. The additional data from the remaining tests is included in Appendix K. A second comparison, between the vibration profiles while the system is in the final operating positions at the three payloads, is also compared and analyzed.

Deployment Cycle Vibration Profile Results (100 lbs and 130 KIAS)

Figures 6-2 thru 6-5 show the x-direction vibration profiles of the OCULUS 1.1 system during the linear extension, rotational deployment, linear retraction and final operating position stages of the deployment process at a $100 \mathrm{lbs}$ payload and an aircraft speed of 130 KIAS. The xdirection was the concentration of this analysis because it consistently showed the highest vibration differences throughout the testing. Each graph plots voltage output (in volts) against its data collection point in that specific process for a particular output channel of the accelerometer. These data output channels (A9, A7, A11 and A13) are labeled in each graph and represent the X-direction output form the accelerometer on the pod frame (top left), vibration plate (top right), sensor pallet (bottom left) and fuselage (bottom right) of figures 6-2 thru 6-5. A consistent amount of data points was attempted throughout each individual process but some overlap is seen as in the "Sensor_Pallet_A11" accelerometer data in Figure 6-3. An overall maximum vibration of approximately $1 \mathrm{~g}$ was seen consistently at the pod frame location of the accelerometer. It should also be noted that vibration plate consistently stayed in tune with the pod frame during deployment and while in the final operating position. These vibration levels were approximated by graphically interpreting the "origin to peak" vibration levels during the These measurement approximations were made using the core data collected while disregarding 
the outlying peak to peak noise seen in the data collection. It should be noted that voltage output scale in the graphs fluctuates based upon the differential from the origin. As expected the voltage output levels are relatively consistent for the accelerometer outputs at the sensor pallet and fuselage locations. There is an increase in magnitude of the vibration profile at the pod frame and vibration plate locations. Once again, these inconsistencies' in vibration profile was expected at these two locations during the deployment process. 


\section{Linear Translation}

Weight $=100 \mathrm{lbs}$

Airspeed $=130 \mathrm{KIAS}$
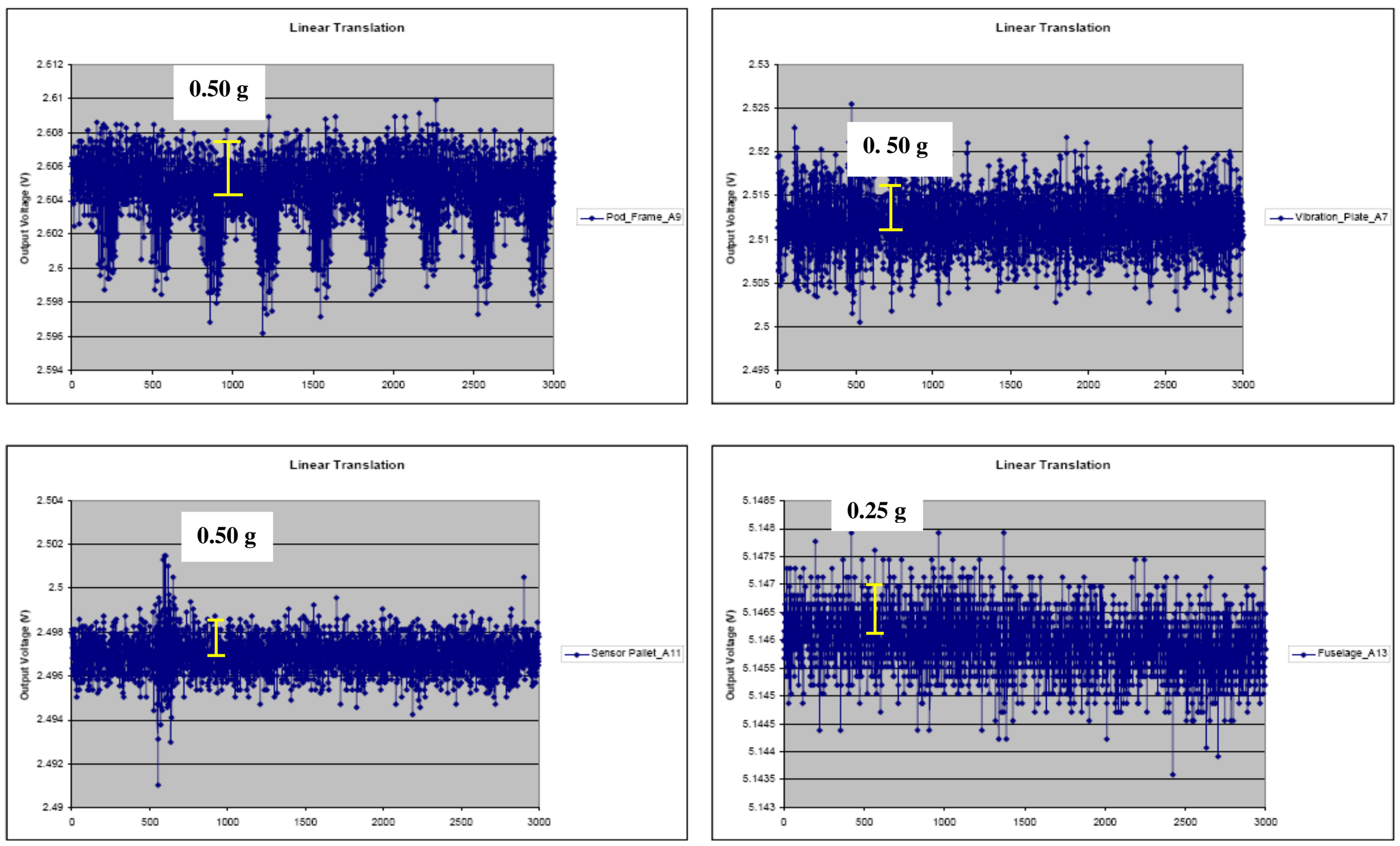

Figure 6-2: Vibration measurements during Linear Translation (100 lbs). 
Pod Rotation (after vertical load transition)

Weight $=100 \mathrm{lbs}$

Airspeed $=130 \mathrm{KIAS}$
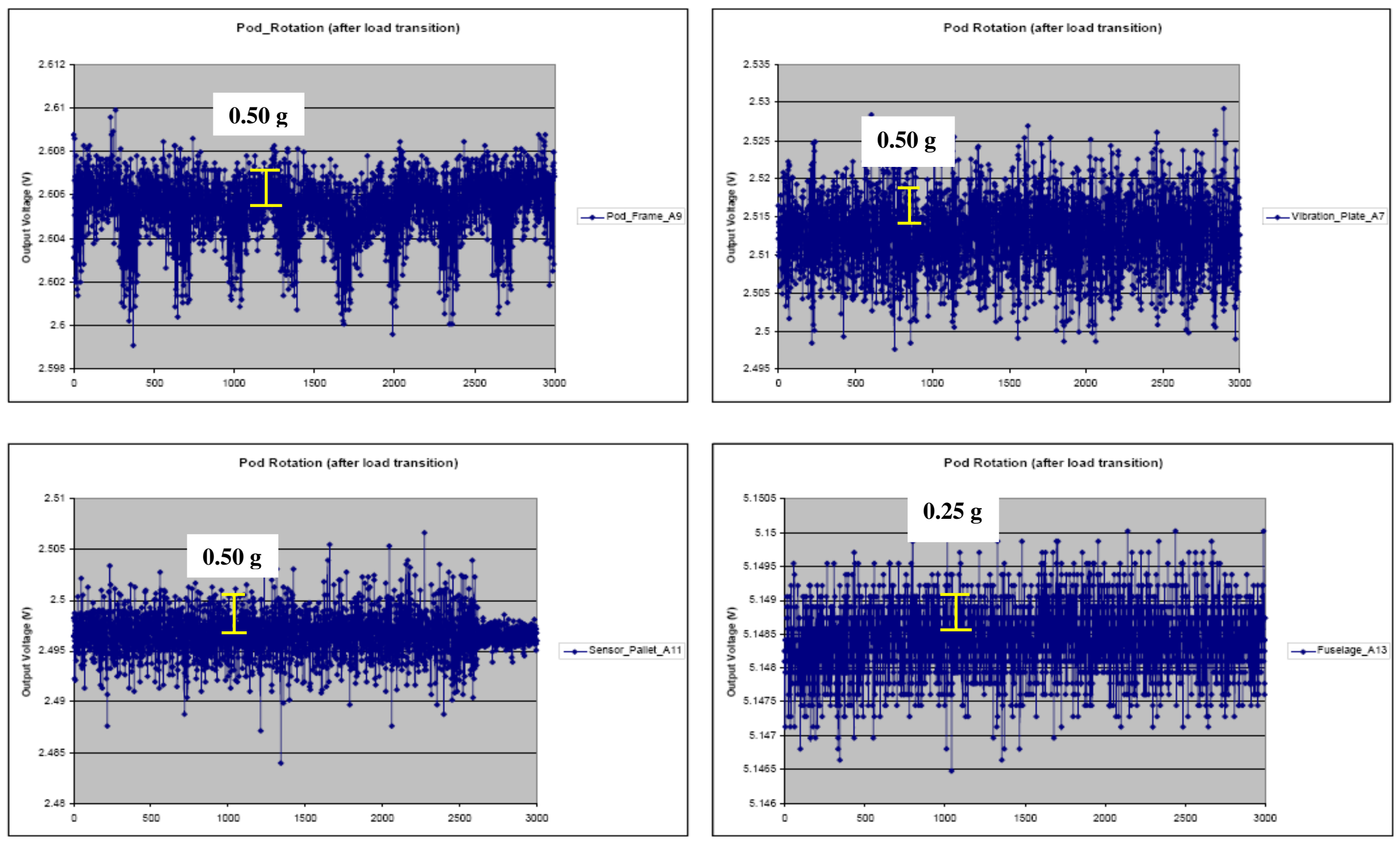

Figure 6-3: Vibration measurements during Pod Rotation (100 lbs). 

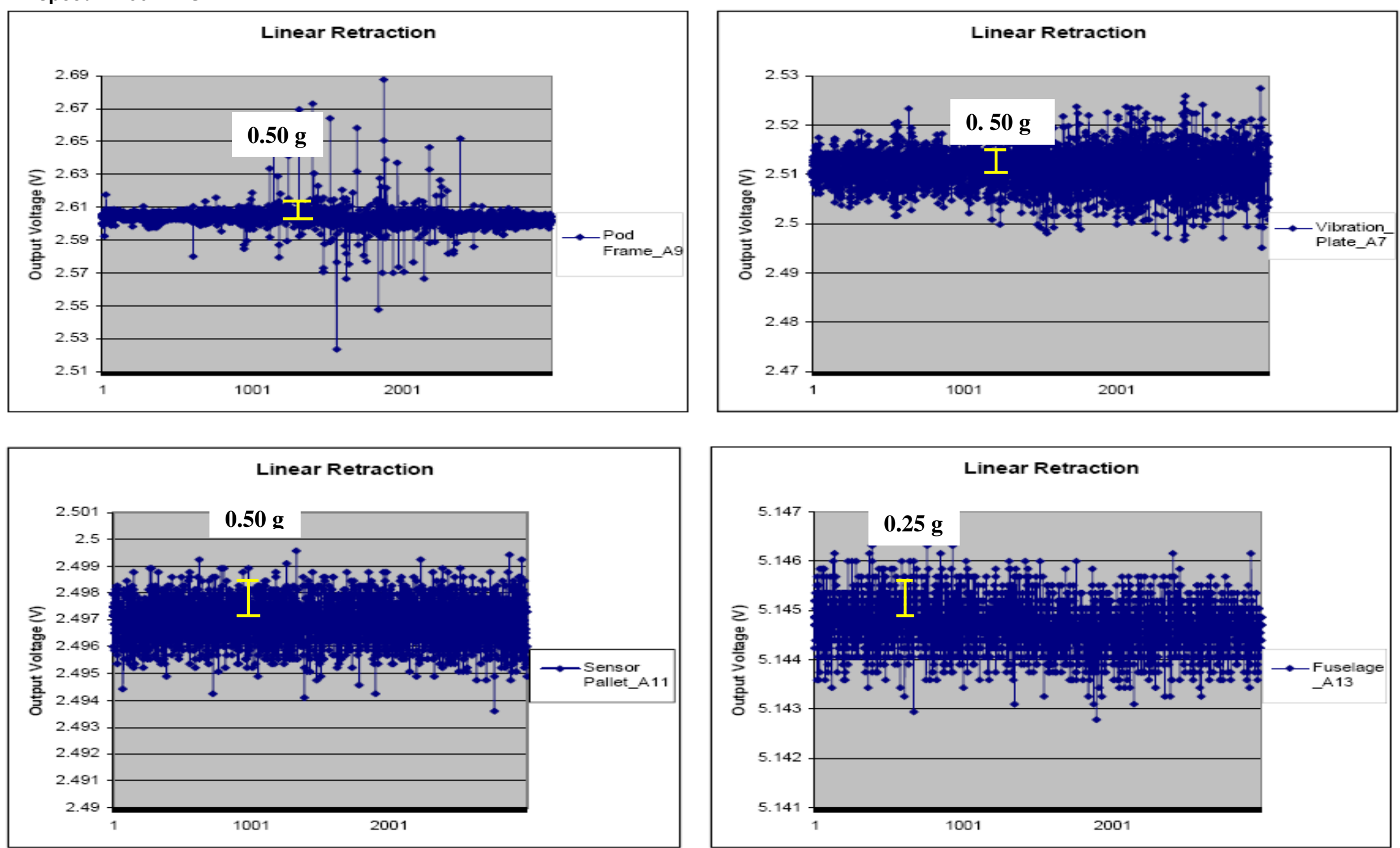

Figure 6-4: Vibration measurements during Linear Retraction (100 lbs). 
Final Operating Position (Deployed)

Weight $=100 \mathrm{lbs}$

Airspeed $=130 \mathrm{KIAS}$
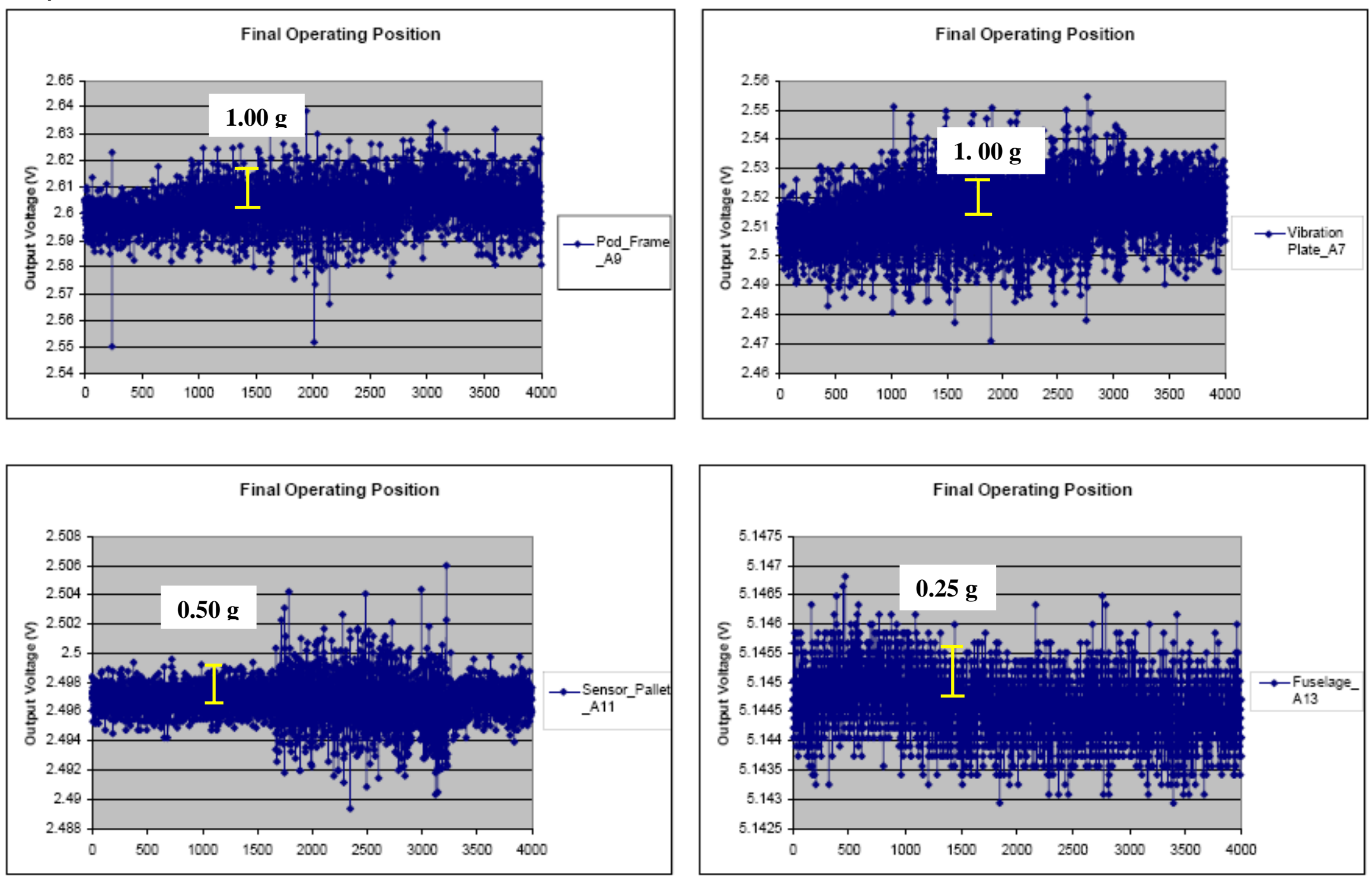

Figure 6-5: Vibration measurements during Final Operating Position (100 lbs). 
Final Operating Position Vibration Profile Results (130 KIAS and 100, 200 and $263 \mathrm{lbs}$ )

Figures 6-5, 6-6 and 6-7 graphically shows the data collected while the OCULUS 1.1 system was in the final operating position at an aircraft speed of 130 KIAS and a payload of 200 and $263 \mathrm{lbs}$, respectively. Once again the maximum origin to peak values is seen at the pod frame and vibration plate (approximately $1 \mathrm{~g}$ values). There seems to be an escalation in vibration magnitude in the vibration plate (top right) during the $200 \mathrm{lb}$ payload case in Figure 66. This may have been caused by inconsistencies in the contact made between the sensor pod and the rear ramp of the C-130 aircraft. As expected the voltage output levels are relatively consistent for the accelerometer outputs at the sensor pallet and fuselage locations. There is an increase in magnitude of the vibration profile at the pod frame and vibration plate locations. There is a relative consistency in magnitude of the vibration profile at the pod frame and vibration plate locations. 
Final Operating Position (Deployed)

Weight $=200 \mathrm{lbs}$

Airspeed $=130 \mathrm{KIAS}$
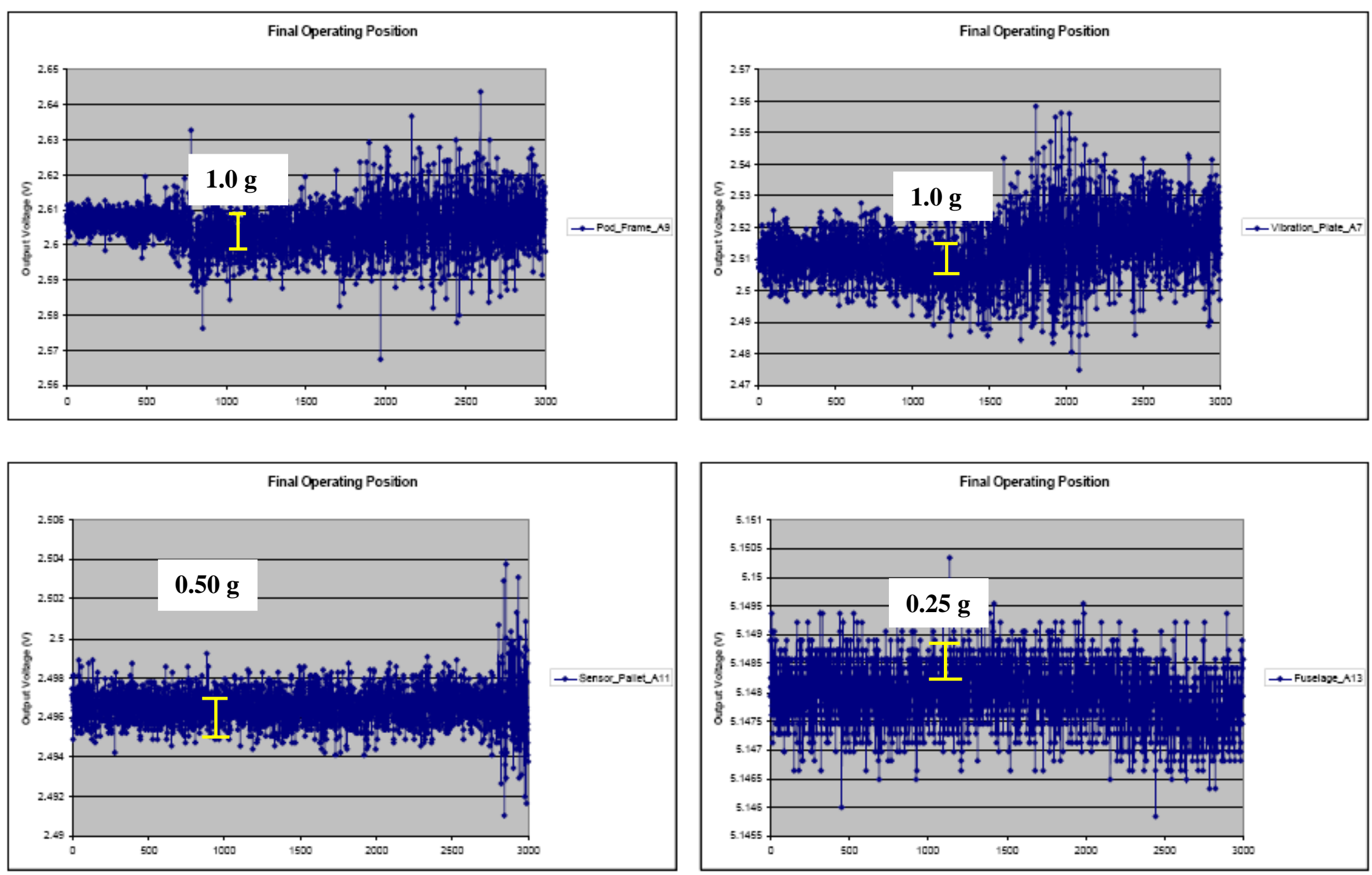

Figure 6-6: Vibration measurements during Final Operating Position (200 lbs). 


\section{Final Operating Position}

\section{Weight $=263 \mathrm{lbs}$}

Airspeed $=130 \mathrm{KIAS}$
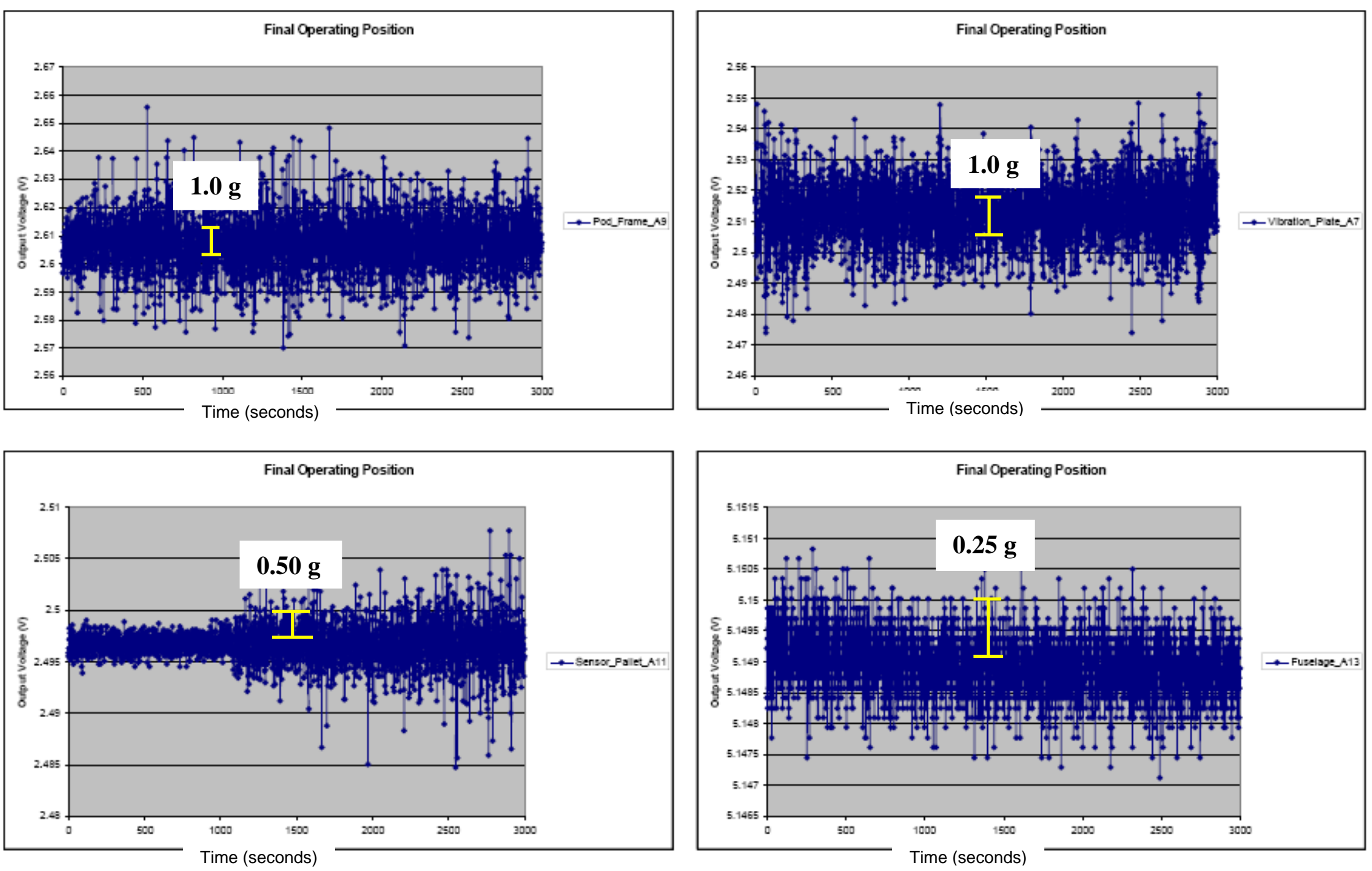

Figure 6-7: Vibration measurements during Final Operating Position (263 lbs). 


\section{Conclusions}

\subsection{Strain Gage Data Conclusions}

The following conclusions were developed after reduction and analysis of the entire set of strain data collected during the flight tests.

1. All registered strain/stress levels fall within the safe region of the material and the mechanical arm/pod system design.

2. The minimum safety factor of the peak strain/stress values of the material and the mechanical arm/pod system during the flight test was 4.4 when compared to the yield strength of the material.

3. The peak stresses seen during an individual deployment process (Tables 6-1 thru 6-4) are higher then the mean stresses which have amplitude on the average of $10 \%$ of the mean.

4. The highest average strain/stress levels occur during the linear retraction/extension procedure. During this process the average safety factor of the material and the mechanical arm/pod system does not fall below 8.00 when compared to the yield strength of the material. It is believed that during the linear retraction/extension of the pod, the pod is buffeted by the air stream and not stabilized by the ramp.

5. The average safety factor of the peak strain/stress values of the material and the mechanical arm/pod system during the flight test was 6.93 when compared to the yield strength of the material with a 1.5 safety factor.

6. Once the system is in the final operating position, standard C- 130 maneuvers $\left(15^{\circ}, 30^{\circ}\right.$ and $45^{\circ}$ banking turns and simulated approaches) do not have an effect on the ramp to mechanical arm/pod system interface. This translates into no effect on the material and the mechanical arm/pod system itself. 
7. No strain/stress data collected during the flight test exceeds the safe value criteria established for the test flight.

8. The data shows that the left outside arm (looking in from the rear of the aircraft) usually recorded the highest peak strain/stress values during the flight test. This may be caused by slight misalignment during fabrication and assembly of the system. Once again these peak values never reached a critical limit.

9. The data shows the inside right arm received the second highest peak strain/stress values during the flight test. Again this may be caused by misalignment during fabrication and assembly of the system. Again these peak values never reached a critical limit.

10. As predicted prior to the flight test, strain gages A1, A2, A5 and A6 yielded the highest strain/stress levels during all maneuvers and procedures of the flight test.

\subsection{Accelerometer Data Conclusions}

The following conclusions were developed after reduction and analysis of the entire set of vibration data collected during the flight tests.

1. During pod rotation, when the pod frame is supported only by the arms, the resonance on the pod due to acoustical coupling caused by the propeller's wash is significantly higher than the magnitude seen in the structure of the aircraft and sensor pallet. It is believed that this resonance is due, in part, to the large thin un-damped side panels of the pod.

2. The vibration isolation plate visibly dampened the above mentioned resonance effect in the sensor pod frame. This noticeable effect is not the ultimate possible effect because the isolation mounts were not intended for use for each weight used (i.e. we did not change out the isolators based on the weight added to the vibration plate. 
3. Peak vibration amplitudes, in all three directions, seen by the Sensor Pod Frame accelerometer were well below critical magnitudes as established for the structural system.

4. Vibration amplitudes of the sensor pallet are approximately the same as the measured aircraft structure (cargo floor, forward of ramp hinge), indicating that neither the ramp or sensor pallet had significantly different vibration amplitudes.

The elastomeric vibration dampers used to couple the vibration isolation plate to the pod frame appeared to be ineffective for the 100-263 lb weights used in the tests. This may have been because the dampers used were designed for much heavier loads and had a higher spring rate than needed for this application. The C-130 maneuvers had little effect on the vibration amplitudes at the four sensor locations, when the pod was fully deployed in the full operating position.

The primary measurements of importance taken during these flight tests were the strain and vibration data taken to verify the safety margins indicated by pre-flight finite element structural modeling and simulation of the OCULUS platform. The results of this data analysis indicate;

- The strains measured in the OCULUS structure were well below the yield strength of the materials used in construction of the system, resulting in an acceptable minimum margin of safety of 4.39 .

- The vibrations recorded were well below levels that might cause undue stresses on the system and no significant resonance frequencies were observed in the data.

- Strain measurements made during the flight tests were consistent with pre-flight theoretical predictions derived using accepted structural analysis procedures. 
- The strain and vibration measurements were not significantly affected by aircraft maneuvers when the pod was fully deployed.

- There was no significant difference in vibration levels or frequencies between the cargo floor and the sensor pallet, indicating that the ramp was not significantly affected by the added load of the sensor pallet/pod.

- Turbulence "buffeting" of the pod did not appear to be significant from the data collected.

\subsection{OCULUS 1.1 Airworthiness Certification}

The OCULUS 1.1 Sensor Deployment System received final written certification approval from WRAFB in February 2008. This certification document declares from the office of the United States Air Force, that the OCULUS 1.1 system is airworthy for flight use on-board a military C-130 aircraft. The actual OCULUS 1.1 certification letter is shown in Appendix L.

\subsection{Mechanical Arm FEA Comparison to Experimental Data}

Although not a requirement for the certification process, the validation of the static stress response from the mechanical arm finite element model would create a major design tool for future work with the OCULUS system. Prior to the experimental test the FE model was validated with ground strain gage testing (54). In this study the static loading model compared with the experimentally found stress values was the main concentration because a dynamic fatigue analysis was previously performed and showed a high fatigue life in the arms - greater then $10^{6}$ life cycles (Figure 7-1). 

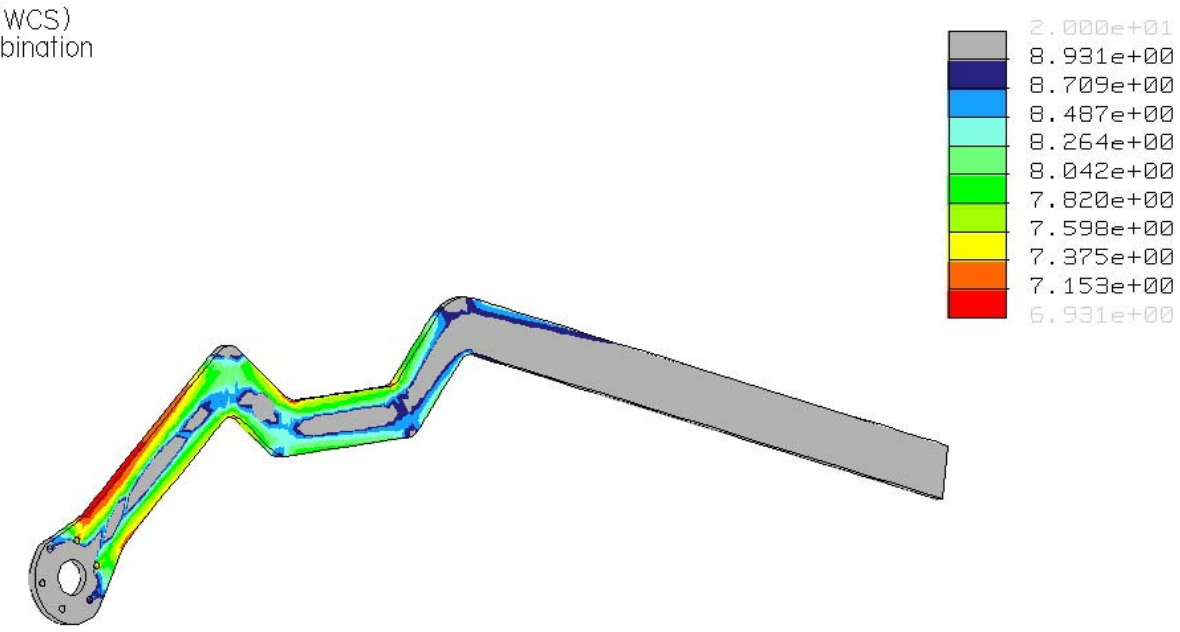

Figure 7-1: Fatigue analysis of the mechanical arm system showing life greater then $10^{6}$ cycles (32).

The validated model could be used to structurally analyze the system with various payloads for future mission use. As explained in Section 2.1.1.2 the underlying goal of the analysis was to provide a holistic model for understanding the high stress regional location on the arms do to the pre-described loading used in the analysis. This type of understanding would also expedite a new design or modification process with WRAFB because of the correlation and success between the simulation and the experiment. Table 7-2 shows the resulting maximum principal stress values of the FEA performed in Section 2.1.1.2 along with the maximum principal stress values collected during the experimental flight test. It should be noted again that this comparison was only performed, in both cases (simulation and experimental), for an analysis of the system in the final operating position and specifically for the in the FEA case by using a worst case approach. This model requires continued refinement to properly understand the additional phenomenon occurring while the system is in the final operating position and during the other steps in the deployment process. 


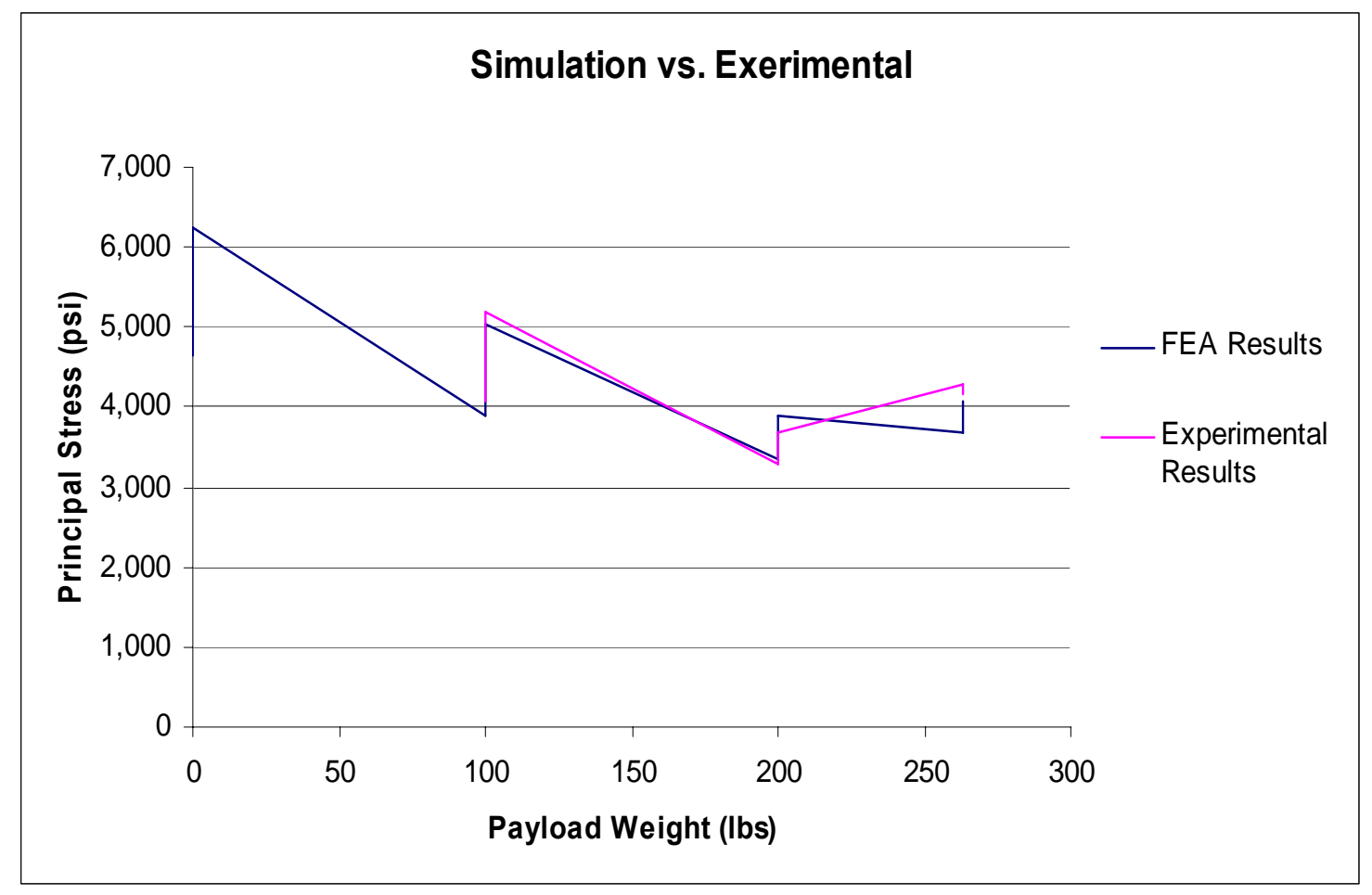

Figure 7-2: Maximum principal stress comparison between the mechanical arm FEA and experimental values collected from the flight test.

In looking at the percent difference between the simulated and experimental values there are several contributing factors that may explain the differential margin and the inconsistencies in the differential from trial to trial. Some potential factors include: (1) unpredictable drag loading which may increase or decrease with wind gusts, non-level flight and improper contact between the sensor pod and the rear ramp of the aircraft, (2) outlier strain data being used as a maximum in the experimental values (Note: For safety of flight certification the maximum values were used in the data analysis to ensure the system did not experience any extreme loading conditions during flight even if the ultimate strains measured may have been caused by noise or an outlying spike in the data recording.) and (3) using a very broad approach in the FEA to look at regional stresses in a relatively large FE model (full scale model of the arm) which could be concentrated by performing a more detailed FEA at the regions that show the high stress concentrations. 


\subsection{New Certification Process}

One of the additional contributions from this work was the development of a streamlined and concentrated certification methodology that is presented in a step-by-step diagramed approach. This process emphasizes that the certification process begin at the conceptual design phase and run through the experimental testing of the system. Beginning at the design concept phase allows for the policing agency's, test agency's, sponsor's and developing organization's to collaborate on the required steps necessary to complete airworthiness certification which will satisfy all party's involved. This also allows for creating a working documentation package at the beginning of the development process to allow for structured and documented modifications that may be made throughout the certification process. This proposed certification methodology is overviewed in Appendix M and was used in completing the OCULUS program. 


\section{References}

(1) Smith, Peter C., Lockheed C-130 Hercules: The World's Favorite Military Transport. Airlife Publishing Ltd., New York, New York, 2001.

(2) Bowman, Martin W., Lockheed C-130 Hercules, Crowood Pr., New York, 1999.

(3) "C-130 Source/Platform Earth Observation Document," Oak Ridge National Laboratory, Source Document C-130, Oak Ridge, TN, November 1987.

(4) “463L Pallet Cargo System," www.GlobalSecurity.org//4631 pallets, Alexandria, VA, 2006.

(5) "Team Condor Overview - 146AW Channel Island ANGS," Major James Fisk, Reno, NV, 4 December 2000.

(6) "California Counter-drug Joint Task Force - Team Condor Capabilities Brief," Major James Fisk, Channel Island, CA, November 2002.

(7) "Trip Report/Meeting Summary for Conference at Nevada NG-CD Headquarters - C-26 KS-87 Digital Upgrade Review Task,” Dr. Bill Owens, 24-26 January 2000 .

(8) "Trip Report/Meeting Summary for Conference at Nevada NG-CD Headquarters - Roll-on/Roll-off Pallet Potential," Lt. Randy Cross, 9-11 July 2001.

(9) "Nevada Air National Guard Pallet Technology Overview Briefing," Maj Chew, Reno, NV, 1- July 2001.

(10) “Aero Union Corp. Pallet System Briefing," Aero Union Corp., Reno, NV, 4 December 2000.

(11) Dave Kunkel, "Wings of Gold: US Coast Guard Aviation: Situation Report," Association of Naval Aviation, Alexandria, VA, Spring 2000.

(12) "Hairy Buffalo may ro-ro roam to C-130s for USCG Homeland Security Missions," Amy Behrman, www.dcmilitary.com, Gaithersburg, MD, 24 July 2003.

(13) “NAVAIR's Hairy Buffalo Provides Network for Sea Strike," Amy Behrman, US Navy Today, Story Number: NNS030207-18, Washington, D.C, Released $02 / 08 / 2003$.

(14) “Airborne Early Warning System with Retractable Dome," Fitzpatrick, Roger S., US Patent Number 4,593,288, June 3, 1986. 
(15) "Aircraft Based Sensing, Detection, Targeting, Communications and Response Apparatus," Lawrence, Richard and Ken Woodland, US Patent Number 5,927,648, July 27, 1999.

(16) "Radome-Antenna Installation with Rotating Equipment Rack," Ettinger, John J.; Winberger, Eric S.; Demartino, John, US Patent Number 5,049,891, September 17, 1991.

(17) "Design of a Standardized Roll-On, Roll-Off Sensor Pallet System for a C-130 Aircraft," Zenovy S. Wowczuk, Kenneth H. Means, Victor H. Mucino, Gregory J. Thompson, James E. Smith II, Adam Naternicola, Jeffrey Auld, Lawrence Feragotti, Bruce J Corso, and James E. Smith, SAE Technical Paper Series No. (2004-01-3092), SAE World Aviation Conference (WAC), November 2-4, 2004, Reno, Nevada.

(18) "Project Oculus: Enhanced Visual Information Platform," Zenovy S. Wowczuk, Jeffrey R.X. Auld, James E. Smith, Taylor and Francis Group, Journal of Modern Optics, London, England, 2006.

(19) "A Cost and Time Effective Alternative For An Aerial Reconnaissance and Surveillance Platform," Zenovy S. Wowczuk, Jeffrey R.X. Auld, James E. Smith, Paper Number ESDA2006-95600, 2006 ASME Conference on Engineering Systems Design and Analysis, Torino, Italy, July 4-7, 2006.

(20) "C-130 Electrical System Schematics," excerpt from the C-130 training manual, Copied from West Virginia Air National Guard Training Manual, Charleston, WV, December 2002.

(21) "C-130 Hercules Fact sheet," Produces by Air Mobility Command - Scott Air Force Base, IL, May 2006.

(22) Workshop on Multi/Hyperspectral Sensors, Measurements, Modeling, and Simulation. Redstone Aresenal, AL. Nov. 7-9, 2000.

(23) Final Report on Spectral Imaging Sensors for Use in the Interdiction of Illegally Grown Marijuana. Air Force Operational Test \& Evaluation Center, Beltsville, MD, April 15, 1998.

(24) White Paper: Technology Assessment of Remote Sensing Applications in Transportation: Hyperspectral Imaging (HSI). riker.unm.edu/DASH new/pdf/ White\%20Papers/Hyperspectral\%20Imaging.pdf. Safety, Hazards and Disaster Assessment/Earth Data Analysis Center. Natl Cosortia on Remote Sensing in Transportation. Albuquerque, NM. University of New Mexico, University of Utah, Georgetown University, and Oak Ridge National Laboratory. Nov. 2001. 
(25) Committee on New Sensor Technologies, Expanding the Vision of Sensor Materials Committee on New Sensor Technologies: Materials and Applications. $<$ www.nap.edu/openbook/0309051754/html/R1.html $>$. National Academy Press. Washington, D.C.. 1995 ISBN: 0-309-05175-4.

(26) Flight Rules and Procedures - AC-130H," Air Force Special Operations Command (SOCOM), AF-SOC Instruction 11-202 Volume 10, Tampa Bay, FL, 1 July 1997.

(27) Angle II, Gerald; Pertl, F. Andy; Smith, James E., "Velocity Profile Measurements Under the Ramp of a Lockheed Martin C-130 Aircraft," SAE Paper No. 2004-01-3099, Warrendale, PA.

(28) Gagnon, Yves, Pro/Mechanica Wildfire Elements and Application Series, Part 1: Idealizations, SDC Publications, Kelowna, 2003.

(29) Johnson III, W., Trickey, C., Forsythe, J., Albertson, J.Liegh, E., "Experimental and Computational Investigation of the Flow Behind a C-130 with Tailgate Down," AIAA Paper 2002-0713, Reston, VA.

(30) Oberg, E., Jones, F.D., Horton, H.L., Ryffel, H.H., Machinery's Handbook $26^{\text {th }}$ Edition, Industrial Press Inc., New York, New York, 2000.

(31) Avallone, E.A., Baumeister III, T., Marks'Standard Handbook for Mechanical Engineers $9^{\text {th }}$ Edition, Mcgraw Hill Book Company, New York, New York, 1987.

(32) "Sensitivity Analysis of the C-130 Sensor Deployment System Arm Using Finite Element Methods," Zenovy S. Wowczuk, Lawrence A. Feragotti, Bruce J Corso, and James E. Smith, 2004 SAE Transactions, Journal of Aerospace, SAE International, Warrendale, Pennsylvania, 2004.

(33) "C-130 Sensor Platform Modified Bracing Structure Analysis," Zenovy S. Wowczuk, Adam Naternicola, and James E. Smith, SEM Technical Paper Series No.2005-477, IMAC-XXIII Conference and Exposition on Structural Mechanics, February 1-3, 2005, Orlando, Florida.

(34) "Dynamic Modal Analysis and Optimization of a Mechanical Sensor Arm Deployment System for a C-130 Aircraft," Zenovy S. Wowczuk, Adam Naternicola, Kenneth H. Means, Victor H. Mucino, Gregory J. Thompson, Lawrence Feragotti, Bruce J Corso, and James E. Smith, SAE Technical Paper Series No. (2004-01-3129), SAE World Aviation Conference (WAC), November 2-4, 2004, Reno, Nevada.

(35) "Fatigue Performance of Production-Quality Aircraft Fastener Holes," W. Carter Ralph, International Journal of Fatigue, Volume 29, Issue 7, July 2007. 
(36) MIL-STD 461D, " Requirements for the Control of Electromagnetic Emissions and Susceptibility," Military Standard, August 1999.

(37) MIL-STD-462D, "Measurement of Electromagnetic Interference Characteristics," Military Standard, August 1999.

(38) Strumpf, William, "Ensuring a Successful Visit to the EMC Test Lab," Compliance Engineering Magazine, Los Angeles, CA. 2003.

(39) Ott, Henry W., "Noise Reduction Techniques in Electronic Systems," $2^{\text {nd }}$ Edition, John Wiley and Sons, Inc., 1988.

(40) Kimmel, William D., and Gerke, Daryl D., "Grounding for the Control of EMI,", Medical Device \& Diagnostics Industry Magazine, Los Angeles, CA, August 1996.

(41) "Electromagnetic Compliance issues of Project OCULUS," Wilhelm, Jay P., Lowery, Andrew D., Pertl, Franz, Nutter, Roy S., Smith, James E., SAE Technical Paper Series no. (2005-01-3394), AeroTech Congress \& Exhibition, Grapevine, Texas, October 3-6, 2004.

(42) Lionel D. Alford and Robert C. Karr, 'General Flight Test Theory Applied to Aircraft Modifications,” Acquisitions Review Quarterly, Fairfax, VA, March 22, 1999.

"GENERAL FLIGHT TEST THEORY APPLIED TO AIRCRAFT MODIFICATIONS," Robert C. Knarr, Acquisitions Review Quarterly, Fairfax, VA, March 22, 1999.

(44) Official US Navy Website, "US Navy and Marine Corps Airworthiness," US Department of the Defense, Updated 2008.

(45) Naval Air Systems Command Solicitation, RFP Number N00421-08-R-0012, "Improvement of Airworthiness Standards and Processes," November 2007.

(46) Official US Navy Website, "Interim Flight Clearances," US Department of Defense, Washington D.C, Updated 2008.

(47) "Modification Form 1067 - Overview," Internal Document, Warner Robins Air Force Base, GA, Updated 2002.

(48) “Developmental System Drawing Packages - Overview," Internal Document, Warner Robins Air Force Base, GA, Updated 2002.

(49) MIL-HDBK 1791 "Designing for Internal Aerial Delivery in Fixed Wing Aircraft". 
(50) "Crash Analysis of a Command and Control System Deployed Out of the Rear Ramp of a C-130 Aircraft" Zenovy S. Wowczuk, Gerald Angle II, Emily D. Pertl, James E. Smith, SAE Technical Paper Series No. (2005-01-3424), AeroTech Congress \& Exhibition, Grapevine, Texas, October 3-6, 2004.

(51) Serrano, Ecole Polytechnique, Palaiseau, France; E. Leigh, W. Johnson, J. Forsythe and S. Morton, U.S. Air Force Academy, U.S. Air Force Academy, CO, Computational Aerodynamics of the C-130 in Airdrop Configurations, American Institute of Aeronautics and Astronautics (AIAA) Paper No. 2003-0229, 2003.

(52) "Maintenance Issues and Fail Safes of the Oculus Sensor Platform System" John W. Hardin, Zenovy S. Wowczuk, Andrew D. Lowery, Jay P. Wilhelm, Franz A. Pertl, James E. Smith, SAE Technical Paper Series No. (2005-01-3427), AeroTech Congress \& Exhibition, , Grapevine, Texas, October 3-6, 2004.

(53) Dally, James W.; Riley, William F., "Experimental Stress Analysis," The McGraw-Hill Companies inc., New York, New York, 1999.

(54) "Experimental Stress/Strain Analysis of an Aircraft Platform Using Experimental Data," Zenovy S. Wowczuk, Seth Lucey, James E. Smith, SEM Technical Paper Series No. 2006-326, 2006 SEM Annual Conference and Exposition, , St. Louis, MO, June 4-7, 2006.

(55) "Experimental Stress/Strain Analysis of a Standardized Sensor Platform for a C130 Aircraft" Seth D. Lucey, Zenovy S. Wowczuk, Kenneth A. Williams, Eric J. Thompson, Kenneth H. Means, Bruce Kang, James E. Smith, SAE Technical Paper Series No. (2005-01-3426), AeroTech Congress \& Exhibition, Grapevine, Texas, October 3-6, 2004. 


\section{Appendix A. Material Properties of Aluminum 6061}

Table A-1 lists the mechanical properties of Aluminum 6061. These properties were used in the design and analysis of the OCULUS 1.1 systems mechanical arm system. 
Table A-1: Aluminum 6061-T6 physical properties (30,31).

\begin{tabular}{|l|c|c|}
\hline & Metric & English \\
\hline Density & $2.7 \mathrm{~g} / \mathrm{cc}$ & $0.0975 \mathrm{lb} / \mathrm{in}^{3}$ \\
\hline Hardness, Brinnell & 95 & 95 \\
\hline Hardness, Knoop & 120 & 120 \\
\hline Hardness, Rockwell A & 40 & 40 \\
\hline Hardness, Rockwell B & 60 & 60 \\
\hline Hardness, Vickers & 107 & 107 \\
\hline Strength, Ultimate & $310 \mathrm{MPa}$ & $45000 \mathrm{psi}$ \\
\hline Strength, Yield & $275 \mathrm{MPa}$ & $39900 \mathrm{psi}$ \\
\hline Elongation at Break & $12 \%$ & $12 \%$ \\
\hline Modulus of Elasticity & $69 \mathrm{GPa}$ & $10000 \mathrm{ksi}$ \\
\hline Poisson Ratio & 0.33 & 0.33 \\
\hline
\end{tabular}




\section{Appendix B. OCULUS 1.1 1067 Modification Form}

The following attachment is the completed OCULUS 1.1 system 1067 Modification

Form for flight clearance. The form requires the listing of sponsoring agency (s), the project or program title, and a brief describing why the modification is necessary. The form also requires the agency’s involved to list any constraints, assumptions and hazards that may visibly be associated with the system. 
PAGE \& QF 2

\begin{tabular}{|c|c|c|c|}
\hline \multicolumn{4}{|c|}{ MODIFICATION PROPOSAL } \\
\hline \multicolumn{3}{|l|}{ PART I-REQUEST FQR ACTION } & DATE: 20040604 \\
\hline $\begin{array}{l}\text { INITIATOR } \\
\text { Major David C. Mathew's } \\
130 \text {. AW/130 AS } \\
1679 \text { Coonskin Dr, Bidg } 130 \\
\text { Chsrieston, WV } 25311 \text { Tel 304-341-6605. }\end{array}$ & \multicolumn{2}{|c|}{$\begin{array}{l}\text { 2. INITIATORS POC ORGANIZATION } \\
\text { Major Michael L. Thomas } \\
\text { NGB CDX-X } \\
\text { 925 Dalney St STOP 0841 } \\
\text { Atlanta, GA, 30332, Tel 404-894-0621 }\end{array}$} & $\begin{array}{l}\text { 3. USING COMMANO HO POINi OF CONTAGT } \\
\text { Capiain David Hottle } \\
\text { ANG/LGMA } \\
\text { Andrews AFB, MD } \\
\text { (301) } 836-8946\end{array}$ \\
\hline \multicolumn{4}{|c|}{ C-130 Air Worthiness Test (AWT) for the Oculus IRS Pallet System: } \\
\hline \multicolumn{2}{|c|}{ 5. ORGANLZATION CONTRO_ NUMGER } & 6. OTHER NUMBERS & $\cdot$ \\
\hline \multicolumn{4}{|c|}{ 7. AFFECTED CONFIGURED IFEM/SYSTEM: C $130 \mathrm{Models} \mathrm{A}-\mathrm{H}$} \\
\hline 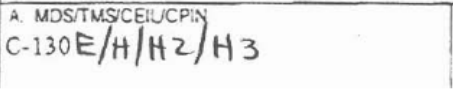 & \multicolumn{2}{|l|}{ B. WUC } & \\
\hline D. SRD CODE & \multicolumn{2}{|c|}{$\begin{array}{l}\text { E. Noun } \\
\text { Enrourc Sensor Surveillance }\end{array}$} & IF. OTHER \\
\hline \multicolumn{4}{|c|}{ 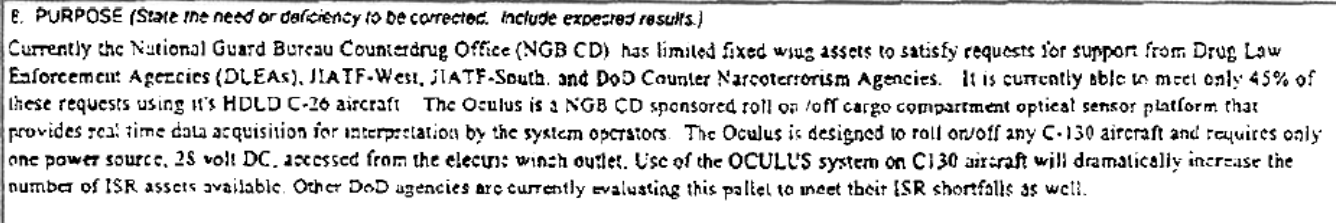 } \\
\hline \multicolumn{4}{|l|}{ G IMPACT (urgancy of need and impact if not satisfied.] } \\
\hline \multicolumn{4}{|c|}{$\begin{array}{l}\text { The Air National Guard finds irseli unable to fill } 55 \% \text { of requests for ISR suppor form DLEAs. Without the Oeulus, DLEAs and } \\
\text { DoD agencies wilt not be able to conduct a:l the necessary surveillance and detection necessary to interdict the now of iliegal } \\
\text { narcorics across the US border and within CONUS AOIs. }\end{array}$} \\
\hline \multicolumn{4}{|c|}{ 10. CONSTRAINTS/ASSUMPTIONSIPROPOSED SOLUTIONS } \\
\hline \multicolumn{4}{|c|}{ 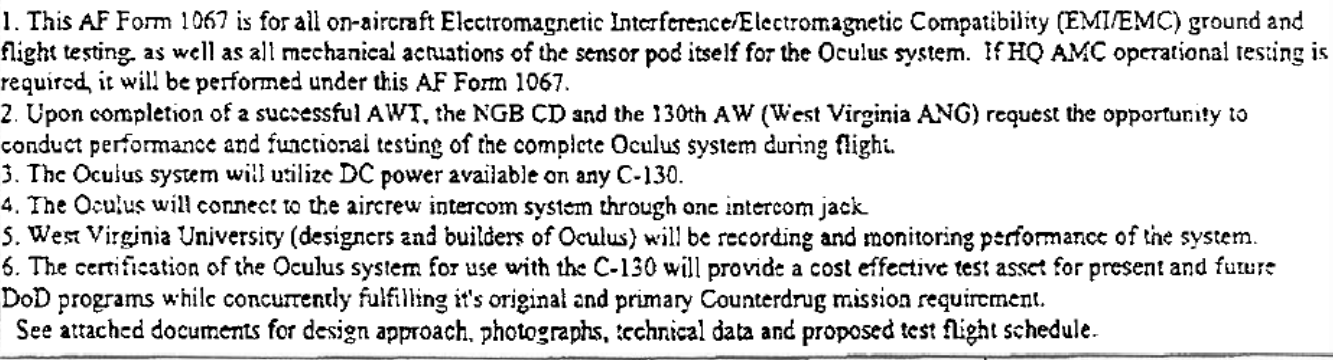 } \\
\hline \multirow{2}{*}{\multicolumn{4}{|c|}{$\begin{array}{l}\text { 11. ORGANIZATION VALIDATION } \\
\text { X A PROPOSED REOUEST IS VALIDATED AS AN ORGANIZATION NEEDIREQUIREMENT WHICH REQUIRES ACTION. }\end{array}$}} \\
\hline & & & \\
\hline \multicolumn{4}{|c|}{$\square$ B. PROPOSED REQUEST IS OISAPPROVED AND IS NOT AN ORGANIZATION NEEOIREQUIREMSNT WHCH REOUIRES ACTION. } \\
\hline \multicolumn{4}{|c|}{ C PROPOSEO REOUEST IS RETURNED YO SUBMITTER FOR ADOTIONAL WNFOROMATION. } \\
\hline \multicolumn{2}{|c|}{\begin{tabular}{l|l} 
O. OATE & $\begin{array}{l}\text { E NAME GRADE. TITLE, ane DSN (Tyoo } \alpha \text { Prinf) } \\
\text { David C. Matthews, Major, 130AW, WVANG } \\
\text { Oculus Liaison Officer, 366-6605 }\end{array}$
\end{tabular}} & $\mid$ & BNATUE \\
\hline
\end{tabular}

Figure A-1: OCULUS 1.1 Certification Form 1067 (page 1). 


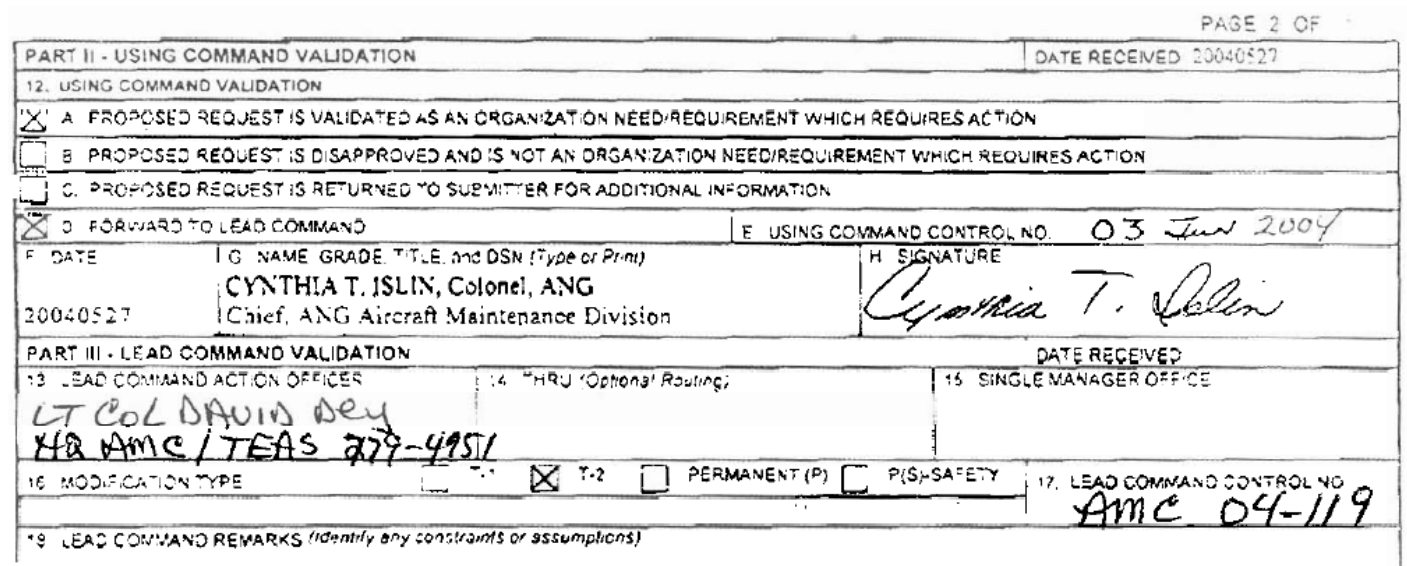

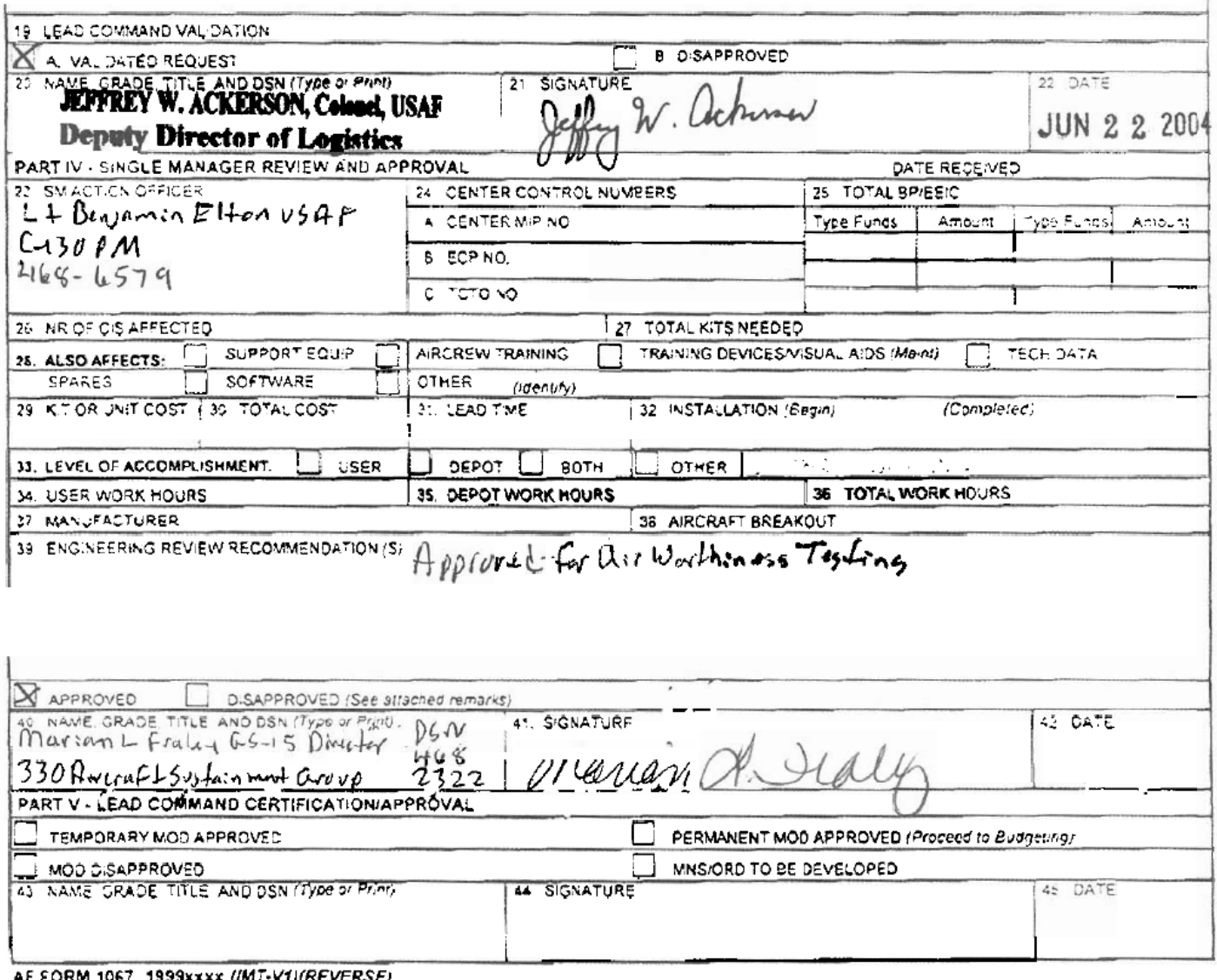

Figure A-2: OCULUS 1.1 Certification Form 1067 (page 2). 


\section{Appendix C. OCULUS 1.1 Indentured Drawing List}

The following list is a drawing hierarchy breakdown for the OCULUS 1.1 system. The system is broken down into 4 major sub-assemblies that have several additional subassemblies include in their makeup along with individual components. The selected drawing number provided for each sub-assembly and component was selected by Warner Robins Air Force Base in accordance with their project coordination. 
A7402-100-000 Installation - Oculus

A7402-100-001 Wiring - Oculus

A7402-200-000 Assembly - Operator's Station (Unit 1)

A7402-200-001 Wiring - Operator's Station Overall

A7402-200-002 Wiring - Operator's Station Input

A7402-200-003 Wiring - Mission Specific Connections

A7402-200-004 Photo Assembly Operators Station Electrical Components 1

A7402-200-005 Photo Assembly Operators Station Electrical Components 2

A7402-200-006 Photo Assembly Operators Station Electrical Components 3

A7402-200-007 Photo Assembly Operator Station Panel 1 Back

A7402-200-008 Photo Assembly Operator Station Panel 2 Back

A7402-200-009 Photo Assembly Operator Station Panel 3 Back

A7402-200-010 Photo Assembly Operator Station Panel 1 Front

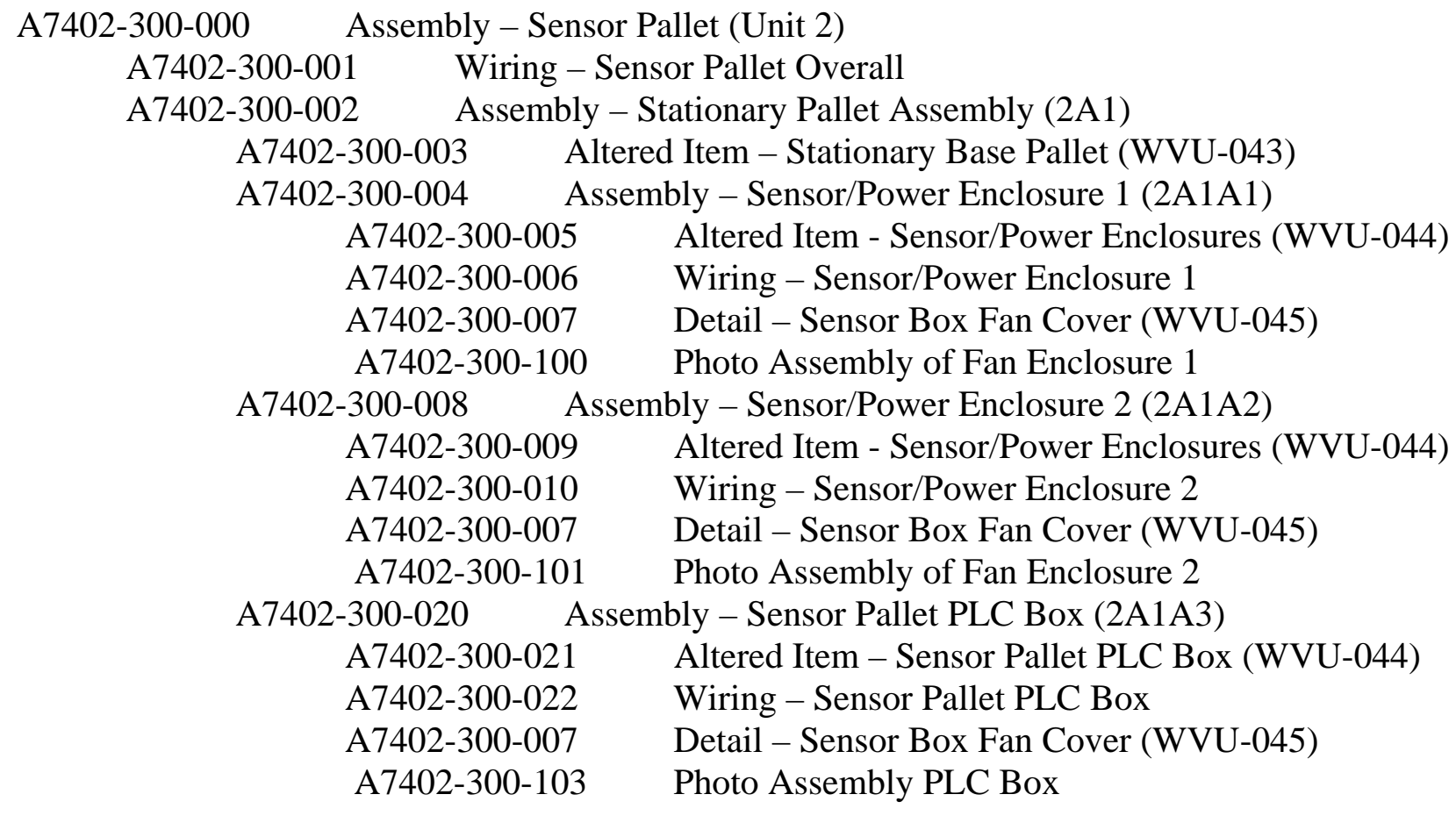




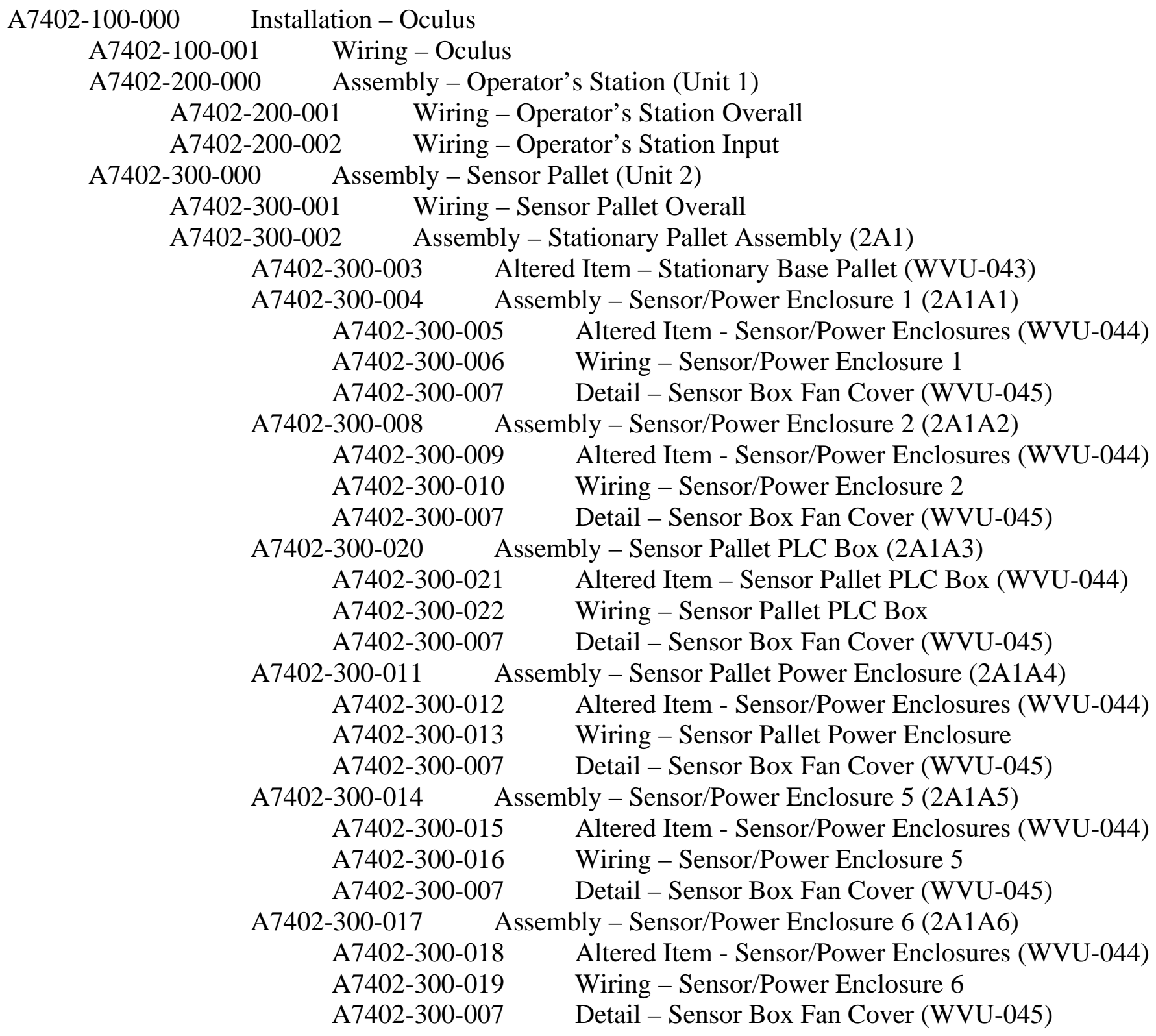


A7402-300-023 Assembly - Linear Motor Safe Step

A7402-300-024 Detail - Linear Motor Safe Step Frame (WVU-054A)

A7402-300-025 Detail - Safe Step Top Plate (WVU-054B)

A7402-300-026 Detail - Safe Step Front Plate (WVU-054C)

A7402-300-027 Detail - Safe Step Back Plate (WVU-054D)

A7402-300-028 Detail - Bottom Mechanical Fail Safe Stop (WVU-055)

A7402-300-031 Detail - Linear Actuator Attachment Bracket (WVU-076)

A7402-300-032 Assembly - Operator's Pendant

A7402-300-082 Wiring - Operator's Pendant

A7402-300-033 Assembly - Linear Translating Pallet Assembly (2A2)

A7402-300-034 Detail - Linear Translating Plate (WVU-035)

A7402-300-035 Detail - Stiffening Support C-Channel (WVU-036)

A7402-300-036 Detail - Diamond Plate (WVU-038)

A7402-300-037 Assembly - Inside Bearing Support Stand (WVU-031A)

A7402-300-038 Detail - Inside Bearing Support Stand Parts (WVU-031C)

A7402-300-039 Assembly - Outside Bearing Support Stand (WVU-031B)

A7402-300-040 Detail - Outside Bearing Support Stand Parts (WVU-031D)

A7402-300-042 Assembly - Left Arm Stand (WVU-039A)

A7402-300-044 Assembly - Right Arm Stand Assembly (WVU-039B)

A7402-300-045 Detail - Right Arm Stand (WVU-039C)

A7402-300-046 Detail - Arm Stand Cover Plate (WVU-039D)

A7402-300-083 Assembly - Rotational Motor Controller Box

A7402-300-066 Wiring - Rotational Motor Controller Box

A7402-300-077 Detail - Top Mechanical Fail Safe Stop (WVU-042)

A7402-300-047 Detail - Mechanical Arm Conduit (WVU-012)

A7402-300-078 Detail - Gear Reducer Support Plate (WVU-075)

A7402-300-081 Detail - Bottom Rail Plate Stop (WVU-080B)

A7402-300-048 Assembly - Sensor Pod Assembly (WVU-008) (2A4)

A7402-300-049 Detail - Pod Skin 1 (WVU-008A)

A7402-300-050 Detail - Pod Skin 2 (WVU-008B)

A7402-300-051 Detail - Pod Skin 3 (WVU-008C)

A7402-300-052 Detail - Pod Skin 4 (WVU-008D)

A7402-300-053 Detail - Pod Skin 5 (WVU-008E) 


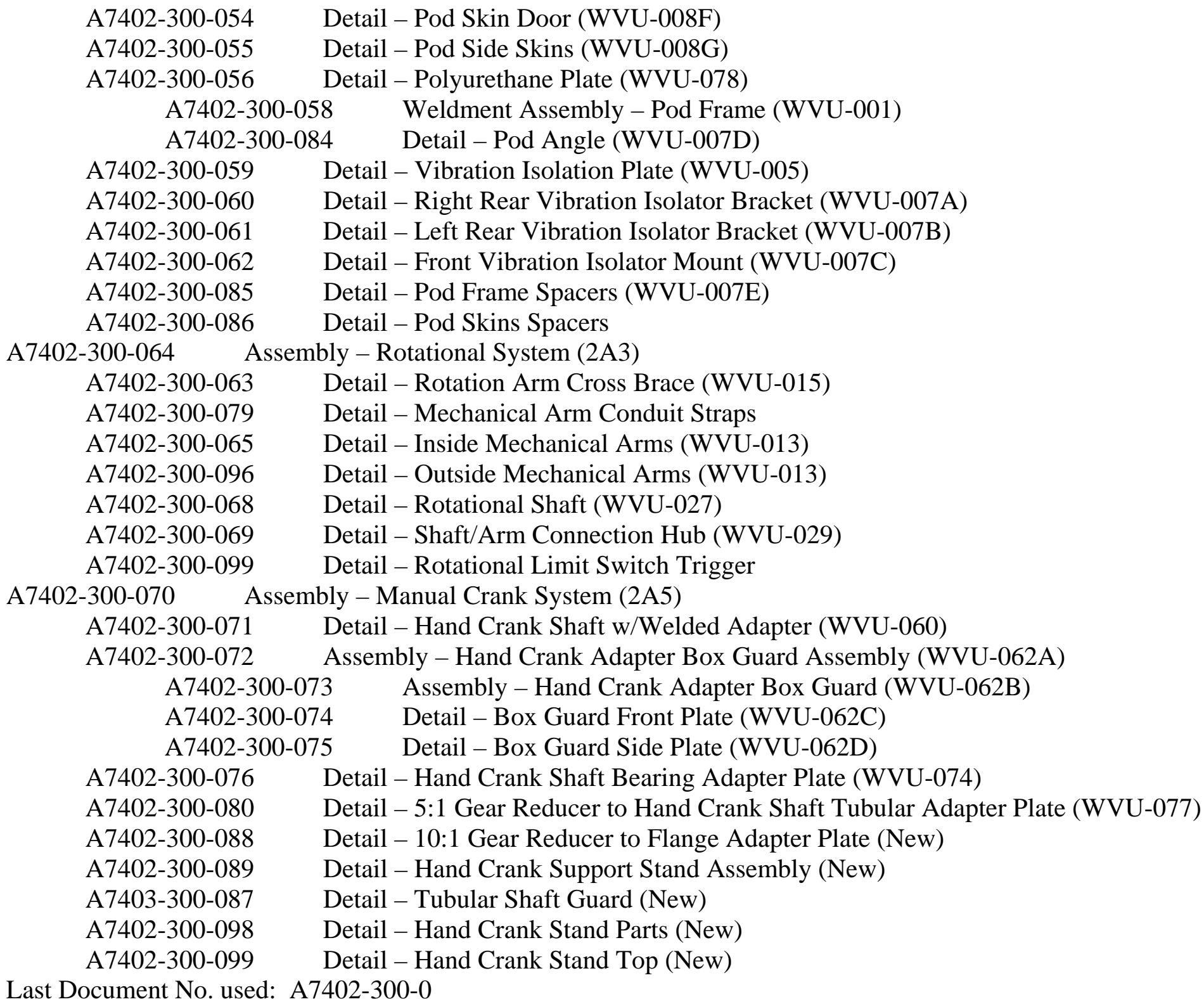

Last Document No. used: A7402-300-0 


\section{Appendix D. Mechanical and Electrical Drawings}

The following is the complete mechanical and electrical drawing package for the

OCULUS 1.1 system. The complete drawing package was created to satisfy the WRAFB recommended Level II drawing requirements for a low-scale production system. These drawings were developed in Pro/Engineer modeling software from the complete solid model OCULUS 1.1 system. 


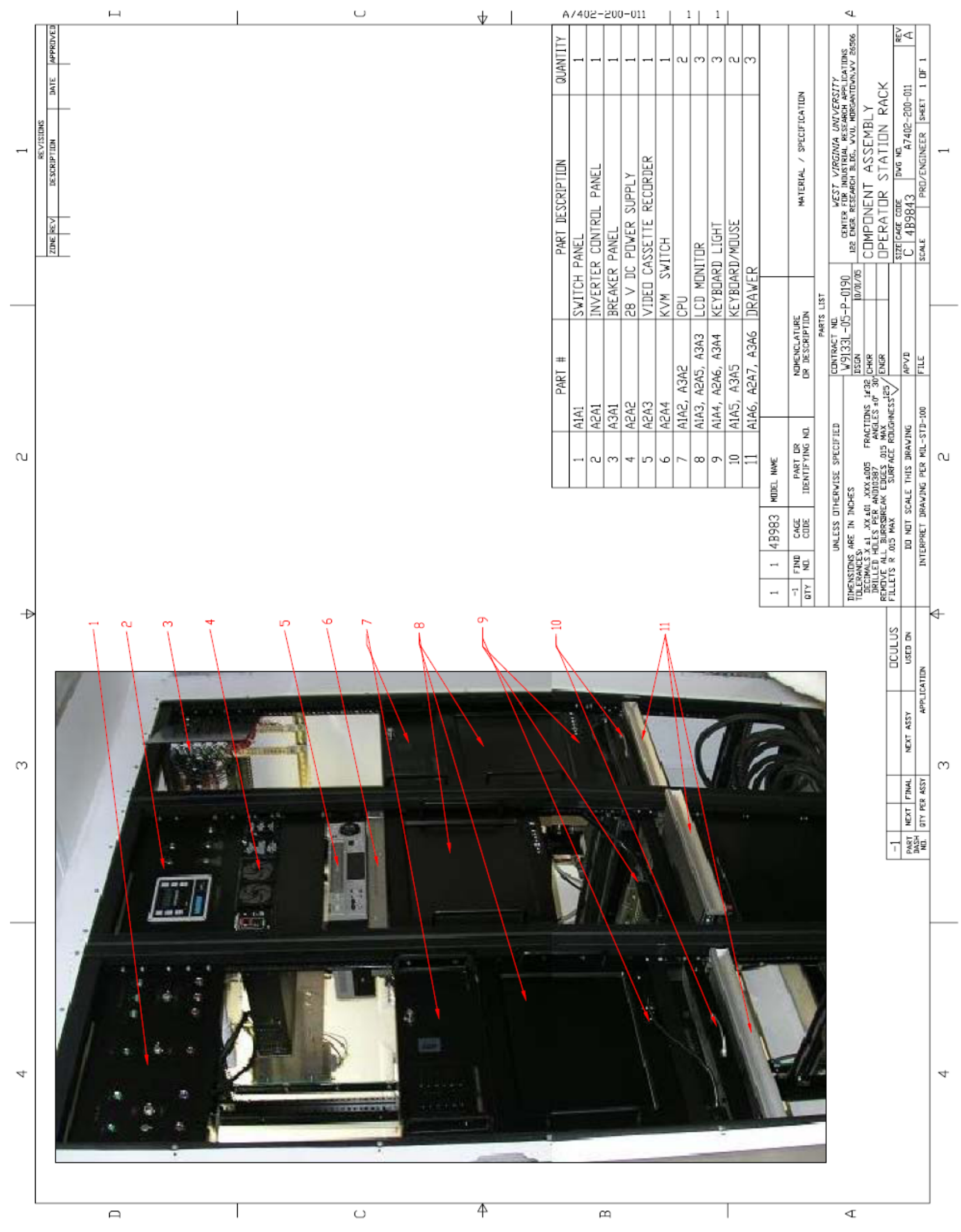




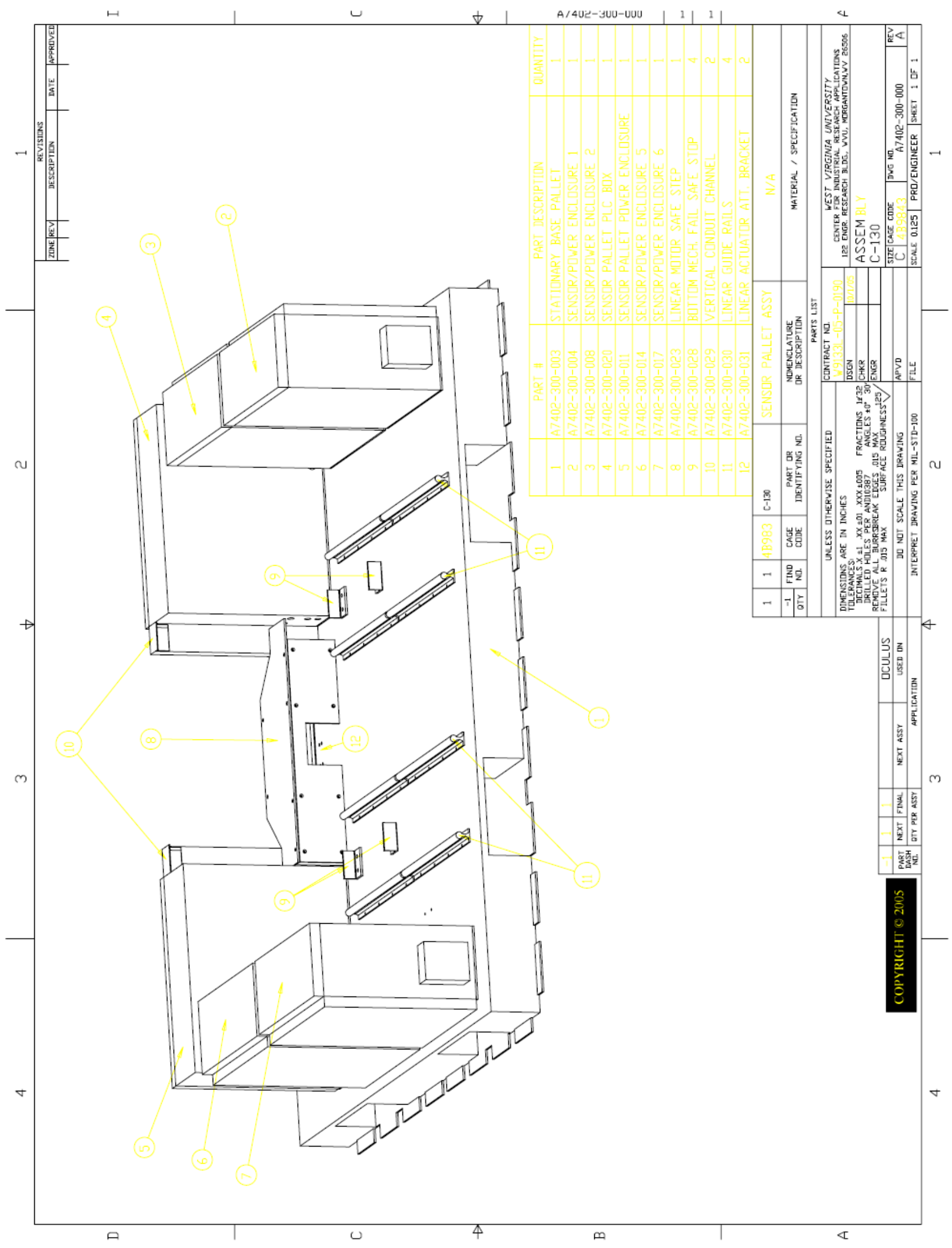




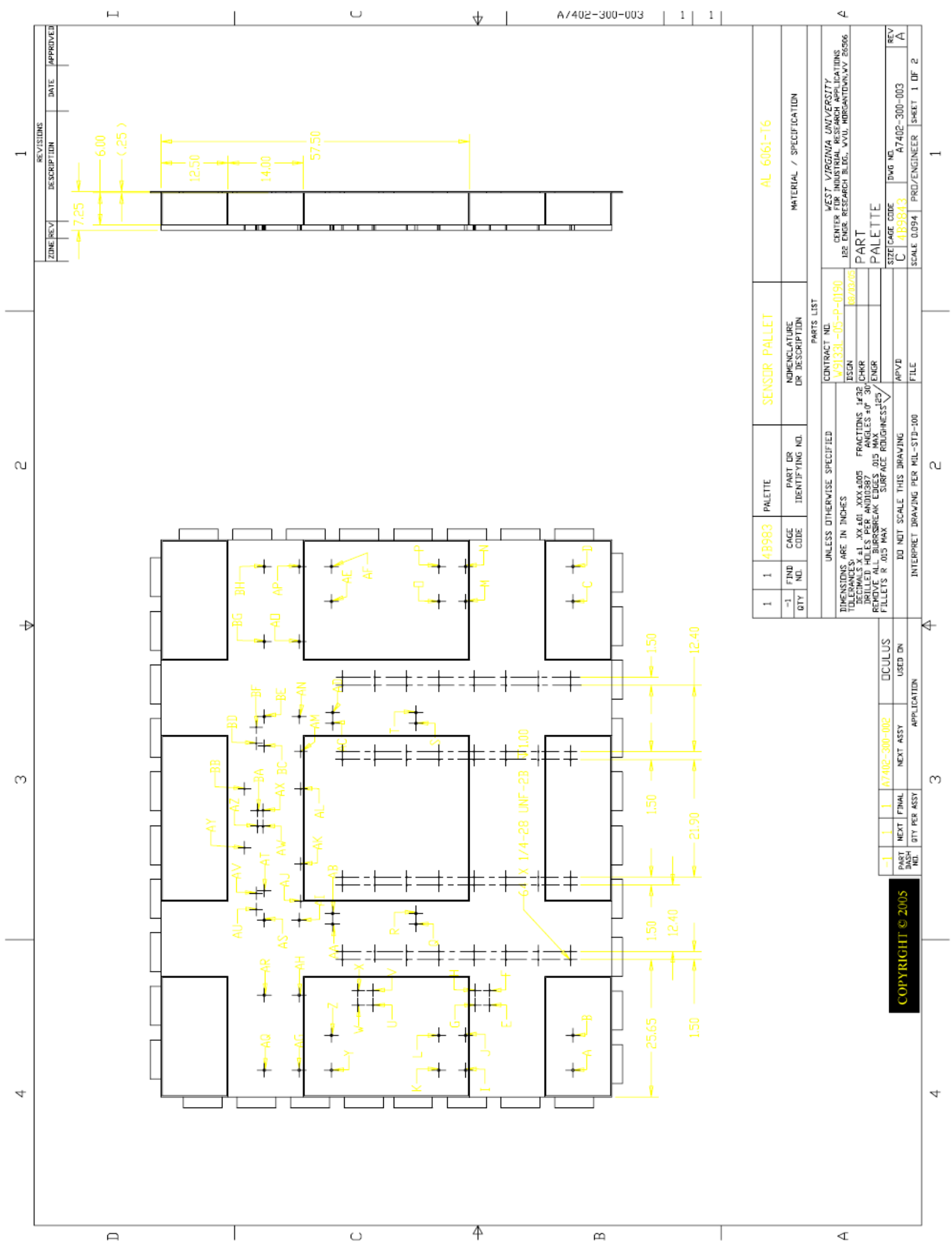




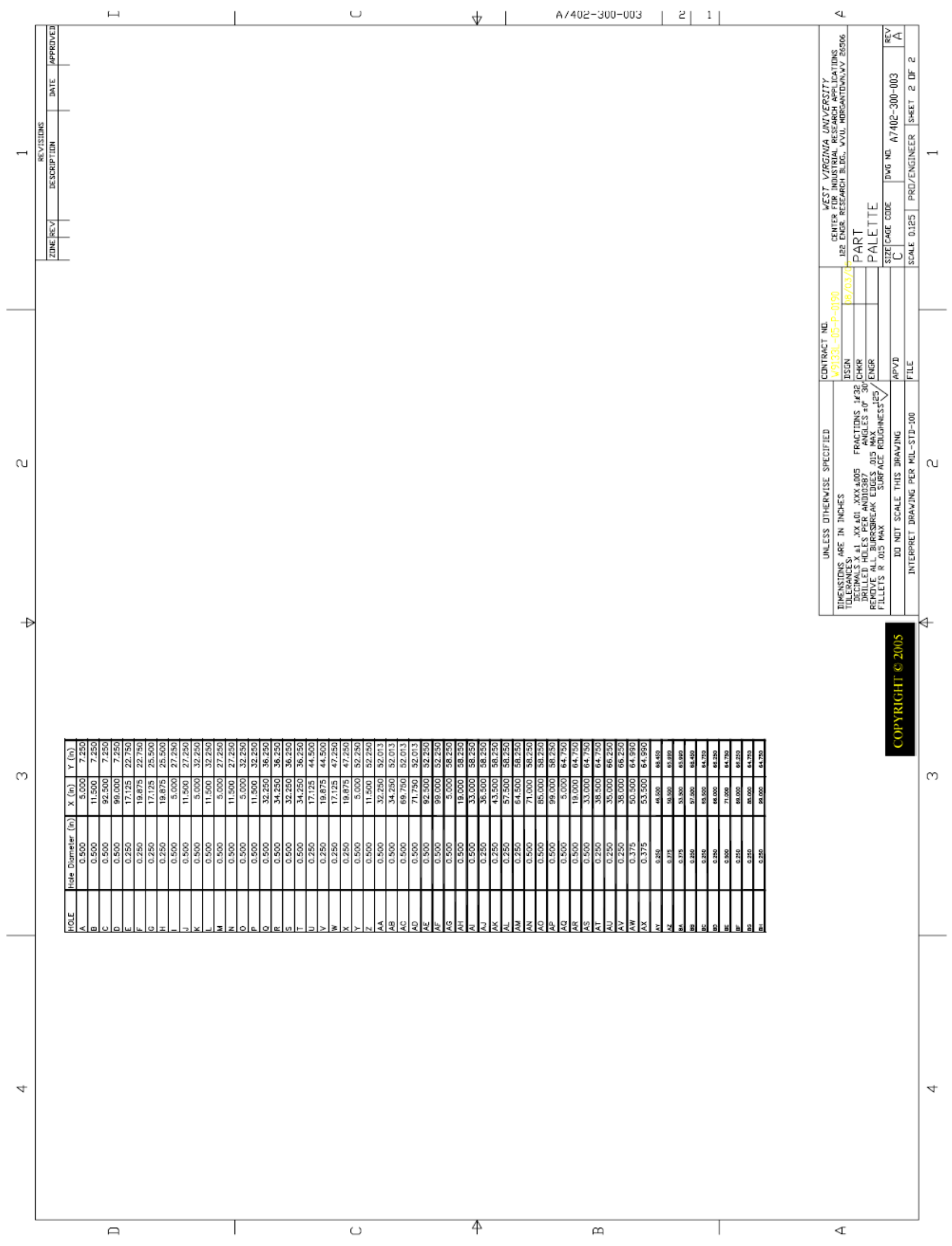





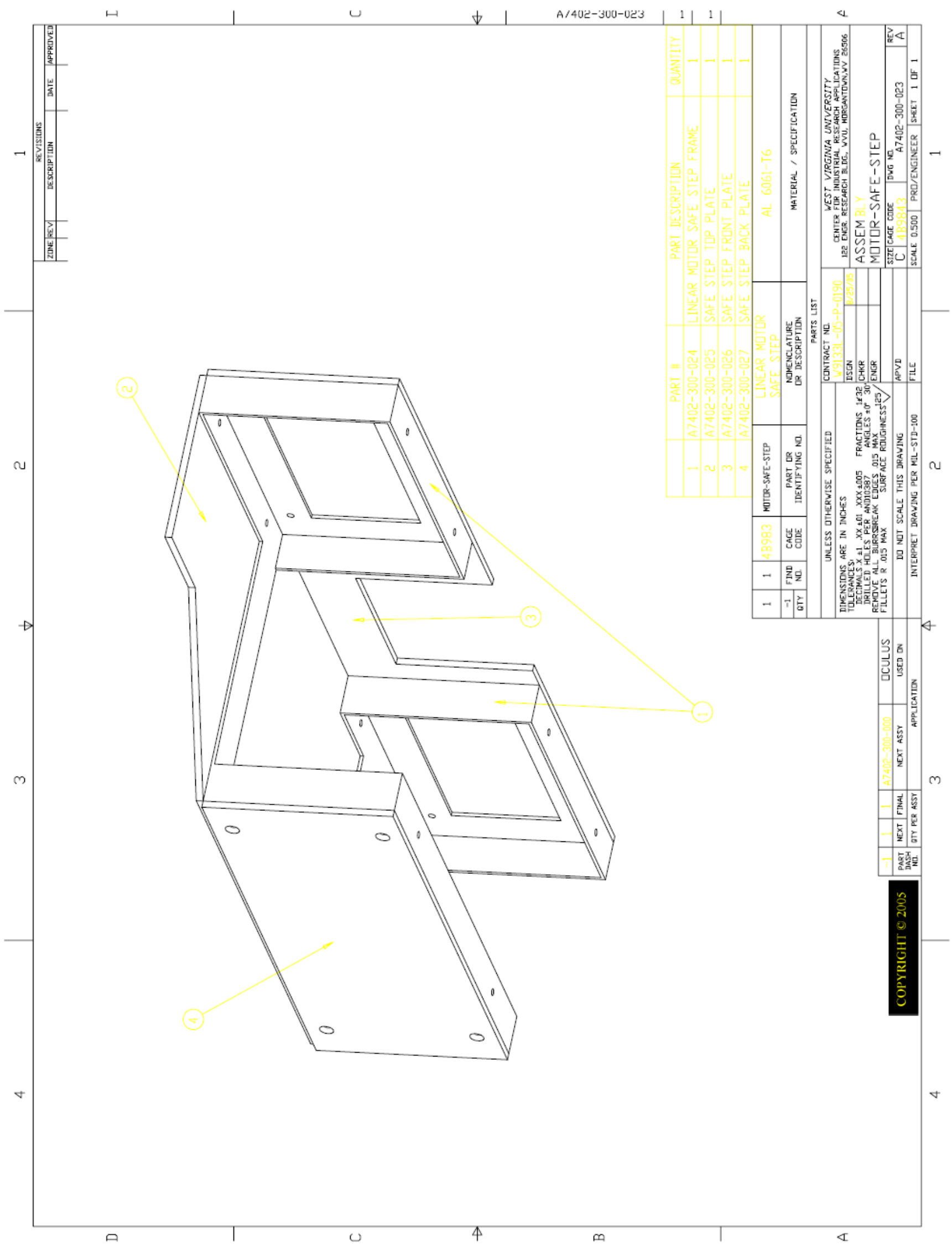




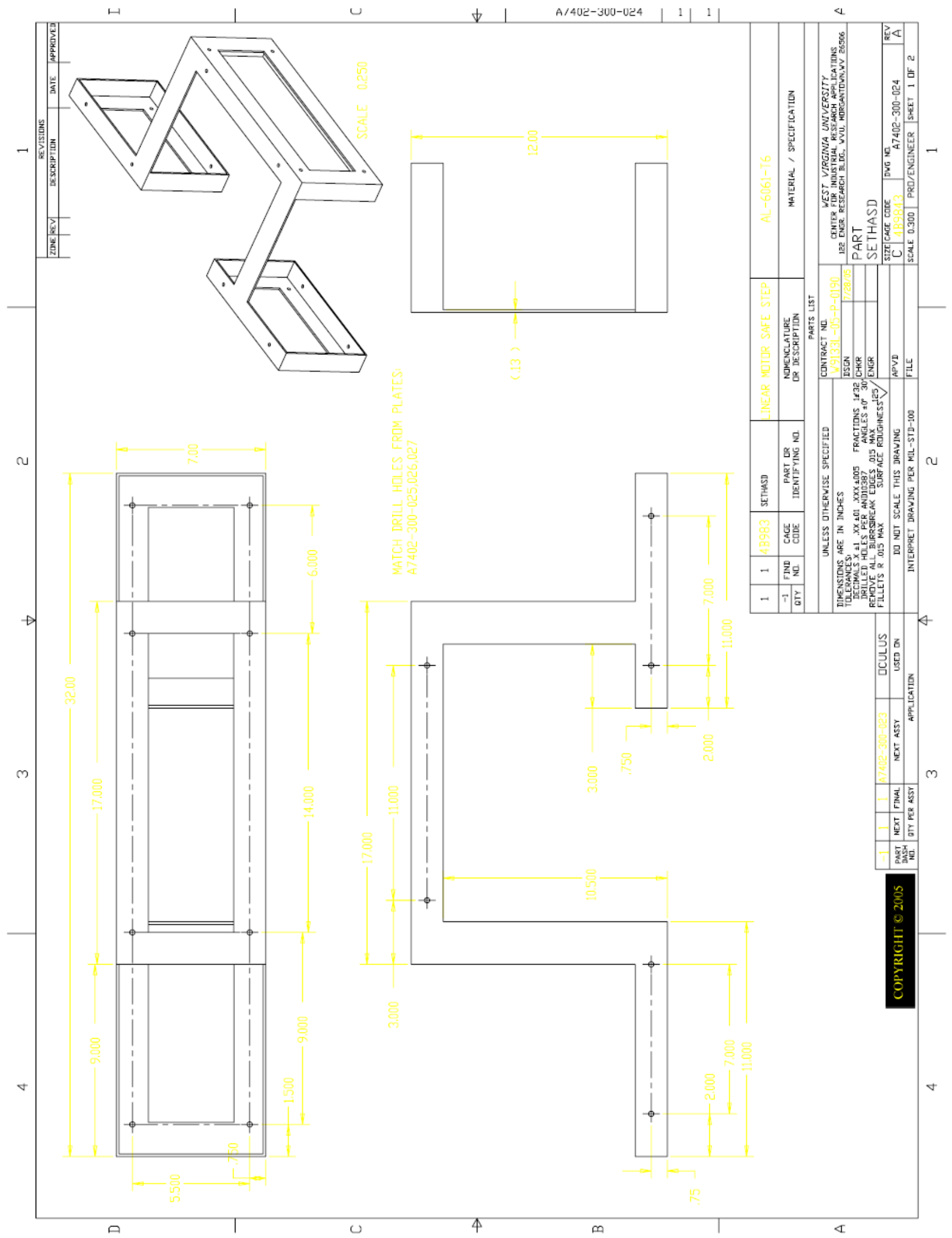

138 


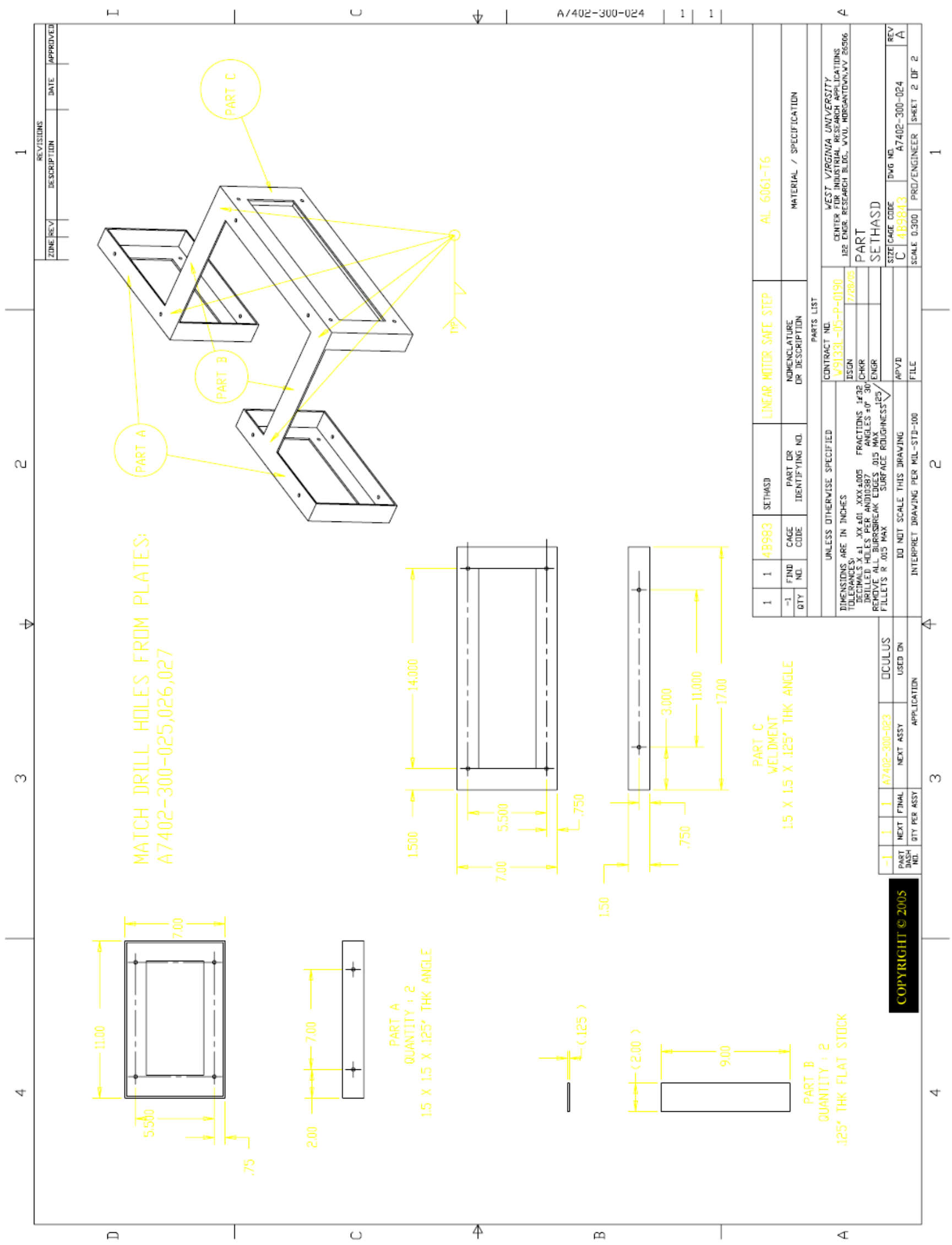




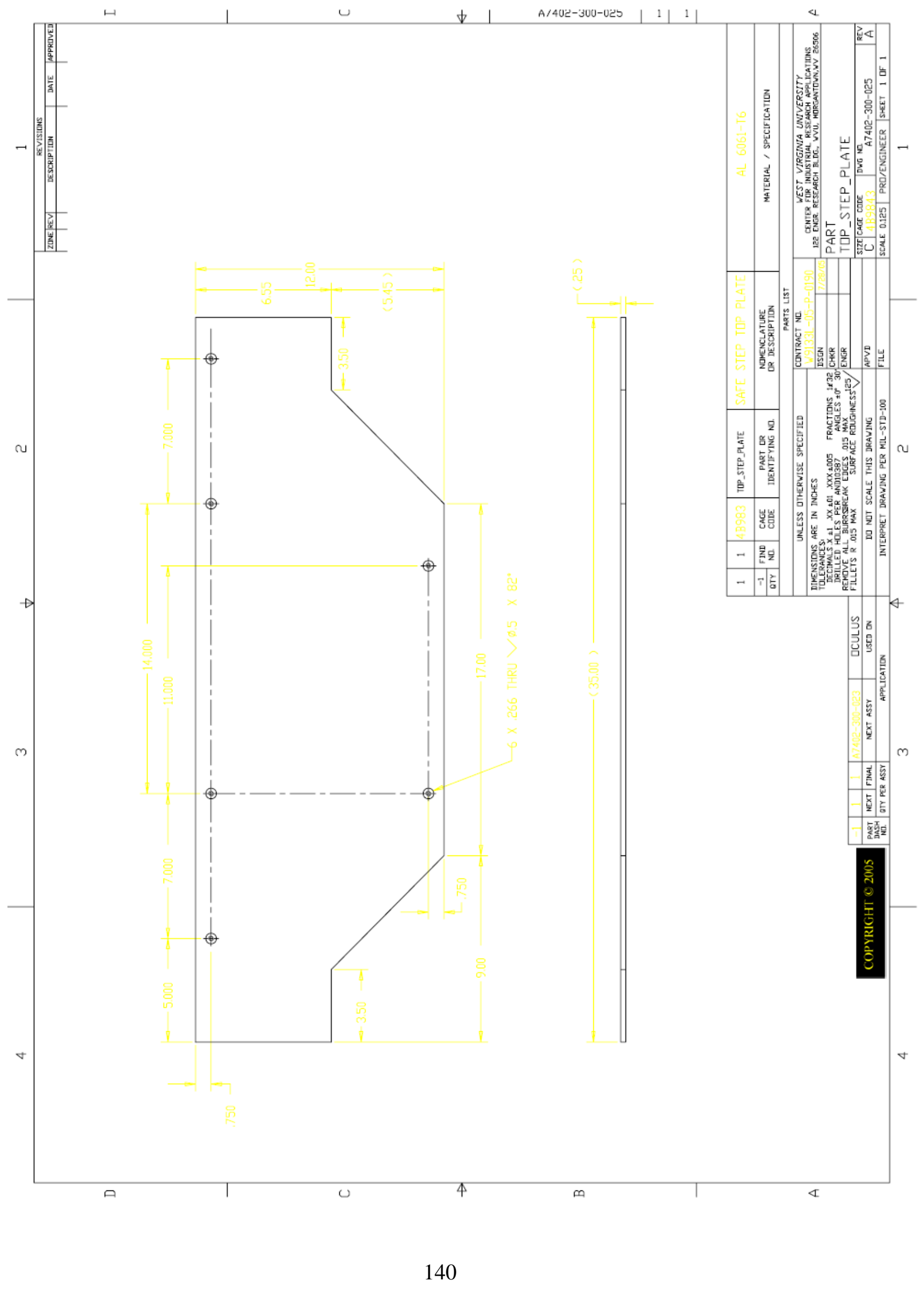




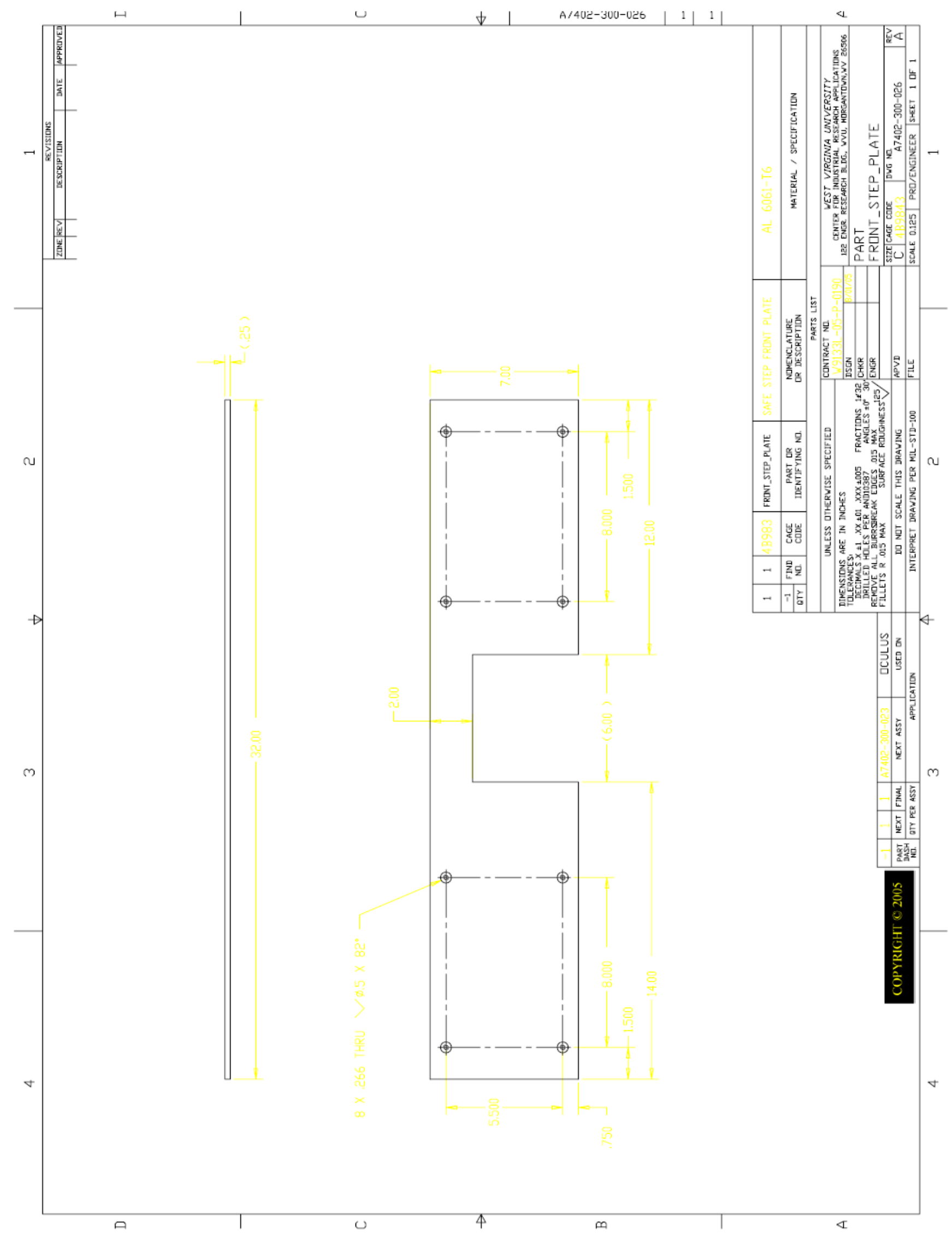




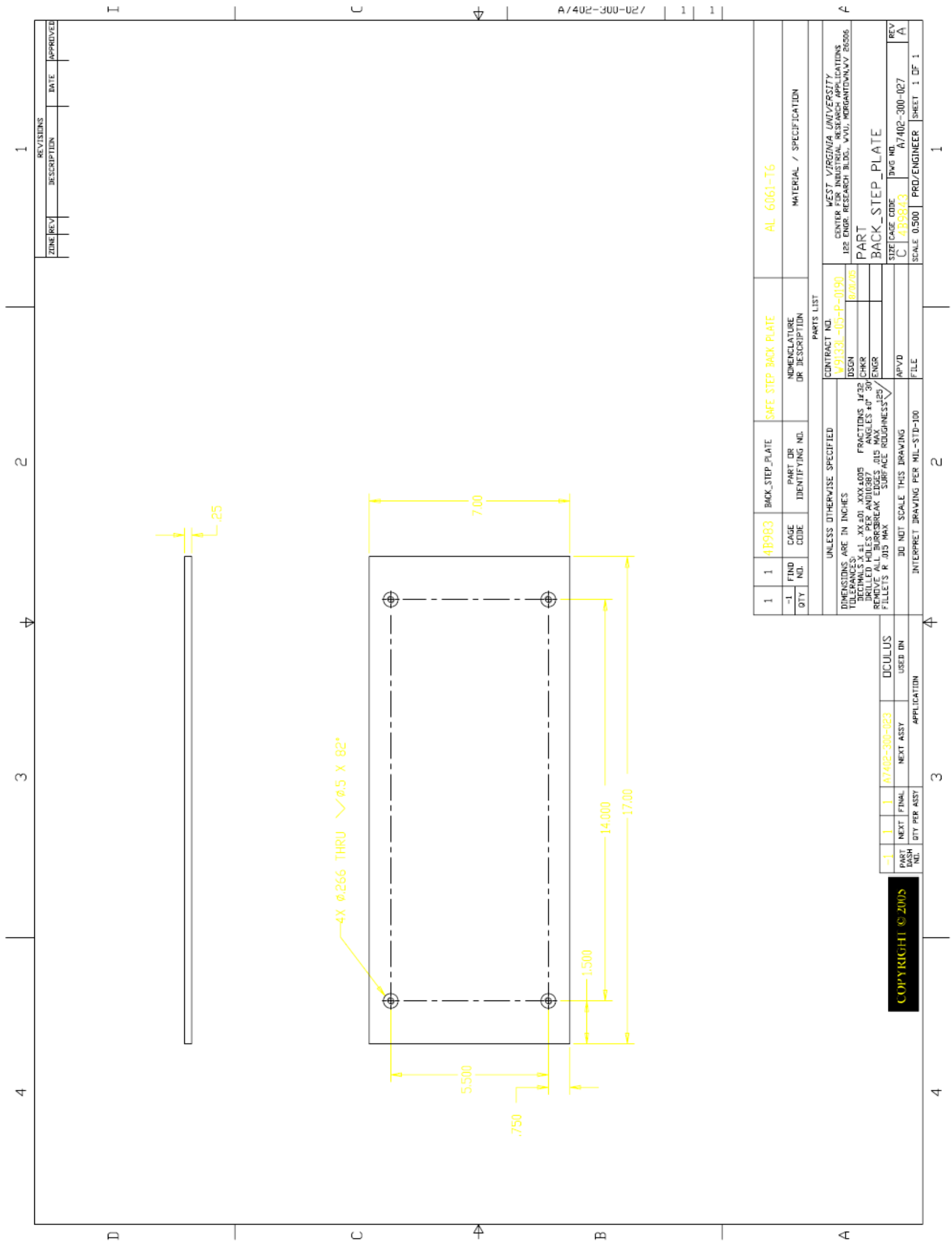

142 


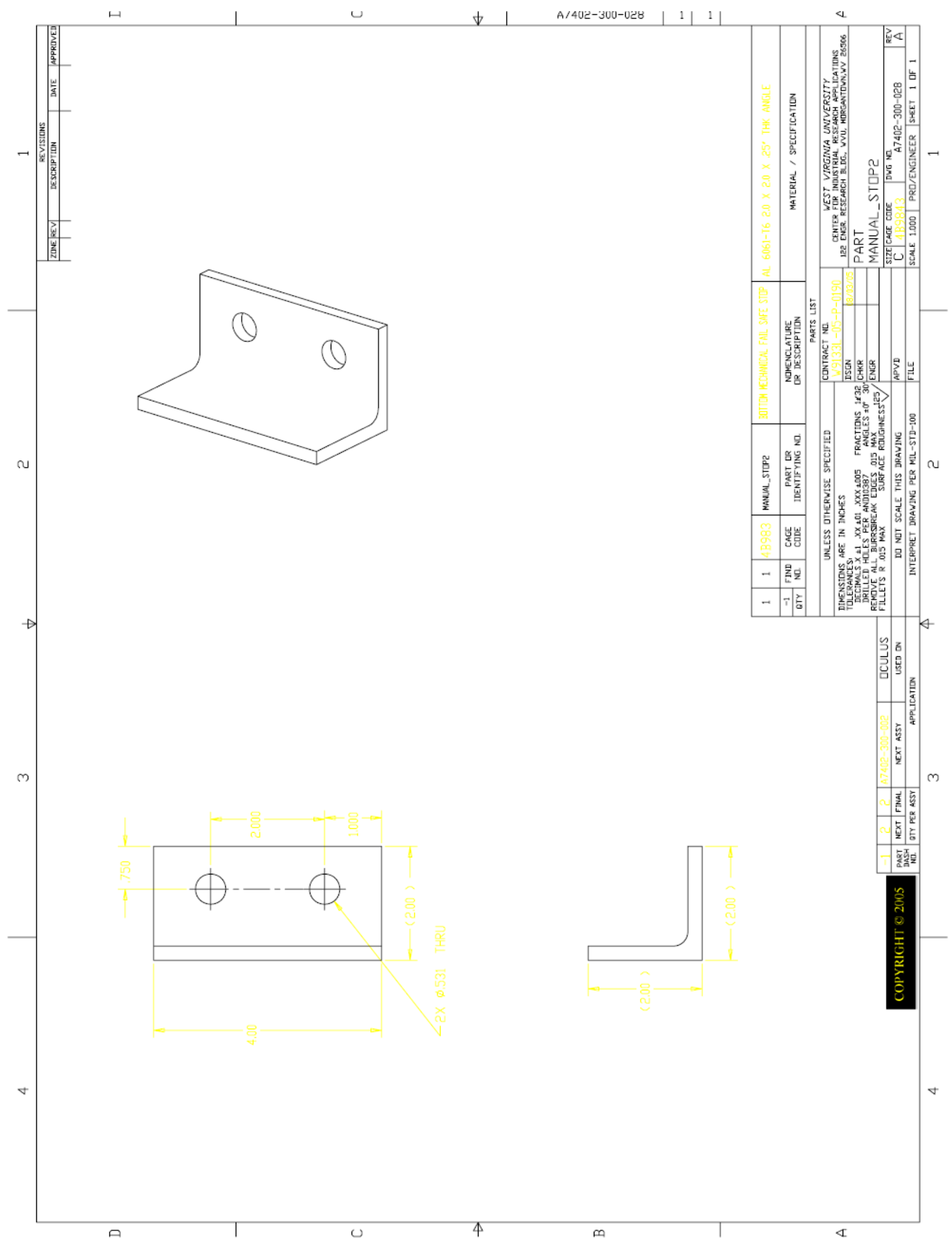

143 


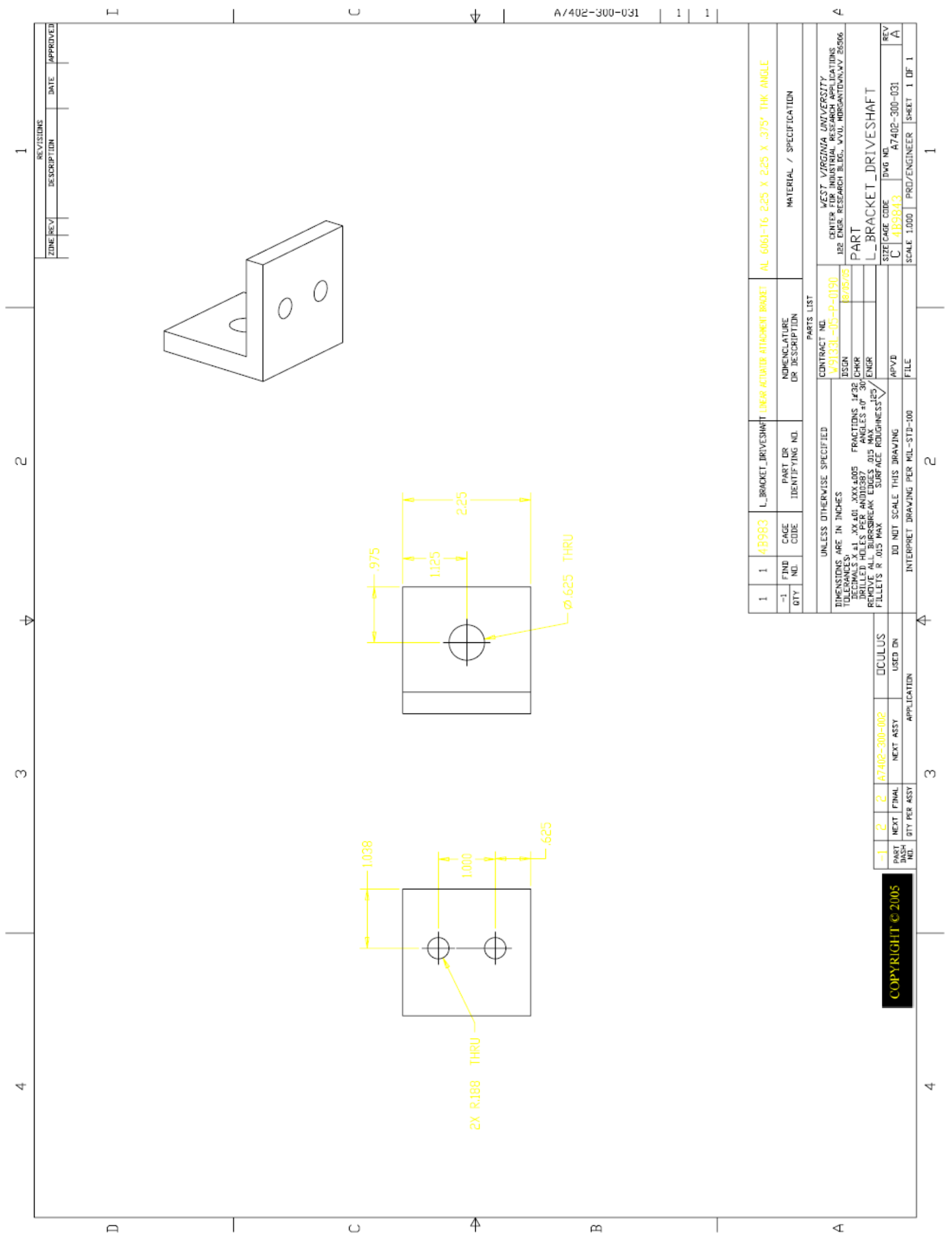




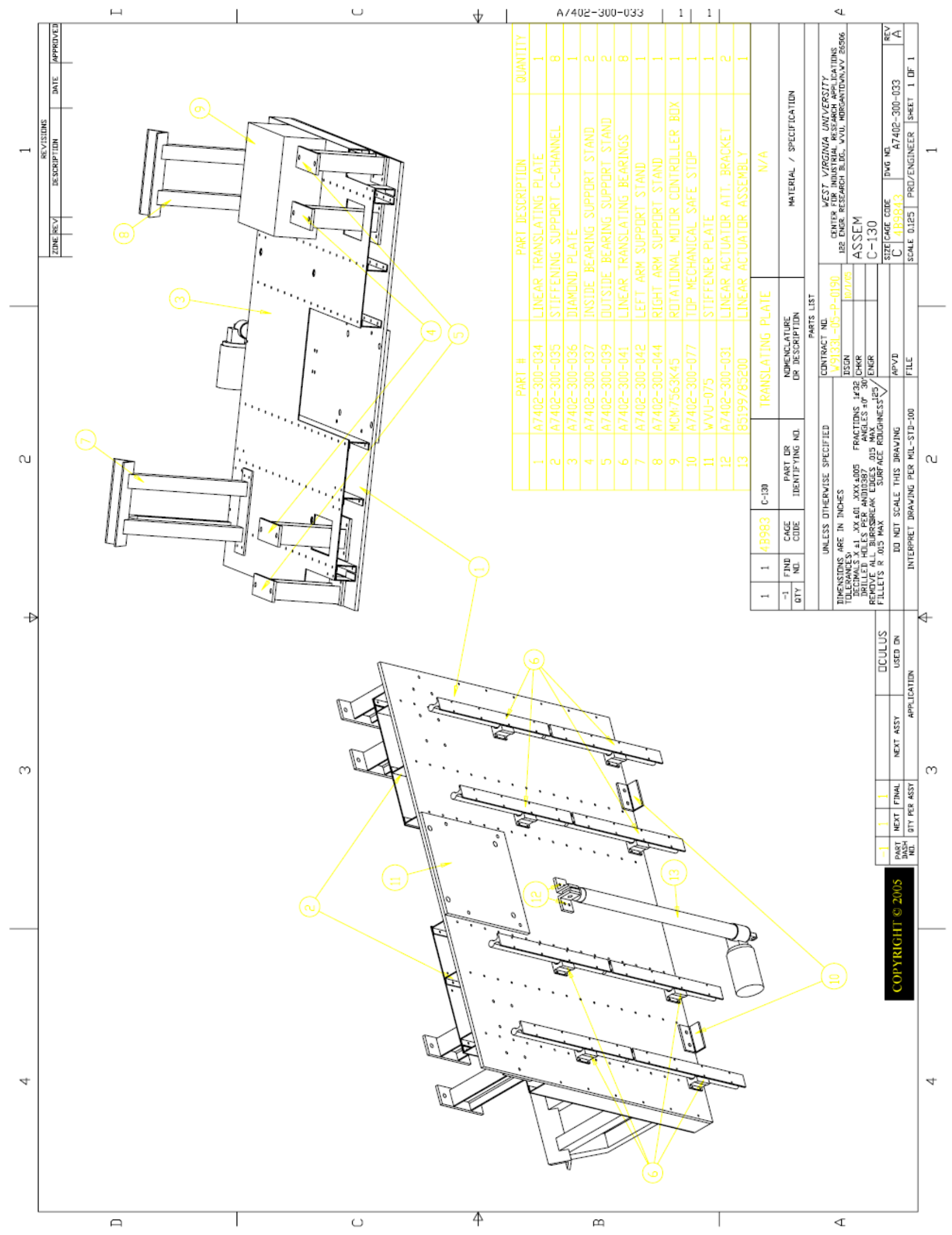




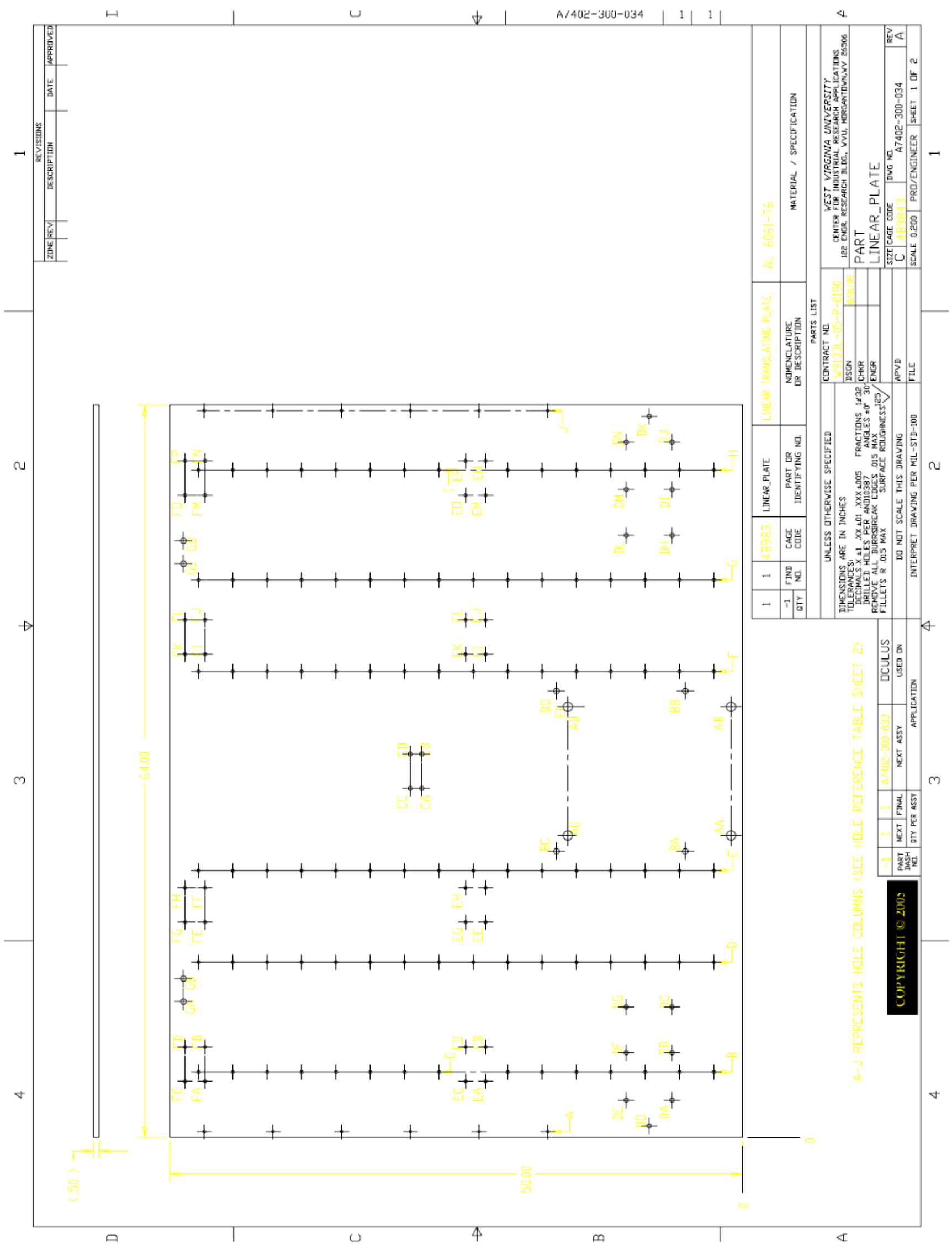




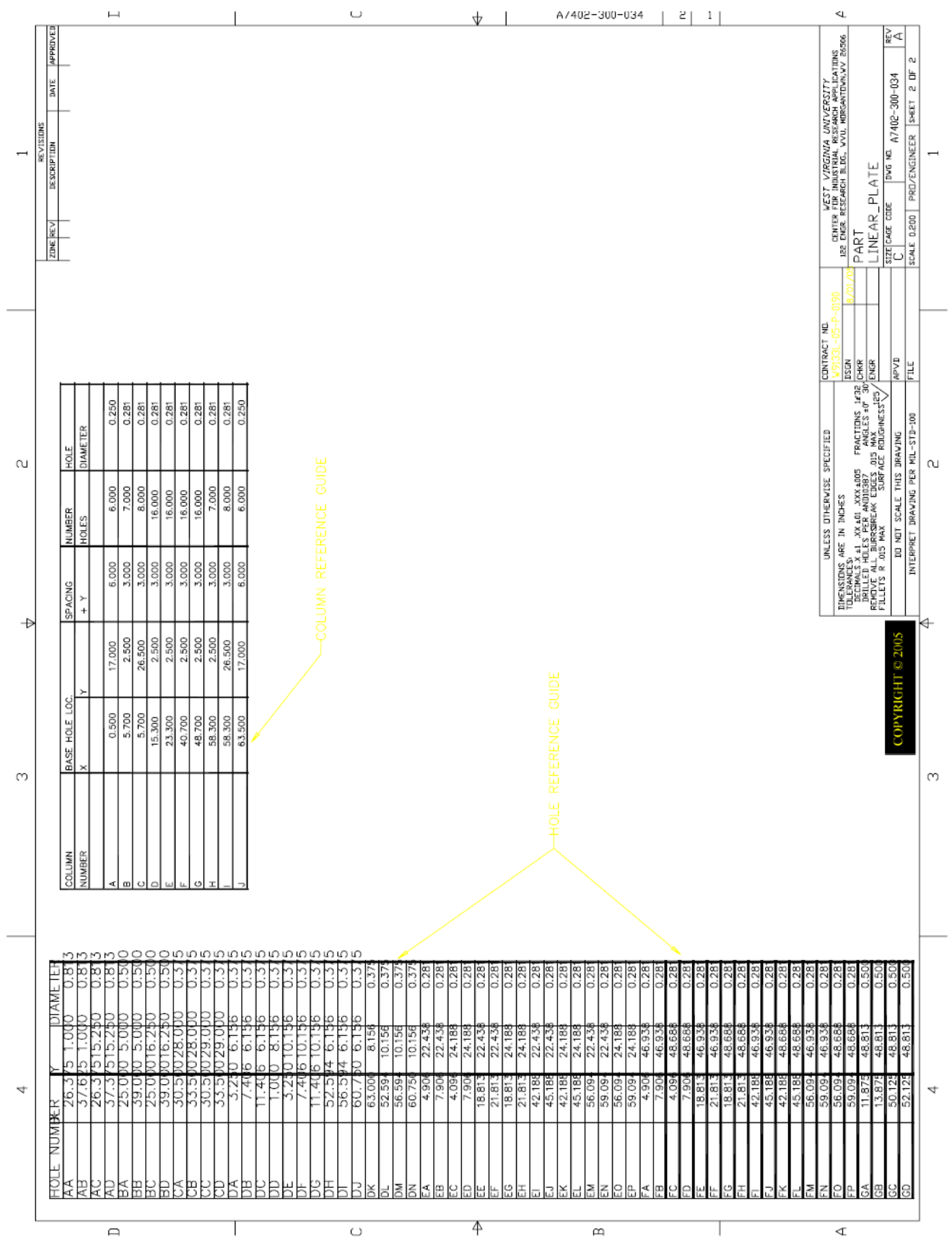




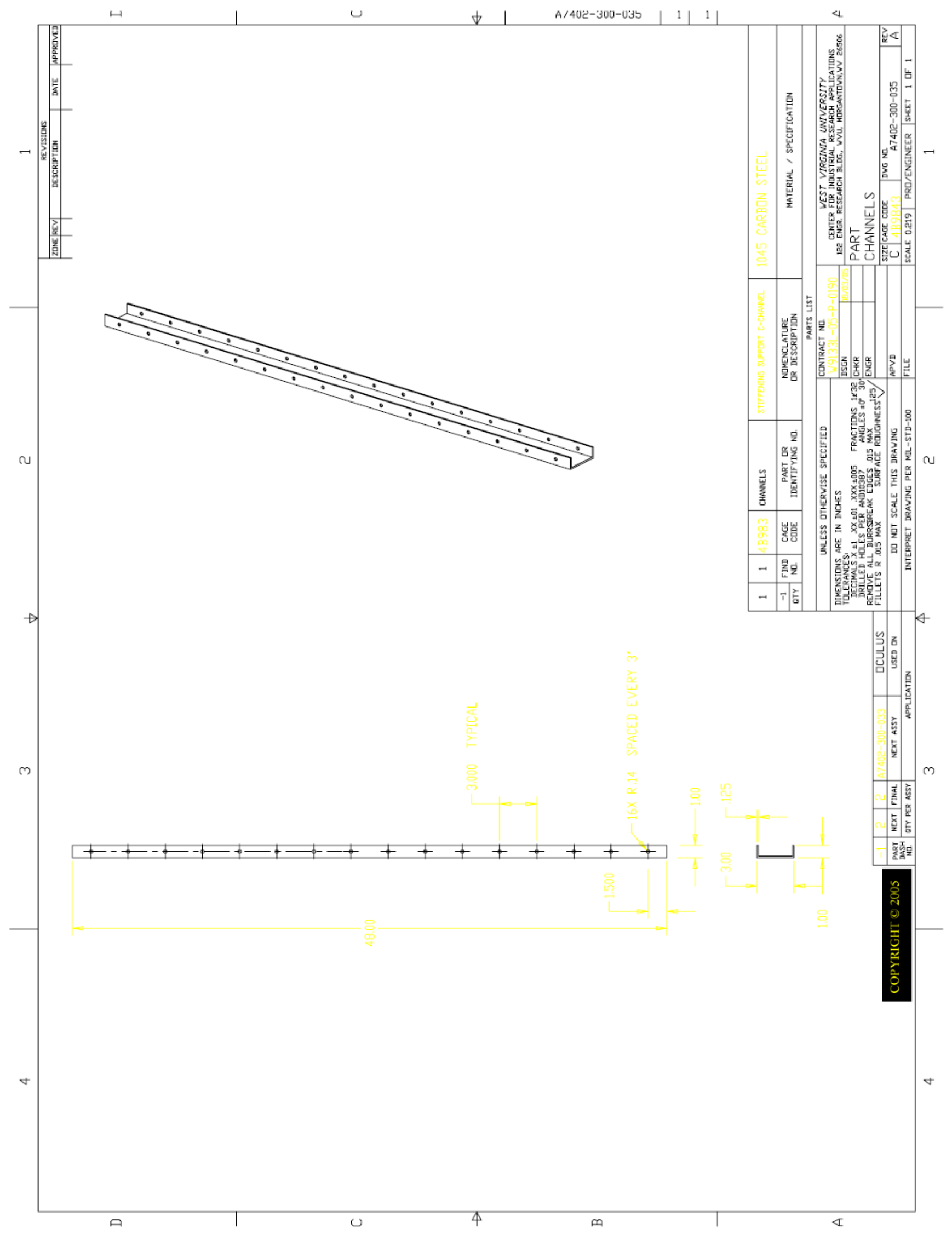




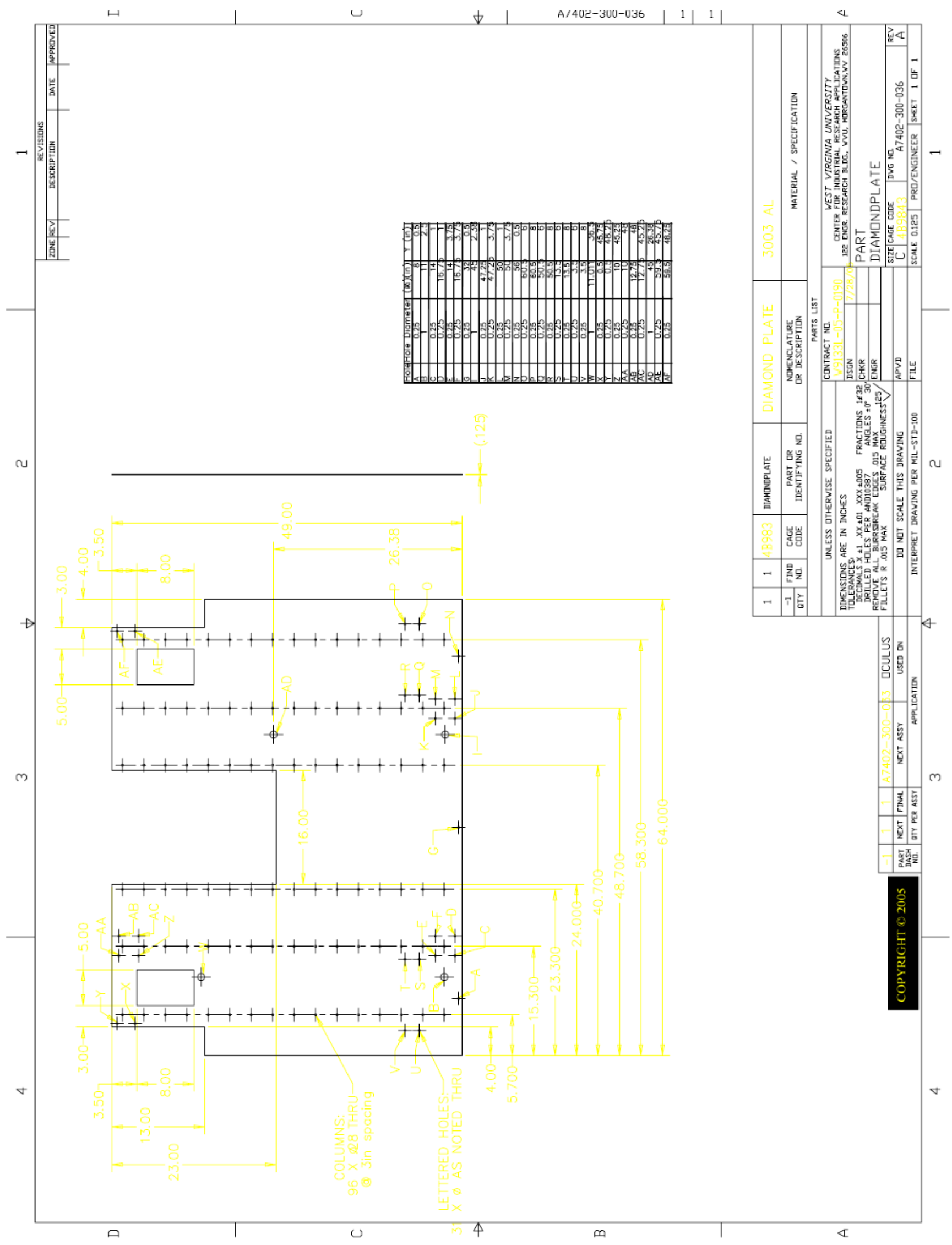




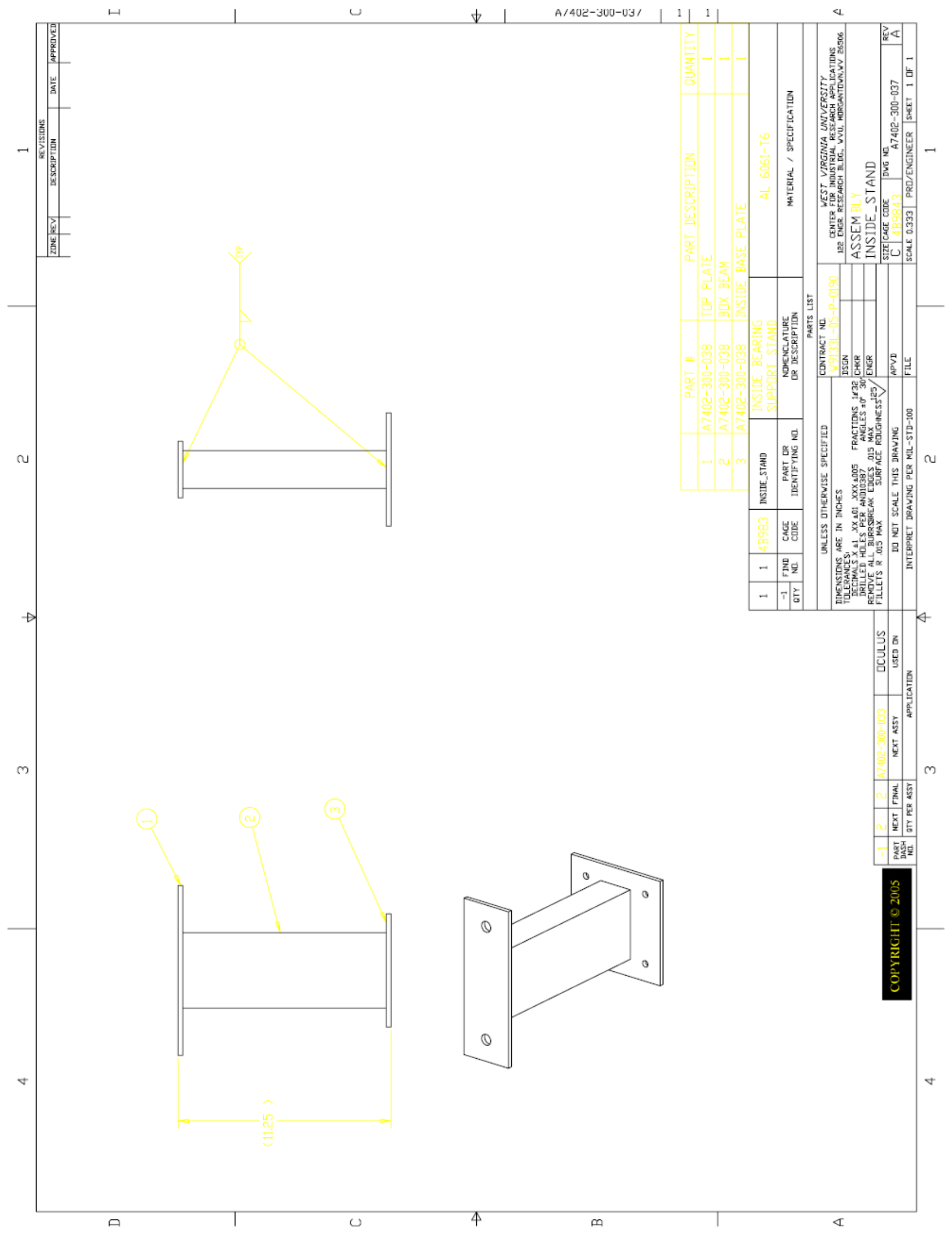




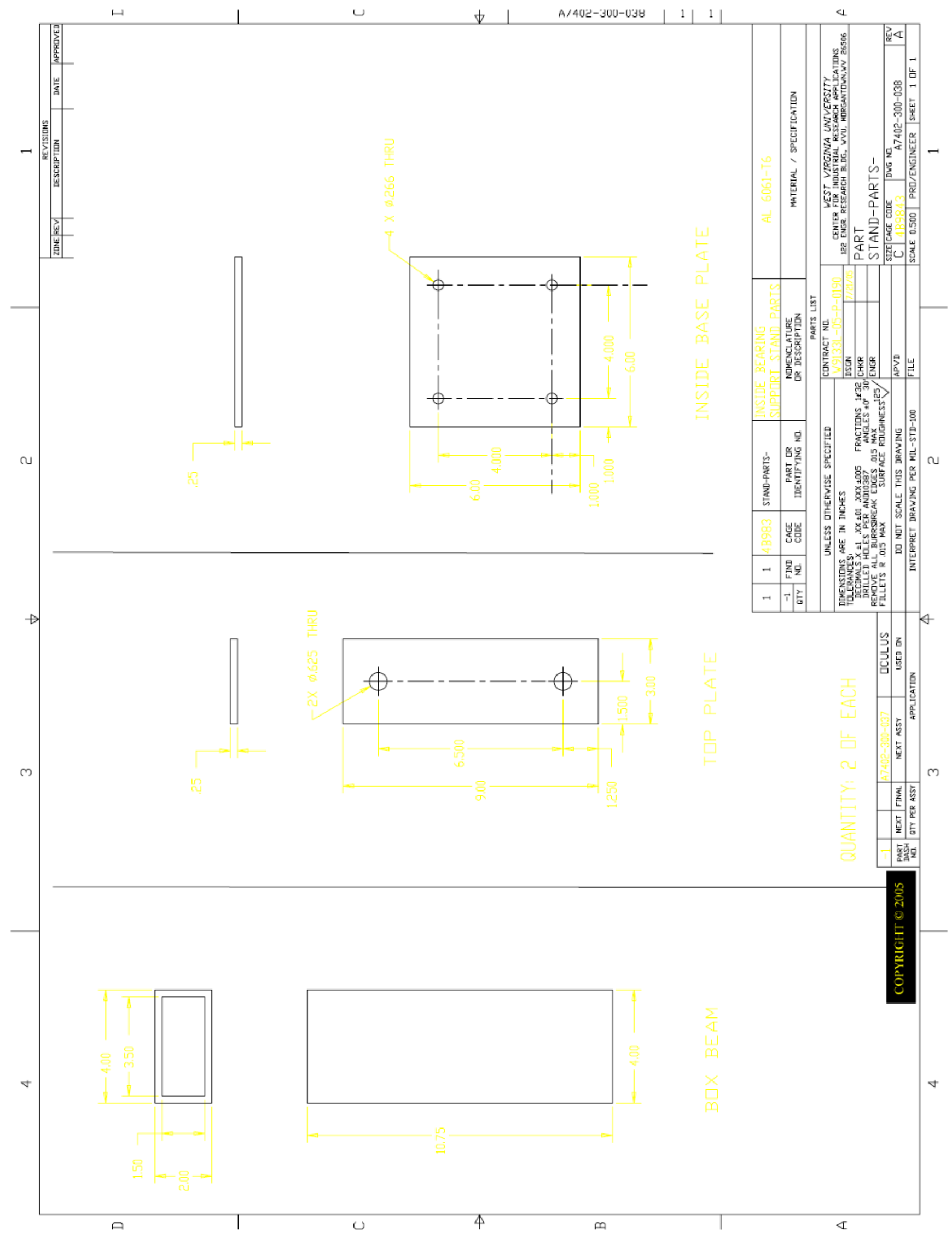




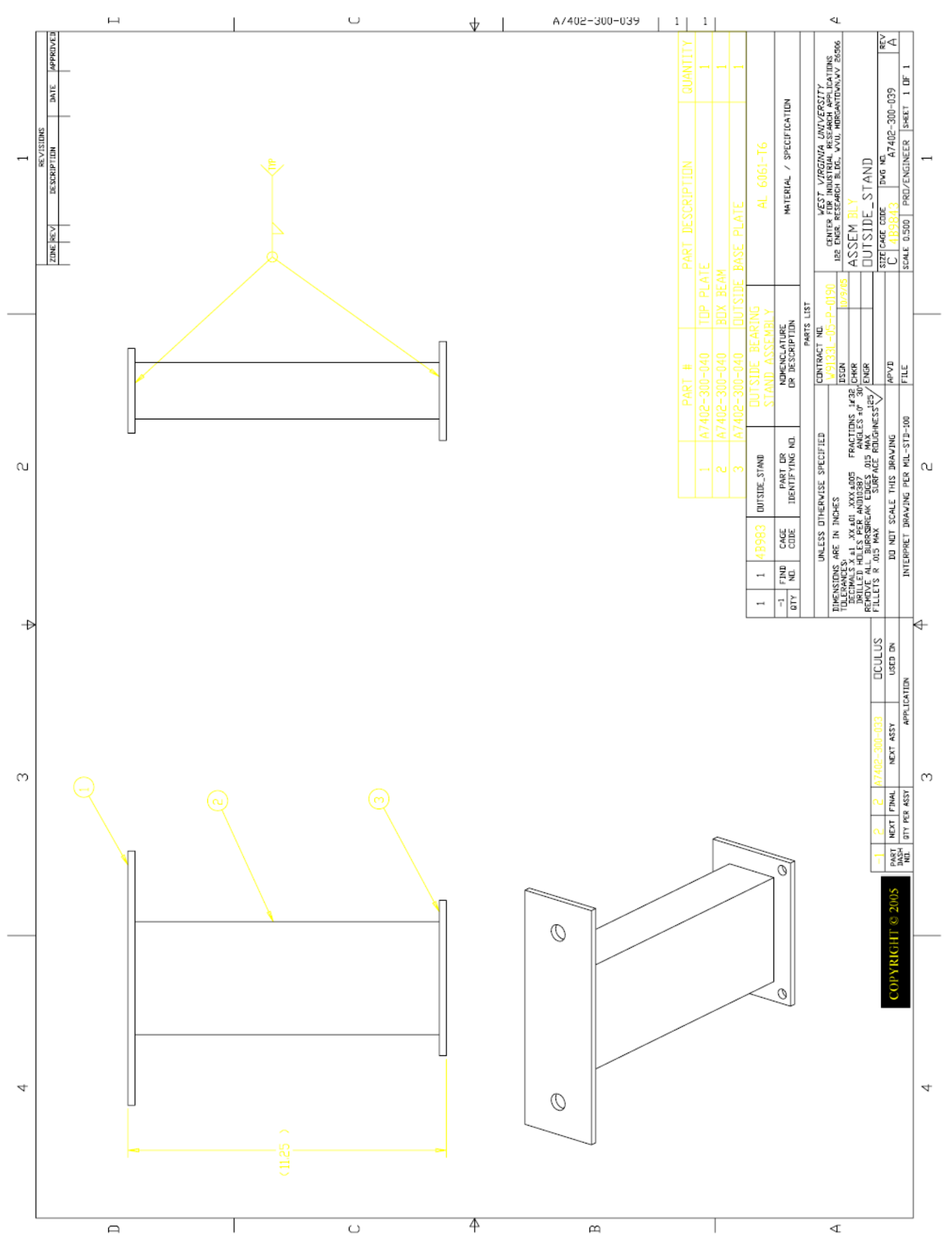




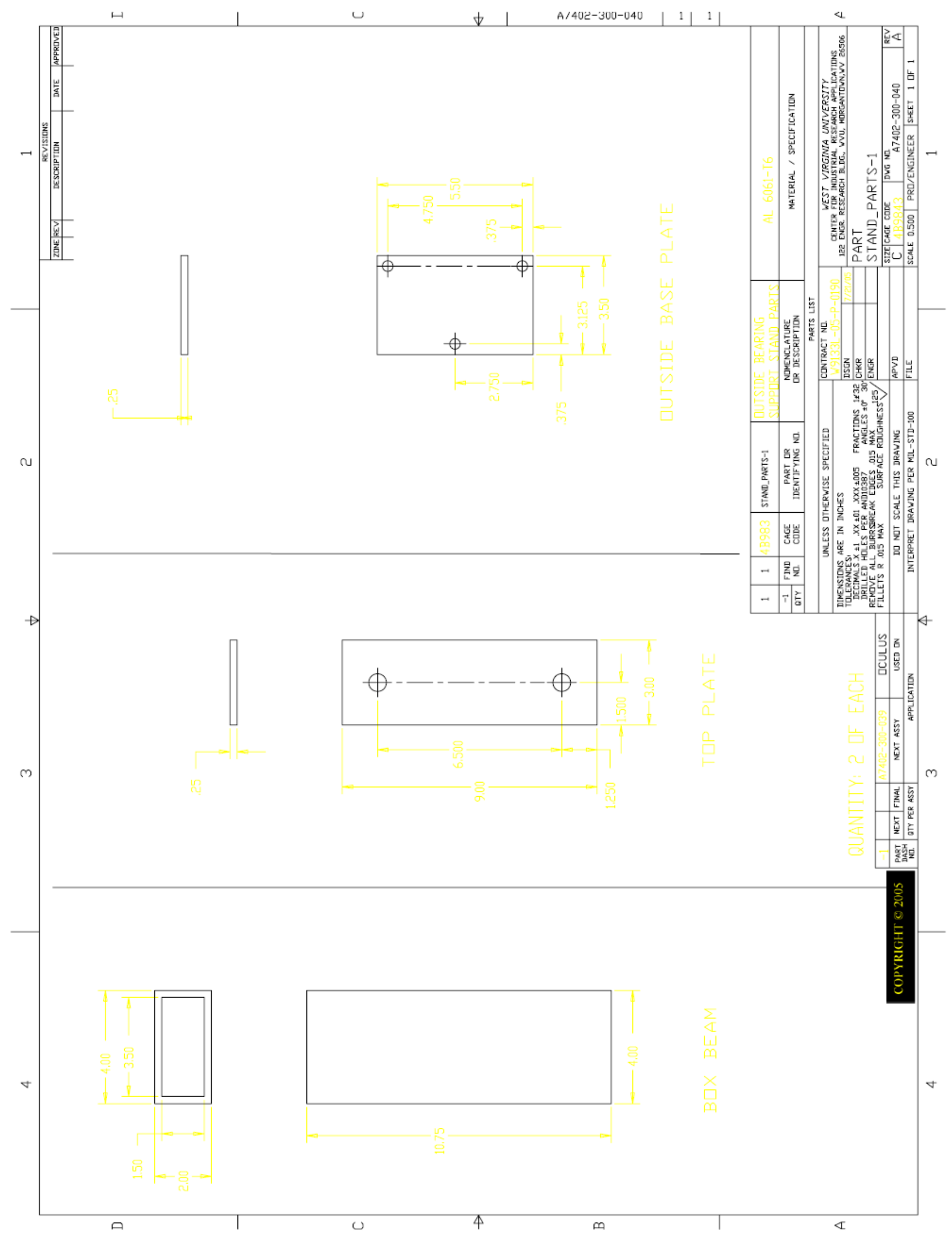




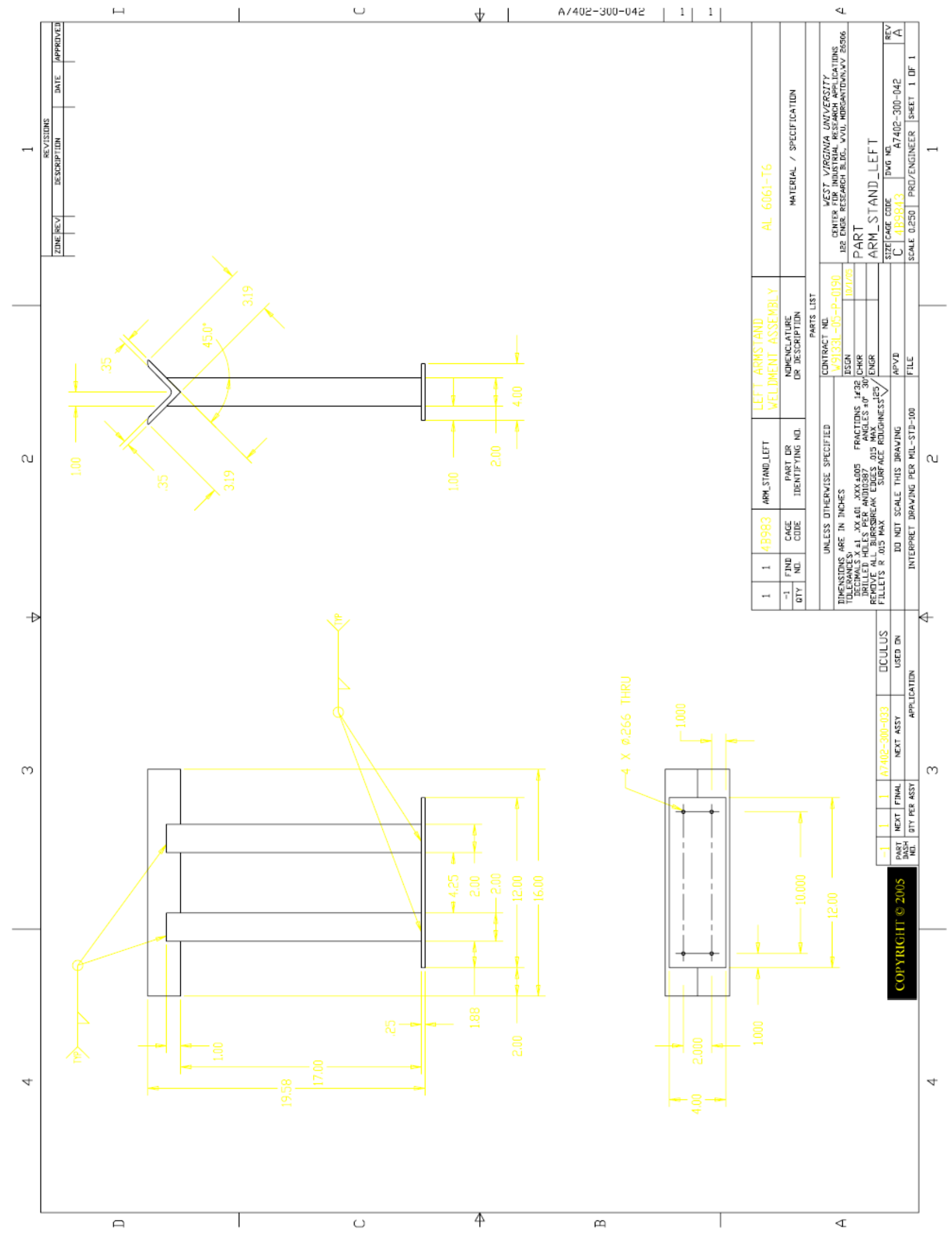




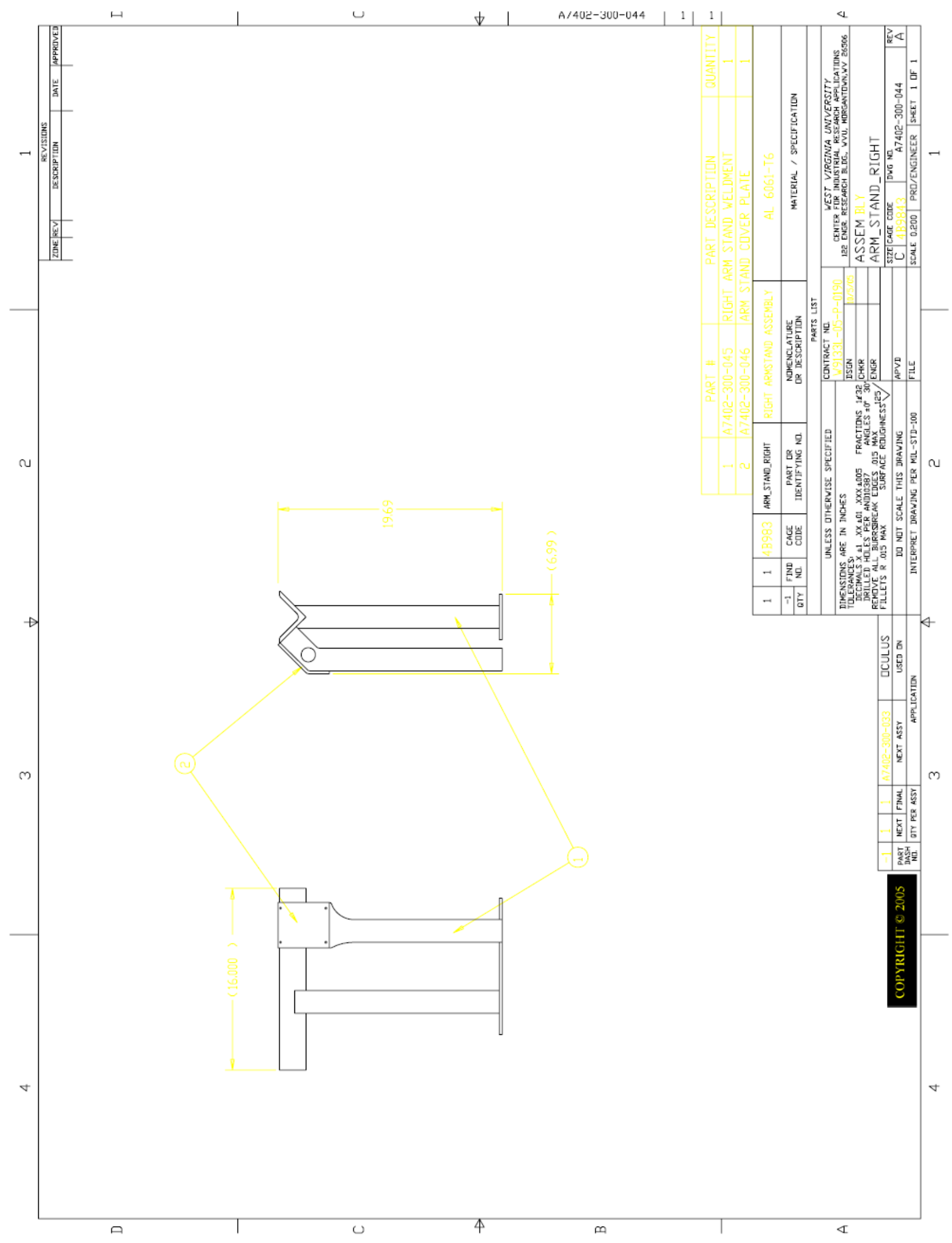




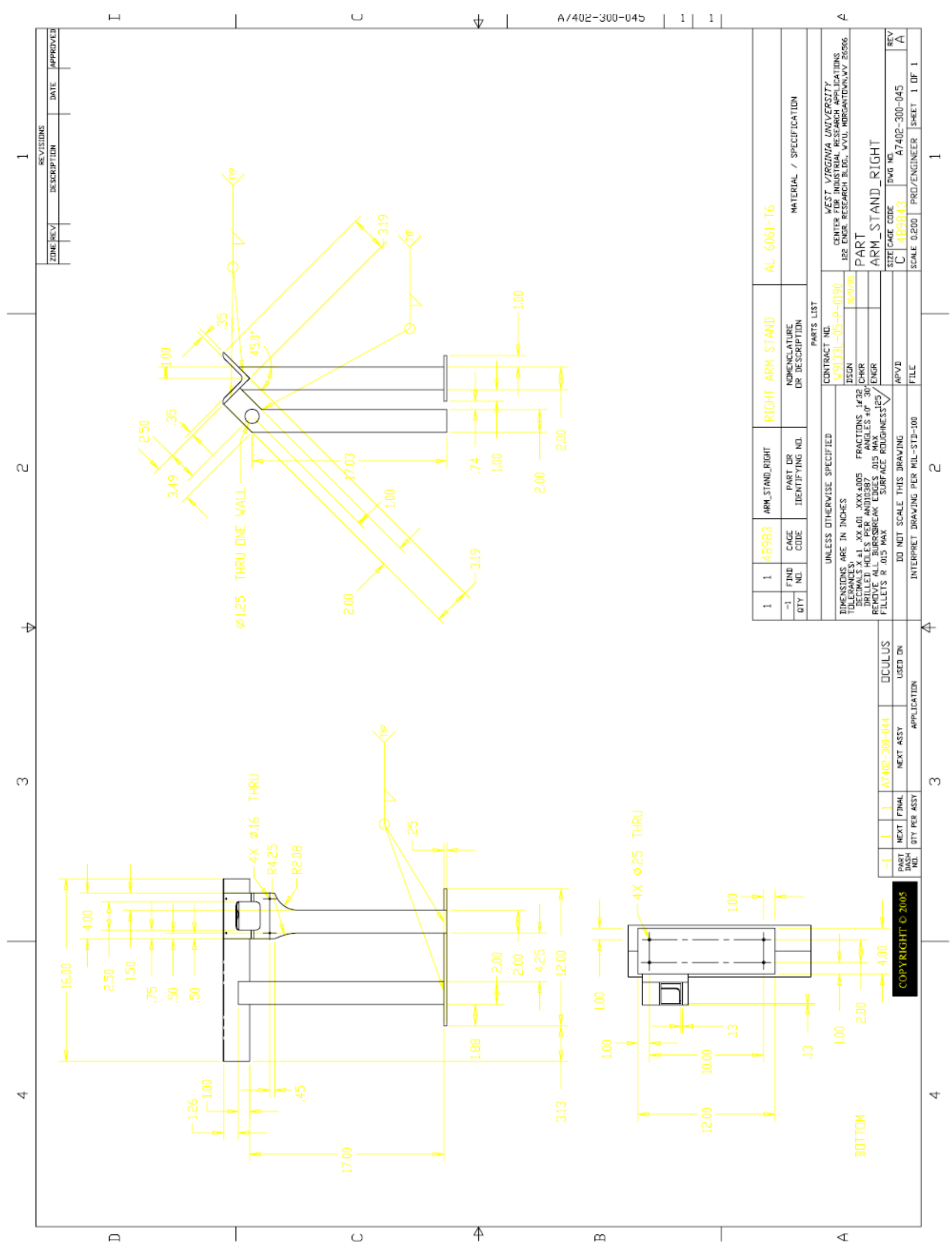




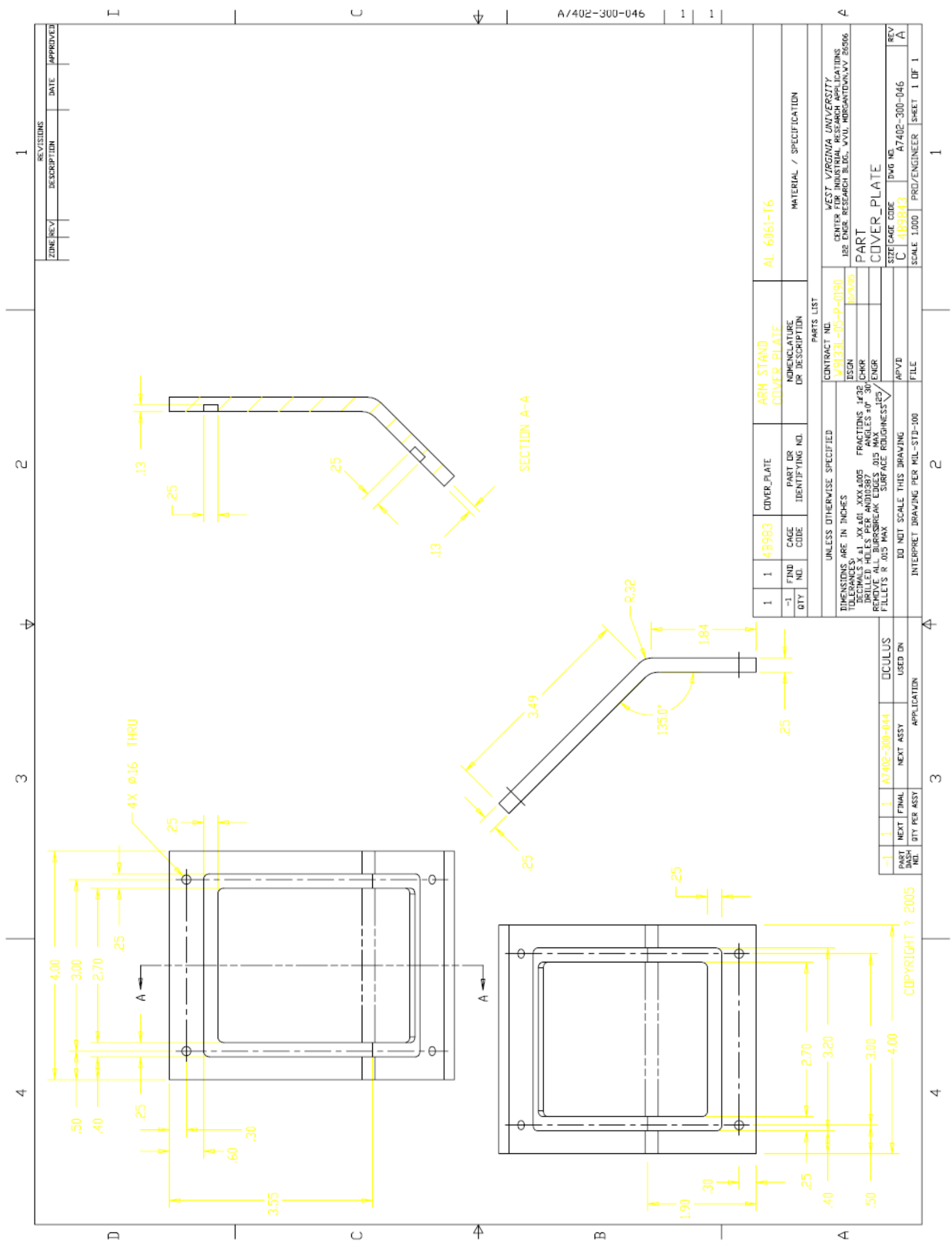




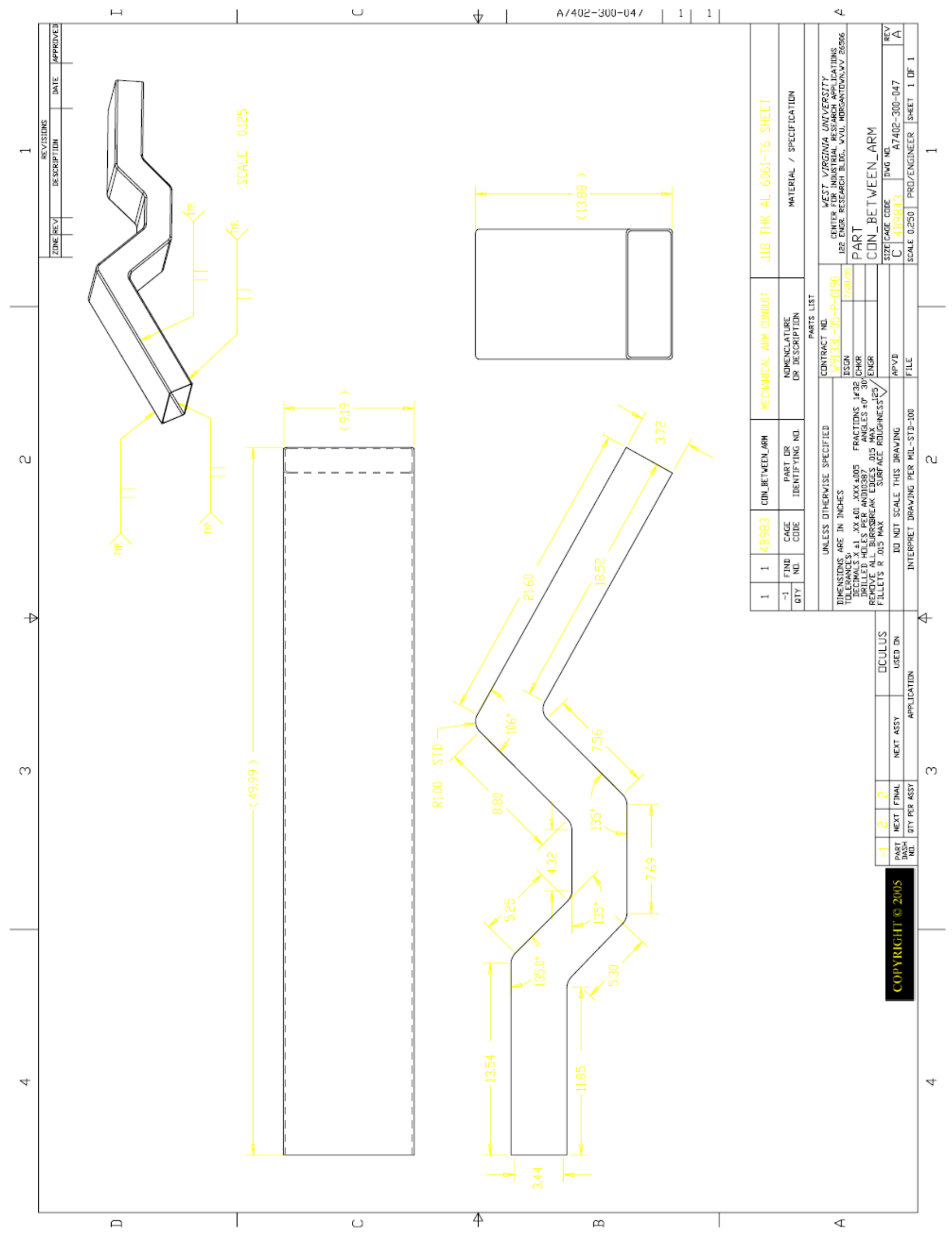




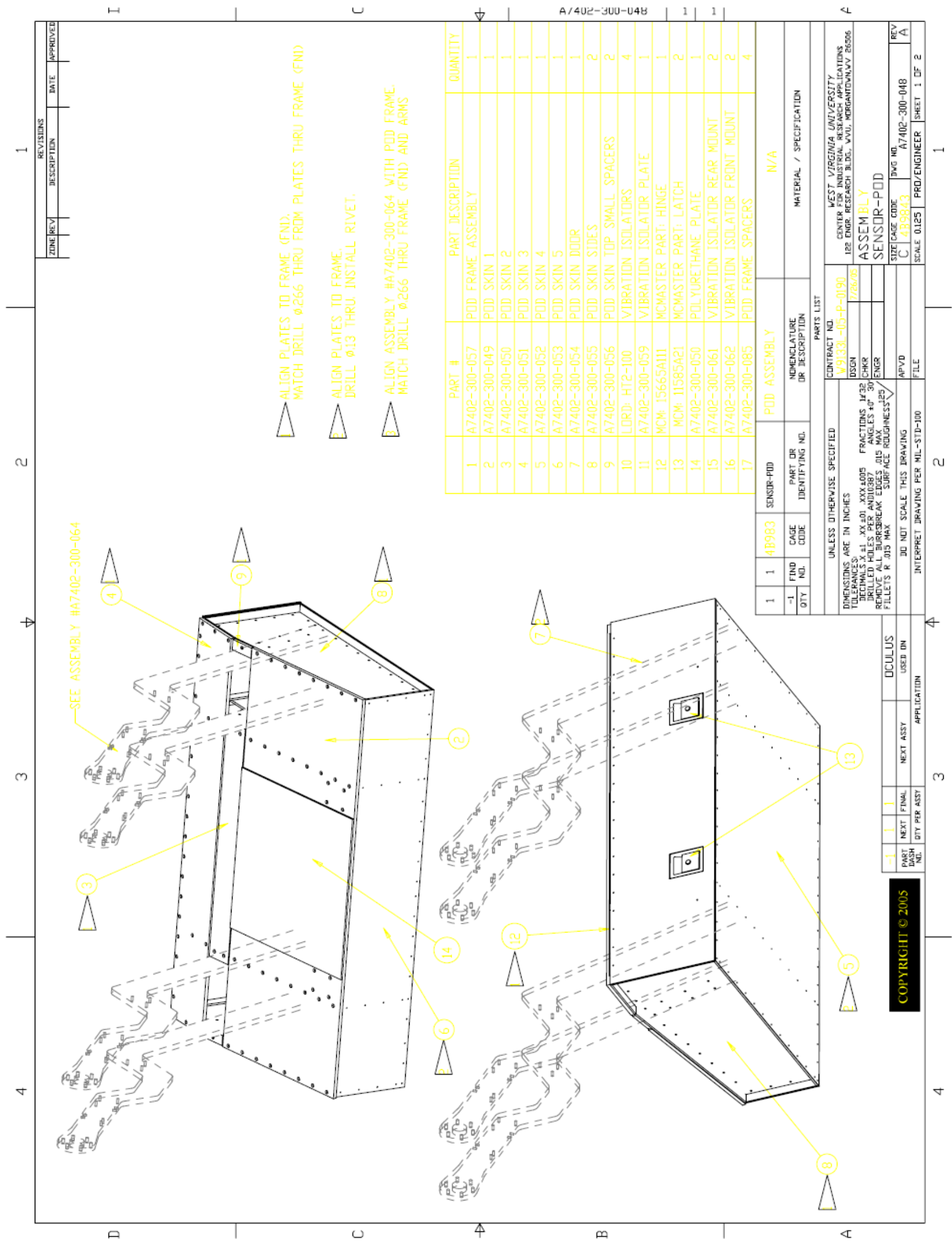




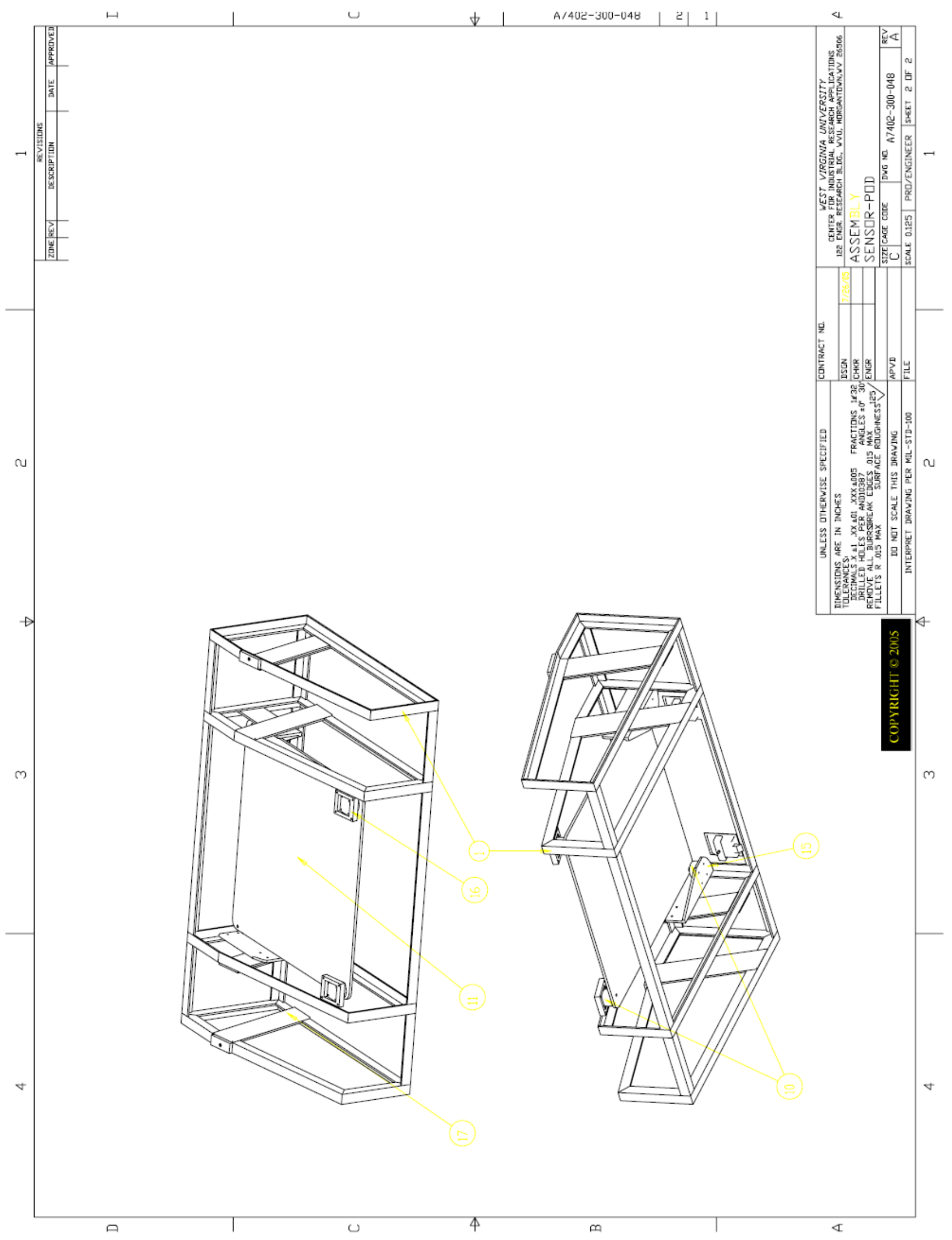




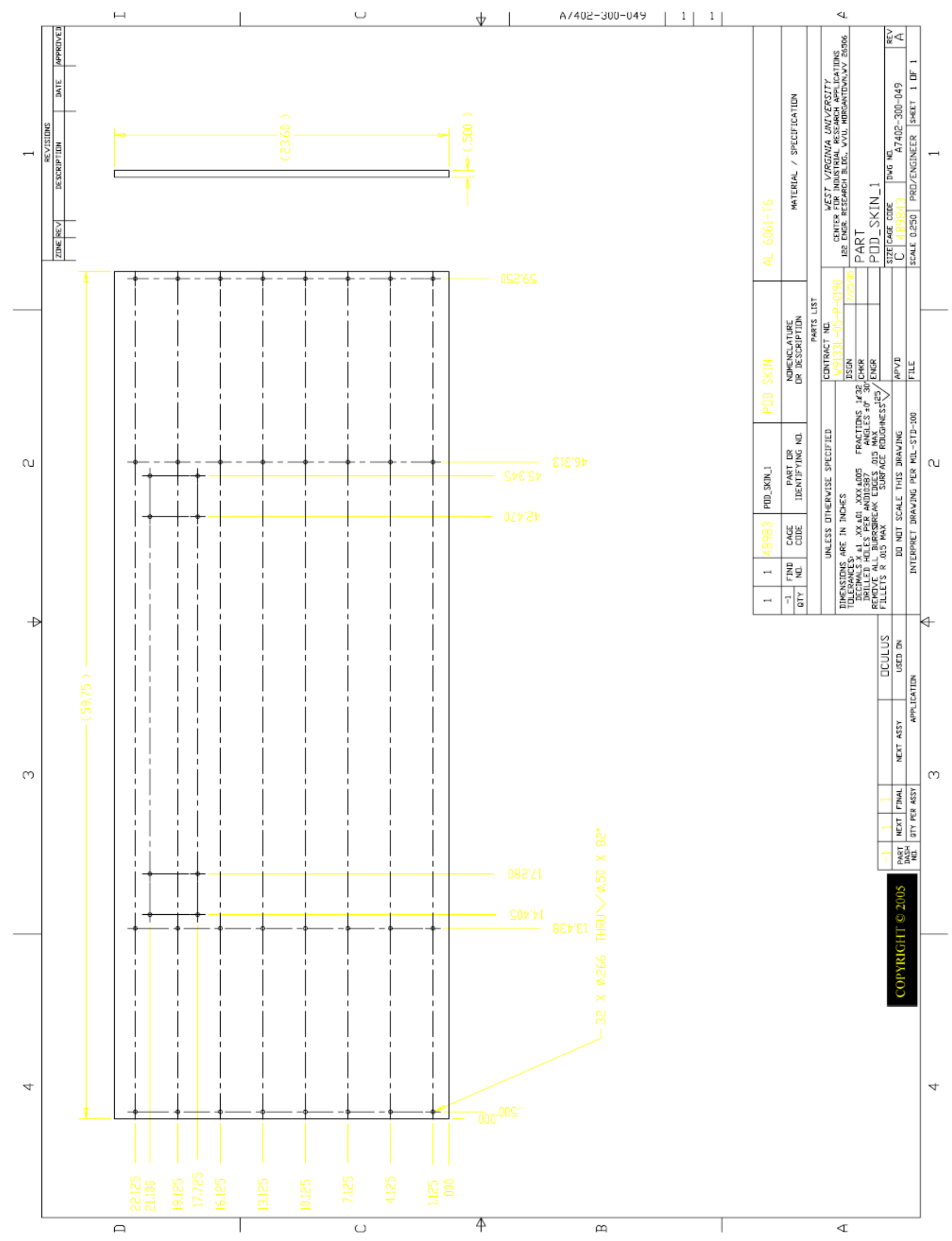




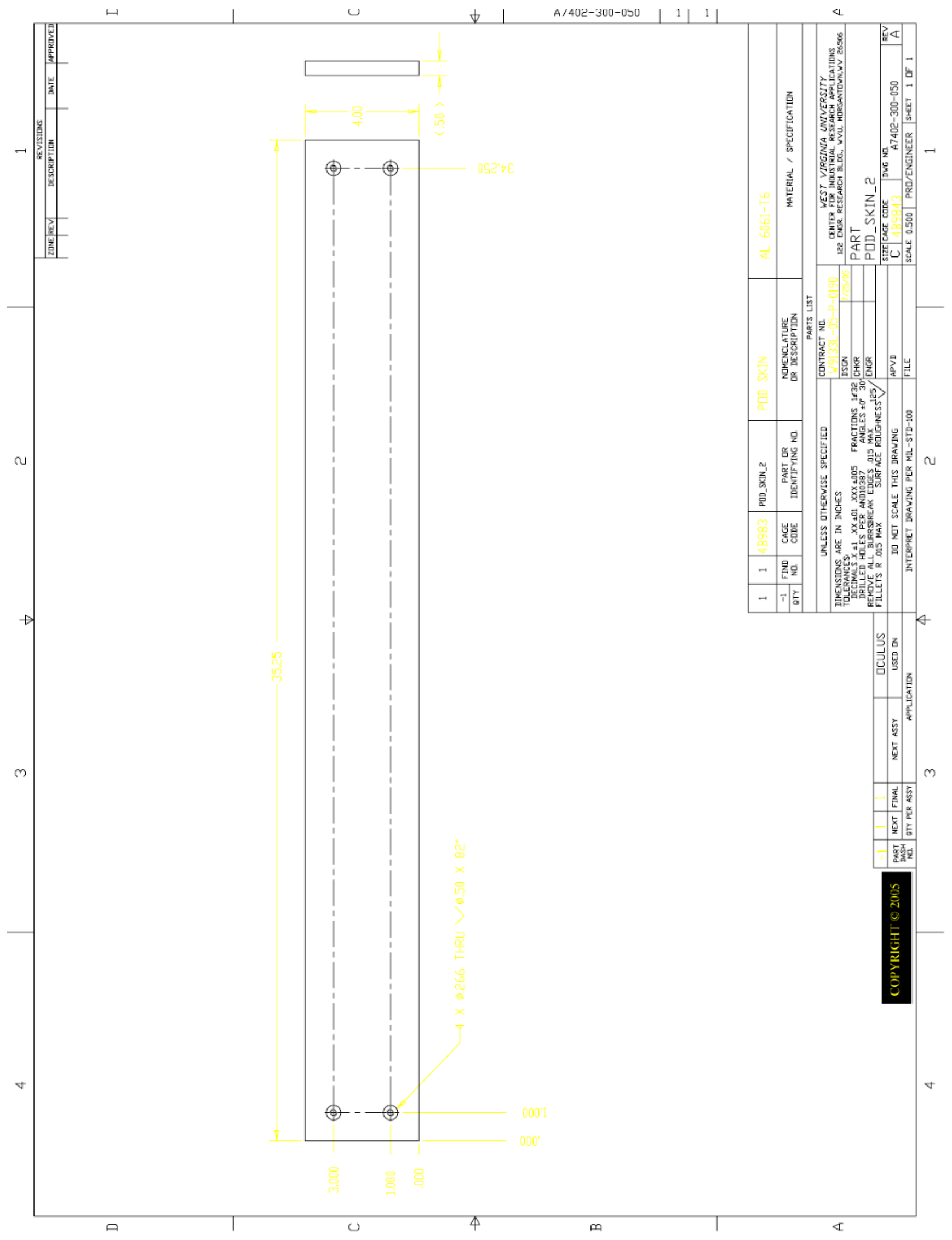




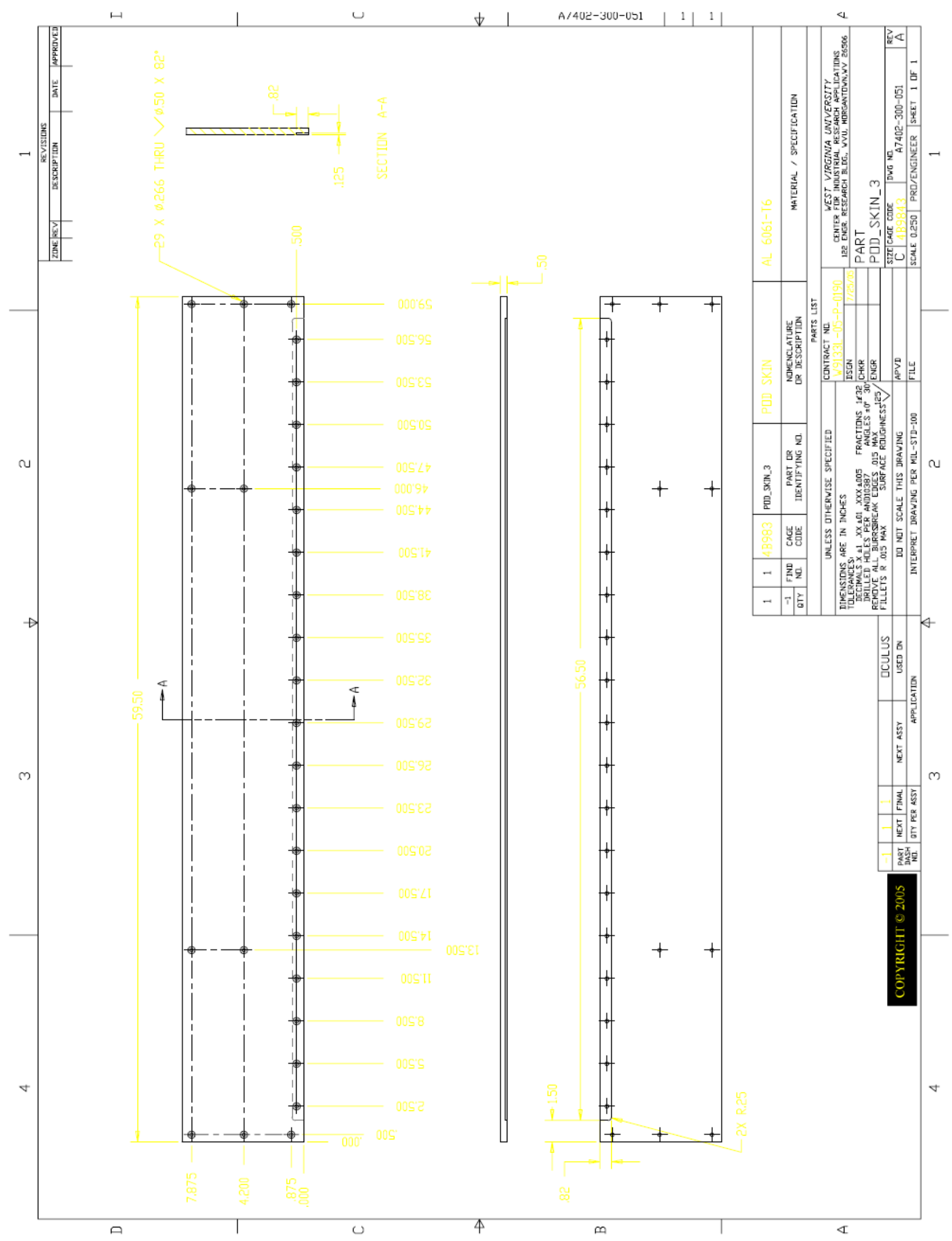




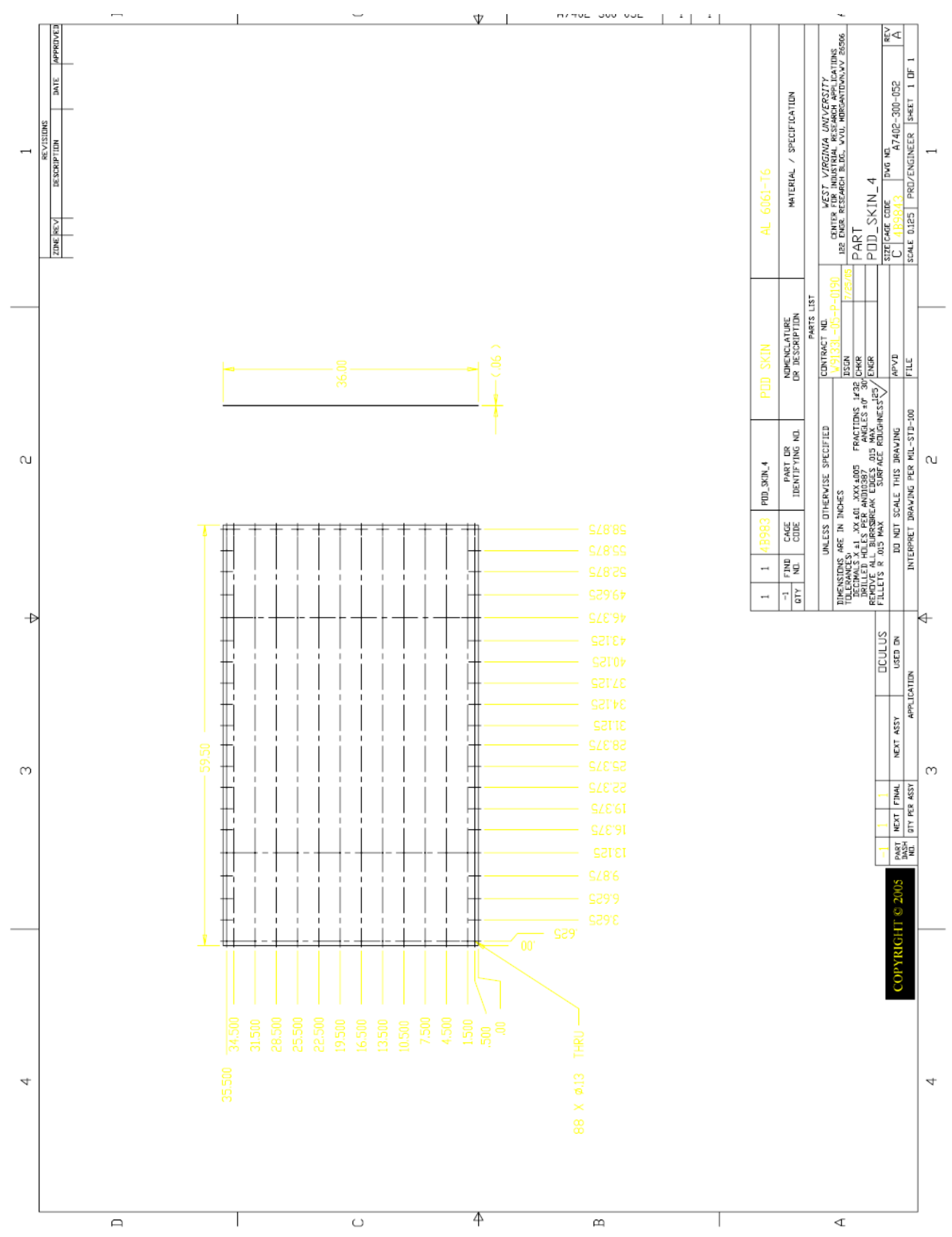




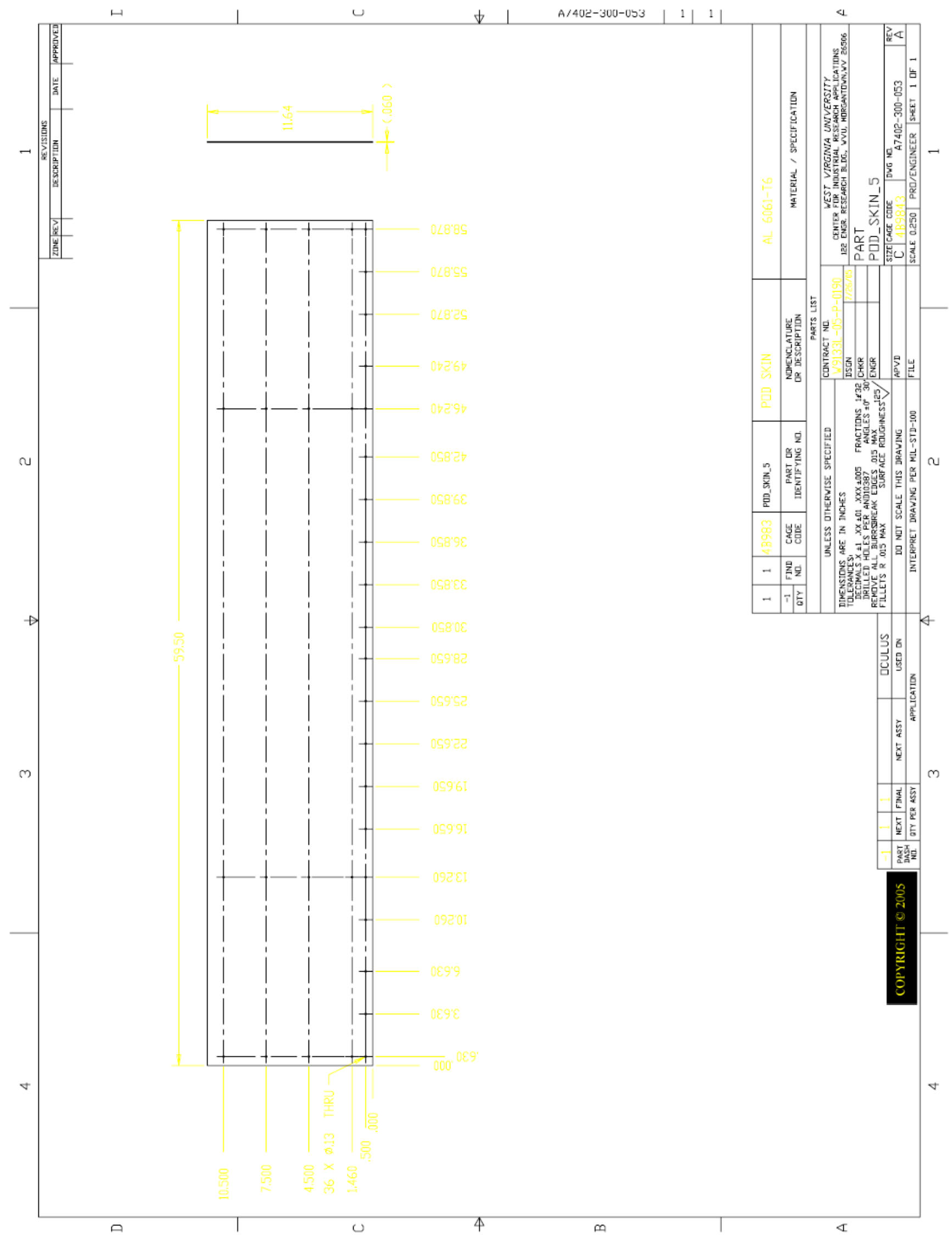




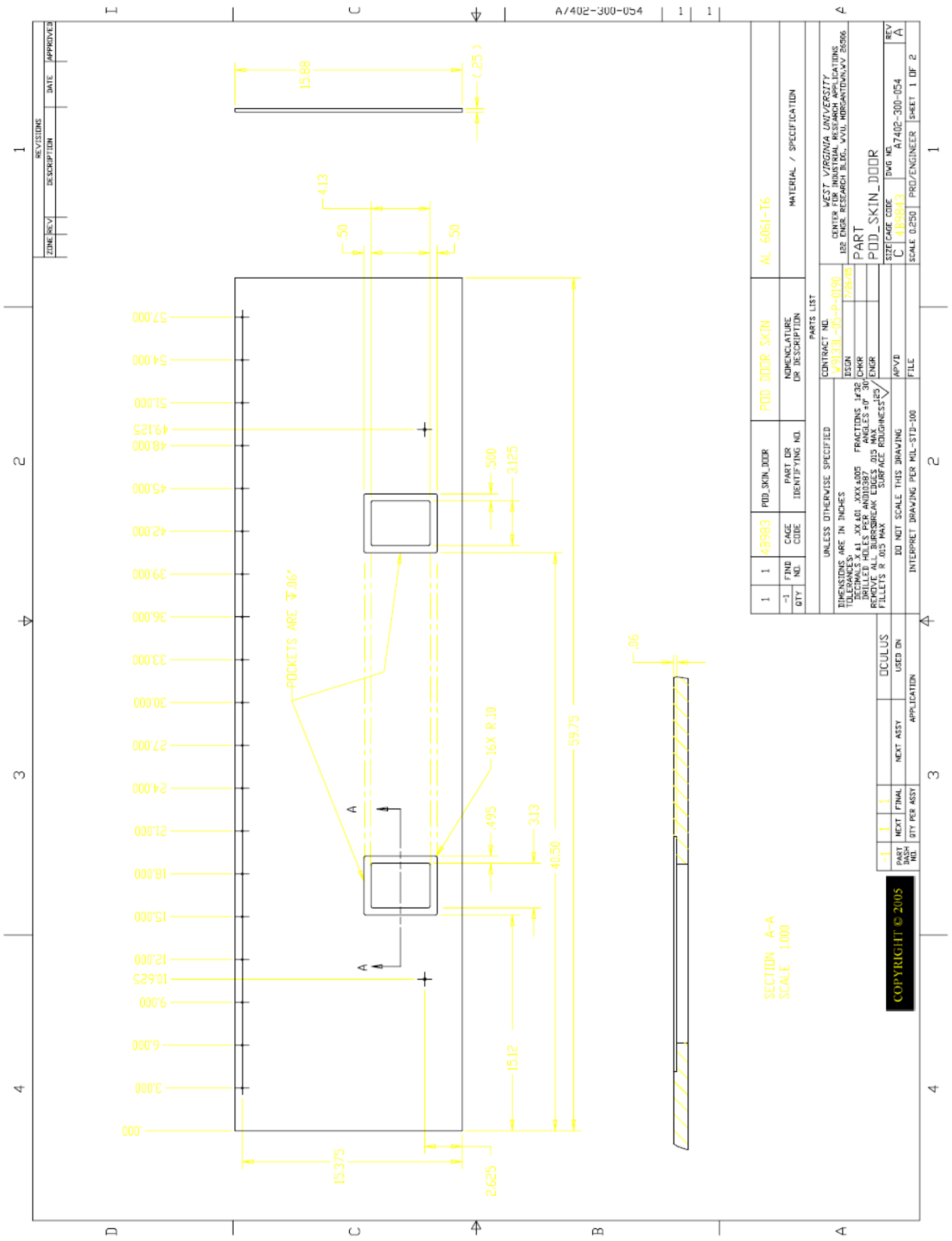

166 


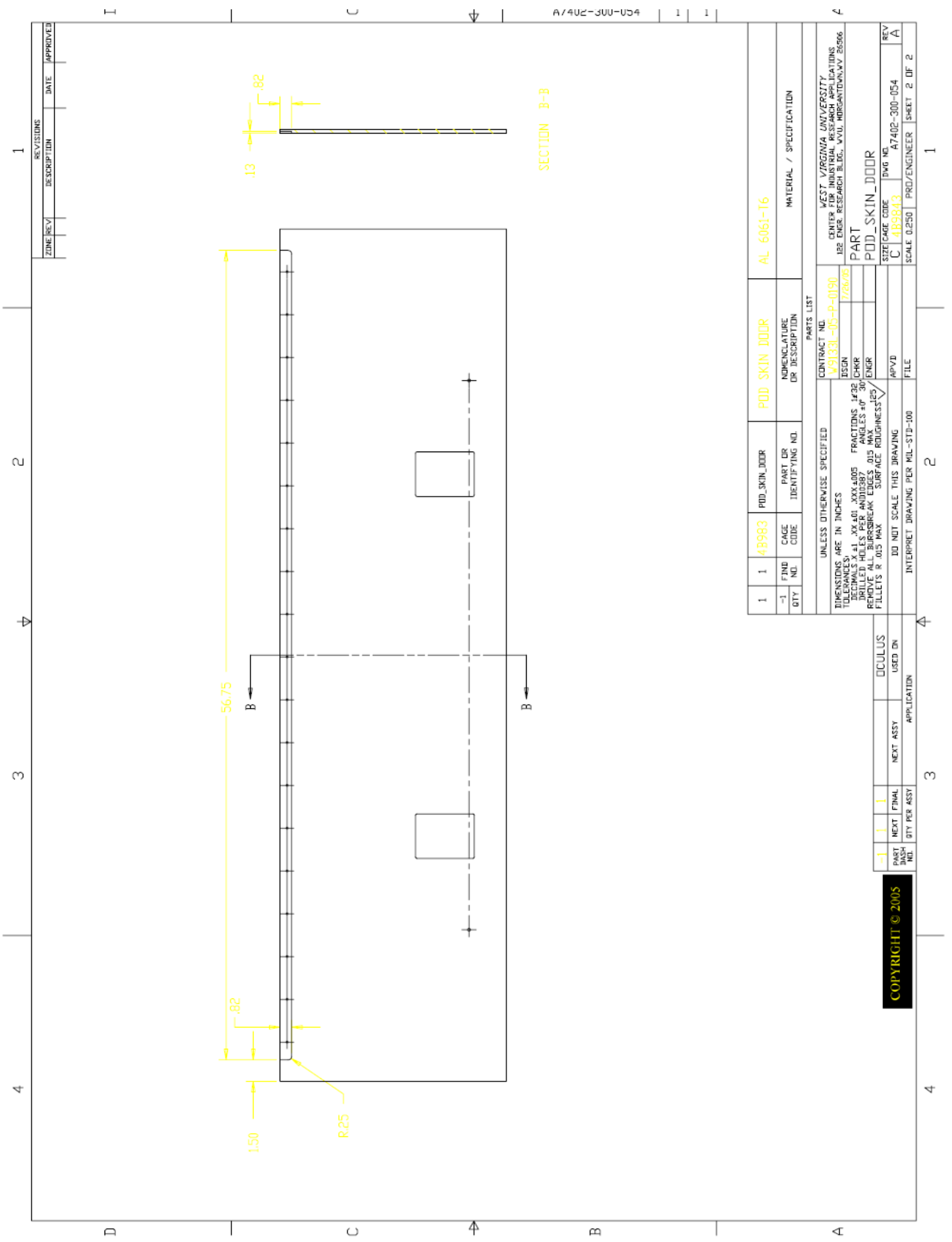

167 


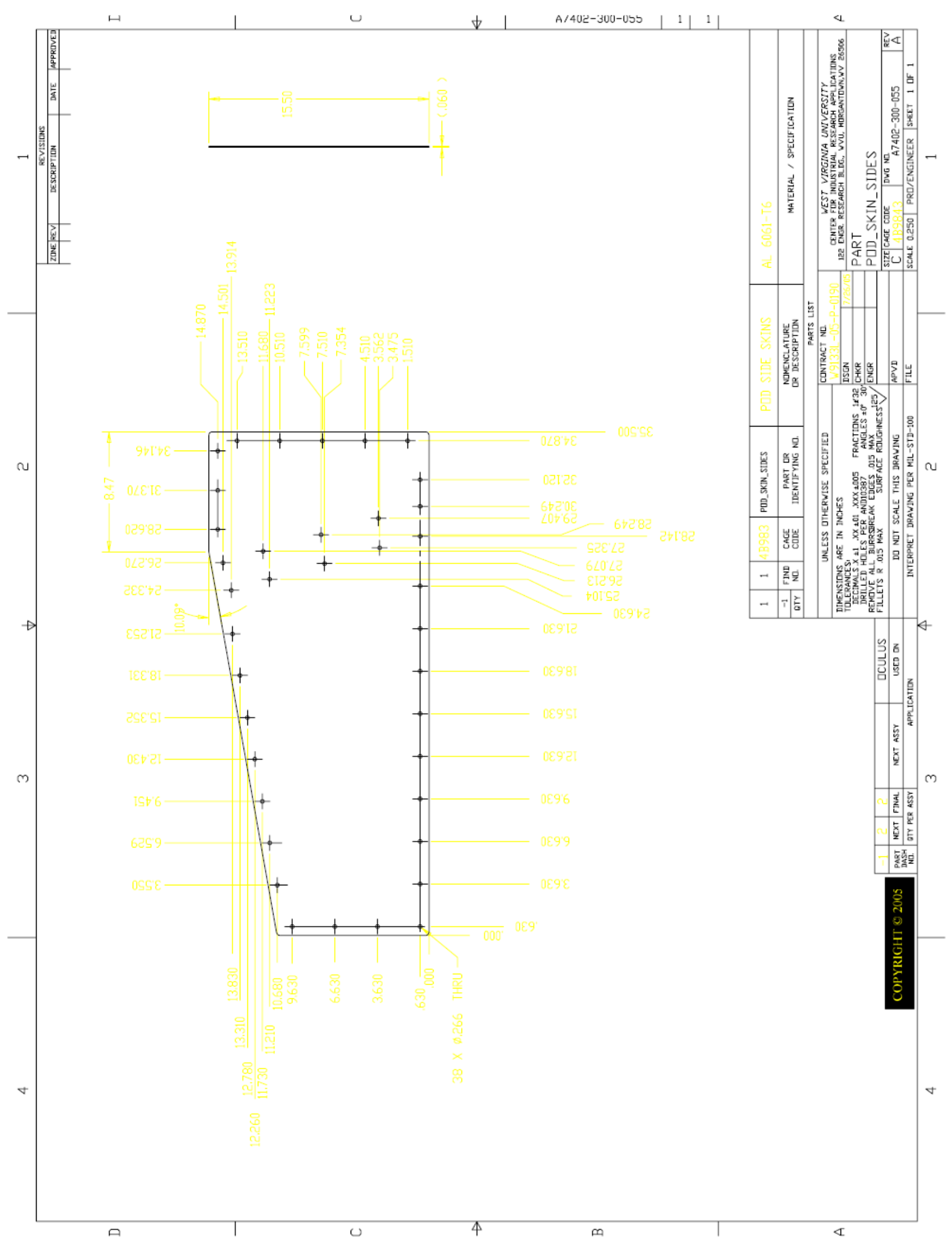




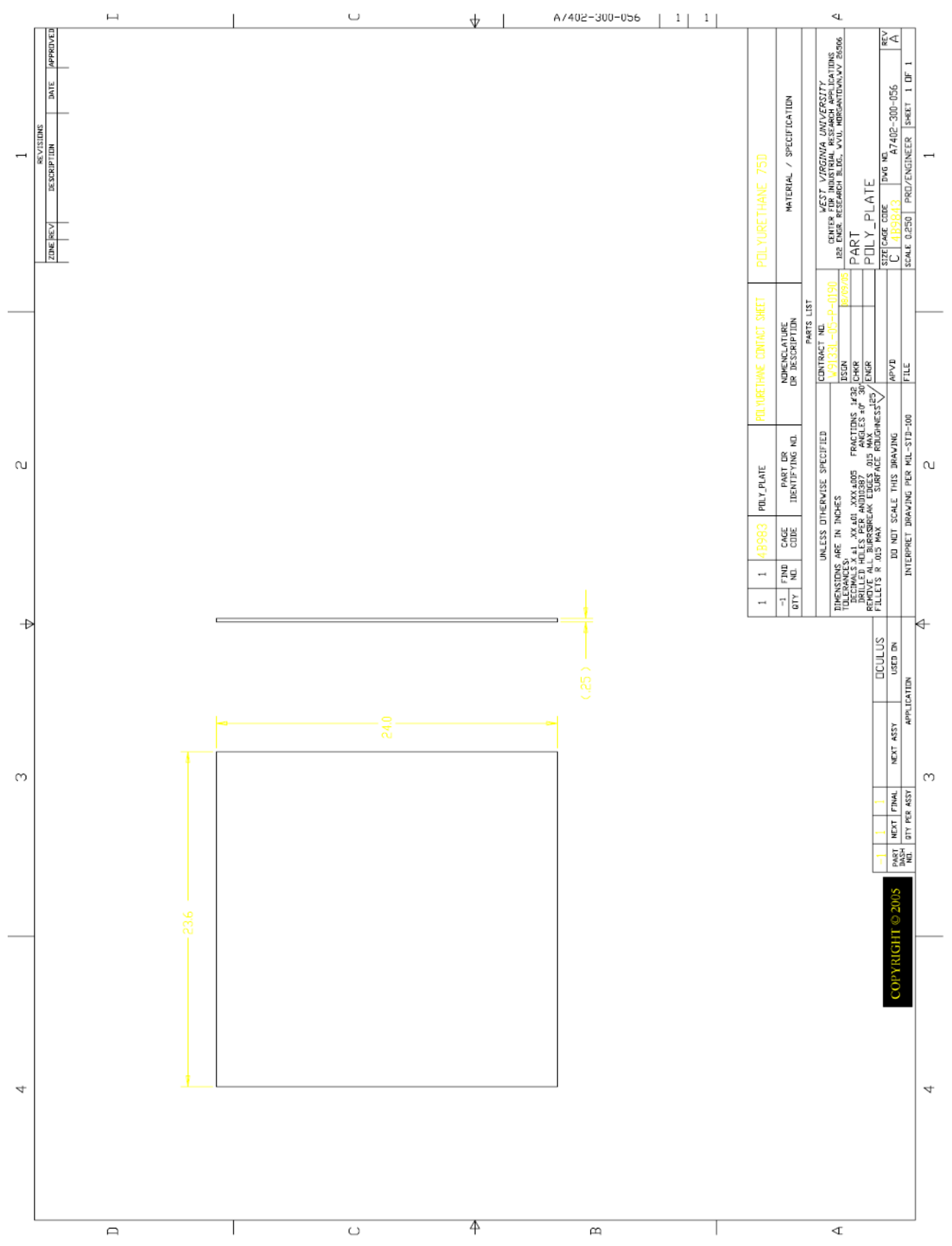




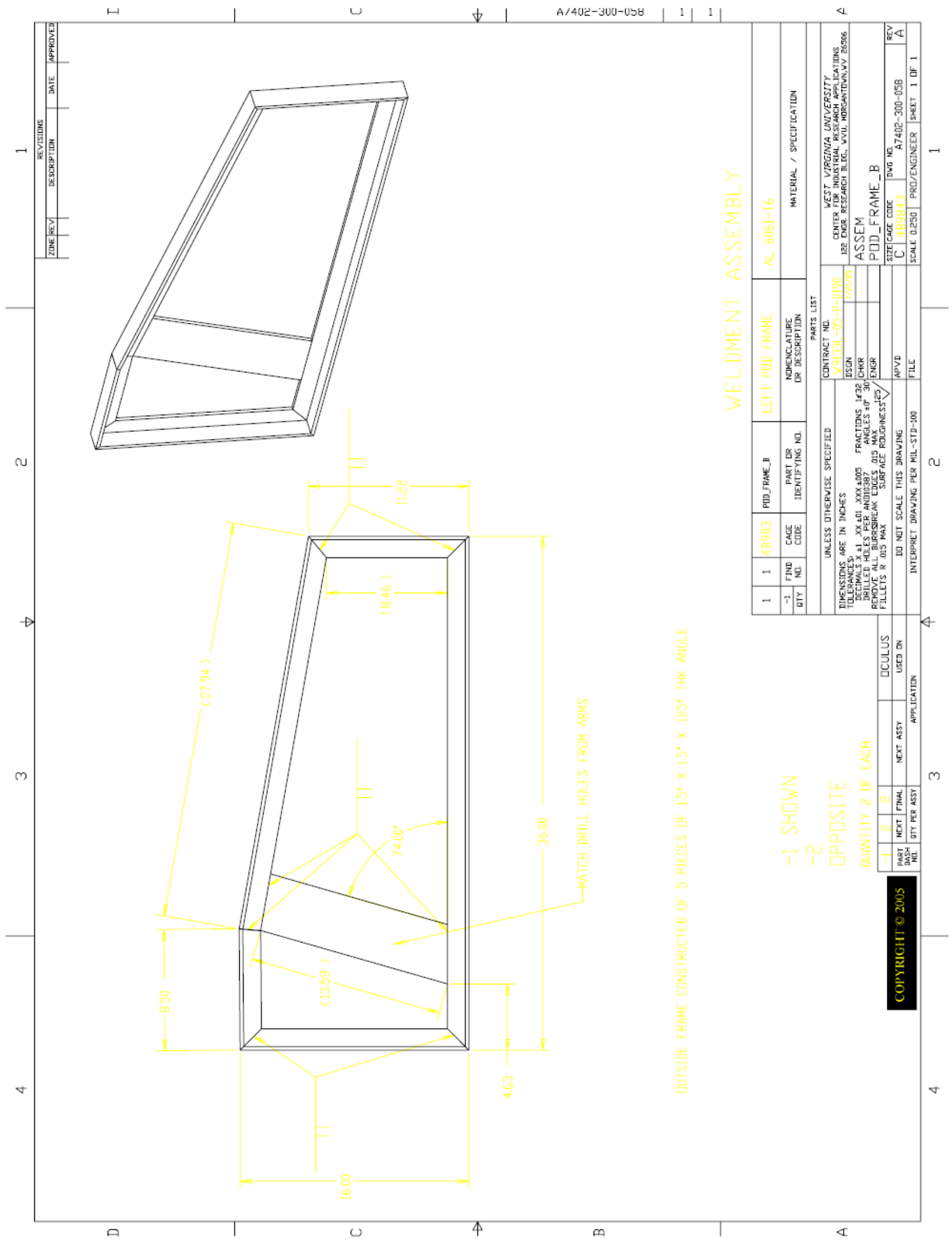

170 



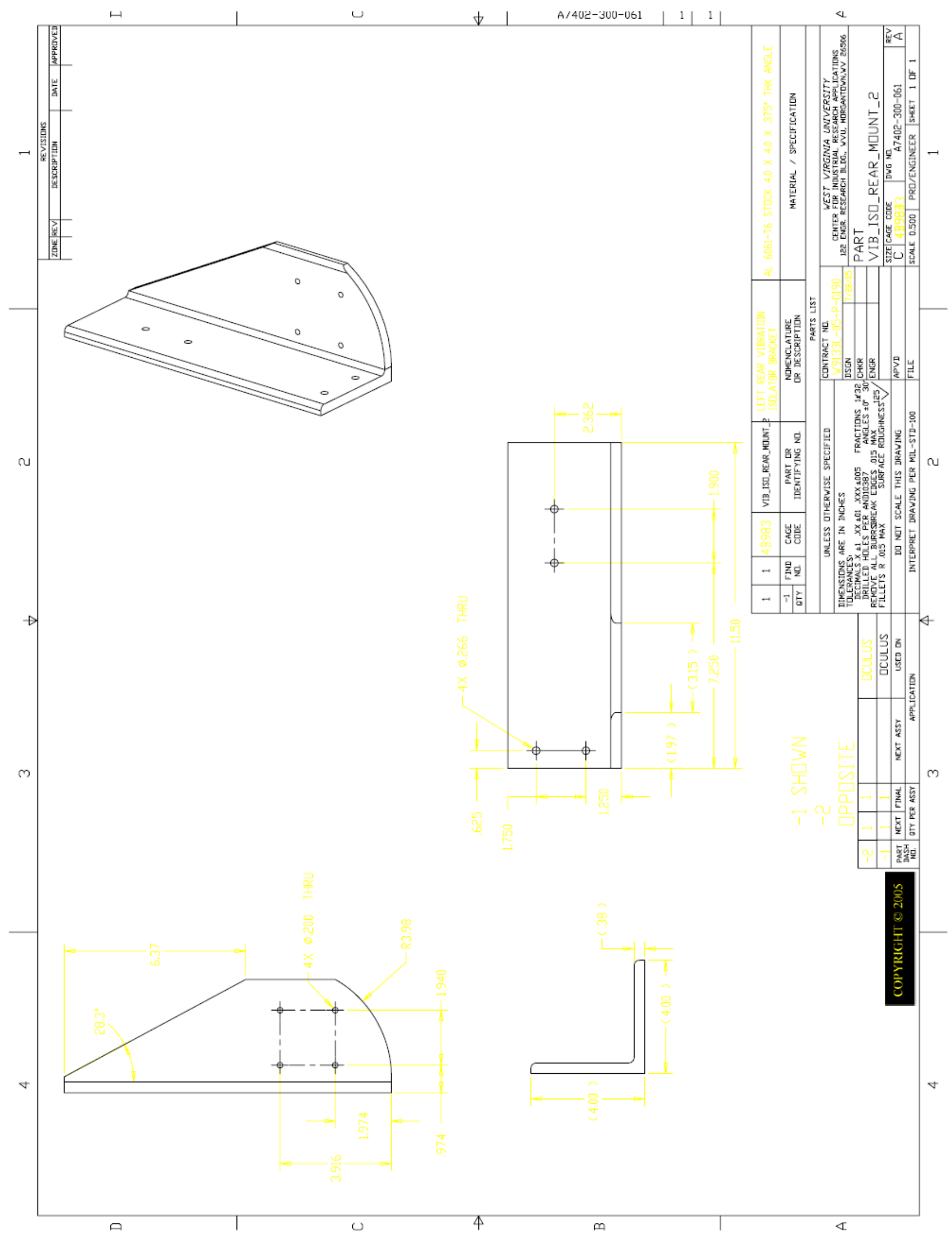




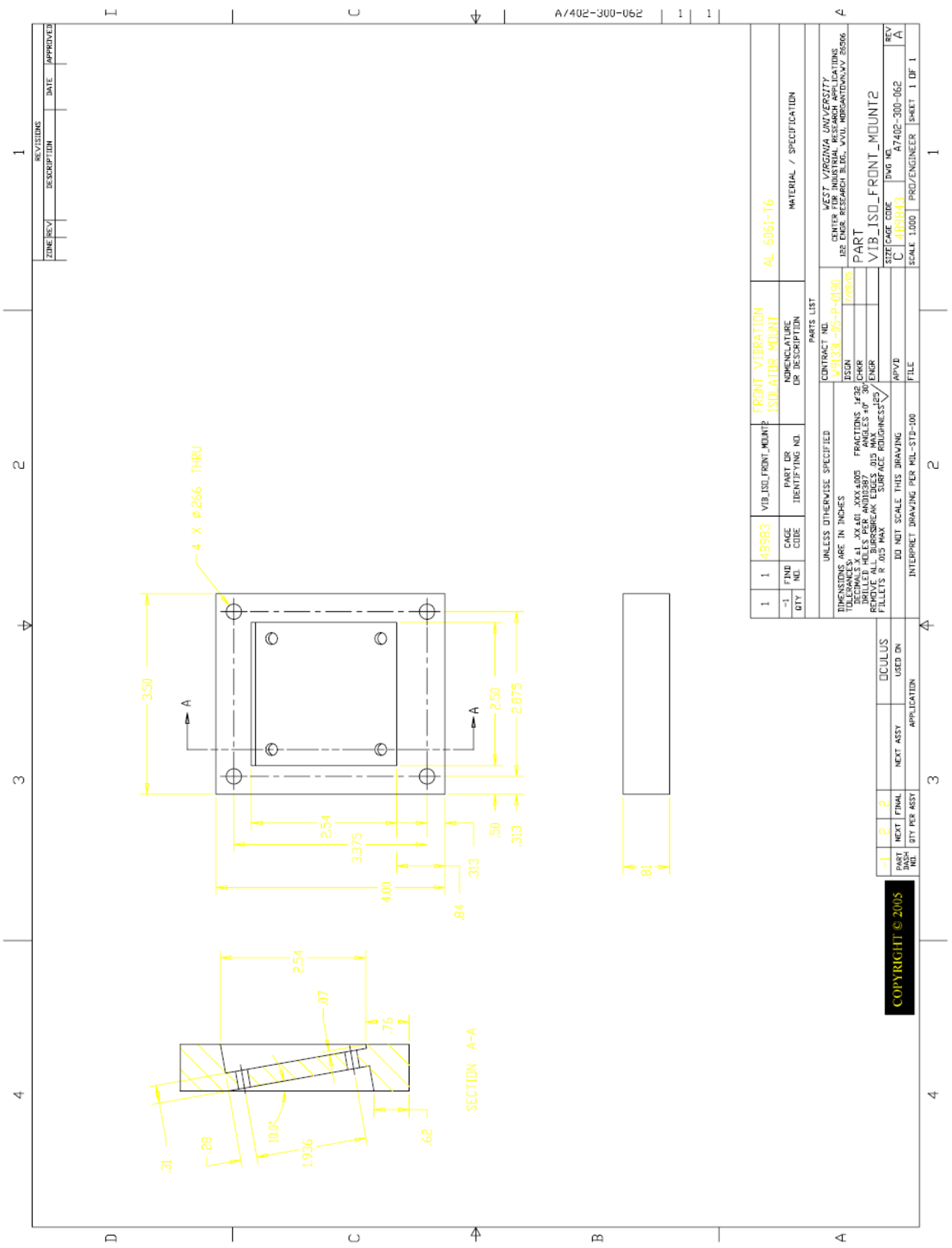

173 


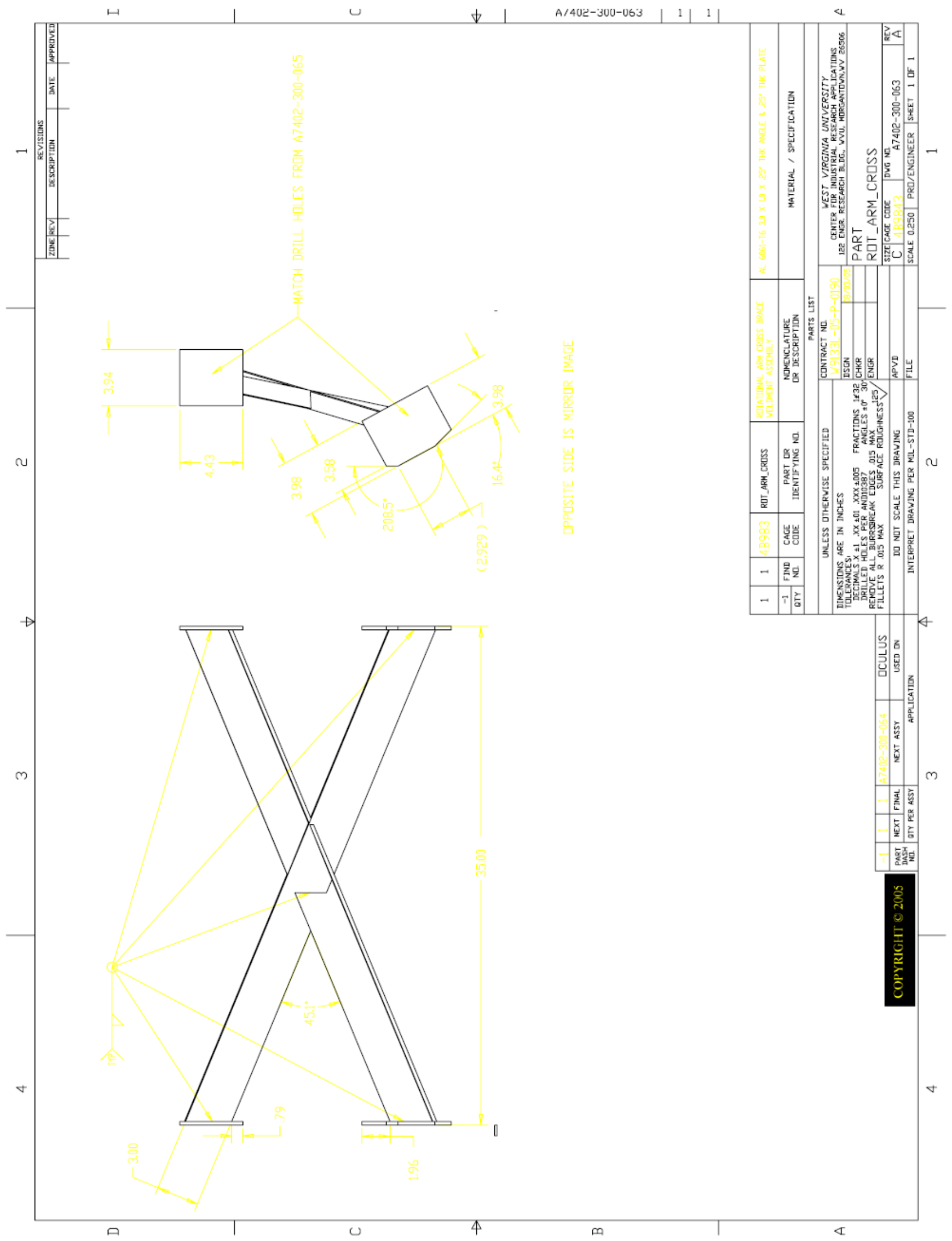

174 


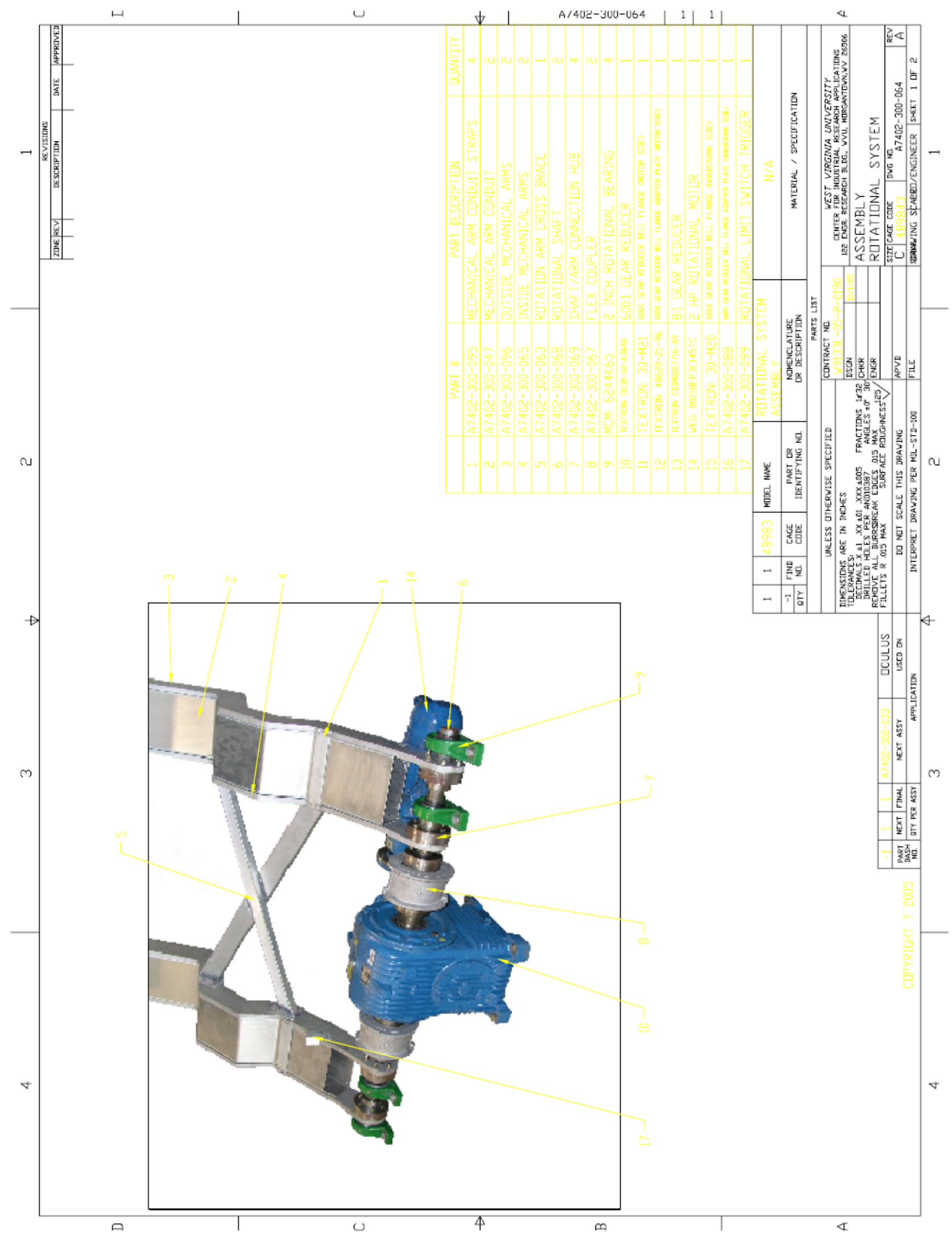




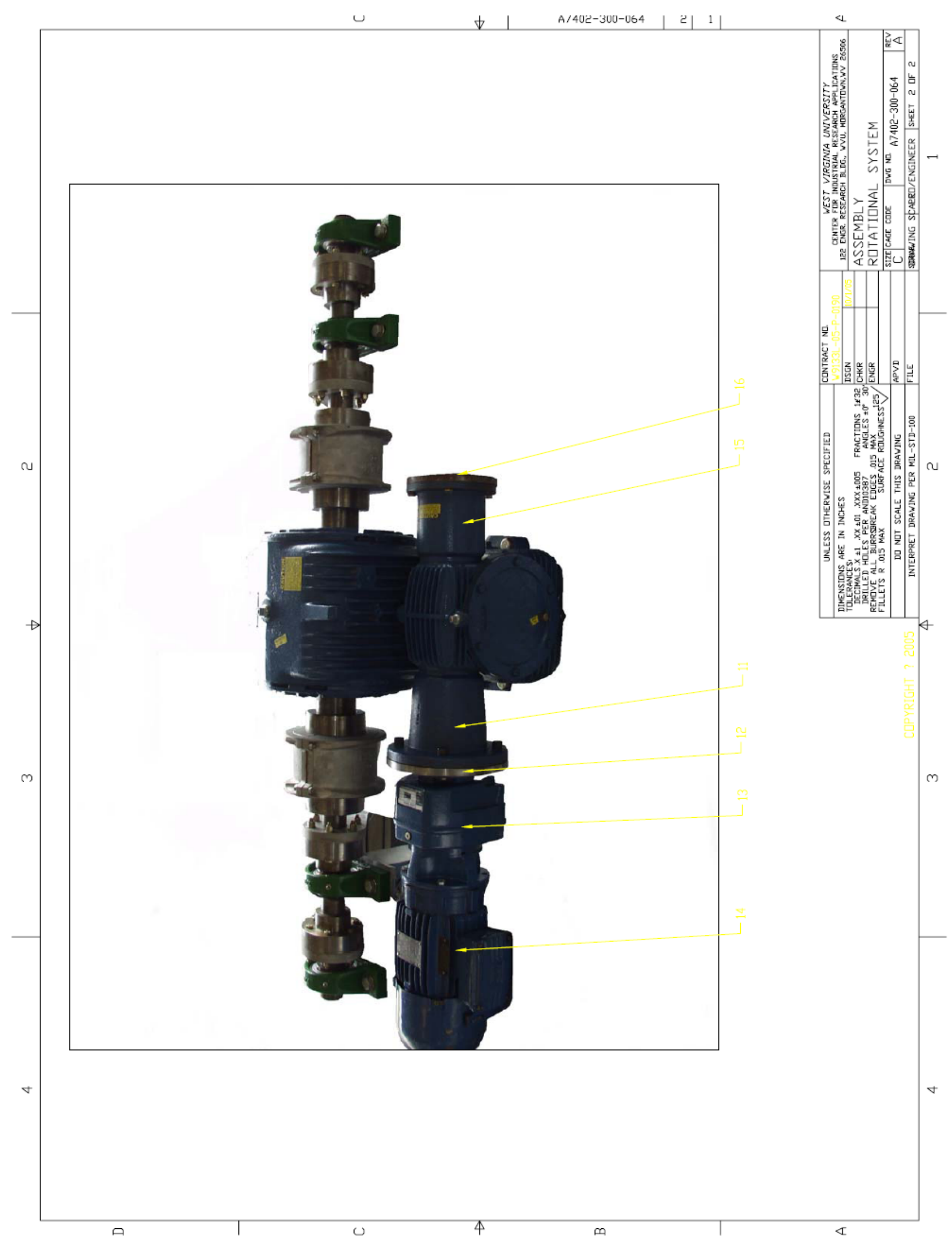




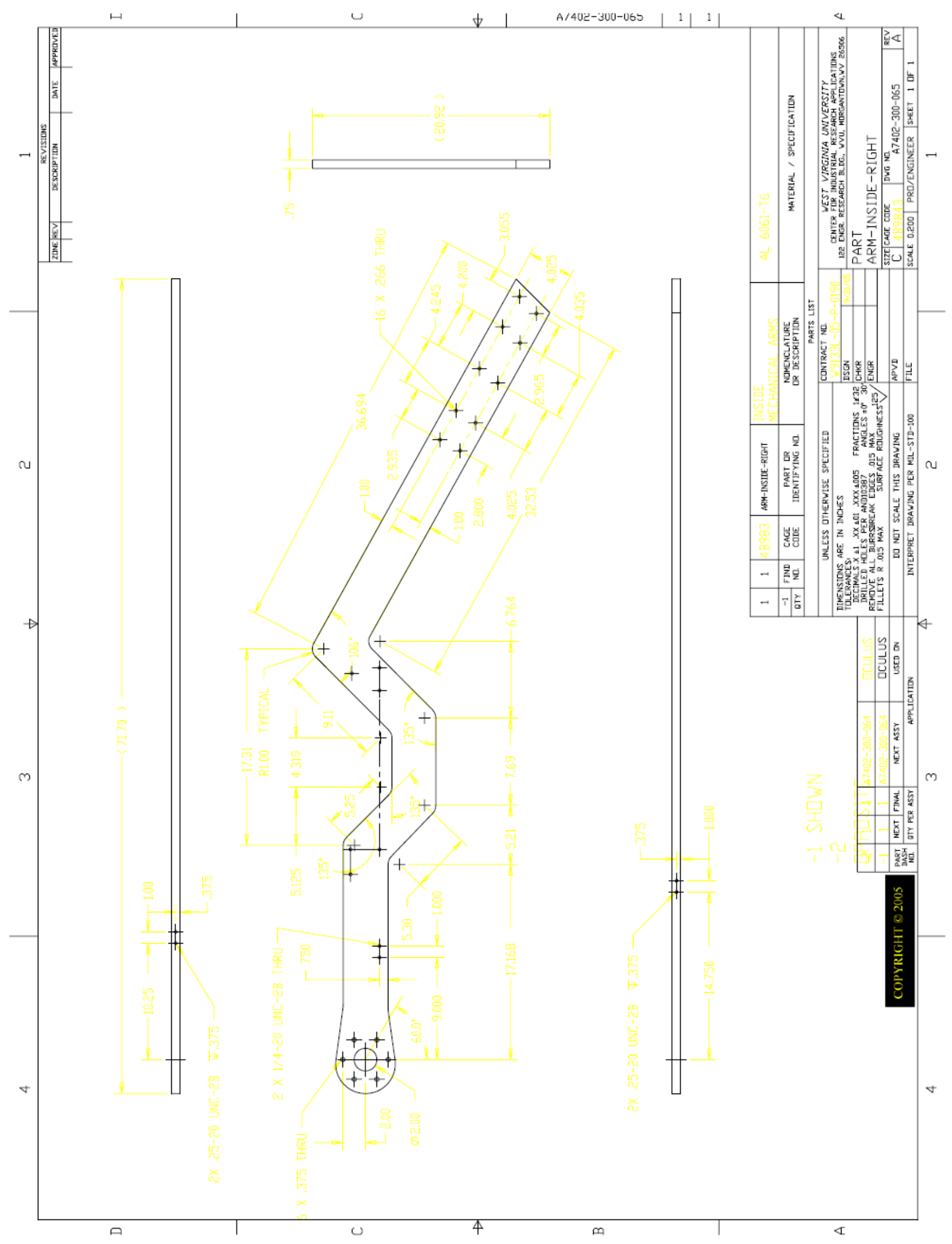




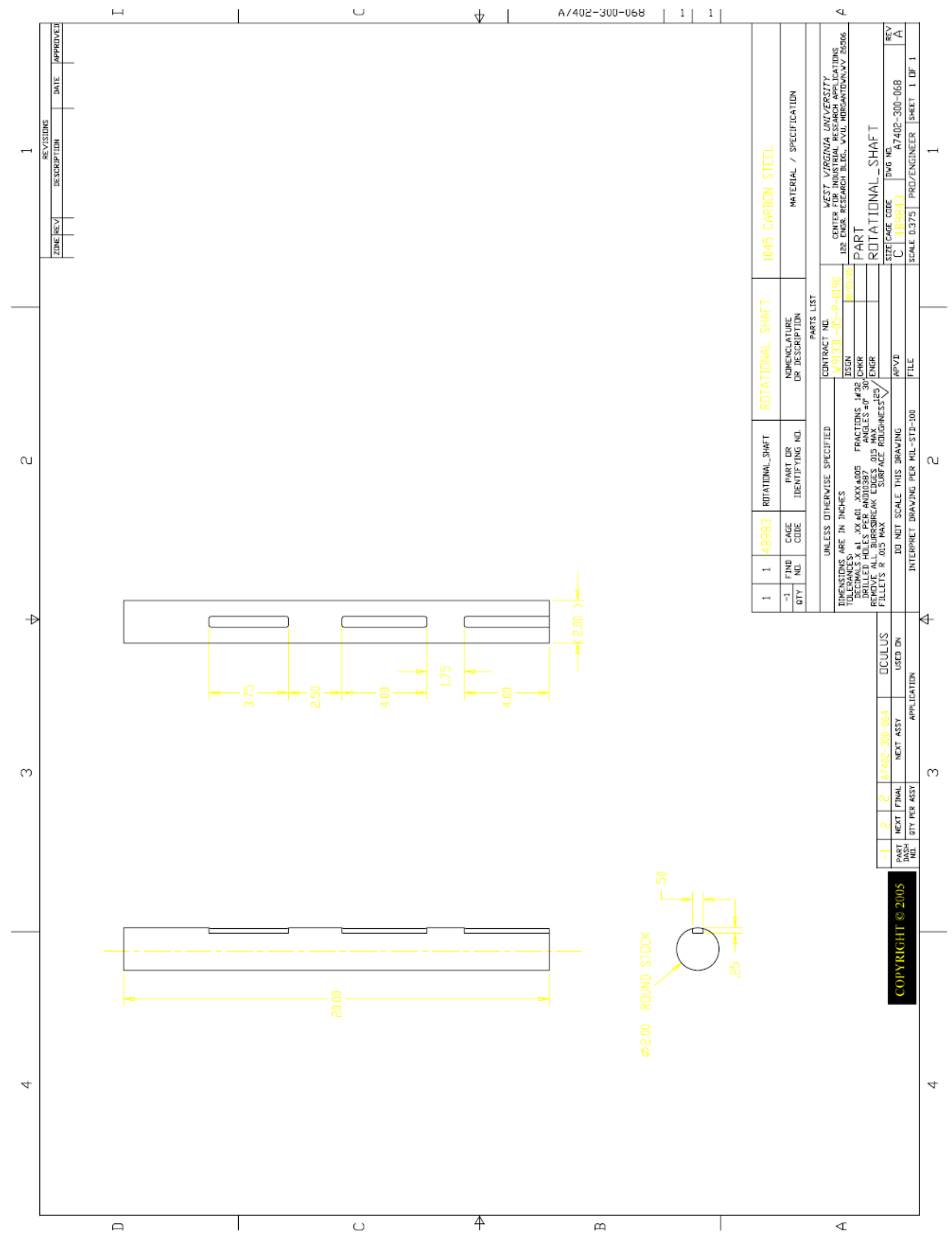




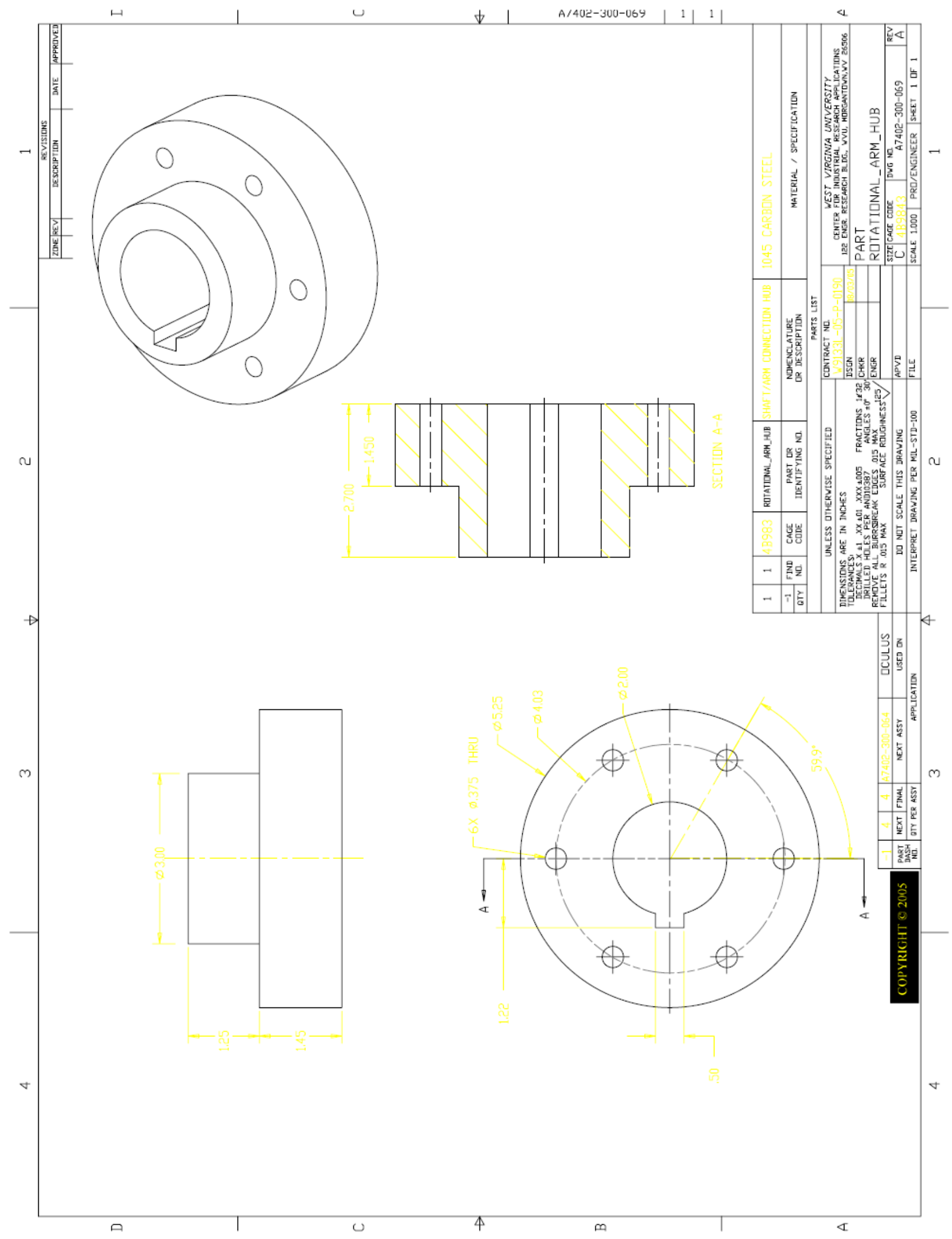




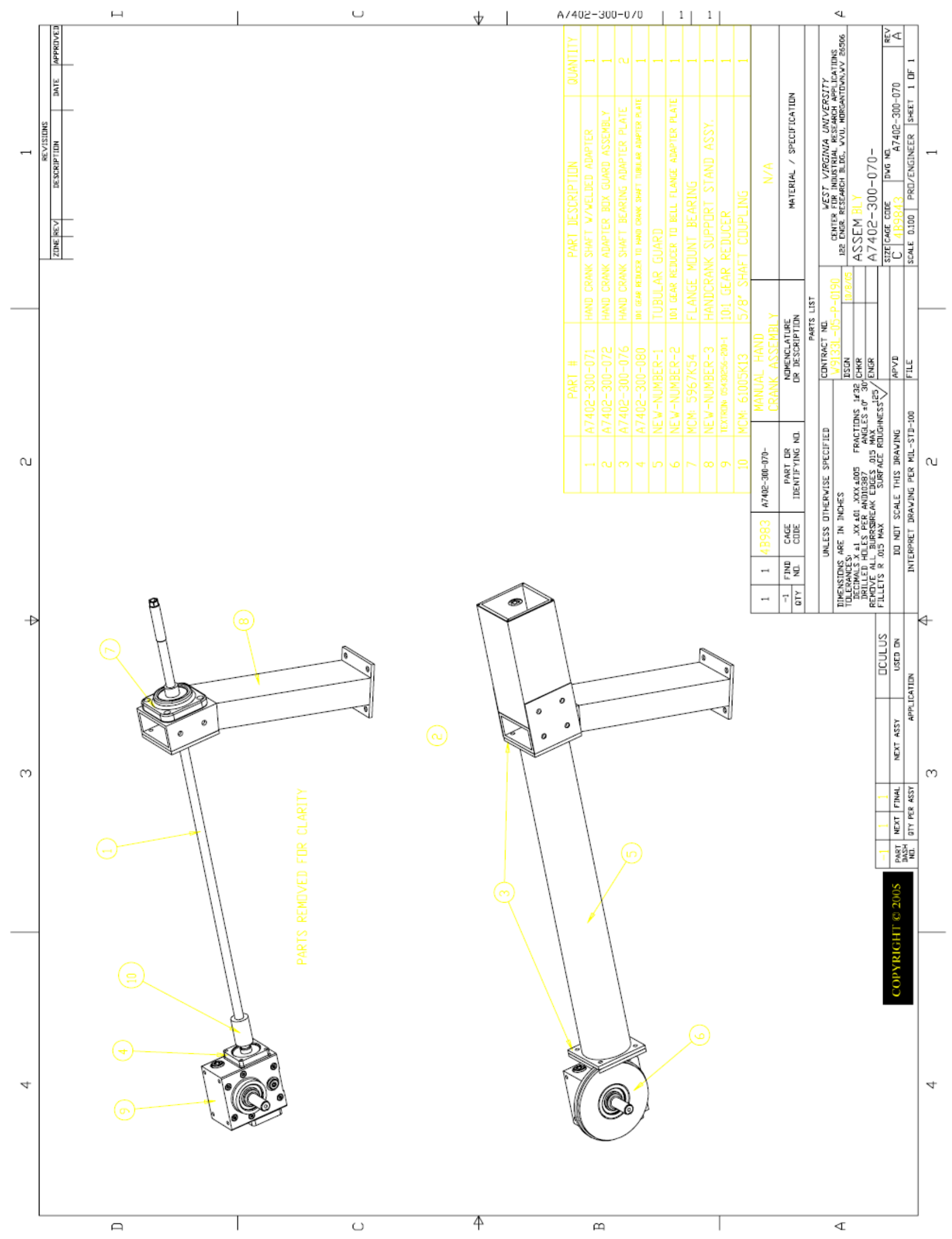




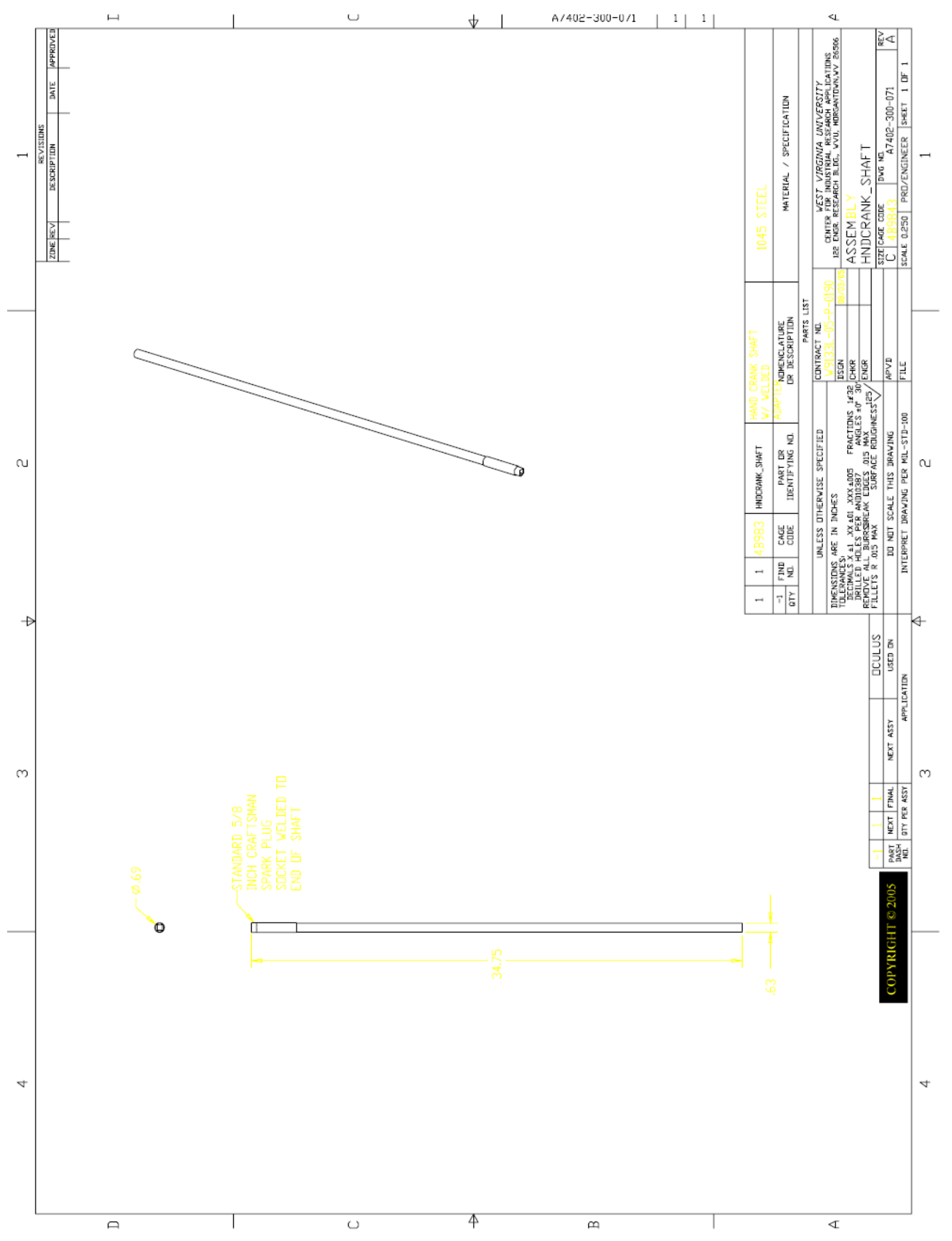




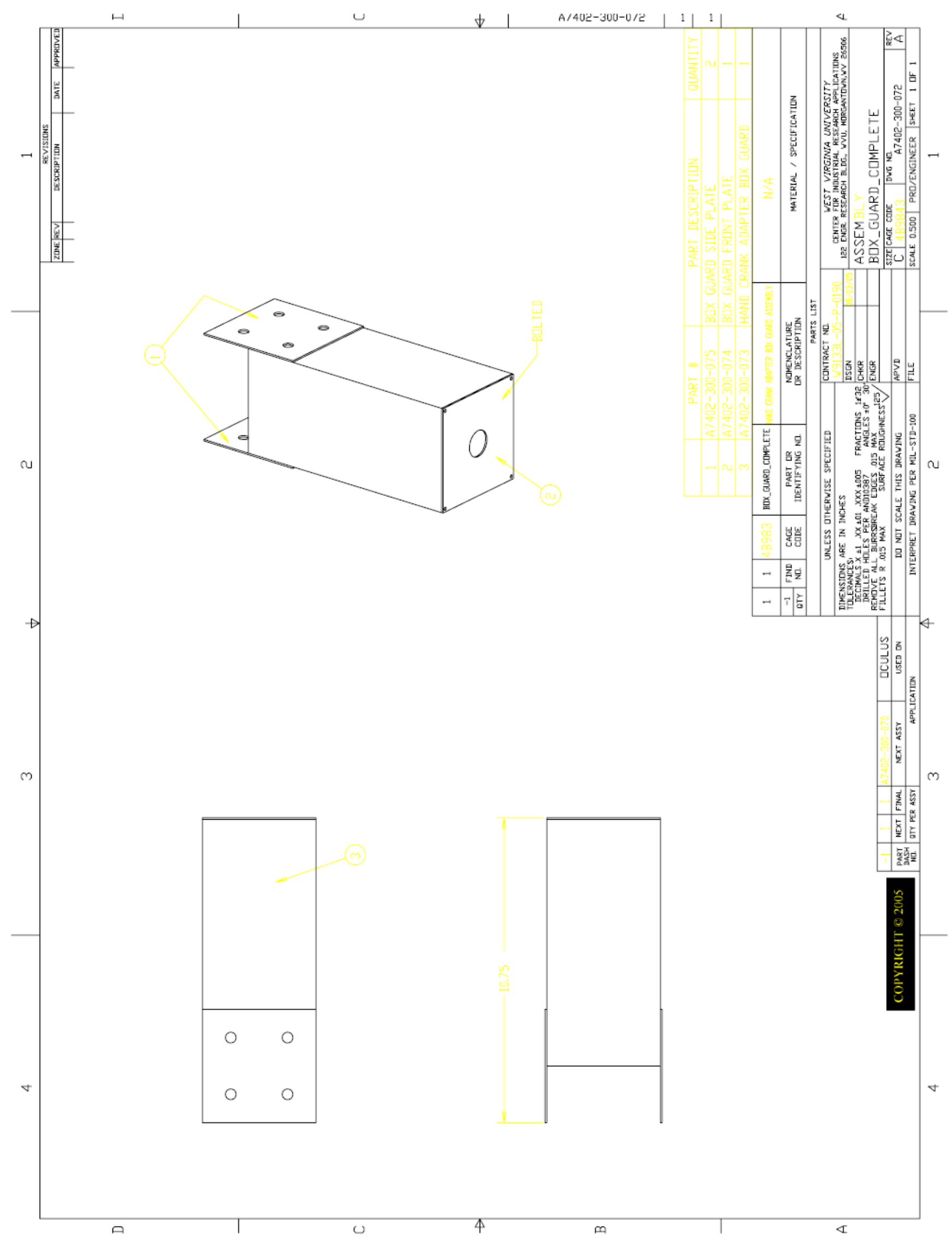




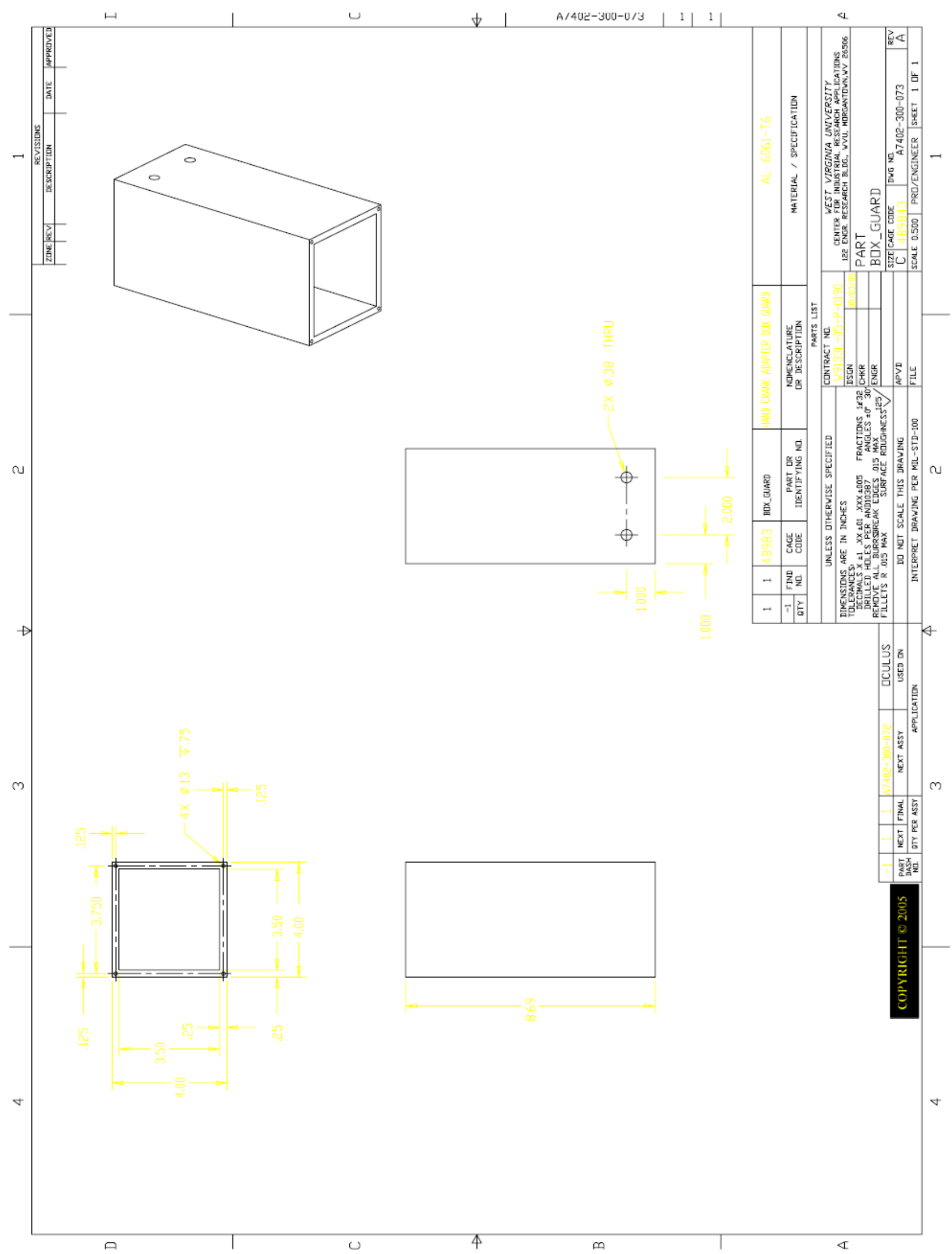




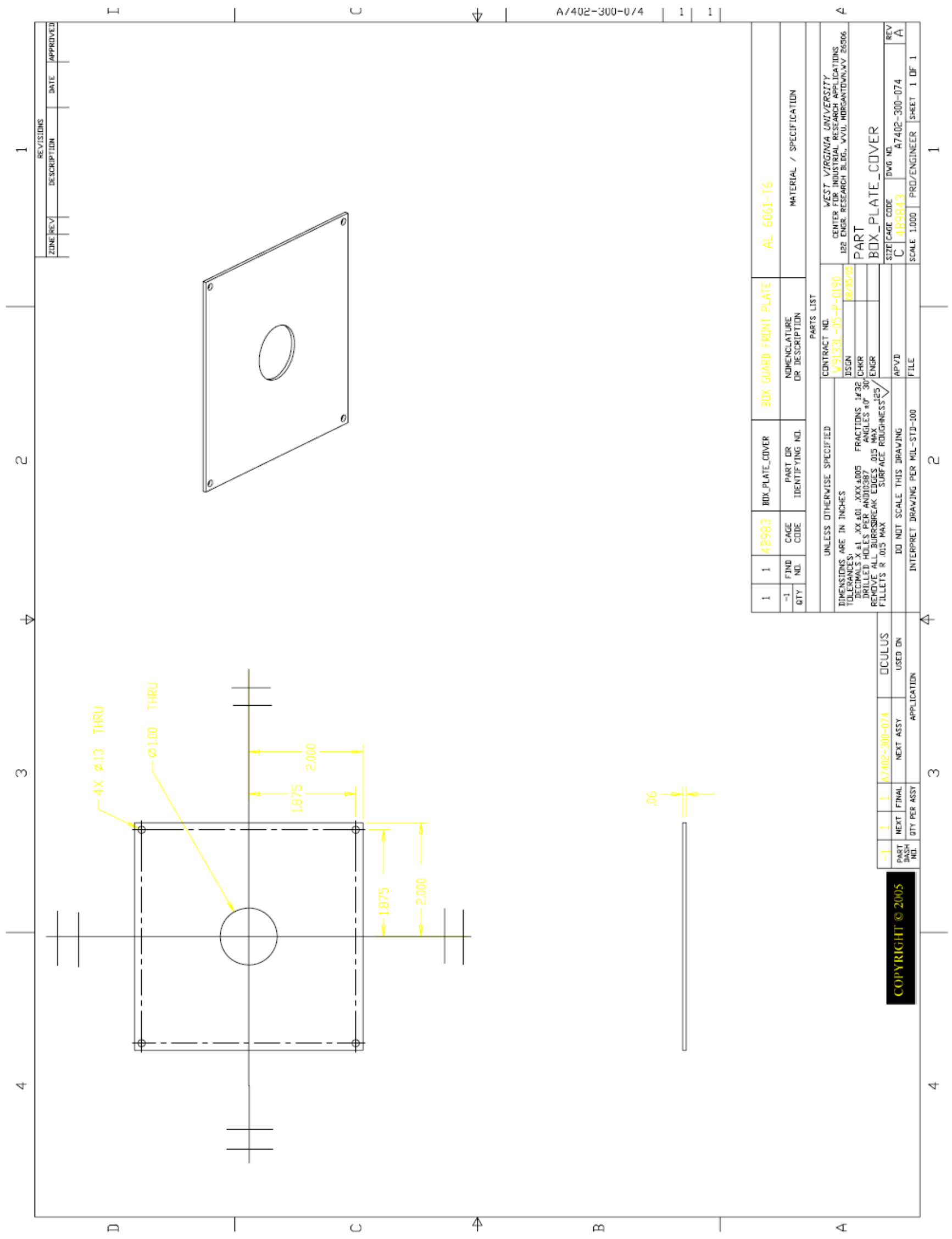

184 


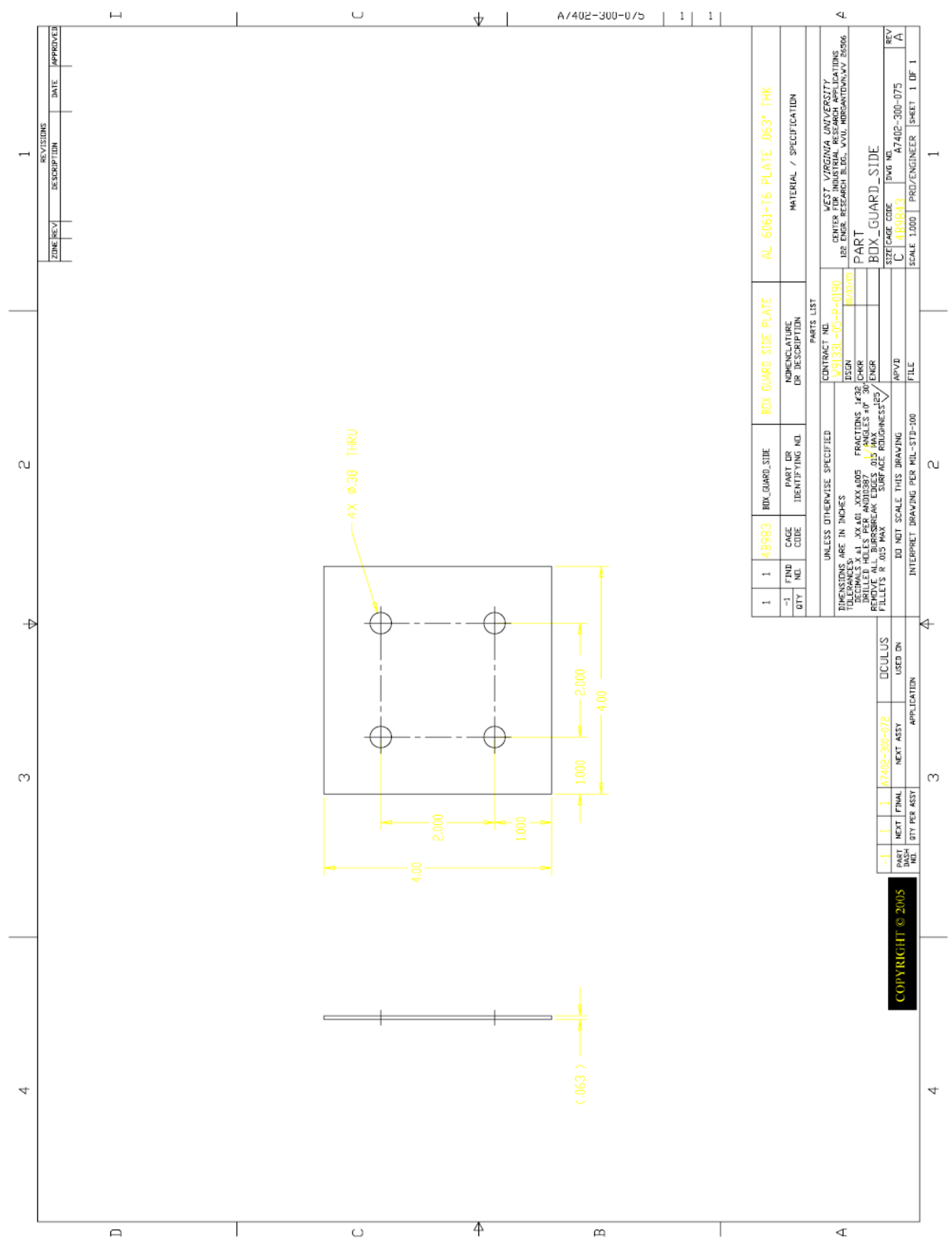

185 


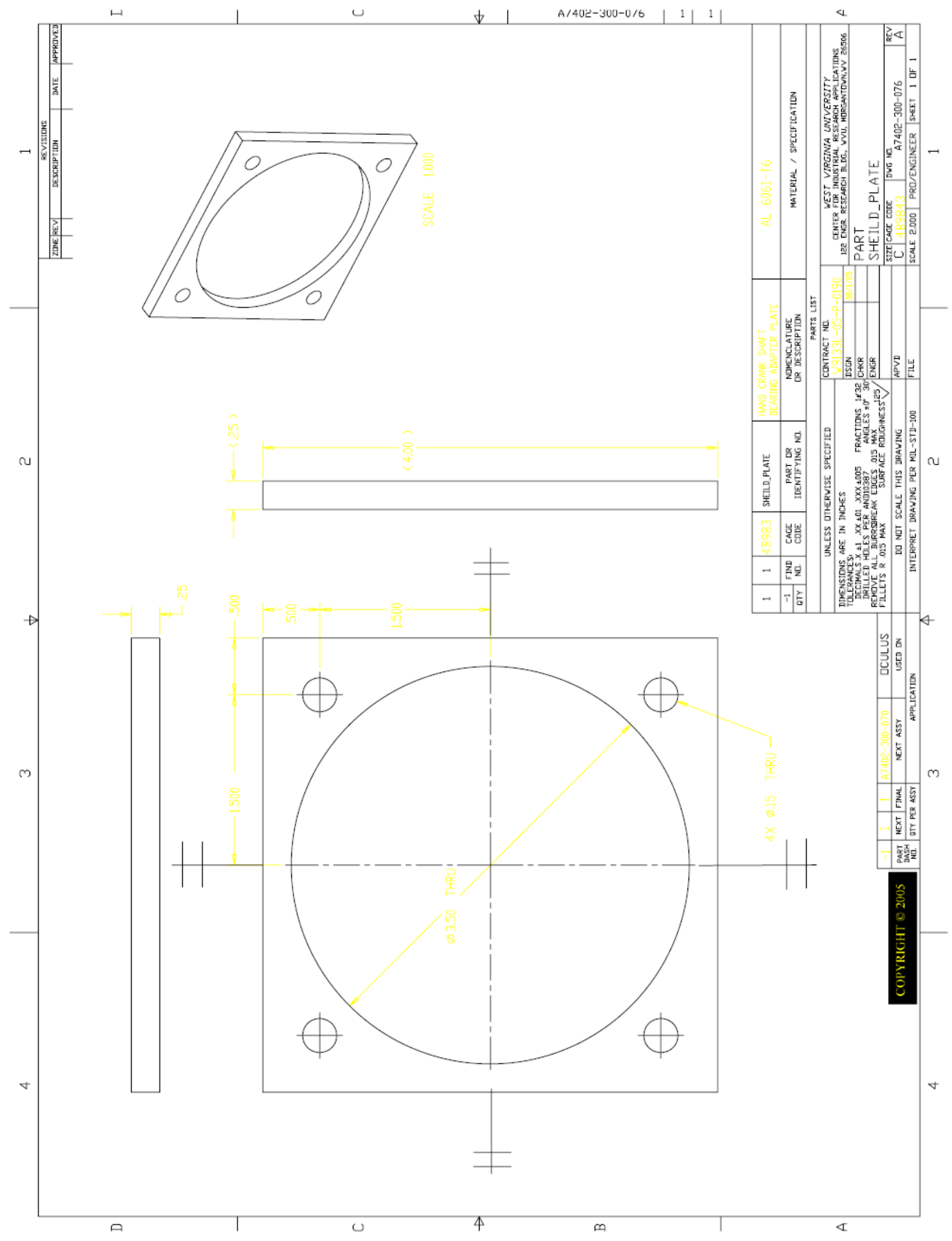

186 


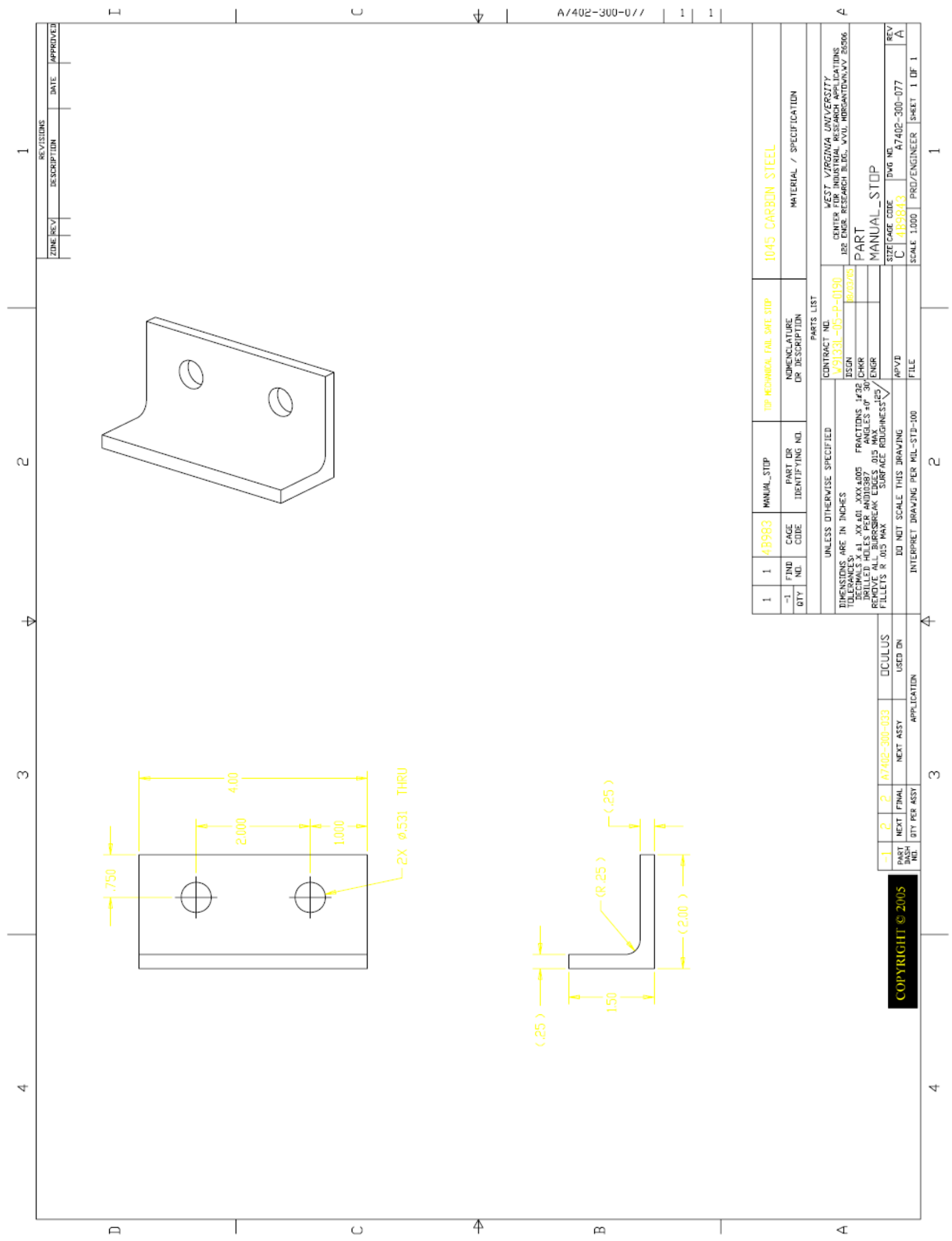

187 


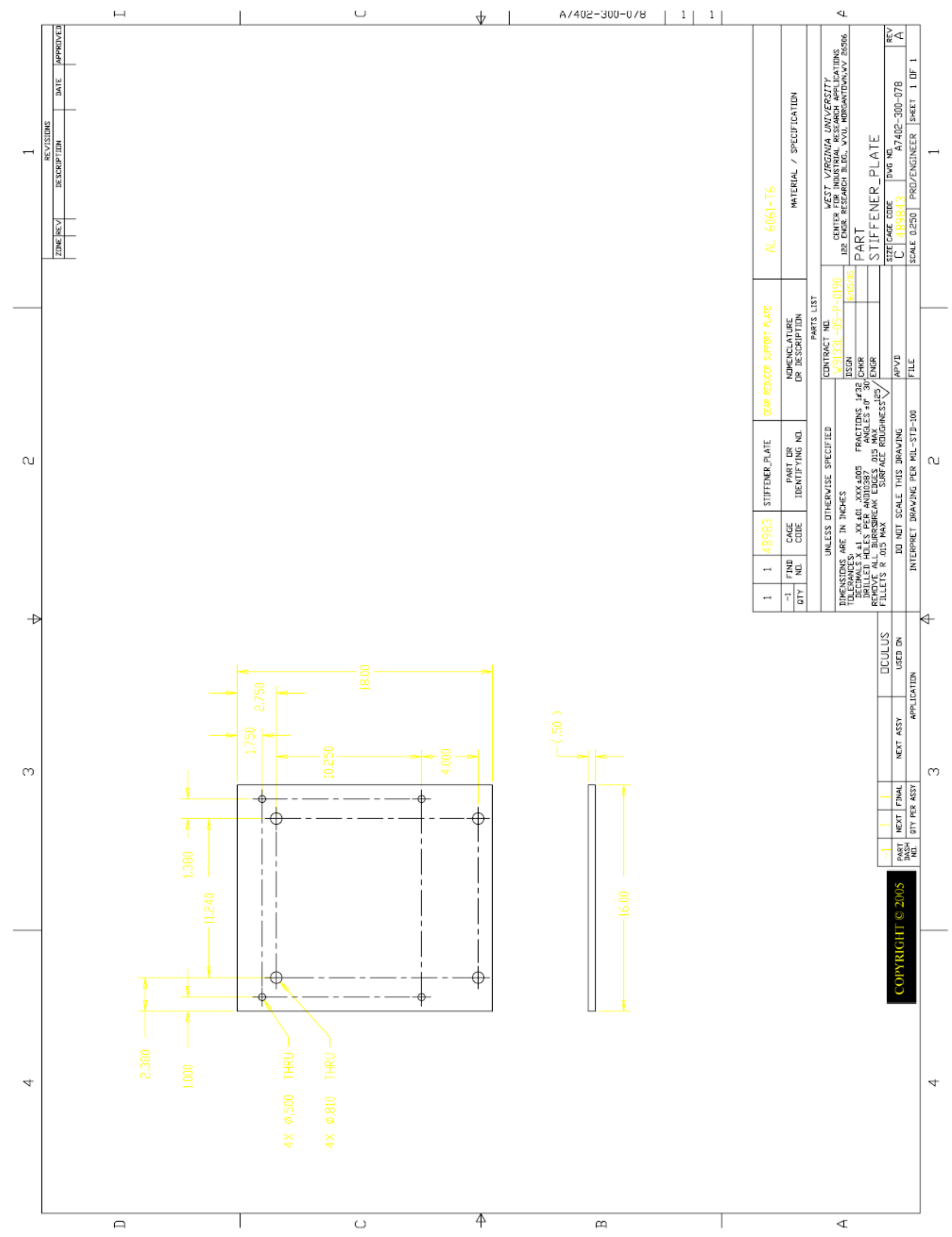




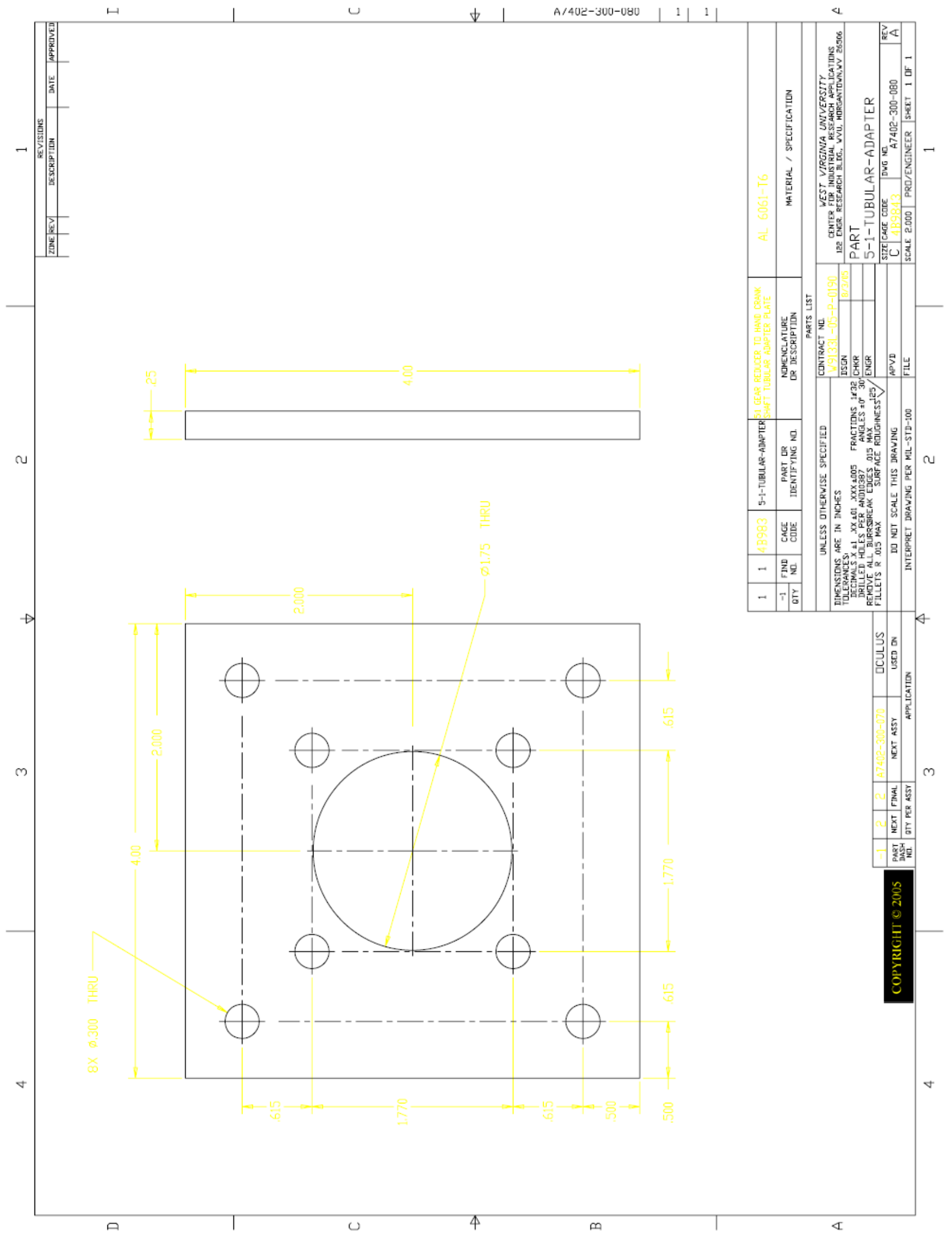




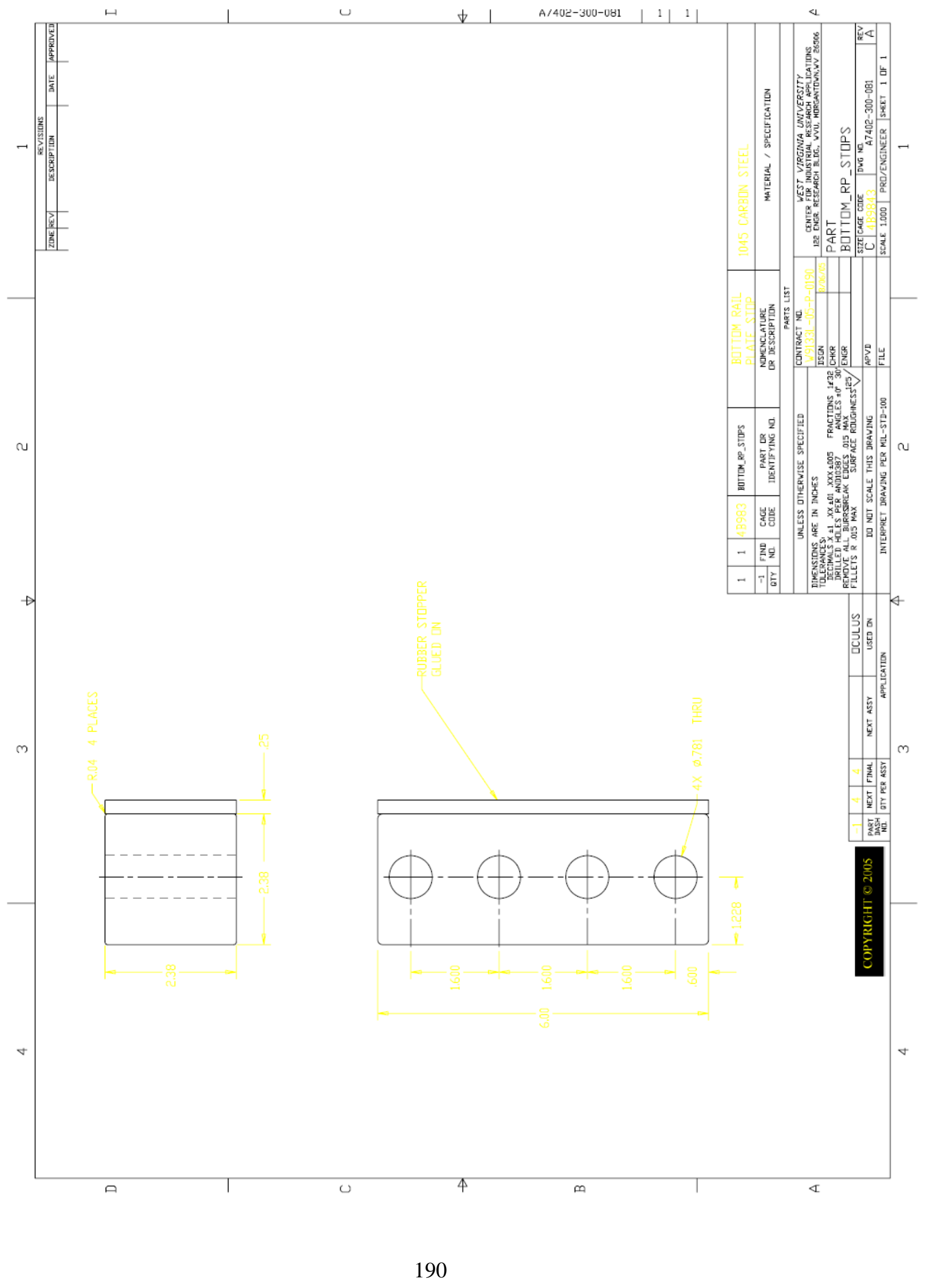




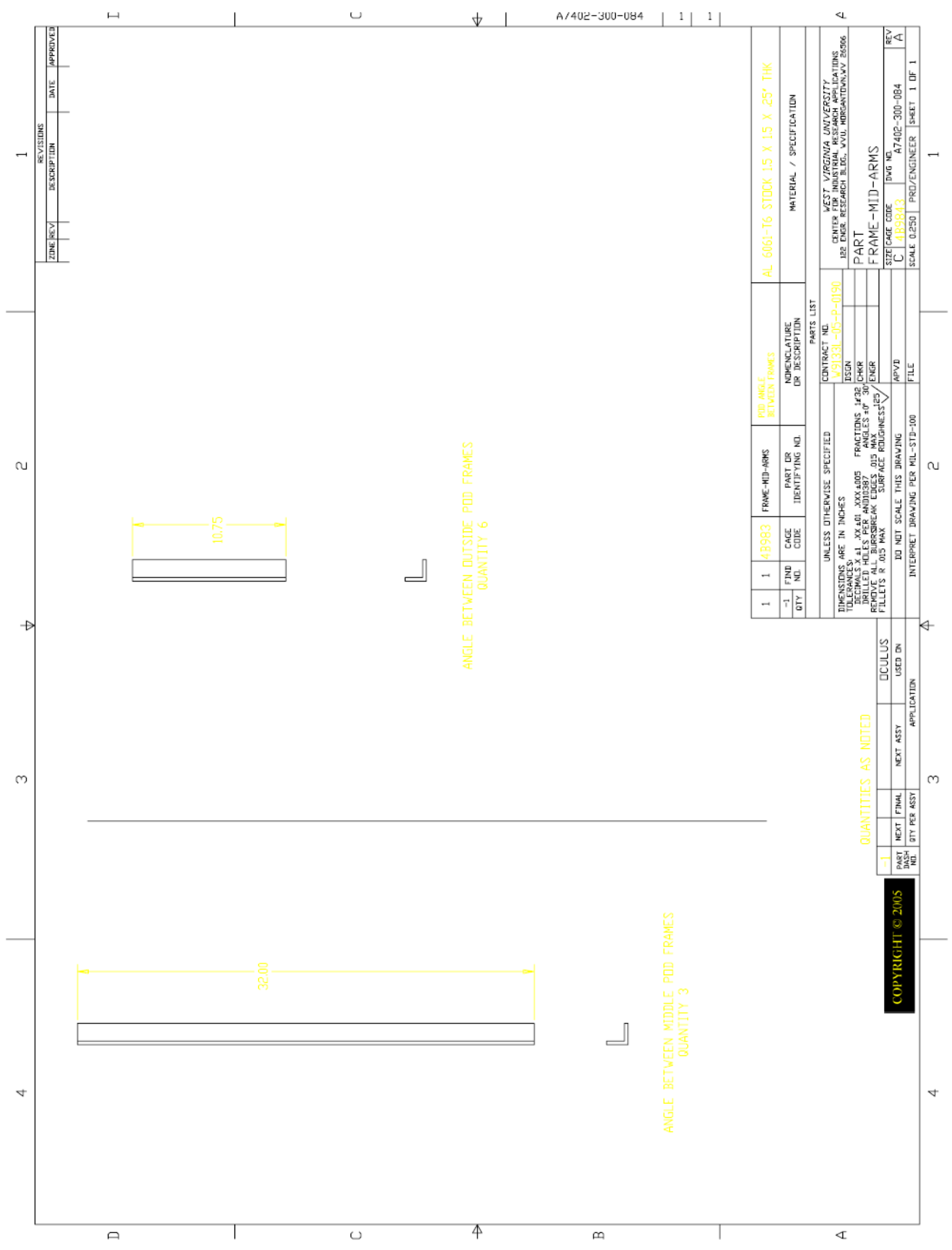




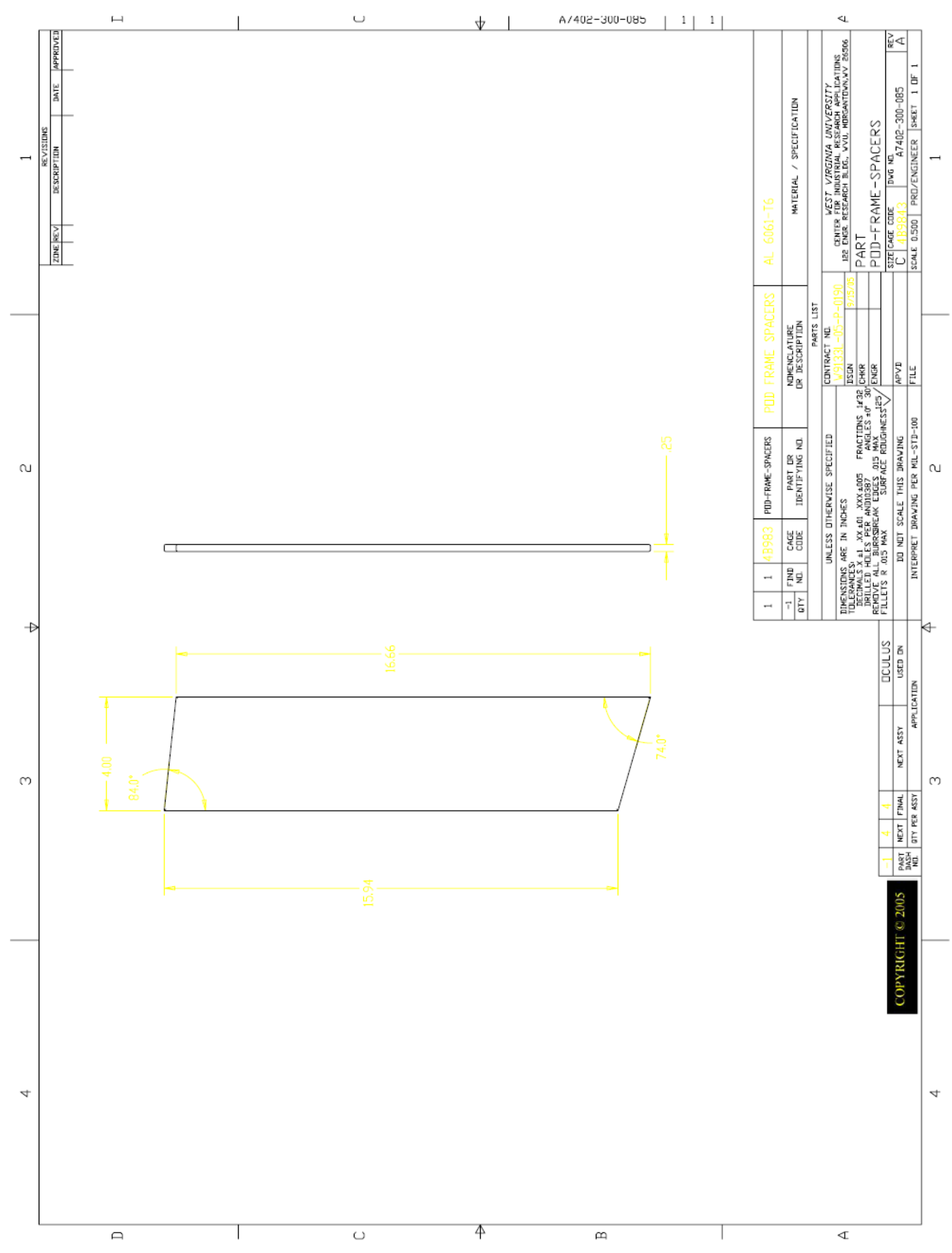




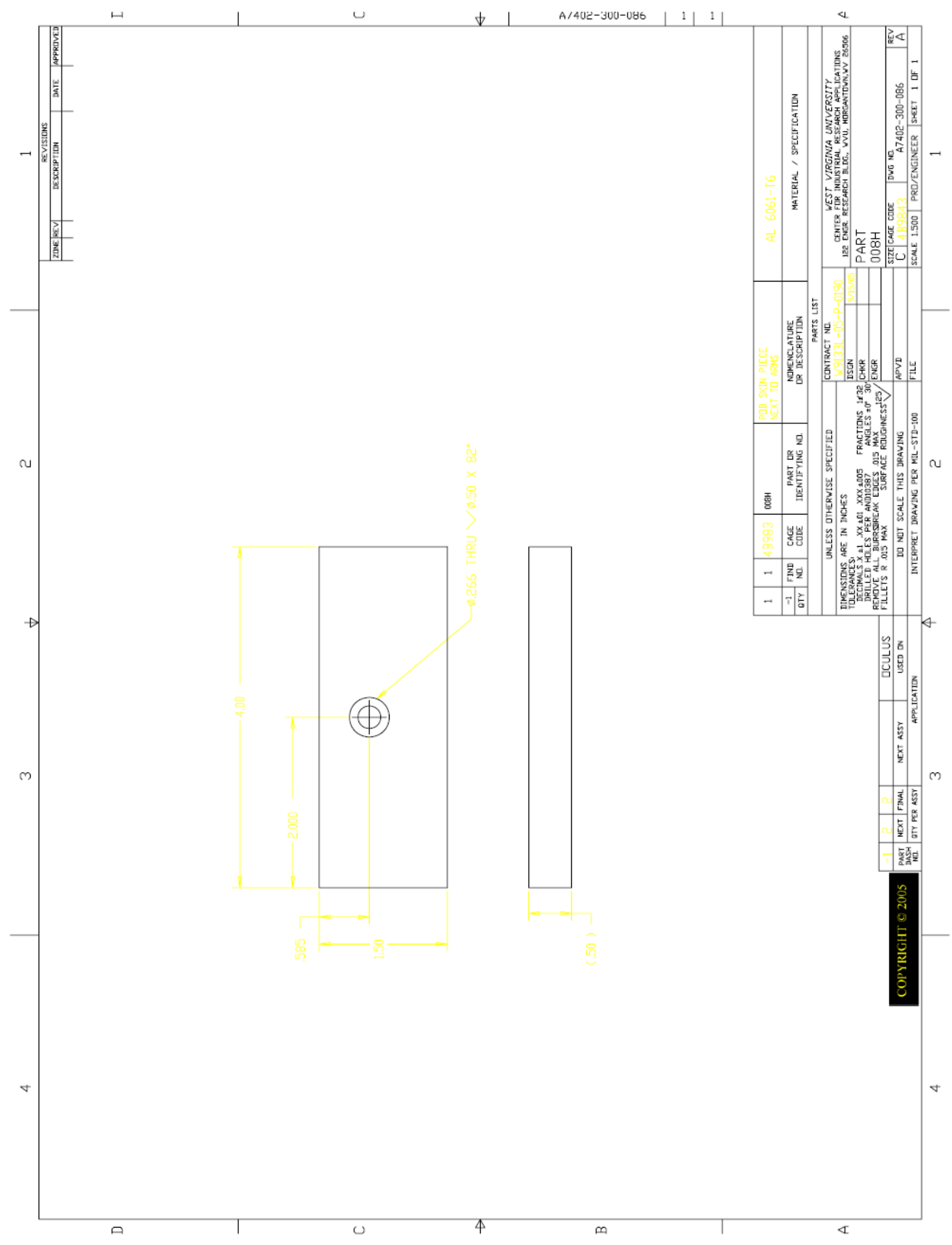




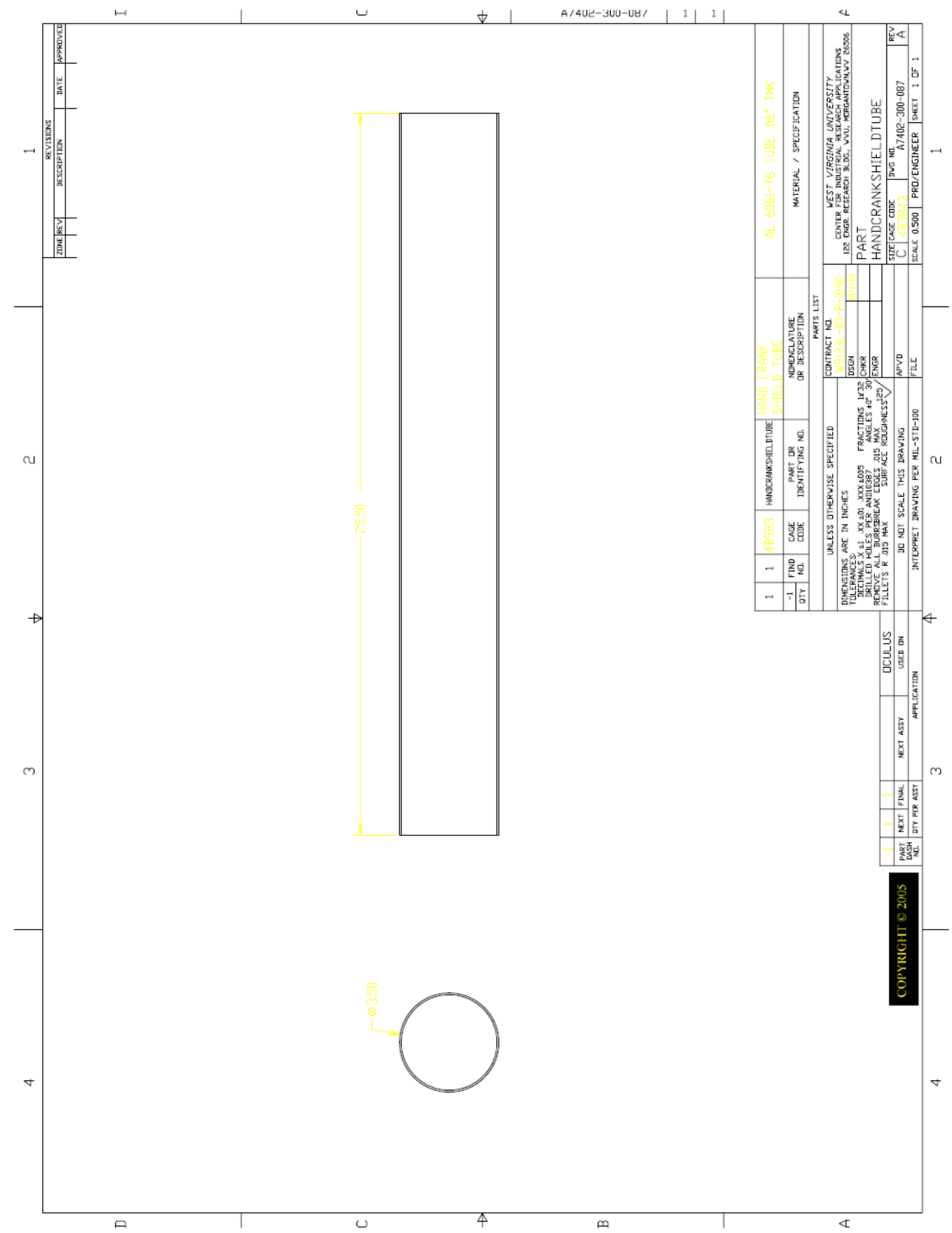




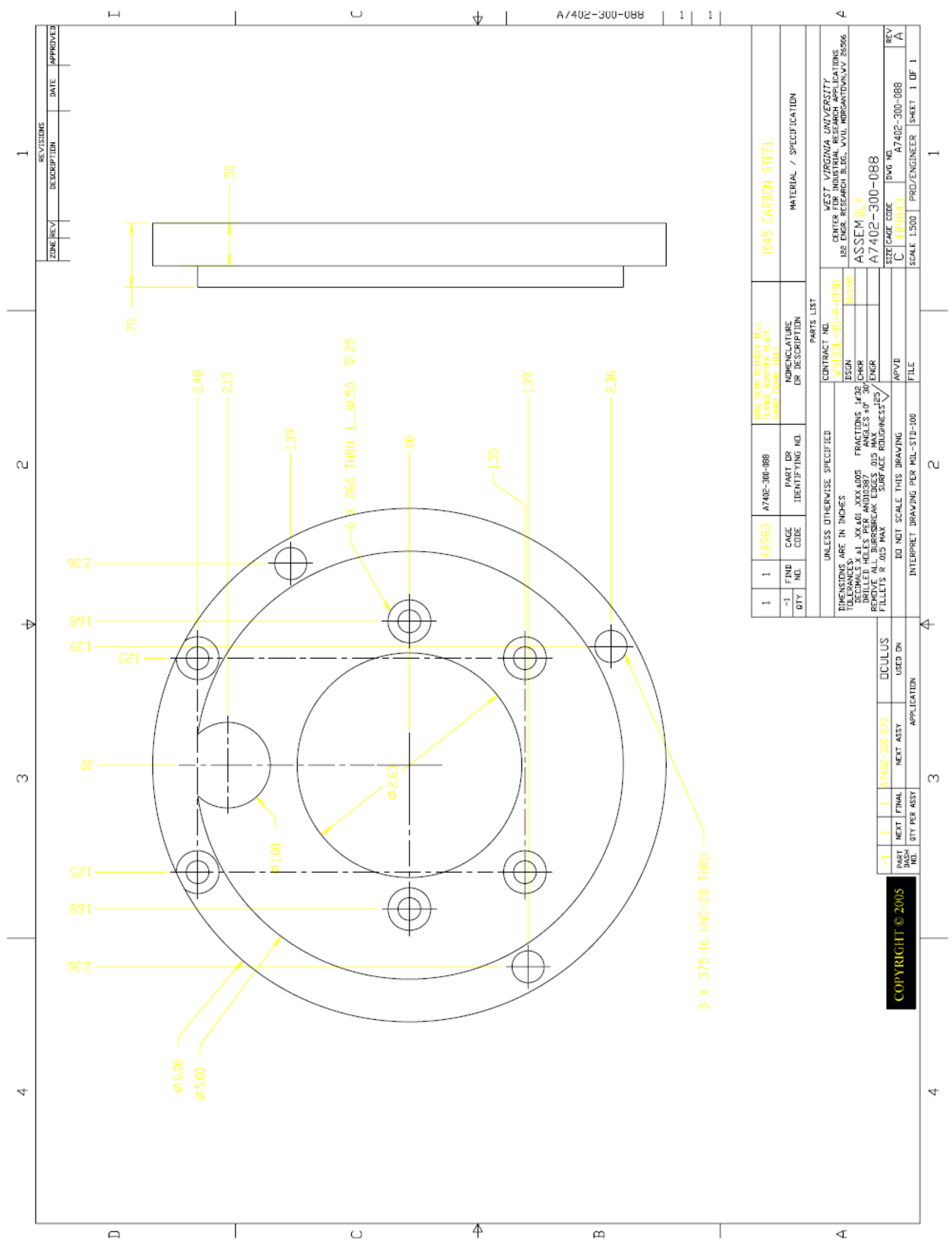




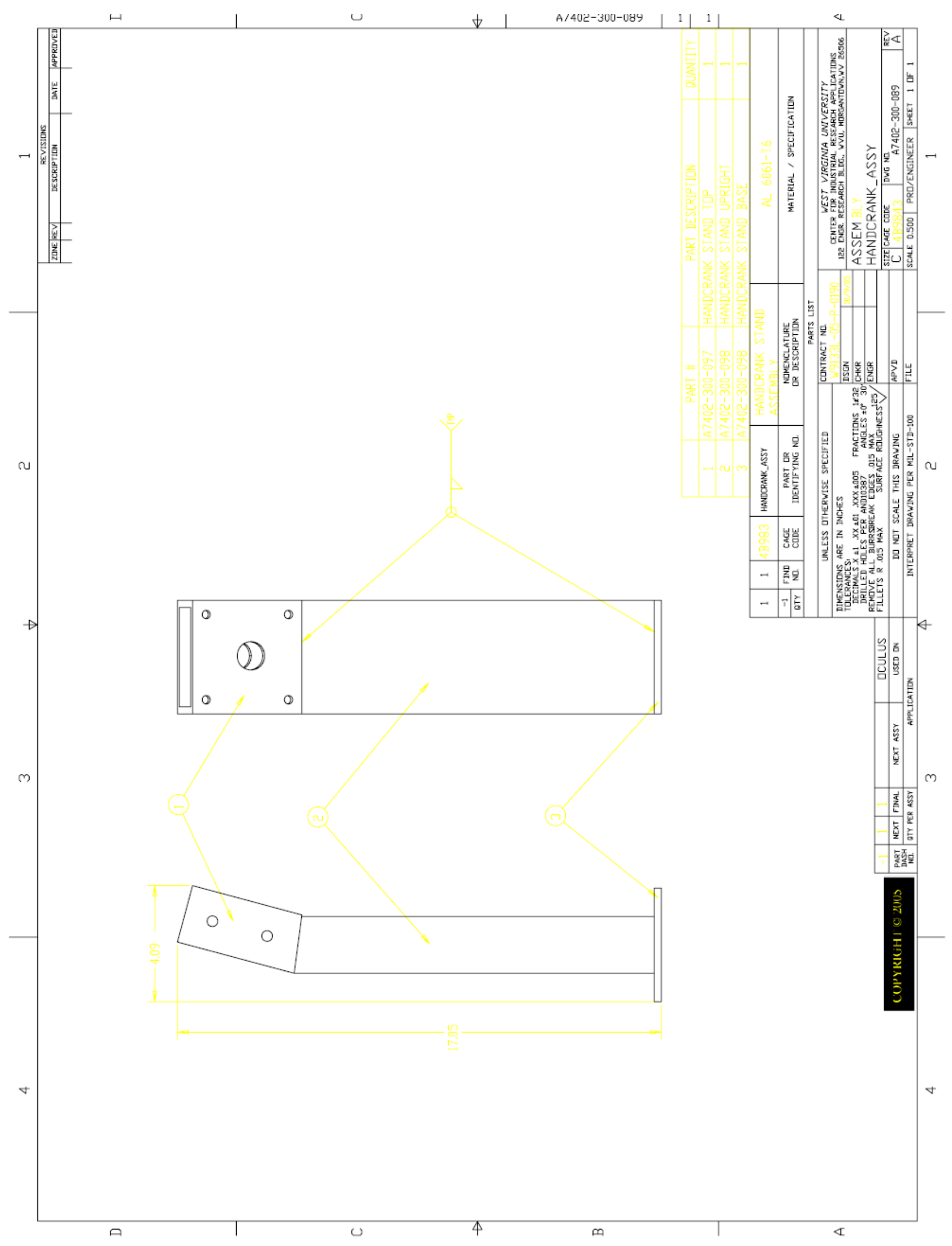




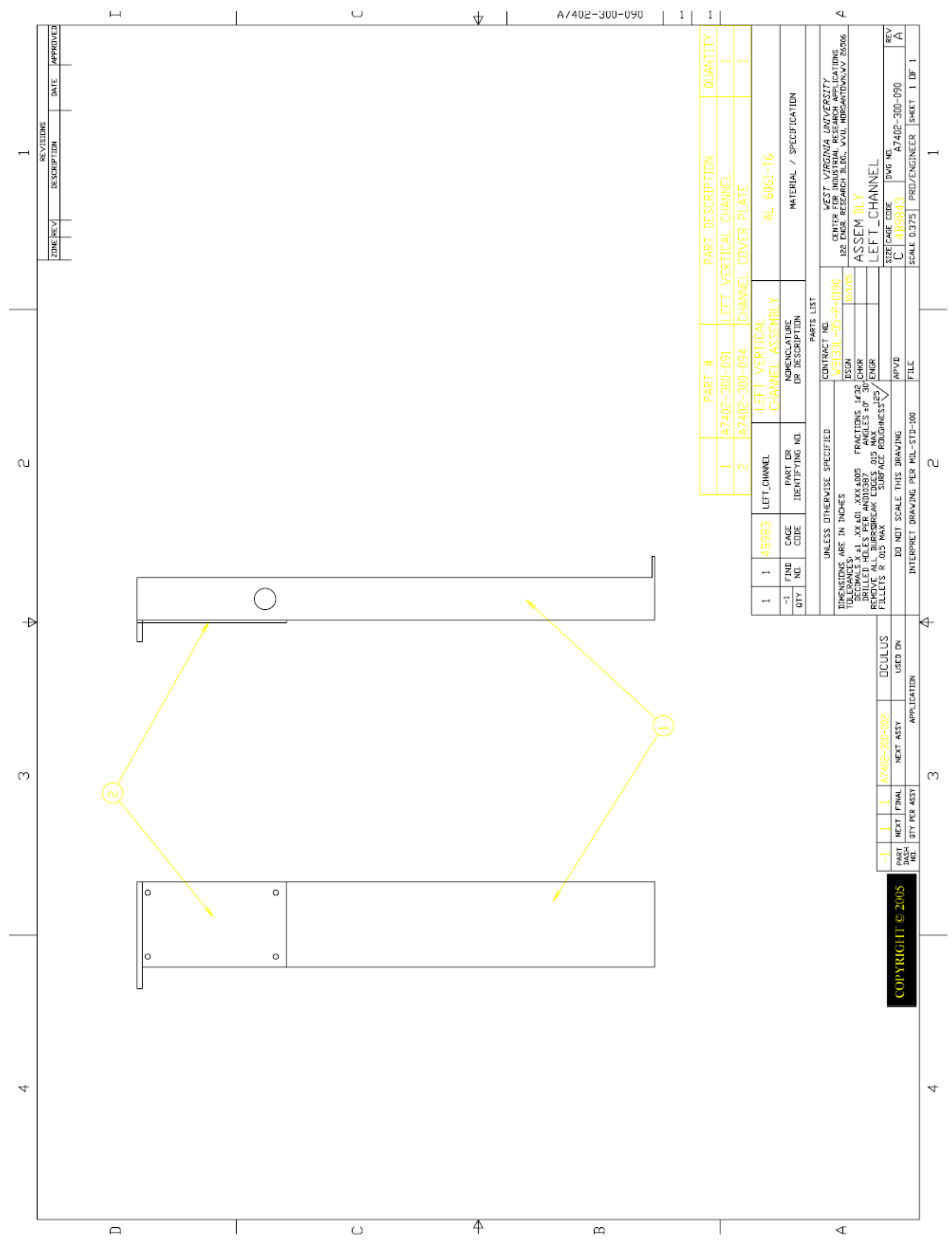




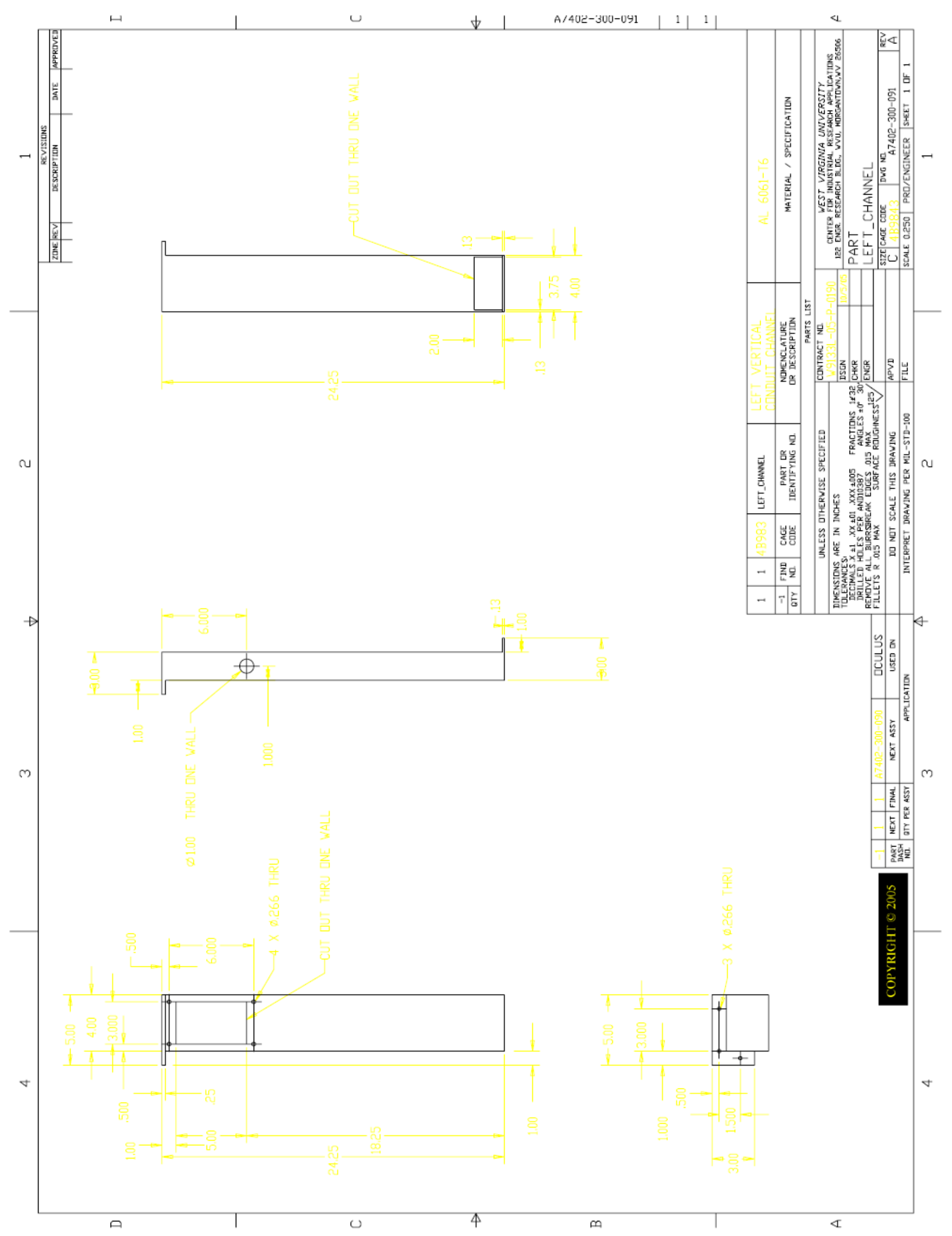




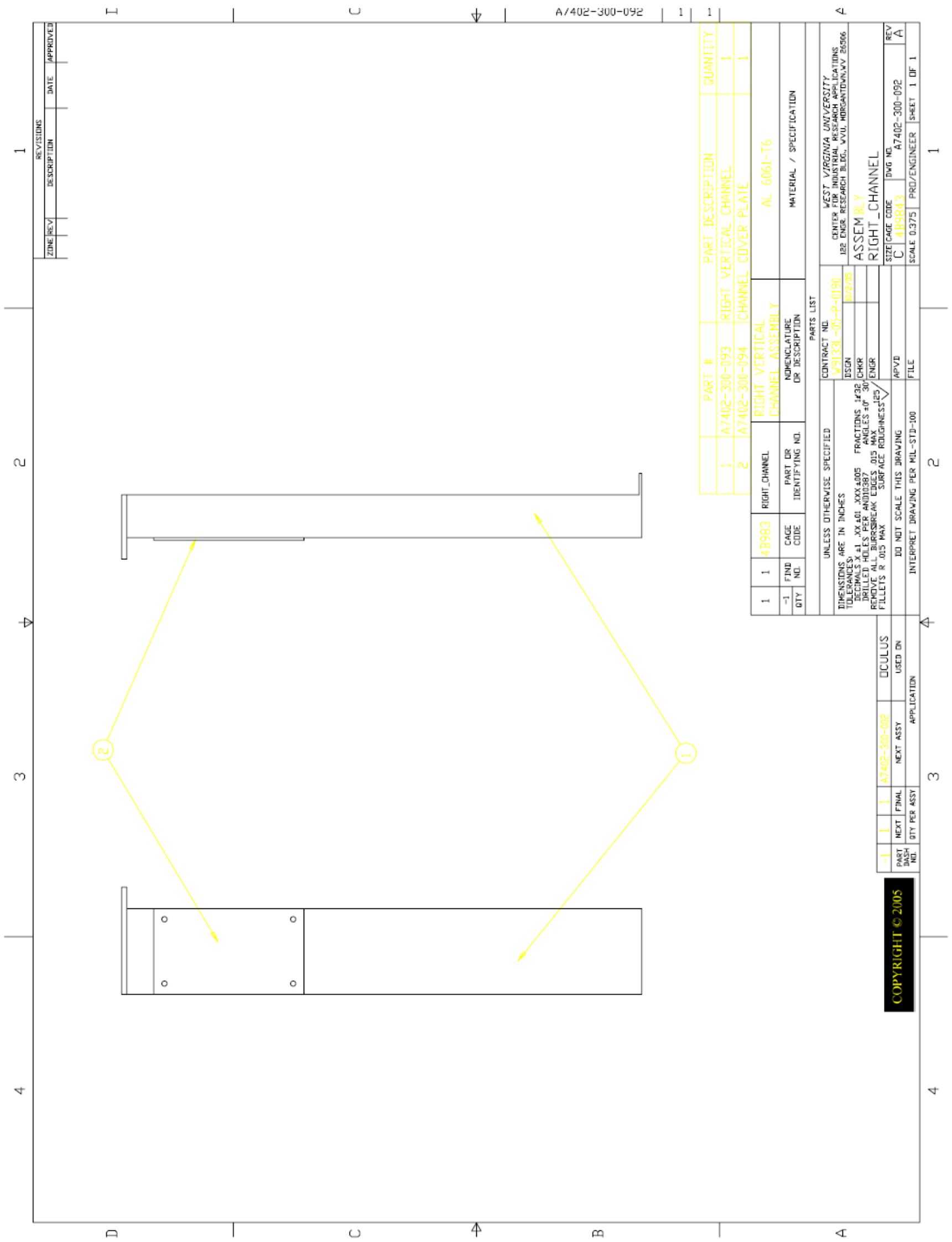

199 


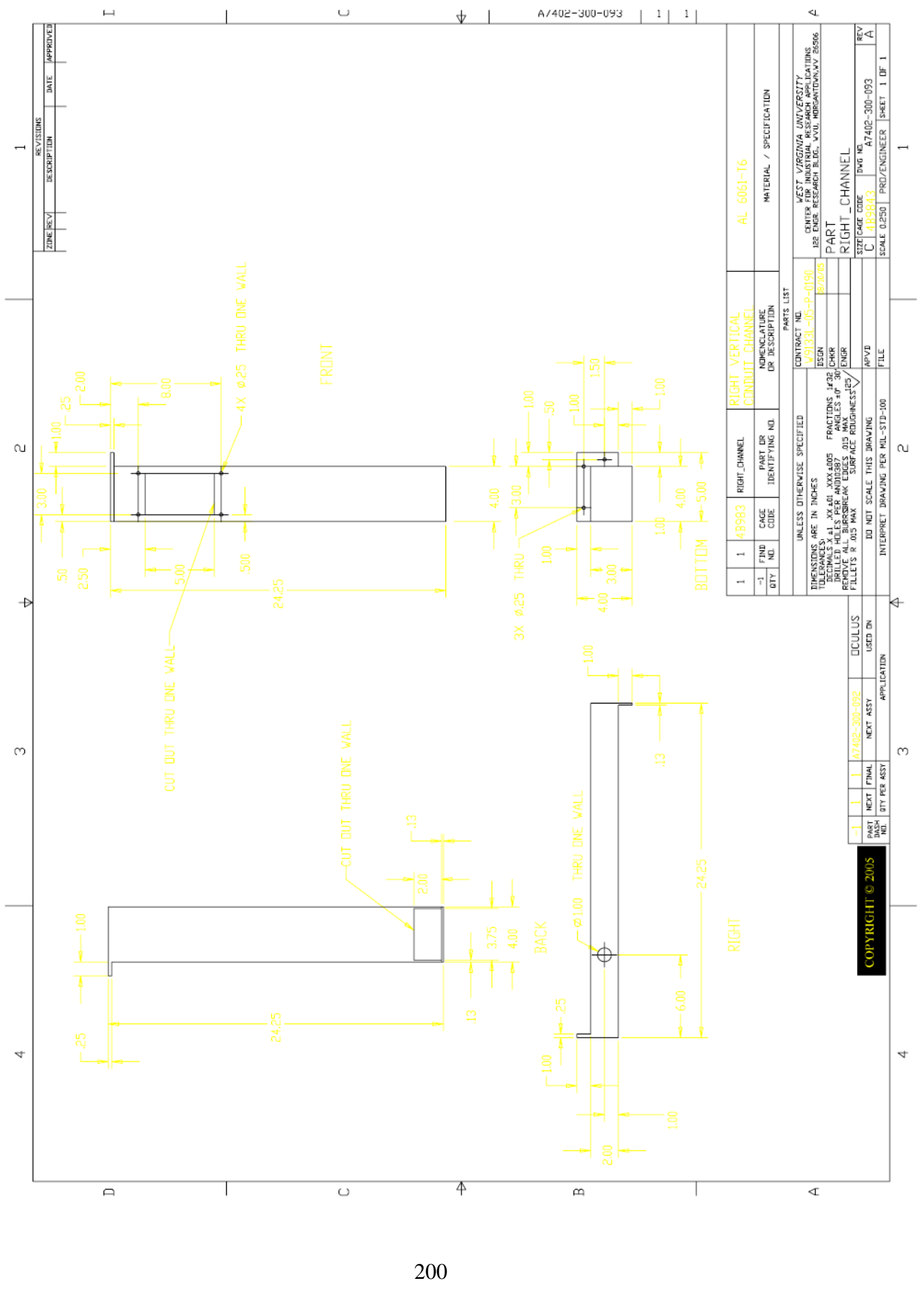




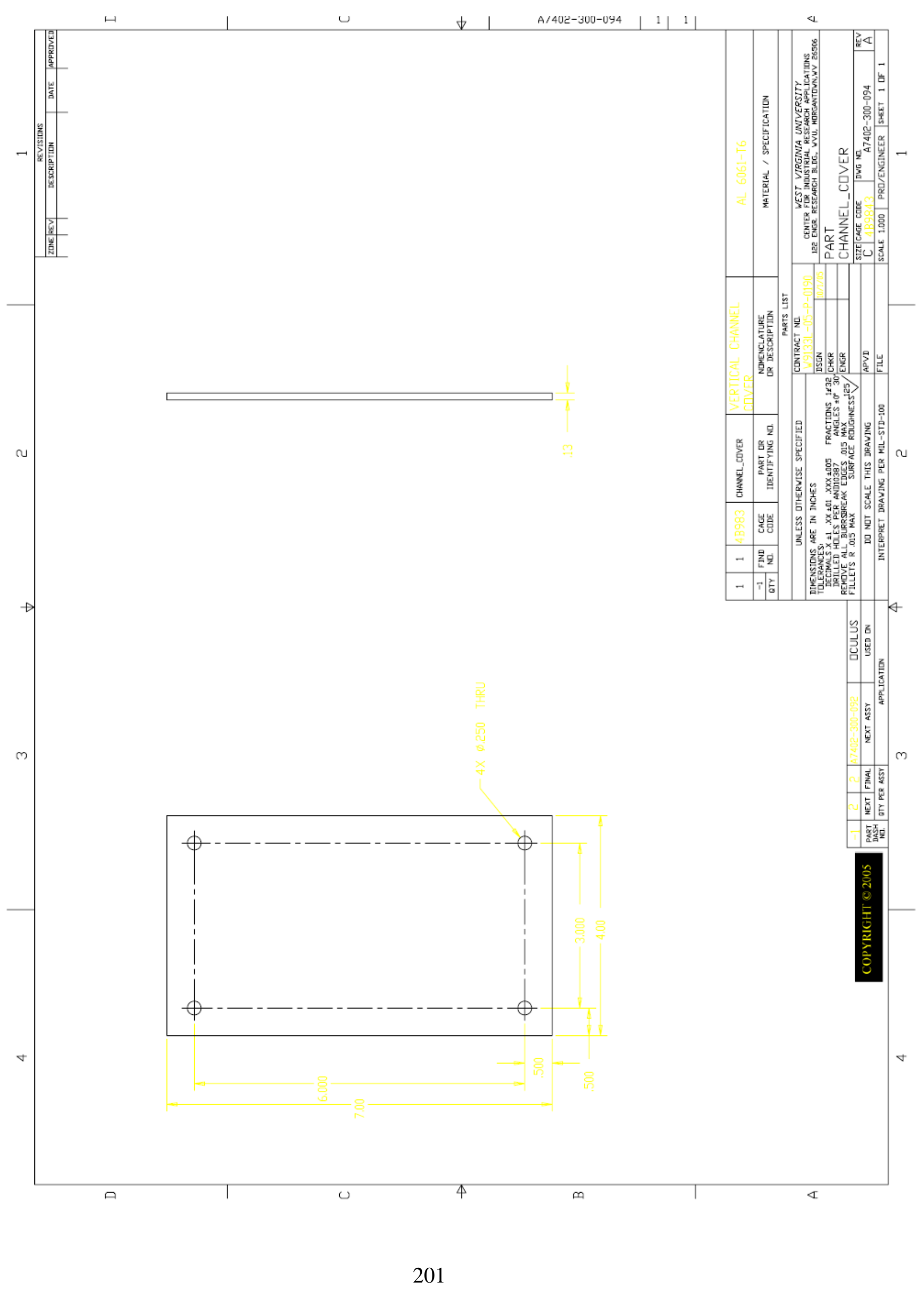




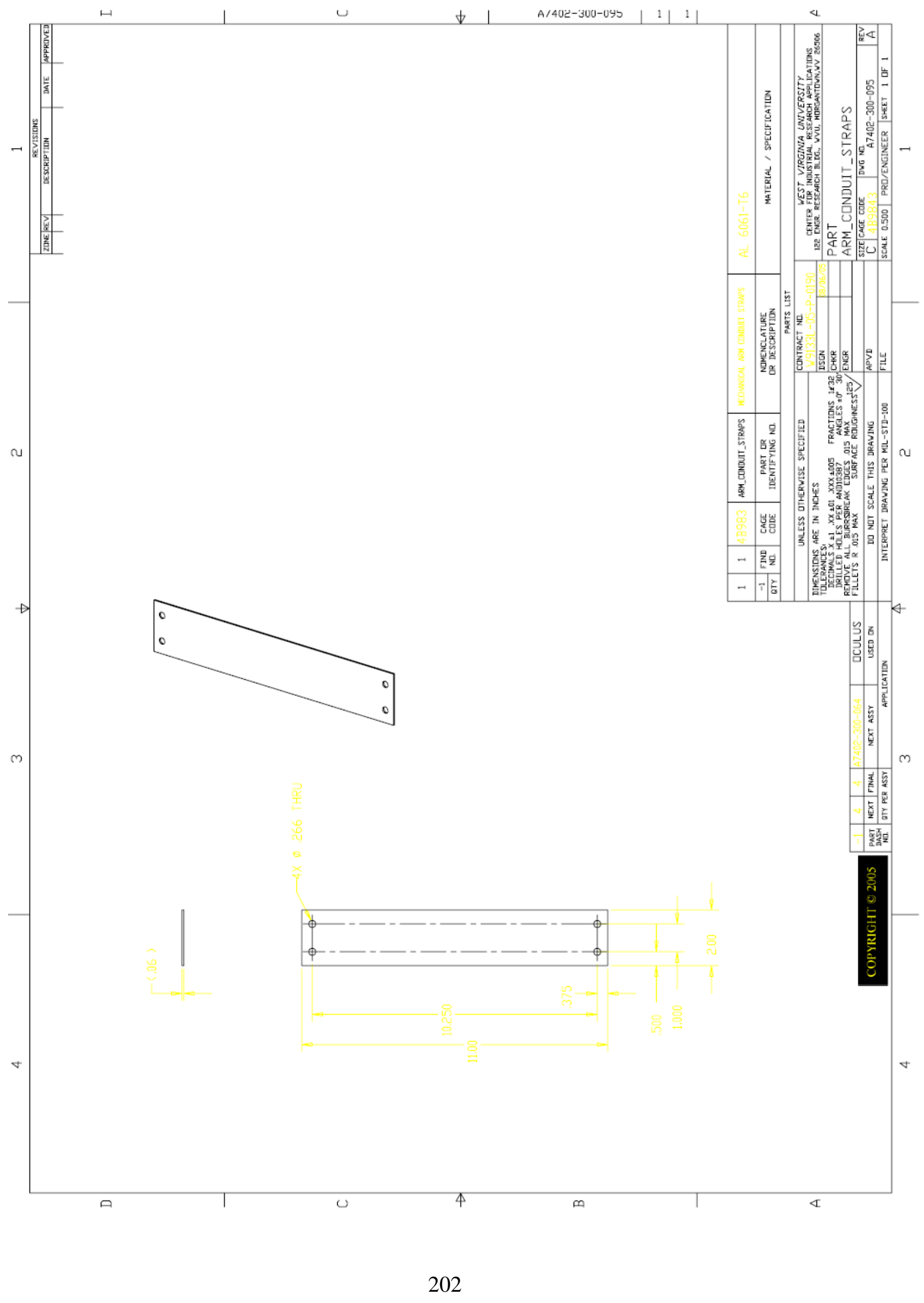




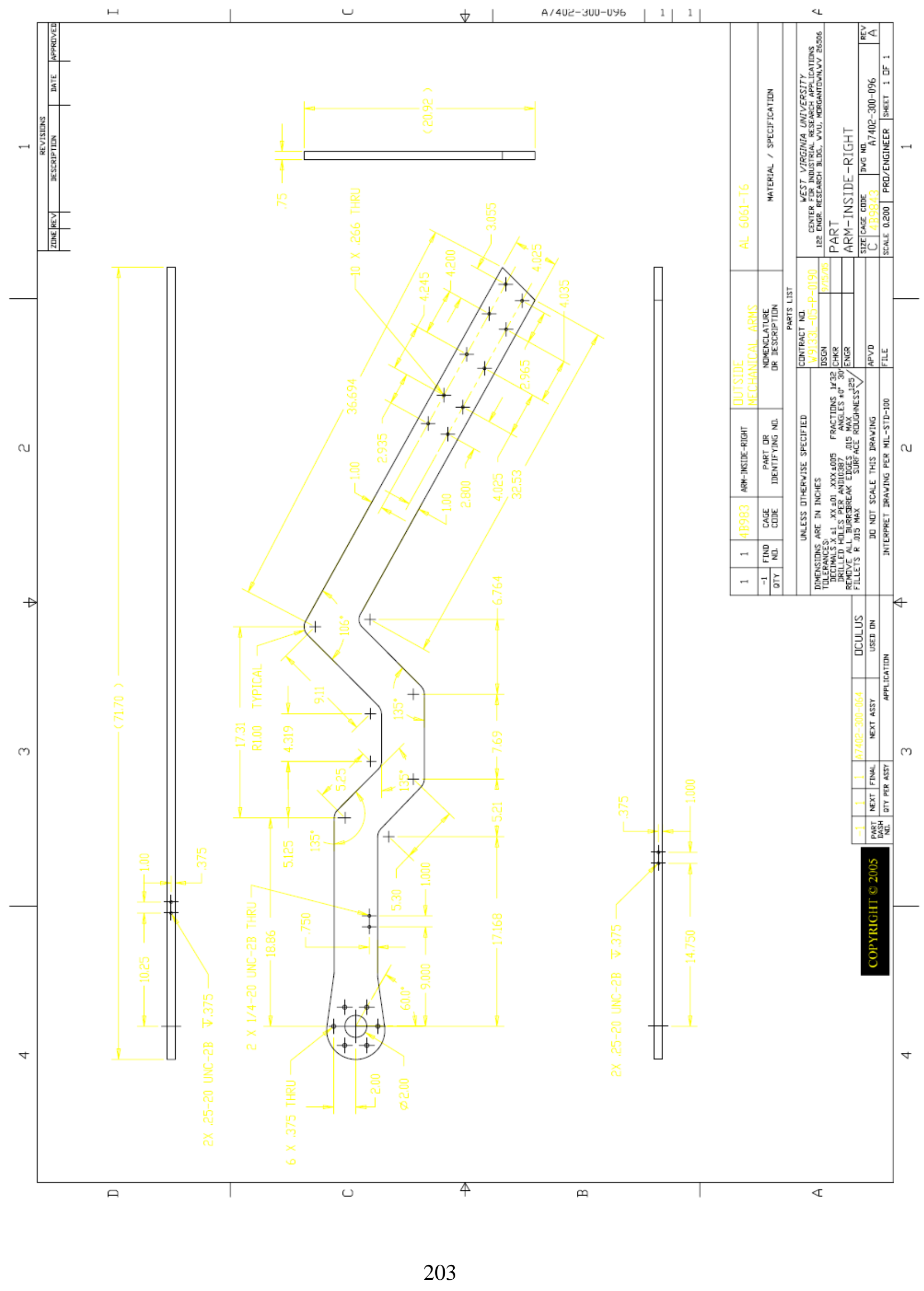




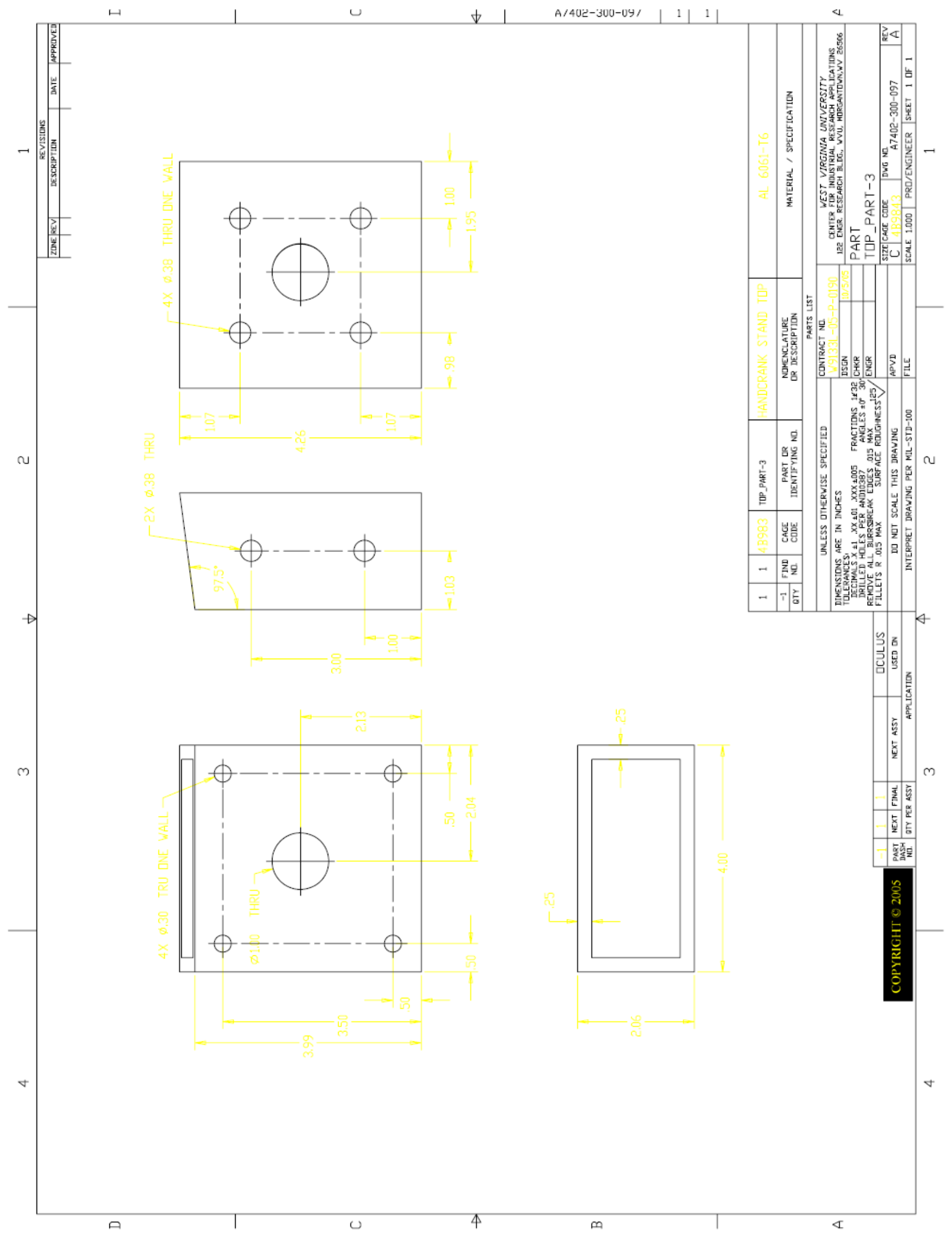

204 


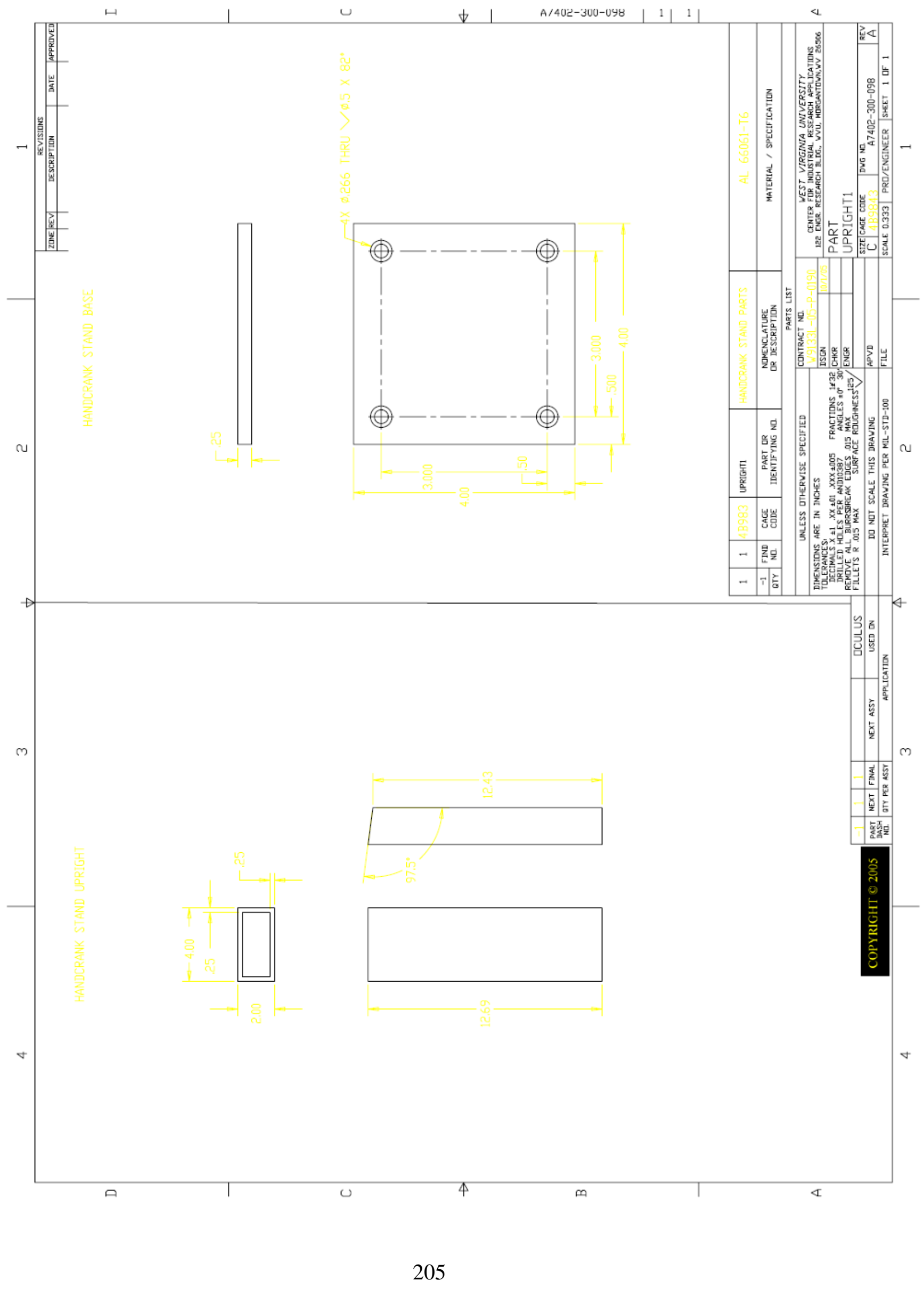




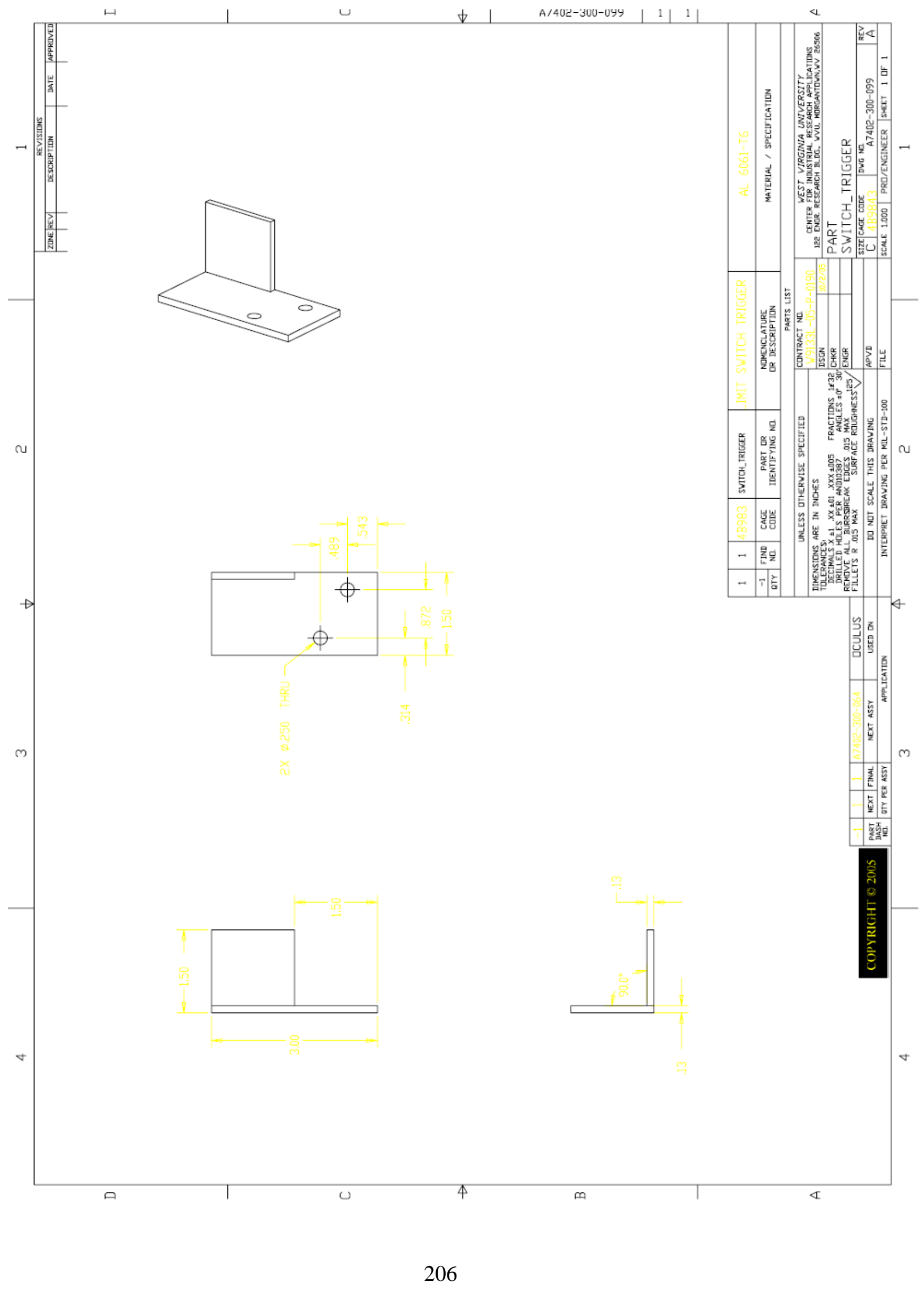


Electrical Drawings 


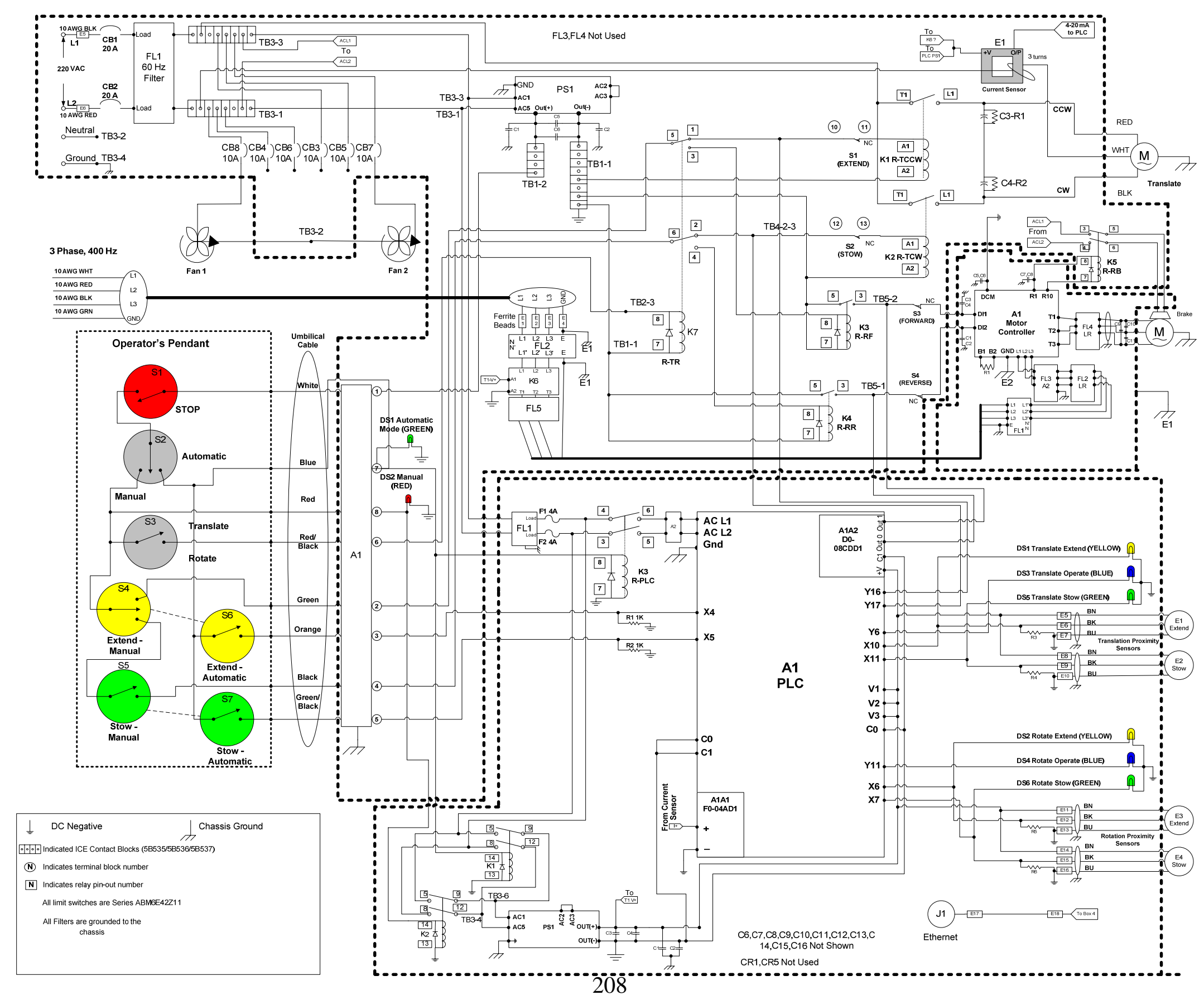




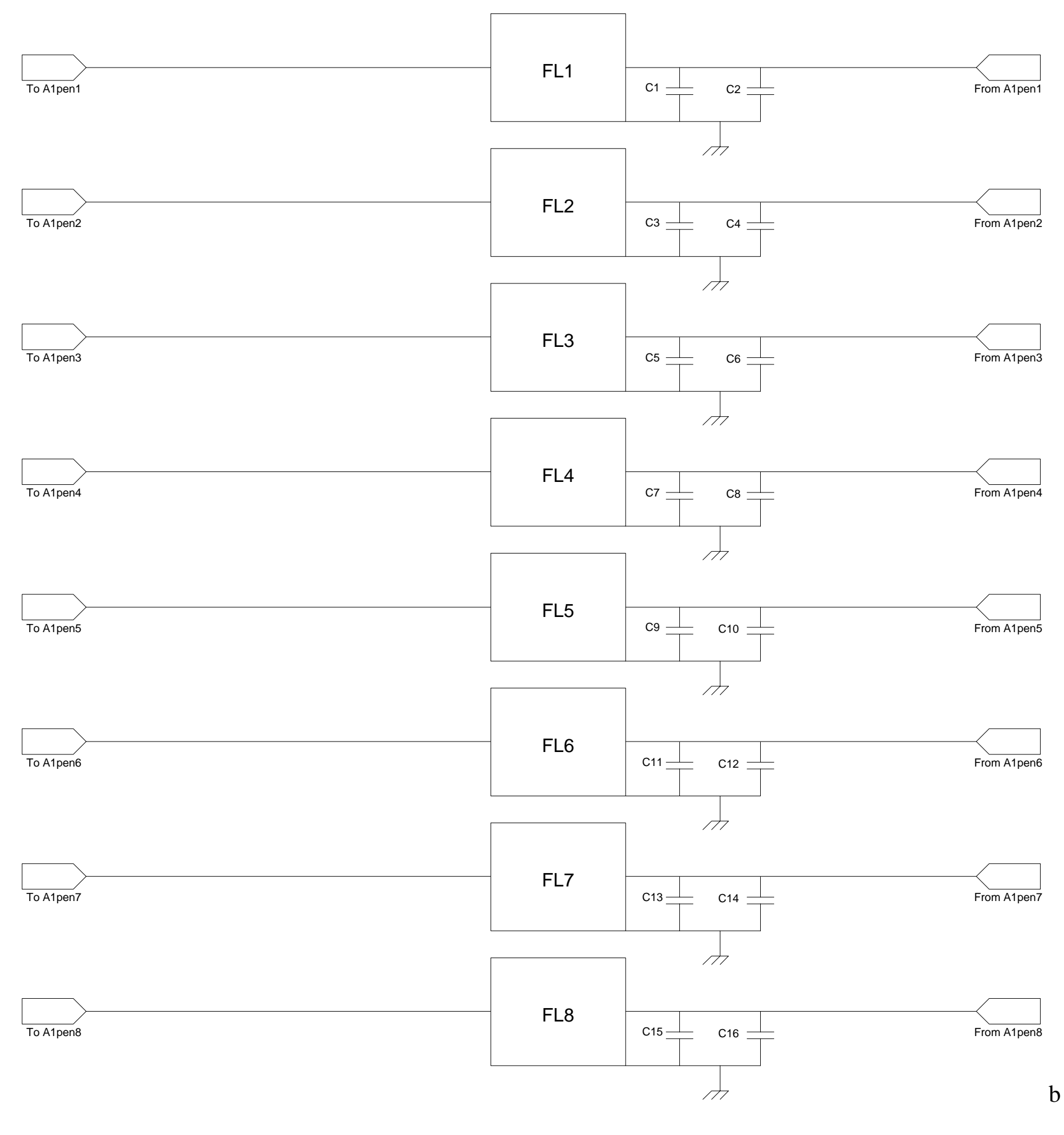




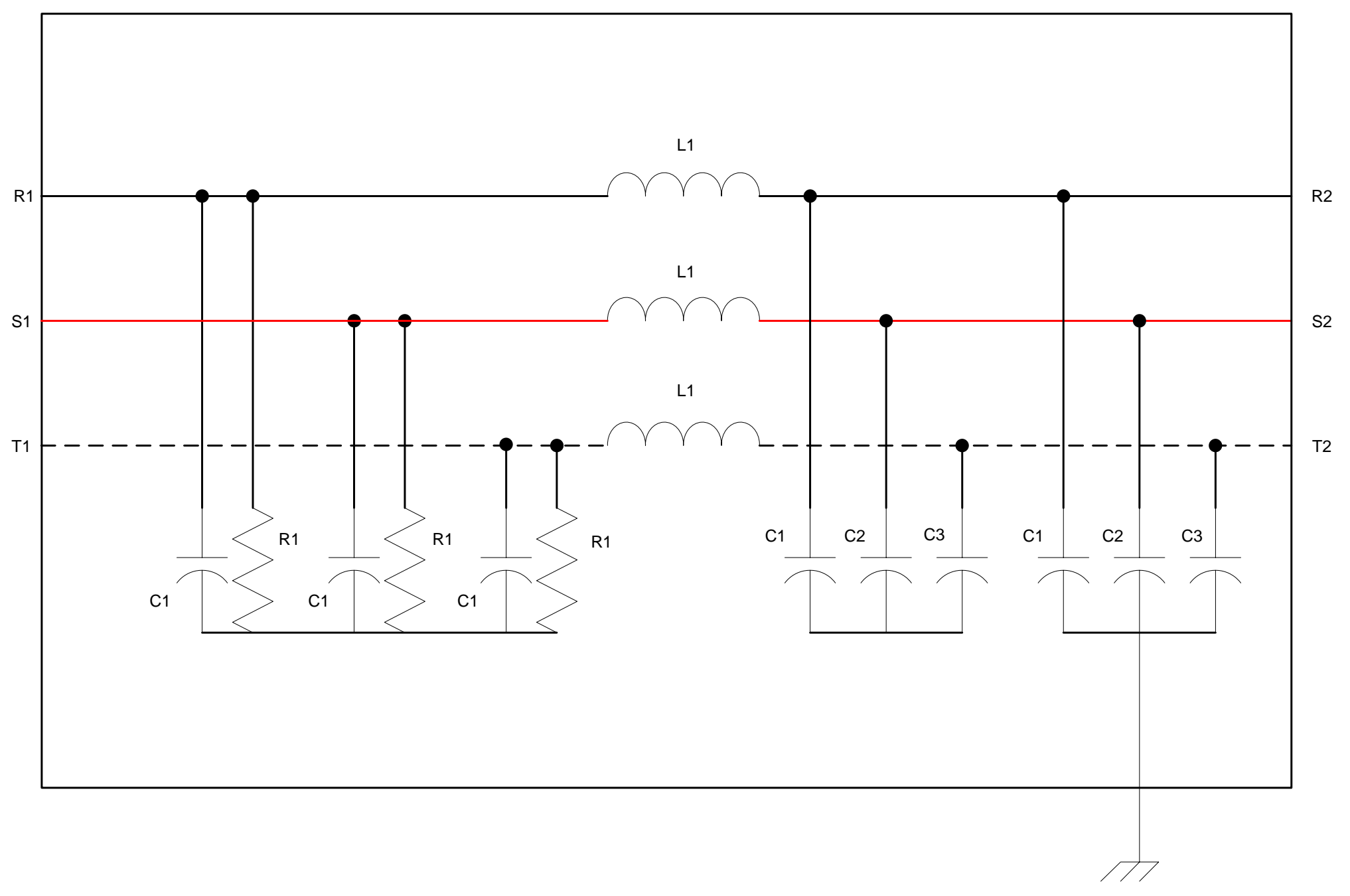




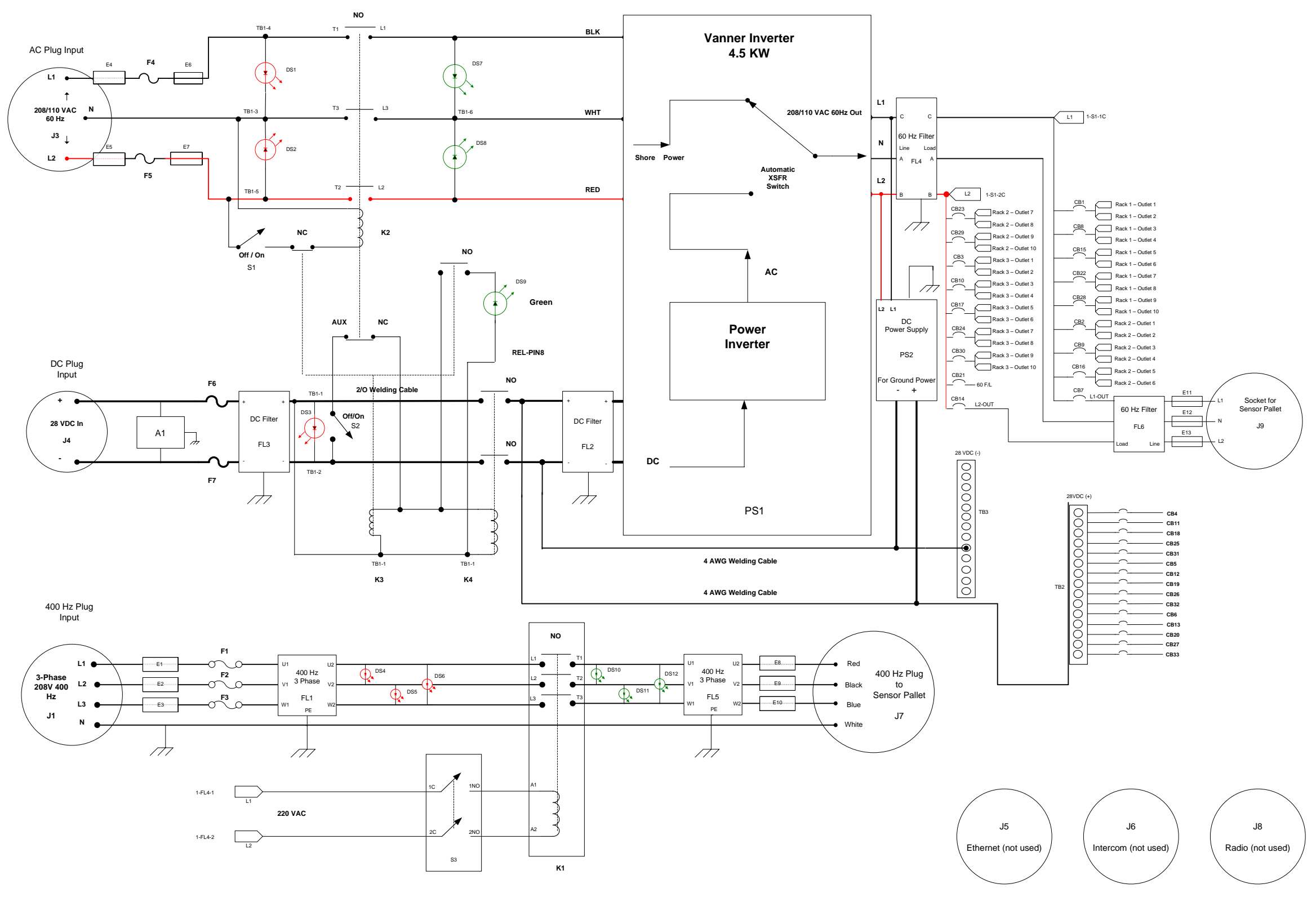




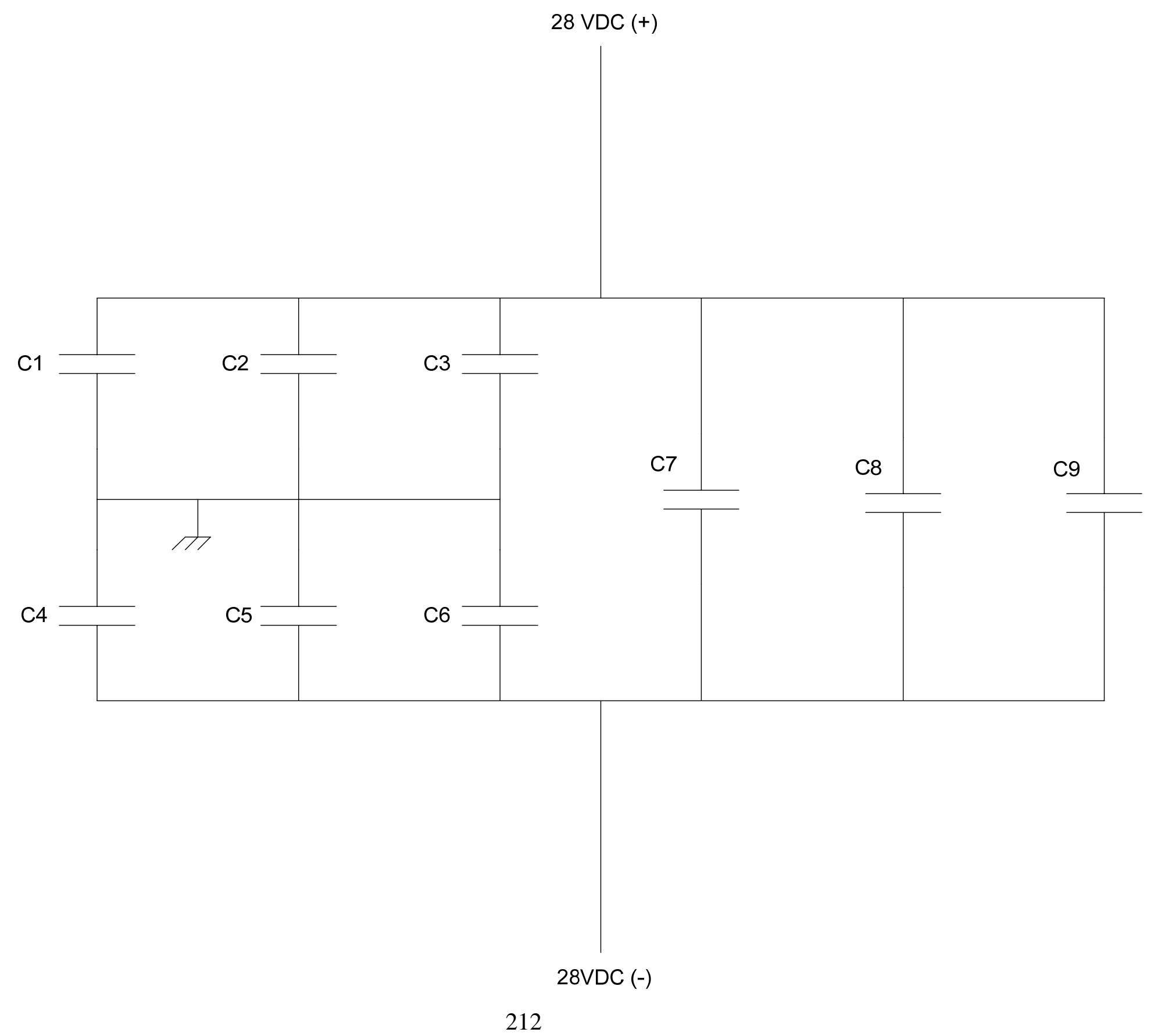




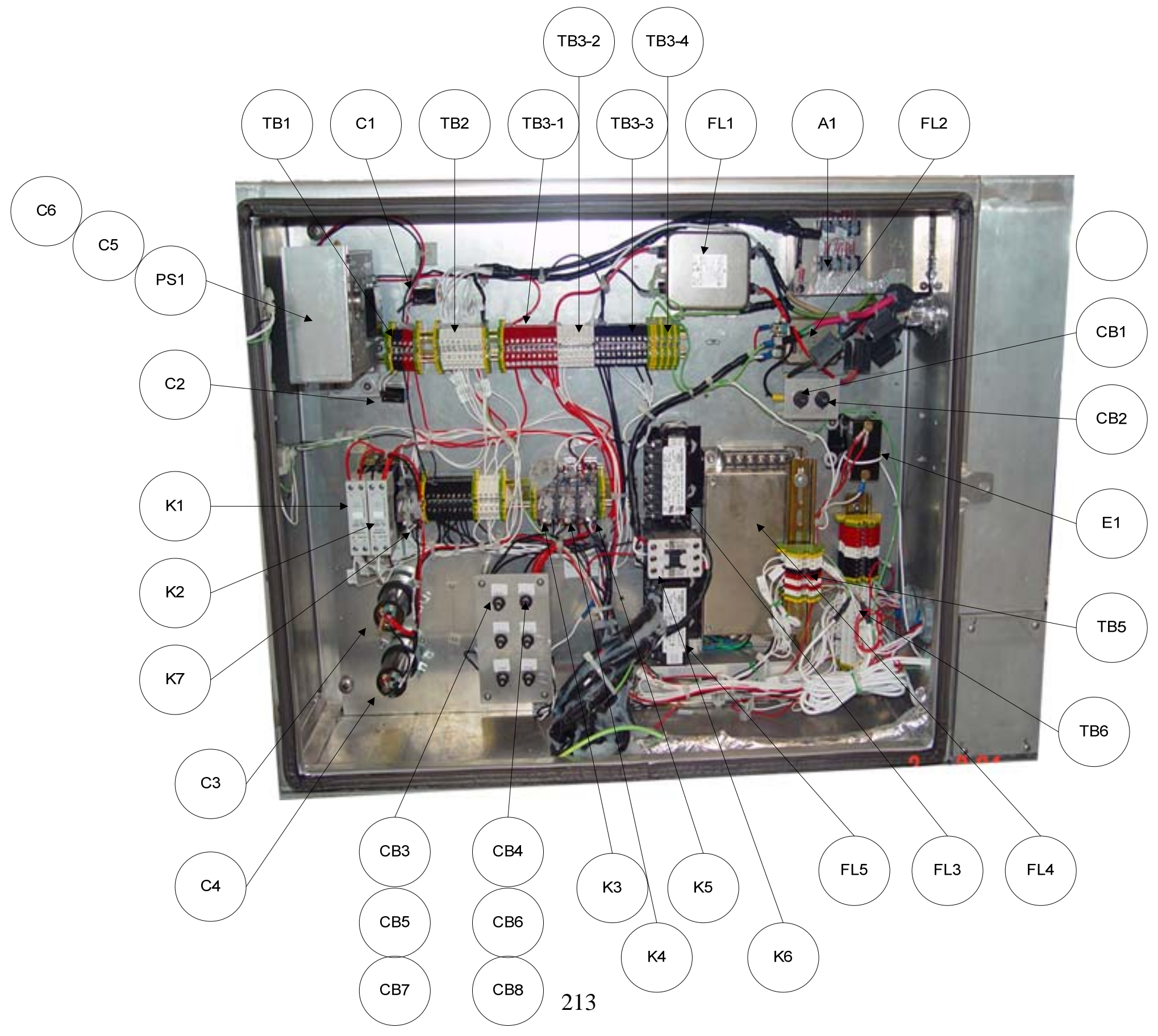




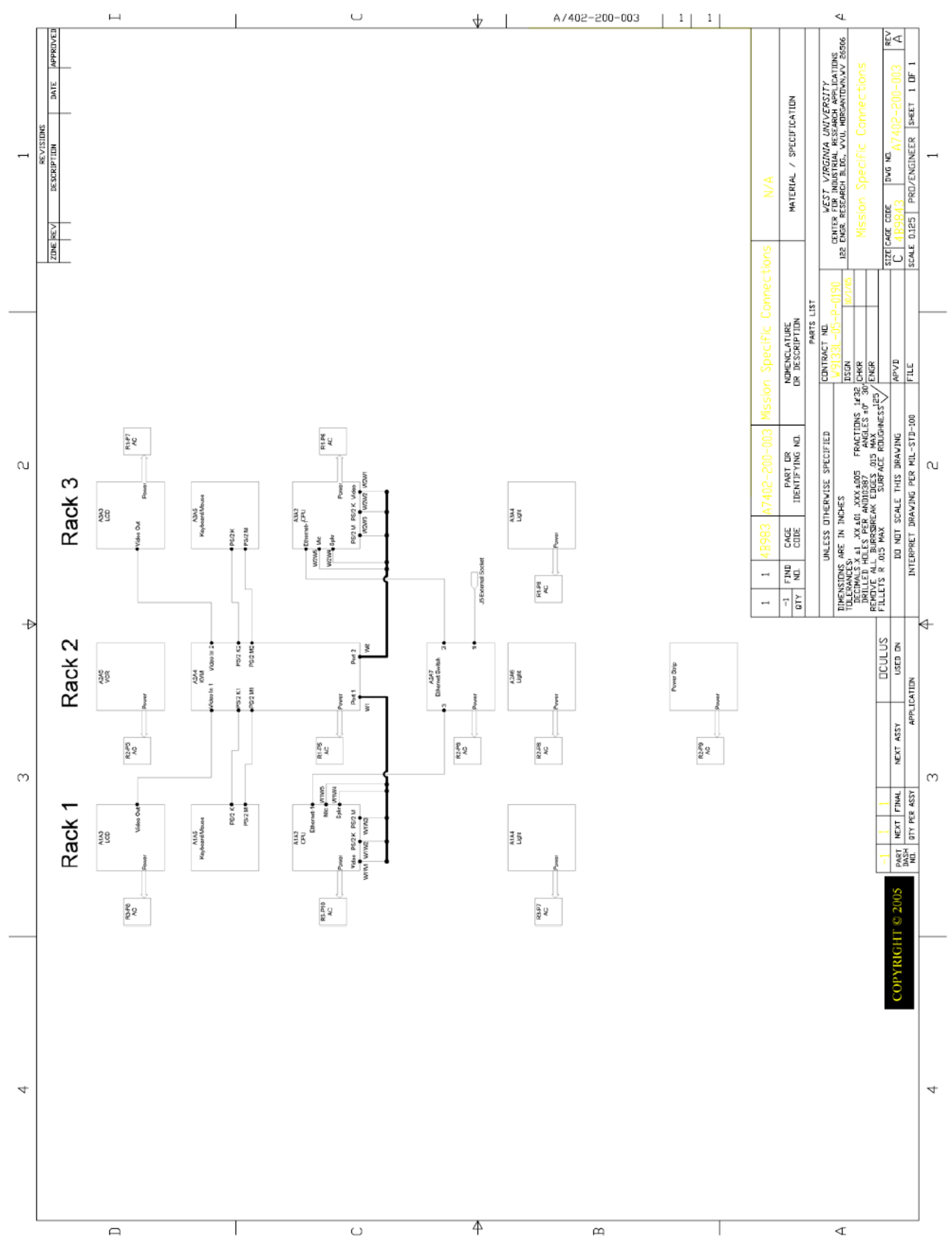




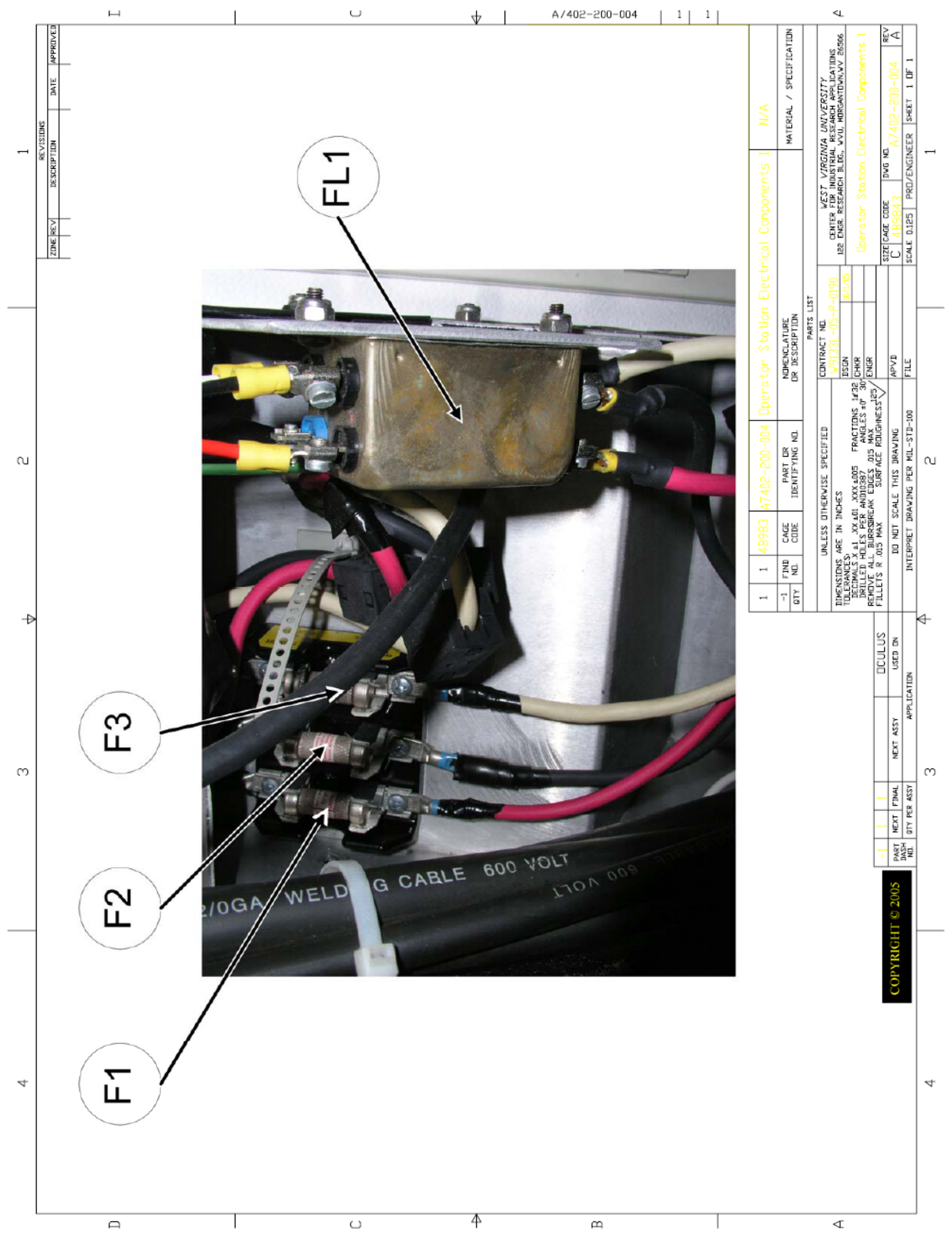




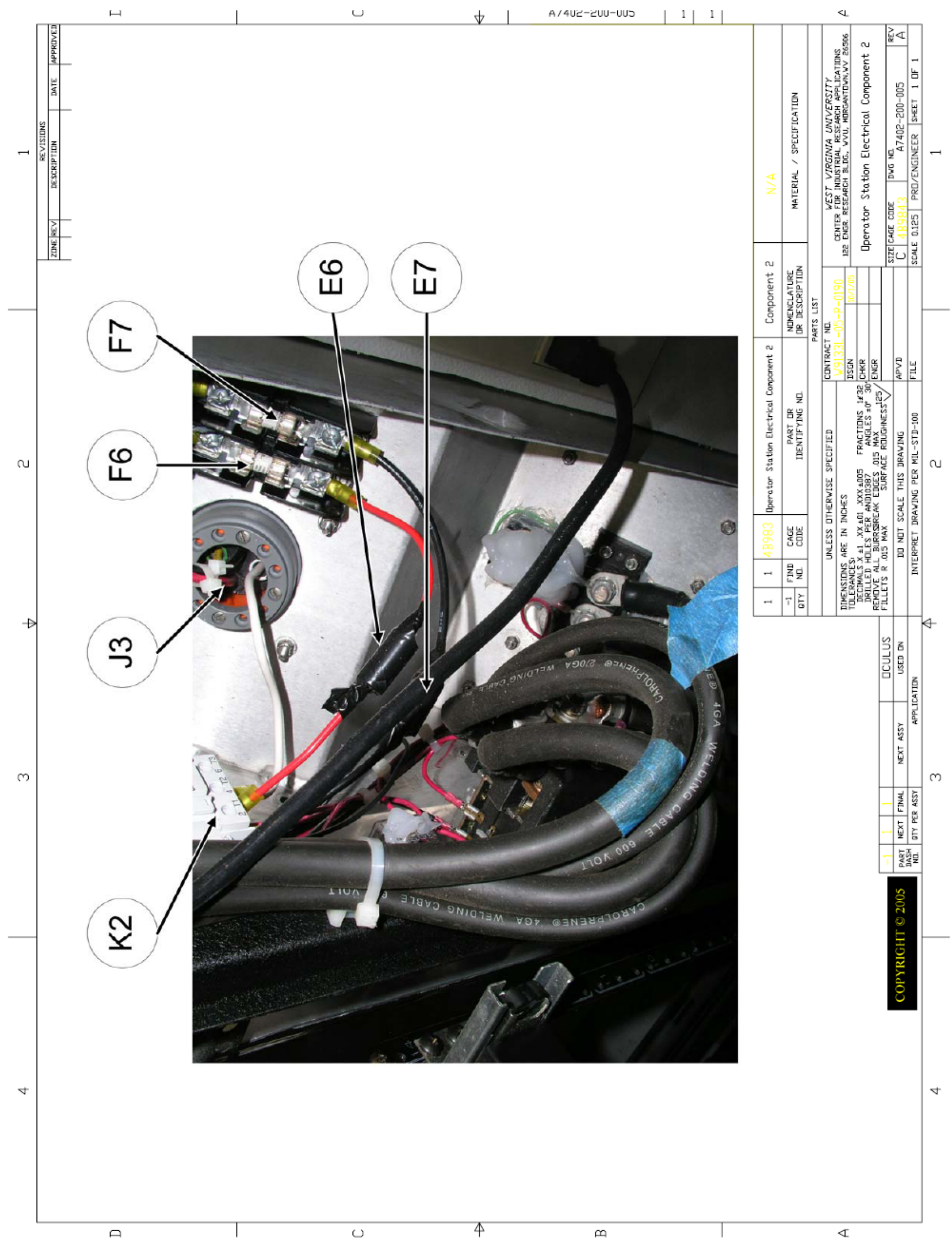




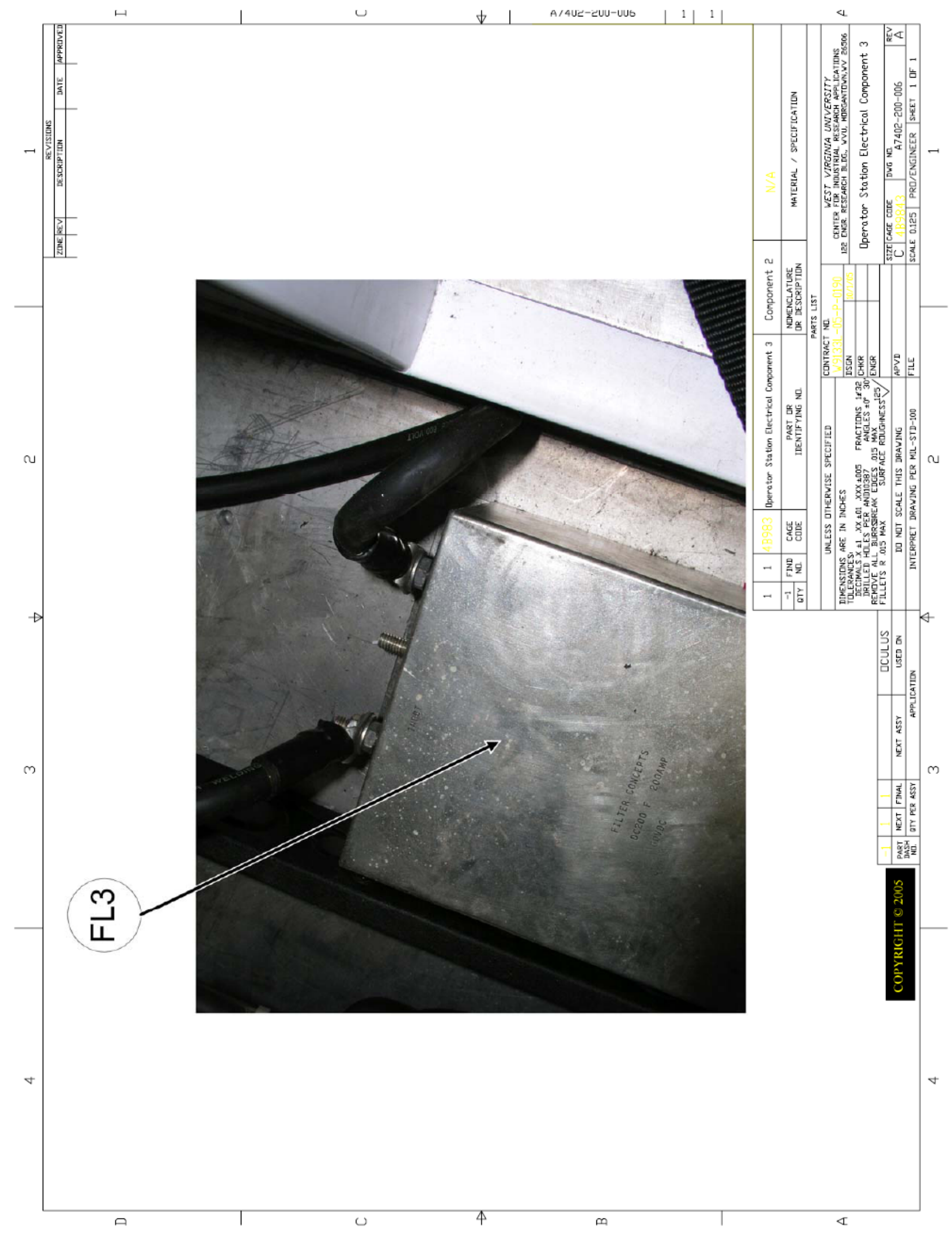




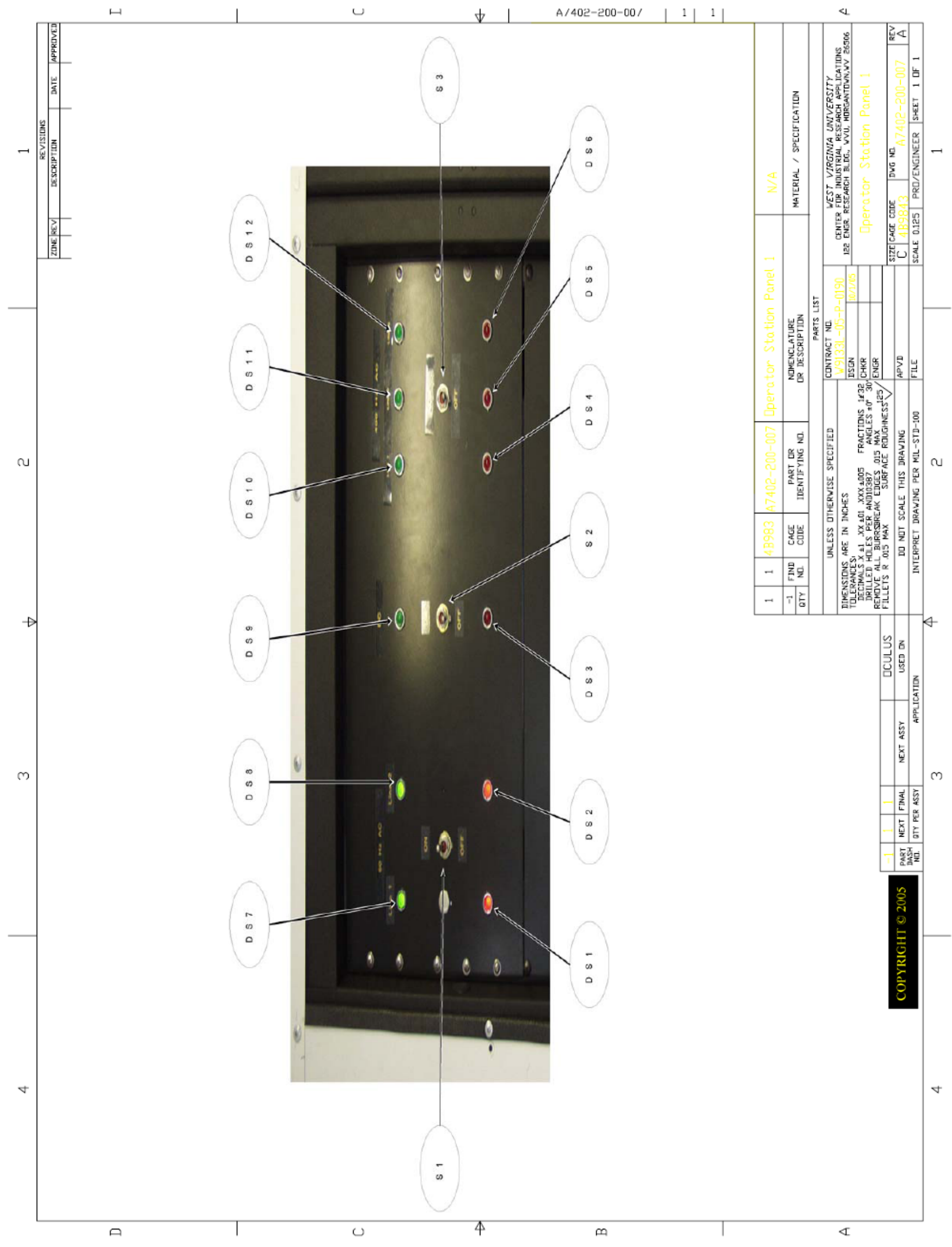




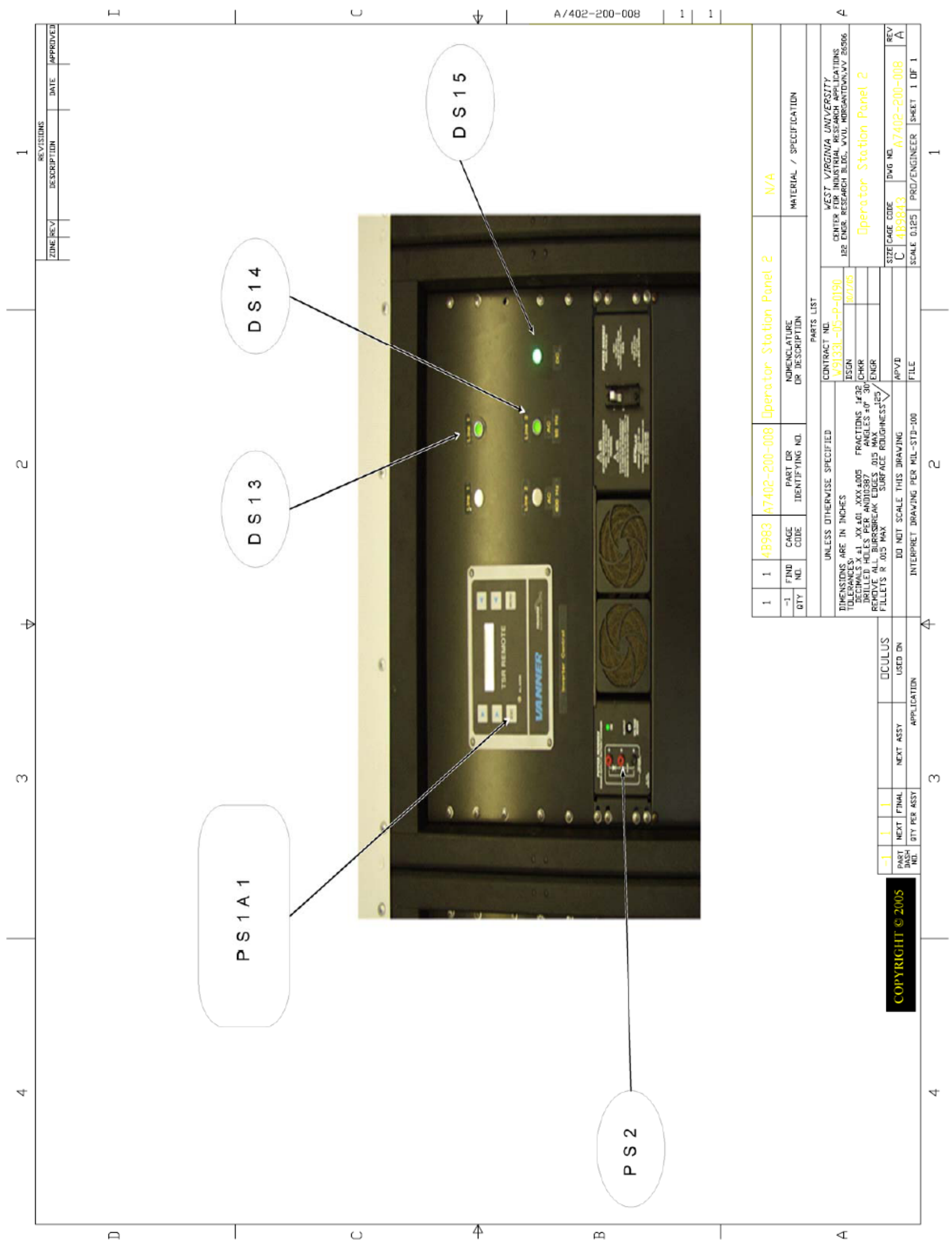




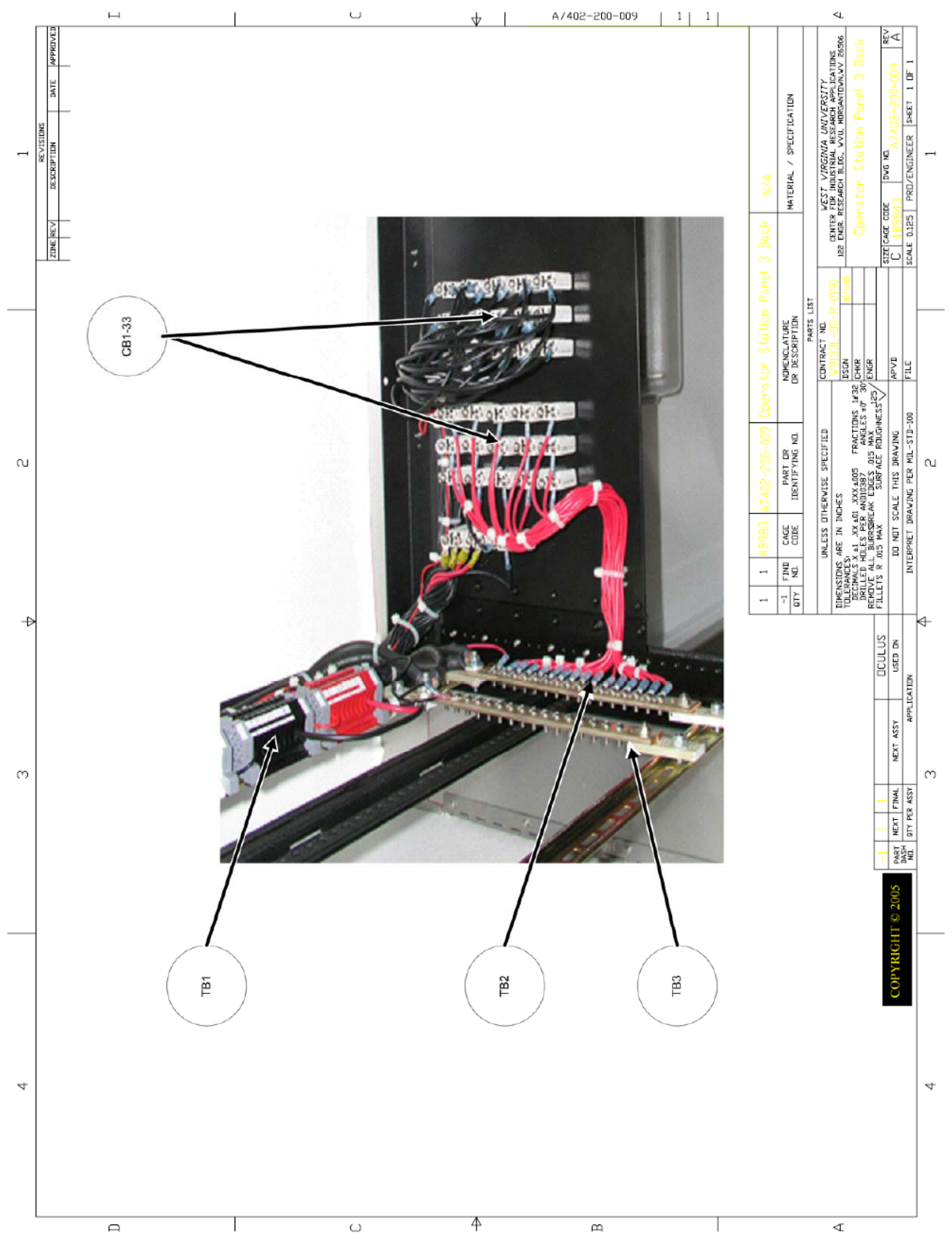




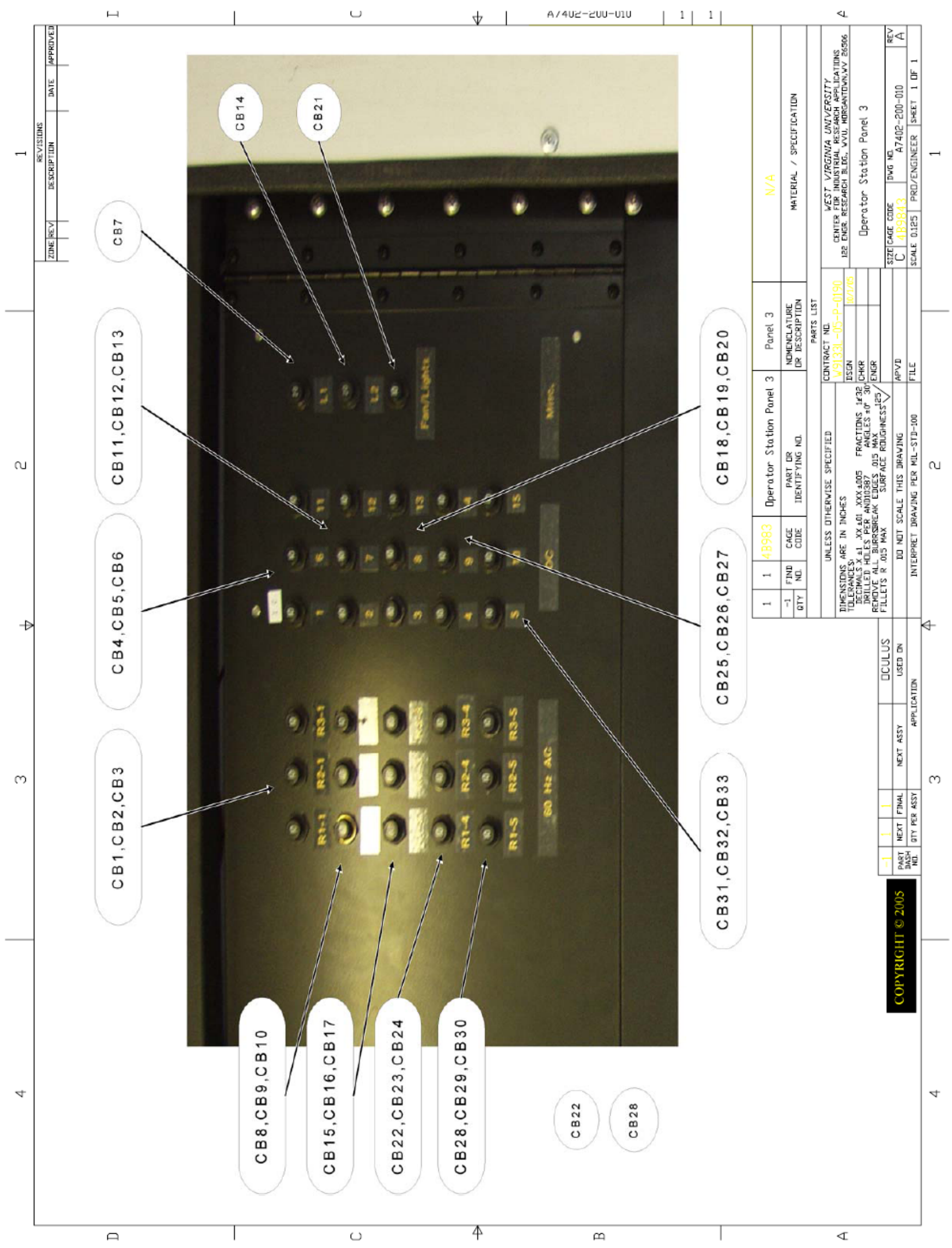




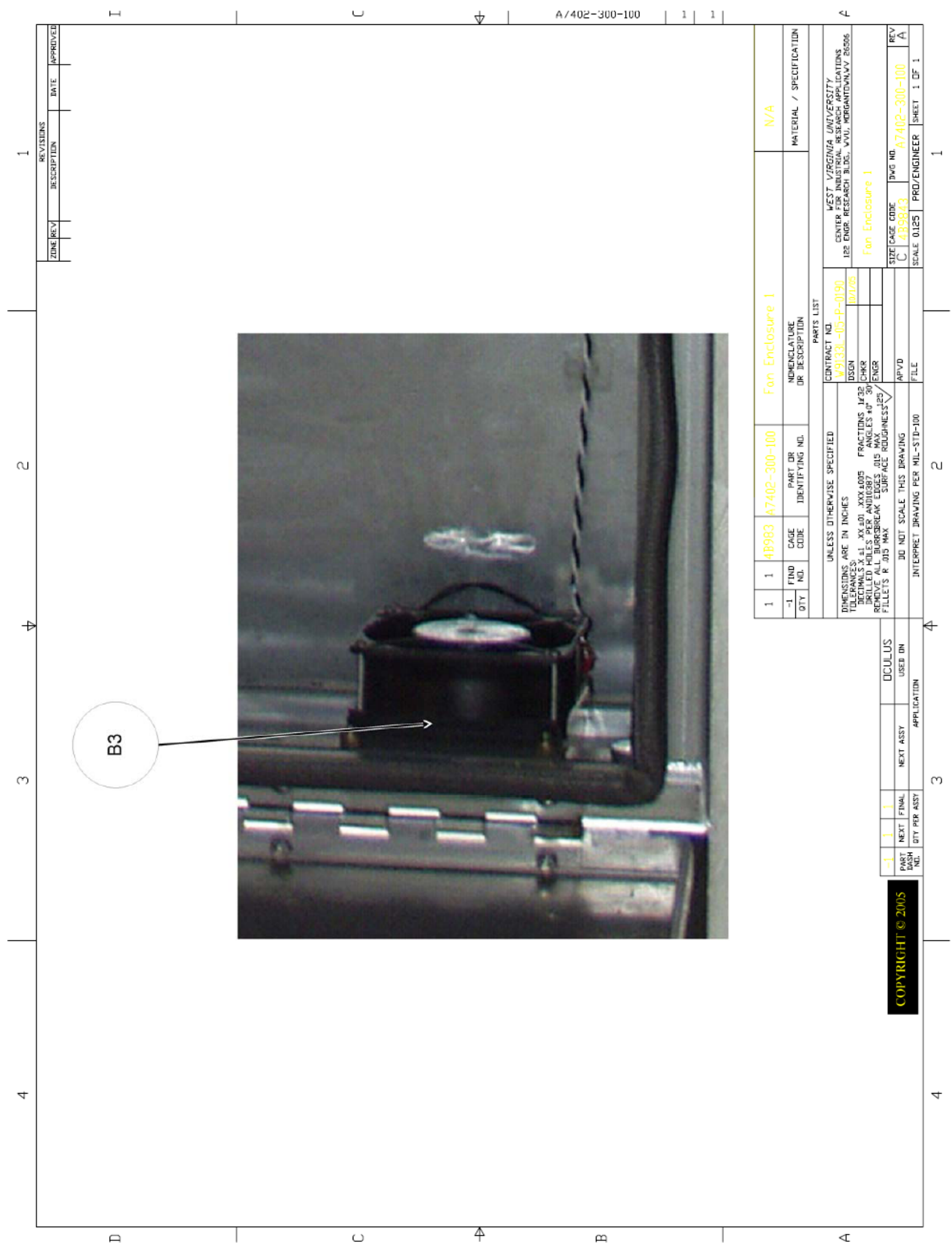




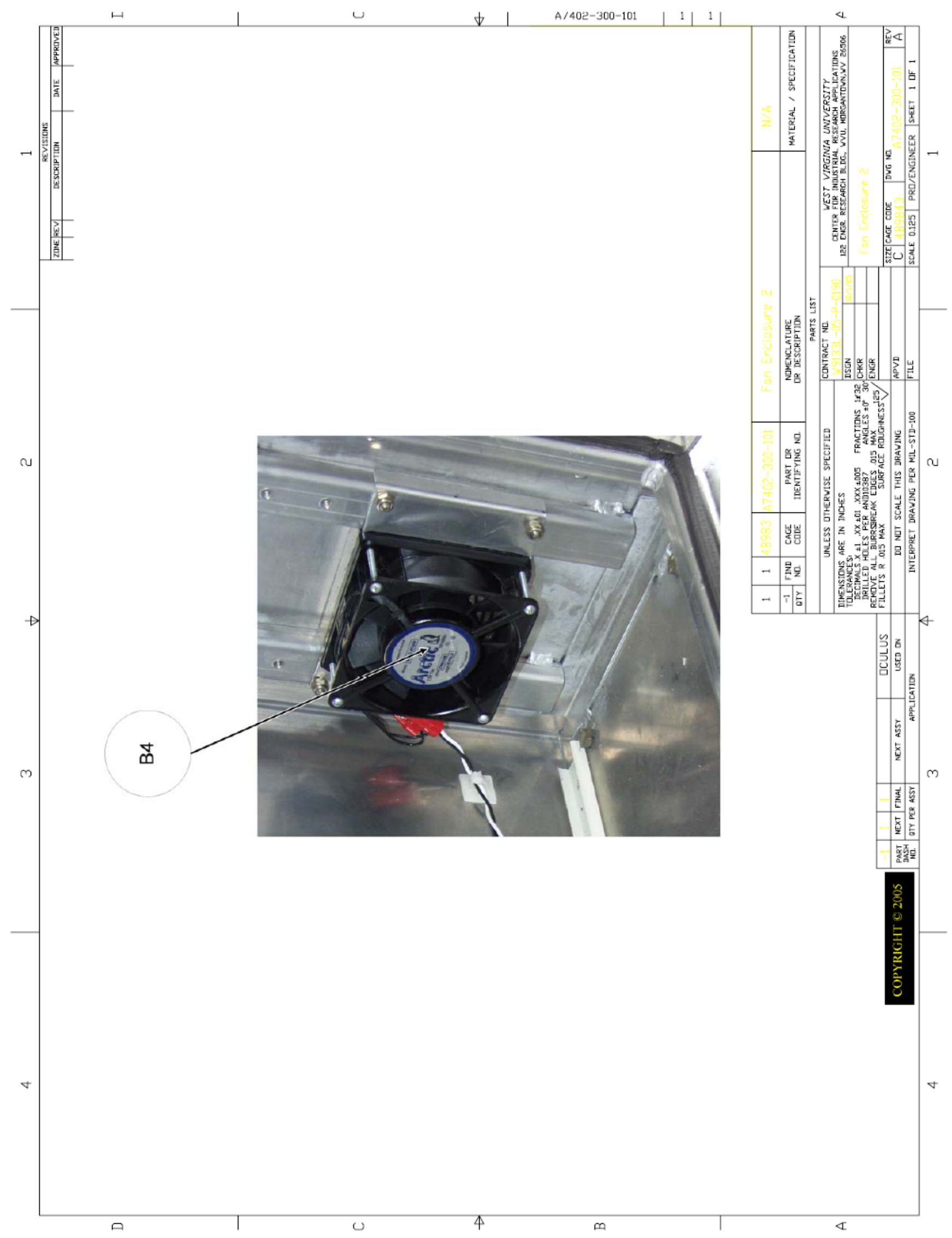




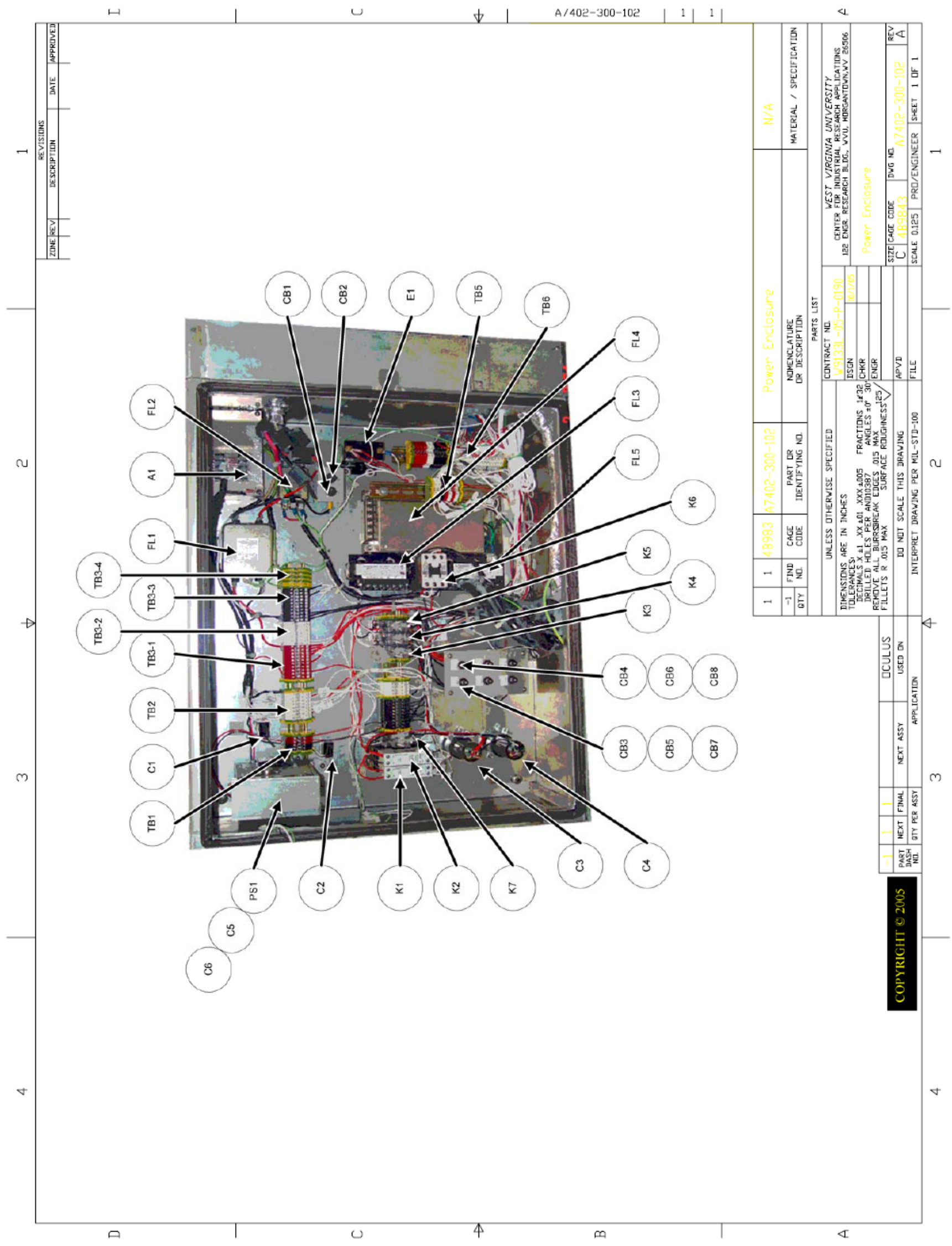




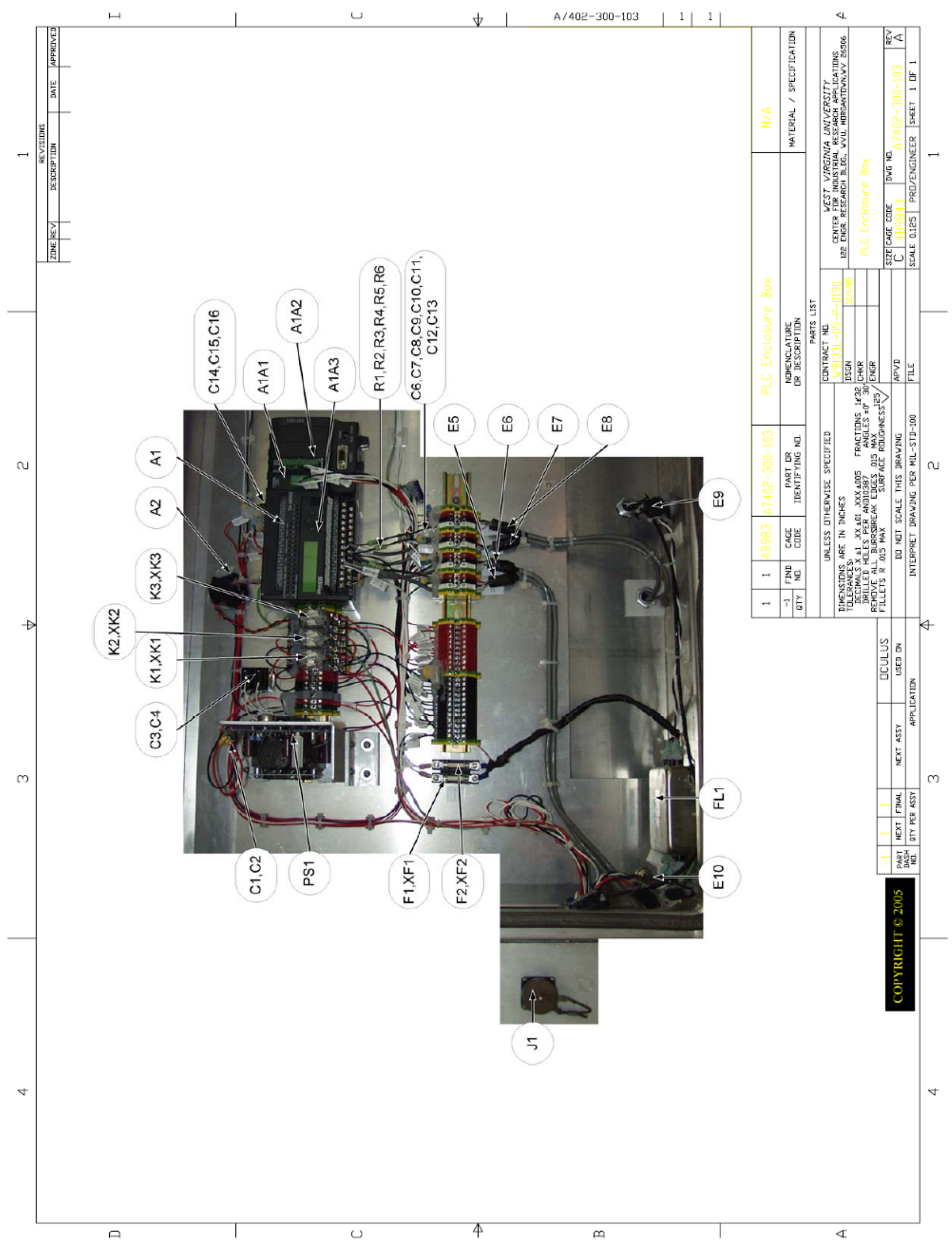




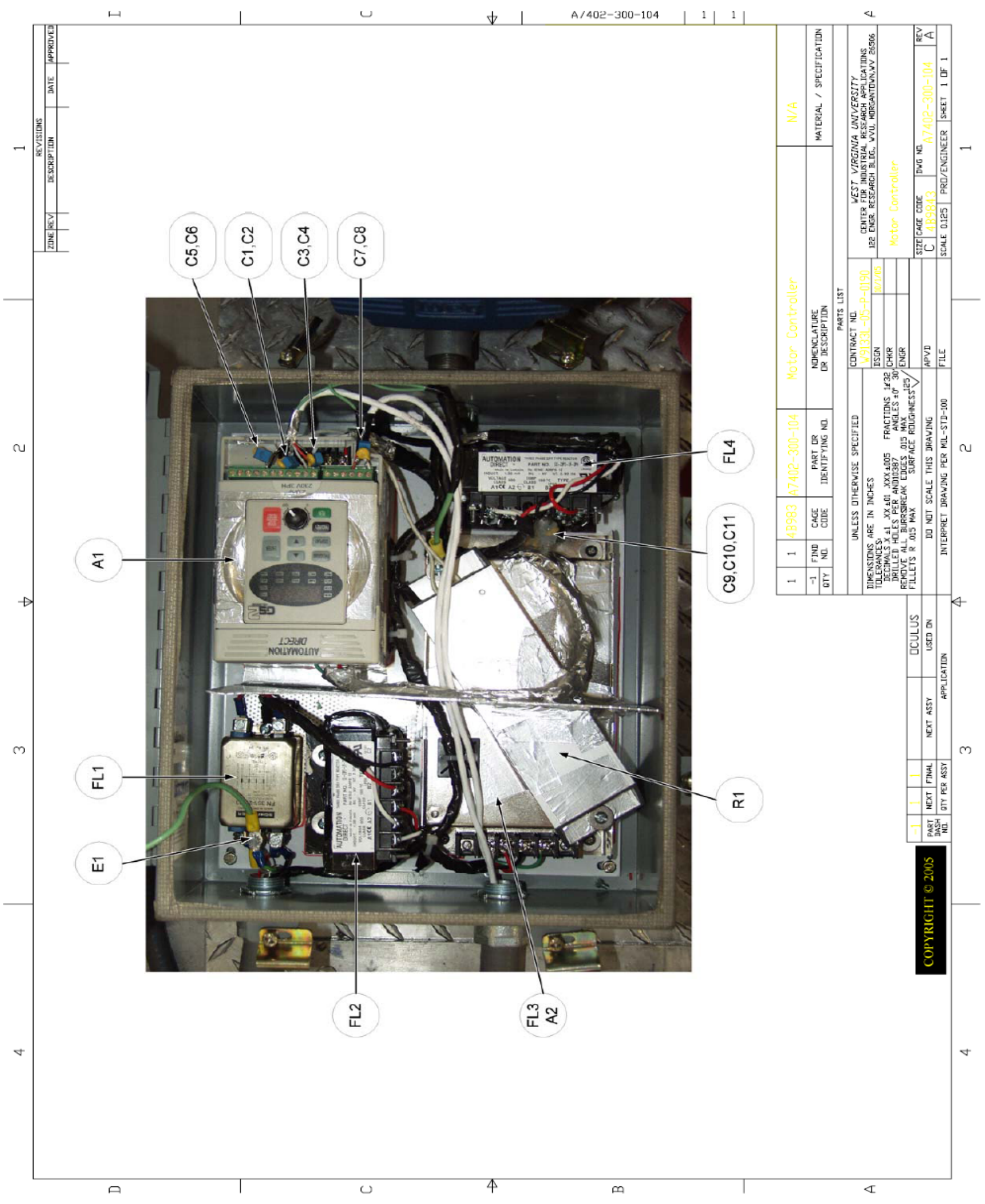




\section{Appendix E. OCULUS 1.1 Crash Survivability Analysis}

The attached report is the detailed crash survivability analysis submitted for WRAFB

during the OCULUS 1.1 certification process. This analysis look at the OCULUS systems reactions to crash loading standards outlined by MIL-HNBK-1791.This analysis pays close attention to the crash survivability of the OCULUS 1.1 sensor platform system due to its openarchitecture design and potential susceptibility to high crash loadings. The report clearly shows that the complete OCULSU 1.1 system is able to meet the crash survivability criterion outline by MIL-HNBK-1791. 


\section{OCULUS Crash Survivability Analysis}

\section{Scope:}

The purpose of this document is to present the results of analysis showing that the OCULUS system meets the load criteria of MIL-HDBK-1791 for installation in a C-130 aircraft. The load criterion is shown in Figure 1.

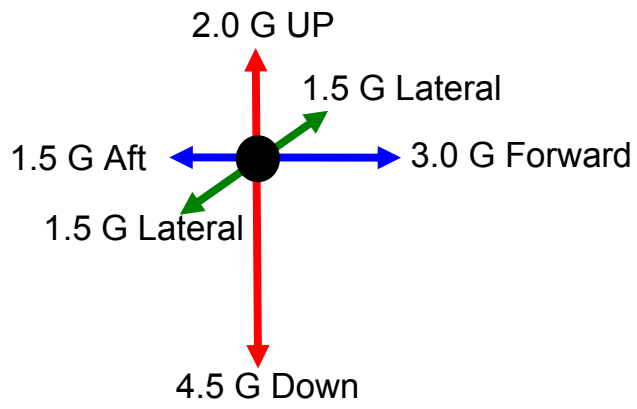

Figure 1. MIL-HDBK-1791 load criteria for C-130 cargo.

The intent behind establishing the load criteria for C-130 cargo was to provide guidelines for cargo equipment/container/pallet/airframe designers so that their designs will provide a reasonable opportunity for $\mathrm{C}-130$ crew members and passengers to survive a relatively minor crash situation. These load criteria were established as a compromise between safety, cost, weight, and other operational requirements. Many parameters effect personnel survival in the event of any emergency situation due to the complexity of the various possible conditions occurring in an emergency situation.

The purpose of this analysis is to show that during an emergency situation, the OCULUS system units, sub-assemblies, parts, components, and cabling that comprise the system do not fail or break free and become flying projectiles that could cause fatal injuries to crew members or passengers.

\section{Assumptions Used In Analysis:}

2.1 The OCULUS system is comprised of two structurally independent units. The units are (1) the Operator Station and (2) the Sensor Pallet.

\subsubsection{Operator Station.}

The Operator Station has been designed for use only in-flight and only for the purpose of acquiring and interpreting data during normal operational mission conditions. The User's Manual and operational CONOPS require that the Operator Station be evacuated of OCULUS mission operator(s) and observers, Operator Station doors closed, mission operators and observers safely secured in aircraft seats prior and during taxi, take-off, landing, specified emergency conditions, or at the request of the aircrew. Sensor pod operation (deploying or stowing) can be performed by an operator who is secured in aircraft seating, using the remote pendant control box with $15 \mathrm{ft}$ cable.

With the above operational constraints imposed, the Operator Station is treated as a modified ISU-96I shelter ("Cadillac container"). Certification from the manufacturer, Sea Box Inc., that this container meets the load criteria for this application is 
shown in Appendix A. Figure 2 below shows a picture of the Operator Station loaded and locked into the rail system of a C-130 aircraft.

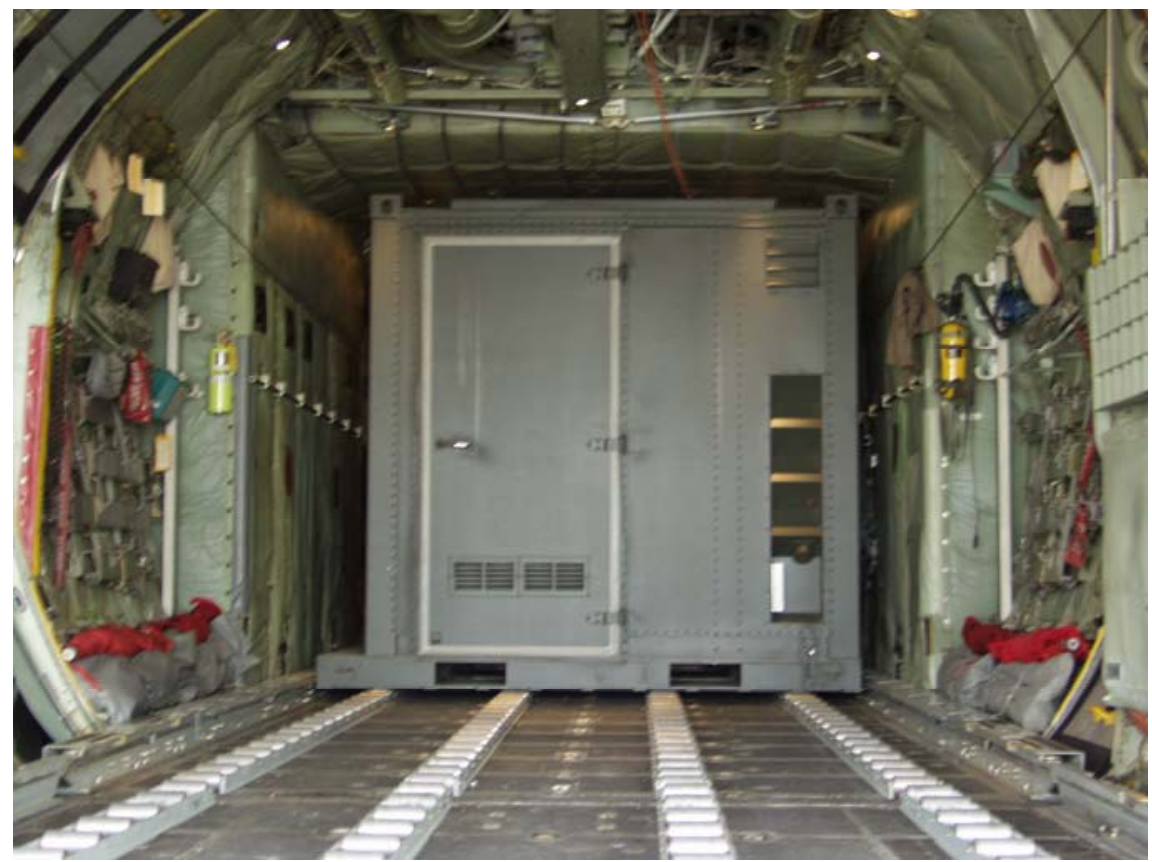

Figure 2 - Operator Station loaded and locked into the C-130 rail system.

\subsubsection{Sensor Pallet.}

The Sensor Pallet is a dynamic assembly that can have different configurations (sensor pod stowed and deployed) and is mounted on the ramp of the C-130 which can have two operational positions. There for this analysis address the following three configurations;

Configuration 1 - Sensor pod in stowed position, ramp locked in horizontal position, as shown in Figure 3.

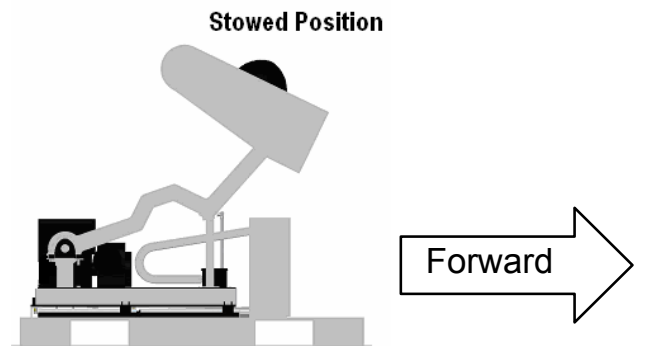

Figure 3 - OCULUS Sensor Pallet with sensor pod in the stowed position.

\section{Configuration 1 Assumptions:}

- OCULUS Sensor Pallet will be securely locked onto rear ramp rail system.

- Sensor pod is fully populated with maximum allowable payload weight (500 pounds).

- All fasteners used on the system are grade 8 high strength bolts.

- The stresses on the arm connection to the rotational shaft are reduced by the support stands.

Configuration 2 - Sensor pod in deployed position, ramp locked in horizontal position, as shown in Figure 4 and Figure 5. 


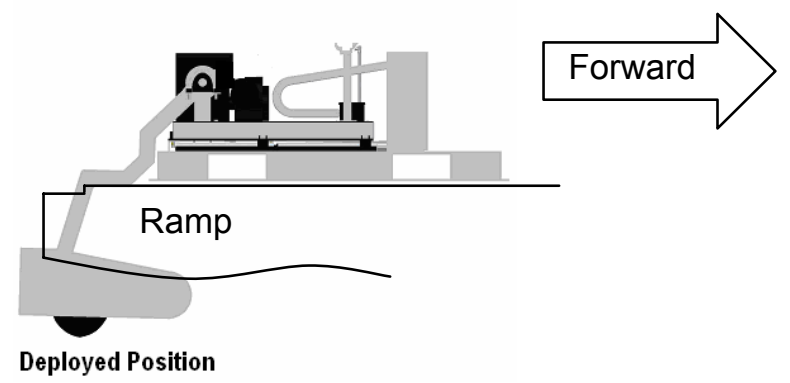

Figure 4 - OCULUS Sensor Pallet with sensor pod in the deployed position and rear ramp horizontal.

Configuration 2 Assumptions:

- OCULUS Sensor Pallet will be securely locked onto rear ramp rail system.

- Sensor pod is fully populated with maximum allowable payload weight (500 pounds).

- All fasteners used on the system are grade 8 high strength bolts.

- The sensor pod is wedged against the rear ramp with two contact positions highlighted by the arrows in Figure 5. This provides enhanced stability for the mechanical arm/pod system.

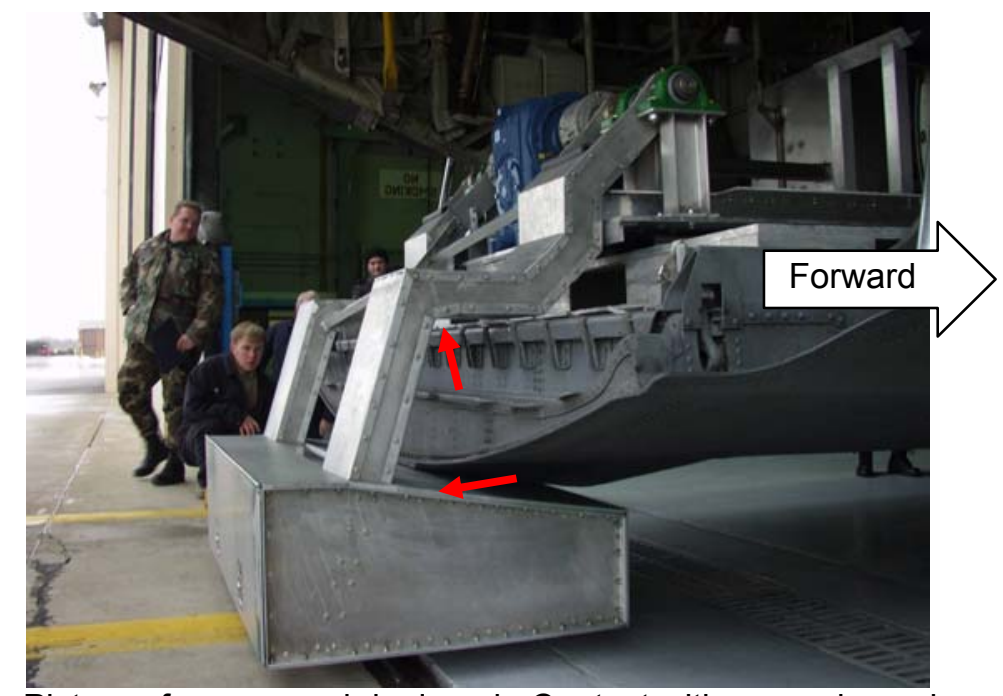

Figure 5 - Picture of sensor pod deployed. Contact with ramp shown by arrows.

Configuration 3 - Sensor pod in deployed position, ramp in closed and locked position with rear top door open, as shown in Figure 6.

\section{Deployed and Ramp Raised}

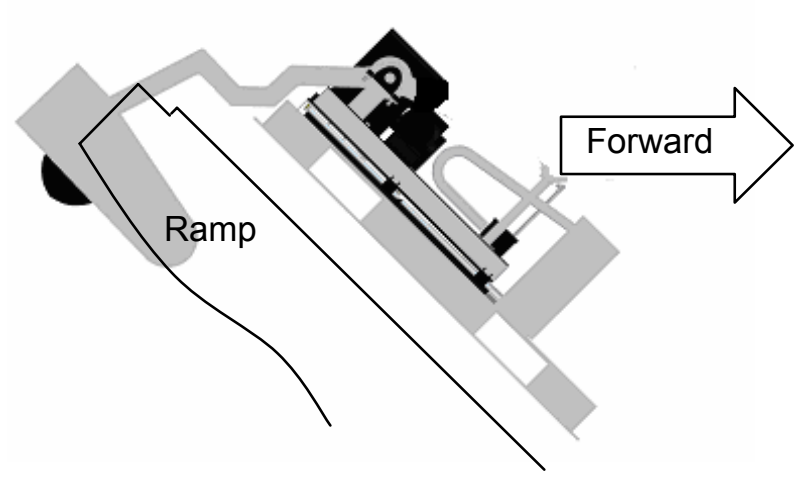


Figure 6 - OCULUS Sensor Pallet with sensor pod in the deployed position and rear ramp closed.

Configuration 3 Assumptions:

- OCULUS Sensor Pallet will be securely locked onto rear ramp rail system.

- Sensor pod is fully populated with maximum allowable payload weight (500 pounds).

- All fasteners used on the system are grade 8 high strength bolts.

- The sensor pod is wedged against the rear ramp with two contact positions highlighted by the arrows in Figure 5. This provides enhanced stability for the mechanical arm/pod system.

\subsection{Fastener Tear-Out Assumptions:}

This analysis was performed using standard bolt/mating component equations. Figure 7 shows an example of a tension (pull out) analysis performed on the fastener and the fastened components. All material data was taken from the Machinery's Handbook and assumed to be at ideal cases (1).

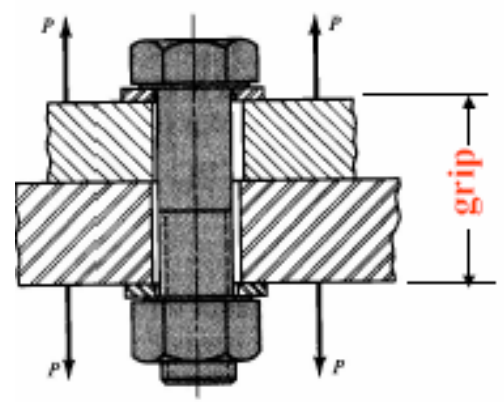

Figure 7 - Diagram of a bolt pull out scenario with applied forces (2).

In the following basic equation $(\mathrm{T})$ is the shear stress found when a specific load $(\mathrm{P})$ is applied to a fastener or component with a specific area $(A)$.

$$
\mathrm{T}=\mathrm{P} / \mathrm{A}
$$

The fastener tear out analysis was performed using the same equation as in (1) but applying different load contact area $(A)$. A different value for $(T)$ was used to correspond to the value for the mating structure (i.e the pallet in the case of the linear rails being joined to the pallet). Additional equations relating to specific cases (i.e using root mean diameter for specific fasteners, bolt pullout of tapped fasteners, etc.) where implemented using standard machine design calculations (Collins, 2003).

\section{Analysis Result:}

This report contains the results of several analysis related to the crash survivability of the OCULUS system.

The first analysis presented consists of the force calculations required for failure of fasteners and components of the OCULUS system. This analysis was performed sequentially from the outer most components in to the base pallet. The maximum values and the associated factor of safety, based upon MIL-HDBK-1791 load criteria of 3.0 G Forward, 1.5 G Aft, 1.5 G Lateral, 2.0 G Up, and 4.5 G Down were presented in tables 2 thru 4.

The second analysis presented investigated the force of dislodged rail plate system impacting the "fail stops" at the end of the linear rails.

The third analysis looks at the lateral loading conditions of the mechanical arm/pod system.

\subsection{Fastener and Component Failure Analysis}




\section{Operator Station}

The Operator Station is built on top of a modified 463L type pallet with the addition of a $3 / 4$ inch aluminum plate for stability and mounting purposes. The Operator Station is locked securely in place by the standard rail system of the $\mathrm{C}-130$ locking mechanisms. This modified structure meets (and well exceeds) the MIL-HDBK-1791 load criteria (Table 1). A complete overview of the analysis is described in Appendix A, Sections 1.0 and 3.0.

Table 1 - Operator station loading threshold.

\begin{tabular}{|l|r|}
\hline Load Direction & $\begin{array}{c}\text { Maximum Loading } \\
\text { Capability (pounds) }\end{array}$ \\
\hline Forward & 98,437 \\
\hline Aft & 98,437 \\
\hline Lateral & 98,437 \\
\hline Up & 155,100 \\
\hline Down & 452,000 \\
\hline
\end{tabular}

Since the Operator Station will be unoccupied and closed during emergency situations, this negates the potential of a crash scenario affecting an operator inside of the Operator Station. It also negates the affect of components inside the Operator Station on personnel outside the operator station during an emergency situation.

\section{Sensor Pallet}

The analysis performed on the Sensor Pallet included attached components most likely to have catastrophic failure during a crash situation (Appendix A, Section 2.0 provides a detailed analysis of the modified 463L pallet). Figure 8 shows an annotated diagram of the major components of the OCULUS Sensor Pallet system. The analysis was performed by investigating the mechanical interface of each specified component to its mating structure (i.e linear rail connection to the pallet). Each analysis looked at the possibility of fastener shear and fastener tear out from its mating structure while subjected to the loading criteria outlined in MIL-HDBK-1791 during the three configurations. Combined affects of components acting on other components during specific cases were also taken into affect (i.e pod stowed on the arm supports adding extra weight and force to the arm supports) along with general engineering assumptions (load distribution, combined acting forces, etc.). Tables 2, 3, and 4 show the results of the analysis performed on each component of the Sensor Pallet for the three configurations. The analysis reports holding forces for each component and a safety factor relative to the load criteria specified in MILHDBK-1791. The components with a safety factor of 10 or below are highlighted but are still well above minimal criteria. 


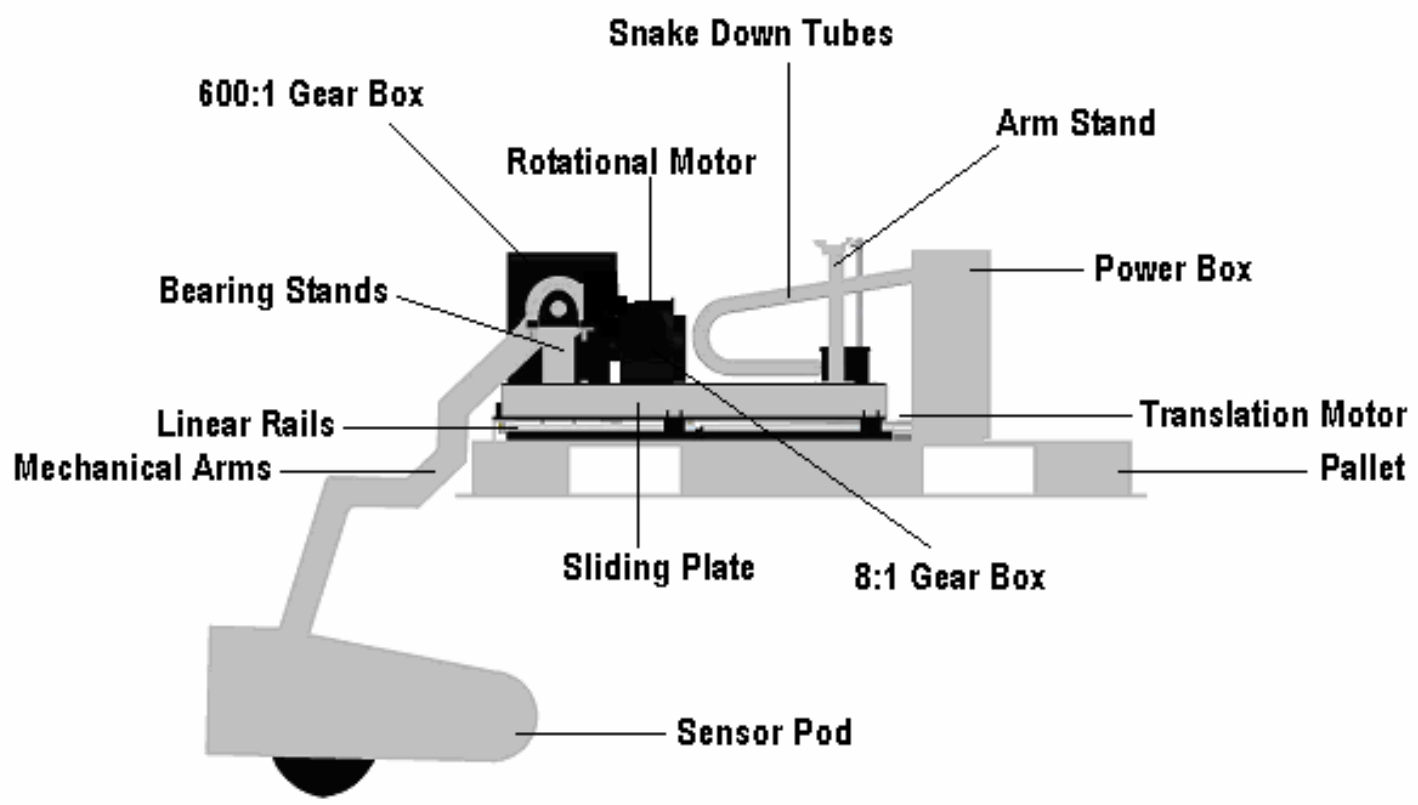

Figure 8 - Component identification diagram of the OCULUS Sensor Pallet. 
Table 2 - Sensor Pallet Configuration 1 (Sensor Pod Stowed, Ramp Horizontal) Analysis Results

\begin{tabular}{|c|c|c|c|c|c|c|c|c|c|c|c|c|c|c|c|c|}
\hline \multirow{3}{*}{$\begin{array}{c}\text { SENSOR PALLET Case 1: } \\
\text { Component }\end{array}$} & \multirow{3}{*}{$\begin{array}{c}\text { Dynamic } \\
\text { Load } \\
\text { lbs }\end{array}$} & \multicolumn{3}{|c|}{ Forward } & \multicolumn{3}{|c|}{ Aft } & \multirow{2}{*}{\multicolumn{2}{|c|}{$\begin{array}{c}\text { Lateral } \\
\text { Holding Force }\end{array}$}} & \multirow{3}{*}{$\begin{array}{l}\text { Factor of } \\
\text { Safety }\end{array}$} & \multicolumn{3}{|c|}{ Up } & \multicolumn{3}{|c|}{ Down } \\
\hline & & \multicolumn{2}{|c|}{ Holding Force } & \multirow{2}{*}{$\begin{array}{c}\text { Factor of } \\
\text { Safety }\end{array}$} & \multicolumn{2}{|c|}{ Holding Force } & \multirow{2}{*}{$\begin{array}{l}\text { Factor of } \\
\text { Safety }\end{array}$} & & & & \multicolumn{2}{|c|}{ Holding Force } & \multirow{2}{*}{$\begin{array}{l}\text { Factor of } \\
\text { Safety }\end{array}$} & \multicolumn{2}{|c|}{ Holding Force } & \multirow{2}{*}{\begin{tabular}{|c|} 
Factor of \\
Safety
\end{tabular}} \\
\hline & & Ibs & $\mathrm{G}$ & & Ibs & $\bar{G}$ & & Ibs & $\bar{G}$ & & Ibs & $\bar{G}$ & & Ibs & $\bar{G}$ & \\
\hline Pod & 730.00 & 75000.00 & 102.74 & 34.25 & 75000.00 & 102.74 & 68.49 & 5800000.00 & 7945.21 & 5296.80 & 75000.00 & 102.74 & 51.37 & 75000.00 & $\overline{102.74}$ & 22.83 \\
\hline Arms (4) & 845.00 & 24030.00 & 28.44 & 9.48 & 24030.00 & 28.44 & 18.96 & 24030.00 & 28.44 & 18.96 & 24030.00 & 28.44 & 14.22 & 24030.00 & 28.44 & 6.32 \\
\hline Arm Conduits (2) & 7.50 & 3748.00 & 499.73 & 166.58 & 3748.00 & 499.73 & 333.16 & 14400000.00 & 1920000.00 & 1280000.00 & 2577.00 & 343.60 & 171.80 & 2577.00 & 343.60 & 76.36 \\
\hline Rotational Shafts (2) & 881.00 & 483560.00 & 548.88 & 182.96 & 483560.00 & 548.88 & 365.92 & 6000.00 & 6.81 & 4.54 & 483560.00 & 548.88 & 274.44 & 483560.00 & 548.88 & 121.97 \\
\hline Bearings (4) & 897.00 & 64000.00 & 71.35 & 23.78 & 64000.00 & 71.35 & 47.57 & 64000.00 & 71.35 & 47.57 & 64000.00 & 71.35 & 35.67 & 76000.00 & 84.73 & 18.83 \\
\hline Flex Couplers (2) & 17.00 & 172000.00 & 10117.65 & 3372.55 & 172000.00 & 10117.65 & 6745.10 & 4000.00 & 235.29 & 156.86 & 172000.00 & 10117.65 & 5058.82 & 172000.00 & \begin{tabular}{|l|}
10117.65 \\
\end{tabular} & 2248.37 \\
\hline Bearing Stands (4) & 913.00 & 44992.00 & 49.28 & 16.43 & 44992.00 & 49.28 & 32.85 & 44992.00 & 49.28 & 32.85 & 82720.00 & 90.60 & 45.30 & 270000.00 & 295.73 & 65.72 \\
\hline $600: 1$ Gearbox & 405.00 & 75000.00 & 185.19 & 61.73 & 75000.00 & 185.19 & 123.46 & 75000.00 & 185.19 & 123.46 & 94000.00 & 232.10 & 116.05 & 720000.00 & 1777.78 & 395.06 \\
\hline 8:1 Gearbox & 25.00 & 86112.00 & 3444.48 & 1148.16 & 86112.00 & 3444.48 & 2296.32 & 51360.00 & 2054.40 & 1369.60 & 86112.00 & 3444.48 & 1722.24 & 86112.00 & 3444.48 & 765.44 \\
\hline Rotational Motor & 35.00 & 57432.00 & 1640.91 & 546.97 & 57432.00 & 1640.91 & 1093.94 & 34240.00 & 978.29 & 652.19 & 57432.00 & 1640.91 & 820.46 & 57432.00 & 1640.91 & 364.65 \\
\hline Left Arm Stand & 422.50 & 44992.00 & 106.49 & 35.50 & 44992.00 & 106.49 & 70.99 & 44992.00 & 106.49 & 70.99 & 82720.00 & 195.79 & 97.89 & 270000.00 & 639.05 & 142.01 \\
\hline Right Arm Stand & 427.00 & 44992.00 & 105.37 & 35.12 & 44992.00 & 105.37 & 70.25 & 44992.00 & 105.37 & 70.25 & 82720.00 & 193.72 & 96.86 & 270000.00 & 632.32 & 140.52 \\
\hline Hand Crank Stand & 5.00 & 3750.00 & 750.00 & 250.00 & 3750.00 & 750.00 & 500.00 & 3750.00 & 750.00 & 500.00 & 4200.00 & 840.00 & 420.00 & 270000.00 & 54000.00 & 12000.00 \\
\hline Hand Crank & 18.00 & 21190.00 & 1177.22 & 392.41 & 21190.00 & 1177.22 & 784.81 & 10500.00 & 583.33 & 388.89 & 21190.00 & 1177.22 & 588.61 & 21190.00 & \begin{tabular}{|l|}
1177.22 \\
\end{tabular} & 261.60 \\
\hline Hand Crank Shaft & 2.00 & 116.00 & 58.00 & 19.33 & 21190.00 & 10595.00 & 7063.33 & 21192.00 & 10596.00 & 7064.00 & 23623.00 & 11811.50 & 5905.75 & 23623.00 & \begin{tabular}{|l|}
11811.50 \\
\end{tabular} & 2624.78 \\
\hline Snakes (2) & 10.00 & 3750.00 & 375.00 & 125.00 & 3750.00 & 375.00 & 250.00 & 3750.00 & 375.00 & 250.00 & 5154.00 & 515.40 & 257.70 & 5154.00 & 515.40 & 114.53 \\
\hline Snake Down Tubes (2) & 14.00 & 19144.00 & 1367.43 & 455.81 & 19144.00 & 1367.43 & 911.62 & 19144.00 & 1367.43 & 911.62 & 2934.00 & 209.57 & 104.79 & 337500.00 & \begin{tabular}{|l|}
24107.14 \\
\end{tabular} & 5357.14 \\
\hline Diamond Plate & 200.00 & 210000.00 & 1050.00 & 350.00 & 210000.00 & 1050.00 & 700.00 & 210000.00 & 1050.00 & 700.00 & 127440.00 & 637.20 & 318.60 & 735000.00 & 3675.00 & 816.67 \\
\hline Sliding Plate & 1300.00 & 28313.00 & 21.78 & 7.26 & 28313.00 & 21.78 & 14.52 & 38220.00 & 29.40 & 19.60 & 10000.00 & 7.69 & 3.85 & 38220.00 & 29.40 & 6.53 \\
\hline Linear Rails (8) & 45.00 & 38220.00 & 849.33 & 283.11 & 38220.00 & 849.33 & 566.22 & 44100.00 & 980.00 & 653.33 & 38220.00 & 849.33 & 424.67 & 38220.00 & 849.33 & 188.74 \\
\hline Translation Motor & 10.00 & 6708.00 & 670.80 & 223.60 & 6708.00 & 670.80 & 447.20 & 8515.00 & 851.50 & 567.67 & 6708.00 & 670.80 & 335.40 & 9708.00 & 970.80 & 215.73 \\
\hline Power Box & 30.00 & 8437.00 & 281.23 & 93.74 & 8437.00 & 281.23 & 187.49 & 8437.00 & 281.23 & 187.49 & 13248.00 & 441.60 & 220.80 & 1530000.00 & 51000.00 & \begin{tabular}{|l|}
11333.33 \\
\end{tabular} \\
\hline PLC Box & 27.00 & 8437.00 & 312.48 & 104.16 & 8437.00 & 312.48 & 208.32 & 8437.00 & 312.48 & 208.32 & 13248.00 & 490.67 & 245.33 & 1530000.00 & \begin{tabular}{|l|}
56666.67 \\
\end{tabular} & \begin{tabular}{|l|}
12592.59 \\
\end{tabular} \\
\hline Box 1 & 14.00 & 5625.00 & 401.79 & 133.93 & 5625.00 & 401.79 & 267.86 & 5625.00 & 401.79 & 267.86 & 8832.00 & 630.86 & 315.43 & 1530000.00 & 109285.71 & \begin{tabular}{|l|}
24285.71 \\
\end{tabular} \\
\hline Box 2 & 14.00 & 5625.00 & 401.79 & 133.93 & 5625.00 & 401.79 & 267.86 & 5625.00 & 401.79 & 267.86 & 8832.00 & 630.86 & 315.43 & 1530000.00 & 109285.71 & \begin{tabular}{|l|}
24285.71 \\
\end{tabular} \\
\hline Box 3 & 14.00 & 5625.00 & 401.79 & 133.93 & 5625.00 & 401.79 & 267.86 & 5625.00 & 401.79 & 267.86 & 8832.00 & 630.86 & 315.43 & 1530000.00 & 109285.71 & \begin{tabular}{|l|}
24285.71 \\
\end{tabular} \\
\hline Box 4 & 14.00 & 5625.00 & 401.79 & 133.93 & 5625.00 & 401.79 & 267.86 & 5625.00 & 401.79 & 267.86 & 8832.00 & 630.86 & 315.43 & 1530000.00 & 109285.71 & \begin{tabular}{|l|}
24285.71 \\
\end{tabular} \\
\hline Step & 7.00 & 7500.00 & 1071.43 & 357.14 & 7500.00 & 1071.43 & 714.29 & 7500.00 & 1071.43 & 714.29 & 20680.00 & 2954.29 & 1477.14 & 2400000.00 & 342857.14 & 76190.48 \\
\hline Translation Limit Switches (2) & 2.00 & 3750.00 & 1875.00 & 625.00 & 3750.00 & 1875.00 & 1250.00 & 3750.00 & 1875.00 & 1250.00 & 5144.00 & 2572.00 & 1286.00 & 5144.00 & 2572.00 & 571.56 \\
\hline Translation Proximity Sensors (2) & 2.00 & 3750.00 & 1875.00 & 625.00 & 3750.00 & 1875.00 & 1250.00 & 3750.00 & 1875.00 & 1250.00 & 5144.00 & 2572.00 & 1286.00 & 5144.00 & 2572.00 & 571.56 \\
\hline 463 L-Type Pallet & 1078.00 & 170000.00 & 157.70 & 52.57 & 170000.00 & 157.70 & 105.13 & 120000.00 & 111.32 & 74.21 & 130000.00 & 120.59 & 60.30 & 540000.00 & 500.93 & 111.32 \\
\hline
\end{tabular}

Note 1: See Appendix A Section 2.0 (Structural Analysis of a Modified 463L Pallet). 
Table 3 - Sensor Pallet Configuration 2 (Sensor Pod Deployed, Ramp Horizontal) Analysis Results

\begin{tabular}{|c|c|c|c|c|c|c|c|c|c|c|c|c|c|c|c|c|}
\hline \multirow{3}{*}{$\begin{array}{c}\text { SENSOR PALLET Case 2: } \\
\text { Component } \\
\end{array}$} & \multirow{3}{*}{\begin{tabular}{|c|} 
Dynamic \\
Load \\
lbs
\end{tabular}} & \multicolumn{3}{|c|}{ Forward } & \multicolumn{3}{|c|}{ Aft } & \multicolumn{3}{|c|}{ Lateral } & \multicolumn{3}{|c|}{ Up } & \multicolumn{3}{|c|}{ Down } \\
\hline & & Holding & & \multirow{2}{*}{$\begin{array}{c}\begin{array}{c}\text { Factor of } \\
\text { Safety }\end{array} \\
\end{array}$} & \multicolumn{2}{|c|}{ Holding Force } & \multirow{2}{*}{$\begin{array}{c}\text { Factor of } \\
\text { Safety }\end{array}$} & \multicolumn{2}{|c|}{ Holding Force } & \multirow{2}{*}{$\begin{array}{c}\text { Factor of } \\
\text { Safety }\end{array}$} & \multicolumn{2}{|c|}{ Holding Force } & \multirow{2}{*}{$\begin{array}{c}\text { Factor of } \\
\text { Safety }\end{array}$} & \multicolumn{2}{|c|}{ Holding Force } & \multirow{2}{*}{$\begin{array}{c}\text { Factor of } \\
\text { Safety }\end{array}$} \\
\hline & & Ibs & $G$ & & Ibs & G & & Ibs & $\mathrm{G}$ & & Ibs & G & & Ibs & G & \\
\hline Pod & 730.00 & \begin{tabular}{|l|}
75000.00 \\
\end{tabular} & 102.74 & 34.25 & 75000.00 & 102.74 & 68.49 & 5800000.00 & 7945.21 & 5296.80 & 75000.00 & 102.74 & 51.37 & 75000.00 & 102.74 & 22.83 \\
\hline Arms (4) & 845.00 & \begin{tabular}{|l|}
24030.00 \\
\end{tabular} & 28.44 & 9.48 & 24030.00 & 28.44 & 18.96 & 24030.00 & 28.44 & 18.96 & 24030.00 & 28.44 & 14.22 & 24030.00 & 28.44 & 6.32 \\
\hline Arm Conduits (2) & 7.50 & \begin{tabular}{|l|}
2577.00 \\
\end{tabular} & 343.60 & 114.53 & 2577.00 & 343.60 & 229.07 & 14400000.00 & 1920000.00 & 1280000.00 & 3478.00 & 463.73 & 231.87 & 3478.00 & 463.73 & 103.05 \\
\hline Rotational Shafts (2) & 881.00 & 483560.00 & 548.88 & 182.96 & 483560.00 & 548.88 & 365.92 & 6000.00 & 6.81 & 4.54 & 483560.00 & 548.88 & 274.44 & 483560.00 & 548.88 & 121.97 \\
\hline Bearings (4) & 897.00 & \begin{tabular}{|l|}
64000.00 \\
\end{tabular} & 71.35 & 23.78 & 64000.00 & 71.35 & 47.57 & 64000.00 & 71.35 & 47.57 & 64000.00 & 71.35 & 35.67 & 76000.00 & 84.73 & 18.83 \\
\hline Flex Couplers (2) & 17.00 & 172000.00 & \begin{tabular}{|l|}
10117.65 \\
\end{tabular} & 3372.55 & 172000.00 & 10117.65 & 6745.10 & 4000.00 & 235.29 & 156.86 & 172000.00 & 10117.65 & 5058.82 & 172000.00 & \begin{tabular}{|l|}
10117.65 \\
\end{tabular} & 2248.37 \\
\hline Bearing Stands (4) & 1200.00 & \begin{tabular}{|l|}
44992.00 \\
\end{tabular} & 37.49 & 12.50 & 44992.00 & 37.49 & 25.00 & 44992.00 & 37.49 & 25.00 & 82720.00 & 68.93 & 34.47 & 270000.00 & 225.00 & 50.00 \\
\hline 600:1 Gearbox & 405.00 & \begin{tabular}{|l|}
75000.00 \\
\end{tabular} & 185.19 & 61.73 & 75000.00 & 185.19 & 123.46 & 75000.00 & 185.19 & 123.46 & 94000.00 & 232.10 & 116.05 & 720000.00 & 1777.78 & 395.06 \\
\hline 8:1 Gearbox & 25.00 & \begin{tabular}{|l|}
86112.00 \\
\end{tabular} & 3444.48 & 1148.16 & 86112.00 & 3444.48 & 2296.32 & 51360.00 & 2054.40 & 1369.60 & 86112.00 & 3444.48 & 1722.24 & 86112.00 & 3444.48 & 765.44 \\
\hline Rotational Motor & 35.00 & \begin{tabular}{|l|}
57432.00 \\
\end{tabular} & 1640.91 & 546.97 & 57432.00 & 1640.91 & 1093.94 & 34240.00 & 978.29 & 652.19 & 57432.00 & 1640.91 & 820.46 & 57432.00 & 1640.91 & 364.65 \\
\hline Left Arm Stand & 3.00 & \begin{tabular}{|l|}
44992.00 \\
\end{tabular} & 14997.33 & 4999.11 & 44992.00 & 14997.33 & 9998.22 & 44992.00 & 14997.33 & 9998.22 & 82720.00 & 27573.33 & 13786.67 & 270000.00 & 90000.00 & 20000.00 \\
\hline Right Arm Stand & 4.50 & \begin{tabular}{|l|}
44992.00 \\
\end{tabular} & 9998.22 & 3332.74 & 44992.00 & 9998.22 & 6665.48 & 44992.00 & 9998.22 & 6665.48 & 82720.00 & 18382.22 & 9191.11 & 270000.00 & \begin{tabular}{l|}
60000.00 \\
\end{tabular} & 13333.33 \\
\hline Hand Crank Stand & 5.00 & 3750.00 & 750.00 & 250.00 & 3750.00 & 750.00 & 500.00 & 3750.00 & 750.00 & 500.00 & 4200.00 & 840.00 & 420.00 & 270000.00 & \begin{tabular}{|l|}
54000.00 \\
\end{tabular} & 12000.00 \\
\hline Hand Crank & 18.00 & 21190.00 & 1177.22 & 392.41 & 21190.00 & 1177.22 & 784.81 & 10500.00 & 583.33 & 388.89 & 21190.00 & 1177.22 & 588.61 & 21190.00 & 1177.22 & 261.60 \\
\hline Hand Crank Shaft & 2.00 & 116.00 & 58.00 & 19.33 & 21190.00 & 10595.00 & 7063.33 & 21192.00 & 10596.00 & 7064.00 & 23623.00 & 11811.50 & 5905.75 & 23623.00 & \begin{tabular}{|l|}
11811.50 \\
\end{tabular} & 2624.78 \\
\hline Snakes (2) & 10.00 & 3750.00 & 375.00 & 125.00 & 3750.00 & 375.00 & 250.00 & 3750.00 & 375.00 & 250.00 & 5154.00 & 515.40 & 257.70 & 5154.00 & 515.40 & 114.53 \\
\hline Snake Down Tubes (2) & 14.00 & \begin{tabular}{|l|}
19144.00 \\
\end{tabular} & 1367.43 & 455.81 & 19144.00 & 1367.43 & 911.62 & 19144.00 & 1367.43 & 911.62 & 2934.00 & 209.57 & 104.79 & 337500.00 & \begin{tabular}{|l|}
24107.14 \\
\end{tabular} & 5357.14 \\
\hline Diamond Plate & 200.00 & 210000.00 & 1050.00 & 350.00 & 210000.00 & 1050.00 & 700.00 & 210000.00 & 1050.00 & 700.00 & 127440.00 & 637.20 & 318.60 & 735000.00 & 3675.00 & 816.67 \\
\hline Sliding Plate & 1500.00 & \begin{tabular}{|l|}
28313.00 \\
\end{tabular} & 18.88 & 6.29 & 28313.00 & 18.88 & 12.58 & 38220.00 & 25.48 & 16.99 & 10000.00 & 6.67 & 3.33 & 38220.00 & 25.48 & 5.66 \\
\hline Linear Rails (8) & 45.00 & 38220.00 & 849.33 & 283.11 & 38220.00 & 849.33 & 566.22 & 44100.00 & 980.00 & 653.33 & 38220.00 & 849.33 & 424.67 & 38220.00 & 849.33 & 188.74 \\
\hline Translation Motor & 10.00 & 6708.00 & 670.80 & 223.60 & 6708.00 & 670.80 & 447.20 & 8515.00 & 851.50 & 567.67 & 6708.00 & 670.80 & 335.40 & 9708.00 & 970.80 & 215.73 \\
\hline Power Box & 30.00 & 8437.00 & 281.23 & 93.74 & 8437.00 & 281.23 & 187.49 & 8437.00 & 281.23 & 187.49 & 13248.00 & 441.60 & 220.80 & 1530000.00 & \begin{tabular}{|l|}
51000.00 \\
\end{tabular} & 11333.33 \\
\hline PLC Box & 27.00 & 8437.00 & 312.48 & 104.16 & 8437.00 & 312.48 & 208.32 & 8437.00 & 312.48 & 208.32 & 13248.00 & 490.67 & 245.33 & 1530000.00 & \begin{tabular}{|l|}
56666.67 \\
\end{tabular} & 12592.59 \\
\hline Box 1 & 14.00 & 5625.00 & 401.79 & 133.93 & 5625.00 & 401.79 & 267.86 & 5625.00 & 401.79 & 267.86 & 8832.00 & 630.86 & 315.43 & 1530000.00 & \begin{tabular}{|l|}
109285.71 \\
\end{tabular} & 24285.71 \\
\hline Box 2 & 14.00 & 5625.00 & 401.79 & 133.93 & 5625.00 & 401.79 & 267.86 & 5625.00 & 401.79 & 267.86 & 8832.00 & 630.86 & 315.43 & 1530000.00 & 109285.71 & 24285.71 \\
\hline Box 3 & 14.00 & 5625.00 & 401.79 & 133.93 & 5625.00 & 401.79 & 267.86 & 5625.00 & 401.79 & 267.86 & 8832.00 & 630.86 & 315.43 & 1530000.00 & \begin{tabular}{|l|}
109285.71 \\
\end{tabular} & 24285.71 \\
\hline Box 4 & 14.00 & 5625.00 & 401.79 & 133.93 & 5625.00 & 401.79 & 267.86 & 5625.00 & 401.79 & 267.86 & 8832.00 & 630.86 & 315.43 & 1530000.00 & 109285.71 & 24285.71 \\
\hline Step & 7.00 & 7500.00 & 1071.43 & 357.14 & 7500.00 & 1071.43 & 714.29 & 7500.00 & 1071.43 & 714.29 & 20680.00 & 2954.29 & 1477.14 & 2400000.00 & 342857.14 & 76190.48 \\
\hline Translation Limit Switches (2) & 2.00 & 3750.00 & 1875.00 & 625.00 & 3750.00 & 1875.00 & 1250.00 & 3750.00 & 1875.00 & 1250.00 & 5144.00 & 2572.00 & 1286.00 & 5144.00 & 2572.00 & 571.56 \\
\hline Translation Proximity Sensors (2) & 2.00 & 3750.00 & 1875.00 & 625.00 & 3750.00 & 1875.00 & 1250.00 & 3750.00 & 1875.00 & 1250.00 & 5144.00 & 2572.00 & 1286.00 & 5144.00 & 2572.00 & 571.56 \\
\hline 463 L-Type Pallet & 1078.00 & 157000.00 & 145.64 & 48.55 & 157000.00 & 145.64 & 97.09 & 120000.00 & 111.32 & 74.21 & 125000.00 & 115.96 & 57.98 & 450000.00 & 417.44 & 92.76 \\
\hline
\end{tabular}

Note 1: See Appendix A Section 2.0 (Structural Analysis of a Modified 463L Pallet). 
Table 4 - Sensor Pallet Configuration 3 (Sensor Pod Deployed, Ramp Closed) Analysis Results

\begin{tabular}{|c|c|c|c|c|c|c|c|c|c|c|c|c|c|c|c|c|}
\hline \multirow{3}{*}{$\begin{array}{c}\text { SENSOR PALLET Case 3: } \\
\text { Component } \\
\end{array}$} & \multirow{3}{*}{$\begin{array}{c}\text { Dynamic } \\
\text { Load } \\
\text { lbs }\end{array}$} & \multicolumn{3}{|c|}{ Forward } & \multicolumn{3}{|c|}{ Aft } & \multirow{2}{*}{\multicolumn{2}{|c|}{$\begin{array}{c}\text { Lateral } \\
\text { Holding Force }\end{array}$}} & \multirow{3}{*}{$\begin{array}{l}\text { Factor of } \\
\text { Safety }\end{array}$} & \multicolumn{3}{|c|}{ Up } & \multicolumn{3}{|c|}{ Down } \\
\hline & & \multicolumn{2}{|c|}{ Holding Force } & \multirow{2}{*}{$\begin{array}{l}\text { Factor of } \\
\text { Safety }\end{array}$} & \multicolumn{2}{|c|}{ Holding Force } & \multirow{2}{*}{$\begin{array}{l}\text { Factor of } \\
\text { Safety }\end{array}$} & & & & \multicolumn{2}{|c|}{ Holding Force } & \multirow{2}{*}{\begin{tabular}{|c|}
$\begin{array}{c}\text { Factor of } \\
\text { Safety }\end{array}$ \\
\end{tabular}} & \multicolumn{2}{|c|}{ Holding Force } & \multirow{2}{*}{$\begin{array}{l}\begin{array}{c}\text { Factor of } \\
\text { Safety }\end{array} \\
\end{array}$} \\
\hline & & Ibs & 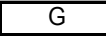 & & Ibs & $G$ & & Ibs & $\bar{G}$ & & $\mathrm{Ibs}$ & $\bar{G}$ & & $\mathrm{lbs}$ & $\bar{G}$ & \\
\hline Pod & 730.00 & 53025.00 & 72.64 & 24.21 & 53025.00 & 72.64 & 48.42 & 4100600.00 & 5617.26 & 3744.84 & 53025.00 & 72.64 & 36.32 & 53025.00 & 72.64 & 16.14 \\
\hline Arms (4) & 845.00 & 16989.21 & 20.11 & 6.70 & 16989.21 & 20.11 & 13.40 & 16989.21 & 20.11 & 13.40 & 16989.21 & 20.11 & 10.05 & 16989.21 & 20.11 & 4.47 \\
\hline Arm Conduits (2) & 7.50 & 1821.94 & 242.93 & 80.98 & 1821.94 & 242.93 & 161.95 & 10180800.00 & 1357440.00 & 904960.00 & 2458.95 & 327.86 & 163.93 & 2458.95 & 327.86 & 72.86 \\
\hline Rotational Shafts (2) & 881.00 & 341876.92 & 388.06 & 129.35 & 341876.92 & 388.06 & 258.70 & 4242.00 & 4.81 & 3.21 & 341876.92 & 388.06 & 194.03 & 341876.92 & 388.06 & 86.23 \\
\hline Bearings (4) & 897.00 & 45248.00 & 50.44 & 16.81 & 45248.00 & 50.44 & 33.63 & 45248.00 & 50.44 & 33.63 & 53732.00 & 59.90 & 29.95 & 53732.00 & 59.90 & 13.31 \\
\hline Flex Couplers (2) & 17.00 & 121604.00 & 7153.18 & 2384.39 & 121604.00 & 7153.18 & 4768.78 & 2828.00 & 166.35 & 110.90 & 121604.00 & 7153.18 & 3576.59 & 121604.00 & 7153.18 & 1589.59 \\
\hline Bearing Stands (4) & 900.00 & \begin{tabular}{|l|}
44992.00 \\
\end{tabular} & 49.99 & 16.66 & 31809.34 & 35.34 & 23.56 & 31809.34 & 35.34 & 23.56 & 190890.00 & 212.10 & 106.05 & 190890.00 & 212.10 & 47.13 \\
\hline 600:1 Gearbox & 405.00 & 53025.00 & 130.93 & 43.64 & 53025.00 & 130.93 & 87.28 & 53025.00 & 130.93 & 87.28 & 509040.00 & 1256.89 & 628.44 & 509040.00 & 1256.89 & 279.31 \\
\hline $8: 1$ Gearbox & 25.00 & \begin{tabular}{|l|}
60881.18 \\
\end{tabular} & 2435.25 & 811.75 & 60881.18 & 2435.25 & 1623.50 & 36311.52 & 1452.46 & 968.31 & 60881.18 & 2435.25 & 1217.62 & 60881.18 & 2435.25 & 541.17 \\
\hline Rotational Motor & 35.00 & 40604.42 & 1160.13 & 386.71 & 40604.42 & 1160.13 & 773.42 & 24207.68 & 691.65 & 461.10 & 40604.42 & 1160.13 & 580.06 & 40604.42 & 1160.13 & 257.81 \\
\hline Left Arm Stand & 3.00 & 31809.34 & 10603.11 & \begin{tabular}{|l|}
3534.37 \\
\end{tabular} & 31809.34 & 10603.11 & 7068.74 & 31809.34 & 10603.11 & 7068.74 & 190890.00 & 63630.00 & 31815.00 & 190890.00 & 63630.00 & 14140.00 \\
\hline Right Arm Stand & 4.50 & \begin{tabular}{|l|}
31809.34 \\
\end{tabular} & \begin{tabular}{|l|}
7068.74 \\
\end{tabular} & 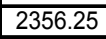 & 31809.34 & 7068.74 & 4712.50 & 31809.34 & 7068.74 & 4712.50 & 190890.00 & 42420.00 & \begin{tabular}{|l|}
21210.00 \\
\end{tabular} & 190890.00 & 42420.00 & 9426.67 \\
\hline Hand Crank Stand & 5.00 & 2651.25 & 530.25 & 176.75 & 2651.25 & 530.25 & 353.50 & 2651.25 & 530.25 & 353.50 & 190890.00 & 38178.00 & \begin{tabular}{|l|}
19089.00 \\
\end{tabular} & 190890.00 & 38178.00 & 8484.00 \\
\hline Hand Crank & 18.00 & 14981.33 & 832.30 & 277.43 & 14981.33 & 832.30 & 554.86 & 7423.50 & 412.42 & 274.94 & 14981.33 & 832.30 & 416.15 & 14981.33 & 832.30 & 184.95 \\
\hline Hand Crank Shaft & 2.00 & 14981.33 & 7490.67 & 2496.89 & 14981.33 & 7490.67 & 4993.78 & 14982.74 & 7491.37 & 4994.25 & 16701.46 & 8350.73 & 4175.37 & 16701.46 & 8350.73 & 1855.72 \\
\hline Snakes (2) & 10.00 & 2651.25 & 265.13 & 88.38 & 2651.25 & 265.13 & 176.75 & 2651.25 & 265.13 & 176.75 & 3643.88 & 364.39 & 182.19 & 3643.88 & 364.39 & 80.98 \\
\hline Snake Down Tubes (2) & 14.00 & 13534.81 & 966.77 & 322.26 & 13534.81 & 966.77 & 644.51 & 13534.81 & 966.77 & 644.51 & 238612.50 & 17043.75 & 8521.88 & 238612.50 & 17043.75 & 3787.50 \\
\hline Diamond Plate & 200.00 & 148470.00 & 742.35 & 247.45 & 148470.00 & 742.35 & 494.90 & 148470.00 & 742.35 & 494.90 & 519645.00 & 2598.23 & \begin{tabular}{|l|}
1299.11 \\
\end{tabular} & 519645.00 & 2598.23 & 577.38 \\
\hline Sliding Plate & 1500.00 & 20017.29 & 13.34 & 4.45 & 20017.29 & 13.34 & 8.90 & 27021.54 & 18.01 & 12.01 & 27021.54 & 18.01 & 9.01 & 27021.54 & 18.01 & 4.00 \\
\hline Linear Rails (8) & 45.00 & \begin{tabular}{|l|}
27021.54 \\
\end{tabular} & 600.48 & 200.16 & 27021.54 & 600.48 & 400.32 & 31178.70 & 692.86 & 461.91 & 27021.54 & 600.48 & 300.24 & 27021.54 & 600.48 & 133.44 \\
\hline Translation Motor & 10.00 & 4742.56 & 474.26 & 158.09 & 4742.56 & 474.26 & 316.17 & 6020.11 & 602.01 & 401.34 & 6863.56 & 686.36 & 343.18 & 6863.56 & 686.36 & 152.52 \\
\hline Power Box & 30.00 & 5964.96 & 198.83 & 66.28 & 5964.96 & 198.83 & 132.55 & 5964.96 & 198.83 & 132.55 & 1081710.00 & 36057.00 & \begin{tabular}{|l|}
18028.50 \\
\end{tabular} & 1081710.00 & 36057.00 & 8012.67 \\
\hline PLC Box & 27.00 & 5964.96 & 220.92 & 73.64 & 5964.96 & 220.92 & 147.28 & 5964.96 & 220.92 & 147.28 & 1081710.00 & 40063.33 & \begin{tabular}{|l|}
20031.67 \\
\end{tabular} & 1081710.00 & 40063.33 & 8902.96 \\
\hline Box 1 & 14.00 & 3976.88 & 284.06 & 94.69 & 3976.88 & 284.06 & 189.38 & 3976.88 & 284.06 & 189.38 & 1081710.00 & 77265.00 & \begin{tabular}{|l|}
38632.50 \\
\end{tabular} & 1081710.00 & 77265.00 & 17170.00 \\
\hline Box 2 & 14.00 & 3976.88 & 284.06 & 94.69 & 3976.88 & 284.06 & 189.38 & 3976.88 & 284.06 & 189.38 & 1081710.00 & 77265.00 & \begin{tabular}{|l|}
38632.50 \\
\end{tabular} & 1081710.00 & \begin{tabular}{|l|}
77265.00 \\
\end{tabular} & 17170.00 \\
\hline Box 3 & 14.00 & 3976.88 & 284.06 & 94.69 & 3976.88 & 284.06 & 189.38 & 3976.88 & 284.06 & 189.38 & 1081710.00 & 77265.00 & 38632.50 & 1081710.00 & 77265.00 & 17170.00 \\
\hline Box 4 & 14.00 & 3976.88 & 284.06 & 94.69 & 3976.88 & 284.06 & 189.38 & 3976.88 & 284.06 & 189.38 & 1081710.00 & 77265.00 & 38632.50 & 1081710.00 & 77265.00 & 17170.00 \\
\hline Step & 7.00 & 5302.50 & 757.50 & 252.50 & 5302.50 & 757.50 & 505.00 & 5302.50 & 757.50 & 505.00 & 1696800.00 & 242400.00 & 121200.00 & 1696800.00 & 242400.00 & 53866.67 \\
\hline Translation Limit Switches (2) & 2.00 & 2651.25 & 1325.63 & 441.88 & 2651.25 & 1325.63 & 883.75 & 2651.25 & 1325.63 & 883.75 & 3636.81 & 1818.40 & \begin{tabular}{|l|}
909.20 \\
\end{tabular} & 3636.81 & 1818.40 & 404.09 \\
\hline Translation Proximity Sensors (2) & 2.00 & 2651.25 & 1325.63 & 441.88 & 2651.25 & 1325.63 & 883.75 & 2651.25 & 1325.63 & 883.75 & 3636.81 & 1818.40 & 909.20 & 3636.81 & 1818.40 & 404.09 \\
\hline 463 L-Type Pallet & 1078.00 & 200000.00 & 185.53 & 61.84 & 115000.00 & 106.68 & 71.12 & 115000.00 & 106.68 & 71.12 & 74523.00 & 69.13 & 34.57 & 510000.00 & 473.10 & 105.13 \\
\hline
\end{tabular}

Note 1: See Appendix A Section 2.0 (Structural Analysis of a Modified 463L Pallet). 


\subsection{Rail Plate Analysis}

A second analysis investigated the force of a dislodged rail plate system impacting the "fail stops" at the end of the linear rails. This analysis used energy and force equations to simulate an impact at the loading criteria specified in MIL-HDBK-1791. The worst case scenario of the impact situation analyzed a free falling object (the entire rail system) translating along the linear rails. This analysis does not take into affect the opposite holding force of the linear actuator component acting against the specified loading in MIL-HDBK-1791.

The analysis showed that increasing the thickness of the "fail stops" from $1 / 4$ inch to 1 inch and applying a $1 / 2$ inch polyurethane dampening component to the impact area (50 Shore A durometer rating) will reduce the energy force created by the loading criteria described in MILHDBK-1791 to an allowable fail safe system. In addition implementing a third stop between the center two linear rails will further reduce the stresses in the tie down bolts and reduce the yield stresses in the "fail stops" material to prevent a catastrophic failure.

\subsection{Arm/Pod Loading Analysis}

A detailed model was created to analyze the lateral loading conditions of the mechanical arm/pod system using specified criteria from MIL-HDBK-1791. The critical areas in this analysis are the mechanical arm/pod connection points and the rotational shaft to hub to arm connection locations. The highlighted areas in Figure 9 show the maximum stress locations when the mechanical arm/pod system is subjected to the lateral loading criteria listed in MILHDBK-1791. The maximum value found in these critical locations are $24,030 \mathrm{psi}$, which is well below the yield strength of the T6-6061 Aluminum used (40,000 psi) in both the arm and pod material.

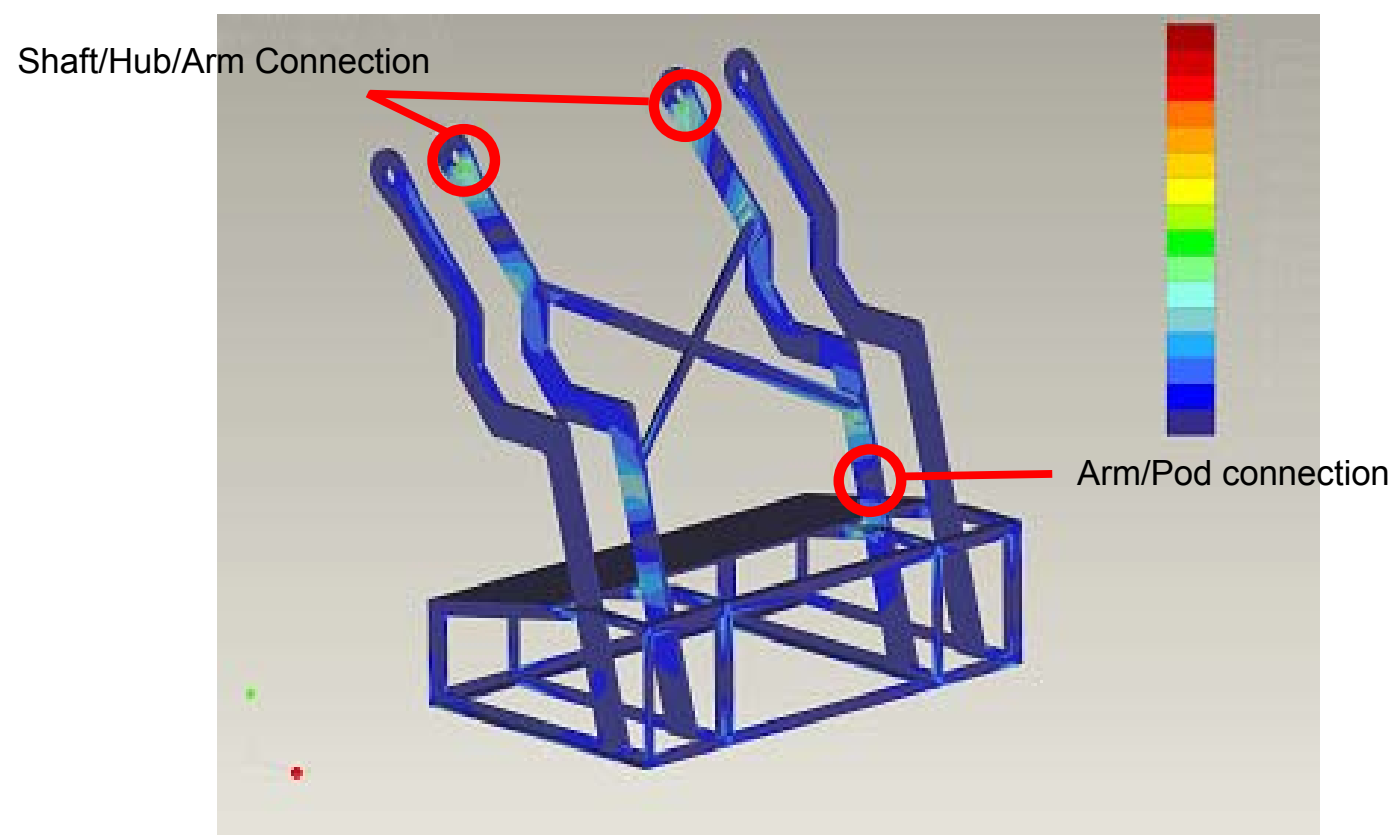

Figure 9 - FEA plot of the mechanical arm/pod system subjected to specified lateral loading from MIL-HDBK-1791. 


\section{Operator Station Assembly Description}

The operator station used as the command and control center of the OCULUS system is built on top of a modified 463L type pallet (same type used for the sensor pallet). The structure built on top of the modified 463L type pallet is fastened to the pallet using $3 / 8$ inch grade 8 steel bolts spaced every 12 inches (these are located on the interior section of the walls). In addition, the structure is also welded to the modified 463L type pallet with increased weld concentration at the support posts (the welds were applied to the exterior section of the walls).

The operator station structure is a 4-wall container structure attached at all four corners by heavy grade support structures (the operator station is slingable and stackable). Each wall structure is fastened to the structural support posts using $1 / 4$ inch rivets spaced every 2 inches.

\section{Structural Analysis of a Modified 463L Pallet}

The pallets used as the base platform for each unit (sensor platform and operator station) of the OCULUS system are modified military 463L type pallets. The modification made to the standard 463L type design is the addition of a $3 / 4$ inch aluminum (T6-6061) plate instead of the balsa wood sheet/aluminum skin sheet plate used on standard $463 \mathrm{~L} 1$ type pallets. This is the sole difference between the two pallets and will be the concentration of this analysis.

The $3 / 4$ inch aluminum skin added to the pallet is actually two $54 \times 44$ inch aluminum plates fastened to the base pallet structure (these slabs are denoted by a 1 and 2 in figure 10). The remainder of the pallet (forklift channels, rail locking flanges, tie-down rings, etc.) structure remains the same as the standard 463L type pallet (see attachment letter).

The aluminum plate is attached to the pallet by standard HUCK MGLP R8-18 rivets (information in Table 5). Each aluminum plate $(1,2)$ is fastened to the standard 463L structure using 68 rivets. Figure 11 shows a close-up view of the rivet attachment pattern. The rivet pattern for each aluminum plate is shown along the perimeter of each plate $(1,2)$ and denoted by the black dots. The design of the sensor platform system places the majority of the force and loading (caused by the mass of the system and the deployment positions) on the aft facing plate connection region (1) as apposed to the forward looking plate connection region (2).

This analysis looked at crash loading analysis (as specified by MIL-HDBK-1791) of the pallet with concentration on the rivet attachment region of both aluminum plates (with added emphasis on the aft facing component (1)). Each analysis performed assumed distributed loading to the rivets throughout each aluminum plate (ideal case). The analysis considered shear of the rivets as well as the possibility of rivet pull-out at each of the three sensor pallet position configurations. The maximum loading capability per rivet is 2,500 pounds in shear and 1,850 pounds in tension.

The analysis showed that for Configurations 1 and 2 it would require 170,000 pounds/plate of loading to shear the rivets in one aluminum plate. The system would also need to experience 125,000 pounds/plate off loading for a rivet pull-out scenario to occur. These values are applicable to Configuration's 1 and 2 for loading values in the For/Aft/left/Right directions specified by MIL-HDBK-1791. The down loading condition does not have any relevance or need for consideration during these scenarios because the plane would need to fail prior to a pallet failure situation.

The analysis showed with the system in Configuration 3 rivet pull-out will yield the lowest safety factor. The system would need to experience 74,523 pounds of loading in the up direction for failure to occur. 
Table 5 - Pallet rivet description and specification. MFG Part \# MGLP-R8-18

MFG Name: Huck

\begin{tabular}{|l|l|}
\hline Alloy I Material & steel \\
\hline $\begin{array}{l}\text { Diameter of } \\
\text { Body }\end{array}$ & $1 / 4 "$ \\
\hline $\begin{array}{l}\text { Grip Range: } \\
\text { Total thickness } \\
\text { to be Fastened }\end{array}$ & $.830-1.125$ \\
\hline Head Style & protruding head \\
\hline Shear Strength & $2,500 \mathrm{lbs}$ \\
\hline Tensile Strength & $1,850 \mathrm{lbs}$ \\
\hline
\end{tabular}

AFT

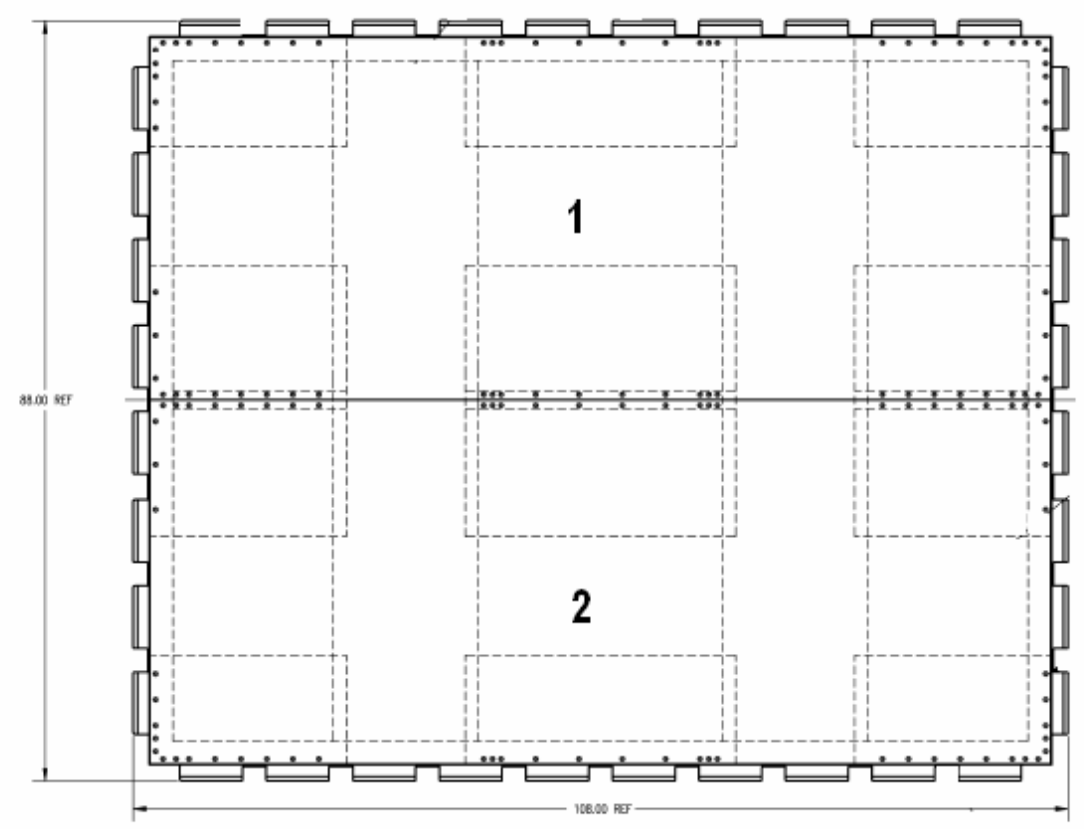

FORWARD

Figure 10 - Rivet pattern of modified 463L pallet. 


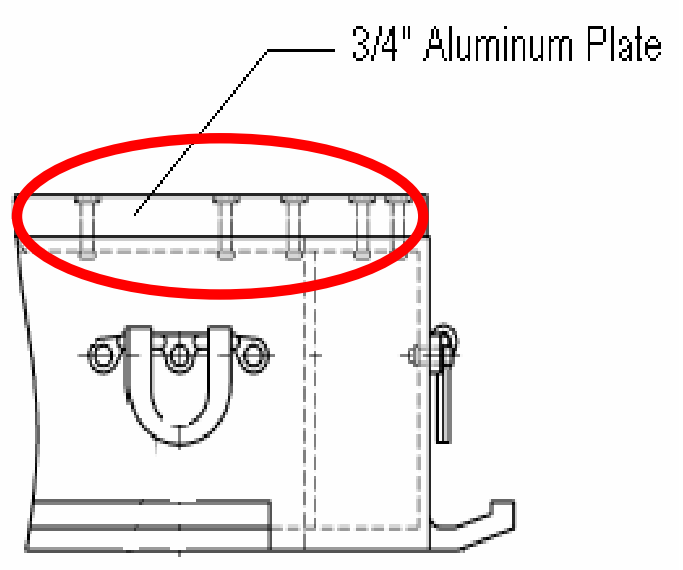

Figure 11 - Close-up view of rivet attachments.

The summary of the analysis explained shows that the modified 463L type pallets built by AAR Mobility Systems Inc. meet the requirements outlined in MIL-HDBK-1791.

\section{Structural Analysis of an Operator Station Assembly}

The loading analysis (in accordance with MIL-HDBK-1791) performed on the operator station showed high loading thresholds in each crash loading direction (forward, aft, lateral, up and down). In the forward, aft, and lateral directions the load required to shear the fasteners is 315,510 pounds and to pull out the bolts is 98,437 pounds. In the upward direction the operator station must be subjected to 155,100 pounds in tension for failure to occur. In the downward direction the operator station must tear through the base pallet structure for failure to occur. The downward loading condition scenario will never be the cause of failure.

It should be noted that this analysis was performed by solely analyzing the bolt fasteners of the operator station. The welded components were not taken into account. The addition of the weld joints increased the safety factor of the system by several factors.

\section{Conclusions:}

\section{Operator Station}

The OCULUS operator station meets all crash survivability requirements specified by MILHDBK-1791. Both the shelter and the modified 463-L type pallet are structurally sound systems for flight on a C-130 aircraft.

\section{Sensor Pallet}

All components meet the loading criteria specified in MIL-HDBK-1791. The additional components to be added to the "fail stops" of the translating rail system will allow the Sensor Pallet to meet the design requirements of MIL-HDBK-1791 due to failure of the translation drive mechanism. 
8. References:

Oberg, Erik; Jones, Franklin D.; Horton, Holbrook L.; Ryffel, Henry H., "Machinery's Handbook," $26^{\text {th }}$ Edition, Industrial Press Inc, New York, 2000.

Collins, Jack A., "Machine Design of Mechanical Elements and Machines," John Wiley \& Sons, New York, 2003. 


\section{Appendix F. OCULUS 1.1 Electrical Load Analysis}

The following electrical load analysis of the OCULUS 1.1 system was performed to ensure the system did not in any way endanger the C-130 aircraft of an electrical overload. The analysis was performed by equating all of the drawn power from the C-130 aircraft by the OCULUS system. The analysis shows that the OCULUS 1.1 system will not endanger the C130 aircraft of overloading during combined use. 


\section{OCULUS/C-130Electrical Loads Analysis}

\subsection{Scope}

This analysis is being performed to verify to the C-130 SPO that the OCULUS system does not provide an electrical load or short-circuit hazard to the $\mathrm{C}-130 \mathrm{H}$ aircraft.

\subsection{OCULUS Block Diagram}

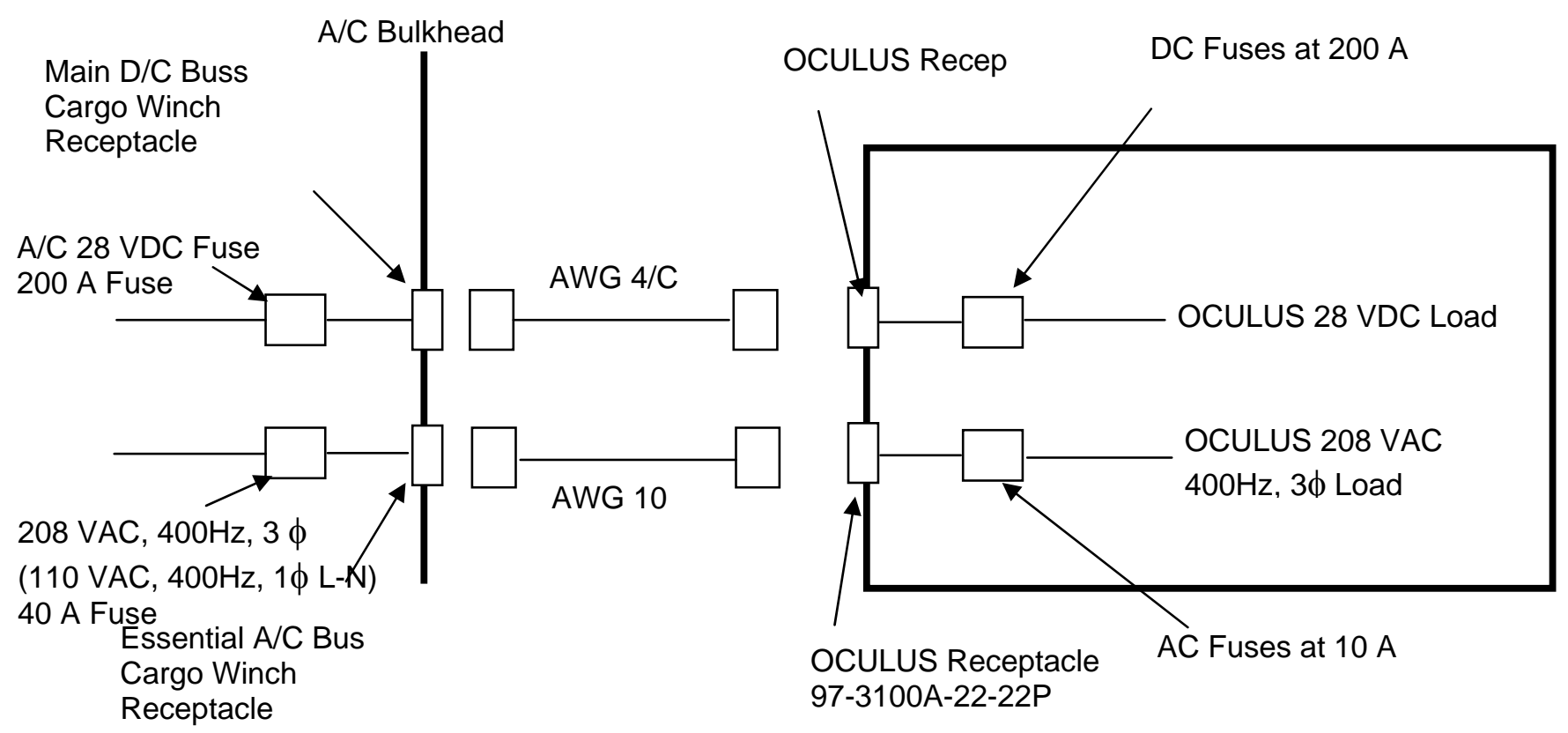

Figure 1 OCULUS Electrical Load Connections

\subsection{C-130H Electrical Load Capabilities}

\subsection{Assumptions:}

OCULUS is powered through the Main D/C Bus Cargo Winch Receptacle and the Essential A/C Bus Cargo Winch Receptacle

\subsection{Electrical Bus Fuses}

The Main D/C Bus Cargo Winch Receptacle is fused at 200 Amps and the Essential A/C Bus Cargo Winch Receptacle is fused at 40 Amps. 


\subsection{OCULUS Electrical Load Requirements}

\subsection{Loads:}

OCULUS uses two types of electrical power: 208VAC, $400 \mathrm{~Hz}$, three phase and 28VDC. The $208 \mathrm{VAC}, 400 \mathrm{~Hz}$, three phase is used only on the sensor pallet for the rotational motion motor. The $28 \mathrm{VDC}$ is used directly for the intercom system, a few relays, and some displays. A 28 VDC-to-220VAC, $60 \mathrm{~Hz}, 2$ phase inverter is the largest 28 VDC load.

\section{2 $\quad$ Assumptions and Analysis}

Table 1 and 2 list all the OCULUS loads. The worst case for power usage and efficiency from the manufacturer's specification was used as the load for each system. This absolute worst case is seldom attainable, but provides insight into the minimum safety margins available.

Table 1 Sensor Pallet Loads

\begin{tabular}{|c|c|c|c|c|}
\hline \multicolumn{5}{|c|}{ Sensor Pallet } \\
\hline $\begin{array}{c}\text { Powered From Power } \\
\text { Box 1(DC) }\end{array}$ & Quantity & Current(A) & & $\begin{array}{l}\text { Comsumed } \\
\text { Power(W) }\end{array}$ \\
\hline Relays & 6 & 0.04 & & 5.904 \\
\hline LED(Auto+Manual) & 2 & 0.02 & & 0.96 \\
\hline Motor Current Sensor & 1 & 0.02 & & 0.48 \\
\hline Three Phase Contactor & 1 & 0.20 & & 4.8 \\
\hline \multicolumn{3}{|c|}{$60 \mathrm{~Hz}$ Power From 24V Linears (Assuning 60\% Efficient) } & & 20.24 \\
\hline $\begin{array}{l}\text { Powered From } \\
\text { PLC Box 2(DC) }\end{array}$ & Quantity & Current(A) & & $\begin{array}{l}\text { Comsumed } \\
\text { Power(W) }\end{array}$ \\
\hline Relays & 3 & 0.04 & & 2.952 \\
\hline LED's & 6 & 0.02 & & 2.88 \\
\hline $\mathrm{PLC}(\mathrm{DC})$ & 1 & 0.05 & & 1.2 \\
\hline Proximity Sensors & 4 & 0.05 & & 4.8 \\
\hline \multicolumn{3}{|c|}{$60 \mathrm{~Hz}$ Power From 24V Linears (Assuning 60\% Efficient) } & & 19.72 \\
\hline Device & Quantity & Power Type & Current(A) & $\begin{array}{c}\text { Comsumed } \\
\text { Power(W) }\end{array}$ \\
\hline \multirow[t]{2}{*}{ GS2 VFD + 2HP Motor } & 1 & 110VAC $400 \mathrm{~Hz}$ & 5.60 & 1164.80 \\
\hline & \multicolumn{3}{|c|}{ Total Power Used $(400 \mathrm{~Hz})$} & 1164.80 \\
\hline Translation Motor & & 208VAC $60 \mathrm{~Hz}$ & 1.19 & 248.00 \\
\hline $\mathrm{PLC}(\mathrm{AC})$ & & 208VAC $60 \mathrm{~Hz}$ & 0.10 & 20.80 \\
\hline Cooling Fans & 2 & 110VAC $60 \mathrm{~Hz}$ & 0.03 & 6.60 \\
\hline 24VDC Supply Box 1 & & 208VAC $60 \mathrm{~Hz}$ & 0.06 & 20.24 \\
\hline \multirow[t]{2}{*}{ 24VDC Supply Box 2} & & 208VAC $60 \mathrm{~Hz}$ & 0.06 & 19.72 \\
\hline & \multicolumn{3}{|c|}{ Total Power Used $(60 \mathrm{~Hz})$} & 315.36 \\
\hline
\end{tabular}


Table 2. Operator's Station Loads

\begin{tabular}{|c|c|c|c|c|}
\hline \multicolumn{5}{|c|}{ Control Room } \\
\hline Device & Quantity & Input Type & Current(A) & $\begin{array}{l}\text { Comsumed } \\
\text { Power(W) }\end{array}$ \\
\hline LED (AC) & 6 & $110 \mathrm{VAC} 400 \mathrm{~Hz}$ & 0.0 & 3.30 \\
\hline KVM Switch & & 110VAC $60 \mathrm{~Hz}$ & 0.1 & 7.20 \\
\hline Rack Mount Light & & $110 \mathrm{VAC} 60 \mathrm{~Hz}$ & 0.2 & 72.00 \\
\hline Radio & & $110 \mathrm{VAC} 60 \mathrm{~Hz}$ & 0.5 & 54.00 \\
\hline Sony VCR & & 110VAC $60 \mathrm{~Hz}$ & 0.1 & 16.00 \\
\hline Dehumidifier & & $110 \mathrm{VAC} 60 \mathrm{~Hz}$ & 1.5 & 180.00 \\
\hline Overhead Lights & & $110 \mathrm{VAC} 60 \mathrm{~Hz}$ & 0.3 & 68.00 \\
\hline Exhaust Fan & & $110 \mathrm{VAC} 60 \mathrm{~Hz}$ & 1.4 & 336.00 \\
\hline Computers & 2 & $110 \mathrm{VAC} 60 \mathrm{~Hz}$ & 3.0 & 700.00 \\
\hline LED (AC) & & $110 \mathrm{VAC} 60 \mathrm{~Hz}$ & 0.0 & 3.30 \\
\hline Contactor $60 \mathrm{HzAC}$ & & $110 \mathrm{VAC} 60 \mathrm{~Hz}$ & 0.5 & 55.00 \\
\hline Contactor $400 \mathrm{HzAC}$ & & $110 \mathrm{VAC} 60 \mathrm{~Hz}$ & 0.2 & 52.00 \\
\hline & \multicolumn{3}{|c|}{ Total Power Used $(60 \mathrm{~Hz})$} & 1546.80 \\
\hline \begin{tabular}{|l|} 
Total $60 \mathrm{~Hz}$ Inverter \\
Output Power \\
\end{tabular} & \multicolumn{3}{|c|}{ (Opperators Station + Sensor Pallet) } & 1862.16 \\
\hline \multicolumn{5}{|l|}{ Inverter Input Power } \\
\hline (Assuming Efficiency 80\%) & & & & 2327.70 \\
\hline LCD Monitors & & $28 \mathrm{VDC}$ & 2.2 & 189.00 \\
\hline LED (DC) & & $328 \mathrm{VDC}$ & 0.0 & 1.44 \\
\hline Contactor DC & & $28 \mathrm{VDC}$ & 1.0 & 28.00 \\
\hline Relay & 1 & $28 \mathrm{VDC}$ & 0.0 & 1.01 \\
\hline \multirow[t]{2}{*}{ Intercom System } & 1 & 28VDC & 2.0 & 48.00 \\
\hline & & \multicolumn{2}{|c|}{ Total 28VDC Power } & 2595.15 \\
\hline
\end{tabular}

\subsection{OCULUS Fuses:}

The 28 VDC from the Main D/C Bus Cargo Winch Receptacle goes through a pair of 200 Amp DC fuses in the control room. (Both the $28 \mathrm{VDC}$ and the return are fused.) The $110 \mathrm{VAC}$ three-phase from the Essential A/C Bus Cargo Winch Receptacle goes through three $10 \mathrm{Amp}$ fuses.

\subsection{Load vs Capability Analysis}

Table 2 OCULUS Total Power Usage

\begin{tabular}{|c|c|c|c|c|}
\hline \multicolumn{5}{|c|}{ OCULUS Totals } \\
\hline Total 28VDC Used & 2595.15 & Watts & 93 & Amps \\
\hline Available & 5600 & Watts & 200 & Amps \\
\hline Percent Used & 46.34 & $\%$ & & \\
\hline \multicolumn{7}{|c|}{} \\
\hline $\begin{array}{c}\text { Total 400Hz } \\
\text { Power }\end{array}$ & 1164.80 & Watts & 10 & $\begin{array}{c}\text { Amps } \\
\text { (average /phase) }\end{array}$ \\
\hline Available & 13800 & Watts & 40 & Amps \\
\hline Percent Used & 8.44 & $\%$ & & \\
\hline
\end{tabular}




\subsection{Summary}

Table 3 indicates that the maximum 28 VDC current that OCULUS can use is $46 \%$ of the fused current available. This table also indicates that OCULULS uses $8.4 \%$ of the current allocated to the 110 VAC, three-phase source.

\subsection{Conclusion}

The OCULUS system presents no danger or hazard to the $\mathrm{C}-130 \mathrm{H}$ electrical power system during a maximum load condition. The $\mathrm{C}-130 \mathrm{H}$ electrical power system is protected from OCULUS short circuit conditions in a double redundant manner by fuses inside the operator station and a cut-off junction box between the operator station and the C-130 receptacle. 


\section{Appendix G. OCULUS 1.1 EMI Analysis}

The following is a detailed evaluation of the OCULUS 1.1 systems EMI magnitudes and analysis of whether the system, in conjunction with the electronics of the C-130 aircraft, meet the required emissions guidelines outlined by MIL-STD-461E. The analysis clearly shows that the OCULUS system does not create or radiate EMI outside of the threshold set by the standard. 


\section{OCULUS EMI Test Results}

\subsection{Scope.}

The purpose of this document is to show EMI test results indicating that the OCULUS system (without sensors, radars, or communications equipment) has conducted and radiated emissions that meet the guidelines given in MIL-STD-461E. This document provides the results of EMI-461E testing performed on the OCULUS system at DLS Electronic Systems Inc., Wheeling, Illinois, on March 1-4, 2005.

\subsection{OCULUS Description}

OCULUS is a removable sensor platform designed for deployment on the C-130 aircraft. The OCULUS system is comprised of two modules: the Sensor Pallet and the Operator's Station. The Sensor Pallet is attached to the C-130 cargo ramp. During take-off and landing the sensor pallet is in the stowed position and the cargo ramp is closed. To deploy the sensor pallet; (1) the cargo ramp is opened to the level position; (2) the sensor pallet slides out; (3) the arm holding the sensor pod rotates out placing the sensor pod below the bottom level of the cargo ramp and; (4) the sensor pallet slides back to lock the sensor box outside the cargo ramp. The control room houses the OCULUS operators, power switch controls, sensor controls and data recording devices.

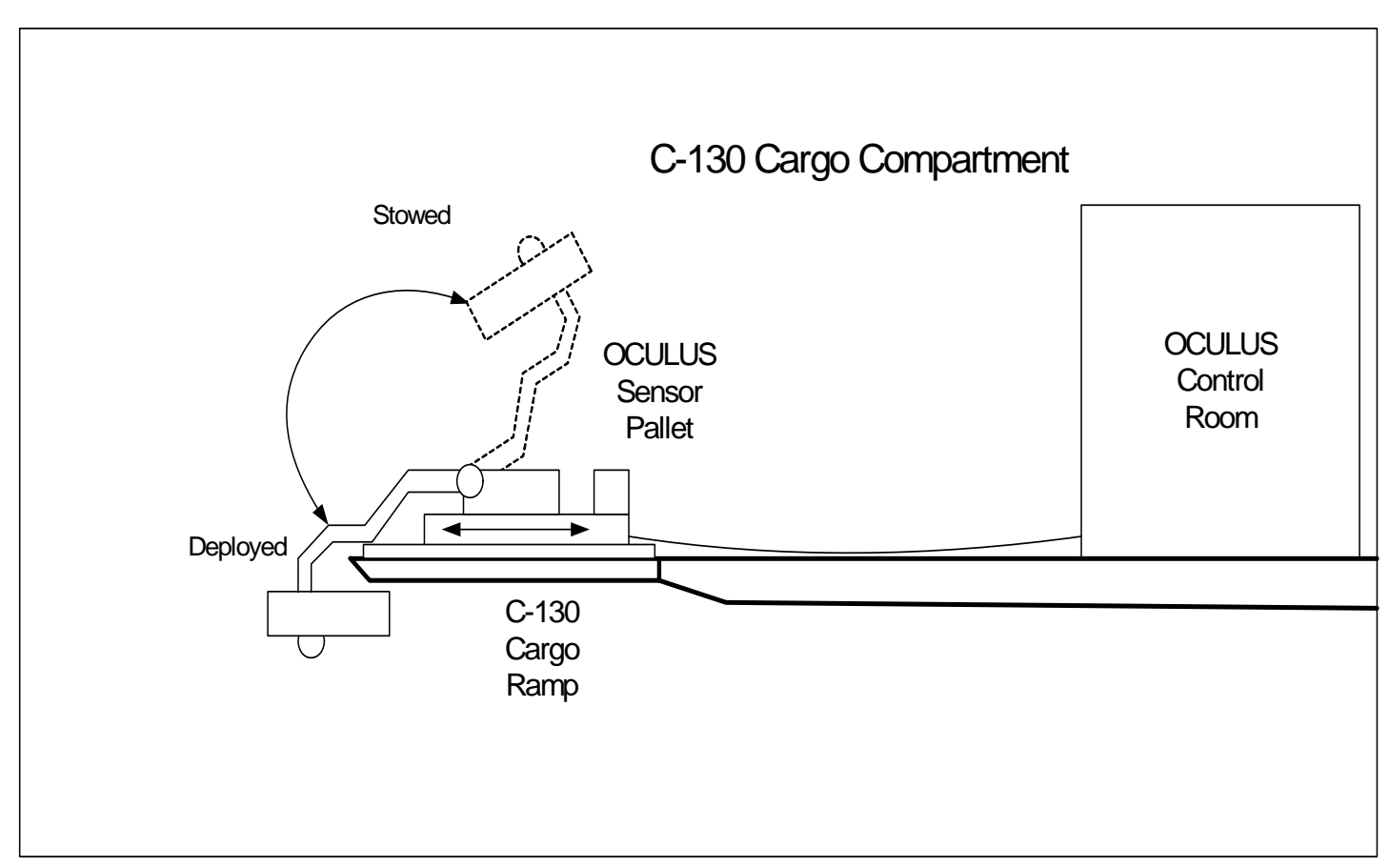

Figure 1. OCULUS Block Diagram 


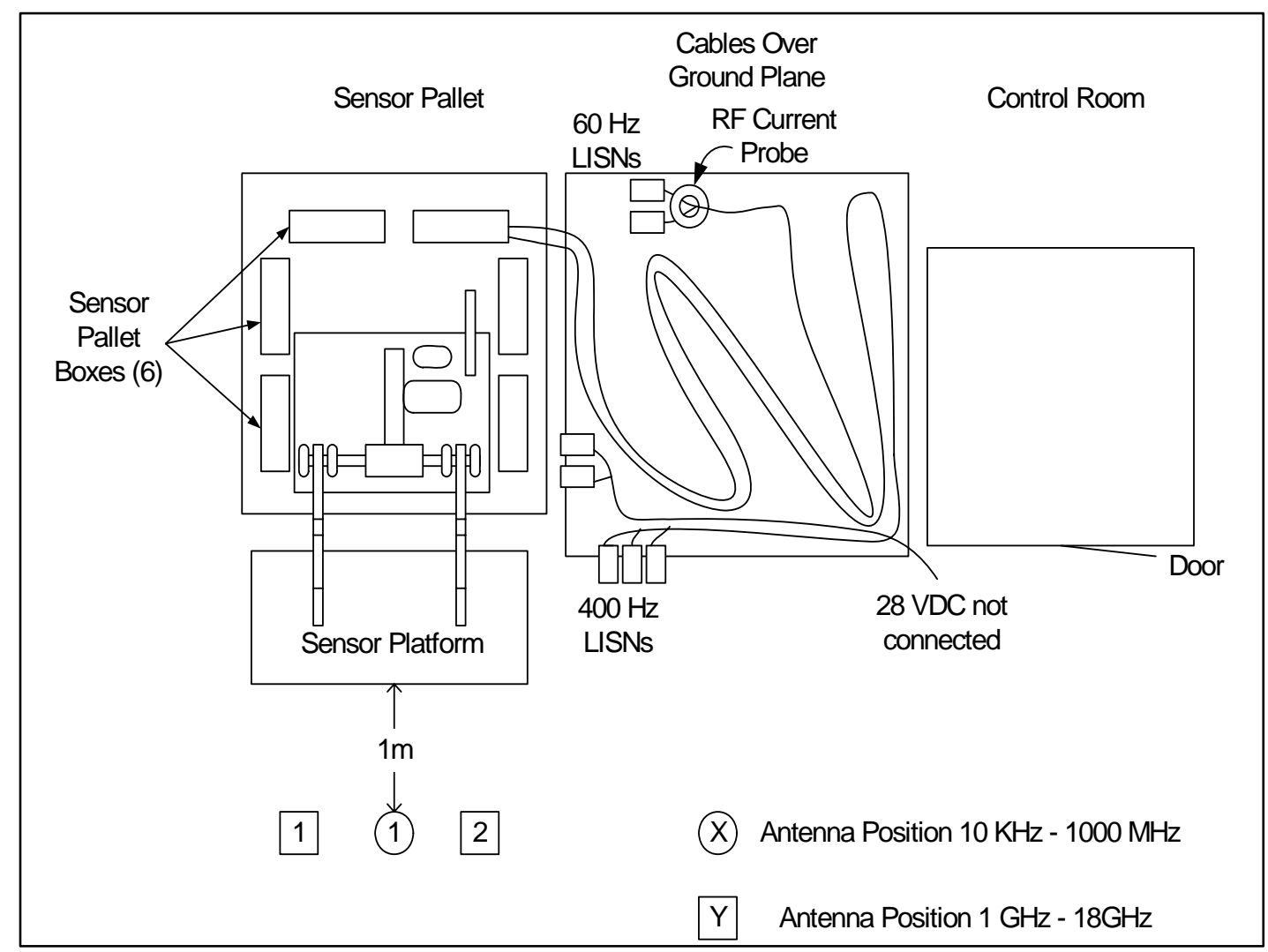

Figure 2. OCULUS Sensor Pallet Test Configuration

\subsection{Test Set-up Description}

Because OCULUS has parts deployed outside and inside the aircraft, the EMI test were performed in two configurations. The sensor pallet was tested to the more stringent MIL-STD-461E external level. The sensor pallet EMI test configuration is shown in Figure 2. The entire system was then tested to the less stringent MIL-STD-461E aircraft interior levels. The whole OCULUS EMI test configuration is shown in Figure 3. 


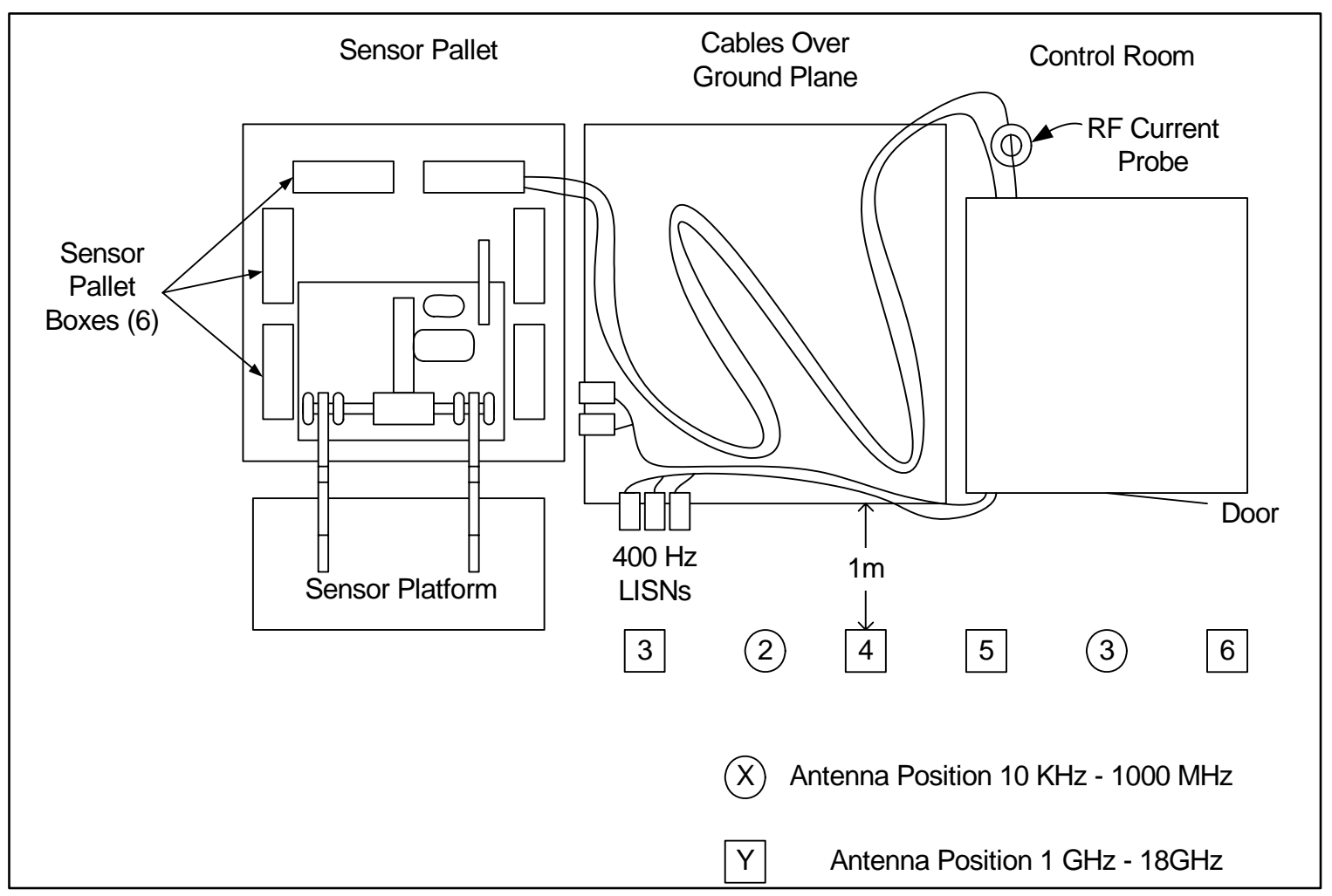

Figure 3. OCULUS Control Room EMI Test Configuration

\subsection{Test Personnel}

The EMI tests were performed by Mark Rozema(DLS). Juan Santamaria (GTRI) observed the tests. Andy Pertl, Jay Wilhelm, and Zenoby Wowczuk (West Virginia University) provided OCULUS operational support.

\subsection{Results of Test (March 1-4 , 2005)}

Worse case conductive and radiated emissions from the Operator's Station and Sensor Pallet are shown below.

\section{$5.1 \quad$ System Conducted (CE102) Emissions.}

Figure 8 represent the CE102 measurement results for the OCULUS system.

\subsection{Sensor Pallet Radiated (RE102) Emissions}

Figure 9 shows the RE102 emissions from the sensor pallet during various stages of the deployment. It should be noted that some emissions occured during deployment and stowing, which lasts less than one minute during a mission. 


\subsection{Operator's Station Radiated (RE102) Emissions.}

The control room emissions are shown in figure 4-13. These emissions were $1.6 \mathrm{~dB}$ over their limit at $23.9 \mathrm{MHz}$.

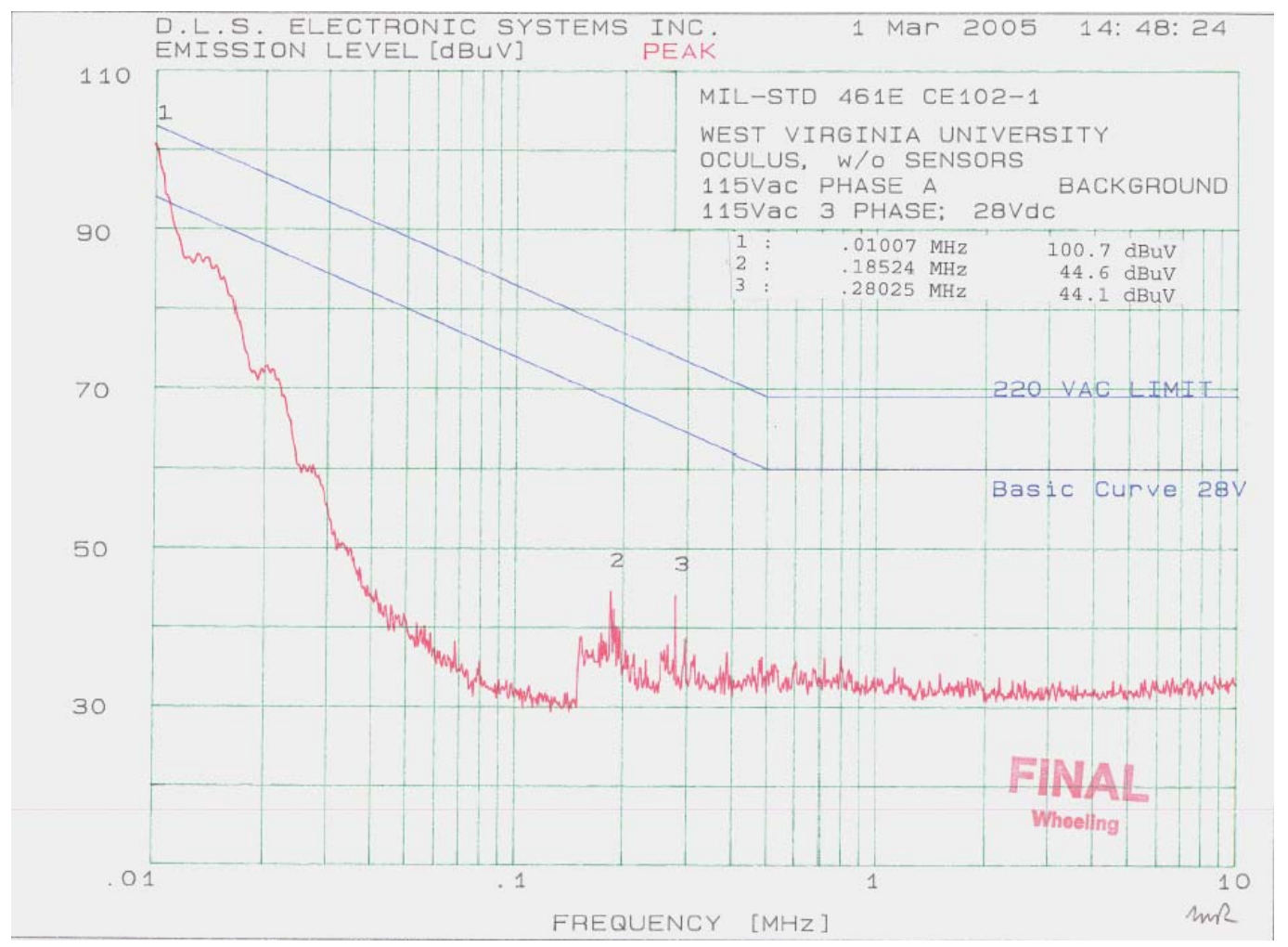

Figure 4. 220VAC noise floor/background (typical: phase A shown) 


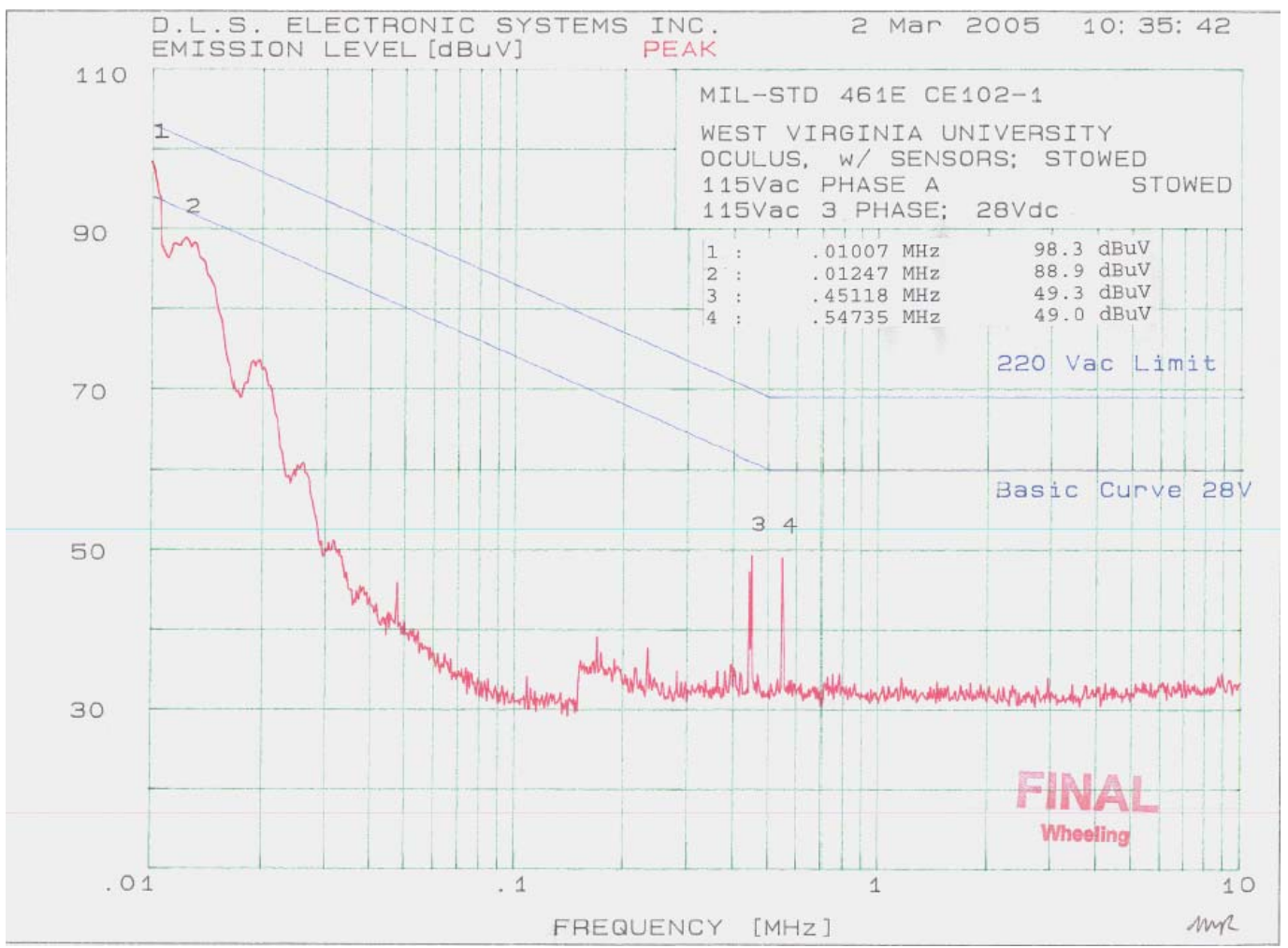

Figure 5. 220 VAC conducted emissions, sensor pod stowed. 


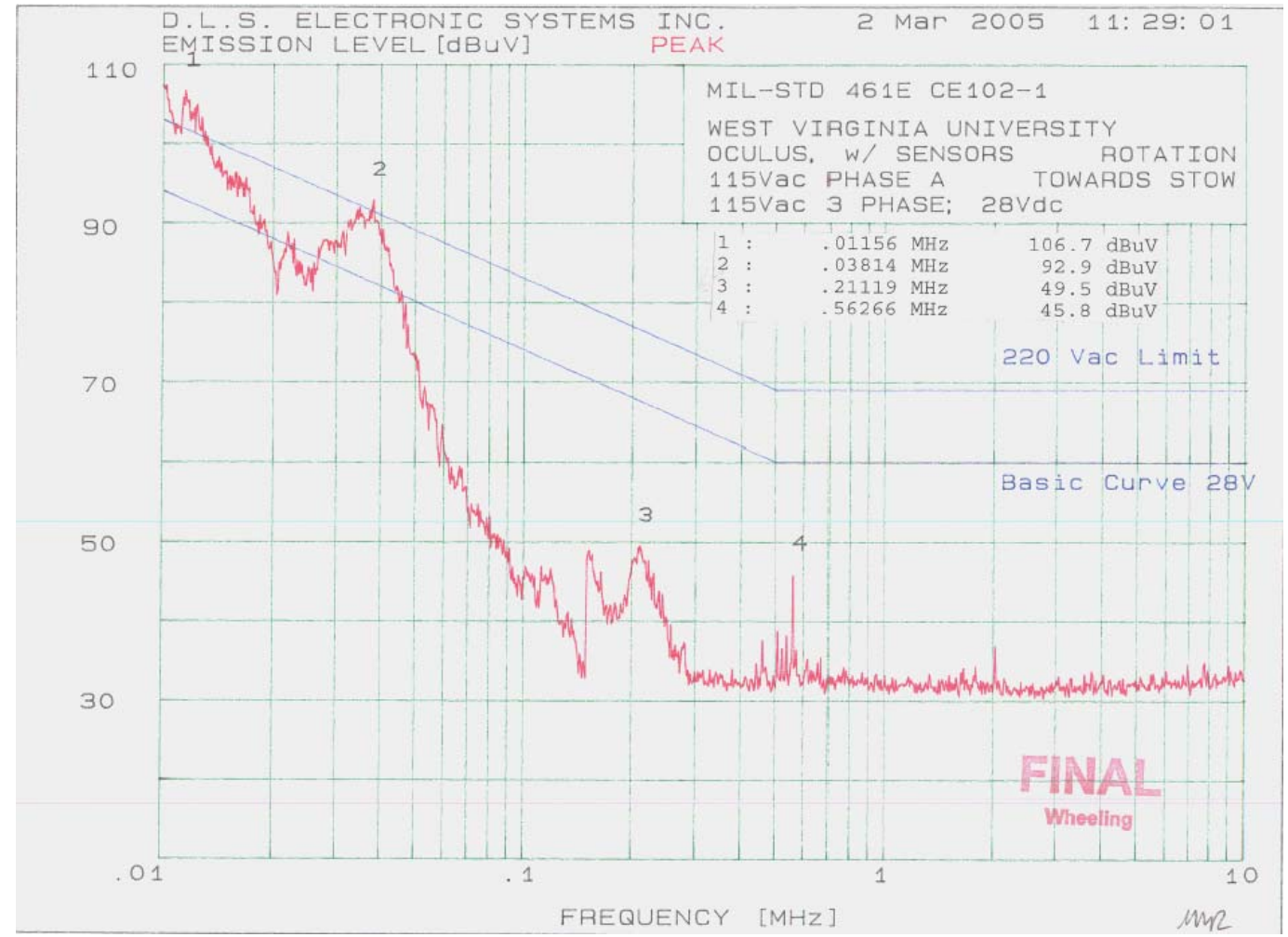

Figure 6. 220VAC conducted emissions during sensor pod rotation (worse case, phase A shown) 


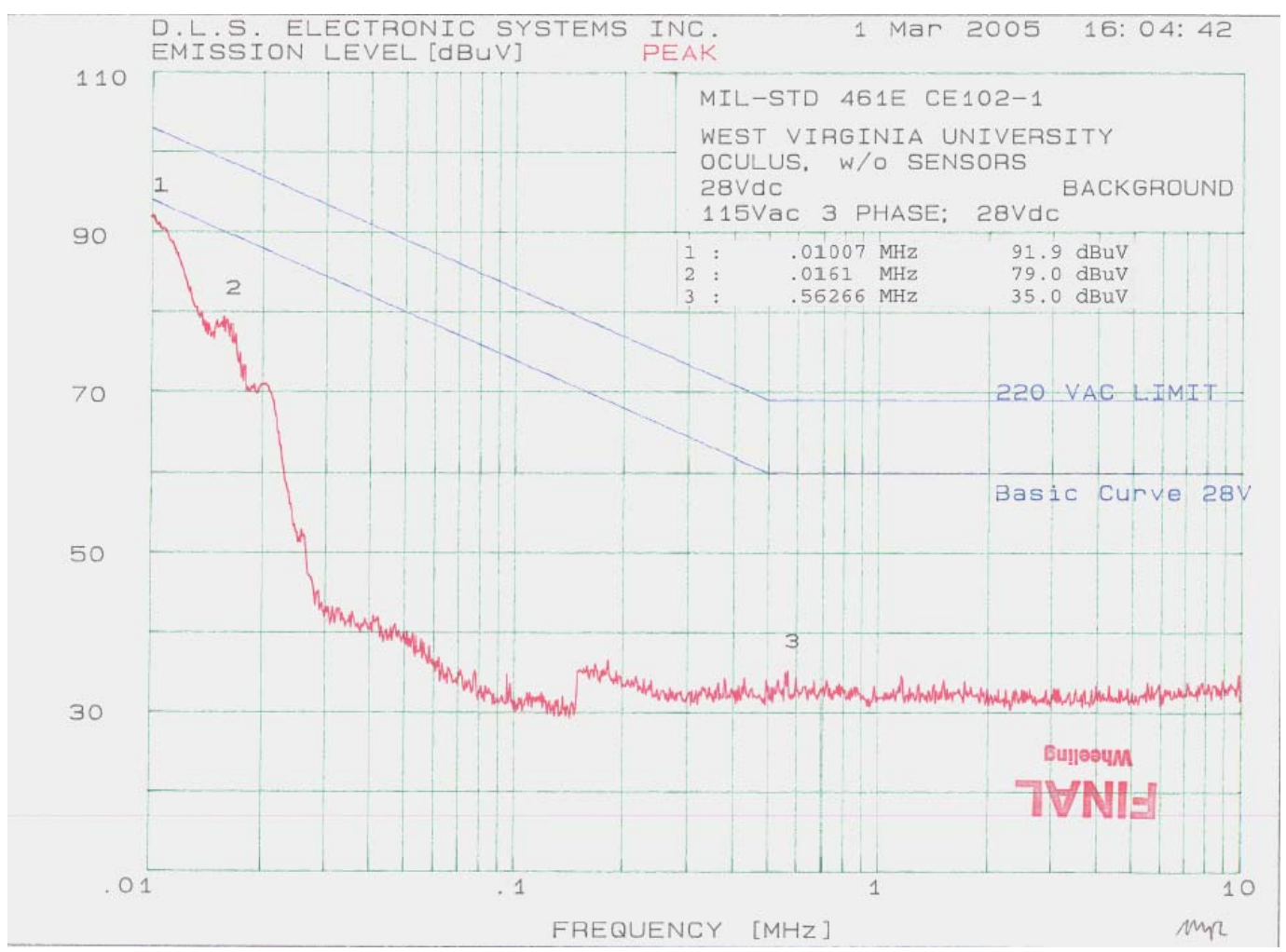

Figure 7. 28 VDC noise floor/background. 


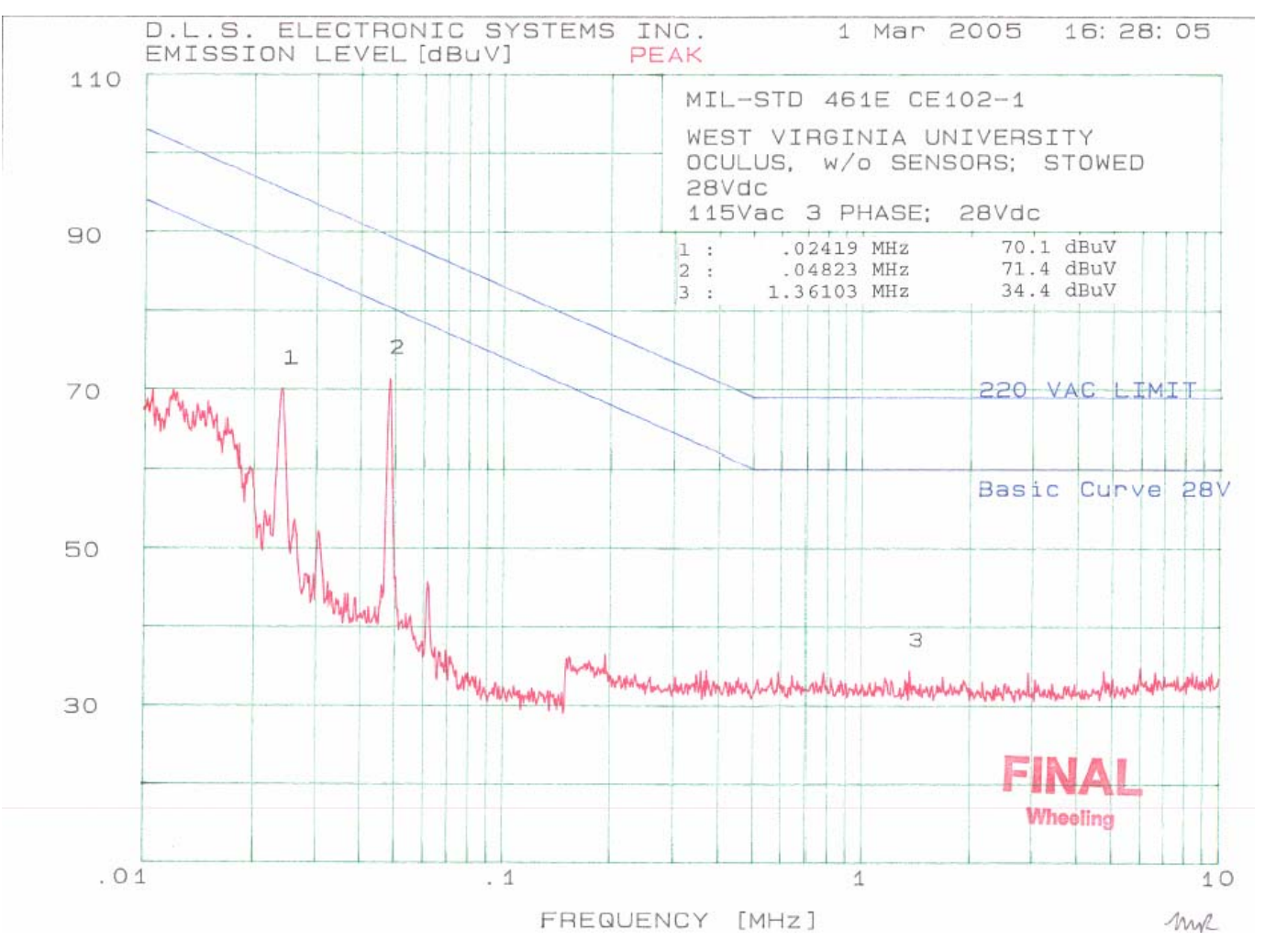

Figure 8. 28 VDC conducted emissions. 


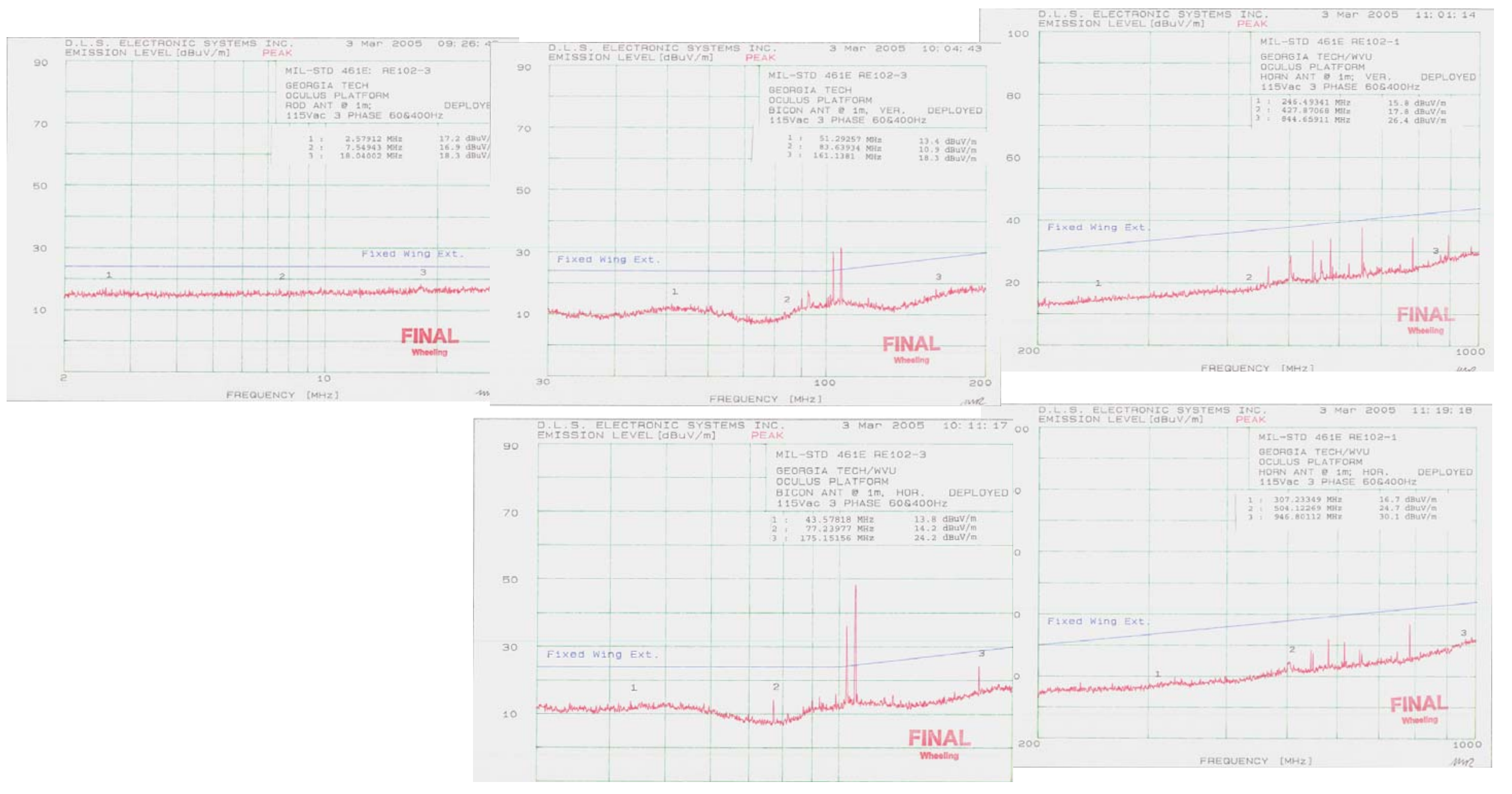

Figure 9. Deployed sensor pallet radiated emissions. 

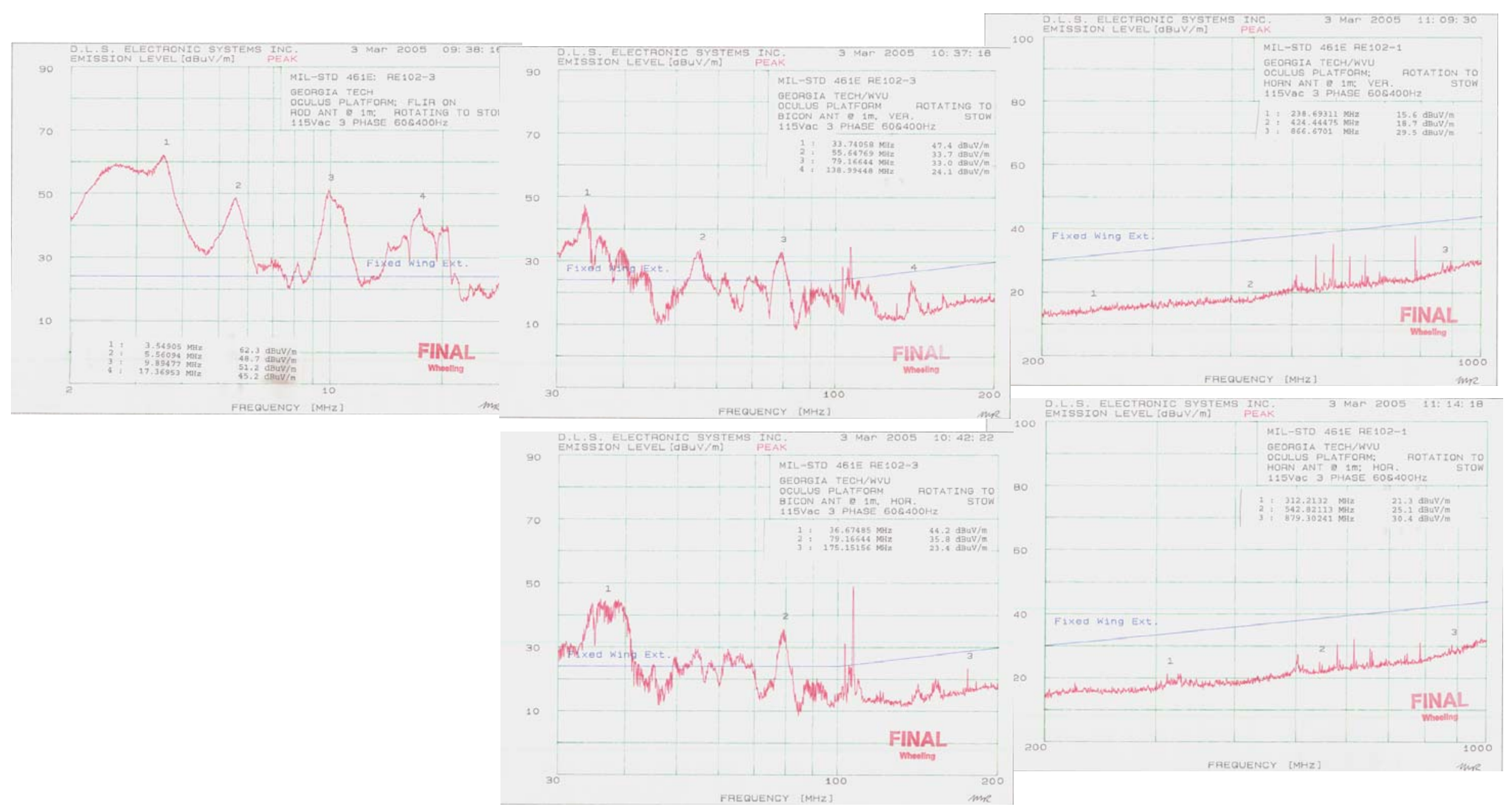

Figure 10. Radiated emissions 2-1,000 MHz (Position 1, sensor pallet rotating to stow position)
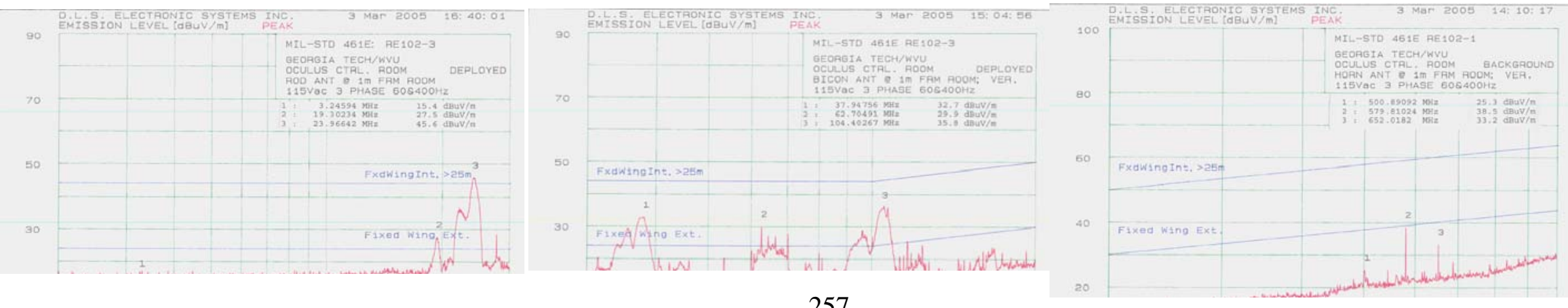
Figure 11. Operator's Station radiated emissions. 


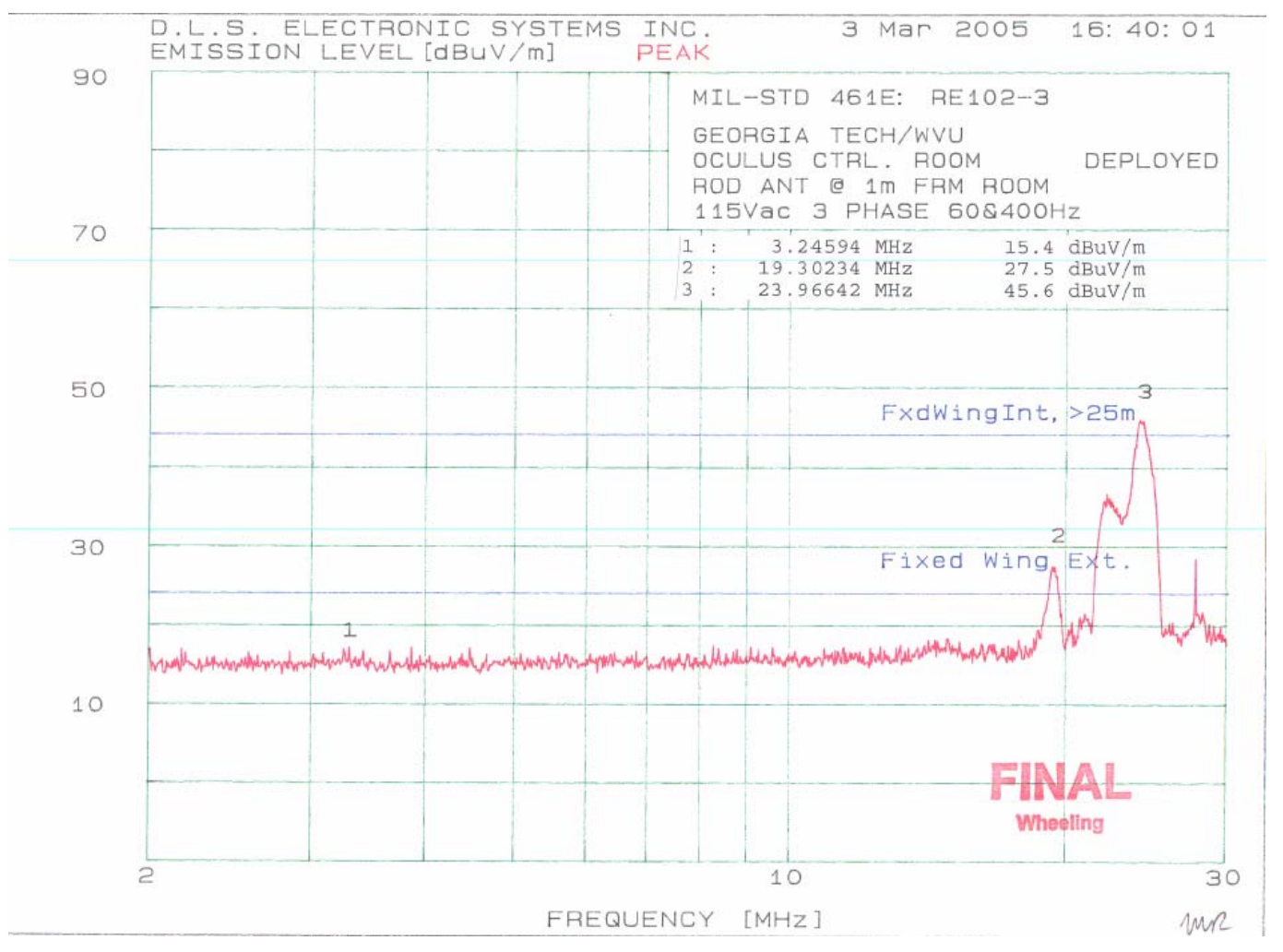

Figure 12. Radiated emissions 2-30 MHz (Position 3, Operator's Station). 

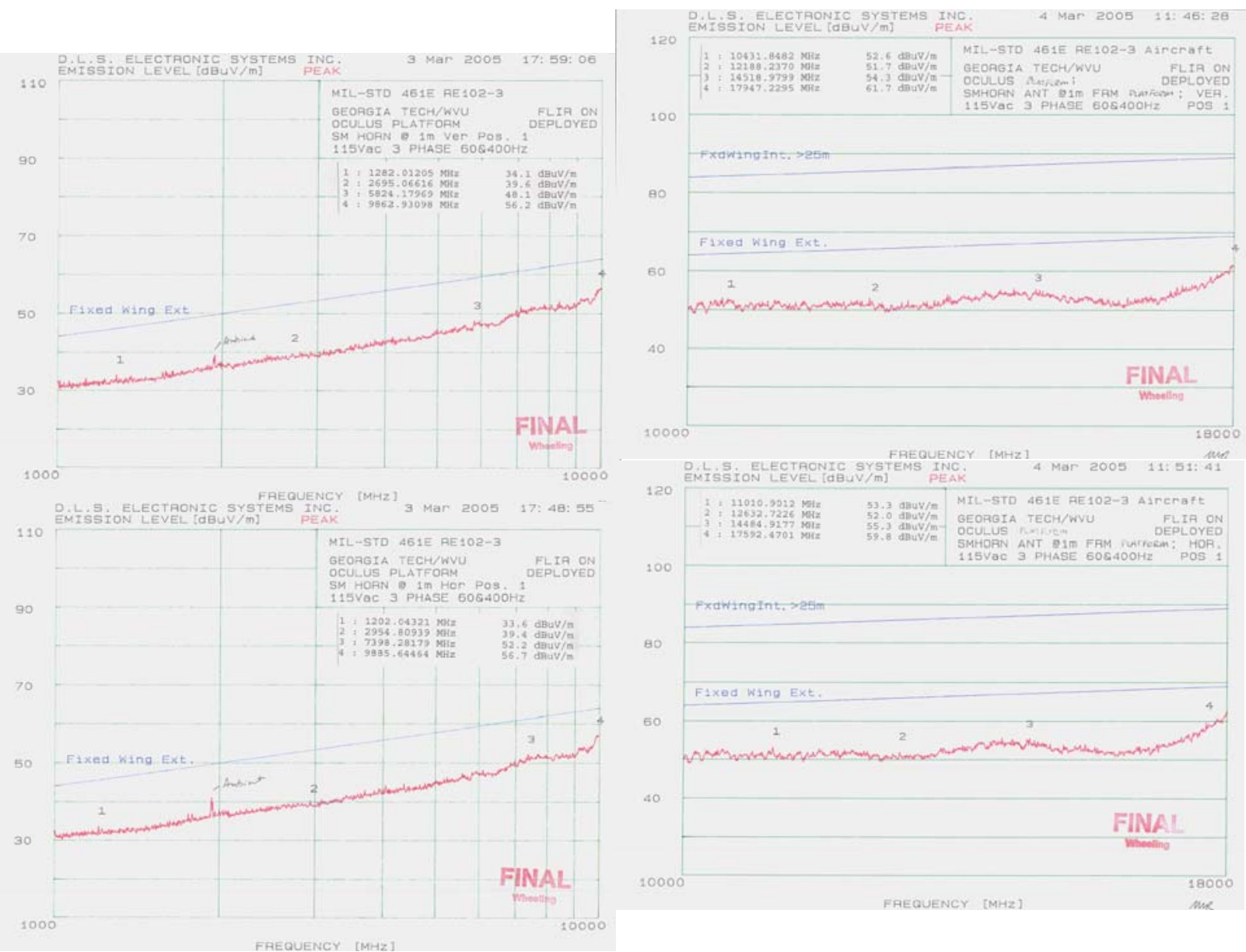

Figure 13. 1-18 GHz (All on, no problems).

\subsection{Conclusion}

The OCULUS system meets EMI levels for conducted and radiated emissions recommended by MILSTD-461E, with two exceptions. At one frequency the control room emissions exceed the limit by $1.6 \mathrm{~dB}$ and the motor and controllers are noisy when the sensor pallet is being deployed or stowed. The periods when the OCULUS system is deployed and stowed last for less than 60 seconds and only occur twice during a typical mission. Furthermore, the crew can control the time the deployment and stowing occur. The minor exceptions stated still still allow for the OCULUS system to meet the EMI levels required. 


\section{Appendix H. Flight Test Instrumentation Equipment}

The following pages list the major components used in the OCULUS 1.1 system's experimental fight testing. The key components are listed with manufacturer, a component figure, and summary of the components specifications. All components used for the testing was COTS equipment and allowable for use during flight on a military aircraft. This set of instrumentation equipment is solely used for the initial flight testing of the system and is not a normal component of the OCULUS 1.1 system. 


\section{Flight Test Instrumentation}

\section{Power Supply for DAQ and Signal Conditioning (5V or 3V)}

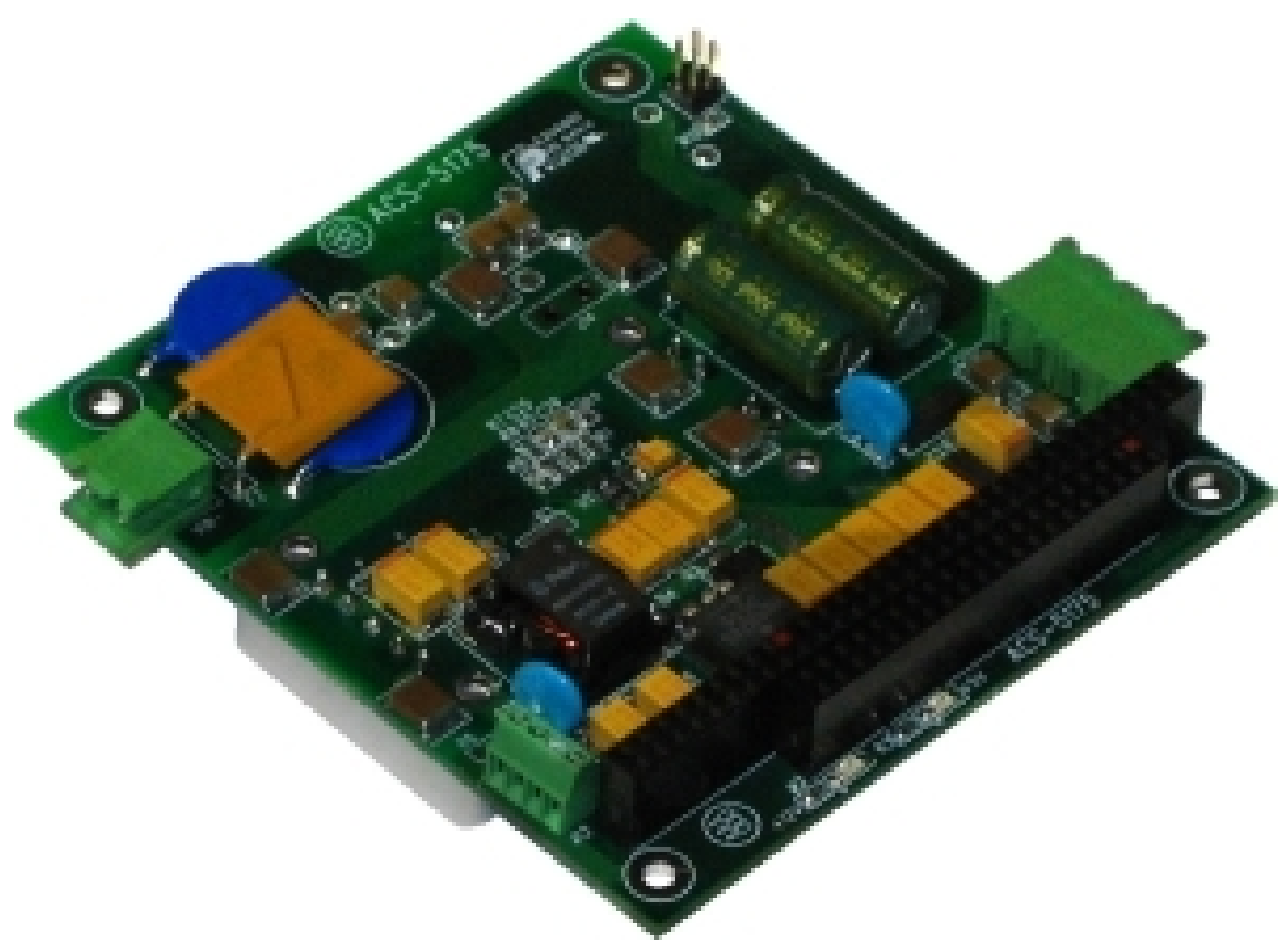

- Isolated 75W aggregate output power

- Ultra wide input ranges: 16-80Vdc and 9-45Vdc

- MIL-STD-704 compliant 28Vdc input range

- MIL-STD-1275 compliant 24Vdc input range

- Outputs: $+5 \mathrm{~V},+12 \mathrm{~V}$

- Power outputs:+5V@15A,+12V@2.5A

- Soft start to minimize inrush current

- External syncronization input

- Overtemperature shutdown of board and system

- Overload protection on all outputs

- Proprietary shielding, 3 stage input filter, 3 stage input protection - reverse, overvoltage, transient and surge

- Meets requirements of EC low voltage directives for CE compliance, immunity and emissions

- MIL-STD-810, MIL-STD-461, MIL-STD-704 and MIL-STD -1275 compliant, tested and certified 
2. Shielded Carriers and Modules (shown Nat. Instr. Corp Product \#SC-2345)

SC-2345 Series - Shielded carriers for up to 20 SCC modules

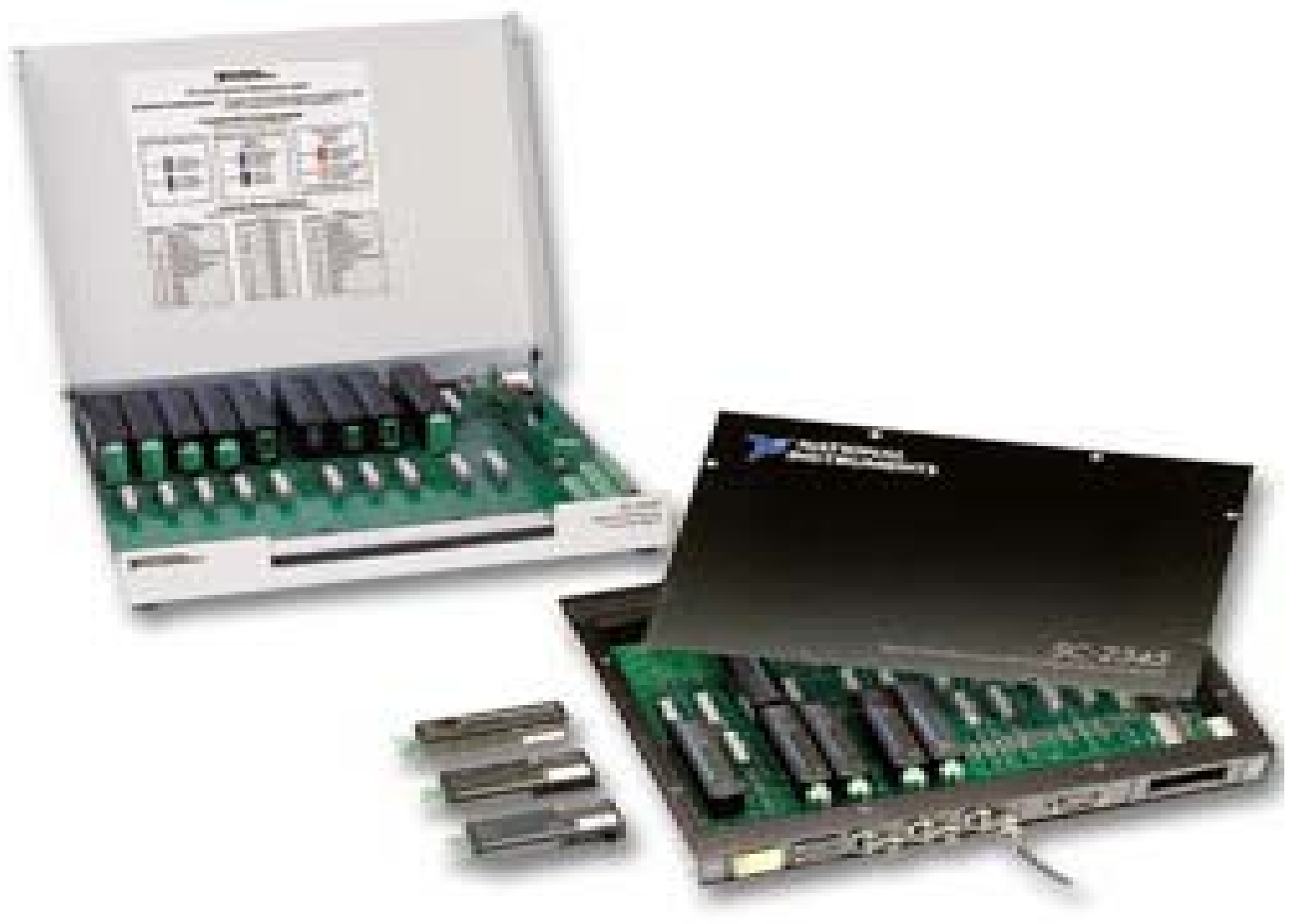

- $\quad$ SC-2345 connector bock

- M Series and E Series DAQ device direct cabling

- Portable, low-profile packaging

- SC-2345 with configurable connectors 


\section{Rack Mountable CPU - (shown Super Logics Product \#SL-2U-CL-945G-DA)}

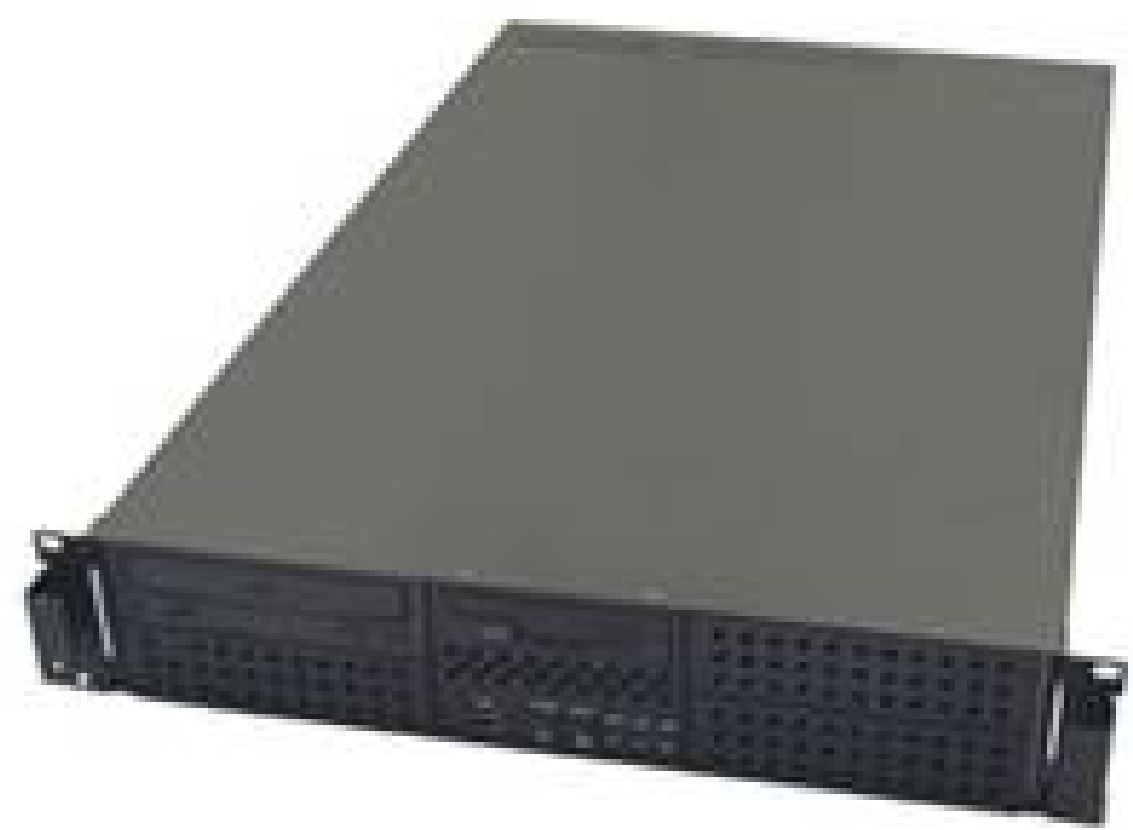

- Intel D945GNTL Motherboard with Dual Core Processor Support and LGA775 Socket

- 2.66Ghz Intel Celeron D LGA775 Processor - Upgradeable

- 80GB 7200RPM Western Digital Hard Drive - Upgradeable

- 52x CD-ROM - Upgradeable

- 256MB DDR2 System Memory - Upgradeable

- 350W Power Supply - Upgradeable

- 1.44MB 3.5" Floppy Disk Drive

- Onboard Intel 10/100 LAN

- Onboard Intel® GMA 950 Onboard Graphics Subsystem

- Onboard Intel High-Definition Audio System

- 6 x USB2.0 Ports (2 Front, 4 Rear)

- 1 x RS232 Serial Port

- 1 x LPT Parallel Port

- 3 Expansion Slots:

- 3 Conventional 32-bit PCI Slots Standard 


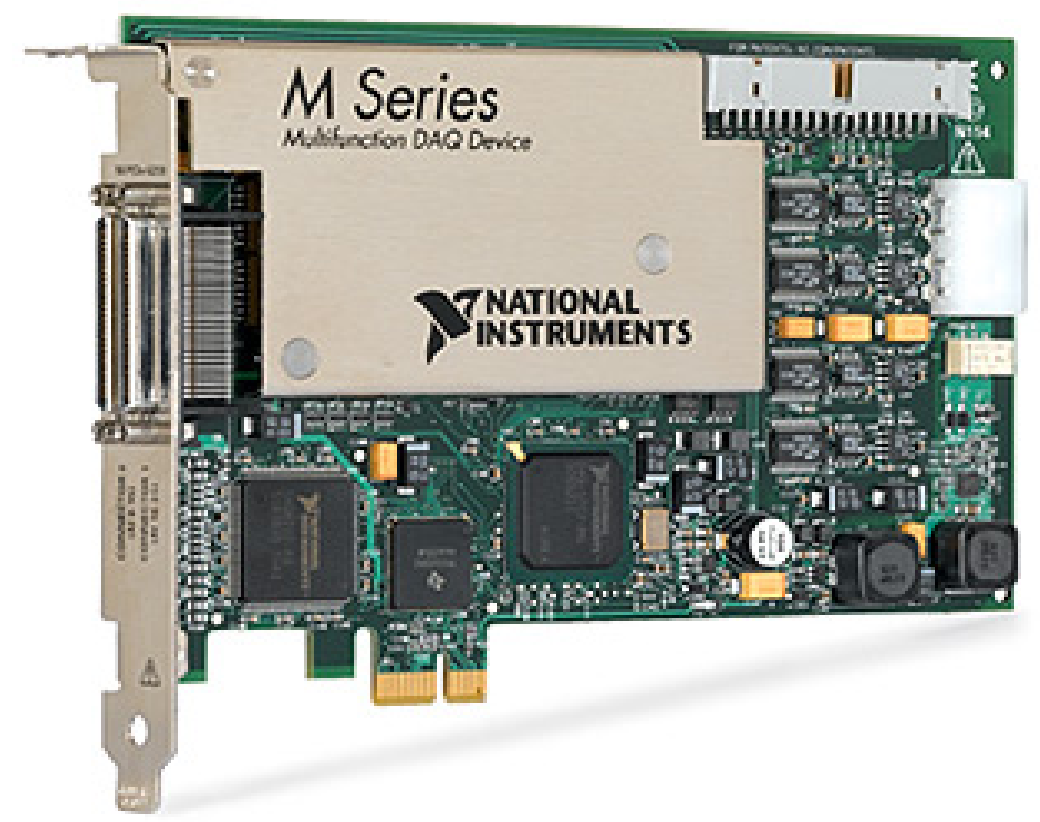

- 1 lane (x1) PCI Express interface for increased bandwidth

- Backward compatibile with software written for PCI

- Four 16-bit analog outputs (2.8 MS/s); 48 digital I/O; 32-bit counters

- Correlated DIO (32 clocked lines, $10 \mathrm{MHz}$ ); analog and digital triggering

- NI-MCal calibration technology for increased measurement accuracy

- Includes NI-DAQmx, VI Logger Lite data-logging software, and other measurement services 
5. Strain Gages - (shown Texas Measurements Inc. Product \#FRA-5-11-3LT)

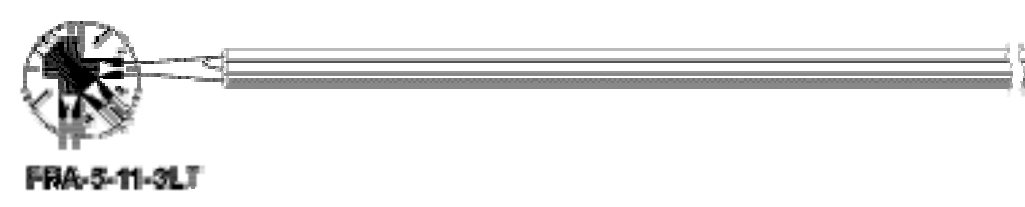

The F series are general-purpose gauges with a pre-attached vinyl lead wire. They can measure strain by merely connecting the lead wire to a strainmeter. Two-wire parallel in 1-, 3- and 5meter lengths are available. Also available are 3-wire parallel in 3- and 5-meter lengths.

\begin{tabular}{|c|c|c|c|}
\hline Main Test Materials & $\begin{array}{c}\text { Metal, Glass } \\
\text { Ceramics }\end{array}$ & Materials Backing & Epoxy \\
\hline $\begin{array}{c}\text { Operating } \\
\text { Temperature }\end{array}$ & -20 to $+80^{\circ} \mathrm{C}$ & Materials Element & Cu-Ni alloy foil \\
\hline Compensation range & +10 to $+80^{\circ} \mathrm{C}$ & $\begin{array}{c}\text { Strain limit } \\
\left(30000 \times 10^{-6}\right)\end{array}$ \\
\hline Bonding adhesive & CN,P-2,EB-2 & $\begin{array}{c}\text { Fatigue life at room } \\
\text { temp. }\end{array}$ & $\begin{array}{c}1 \times 10^{6} \\
\left( \pm 1500 \times 10^{-6}\right)\end{array}$ \\
\hline \hline
\end{tabular}

\section{Accelerometers - (shown Crossbow Technology Inc. Product \# CXL100HF1Z)}

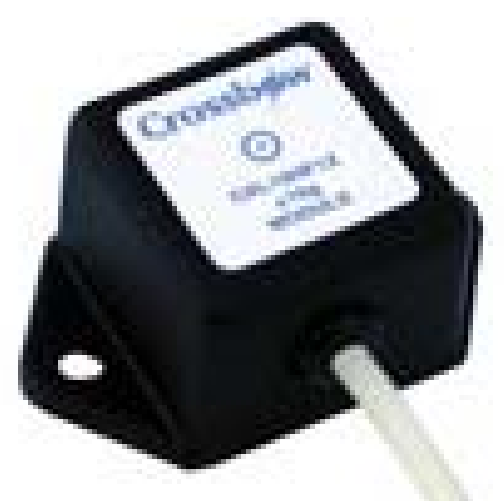

- $\quad$ Low Noise (300uG rms), Wide Bandwidth $(0.3-10,000 \mathrm{~Hz})$

- $\quad$ Easy to Use

- High Frequency Vibration Sensor

- $\quad \pm 10 \mathrm{~g}$ and $\pm 100 \mathrm{~g}$ Ranges 


\section{Cables and Connectors}

\section{MIL-SPEC Amphenol Connector}

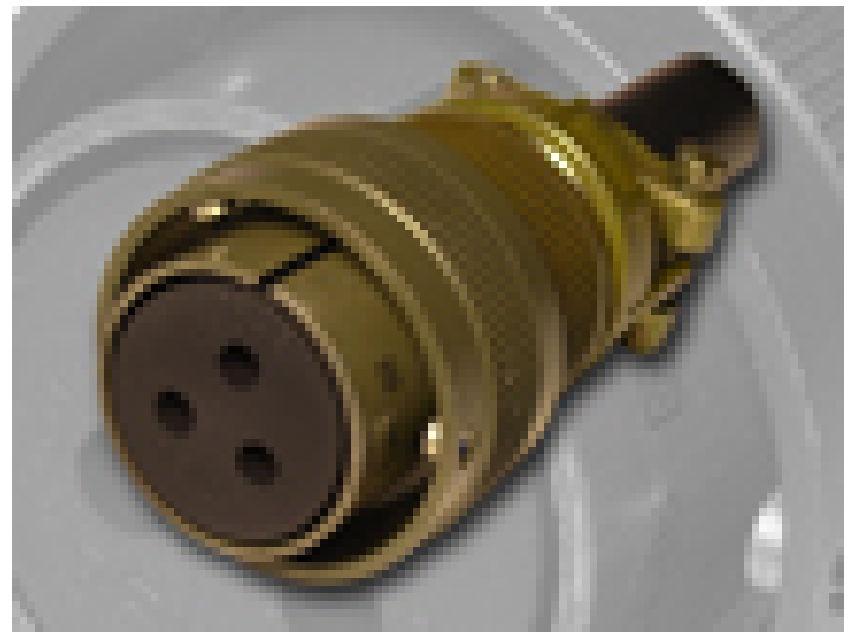

\section{Shielded Cable}

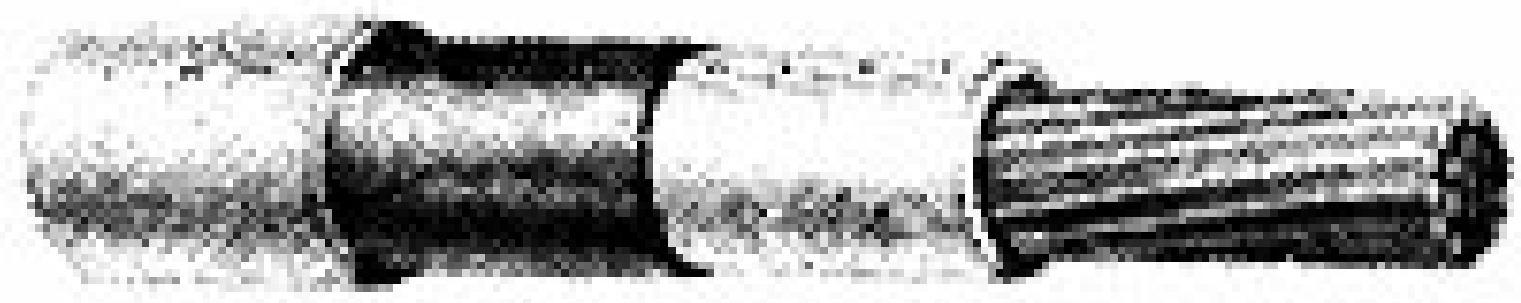

\section{Remote Desktop}

This is something that can be set up in the operator station to view the data being collected near real time at one of the two (or both) computer consoles. 


\section{Appendix I. Collection Data Correlated with Timestamp (taken in flight)}

The following table outlines the entire timestamp period for each flight test during the OCULUS 1.1 experimental flight test. The left two columns of the table give specific placeholder times according to the events that occur during the testing (far right column labeled "Action or Event”). The center three columns record the parameters being used for each individual test being performed which includes flight procedure (i.e straight and level, 15 degree bank, etc.), airspeed (KIAS) and payload weight. This timestamp table was used to correlate the raw data output to the specific procedures and parameters during OCULUS 1.1 flight test. Time stamp data that was not collected during the test flight is denoted by "??" in the timestamp table. 


\begin{tabular}{|c|c|c|c|c|c|c|c|c|c|c|c|c|c|c|}
\hline \multicolumn{5}{|c|}{ UT* } & \multicolumn{3}{|c|}{ EST* $^{*}$} & & & \multicolumn{2}{|r|}{ Procedure } & Airspeed & Weight & \multirow[t]{2}{*}{ Action or Event } \\
\hline \multirow{2}{*}{\multicolumn{15}{|c|}{$\begin{array}{l}\text { * = approximate time (+/- } 1 \text { minute) } \\
\text { Black = annotated test cards }\end{array}$}} \\
\hline & & & & & & & & & & & & & & \\
\hline 15 & : & 45 & : & 00 & 10 & : & 45 & : & 00 & & & & $100 \mathrm{lb}$ & Take-off time \\
\hline & & & & & & & & & & & & 150 & & \\
\hline 16 & : & 02 & : & 44 & 11 & : & 02 & : & 44 & & S\&L & $\begin{array}{c}\text { KIAS } \\
150\end{array}$ & $100 \mathrm{lb}$ & Start translation aft \\
\hline 16 & : & 03 & : & 31 & 11 & : & 03 & : & 31 & & S\&L & $\begin{array}{c}\text { KIAS } \\
150\end{array}$ & $100 \mathrm{lb}$ & Stop translation aft \\
\hline 16 & : & 03 & : & 48 & 11 & : & 03 & : & 48 & & S\&L & $\begin{array}{l}\text { KIAS } \\
150\end{array}$ & $100 \mathrm{lb}$ & Start rotating pod toward deployed position \\
\hline 16 & : & 04 & : & 06 & 11 & : & 04 & : & 06 & & S\&L & $\begin{array}{c}\text { KIAS } \\
150\end{array}$ & $100 \mathrm{lb}$ & Approximate load transition \\
\hline 16 & : & 04 & : & 50 & 11 & : & 04 & : & 50 & & S\&L & $\begin{array}{c}\text { KIAS } \\
150\end{array}$ & $100 \mathrm{lb}$ & Stop rotation at deployed position \\
\hline 16 & : & 05 & : & 01 & 11 & : & 05 & : & 01 & & S\&L & $\begin{array}{c}\text { KIAS } \\
150\end{array}$ & $100 \mathrm{lb}$ & $\begin{array}{l}\text { Start forward translation } \\
\text { Stop forward translation (pod completely }\end{array}$ \\
\hline 16 & : & 05 & : & 28 & 11 & : & 05 & : & 28 & & S\&L & KIAS & $100 \mathrm{lb}$ & deployed) \\
\hline & & & & & & & & & & FT- & Emergency & 150 & & \\
\hline 16 & : & $? ?$ & : & $? ?$ & 11 & : & $? ?$ & : & $? ?$ & $\begin{array}{l}01 \\
\text { FT- }\end{array}$ & $\begin{array}{l}\text { Backup } \\
\text { Emergency }\end{array}$ & $\begin{array}{c}\text { KIAS } \\
150\end{array}$ & $100 \mathrm{lb}$ & Start stowing pod with electric drill \\
\hline 16 & : & 24 & : & 06 & 11 & : & 24 & : & 06 & 01 & Backup & KIAS & $100 \mathrm{lb}$ & Stowed pod with electric drill \\
\hline & & & & & & & & & & FT- & Emergency & 150 & & \\
\hline 16 & : & 33 & : & 33 & 11 & : & 33 & : & 33 & $\begin{array}{l}01 \\
\text { FT- }\end{array}$ & $\begin{array}{l}\text { Backup } \\
\text { Emergency }\end{array}$ & $\begin{array}{l}\text { KIAS } \\
150\end{array}$ & $100 \mathrm{lb}$ & Start stowing pod with battery powered drill \\
\hline 16 & : & 52 & : & 38 & 11 & : & 52 & : & 38 & 01 & Backup & KIAS & $100 \mathrm{lb}$ & Stowed pod with battery powered drill \\
\hline 17 & : & 02 & : & $? ?$ & 12 & : & 02 & : & $? ?$ & $\begin{array}{l}\text { FT- } \\
02\end{array}$ & EMC-Flight & $\begin{array}{c}150 \\
\text { KIAS } \\
150\end{array}$ & $100 \mathrm{lb}$ & Start one deploy/stow cycle \\
\hline 17 & : & 04 & : & 45 & 12 & : & 04 & : & 45 & & S\&L & $\begin{array}{l}\text { KIAS } \\
150\end{array}$ & $100 \mathrm{lb}$ & Start rotation toward deploy \\
\hline 17 & : & 05 & : & 57 & 12 & : & 05 & : & 57 & & S\&L & KIAS & $100 \mathrm{lb}$ & Start translation forward \\
\hline
\end{tabular}




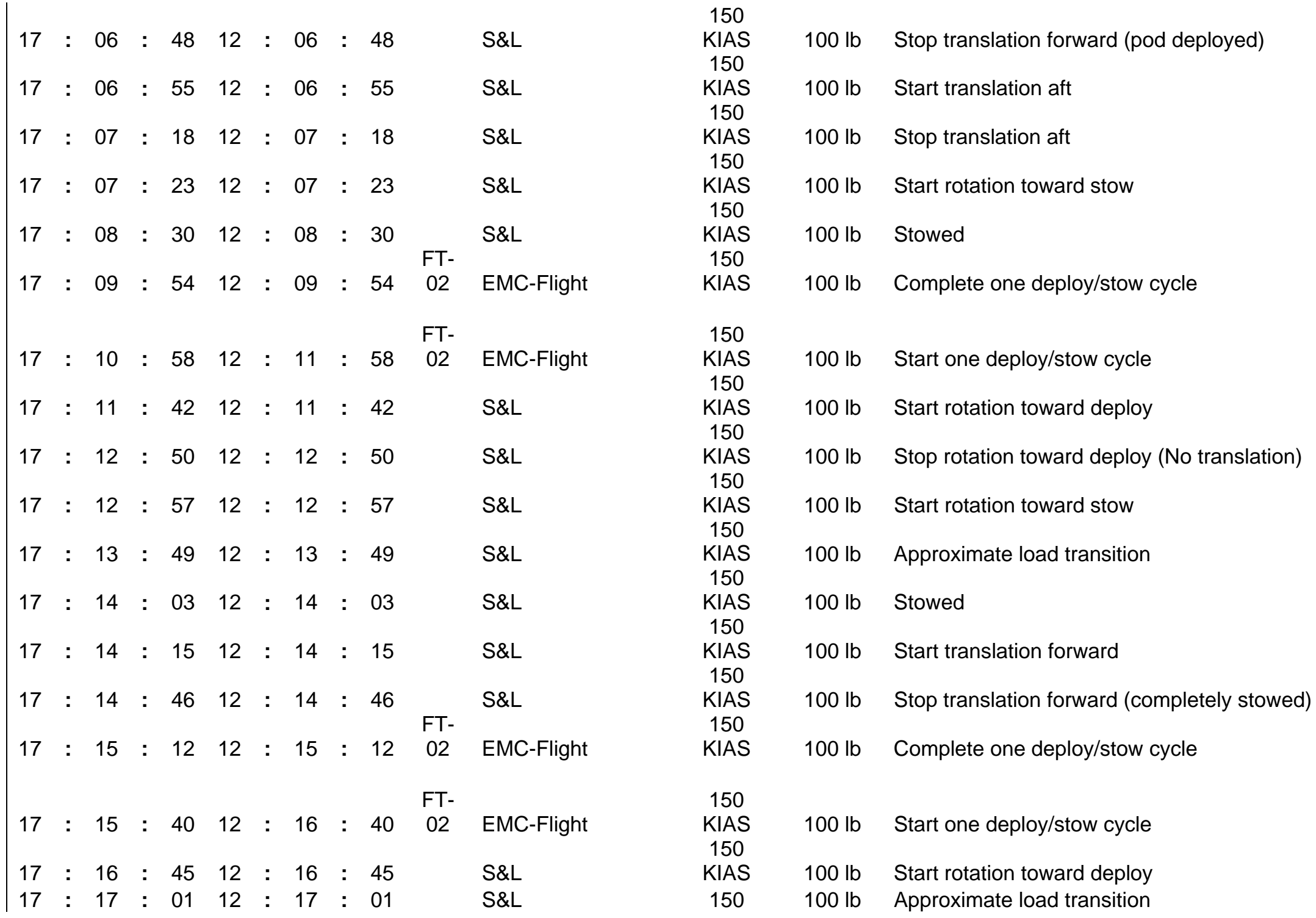




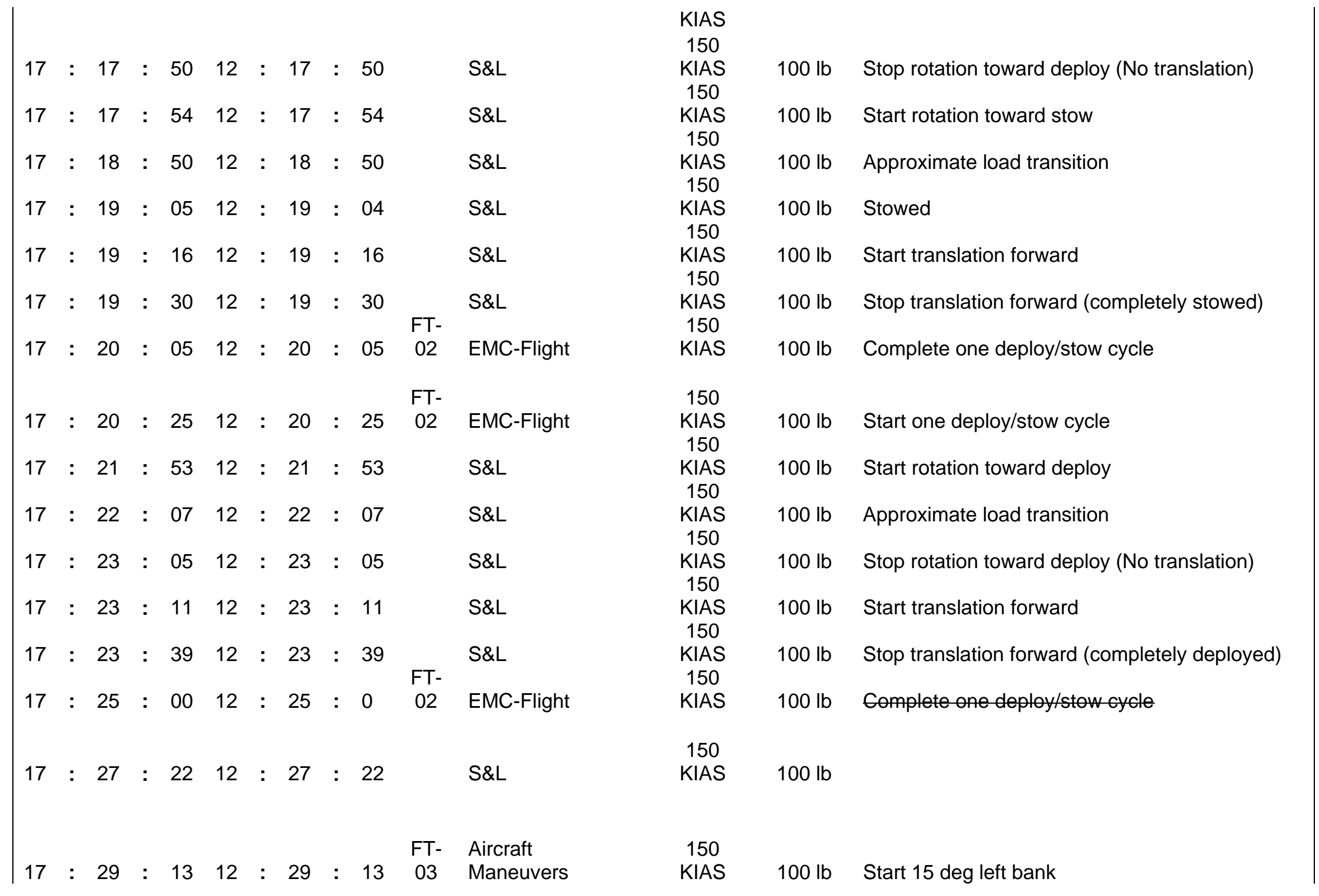




\begin{tabular}{|c|c|c|c|c|c|c|c|c|c|c|c|c|c|c|}
\hline 17 & : & 29 & : & 54 & 12 & : & 29 & : & 54 & $\begin{array}{l}\text { FT- } \\
03\end{array}$ & $\begin{array}{l}\text { Aircraft } \\
\text { Maneuvers }\end{array}$ & $\begin{array}{l}150 \\
\text { KIAS }\end{array}$ & $100 \mathrm{lb}$ & End 15 deg left bank \\
\hline 17 & : & 30 & : & 13 & 12 & $:$ & 30 & : & 13 & $\begin{array}{l}\text { FT- } \\
03 \\
\text { FT- }\end{array}$ & $\begin{array}{l}\text { Aircraft } \\
\text { Maneuvers } \\
\text { Aircraft }\end{array}$ & $\begin{array}{c}150 \\
\text { KIAS } \\
150\end{array}$ & $100 \mathrm{lb}$ & Start 15 deg right bank \\
\hline 17 & $:$ & 30 & : & 49 & 12 & $:$ & 30 & : & 49 & 03 & Maneuvers & KIAS & $100 \mathrm{lb}$ & End 15 deg right bank \\
\hline 17 & : & 31 & : & 00 & 12 & : & 31 & : & 00 & $\begin{array}{l}\text { FT- } \\
03 \\
\text { FT- }\end{array}$ & $\begin{array}{l}\text { Aircraft } \\
\text { Maneuvers } \\
\text { Aircraft }\end{array}$ & $\begin{array}{c}150 \\
\text { KIAS } \\
150\end{array}$ & $100 \mathrm{lb}$ & Start 30 deg left bank \\
\hline 17 & : & 31 & : & 26 & 12 & $:$ & 31 & : & 26 & 03 & Maneuvers & KIAS & $100 \mathrm{lb}$ & End 30 deg left bank \\
\hline 17 & $:$ & 31 & : & 49 & 12 & : & 31 & : & 49 & $\begin{array}{l}\text { FT- } \\
03 \\
\text { FT- }\end{array}$ & $\begin{array}{l}\text { Aircraft } \\
\text { Maneuvers } \\
\text { Aircraft }\end{array}$ & $\begin{array}{c}150 \\
\text { KIAS } \\
150\end{array}$ & $100 \mathrm{lb}$ & Start 30 deg right bank \\
\hline 17 & : & 32 & : & 12 & 12 & $:$ & 32 & : & 12 & 03 & Maneuvers & KIAS & $100 \mathrm{lb}$ & End 30 deg right bank \\
\hline 17 & $:$ & 32 & : & 50 & 12 & : & 32 & : & 50 & $\begin{array}{l}\text { FT- } \\
03 \\
\text { FT- }\end{array}$ & $\begin{array}{l}\text { Aircraft } \\
\text { Maneuvers } \\
\text { Aircraft }\end{array}$ & $\begin{array}{c}150 \\
\text { KIAS } \\
150\end{array}$ & $100 \mathrm{lb}$ & Start 45 deg left bank \\
\hline 17 & : & 33 & : & 02 & 12 & $:$ & 33 & : & 02 & 03 & Maneuvers & KIAS & $100 \mathrm{lb}$ & End 45 deg left bank \\
\hline 17 & $:$ & 33 & : & 43 & 12 & : & 33 & : & 43 & $\begin{array}{l}\text { FT- } \\
03 \\
\text { FT- }\end{array}$ & $\begin{array}{l}\text { Aircraft } \\
\text { Maneuvers } \\
\text { Aircraft }\end{array}$ & $\begin{array}{c}150 \\
\text { KIAS } \\
150\end{array}$ & $100 \mathrm{lb}$ & Start 45 deg right bank \\
\hline 17 & : & 33 & : & 57 & 12 & $:$ & 33 & : & 57 & 03 & Maneuvers & KIAS & $100 \mathrm{lb}$ & End 45 deg right bank \\
\hline 17 & : & 34 & : & 00 & 12 & : & 34 & : & 00 & & $150->130 \mathrm{~S} \& \mathrm{~L}$ & & & Transition airspeed \\
\hline 17 & : & 36 & : & 03 & 12 & : & 36 & : & 03 & & $\begin{array}{l}\text { Aircraft } \\
\text { Maneuvers } \\
\text { Aircraft }\end{array}$ & $\begin{array}{c}130 \\
\text { KIAS } \\
130\end{array}$ & $100 \mathrm{lb}$ & Start 15 deg left bank \\
\hline 17 & : & 37 & : & 06 & 12 & : & 37 & : & 06 & & Maneuvers & KIAS & $100 \mathrm{lb}$ & End 15 deg left bank \\
\hline
\end{tabular}




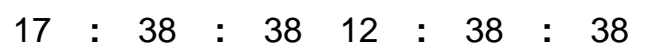

$\begin{array}{llllllllll} & 17 & 39 & : & 39 & 12 & : & 39 & : & 39\end{array}$

$\begin{array}{llllllllll}17 & : & 39 & : & 48 & 12 & : & 39 & : & 48\end{array}$

$17: 40: 12 \quad 12: 40: 12$

$17: \begin{array}{llllllll} & 40 & 37 & 12 & : & 40 & : & 37\end{array}$

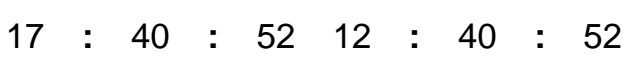

$17: 41: \begin{array}{llllll}16 & 12 & : & 41 & : & 16\end{array}$

$\begin{array}{llllllllll}17 & : & 41 & : & 28 & 12 & : & 41 & : & 28\end{array}$

$17: 41 \quad: \quad 50 \quad 12 \quad: \quad 41 \quad: 50$

$17: \begin{array}{lllllllll} & 41 & 56 & 12 & : & 41 & : & 56\end{array}$

$17: \begin{array}{llllllll} & 4 & 4 & 12 & : & 42 & : & 44\end{array}$

$17: 43 \quad: \quad 32 \quad 12 \quad: \quad 43 \quad: \quad 32$

$\begin{array}{llllll}17 & 44 & 01 & 12 & 44 & 01\end{array}$

$\begin{array}{llllll}17 & 44 & 21 & 12 & 44 & 21\end{array}$

$\begin{array}{llllll}17 & 54 & 04 & 12 & 54 & 04\end{array}$
Aircraft

Maneuvers

Aircraft

Maneuvers

Aircraft

Maneuvers

Aircraft

Maneuvers

Aircraft

Maneuvers

Aircraft

Maneuvers

Aircraft

Maneuvers

Aircraft

Maneuvers

Aircraft

Maneuvers

Aircraft

Maneuvers

Aircraft

Maneuvers

Aircraft

Maneuvers

S\&L

S\&L

$S \& L$
130

KIAS

130

KIAS

$100 \mathrm{lb} \quad$ Start $15 \mathrm{deg}$ right bank

$100 \mathrm{lb} \quad$ End 15 deg right bank

130
KIAS $\quad 100 \mathrm{lb} \quad$ Start 30 deg left bank

KIAS

$100 \mathrm{lb} \quad$ End 30 deg left bank

130

KIAS

130

KIAS

$100 \mathrm{lb}$ Start 30 deg right bank

$100 \mathrm{lb}$ End 30 deg right bank

130

KIAS

130

KIAS

$100 \mathrm{lb} \quad$ Start 45 deg left bank

$100 \mathrm{lb}$ End 45 deg left bank

130

KIAS

130

KIAS

$100 \mathrm{lb} \quad$ Start 45 deg right bank

$100 \mathrm{lb}$ End 45 deg right bank

130

KIAS

130

KIAS

$100 \mathrm{lb} \quad$ Start 45 deg right bank

$100 \mathrm{lb} \quad$ End 45 deg right bank

130

KIAS

130

KIAS

130
$100 \mathrm{lb}$ Start raising ramp (pod still deployed)

$100 \mathrm{lb}$ Ramp up (pod deployed)

$100 \mathrm{lb} \quad$ Start lowering ramp (pod deployed) 


\begin{tabular}{|c|c|c|c|c|c|c|c|c|c|}
\hline 17 & 54 & 25 & 12 & 54 & 25 & $\mathrm{~S} \& \mathrm{~L}$ & $\begin{array}{c}\text { KIAS } \\
130 \\
\text { KIAS }\end{array}$ & $100 \mathrm{lb}$ & Ramp down (pod deployed) \\
\hline 17 & 54 & 51 & 12 & 54 & 51 & S\&L & $\begin{array}{c}130 \\
\text { KIAS } \\
130\end{array}$ & $100 \mathrm{lb}$ & Start translation aft \\
\hline 17 & 55 & 25 & 12 & 55 & 25 & S\&L & $\begin{array}{c}\text { KIAS } \\
130\end{array}$ & $100 \mathrm{lb}$ & Stop translation aft \\
\hline 17 & 55 & 35 & 12 & 55 & 35 & S\&L & $\begin{array}{c}\text { KIAS } \\
130\end{array}$ & $100 \mathrm{lb}$ & Start rotation toward stow \\
\hline 17 & 56 & 25 & 12 & 56 & 25 & S\&L & $\begin{array}{c}\text { KIAS } \\
130\end{array}$ & $100 \mathrm{lb}$ & Approximate load transition \\
\hline 17 & 56 & 39 & 12 & 56 & 39 & S\&L & $\begin{array}{c}\text { KIAS } \\
130\end{array}$ & $100 \mathrm{lb}$ & Stow \\
\hline 17 & 56 & 42 & 12 & 56 & 42 & S\&L & $\begin{array}{c}\text { KIAS } \\
130\end{array}$ & $100 \mathrm{lb}$ & Start translation forward \\
\hline 17 & 57 & 32 & 12 & 57 & 32 & S\&L & KIAS & $100 \mathrm{lb}$ & Stop translation forward (fully stowed) \\
\hline 17 & 57 & 59 & 12 & 57 & 59 & S\&L & $\begin{array}{c}130 \\
\text { KIAS } \\
130\end{array}$ & $100 \mathrm{lb}$ & Start raising ramp (pod stowed) \\
\hline 17 & 58 & 20 & 12 & 58 & 20 & S\&L & $\begin{array}{c}\text { KIAS } \\
130\end{array}$ & $100 \mathrm{lb}$ & Ramp up \\
\hline 17 & 58 & 26 & 12 & 58 & 26 & S\&L & $\begin{array}{c}\text { KIAS } \\
130\end{array}$ & $100 \mathrm{lb}$ & Start closing rear door \\
\hline 17 & 58 & 36 & 12 & 58 & 36 & S\&L & KIAS & $100 \mathrm{lb}$ & Rear door closed \\
\hline 18 & 01 & 20 & 13 & 01 & 20 & Oper & red off & brox) & \\
\hline 18 & 15 & ?? & 13 & 15 & ?? & & & & Land \\
\hline$? ?$ & ?? & ?? & & & & $\begin{array}{l}\text { Lunc } \\
\text { Load } \\
\text { total) }\end{array}$ & to pod & lb & \\
\hline
\end{tabular}




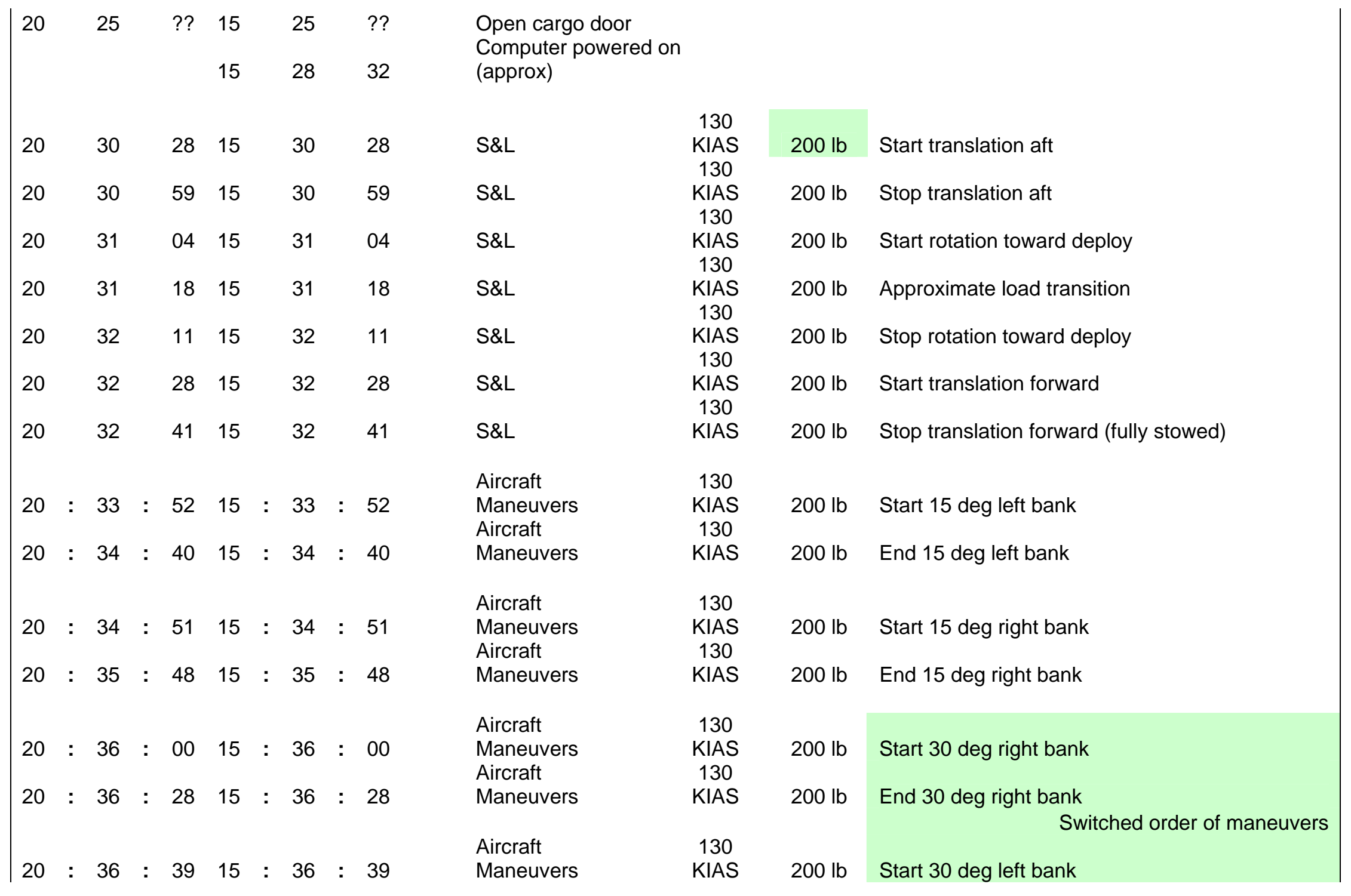




\begin{tabular}{|c|c|c|c|c|c|c|c|c|c|c|c|c|c|}
\hline 20 & : & 37 & : & 07 & 15 & : & 37 & : & 07 & $\begin{array}{l}\text { Aircraft } \\
\text { Maneuvers }\end{array}$ & $\begin{array}{c}130 \\
\text { KIAS }\end{array}$ & $200 \mathrm{lb}$ & End 30 deg left bank \\
\hline 20 & : & 37 & : & 41 & 15 & : & 37 & : & 41 & $\begin{array}{l}\text { Aircraft } \\
\text { Maneuvers } \\
\text { Aircraft }\end{array}$ & $\begin{array}{c}130 \\
\text { KIAS } \\
130\end{array}$ & $200 \mathrm{lb}$ & Start 45 deg left bank \\
\hline 20 & : & 38 & : & 02 & 15 & : & 38 & : & 02 & Maneuvers & KIAS & $200 \mathrm{lb}$ & End 45 deg left bank \\
\hline 20 & : & 38 & : & 12 & 15 & : & 38 & : & 12 & $\begin{array}{l}\text { Aircraft } \\
\text { Maneuvers } \\
\text { Aircraft }\end{array}$ & $\begin{array}{c}130 \\
\text { KIAS } \\
130\end{array}$ & $200 \mathrm{lb}$ & Start 45 deg right bank \\
\hline 20 & : & 38 & : & 31 & 15 & : & 38 & $:$ & 31 & Maneuvers & KIAS & $200 \mathrm{lb}$ & End 45 deg right bank \\
\hline 20 & $:$ & 38 & $:$ & 49 & 15 & : & 38 & : & 49 & $\begin{array}{l}\text { Aircraft } \\
\text { Maneuvers } \\
\text { Aircraft }\end{array}$ & $\begin{array}{c}130 \\
\text { KIAS } \\
130\end{array}$ & $200 \mathrm{lb}$ & Start slip left \\
\hline 20 & $:$ & 38 & : & 58 & 15 & : & 38 & : & 58 & Maneuvers & KIAS & $200 \mathrm{lb}$ & End slip left \\
\hline 20 & : & 39 & : & 05 & 15 & : & 39 & : & 05 & $\begin{array}{l}\text { Aircraft } \\
\text { Maneuvers } \\
\text { Aircraft }\end{array}$ & $\begin{array}{c}130 \\
\text { KIAS } \\
130\end{array}$ & $200 \mathrm{lb}$ & Start slip right \\
\hline 20 & $:$ & 39 & : & 26 & 15 & : & 39 & : & 26 & Maneuvers & KIAS & $200 \mathrm{lb}$ & End slip right \\
\hline 20 & $:$ & 41 & : & 26 & 15 & : & 41 & : & 26 & $\begin{array}{l}\text { Aircraft } \\
\text { Maneuvers } \\
\text { Aircraft }\end{array}$ & $\begin{array}{c}150 \\
\text { KIAS } \\
150\end{array}$ & $200 \mathrm{lb}$ & Start 15 deg left bank \\
\hline 20 & : & 42 & : & 18 & 15 & : & 42 & : & 18 & Maneuvers & KIAS & $200 \mathrm{lb}$ & End 15 deg left bank \\
\hline 20 & $:$ & 42 & : & 28 & 15 & : & 42 & : & 28 & $\begin{array}{l}\text { Aircraft } \\
\text { Maneuvers } \\
\text { Aircraft }\end{array}$ & $\begin{array}{c}150 \\
\text { KIAS } \\
150\end{array}$ & $200 \mathrm{lb}$ & Start 15 deg right bank \\
\hline 20 & : & 43 & : & 12 & 15 & : & 43 & : & 12 & Maneuvers & KIAS & $200 \mathrm{lb}$ & End 15 deg right bank \\
\hline 20 & : & 43 & : & 33 & 15 & : & 43 & : & 33 & $\begin{array}{l}\text { Aircraft } \\
\text { Maneuvers }\end{array}$ & $\begin{array}{c}150 \\
\text { KIAS }\end{array}$ & $200 \mathrm{lb}$ & Start 30 deg right bank \\
\hline
\end{tabular}




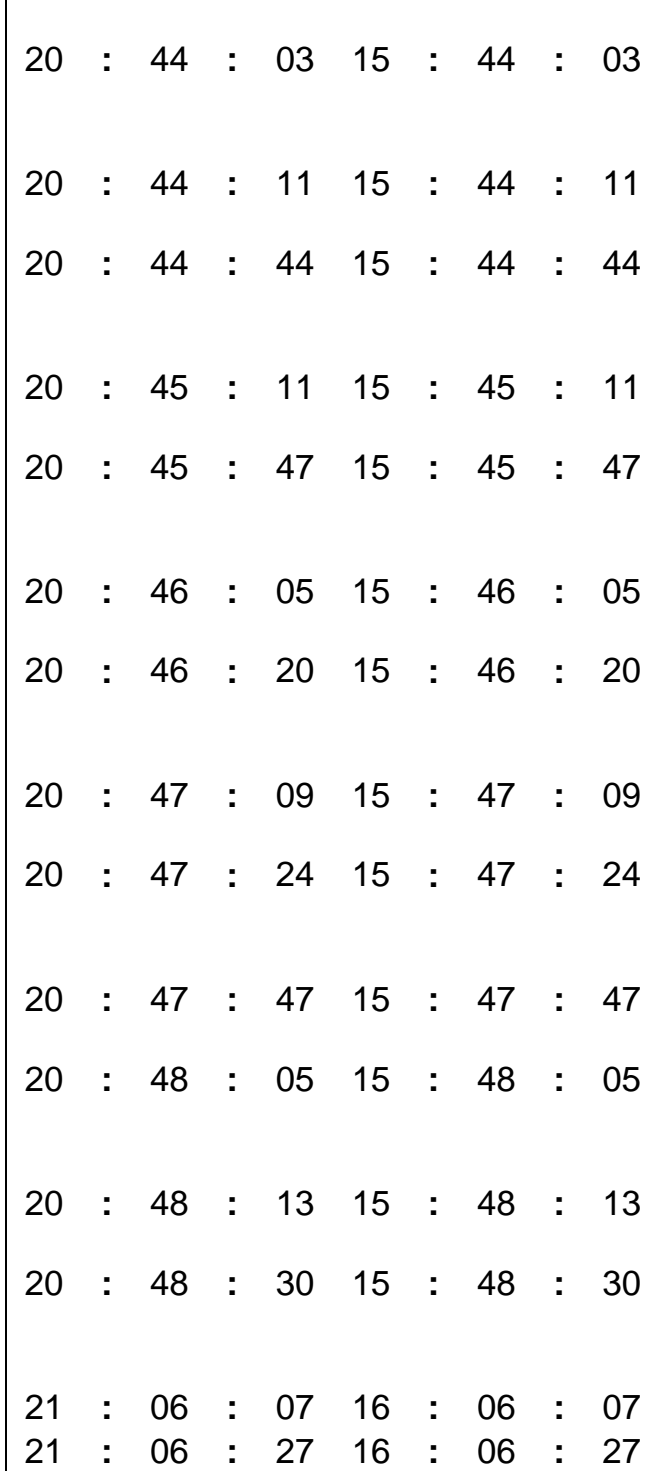

Aircraft
Maneuvers

Aircraft

Maneuvers

Aircraft

Maneuvers

Aircraft

Maneuvers

Aircraft

Maneuvers

Aircraft

Maneuvers

Aircraft

Maneuvers

Aircraft

Maneuvers

Aircraft

Maneuvers

\section{Aircraft}

Maneuvers

Aircraft

Maneuvers

Aircraft

Maneuvers

Aircraft

Maneuvers
150

KIAS

150

KIAS

150

KIAS

150

KIAS

150

KIAS

150

KIAS

150

KIAS

150

KIAS

150

KIAS

150

KIAS

150

KIAS

150

KIAS

150

KIAS

150

KIAS

150
$200 \mathrm{lb}$ End 30 deg right bank

Switched order of maneuvers

$200 \mathrm{lb} \quad$ Start 30 deg left bank

$200 \mathrm{lb}$ End 30 deg left bank

$200 \mathrm{lb} \quad$ Start 45 deg left bank

$200 \mathrm{lb} \quad$ End 45 deg left bank

$200 \mathrm{lb} \quad$ Start 45 deg right bank

$200 \mathrm{lb} \quad$ End 45 deg right bank

200 lb Start slip left

$200 \mathrm{lb} \quad$ End slip left

Performed two left slips

200 lb Start slip left

$200 \mathrm{lb} \quad$ End slip left

200 lb Start slip right

$200 \mathrm{lb} \quad$ End slip right

$200 \mathrm{lb}$ Start raising ramp (pod deployed)

200 lb Ramp up (pod deployed) 


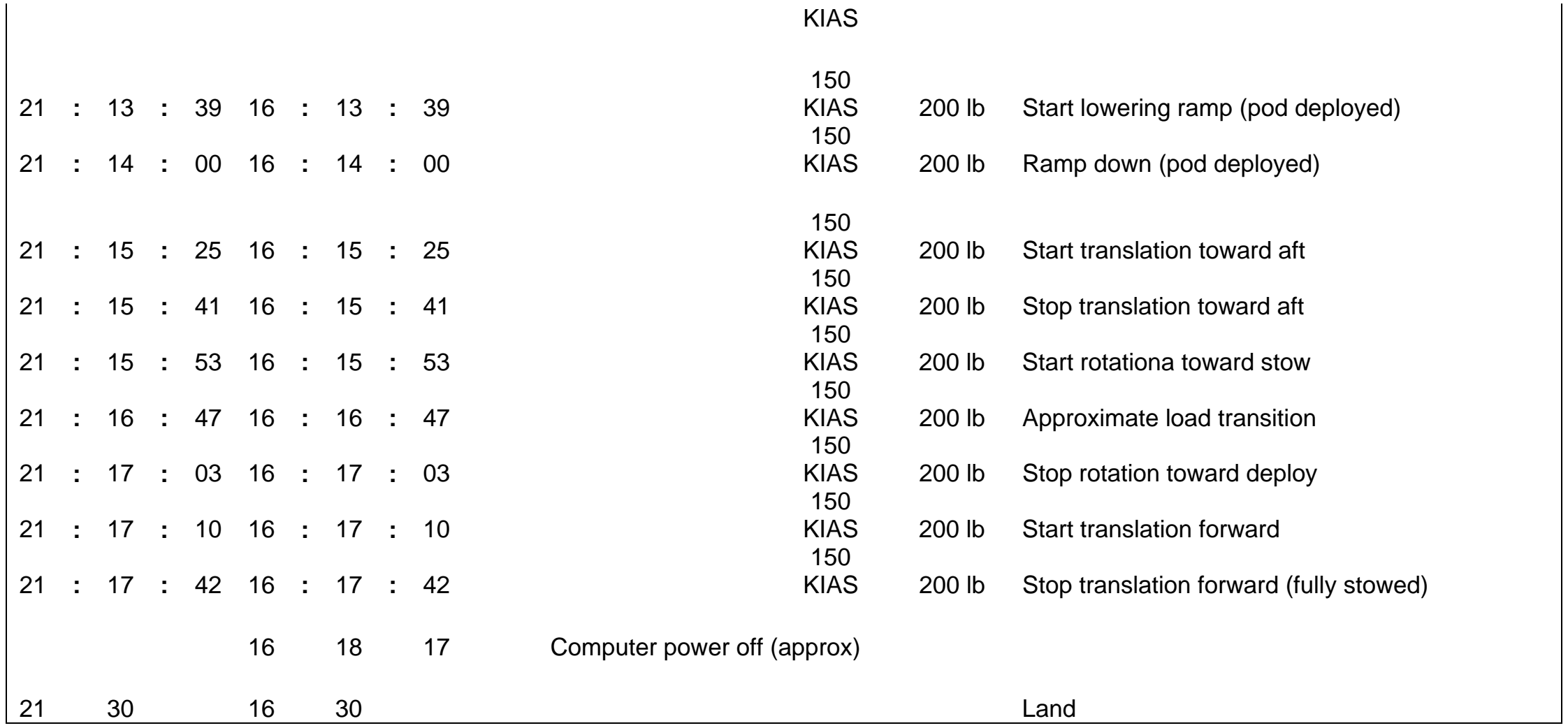




\section{Appendix J. Sample of raw test data converted to Microsoft Excel format.}

Figure I-1 shows a sample of the converted raw flight test data in Microsoft Excel format. The headings at the top represent (from left to right): (Column 1) the sample number for the data collected, (Columns 2-18 and 26) the strain gage readout data collected and (Columns 19-25 and 27-33) the accelerometer voltage readout data collected. 
Table J-1: Excel spreadsheet snap shot of converted raw flight test data.

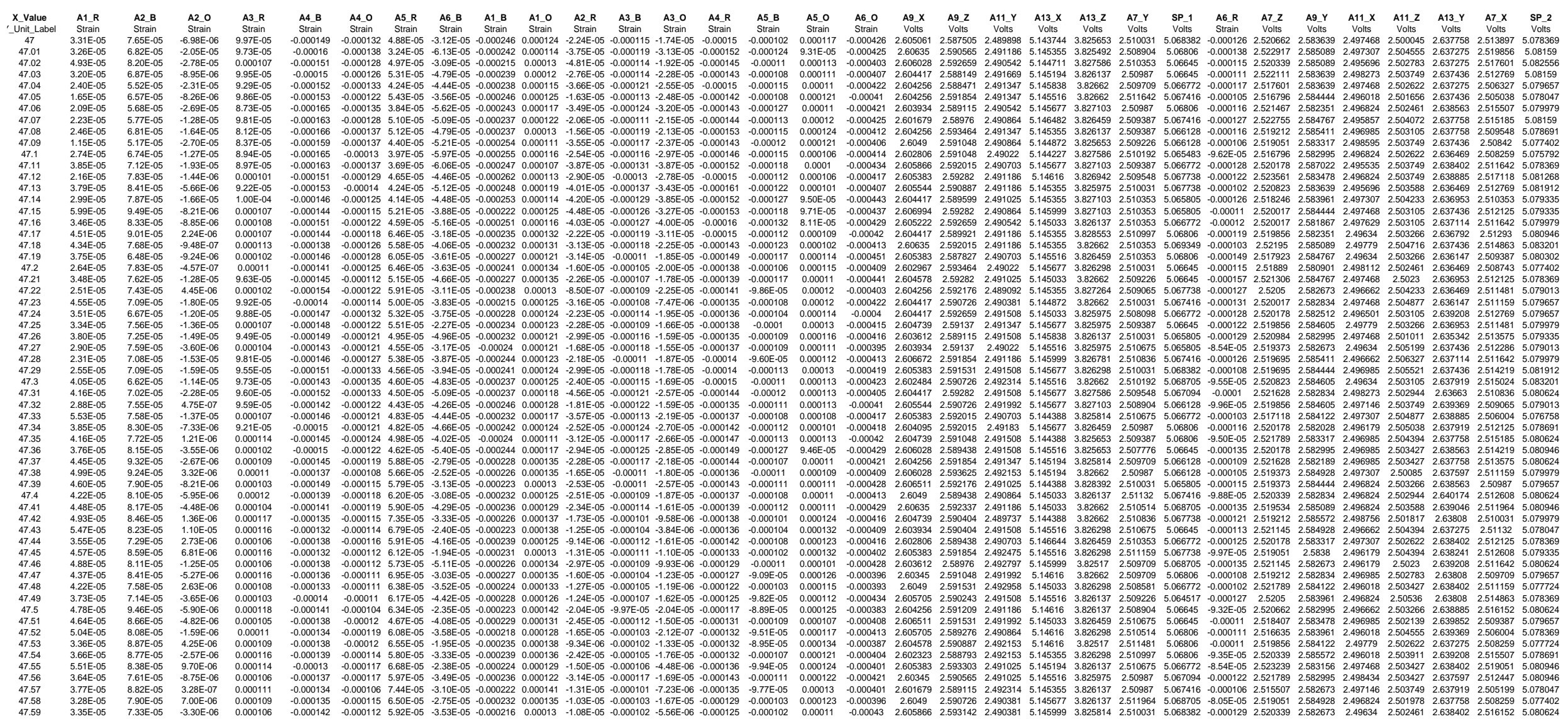




\section{Appendix K. Test Flight Vibration Data}

The following data charts listed in Figure K-1 thru K-4 include the remaining vibration data taken during the OCULUS 1.1 fight. As was explained in Section 7.2 the maximum vibration amplitudes seen correlated to a $1 \mathrm{~g}$ magnitude and usually occurred in the pod frame and vibration plate accelerometer locations. Also explained in section 7.2 is that the aircraft maneuvers performed while the system was in the FOP had little effect on the vibration profiles. Once again this is a good indication that contact was being made between the sensor pod and the rear ramp "belly" when the system was in the final operating position. This data however is not consistent and is shown on case by case bases. This inconsistency occurs because this is an operator deployed system (by using the systems pendant controls) and the FOP cannot insure consistent FOP location for each deployment 
Pod Rotation (after load transition)

Weight $=200 \mathrm{lbs}$

Airspeed $=130 \mathrm{KIAS}$
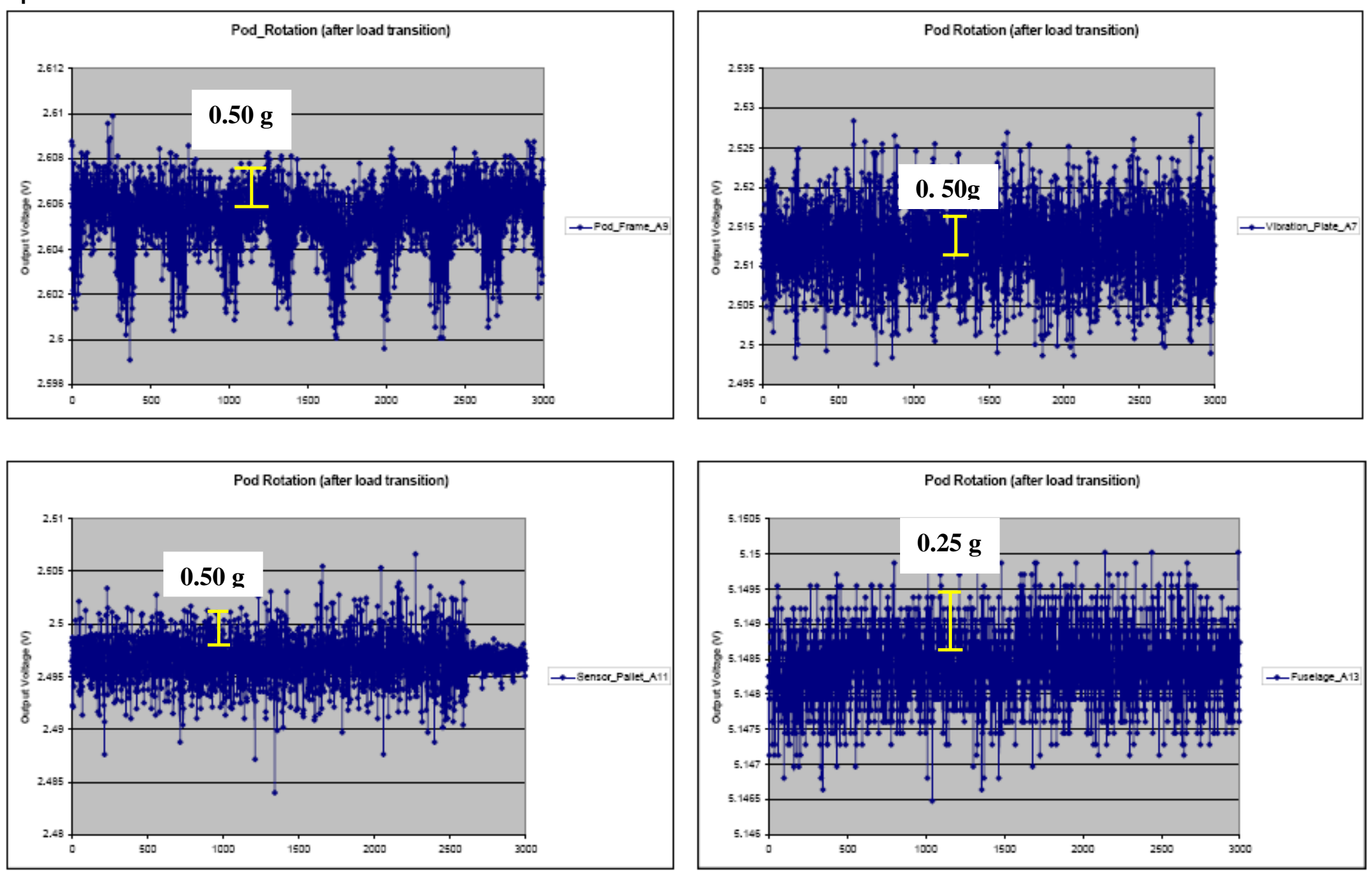

Figure K-1: Vibration measurements during Pod Rotation (200 lbs) 
Linear Retraction

Weight $=200 \mathrm{lbs}$

Airspeed $=130 \mathrm{KIAS}$
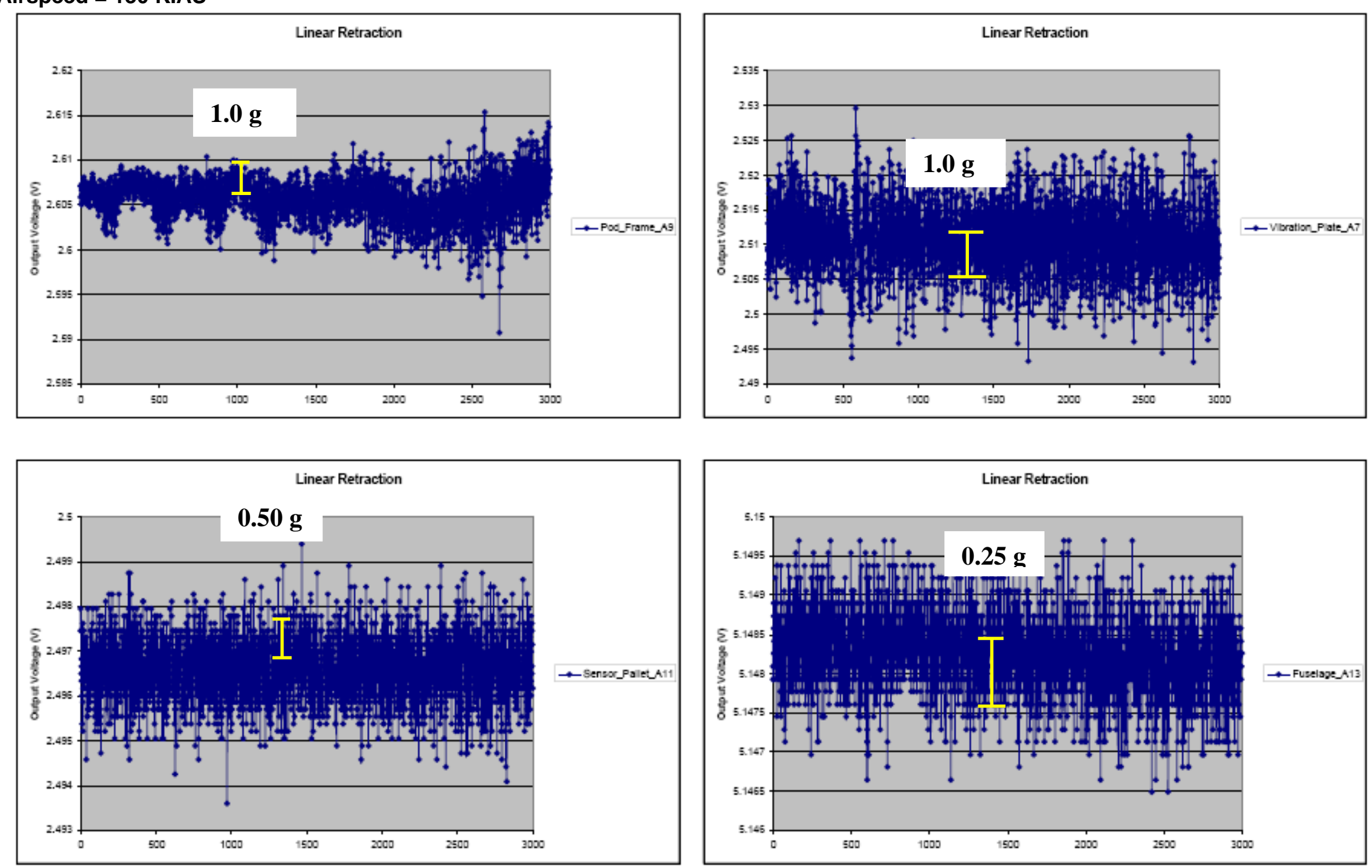

Figure K-2: Vibration measurements during Linear Retraction (200 lbs) 

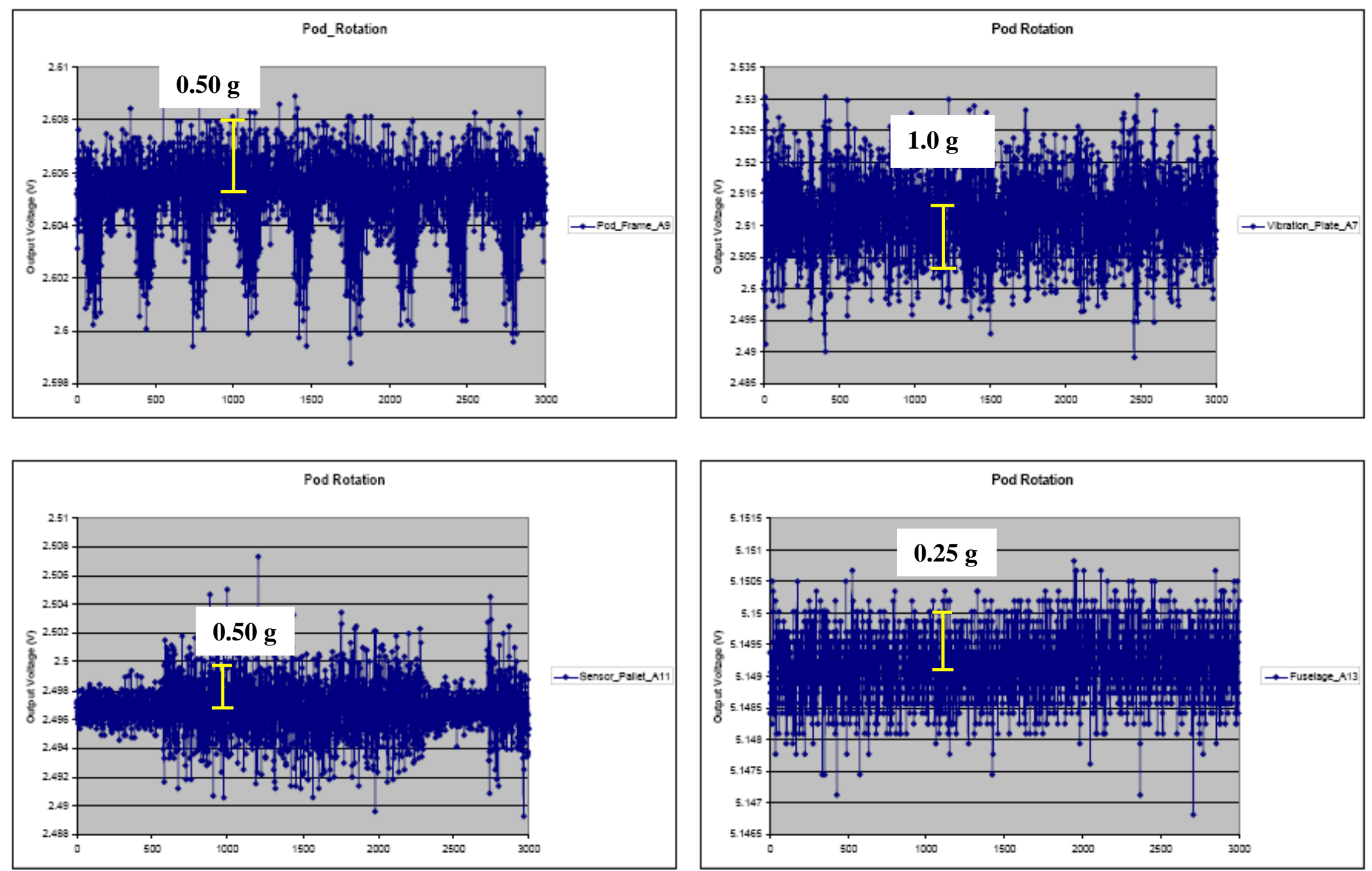

Figure K-3: Vibration measurements during Pod Rotation (263 lbs) 

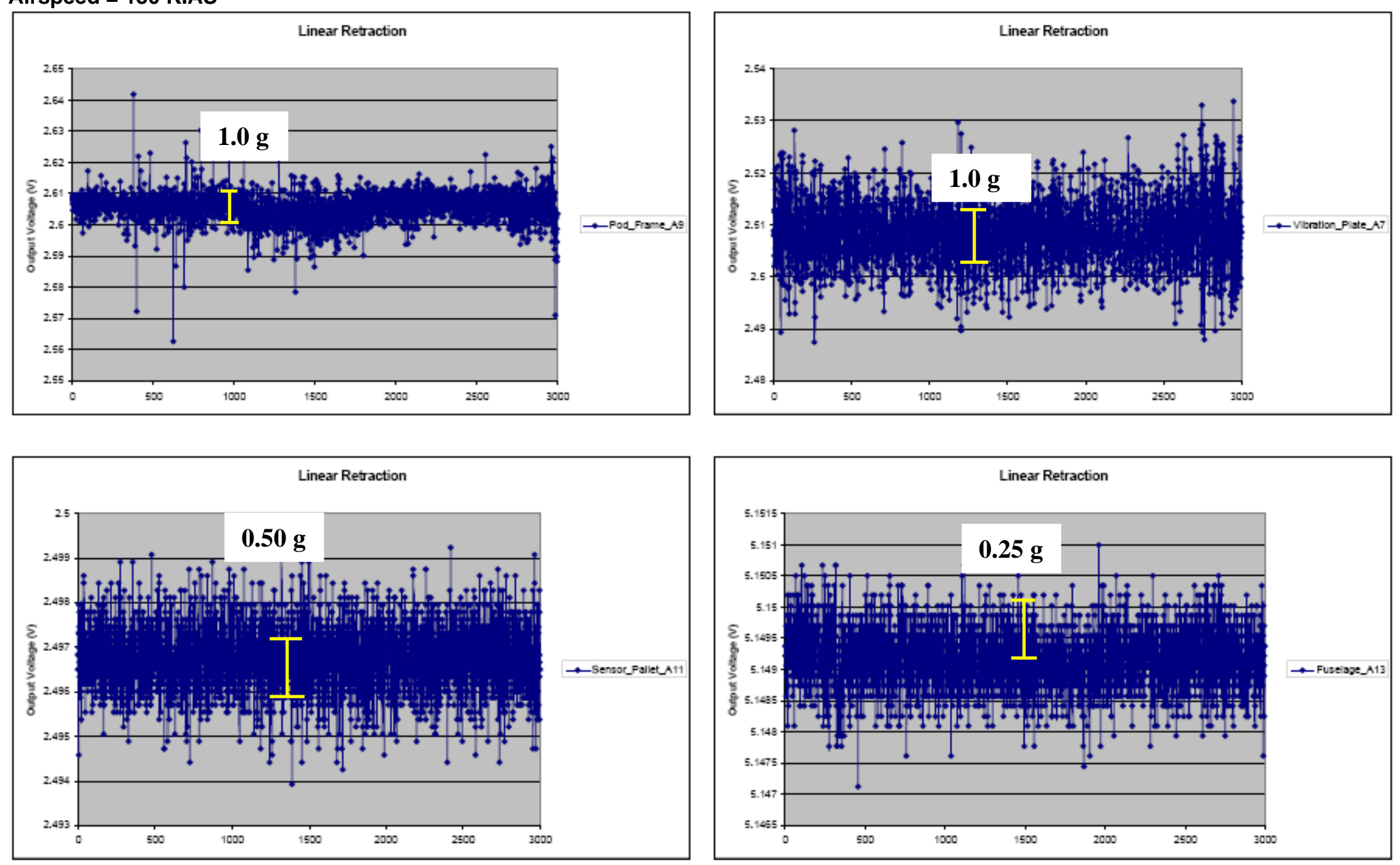

Figure K-4: Vibration measurements during Linear Retraction (263 lbs) 


\section{Appendix L. OCULUS 1.1 Airworthiness Certification Letter}

The attached memorandum (figure L-1) letter is the final certification award for the OCULUS 1.1 system drafted by WRAFB. This letter indicates that the OCULUS 1.1 system has successfully completed airworthiness certification and is deemed safe for flight on-board US Air Force C-130 aircraft. The second attachment is a letter from the flight test director following the OCULUS 1.1 flight test. In the letter, the test director comments on how well planned (flight test plan and general logistics of the actual flight tests) and operated (during flight operations) the OCULUS 1.1 flight tests were and that this is a model flight test procedure for all types of future experimental flight tests. 


\section{DEPARTMENT OF THE AIR FORCE \\ HEADQUARTERS 330TH AIRCRAFT SUSTAINMENT WING (AFMC) \\ ROBINS AIR FORCE BASE, GEORGIA}

MEMORANDUM FOR: ocULUS Development LLC

FROM: $330 \mathrm{ACSG} / \mathrm{EN}$

SUBJECT: OCULUS System Airworthiness Certification

1. AMC 04-119, C-130 Air Worthiness Test (AWT) for the Oculus ISR Pallet System, was a temporary modification proposal that was accepted by the $\mathrm{CCB}$ for ground and flight test.

2. As a result of ground and flight testing completed in the 07 time period, and subsequent analysis of the strain and vibration data collected during these flight tests; the OCULUS 1.1 system successfully fulfilled all requirements to obtain safety of flight/airworthiness certification through the 330 ACSG at WR-ALC for use onboard C$130 \mathrm{E} / \mathrm{H}$ aircraft, with the limitations, guidelines, and constraints as given in the following documents;

a) MODIFICATION FLIGHT MANUAL, C-130 OCULUS, C-130H(3) 95-6712.

b) C-130 OCULUS PROTOTYPE DEVELOPMENTAL TEST \& EVALUATION (DT\&E), Test \# 04-51, Final Report, June 2007; Appendix A: Watch Items (WITs), Deficiency Reports (DRs) and other Write-ups; submitted to the C-130 SPO by EN-2

3. Safety of flight/airworthiness certification is for the basic OCULUS 1.1 system without any payload. Any subsequent testing or additional sensory payload will require submission of another 1067 modification request.

4. The configuration of the OCULUS 1.1 system is maintained by the Oculus Mechanical and Electrical Drawing Package

RANDALL B. IVEY, YF-3

C-130 Chief Engineer

330th Aircraft Sustainment Group

Figure L-1: OCULUS 1.1 System certification letter document. 
To: <William,Robinson@gtri.gatech.edu>

CC: $\quad<$ zwowczukBhotmal.com>

Subject : RE: Test report-revision 1 and answers to questions

Bill \& Zenovy,

This is great. I appreciate you taking the time to answer my questions!

This is just another reason why I have been so impressed with you and your whole team. You have been very professional, quick to provide information, and clearly dedicated to providing the best quality product to the warfighter. This could not be said of al contractors I have encountered. Thank you for your support and I hope that the Air Force continues to use your skills and expertise. You and your team are a great asset to Air Force and to the United States.

Please pass that on to your whole team.

I hope to work with you more in the future.

Sincerely,

Scott J. Robertson, Capt, USAF

Systems Test Engineer

Warner Robins Center Test Authority

WR-A.LC/EN-2

Robins AFB, GA

$\times 2-2683$

Comm: 478-222-2683

DSN: $472-2683$

Figure L-2: Letter form the OCULUS 1.1 flight test captain. 


\section{Appendix M. Deployment System Certification Process}

The major issue in transferring a concept design into the military is the certification process it must undergo for inclusion. This process for a newly developed concept system may take upwards of 5 years to complete the certification process. In the present time in which Developmental Testing and Evaluation (DT\&E) contracts are not guaranteed for 5 years of funding it makes it very difficult for the same organization (the original developer) to lead the entire project through the original design phase through the certification process. This in turn, creates severe bottlenecks in the DT\&E process because each change in contractor requires an additional learning curve time buffer to bring the newly contracted organization up to the knowledge point the previous organization was at the end of its contract funding cycle.

\section{New General Plan Certification Process}

The following Development, Approval, Validation and Certification (DAVC) block diagram (Figure M-1) overviews the proposed certification process for an aircraft deployment system for general military aircraft. The block diagram highlights the individual steps involved in the process. The sections following the block diagram describe each step in the process.

Figure M-1 outlines a new concept certification process. This process' main goal is to streamline and concentrate the certification process without sacrificing any of the safety requirements necessary for the systems full implementation. This process not only concentrates on the specific certified system but also prepares the structure of the certification for future modifications and alternatives which may be made to the baseline system. 


\section{CERTIFICATION METHODOLOGY FOR AN AIRCRAFT DEPLOYMENT SYSTEM}

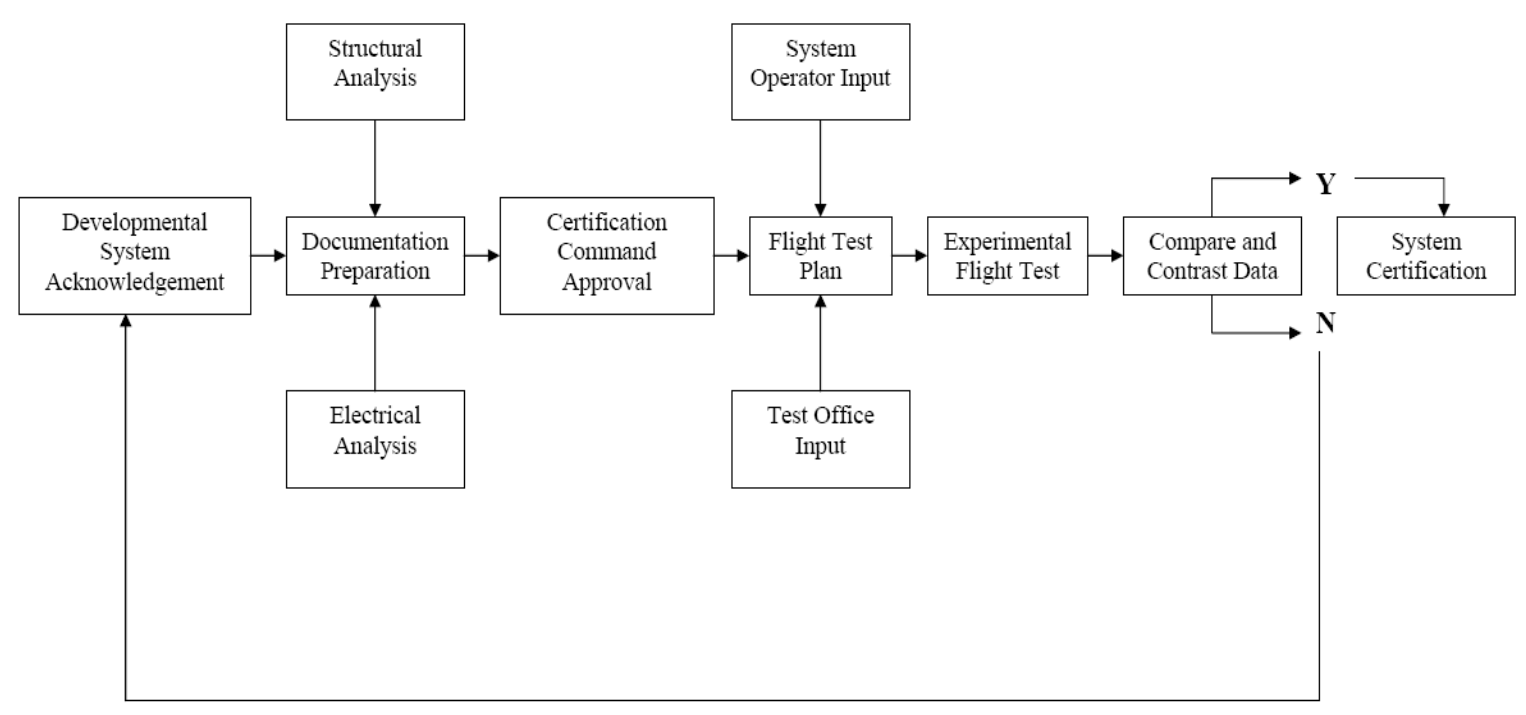

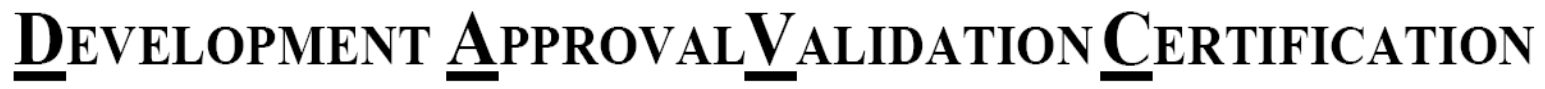

Figure M-1: Certification Methodology Diagram for an aircraft sensor deployment system

\section{Developmental System Acknowledgement}

The initial process in taking deployment system design out of the "concept” phase and into the military certification process begins with the documentation to change the normal operating procedure (NOP) of the airframe. This procedure will always be specific to the military branch it is involved in, and most likely specific to the airframe it is requesting a modification to its NOP. This documentation acknowledges that the sponsor has determined that there is a need requirement for the modification and that the policing agency/division of that particular airframe should conduct an assessment to see if the modification is safe and feasible. 


\section{Documentation Preparation}

Once the initial documentation for modification of a deployment system for an airframe has been acknowledged, the next procedure in the proposed general certification process is to prepare the proper engineering documentation which clearly describes the system that is being investigated. The documentation package will again be specific to the airframe that the proposed deployment system will be considered a modification to the NOP. Even with the documentation specific to the airframe and the dynamics of the deployment system the documentation will cover (1) a detailed drawing description of the system, (2) a structural analysis of the system during normal flight characteristics (this will include boundary conditions and loading), (3) an electrical effect analysis to ensure the system does not in anyway detrimentally effect the airframe during NOP and (4) a crash analysis to ensure the system can handle the airframes design specifications.

\section{Command Board Approval}

Once the system and aircraft specific documentation package has been completed, it must be approved by the airframes policing agency. This process consists of a documentation review by the airframe policing agency's engineers and operators to ensure the documentation is thoroughly complete, and covers all aspects of safety of flight. This is usually a working procedure which the deployment system designers work closely with the engineers of the policing agency to ensure a thorough investigation is completed.

\section{Flight Test Plan}

This development of the flight test plan in the proposed certification process follows the modification approved from the airframes policing agency and involves collaboration from the testing agency, the deployment system developers, the sponsoring agency, and the airframes policing agency. The flight test plan should perform normal flight maneuvers at normal flight 
altitudes with the proposed system during deployment and while in its final operating position (FOP). The plan should also outline what instrumentation should be used to gage whether the system performs safely during the flight and land for post processing whether the experimental date correlates to the analysis performed in the documentation package.

\section{Flight Test}

The flight test of the proposed deployment system will occur when the flight test plan has been accepted by the airframes policing agency and the test agency. The flight test performed should adhere to the approved test plan, and for a complete evaluation, should perform all test cases outlined.

\section{Data Analysis}

The data analysis or "post processing” procedure of this methodology will determine whether the system should be considered a certified safe modification by the aircraft's policing agency. The most important aspects of this step is to analyze the data from the instrumentation test and ensure the system performed safely during the flight and also analyze the aircraft flight date to ensure that the proposed system did not detrimentally effect the dynamics of the aircraft. The additional goal of this step is to verify the structural (and electrical) analysis of proposed system outlined in the documentation package. This validation of the analysis will provide a level of confidence for any future modifications/enhancements/additions made to the proposed system and therefore expedite the certification process. This step also provided any negative or questionable results which will require the redesign or modification of the proposed system and a repeat of the certification process. 


\section{Certification}

The final process in the certification procedure is the notification of certification of the proposed deployment system. If the system has met all required safety of flight requirements outlined by the aircraft policing agency and the flight testing agency and the system's documentation package has been validated and approved, the system should be granted safety of flight certification for use on the specified airframe. To ensure proper notification of this, a certification letter/document should be drafted by the policing agency that acknowledges the proposed system has fulfilled and completed the required steps for certification. This letter/document should reference any and all documentation related to the proposed system, that it deems necessary to reference.

\section{Specific OCULUS Certification Process}

As previously described there are general guidelines to the steps and procedures outlined in this proposed (DAVC) certification process. Even with a general guideline set, each step will have specific requirements/objectives based on the deployment parameters and more importantly the specific aircraft and policing agency of that airframe. This tailoring of the proposed general certification process to a specific project allows for a more thorough and complete certification procedure which will better validate the safety of flight for a proposed system.

The specified OCULUS system certification process follows the guidelines of the DAVC process outlines in the block diagram (Figure M-2). The process diagram (Figure M-2) specific to the OCULUS 1.1 system lists specific titles to each process (and sub-process) step involved in the certification process. These process steps were developed in collaboration with the 
specific policing agency, WRAFB, and the testing agency, WVANG, involved in the certification of the OCULUS 1.1 system.

\section{OCULUS CERTITIFACTION METHODOLOGY}

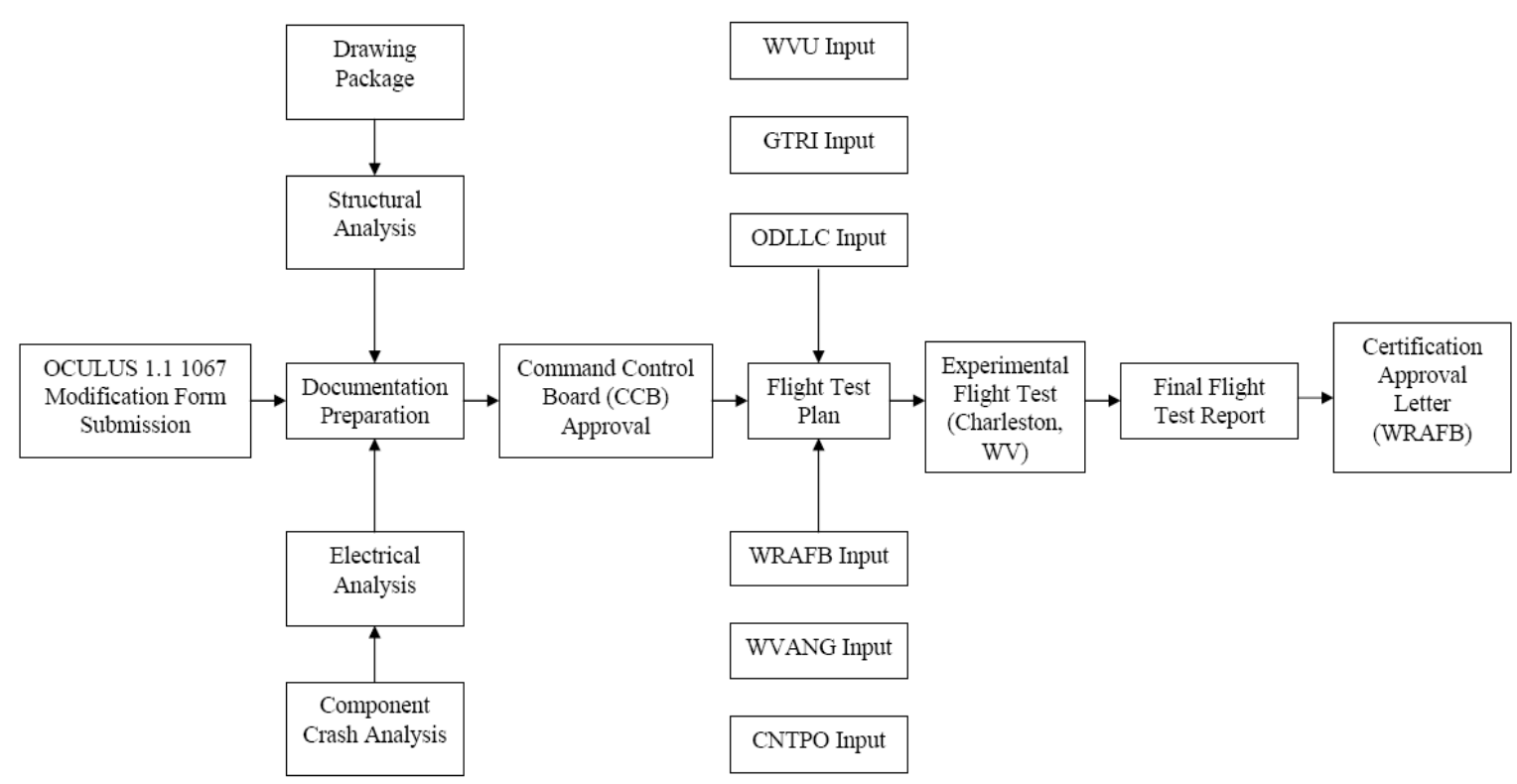

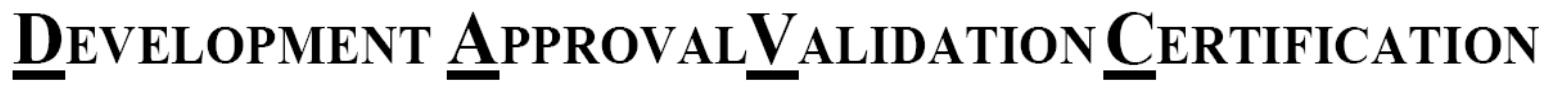

Figure M-2: OCULUS 1.1 Specific Certification Methodology diagram. 